Institut für Organische und Biomolekulare Chemie

Georg-August-Universität Göttingen

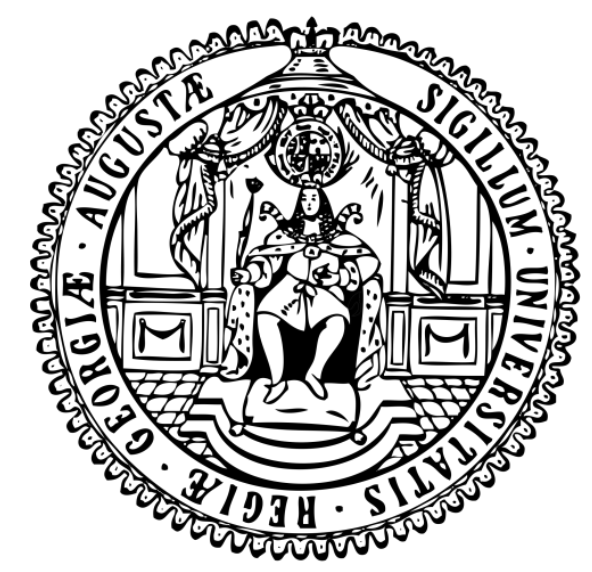

\title{
Phospholipidmembranen auf mikroporösen Substraten: in situ Bildung elektrochemischer Gradienten
}

\author{
Dissertation \\ zur Erlangung des mathematisch-naturwissenschaftlichen Doktorgrades \\ "Doctor rerum naturalium" \\ der Georg-August-Universität Göttingen \\ im Promotionsprogramm Chemie \\ der Georg-August University School of Science (GAUSS) \\ vorgelegt von \\ Daniel Frese \\ aus Nienburg/Weser
}

Göttingen, 2013 


\section{Betreuungsausschuss}

Prof. Dr. Claudia Steinem, Institut für Organische und Biomolekulare Chemie

Prof. Dr. Markus Zweckstetter, Max-Planck-Institut für Biophysikalische Chemie

\section{Mitglieder der Prüfungskommission}

Referentin:

Prof. Dr. Claudia Steinem, Institut für Organische und Biomolekulare Chemie

Korreferent:

Prof. Dr. Markus Zweckstetter, Max-Planck-Institut für Biophysikalische Chemie

Weitere Mitglieder der Prüfungskommission:

Prof. Dr. Ulf Diederichsen, Institut für Organische und Biomolekulare Chemie

Prof. Dr. Ralf Ficner, Institut für Mikrobiologie und Genetik

Dr. Thomas Burg, Max-Planck-Institut für Biophysikalische Chemie

Prof. Dr. Kai Tittmann, Albrecht-von-Haller-Institut, Abteilung Bioanalytik

Tag der mündlichen Prüfung: $\quad$ 25.06.2013 
Meiner Familie

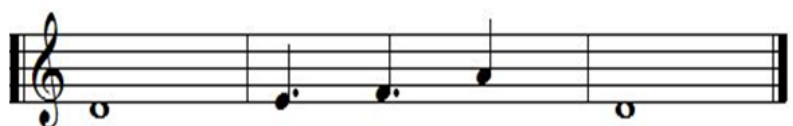



Abstract. Electrochemical gradients are of utmost importance for cellular processes, such as the generation of action potentials or the production of ATP in mitochondria. They are established by membrane proteins, which consume energy to provide an active transport of e.g. ions across membranes. Membrane proteins are the main targets for pharmaceutical drugs and they are controlled very sensitively by external stimuli (e.g. light, potential differences, temperature), raising interest in their application as biosensors.

A model system based on artificial membranes spanning well-defined picolitre cavities on microporous substrates was developed for the functional reconstitution of the membrane protein bacteriorhodopsin (bR) and the in situ generation of electrochemical gradients. The formation of pore-spanning membranes (PSMs), either by spreading of giant unilamellar vesicles (GUVs) onto hydrophilically functionalized substrates, or by application of lipids dissolved in $n$-decane onto hydrophobically functionalized substrates (painting-technique), was investigated by three-dimensional confocal laser scanning microscopy (CLSM), fluorescence recovery after photobleaching (FRAP) experiments and scanning ion conductance microscopy (SICM). The amount of residual solvent in painted PSMs could be reduced by solvent freeze-out. Spreading of GUVs on hydrophilically functionalized porous substrates yielded not only planar, but also hemispherical PSMs, protruding several micrometers into the bulk solution.

The $\mathrm{pH}$-sensitive dye pyranine was stably entrapped within membrane suspended pores derived from vesicle spreading as well as from the painting-technique. Changes in the intensity of entrapped pyranine were used to monitor the formation of nigericin-induced proton gradients across PSMs. Proton gradients of up to $\Delta \mathrm{pH}=2$ units were generated and the initial rate for nigericin-mediated proton transport across PSMs was determined to be $10^{14} \mathrm{H}^{+} \cdot \mathrm{s}^{-1} \cdot \mathrm{cm}^{-2}$.

Several strategies were used to reconstitute bR into liposomes and PSMs, conserving its function as a light-driven proton pump. Photocurrents were recorded, verifying the functionality of bR in large unilamellar vesicles (LUVs), as well as in GUVs. A net-transport of protons into the liposomes or from the liposomes into the bulk solution could neither be observed by changes in pyranine intensity, nor directly via $\mathrm{pH}$-electrode. After its reconstitution into PSMs by spreading of proteo-GUVs, bR was shown to be laterally mobile with a diffusion coefficient of approximately $D=0,2 \pm 0,1 \mu \mathrm{m}^{2} \cdot \mathrm{s}^{-1}$ and a mobile fraction of $M=68 \pm 16 \%$.

The developed model system therefore provides highly ordered, well-defined picolitre cavities that can be addressed by optical microscopy and scanning probe techniques (e.g. SICM). Cavities can tightly be sealed with PSMs as indicated via the generation of electrochemical gradients. These features in combination with the ability to reconstitute membrane proteins (bR) make the developed setup a promising tool for pharmaceutical screening applications and biosensor devices. 



\section{Inhaltsverzeichnis}

\section{$1 \quad$ Einleitung .............................................................................................. 1}

1.1 Porenüberspannende Lipiddoppelschichten ....................................................... 1

1.1.1 Membransysteme zur Untersuchung von Transportprozessen ...........................2

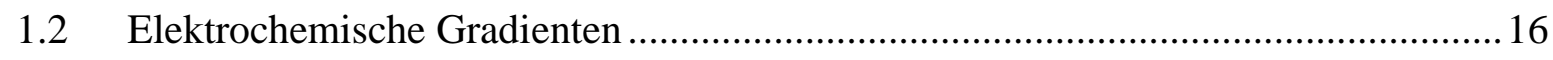

1.2.1 Aufbau elektrochemischer Gradienten durch Ionophore................................. 17

1.2.2 Lichtinduzierter Aufbau elektrochemischer Gradienten durch Bacteriorhodopsin 20

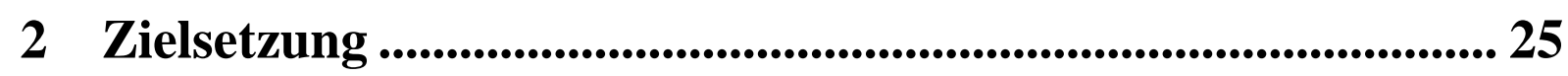

3 Materialien und Methoden ..................................................... 27

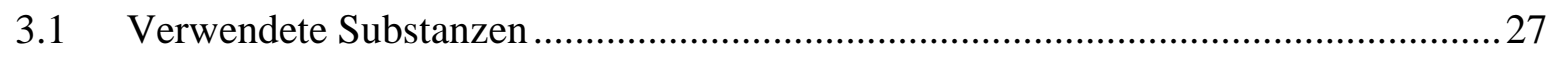

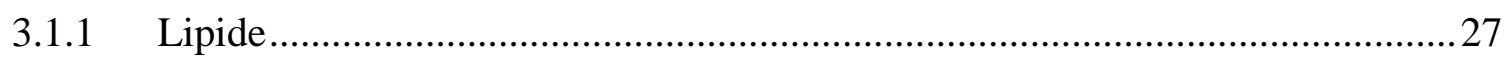

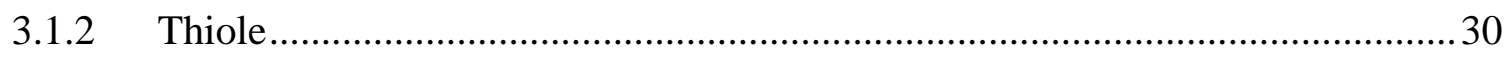

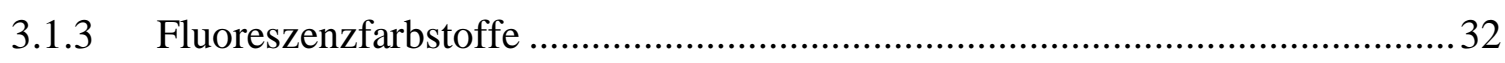

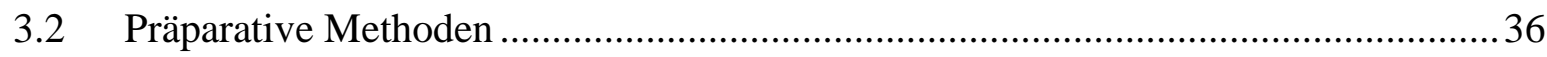

3.2.1 Isolierung von Purpurmembranfragmenten aus Halobacterium salinarum ........ 36

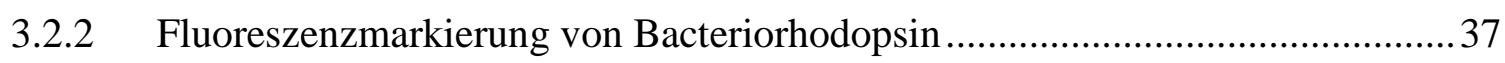

3.2.3 Präparation goldunterstützter lösungsmittelhaltiger Membranen....................... 39

3.2.4 Präparation unilamellarer Vesikel zur funktionellen Rekonstitution von

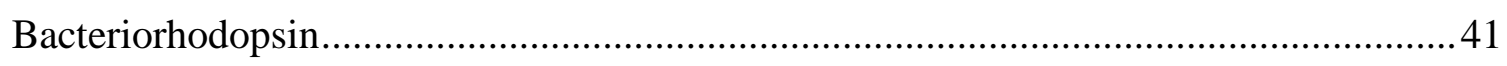

3.2.5 Präparation mikrometergroßer unilamellarer Vesikel ..................................... 43

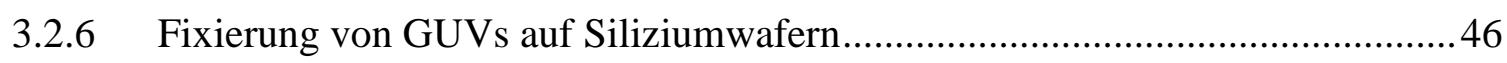

3.2.7 Präparation poröser Siliziumsubstrate ….................................................... 47

3.2.8 Funktionalisierung poröser Substrate ............................................................. 50

3.2.9 Präparation lösungsmittelhaltiger porenüberspannender Membranen (painting-

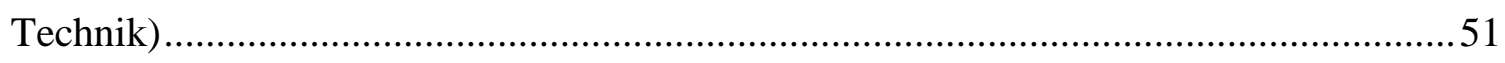

3.2.10 Ausfrieren des remanenten Lösungsmittels in porenüberspannenden painted

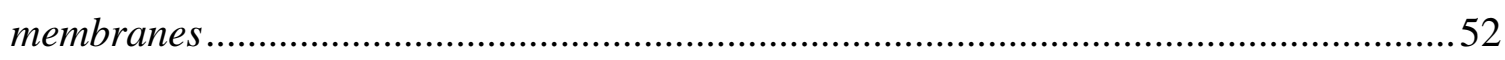


3.2.11 Präparation lösungsmittelfreier porenüberspannender Membranen durch

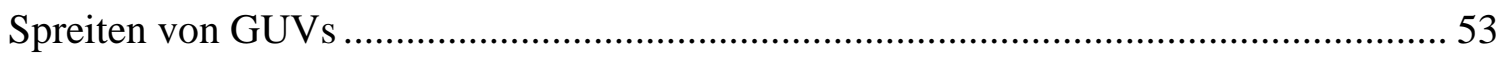

3.2.12 Wiederverwertung goldbeschichteter Siliziumsubstrate ................................. 54

3.3 Messung der Protonenpumpaktivität von Bacteriorhodopsin ................................ 55

3.3.1 Photostrommessungen an bR-haltigen Membranen ...................................... 55

3.3.2 Messung der Protonenpumpaktivität von in Vesikeln rekonstituiertem bR

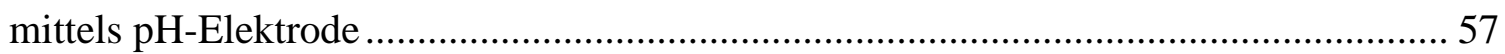

3.3.3 Messung der Protonenpumpaktivität von in Vesikeln rekonstituiertem bR durch

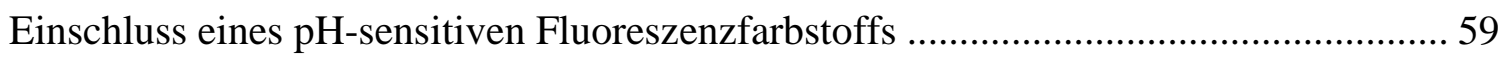

3.3.4 Messung der Protonenpumpaktivität von in porenüberspannenden Membranen rekonstituiertem bR durch Einschluss eines pH-sensitiven Fluoreszenzfarbstoffs ......... 60

3.4 Untersuchung nigericininduzierter elektrochemischer Gradienten ......................... 60

3.4.1 Fluoreszenzspektrometrische Untersuchung des nigericininduzierten Protonen-

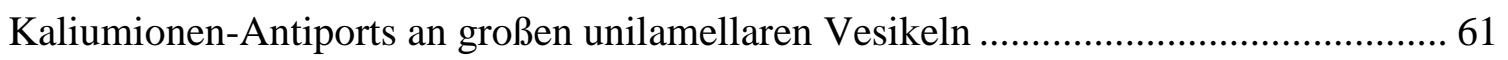

3.4.2 Fluoreszenzmikroskopische Untersuchung des nigericininduzierten ProtonenKaliumionen-Antiports an GUVs

3.4.3 Fluoreszenzmikroskopische Untersuchung des nigericininduzierten ProtonenKaliumionen-Antiports an porenüberspannenden Membranen .................................... 62

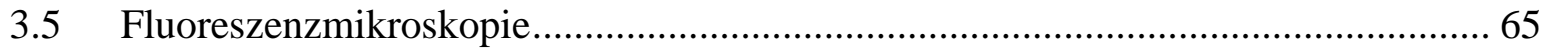

3.5.1 Fluorescence Recovery After Photobleaching ............................................... 71

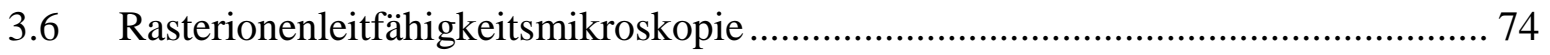

4 Ergebnisse ........................................................................................... 79

4.1 Präparation und Charakterisierung porenüberspannender Membranen ................... 79

4.1.1 Lösungsmittelhaltige porenüberspannende Membranen (painted membranes) 79

4.1.2 Lösungsmittelfreie porenüberspannende Membranen ..................................... 90

4.2 Bildung nigericininduzierter elektrochemischer Gradienten .............................. 117

4.2.1 Bildung elektrochemischer Gradienten in Liposomen.................................. 119

4.2.2 Bildung elektrochemischer Gradienten in GUVs ........................................ 121

4.2.3 Bildung elektrochemischer Gradienten in porenüberspannenden Membranen 125

4.3 Rekonstitution von Bacteriorhodopsin in Lipidmembranen ................................. 131

4.3.1 Isolierung von Purpurmembranfragmenten aus Halobacterium salinarum .... 132 


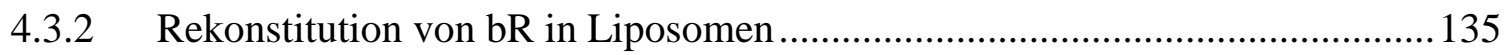

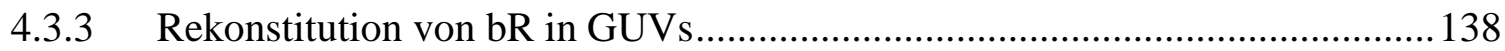

4.3.4 Rekonstitution von bR in porenüberspannende Membranen ........................... 146

\section{Diskussion}

5.1 Präparation und Charakterisierung von Membranen auf porösen Substraten ......... 153

5.1.1 Ausfrieren remanenten Lösungsmittels in porenüberspannenden painted membranes.....

5.1.2 Spreiten von GUVs auf porösen Substraten ................................................... 160

5.2 Nigericininduzierte elektrochemische Gradienten ............................................. 177

5.2.1 Bildung von Protonengradienten in Vesikeln................................................. 177

5.2.2 Bildung von Protonengradienten in porenüberspannenden Membranen ......... 179

5.3 Rekonstitution von Bacteriorhodopsin in artifiziellen Membranen ....................... 194

5.3.1 Isolierung von bR und Rekonstitution in Vesikeln ..................................... 195

5.3.2 Rekonstitution von bR in porenüberspannenden Membranen ........................204

6 Zusammenfassung.................................................................. 209

7 Literaturverzeichnis........................................................................ 211

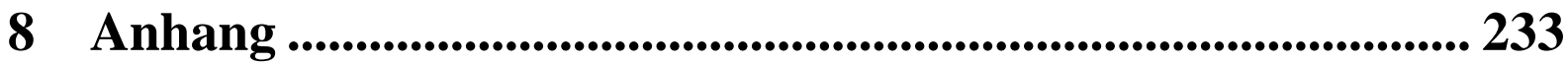

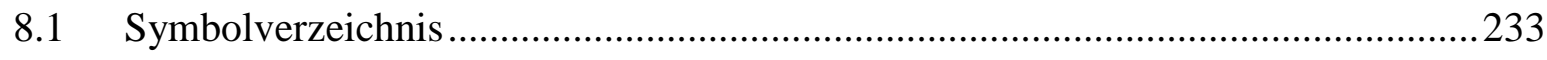

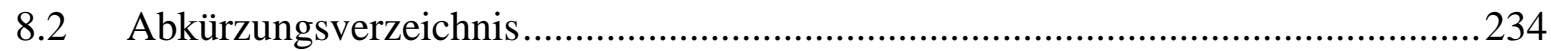

8.3 Chemikalien, Geräte, Materialien und Software ..............................................238

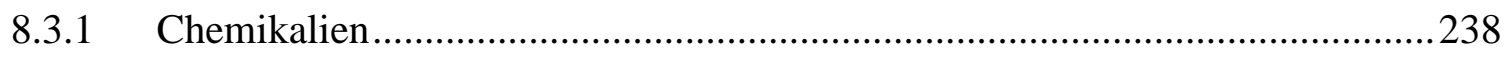

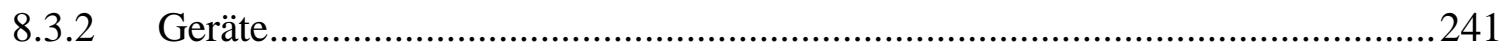

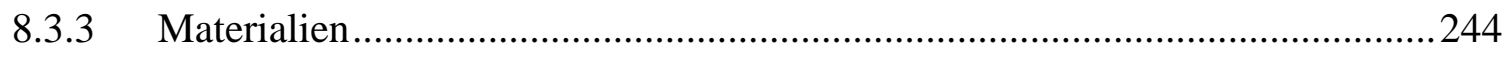

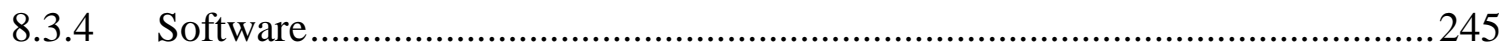

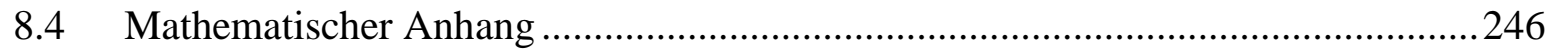

8.4.1 Herleitung von Gl. 5.1 (Verhältnis der Oberflächen poröser und unporöser

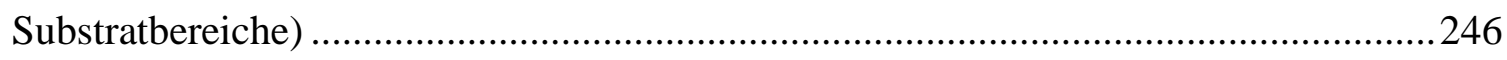

8.4.2 Berechnung der Konzentrationen von Kaliumionen und Protonen im Verlauf

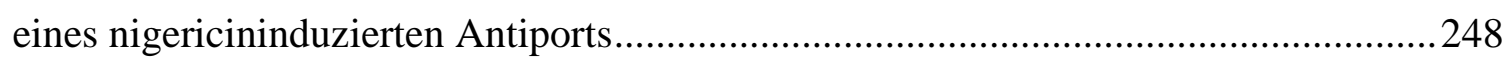




\section{Einleitung}

\subsection{Porenüberspannende Lipiddoppelschichten}

Lipiddoppelschichten sind in Form der Plasmamembran, der Membran einzelner Zellorganellen wie Mitochondrien, Chloroplasten oder dem Golgi-Apparat und in Form von zytosolischen Vesikeln in pro- wie eukaryotischen Zellen präsent. Lipidmembranen erfüllen dabei verschiedene Zwecke, wie die Trennung verschiedener wässriger Reaktionsräume und sie dienen als Matrix für membranständige Proteine.

Um Lipidmembranen und membranständige Proteine isoliert vom Einfluss anderer Zellkomponenten und mit verschiedenen biophysikalischen Methoden $\mathrm{zu}$ untersuchen, wurden verschiedene Modellmembransysteme entwickelt. Solche Systeme sind aufgebaut aus einer Lipiddoppelschicht gewählter Zusammensetzung und gegebenenfalls einem unterstützenden Substrat. Beispiele sind festkörperunterstützte Membranen (solid supported membranes, SSMs) ${ }^{[1,2]}$ freistehende Membranen (black lipid membranes, BLMs), ${ }^{[3]}$ und Lipidvesikel. ${ }^{[4]}$ Jedes dieser Modellsysteme weist unterschiedliche Vor- und Nachteile in Bezug auf Stabilität, Anwendbarkeit biophysikalischer Methoden und biologische Relevanz auf.

Ein System, über welches aufgrund seiner Überlegenheit gegenüber anderen Modellsystemen in Bezug auf potentielle biotechnologische und pharmazeutische Anwendungen verstärkt berichtet wurde, sind Membranen auf nano- und mikroporösen Substraten (porenüberspannende Membranen). ${ }^{[5-10]}$ Porenüberspannende Membranen trennen zwei wässrige Kompartimente voneinander und erlauben durch optische oder elektrische Adressierung beider Kompartimente die Untersuchung von z. B. proteingesteuerten Transportprozessen. ${ }^{[11-}$ ${ }^{13]}$ Da Transmembranproteine rund $60 \%$ der bekannten Angriffspunkte von pharmazeutischen Wirkstoffen ausmachen (Daten aus dem Jahr 2009) und viele dieser Proteine an Transportprozessen beteiligt sind, ${ }^{[14]}$ ist ein Modellsystem, welches eine funktionelle Rekonstitution dieser Proteine erlaubt sehr interessant in Hinblick auf die Testung neuer Wirkstoffe. Die Bildung sogenannter arrays einzeln adressierbarer porenüberspannender transmembranproteinhaltiger Membranen, würde eine hohe Durchsatzrate bei der Untersuchung der Wirksamkeit potentieller Wirkstoffe auf Membranproteine erlauben (high throughput screening). Da solche Proteine spezifisch und hochsensitiv auf z. B. bestimmte Substrate, Licht (Rhodopsine), elektrische Potentiale (spannungsabhängige Kanäle) oder osmotische Drücke (mechanosensitive Kanäle) reagieren, wird eine biotechnologische Anwendung proteinhaltiger Membran-arrays als Biosensoren diskutiert. ${ }^{[5,15]}$ 


\title{
1.1.1 Membransysteme zur Untersuchung von Transportprozessen
}

Grundlage für eine Untersuchung und spätere technische Anwendung membranständiger Transportproteine ist die Bildung stabiler porenüberspannender Membranen. Solche Membranen müssen für eine elektrische Messung von Ionenströmen z. B. durch Kanalproteine hohe Widerstände aufweisen und für eine optische Untersuchung membranumschlossener Reaktionsräume oder den Aufbau (elektro-)chemischer Gradienten hochgradig impermeabel für Ionen und andere Teilchen sein.

\section{Membranüberspannte Einzelporen}

Systeme auf Basis einzelner membranüberspannter Poren wurden bereits zur Untersuchung von peptid- und proteinvermittelten Transportprozessen entwickelt und genutzt. Bereits in den 1970er Jahren nutzten Jain et al. klassische BLMs, um darin den durch die Membranproteine $\mathrm{Na}$, K-ATPase und Mg-ATPase vermittelten Kationentransport anhand von elektrischen Messungen $\mathrm{zu}$ untersuchen. ${ }^{[16]}$ Ausgehend von diesem System wurden freistehende Membranen über Öffnungen feiner Glaspipetten gebildet und zur Untersuchung von Transportprozessen durch das Membranprotein $\alpha$-Hämolysin ( $\alpha$-HL) genutzt (Abb. 1.1). ${ }^{[17]}$ Beide Seiten der Membran sind elektrisch kontaktierbar, die Membran kann fluoreszenzmikroskopisch untersucht werden und hydrostatischer Druck kann auf die Membran ausgeübt werden. ${ }^{[18,19]}$
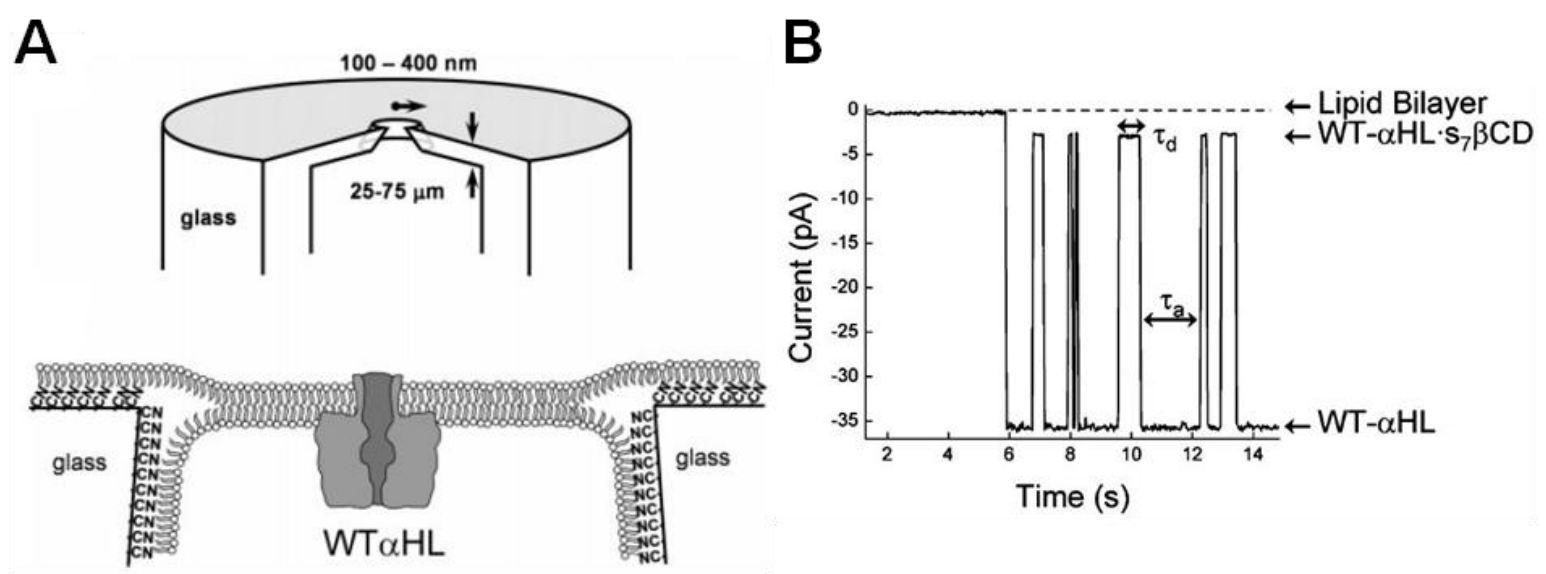

\begin{abstract}
Abb. 1.1: A Schematische Darstellung einer Glaspipette mit einer wenigen hundert Nanometer großen Öffnung (oben, maßstabsgetreu). Durch Aufbringen eines Lipid-Lösungsmittelgemisches auf die Öffnung bildet sich eine porenüberspannende Membran, in welche durch spontane Einlagerung von monomerem $\alpha$-HL (wild type, wt) heptamere Kanäle gebildet werden können (unten, nicht maßstabsgetreu). B Elektrische Messungen an solchen Membranen (DPhPC) bestätigen durch ein Fließen von Picoampereströmen die erfolgreiche Insertion von $\alpha$-HL in Form von Kanälen. Abbildungen nach White et al. ${ }^{[19]}$
\end{abstract}

Das Protein $\alpha$-HL, sowie die antibiotisch wirksamen Peptide Gramicidin und Alamethicin sind die mit Abstand meistuntersuchten Kanäle in porenüberspannenden Membranen. A-HL ist ein bakterielles Exotoxin, welches als wasserlösliches Monomer von Staphylococcus 
aureus exprimiert wird und in Lipidmembranen heptamere Poren formt. ${ }^{[20]}$ Durch diese Poren können Ionen und kleine Moleküle passiv über Membranen transportiert werden. Gramicidin und Alamethicin sind Peptide aus 15 Aminosäuren bzw. 19 Aminosäuren und einem Aminoalkohol, welche sich spontan in Membranen einlagern und dort Kanäle bilden, die selektiv einen passiven Transport monovalenter Kationen erlauben. ${ }^{[21]}$

Neben den oben vorgestellten Membranen finden sich weitere Beispiele für die Bildung einzelner porenüberspannender Membranen. Sandison et al. präsentieren einen MikrofluidikAufbau, durch welchen Messungen weitgehend automatisiert werden können ${ }^{[22]}$ und zeigen elektrische Untersuchungen von Gramicidinkanälen. ${ }^{[23]}$ Ähnliche Systeme konnten bereits für elektrische Messungen an $\alpha$-HL-Kanälen verwendet werden. ${ }^{[24,25]}$ Durch Fusion von submikrometergroßen Proteo-Vesikeln mit planaren einzelporenüberspannenden Membranen, konnten auch sensiblere Proteine, wie der Kaliumionenkanal KcsA in solche Membranen insertiert und ein passiver $\mathrm{K}^{+}$-Transport elektrisch verfolgt werden. ${ }^{[26]}$

Um einen Einfluss des remanenten Lösungsmittels in solch porenüberspannenden Membranen auf insertierte Transportproteine auszuschließen, wurden Techniken zur Bildung lösungsmittelfreier einzelporenüberspannender Membranen entwickelt. So wurden durch Spreiten von mikrometergroßen Vesikeln (giant unilamellar vesicles, GUVs) lösungsmittelfreie Membranen gebildet und darin rekonstituierte Alamethicinkanäle elektrisch untersucht. ${ }^{[27]}$

Eine Erweiterung membranüberspannter Einzelporen um die Möglichkeit, neben elektrischen Messungen der Kanalaktivität die Membranen auch optisch zu untersuchen, präsentieren Kendall et al. ${ }^{[28,29]}$ Stimberg et al. wendeten ebenfalls elektrische wie optische Methoden an, um die Funktionalität von $\alpha$-HL und Gramicidin in membranüberspannten Einzelporen zu untersuchen. ${ }^{[30]}$ Eine schematische Darstellung eines einfachen mikrofluidischen Aufbaus zur Bildung einer porenüberspannenden Membran ist in Abb. 1.2 gezeigt. 


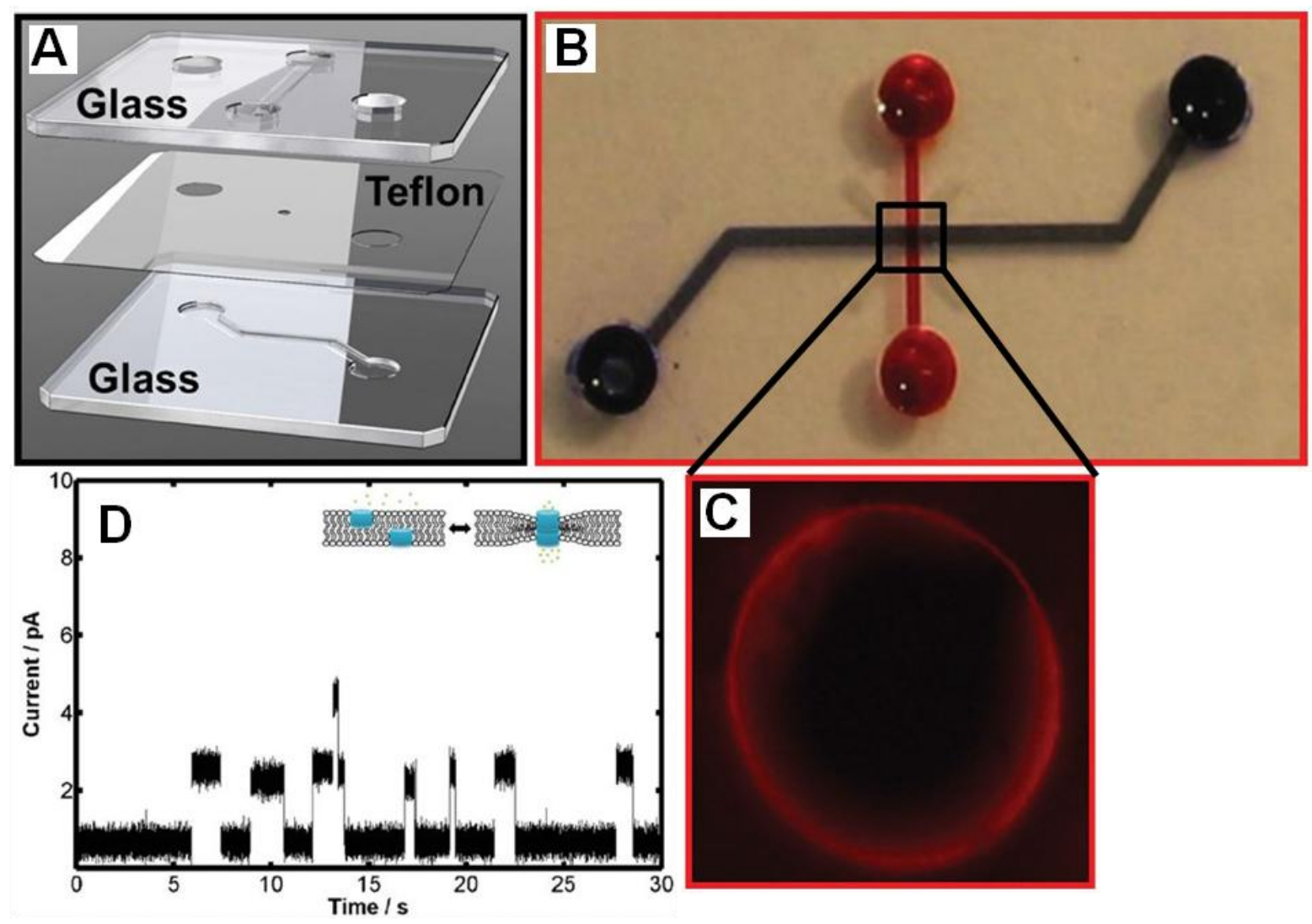

Abb. 1.2: A Offene Ansicht und B fotografische Aufnahme eines mikrofluidischen Aufbaus. Zwei Kanäle (Höhe: $100 \mu \mathrm{m}$, Breite: $300 \mu \mathrm{m}$, farblich voneinander abgehoben) mit einem Berührungspunkt in einer einzelnen Pore $(d=100 \mu \mathrm{m})$ in der Mitte des Aufbaus erlauben durch Spülen mit einem Lipid-Lösungsmittelgemisch, gefolgt von wässriger Pufferlösung die Bildung einer porenüberspannenden Membran. C Konfokalmikroskopische Aufnahme einer porenüberspannenden Membran (DPhPC/Rhodamin B DOPE, 99:1, rot). D Eine Kontaktierung der Mikrofluidik-Kanäle mit Elektroden ermöglicht die Aufnahme der Kanalaktivität von in der Membran eingelagertem Gramicidin (blau). Abbildungen nach Stimberg et al. ${ }^{[30]}$

\section{Membranüberspannte Multiporensysteme (arrays)}

Hauptnachteil von einzelporenüberspannenden Membranen ist neben einer im Vergleich zu substratunterstützten Membranen geringen Stabilität die fehlende Kapazität für Durchsatzraten im Bereich von high throughput screenings. Hierzu wäre eine große Anzahl symmetrisch angeordneter, gleichartiger, membranüberspannter Poren nötig, die unabhängig voneinander adressiert werden können (sog. arrays).

Erste Ansätze zur Bildung von Membranen auf multiporösen Substraten beschränkten sich auf mesoporöses Silizium. Rasterkraftmikroskopische, ${ }^{[31]}$ sowie fluoreszenzmikroskopische und Schwingquarzmikrowaage-Studien ${ }^{[32]}$ zeigen, dass auf mesoporösem Silizium mit Porendurchmessern im Bereich von 2-20 nm durch Vesikelspreiten erfolgreich porenüberspannende Membranen gebildet werden können (Abb. 1.3, A). Durch die eher inhomogene Verteilung der Poren über die Substratoberfläche, die geringen Porendurchmesser und die nicht bestehende Möglichkeit, einzelne, wohldefinierte membranüberspannte 
Volumina zu adressieren, fanden mesoporöse Siliziumsubstrate bisher keine Anwendung für die Untersuchung von Transportproteinen.

Eine ähnliche Geometrie eines mesoporösen Netzwerks, jedoch mit oberflächlichen Porenöffnungen von $300 \mu \mathrm{m}$ Durchmesser und auf Basis einer Ethylentetrafluorethylen (ETFE)/Hydrogel-Mischung, konnte bereits erfolgreich zur Rekonstitution und elektrischen Untersuchung von $\alpha$-HL genutzt werden (Abb. 1.3, B). ${ }^{[33]}$ Auch hier schränkt ein nicht definiertes Volumen der membranbedeckten Poren eine genauere und quantitative Analyse von Transportprozessen ein.
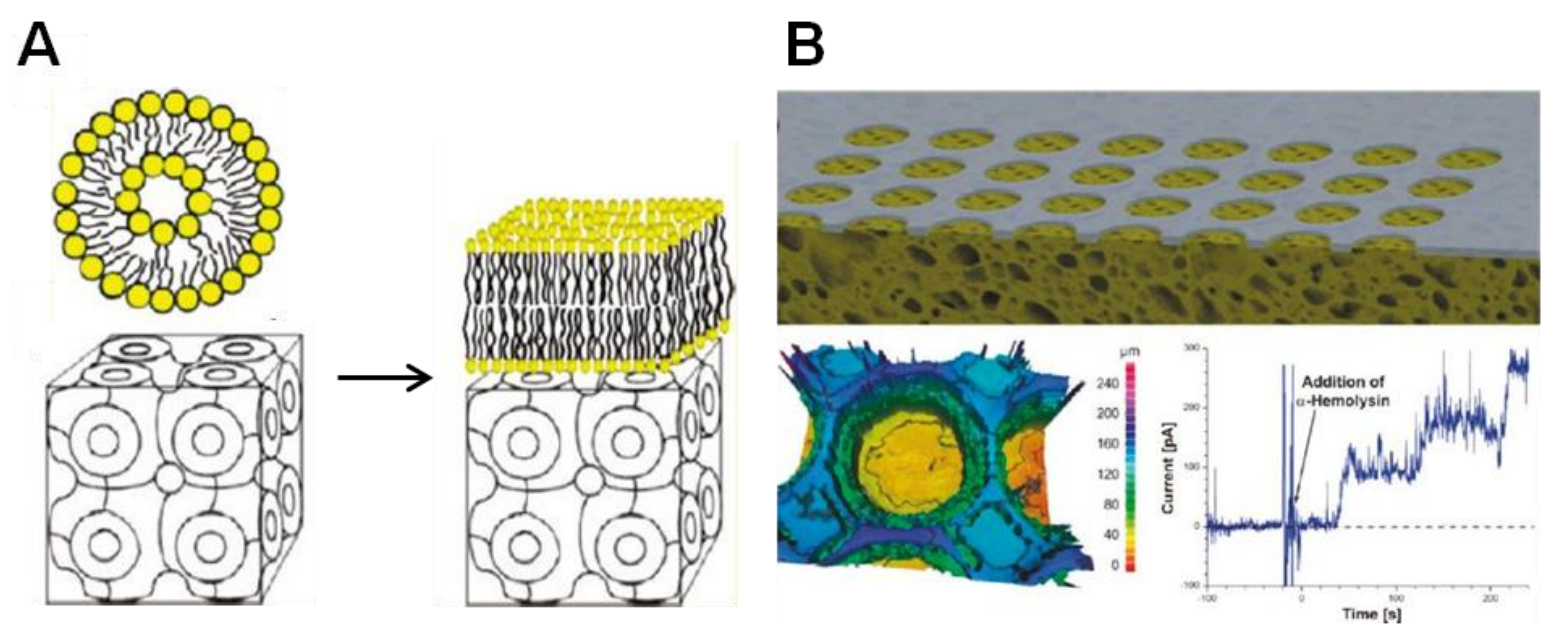

Abb. 1.3: A Schematische Darstellung der Bildung porenüberspannender Membranen durch Vesikelspreiten auf mesoporösem Silizium (nicht maßstabsgetreu, nach Claesson et al.). ${ }^{[32]}$ B Schematische Darstellung eines ETFE/Hydrogel-Substrates zur Bildung porenüberspannender Membranen (oben). Dreidimensionale optische rastermikroskopische Aufnahmen einer Einzelpore (unten links, Porendurchmesser $300 \mu \mathrm{m}$ ) und zeitlicher Verlauf des Stromsignals bei Zugabe von $\alpha$-HL (unten rechts) verdeutlichen die Eignung eines solchen Substrates zur Untersuchung von Transportprozessen an Membranen. Abbildung nach Roerdink Lander. ${ }^{[33]}$

Um eine automatisierte Analyse von Transportprozessen über freistehende Membranen zu ermöglichen, wurden bereits auf Basis von Lipidvesikeln Systeme für eine regelmäßige Anordnung bei voller Kontrolle über die Volumina der membrangetrennten Kompartimente entwickelt. So präsentierten Wittenberg et al. ein mit $\mathrm{Al}_{2} \mathrm{O}_{3}$ beschichtetes Siliziumsubstrat mit hochgeordneten, mikrometergroßen Poren mit geschlossenen Böden. ${ }^{[34]}$ Vesikel können innerhalb der geschlossenen Poren eingelagert werden und so eine regelmäßige Anordnung für automatisierte Analysen erreicht werden.

Eine Weiterentwicklung dieser Idee stellen sogenannte droplet interface bilayer Systeme dar. Syeda et al. präsentieren in diesem Zusammenhang eine Methode, um voneinander separierte, mit einer Lipidmonoschicht überspannte Poren nacheinander in einem screening Prozess elektrisch zu kontaktieren. ${ }^{[35]}$ Ein mit einer zweiten Lipidmonoschicht bedeckter Tropfen wird an einer Elektrode hängend jeweils mit einer monoschichtbedeckten Pore in Kontakt gebracht, sodass sich eine Lipiddoppelschicht ausbilden kann. Bei Insertion von Transportproteinen ( $\alpha$-HL oder der Kaliumkanal Kcv) können so in jedem Kompartiment andere 
Substrate platziert und ihr Einfluss auf das detektierte Stromsignal des Kanals untersucht werden (Abb. 1.4, A und B).

Einen ähnlichen Ansatz verfolgten auch Castell et al. und präparierten Membranen an den Grenzschichten zwischen wässriger Phase und Ölphase in einem Mikrofluidik-Substrat (Abb. 1.4, C). ${ }^{[36]}$ Durch total internal reflection fluorescence (TIRF)-Mikroskopie konnte so der passive Transport von Calciumionen durch membranständiges $\alpha$-HL und die Wirkung von $\gamma$-Cyclodextrin auf den Kanal untersucht werden.

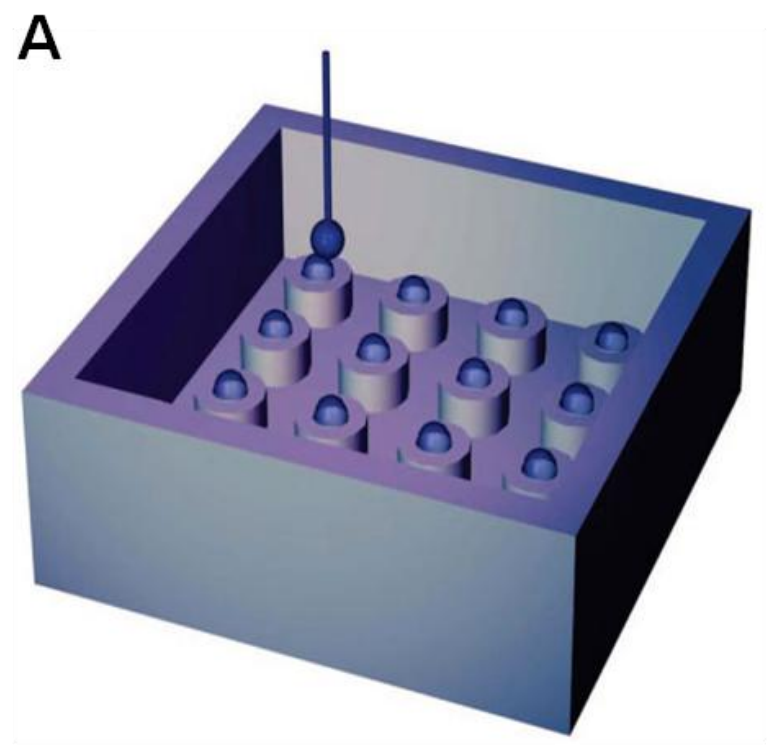

B
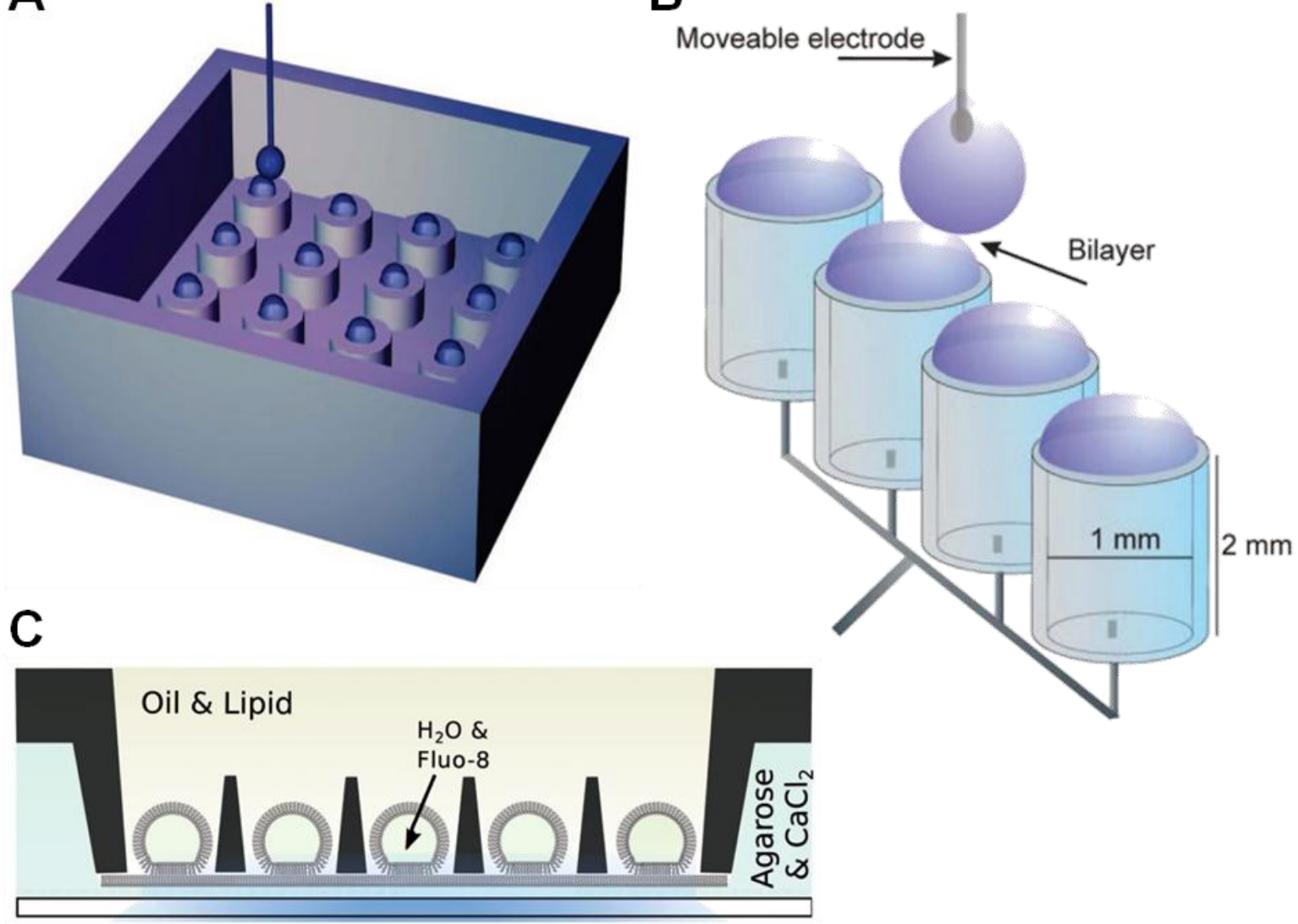

Abb. 1.4: Schematische Darstellung von droplet interface bilayer Systemen. A Ein array aus 16 elektrisch kontaktierten Poren, gefüllt mit wässriger Lösung und versetzt mit unterschiedlichen molekularen Hemmstoffen. Die einzelnen Tropfen sind jeweils mit einer Lipidmonoschicht bedeckt. B Ein einzelner Tropfen wässriger Lösung an einer beweglichen Elektrode ist ebenfalls bedeckt mit einer Lipidmonoschicht und enthält das zu untersuchende Transportprotein. Bei Kontakt der Lipidmonolage des beweglichen Tropfens mit einer zweiten Lipidmonolage einer Pore bildet sich spontan eine Doppelschicht aus, in welche das Protein insertieren kann. Über beide Elektroden kann eine Spannung angelegt werden und Ströme durch den Proteinkanal in Abhängigkeit der vorhandenen Hemmstoffe gemessen werden. Abbildungen nach Syeda et al. ${ }^{[35]} \mathbf{C}$ In einzelnen Poren platzierte Tropfen wässriger Lösung, umgeben von einem Öl-Lipid-Gemisch bilden an der Grenzschicht eine Lipidmonolage aus. An der Grenzschicht des lipidgefüllten Substrates zu einem zweiten, mit wässriger Lösung gefüllten Kompartiments, bildet sich eine zweite Lipidmonolage aus. An den Grenzflächen der Monolagen bilden sich jeweils Doppelschichten aus, in welche $\alpha$-HL insertiert. Durch Einschluss eines $\mathrm{Ca}^{2+}$-sensitiven Fluoreszenzfarbstoffs in den Tropfen (Fluo-8) kann der Transport von Calciumionen durch $\alpha$-HL aus dem unterliegenden wässrigen Kompartiment in die Tropfen hinein optisch verfolgt werden. Abbildung nicht maßstabsgetreu, nach Castell et al. ${ }^{[36]}$ 
Mit diesen Systemen gelang ein systematisches screening der Aktivität von transmembranständigen Kanalproteinen in Gegenwart unterschiedlicher Substrate. Nachteile der droplet interface bilayer Methode ist die vergleichsweise schwierige Handhabung. Durch das kleine Probenvolumen (z. B. 1,5 $\mu$ L-Tropfen bzw. 0,2 $\mu$ L-Tropfen) bei gleichzeitiger Exposition an Luft, hat Verdampfung einen großen Einfluss auf die Konzentrationen der untersuchten Hemmstoffe. Lipidmonoschichten an Luft sind weiterhin anfällig für Verunreinigungen, sodass unter sterilen Bedingungen gearbeitet werden muss und der Übergang der elektrischen Kontaktierung unterschiedlicher Poren ist bei den beschriebenen Systemen zu zeitintensiv für ein anwendbares high throughput screening.

Ein robustes System mit einer hohen Anzahl einheitlich geformter und hochgeordneter Poren bieten poröse Substrate auf Basis von Aluminium oder Silizium. Substrate aus $\mathrm{Al}_{2} \mathrm{O}_{3}$ mit hexagonal angeordneten Poren mit Durchmessern von $50 \mathrm{~nm} \leq d \leq 440 \mathrm{~nm}$ lassen sich durch einen elektrochemischen Anodisierungsprozess in sauren wässrigen Lösungen präparieren (Abb. 1.5, A und B). ${ }^{[37-39]}$ In Siliziumsubstrate lassen sich durch gezielte chemische Ätzprozesse hochgeordnete Porenstrukturen praktisch beliebiger Form und Größe bilden (Kapitel 3.2.7). ${ }^{[40]}$

Substrate aus $\mathrm{Al}_{2} \mathrm{O}_{3}$ wurden bereits erfolgreich eingesetzt, um durch elektrische Messungen Gramicidin $\mathrm{D}^{[41]}$ und das Kanalprotein outer membrane protein $F(\mathrm{OmpF})^{[42]}$ in lösungsmittelhaltigen porenüberspannenden Membranen $\mathrm{zu}$ untersuchen. Durch Spreiten von Vesikeln konnte weiterhin die lichtgetriebene Protonenpumpe Bacteriorhodopsin (bR), ${ }^{[43]}$ sowie der Wasserkanal Aquaporin $Z^{[44,45]}$ funktionell in porenüberspannende Membranen rekonstituiert werden. Die Oberfläche der $\mathrm{Al}_{2} \mathrm{O}_{3}$-Substrate wurde dazu teilweise mit selbstorganisierenden Monoschichten (self assembled monolayers, SAMs) bzw. Polymerschichten funktionalisiert. Durch ihre optische Transparenz können poröse $\mathrm{Al}_{2} \mathrm{O}_{3}$-Substrate auch mit (fluoreszenz-)mikroskopischen Techniken untersucht werden (Abb. 1.5, C-E). ${ }^{[38,39]}$ 

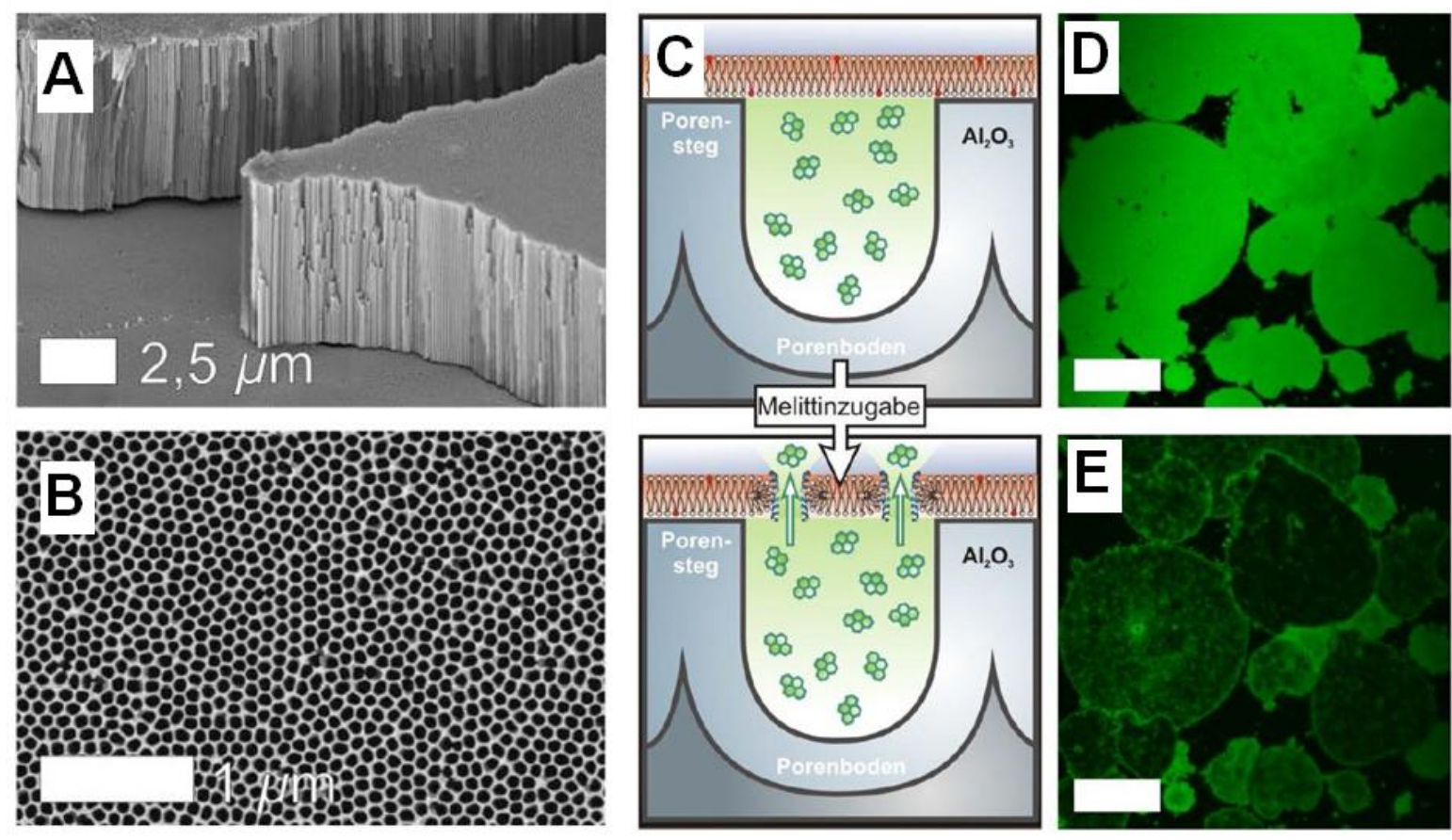

Abb. 1.5: A, B Elektronenmikroskopische Aufnahmen (scanning electron microscopy, SEM) eines porösen $\mathrm{Al}_{2} \mathrm{O}_{3}$-Substrates in der Seitenansicht (A) bzw. Aufsicht (B). Porendurchmesser $d=70 \mathrm{~nm}$. C Schematische Darstellung des Farbstoffeinschluss (oben) unter einer porenüberspannenden Membran (rot) in Poren mit geschlossenen Böden und die Freisetzung des Farbstoffs aus den Poren nach Zugabe des Membrandefekte induzierenden Peptids Melittin (unten, nicht maßstabsgetreu). D, E Konfokalmikroskopische Aufnahmen der Fluoreszenz des eingeschlossenen Farbstoffs vor (D) und nach (E) Zugabe von Melittin. Maßstabsbalken $20 \mu \mathrm{m}$. Alle Abbildungen nach Carnarius. ${ }^{[39]}$

Poröse $\mathrm{Al}_{2} \mathrm{O}_{3}$-Substrate eignen sich für elektrische wie optische Messungen von Transportprozessen über porenüberspannende Membranen, lassen sich mit offenen wie geschlossenen Porenböden präparieren und liefern eine Vielzahl identisch geformter Poren in hexagonaler Anordnung. Nachteile solcher porösen Substrate ist neben dem beschränkten Porendurchmesser (maximal $420 \mathrm{~nm}$ ) ihre mechanische Instabilität. Ihre Handhabung erfordert ein hohes $\mathrm{Maß}$ an Vorsicht, da die dünnen Substrate schnell brechen. In Hinblick auf vollautomatisierte Prozesse für biosensorische oder pharmazeutische Anwendungen wären stabilere Substrate besser geeignet. Eine individuelle Adressierung einzelner Poren durch Elektroden wurde aufgrund der geringen Porendurchmesser bisher ebenfalls noch nicht realisiert.

Als eines der meistverwendeten Materialien zur Bildung poröser Substrate gelten wafer aus Silizium-Einkristallen. Durch die (Weiter-)Entwicklung verschiedener Techniken lassen sich Poren beliebiger Geometrie mit hoher Präzision in solche Substrate ätzen (Kapitel 3.2.7). Oxid- und Nitridschichten können kontrolliert in unterschiedlichen Dicken aufgebracht werden und eignen sich für chemische Modifikationen der Oberflächenstruktur. Die Bildung porenüberspannender Membranen auf porösen Siliziumsubstraten konnte bereits vielfach erfolgreich gezeigt und Membranen mit verschiedenen biophysikalischen Methoden charakterisiert werden. Dabei wurden sowohl lösungsmittelhaltige, ${ }^{[46,47]}$ als auch lösungsmittelfreie porenüberspannende Membranen durch Spreiten unilamellarer Vesikel, ${ }^{[48-53]}$ 
Ausbreitung einer planaren Membran, ${ }^{[54]}$ oder direktes Auftragen durch eine mit einer Lipidmonoschicht bedeckten Luftblase (bubble-collapse deposition) präpariert. ${ }^{[55]}$

Siliziumunterstützte porenüberspannende Membranen konnten weiterhin bereits zur elektrischen wie optischen Untersuchung von Transportprozessen anhand von Gramicidin, ${ }^{[47,56,57]}$ dem viralen Kanalprotein $\mathrm{Vpu}^{[58]}$ und $\alpha-\mathrm{HL}^{[51,59,60]}$ eingesetzt werden. Besonders hervorzuheben sind Anwendungen goldbedeckter poröser Siliziumnitridsubstrate für Oberflächenplasmonenresonanz (surface plasmon resonance, SPR)-Messungen, mit denen die Bindung eines Antikörpers an $\alpha$-HL in porenüberspannende Membranen zeitaufgelöst verfolgt werden konnte (Abb. 1.6). ${ }^{[53]}$

A

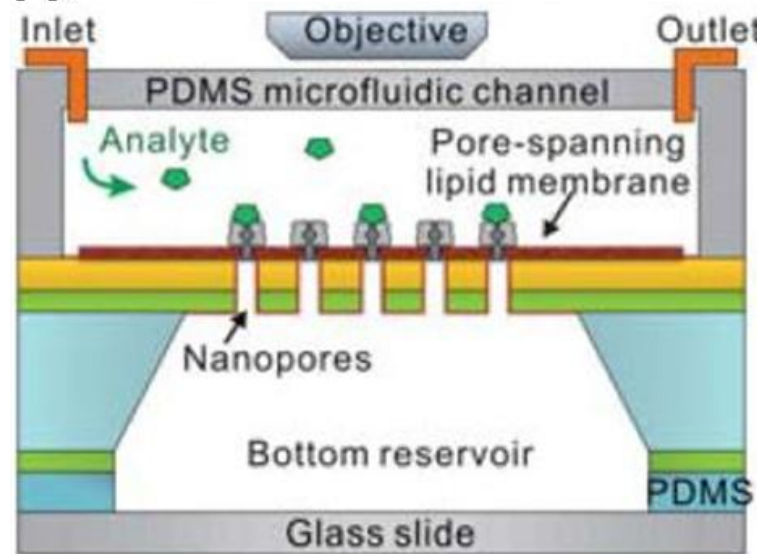

$\mathrm{B}$
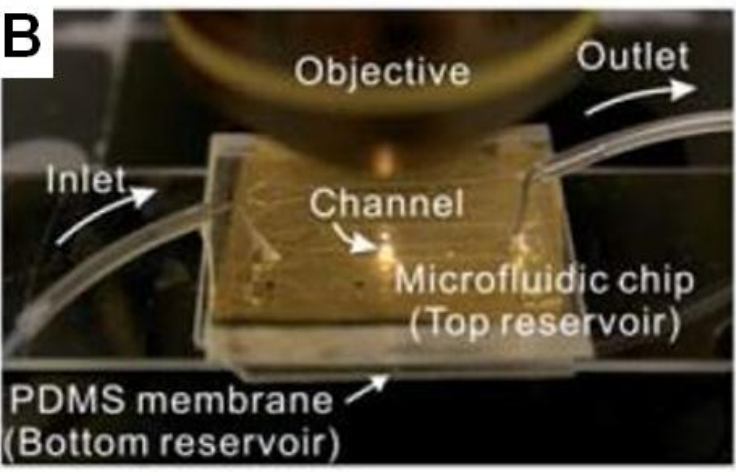

C
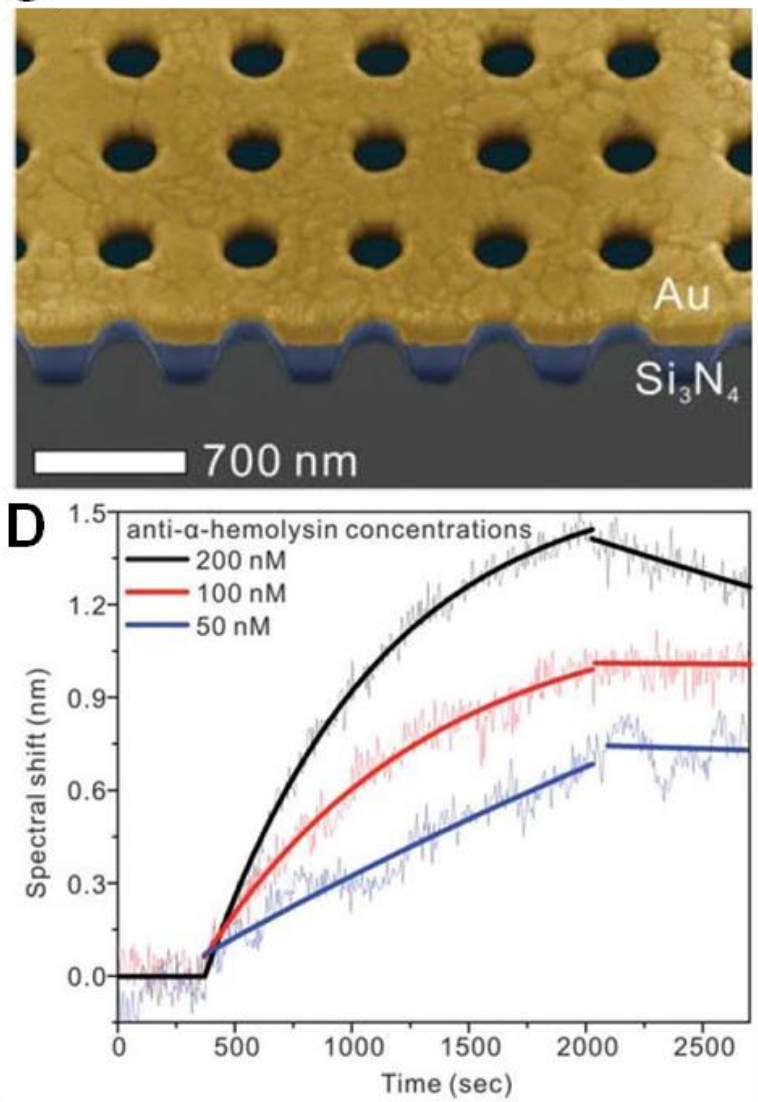

Abb. 1.6: SPR-Messung an porenüberspannenden Membranen auf porösen Siliziumnitridsubstraten nach $\mathrm{Im}$ et al. ${ }^{[53]}$ A Schematische Darstellung des Messaufbaus (nicht maßstabsgetreu). Ein goldbedecktes, poröses Siliziumnitridsubstrat (grün mit gold, Porendurchmesser $d=200 \mathrm{~nm}$ ) wird mit einer porenüberspannenden Membran bedeckt (rot) und $\alpha$-HL insertiert. Das Substrat wird auf Glas zwischen Kammern aus Polydimethylsiloxan (PDMS) fixiert, sodass Analyte mit Hilfe eines Mikrofluidik-Systems appliziert werden können. B Fotografische Aufnahme des Messaufbaus. C Eingefärbte SEM-Aufnahme eines goldbedeckten Siliziumnitridsubstrates. D Zeitlich aufgelöste Bindung eines $\alpha$-HL-Antikörpers an die mit $\alpha$-HL versetzten porenüberspannenden Membranen, gemessen mittels SPR. Alle Abbildungen nach Im et al. ${ }^{[53]}$

Ganesan und Boxer gelang es, ein Membran-Interferometer zu konstruieren, mit welchem sie neben der optischen Untersuchung eines gramicidininduzierten $\mathrm{Na}^{+} / \mathrm{H}^{+}$-Antiports auch die 
genaue Position und Form porenüberspannender Membranen bestimmen konnten (Abb. 1.7). ${ }^{[47]}$
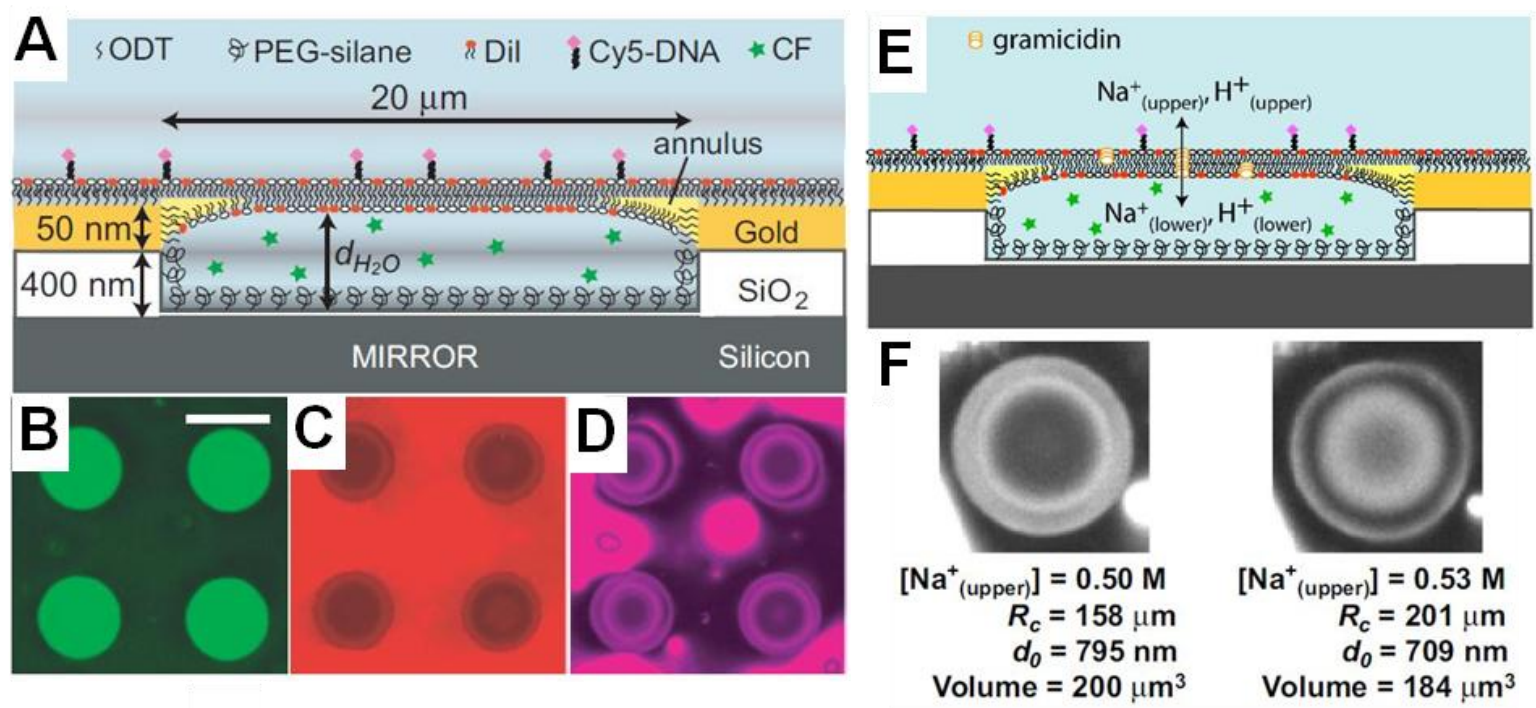

Abb. 1.7: A Schematische Darstellung eines aus einer porenüberspannenden Membran konstruierten MembranInterferometers nach Ganesan und Boxer (nicht maßstabsgetreu). ${ }^{[47]}$ Ein poröses Substrat aus $\mathrm{SiO}_{2}$ auf $\mathrm{Silizium}$ wurde mit einer Schicht aus Gold bedeckt, welche mit Octadekanthiol (ODT) hydrophob funktionalisiert wurde. Die Poreninnenwände wurden mit Polyethylenglycol (PEG)-Silan ausgekleidet. Unterhalb der Membran, welche mit fluoreszenzmarkiertem Lipid (rot) und DNA (violett) dotiert ist, ist im Poreninneren ein $\mathrm{pH}$-sensitiver Fluoreszenzfarbstoff eingeschlossen (grün). B-D Fluoreszenzmikroskopische Aufnahmen eines Bereiches von vier membranüberspannten Poren. B Fluoreszenz des im Poreninneren eingeschlossenen Farbstoffs Carboxyfluorescein (CF), C Fluoreszenz des Membranfarbstoffs DiI, D Fluoreszenz des mit Cy5 markierten DNA-LipidKonjugats innerhalb der Membran. E Schematische Darstellung des gramicidininduzierten $\mathrm{Na}^{+} / \mathrm{H}^{+}$-Antiports (nicht maßstabsgetreu). F Fluoreszenz-Interferenz-Kontrastmikroskopische Aufnahmen erlauben Rückschlüsse auf die Position und Form der porenüberspannenden Membran in Abhängigkeit unterschiedlicher $\mathrm{Na}^{+}$-Konzentrationen in der überstehenden Lösung.

Poröse Substrate auf Siliziumbasis eignen sich somit neben der Untersuchung von peptid- und proteinvermittelten Transportprozessen über Membranen durch elektrische und optische Methoden ebenfalls für die Anwendung speziellerer Methoden, wie SPR und Interferometrie. Durch die Bildung von Poren beliebiger Größe, Geometrie und ihrer symmetrischen Anordnung auf dem Substrat sind prinzipiell vollautomatische Systeme zur Untersuchung von Transportprozessen über Membranen möglich. Ein limitierender Faktor für die technische Anwendung poröser Siliziumsubstrate in biosensorischen oder high throughput screening Systemen, ist ihre optische Intransparenz. Um Prozesse innerhalb von Poren optisch verfolgen zu können, müssen die Poren aufgrund der beschränkten Eindringtiefe von Licht einen gewissen Mindestdurchmesser aufweisen (Kapitel 3.5, Eindringtiefe). Bisher gelang die Bildung porenüberspannender Membranen auf Substraten mit Porendurchmessern größer 2,5 $\mu \mathrm{m}$ nur durch Anwendung der painting-Technik. Dabei in der Membran verbleibendes Lösungsmittel beeinflusst die Struktur und Funktionalität membranständiger Proteine und erschwert dadurch ihre Untersuchung. ${ }^{[61]}$ Dies erklärt, warum bisher nur relativ unempfind- 
liche Transmembranproteine, wie das als Monomer wasserlösliche $\alpha$-HL untersucht worden sind.

Poren mit Durchmessern kleiner 2,5 $\mu \mathrm{m}$ erlauben durch Spreiten von (Proteo-)Liposomen die Bildung lösungsmittelfreier porenüberspannender Membranen. Da die Mengen an Protein, welche z. B. mit Hilfe von Detergens in Liposomen und somit in porenüberspannenden Membranen rekonstituiert werden kann, eher gering ist, lassen sich auf Substraten mit kleinen Porenöffnungen nur wenige hundert Proteine innerhalb der Porenfläche einlagern. Besonders für eine Untersuchung langsamer Transportprozesse, wie dem Protonentransport durch sogenannte Protonenpumpen (Raten im Bereich $100 \mathrm{~s}^{-1}$ ) ergeben sich dadurch schlechte Signal-zu-Rauschen (S/N)-Verhältnisse, die zum Teil mit den momentan verfügbaren Techniken nicht detektiert werden können. Optimal wären demnach lösungsmittelfreie Membranen, welche Poren mit Durchmessern im Bereich von z. B. $10 \mu \mathrm{m}$ überspannen und so eine uneingeschränkte optische Untersuchung proteingesteuerter Transportprozesse bei gutem S/N-Verhältnis ermöglichen. Erste Ansätze hierzu präsentierten Sumitomo et al., die durch Aufbringen eines dünnen $(120 \mathrm{~nm})$ und dadurch noch optisch transparenten, in die Porenfläche überstehenden Stegbereichs aus $\mathrm{SiO}_{2}$ eine Bildung lösungsmittelfreier porenüberspannender Membranen über Öffnungen mit Durchmessern bis $8 \mu \mathrm{m}$ ermöglichten.

Als letztes der für die Untersuchung von Transportprozessen über freistehende Membranen genutzten Systeme sollen nachfolgend Substrate aus Polymeren vorgestellt werden. Durch die breite Vielfalt zur Verfügung stehender Polymere lassen sich hydrophile wie hydrophobe Substrate unterschiedlicher Größe, Form und Flexibilität bilden. Erste Anwendungen poröser Polymerschichten zur Bildung porenüberspannender Membranen fanden Polycarbonatmembranen, wie sie für die Extrusion von Lipidvesikeln zum Einsatz kommen. Sie konnten für elektrische wie optische Untersuchungen des Transports durch $\alpha$-HL-Kanäle verwendet werden $^{[62]}$ bzw. zur elektrischen Untersuchung eines membranständigen Glutamat Rezeptors. ${ }^{[63]}$ Dabei konnten Porendurchmesser zwischen 0,8 und $70 \mu \mathrm{m}$ realisiert werden.

Polymere wie PDMS, Polymethylmethacrylat (PMMA), ETFE, das üblicherweise als Fotolack verwendete SU-8 (ein Epoxidharz) oder Parylene sind die meistverwendeten Substanzen für die Bildung poröser Substrate. Oftmals werden mikrofluidisch zugängliche Substrate aus Polymeren auf unterstützenden Materialien wie Glas präpariert. Durch Anwendung moderner Mikroprint-Techniken und dem Einsatz hochentwickelter Fotolacke und Fotomasken lassen sich komplexe Strukturen mit vielfältigen Einsatzmöglichkeiten präparieren.

An multiporösen Polymersubstraten mit porenüberspannenden Membranen ließen sich erfolgreich elektrisch Transportprozesse vermittelt durch Gramicidin, ${ }^{\text {[64-68] }}$ Alamethicin, ${ }^{[64,65,69]} \alpha-\mathrm{HL}^{[67-71]}$ und dem Porin FomA ${ }^{[68]}$ untersuchen. Dabei wurden z. T. mit Mikrofluidik ausgestattete, hochgeordnete Multiporen-arrays eingesetzt, wie sie unter 
Abb. 1.8 schematisch dargestellt sind. In einzelnen Arbeiten wurde für hier beschriebene porenüberspannende Membranen auf Polymersubstraten Möglichkeiten zur Erhöhung der Stabilität der Membranen präsentiert ${ }^{[67]}$ und Systeme für sensitivere elektrische Messungen des Transports durch Kanalproteine. ${ }^{[64]}$
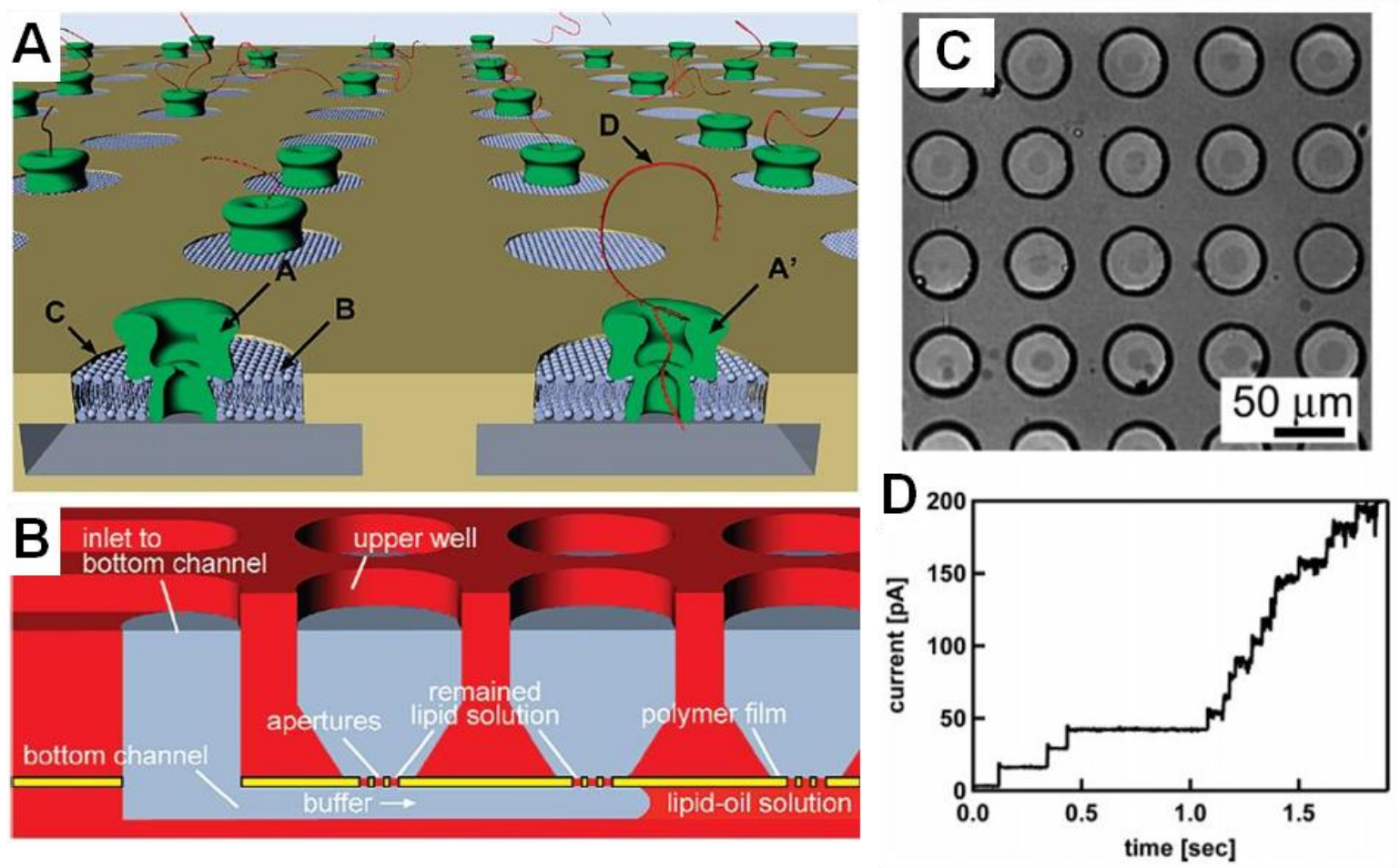

Abb. 1.8: A Schematische Darstellung eines arrays porenüberspannender Membranen zur elektrischen Untersuchung des Transports einzelner DNA-Moleküle (rote Fäden) durch $\alpha$-HL Moleküle (grün). B Seitenansicht eines schematischen Mikrofluidik-Aufbaus zur Bildung porenüberspannender Membranen. Einzelne Kompartimente sind mit wässriger Lösung gefüllt (grau). Am Boden der Kompartimente befinden sich die unter A dargestellten Öffnungen, welche bei Durchfluss einer Lösungsmittel-Lipid-Mischung durch einen unterliegenden Kanal, gefolgt vom Spülen mit einer wässrigen Lösung mit Membranen überspannt werden können. C Mikroskopische Aufnahme regelmäßig angeordneter membranüberspannter Poren. Der dunklere Bereich im Zentrum der Poren entspricht den Membranen, der hellere Rand im Porenbereich entspricht der Plateau-Gibbs-Phasengrenze (Kapitel 4.1.1, Ausfrieren des Lösungsmittels). D Zeitaufgelöstes Stromsignal einer einzeln adressierten membranüberspannten Pore bei Insertion von $\alpha$-HL. Abbildungen A und B nach Osaki $e t$ $a l .,{ }^{[70]} \mathrm{C}$ und D nach Le Pioufle et al. ${ }^{[65]}$

Neben arrays offener Poren wurden auch Poren mit geschlossenen Böden verwendet, um den Transport in membraneingeschlossene Kompartimente optisch zu verfolgen. Ota et al. entwickelten hierzu einen mit einer Vielzahl identischer Kammern bestückten MikrofluidikKanal, in dessen Kammern sie einen Fluoreszenzfarbstoff unterhalb einer Membran einschliessen und dessen Austritt durch $\alpha$-HL-Kanäle verfolgen konnten (Abb. 1.9). ${ }^{[72]}$ Mikrofluidisch adressierbare Systeme mit unter einer porenüberspannenden Membran eingeschlossenen Kompartimenten wurden nicht nur für die Untersuchung von Transportprozessen genutzt, sondern konnten ebenfalls als Femtoliter-Reaktoren für enzymatische Reaktionen ${ }^{[73]}$ und als Mikrotropfen für eine in vitro Proteinsynthese eingesetzt werden. ${ }^{[74]}$ 
A

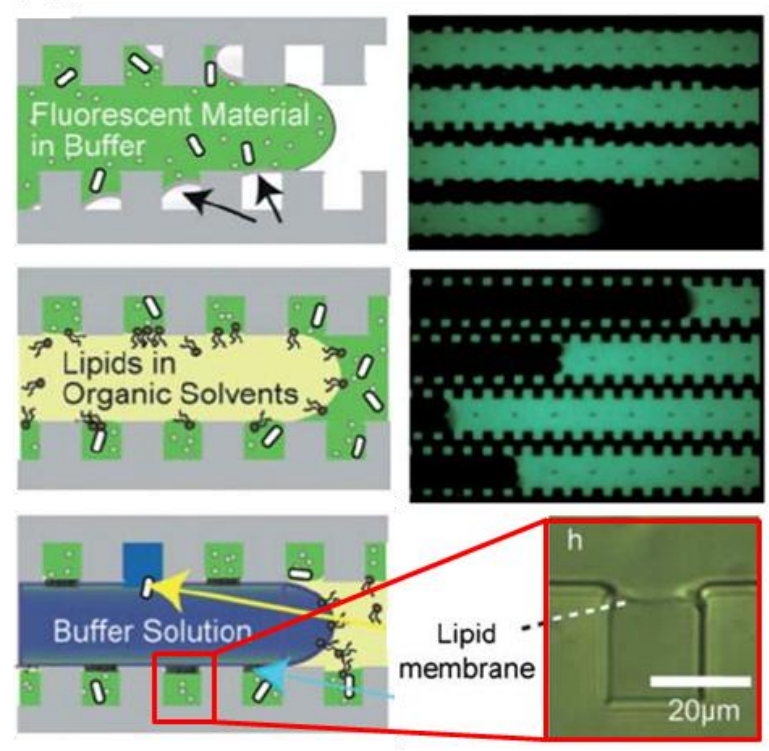

B

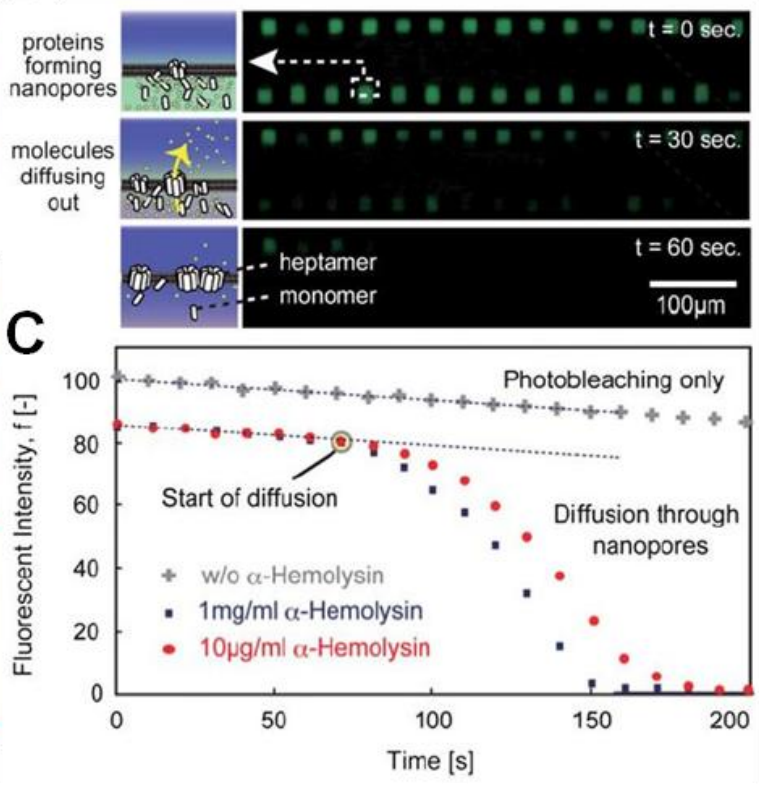

Abb. 1.9: A Schematische Darstellung der Bildung porenüberspannender Membranen zum Einschluss eines Fluoreszenzfarbstoffs (grün) in einzelnen Kompartimenten entlang eines Mikrofluidik-Kanals in einem Polymersubstrat (linke Seite). Entsprechende fluoreszenzmikroskopische Aufnahmen sind rechts dargestellt. Eine wässrige Lösung eines Fluoreszenzfarbstoffs wird durch einen Kanal in einem PDMS-Substrat geführt (oben). Anschließend wird mit einem Lipid-Lösungsmittelgemisch gespült und es bilden sich Lipidmonolagen an der Grenzfläche zu den einzelnen Mikrokammern (Mitte). Durch nachfolgendes Spülen mit wässriger Lösung (diesmal ohne Fluorophor) bilden sich spontan Lipiddoppelschichten und Farbstoff kann stabil in einzelnen Kammern eingeschlossen werden (unten). Eine durchlichtmikroskopische Aufnahme einer individuellen membranbedeckten Kammer ist vergrößert dargestellt (unten rechts). B Durch Spülen des Kanals mit einer $\alpha$-HL-haltigen wässrigen Lösung kann dieses Protein in die porenüberspannenden Membranen insertieren, dort heptamere Kanäle bilden und so zu einem Farbstoffaustritt aus den Kammern führen. C Die Fluoreszenzintensität indvidueller Kammern kann zeitaufgelöst und in Abhängigkeit der Proteinkonzentration verfolgt werden. Abbildungen nach Ota et al..$^{[72]}$

Wie für droplet interface bilayer Systeme (Abb. 1.4), wurden auch für polymerbasierte arrays porenüberspannender Membranen konkrete biosensorische Anwendungen präsentiert. Hervorzuheben sind der Einsatz eines solchen Aufbaus als hochempfindlicher Sensor zur Kokaindetektion. Kawano et al. gelang es, mit einem Zeitaufwand von weniger als einer Minute Kokain in Konzentrationen im Bereich des derzeitigen Detektionslimits für konventionelle Verfahren nachzuweisen. ${ }^{[75]}$ Sie nutzten dazu ein kokainbindendes DNA-Aptamer in Kombination mit $\alpha$-HL-haltigen porenüberspannenden Membranen. Das Stromsignal bei einem Transport des DNA-Aptamers durch $\alpha$-HL-Poren unterschied sich dabei vom Signal, welches bei Eintritt eines kokaingebundenen DNA-Aptamers in eine $\alpha$-HL-Pore detektiert wurde (Abb. 1.10). 

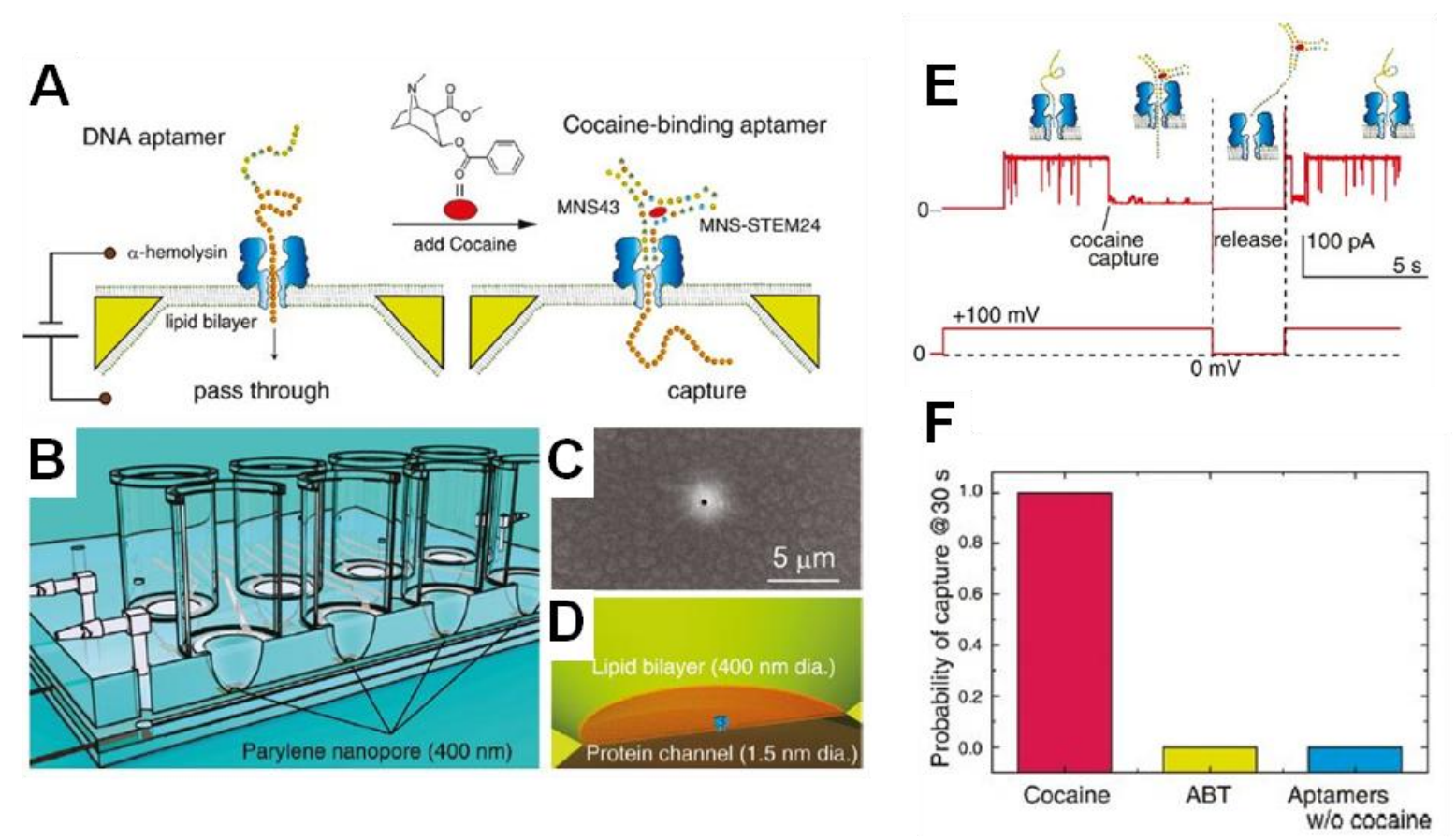

Abb. 1.10: A Schematische Darstellung der Nutzung porenüberspannender Membranen als Kokain-Sensor. DNA-Aptamere passieren bei Anlegen einer elektrischen Spannung die Membran durch $\alpha$-HL-Kanäle in den Membranen. Bindet Kokain an ein DNA-Aptamer, so verändert sich dessen Struktur und es kann den $\alpha$-HLKanal nicht passieren. B Schematische Darstellung des Messaufbaus. Einzelne Poren sind in ein Parylenesubstrat eingefügt und über Mikrofluidik-Kanäle miteinander verbunden. C SEM-Aufnahme einer individuellen Pore am Boden einer einzelnen Kammer, wie sie in B dargestellt ist. D Schematische Darstellung einer porenüberspannenden Membran mit integriertem $\alpha$-HL (blau). E Stromsignal (oben) bei angelegter Transmembranspannung (unten) von 100 bzw. $0 \mathrm{mV}$. Das Passieren einzelner DNA-Aptamere durch einen $\alpha$-HL-Kanal ist durch punktuelle Ausschläge gekennzeichnet. Bei Blockierung des Kanals mit kokainbindendem DNA-Aptamer fällt das Stromsignal dauerhaft ab. F Auftragung der Wahrscheinlichkeit einer Kanalblockierung innerhalb von $30 \mathrm{~s}$ in Gegenwart unterschiedlicher Substrate. Die Auftragung verdeutlicht die hohe Sensitivität gegenüber Kokain (rot) im Vergleich zu kokainfreien Proben (blau) und dem Kokain-Analogon Aminobenztropin (ABT, gelb). Schematische Darstellungen bis auf B nicht maßstabsgetreu. Abbildungen nach Kawano et al..$^{[75]}$

Baaken et al. etablierten die Nutzung eines membranüberspannten Porenarrays, mit welchem sie ionenleitfähigkeitsbasiert Einzelmolekül-Massenspektrometrie an Mischungen von Polyethylenglycolmolekülen unterschiedlicher Länge durchführen konnten. ${ }^{[76]}$ Dies war durch eine individuelle elektrische Kontaktierung jeder Pore eines $4 \cdot 4$ arrays bei gleichzeitiger Insertion von $\alpha-\mathrm{HL}$ in den porenüberspannenden Membranen möglich (Abb. 1.11). 

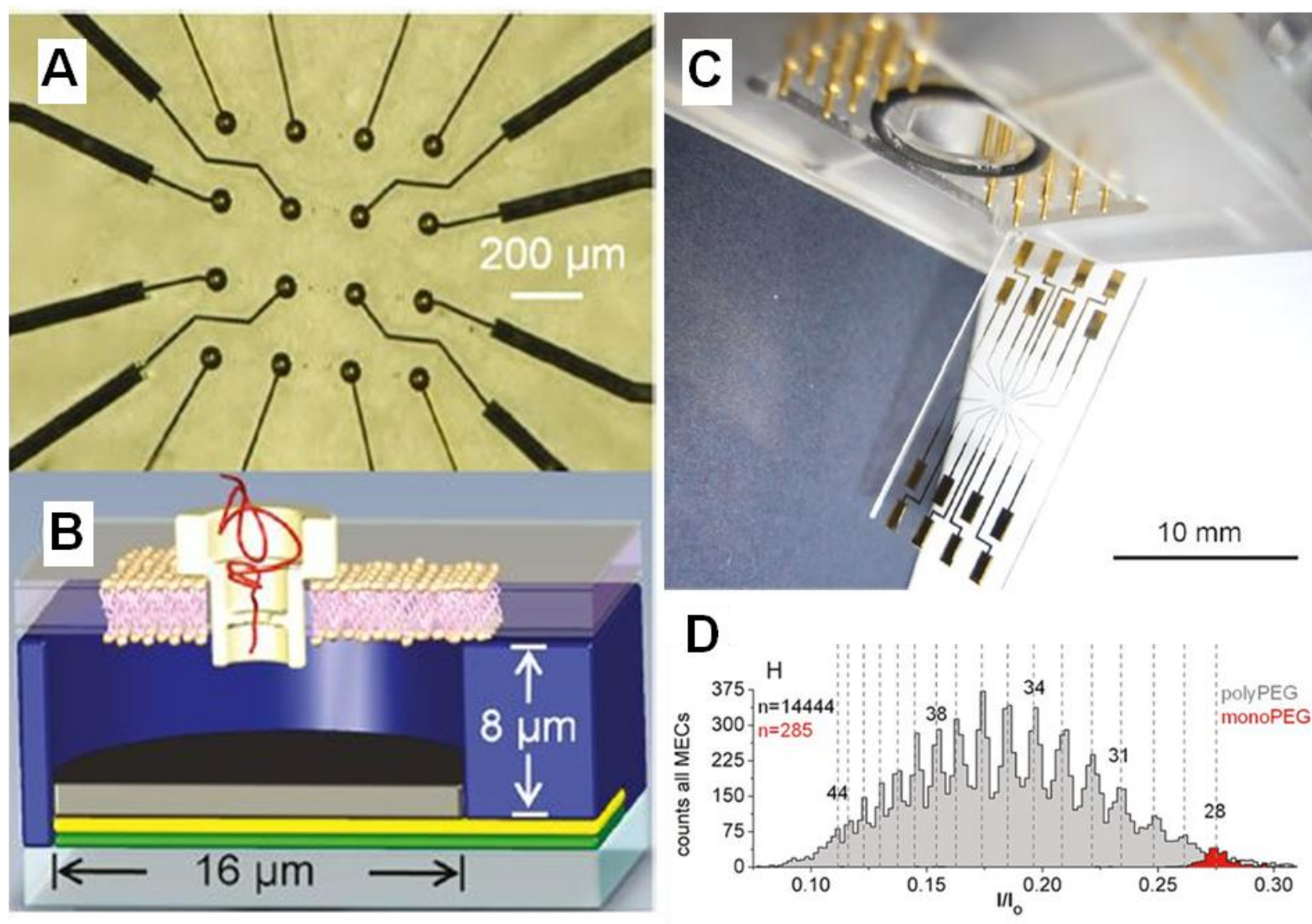

Abb. 1.11: A Fotografische Aufnahme eines 4.4 arrays von mit Elektroden individuell kontaktierten Poren auf einem Glassubstrat. B Schematische Darstellung einer individuellen Pore aus SU-8 (blau) mit einer $\alpha$-HLhaltigen porenüberspannenden Membran. Auf dem Boden der geschlossenen Pore ist eine Ag/AgCl-Elektrode (grau) auf einer Gold- (gelb) und einer Chromschicht (grün) aufgebracht (Darstellung nicht maßstabsgetreu). C Fotografische Aufnahme einer Kammer zur elektrischen Kontaktierung eines in A dargestellten Chips. D Histogramm der normalisierten Reststromwerte bei Blockierung einzelner $\alpha$-HL-Poren durch PEG-Moleküle unterschiedlicher Länge. Durch Auftragung dieser Stromwerte können die PEG-Moleküle in massenspektrometrischer Art voneinander getrennt detektiert werden. Abbildungen nach Baaken et al. ${ }^{[76]}$

Besonders am Beispiel der zuletzt vorgestellten multiporösen Substrate und ihrer Anwendung für sensorische Zwecke wird deutlich, dass porenüberspannende Membranen vielversprechende Modellsysteme für technische Anwendungen sind. Poren lassen sich in beliebiger Form hochgeordnet in Substraten bilden, mit mikrofluidischen Systemen kombinieren und erlauben so die Konstruktion vollautomatischer (Bio-)Sensoren und high throughput screening Systeme. Arbeiten zur Verbesserung der Stabilität porenüberspannender Membranen und verbesserte Detektoren treiben die Entwicklung in diesem Gebiet weiter voran. Trotz der großen Fortschritte und vorgeschlagener möglicher Anwendungen solcher Systeme wurden bisher nur eine Handvoll Proteine und Peptide funktionell in porenüberspannende Membranen rekonstituiert. Komplexere und empfindlichere Transmembranproteine bieten oftmals interessante sensorische Anwendungen, brauchen aber neue und schonendere Rekonstitutionsmethoden und Systeme, die diese erlauben. Dementsprechend bietet das Gebiet mikro- und nanoporöser membranüberspannter Substrate trotz der Entwicklung der 
letzten Jahre besonders in Bezug auf die Untersuchung von Transportprozessen durch Membranproteine noch Raum für Optimierungen.

\subsection{Elektrochemische Gradienten}

Eine Hauptfunktion von Transportproteinen in biologischen Membranen ist der Aufbau und die Nutzung (elektro-)chemischer Gradienten. Voraussetzung für den Aufbau stabiler Gradienten, ist die Trennung zweier wässriger Kompartimente durch hochgradig impermeable Membranen. Selektiver Transport von Stoffen durch membranständige Proteine führt zu deren Anreicherung in einem der beiden Kompartimente und so zur Bildung eines Gradienten. Solche Gradienten sind von großer Bedeutung für eine Vielzahl zellulärer Prozesse, wie den Aufbau von Aktionspotentialen für die Reizweiterleitung, oder die Bildung von Adenosintriphosphat (ATP) in Mitochondrien. ${ }^{[77,78]}$ Die nötige Energie für einen aktiven Transport von Stoffen über eine Membran beziehen Transportproteine z. B. aus Redox-Reaktionen (Komplexe I, III und IV der Atmungskette) oder aus der Hydrolyse von ATP (ATPasen). Eine schematische Darstellung eines (elektro-)chemischen Gradienten ist in Abb. 1.12 aufgeführt.

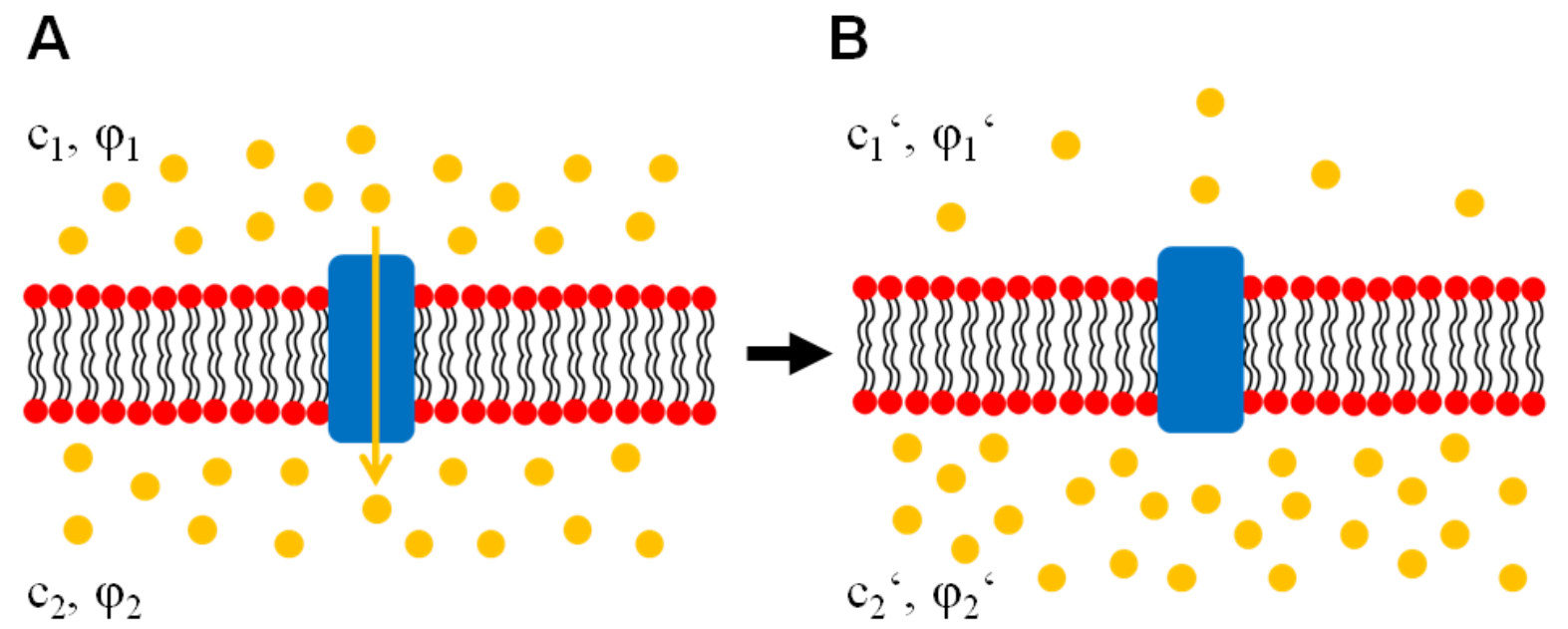

Abb. 1.12: Schematische Darstellung des Aufbaus eines elektrochemischen Gradienten. A Zu Beginn liegt ein chemisches Gleichgewicht zwischen beiden durch eine Lipidmembran (rot) getrennten Kompartimenten vor $\left(c_{1}=c_{2}, \varphi_{1}=\varphi_{2}\right)$. Unter Verbrauch von Energie werden Teilchen (gelb) durch einen membranständigen Transporter (blau) von Kompartiment 1 in Kompartiment 2 befördert. B Durch den aktiven Transport der Teilchen wird ein Konzentrationsgradient über die Membran erzeugt $\left(c_{1}{ }^{6}<c_{2}{ }^{6}\right)$. Sind die beförderten Teilchen geladen, so ergibt sich zusätzlich ein elektrischer Gradient $\left(\varphi_{1}{ }^{\circ}<\varphi_{2}{ }^{\circ}\right)$.

Die freie Enthalpie, welche in Form eines solchen Gradienten über einer Membran gespeichert werden kann, ergibt sich gemäß Gl. 1.1: 


$$
\Delta G=R \cdot T \cdot \ln \left(\frac{\mathrm{c}_{1}}{\mathrm{c}_{2}}\right)+z \cdot F \cdot\left(\varphi_{1}-\varphi_{2}\right)
$$

Dabei ist $\mathrm{R}$ die universelle Gaskonstante $\left(8,3145 \mathrm{~J} \cdot \mathrm{mol}^{-1} \cdot \mathrm{K}^{-1}\right), T$ die absolute Temperatur in $\mathrm{K}$, $c_{\mathrm{n}}$ die Konzentration einer Teilchenart in Kompartiment $\mathrm{n}, z$ die Ladung der Teilchenart, $\mathrm{F}$ die Faraday Konstante $\left(96485 \mathrm{C} \cdot \mathrm{mol}^{-1}\right.$ ) und $\varphi_{\mathrm{n}}$ das elektrische Potential des Kompartiments n. Bei konstanter Temperatur von $36^{\circ} \mathrm{C}$ ergibt sich beispielsweise unter der Annahme eines $\mathrm{pH}-$ Gradienten von $\Delta \mathrm{pH}=1$ Einheit und einem elektrischen Potential von $\Delta \varphi=180 \mathrm{mV}$ ein Wert von $\Delta G=23,3 \mathrm{~kJ} \cdot \mathrm{mol}^{-1}$ für die Änderung der freien Energie des Protonentransports über die innere Mitochondrienmembran. Verschiedene Transportarten verändern den Wert der in Form des Gradienten gespeicherten freien Energie in unterschiedlicher Weise. Ein gerichteter Uniport einer Ionensorte (z. B. durch eine Protonenpumpe wie bR, Kapitel 1.2.2) verändert sowohl die Konzentration $c$ der transportierten Ionensorte, als auch das elektrische Potential $\varphi$, welches von der Gesamtheit der vorliegenden Ionen abhängt. Ein ladungsneutraler Antiport zweier Ionensorten (z. B. durch Nigericin, Kapitel 1.2.1) verändert die Konzentrationen $c$ beider transportierter Ionensorten, das elektrische Potential $\varphi$ beider Kompartimente bleibt jedoch unverändert.

\subsubsection{Aufbau elektrochemischer Gradienten durch Ionophore}

Eine Klasse von Komponenten, die die Bildung elektrochemischer Gradienten beeinflussen können, sind Ionophore (für einen Überblick siehe Pressman ${ }^{[79]}$ ). Der Begriff beschreibt Moleküle mit moderater Molmasse (etwa $200-2000 \mathrm{~g} \cdot \mathrm{mol}^{-1}$ ), welche mit metallischen Kationen lipidlösliche Komplexe bilden und diese so über Lipidmembranen transportieren können. Dabei wird zwischen neutralen Ionophoren, wie Valinomycin oder synthetischen Polyethern und Ionophoren mit Säuregruppe, wie Nigericin oder Monensin unterschieden. Die Struktur des $\mathrm{K}^{+}$-Ionophors Valinomycin, sowie des $\mathrm{K}^{+} / \mathrm{H}^{+}$-Antiporters Nigericin sind in Abb. 1.13 dargestellt. Gemeinsames Strukturmotiv der Ionophor-Kationkomplexe ist die Komplexierung des Zentralions durch fünf bis sechs Sauerstoffatome. Dadurch wird dessen Ladung abgeschirmt und ein passiver Transport durch den hydrophoben Kern einer Lipiddoppelschicht ermöglicht. 
A

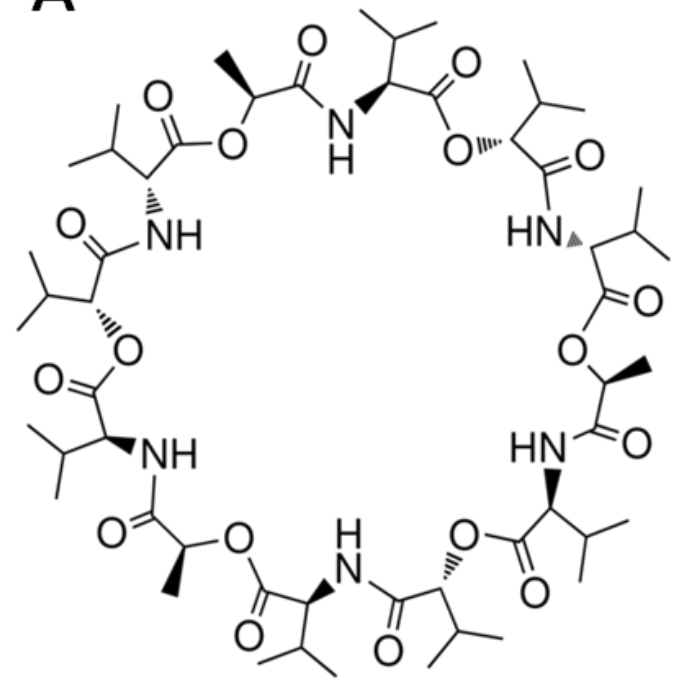

C

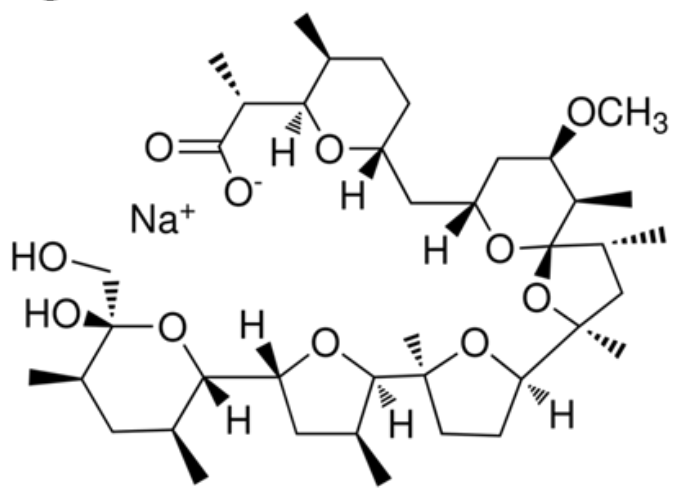

B

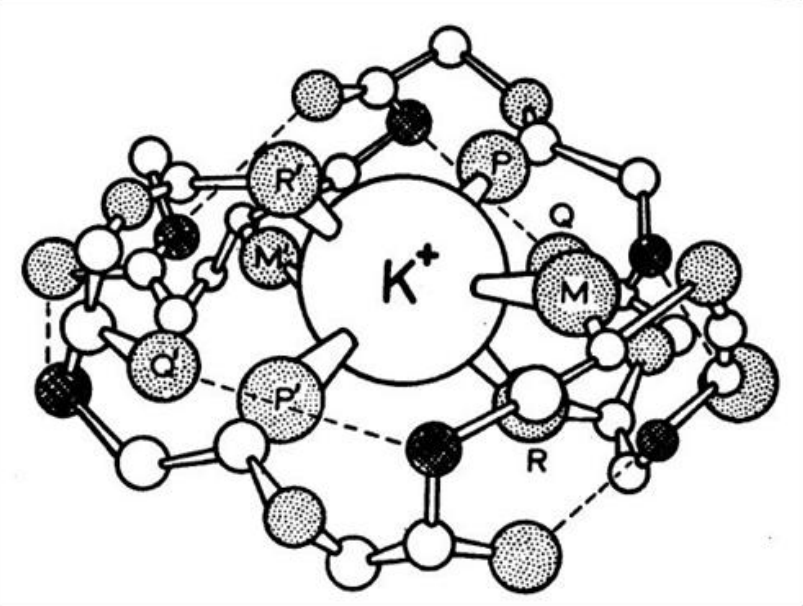

D



Abb. 1.13: Struktur ausgewählter Ionophore. A Struktur von Valinomycin. ${ }^{[80]}$ B Darstellung der Kristallstruktur eines Valinomycin-Kaliumionenkomplexes. Kohlenstoff- (weiß), Sauerstoff- (grau) und Stickstoffatome (schwarz) sind entsprechend eingefärbt. Wasserstoffbrücken sind durch gestrichelte Linien angedeutet. ${ }^{[81]} \mathbf{C}$ Struktur von Nigericin (Natriumsalz). ${ }^{[82]}$ D Darstellung der Kristallstruktur eines Nigericin-Kaliumionenkomplexes. ${ }^{[83]}$

Valinomycin (Abb. 1.13, A und B) ermöglicht einen passiven Durchtritt von Alkaliionen durch Membranen mit einer hohen Spezifität für Kaliumionen. ${ }^{[84]}$ Dadurch kann es zum Abbau von elektrischen Transmembranpotentialen eingesetzt werden, welche ihrerseits einer Bildung von Konzentrationsgradienten häufig entgegengerichtet sind (Gl. 1.1). Beispiele für Anwendungen von Valinomycin auf artifizielle Membranen finden sich dazu in Kombination mit ATPasen, ${ }^{[85]}$ bR $^{[86-88]}$ und dem photosynthetischen Reaktionszentrum, ${ }^{[89]}$ wo durch Zugabe von Valinomycin der Aufbau von Protonengradienten ermöglicht wurde.

Im Gegensatz zum Uniporter Valinomycin vermittelt Nigericin (Abb. 1.13, C und D) einen Antiport von Alkaliionen und Protonen über Membranen mit hoher Spezifität für Kaliumionen. Nigericin bildet ähnlich wie Valinomycin mit Kaliumionen einen neutralen Komplex, 
der einen Transport über Membranen erlaubt. Nach Dissoziation des Komplexes an der Membranoberfläche kann das dann als negativ geladenes Anion vorliegende Nigericin protoniert werden und in neutraler Form erneut durch die Membran diffundieren. Eine schematische Darstellung des nigericininduzierten $\mathrm{K}^{+} / \mathrm{H}^{+}$-Antiports ist in Abb. 1.14 aufgeführt.

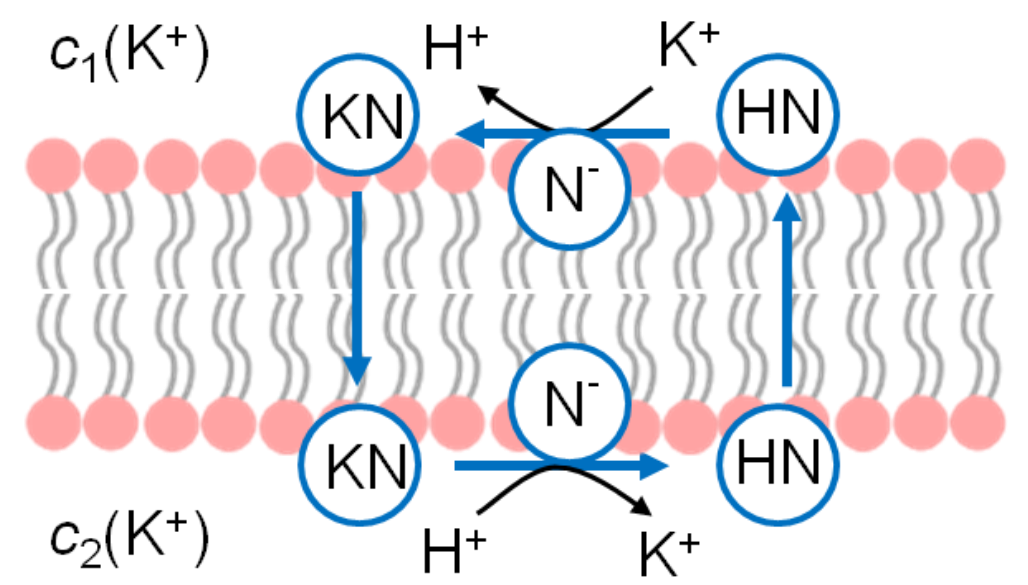

Abb. 1.14: Schematische Darstellung des $\mathrm{K}^{+} / \mathrm{H}^{+}$-Antiports durch Nigericin durch eine Lipidmembran (rot) für unterschiedliche Kaliumionenkonzentrationen beider membrangetrennter Kompartimente $\left(c_{1}\left(\mathrm{~K}^{+}\right)>c_{2}\left(\mathrm{~K}^{+}\right)\right)$. Das Nigericinanion $\left(\mathrm{N}^{-}\right)$komplexiert ein Kaliumion an der Grenzfläche der Membran zu Kompartiment 1 und tritt als neutraler Komplex (KN) durch die Membran. An der Grenzfläche zu Kompartiment 2 wird das Kaliumion freigesetzt und die anionische Form bildet sich zurück. Nach Protonierung kann das neutrale Nigericin (HN) erneut die Membran passieren, an der Grenzfläche zu Kompartiment 1 deprotoniert werden und steht für einen weiteren Zyklus zur Verfügung. Bei dieser Transportform wird netto jeweils ein Kaliumion gegen ein Proton ausgetauscht (ladungsneutraler Transport).

Neben dem ladungsneutralen Transport, bei welchem das Verhältnis transportierter Kaliumionen und entgegengesetzt transportierter Protonen gleich eins ist, wurde bei Nigericinkonzentrationen größer $10^{-6} \mathrm{M}$ ein Nettoladungstransport über Membranen beobachtet. Erklärt wird dieser durch die Bildung eines dimeren Nigericinkomplexes mit einem Kaliumion. ${ }^{[90]}$

Beispiele für den nigericininduzierten Aufbau von Protonengradienten aus Alkaliionengradienten finden sich für biologische Zellen, ${ }^{[84,91]}$ BLMs, ${ }^{[90,92-95]}$ sub-mikrometergroße Vesikel ${ }^{[85,96-98]}$ und porenüberspannende Membranen. ${ }^{[99]}$ Einzelne Studien beschreiben die Selektivität Nigericins gegenüber verschiedenen Kationen, ${ }^{[93]}$ eine effiziente Reinigung des experimentellen Aufbaus, um störende Reste von Nigericin zu entfernen ${ }^{[91]}$ und anhand kinetischer Studien den geschwindigkeitsbestimmenden Schritt des nigericininduzierten Antiports. ${ }^{[94]}$

Neben Substanzen, die den passiven Transport von metallischen Kationen über Membranen ermöglichen, werden insbesondere zum Abbau von Protonengradienten sogenannte Entkoppler eingesetzt. Dabei handelt es sich um Protonophore, also Substanzen, welche in protonierter und deprotonierter Form Membranen überqueren und so einen Transport von 
Protonen bewirken können. Beispiele dafür sind Carbonylcyanid- $m$-chlorphenylhydrazon (CCCP) und Carbonylcyanid-p-(trifluormethoxy)phenylhydrazon (FCCP), deren Struktur in Abb. 1.15 dargestellt sind. Aufgrund der geringen Größe und hydrophoben Struktur der protonierten Form ist diese membrangängig. Bei Vorliegen eines Protonengradienten können beide Entkoppler auf der basischeren Seite der Membran deprotoniert werden, durch die Delokalisierung der negativen Ladung die Membran durchdringen und auf der azideren Seite der Membran protoniert werden. So können Protonengradienten effizient abgebaut werden.

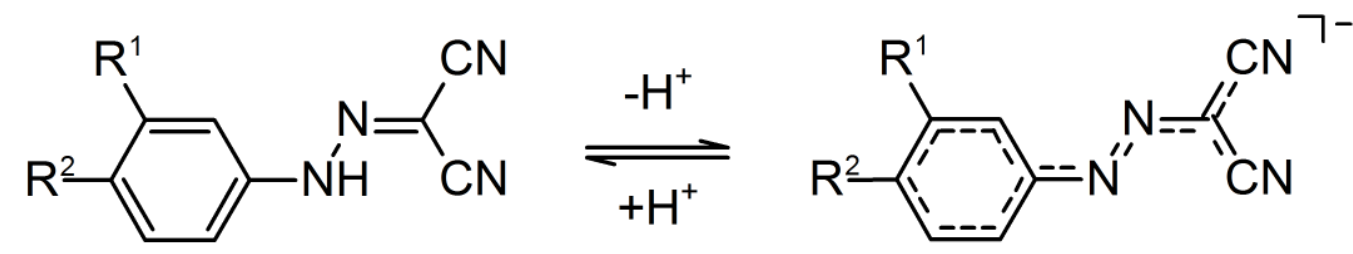

Abb. 1.15: Struktur der protonierten (links) und deprotonierten (rechts) Form der Entkoppler $\mathrm{CCCP}\left(\mathrm{R}^{1}=\mathrm{Cl}\right.$, $\left.\mathrm{R}^{2}=\mathrm{H}\right)$ und FCCP $\left(\mathrm{R}^{1}=\mathrm{H}, \mathrm{R}^{2}=\mathrm{OCF}_{3}\right)$. Die negative Ladung der deprotonierte Form ist über das gesamte Molekül delokalisiert.

CCCP und FCCP werden üblicherweise eingesetzt, um durch andere Ionophore oder Transmembranproteine gebildete Protonengradienten abzubauen oder ihre Bildung zu verhindern. Sie werden in Experimenten Referenzproben beigemischt, um Messdaten eindeutig gebildeten Protonengradienten zuordnen zu können.

\subsubsection{Lichtinduzierter Aufbau elektrochemischer Gradienten durch Bacteriorhodopsin}

Ionophore vermitteln den passiven Transport von Stoffen über Membranen, also einen Transport entlang eines Gradienten. Durch Antiporter lässt sich bei Abbau eines Gradienten parallel ein anderer Gradient bilden, eine Bildung von Gradienten unabhängig vom Transport eines zweiten Stoffes ist jedoch nur möglich durch aktiven Transport einer Substanz. Beim aktiven Transport können Substanzen auch entgegen eines Gradienten unter Verbrauch von Energie über Membranen befördert werden.

Ein viel untersuchtes und weitgehend verstandenes Beispiel für einen aktiven Transport ist die Verschiebung von Protonen durch das Transmembranprotein Bacteriorhodopsin (bR). Als Energiequelle für den aktiven Transport von Protonen nutzt bR Licht. Die Struktur von bR und dessen Photozyklus sind in Abb. 1.16 dargestellt. Das Protein besteht aus sieben $\alpha$-Helices, welche jeweils die Membran durchspannen. Als Cofaktor ist ein Retinal in Form einer Schiffschen Base über eine Lysin-Seitenkette kovalent an bR gebunden. Bei Belichtung $\left(\lambda_{\text {abs,max }}=568 \mathrm{~nm}\right)$ isomerisiert das im Grundzustand in all-trans Form vorliegende Retinal und bildet eine 13-cis Form. Durch den erhöhten sterischen Anspruch verschieben sich in der Folge die umliegenden Helices und eine Protonenübertragungskaskade resultiert in der Freisetzung eines Protons auf der extrazellulären Seite, in welcher sich der N-Terminus 
befindet. Auf der cytosolischen (C-terminalen) Seite wird ein Proton aufgenommen, das Retinal wird zurück in die all-trans Form überführt und der Grundzustand wird wieder erreicht. Effektiv wird so pro durchlaufenen Zyklus (ca. $15 \mathrm{~ms}$ ) ein Proton in Richtung des N-Terminus über die Membran transportiert. Eine ausführliche Darstellung des bR-Photozyklus findet sich bei Lanyi. ${ }^{[100]}$

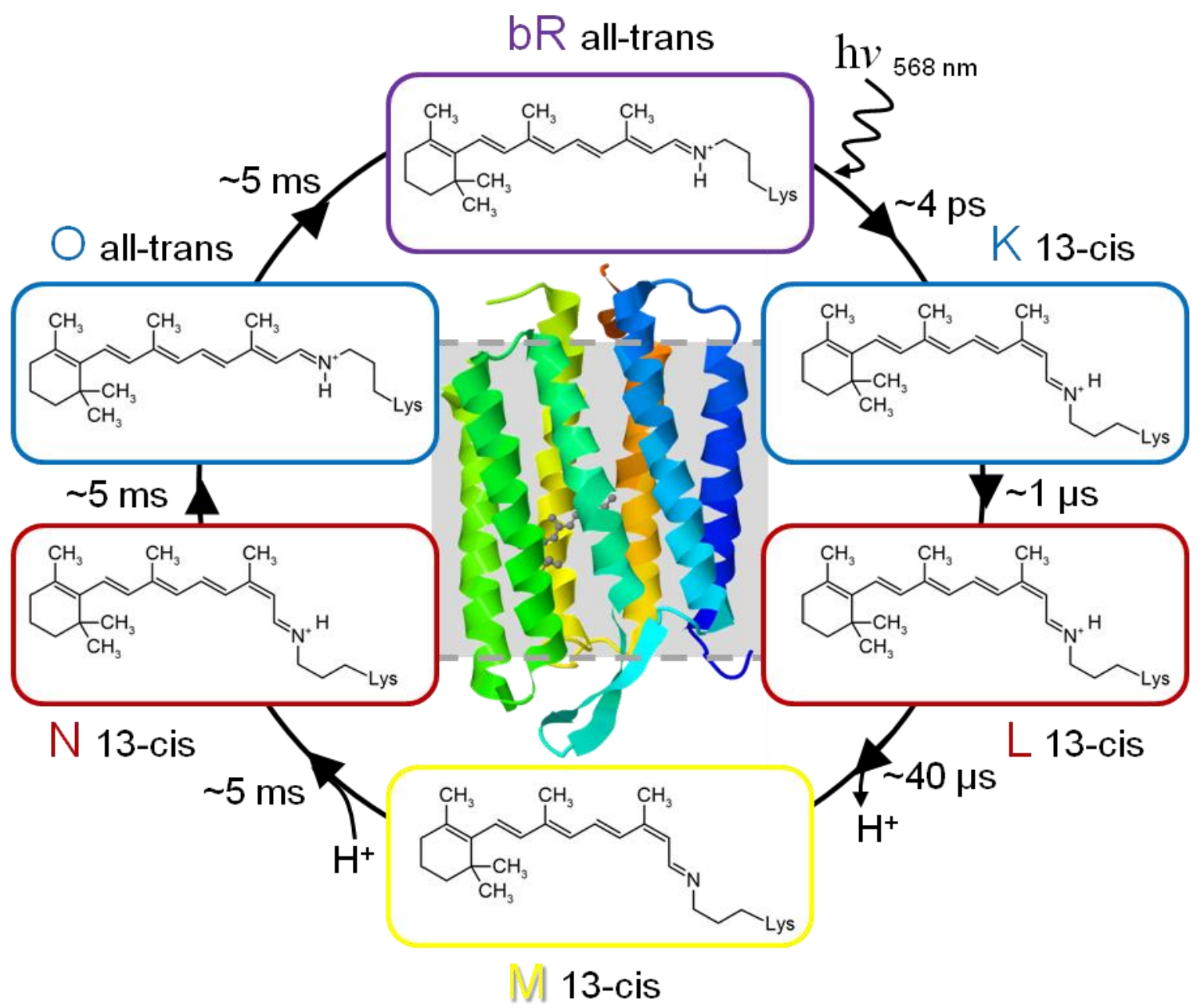

Abb. 1.16: Schematische Darstellung des Photozyklus und der Kristallstruktur (Zentrum; PDB ID: 2NTU) ${ }^{[101]}$ von bR. Eine Membran ist schematisch angedeutet (grau), um die Lage des bR darin zu verdeutlichen. Die Struktur des Cofaktors Retinal in jedem Intermediat ist jeweils dargestellt. Die farblichen Umrandungen deuten Verschiebungen des Absorptionsmaximums des jeweiligen Intermediats an. Die Lebensdauer der Intermediate bei Raumtemperatur ist an den entsprechenden Pfeilen angegeben. Photozyklus modifiziert nach Edman et al. und Kawanabe et al. ${ }^{[102,103]}$

Anfang der 1970er Jahre gelang es Oesterhelt und Stoeckenius, bR in Form von Purpurmembranfragmenten (PM-Fragmenten) aus halophilen Bakterien $\mathrm{zu}$ isolieren. ${ }^{[104]}$ In PM-Fragmenten liegt bR als einziges enthaltenes Protein in Form von Trimeren vor, welche ein zweidimensionales, hexagonales Gitter bilden und rund $75 \%$ der Membranmasse ausmachen. ${ }^{[105]}$ Die Fähigkeit von bR, bei Belichtung Protonen über Membranen zu transportieren, wurde bereits vielfach in verschiedenen artifiziellen Membransystemen 
angewendet. Darunter die Untersuchung des bR-induzierten Protonentransports durch elektrische Messungen an BLMs, ${ }^{[106-109]}$ an porenüberspannenden Membranen, ${ }^{[43]}$, durch elektrische oder optische Messungen an sub-mikrometergroßen Vesikeln ${ }^{[87,110-115]}$ und mikrometergroßen Vesikeln. ${ }^{[116-118]}$

Bereits kurz nach seiner Entdeckung wurde eine Co-Rekonstitution von bR zusammen mit $\mathrm{F}_{\mathrm{O}} \mathrm{F}_{1}$-ATP Synthasen vorgeschlagen, um ein System zur Umwandlung von Lichtenergie in chemische Energie in Form von ATP zu generieren. Neben weiteren potentiellen Anwendungen (für eine Zusammenfassung siehe Lanyi ${ }^{[119]}$ und Oren ${ }^{[120]}$ ) ist die Anwendung von bR für Zwecke der Energieumwandlung, gekoppelt an ATPasen die am intensivsten erforschte. Dementsprechend findet sich eine Vielzahl an Studien, welche die Co-Rekonstitution von bR mit ATPasen in Lipidvesikeln beschreiben. ${ }^{[66,88,121-130]}$ Erste Ansätze, dieses biologische System auf technische Anwendungen zu übertragen finden sich in Form einer Einlagerung von Proteo-Vesikeln in eine Silica-Matrix ${ }^{[131]}$ und der Rekonstitution beider Proteine in Polymerosomen statt Liposomen (Abb. 1.17). ${ }^{[132]}$

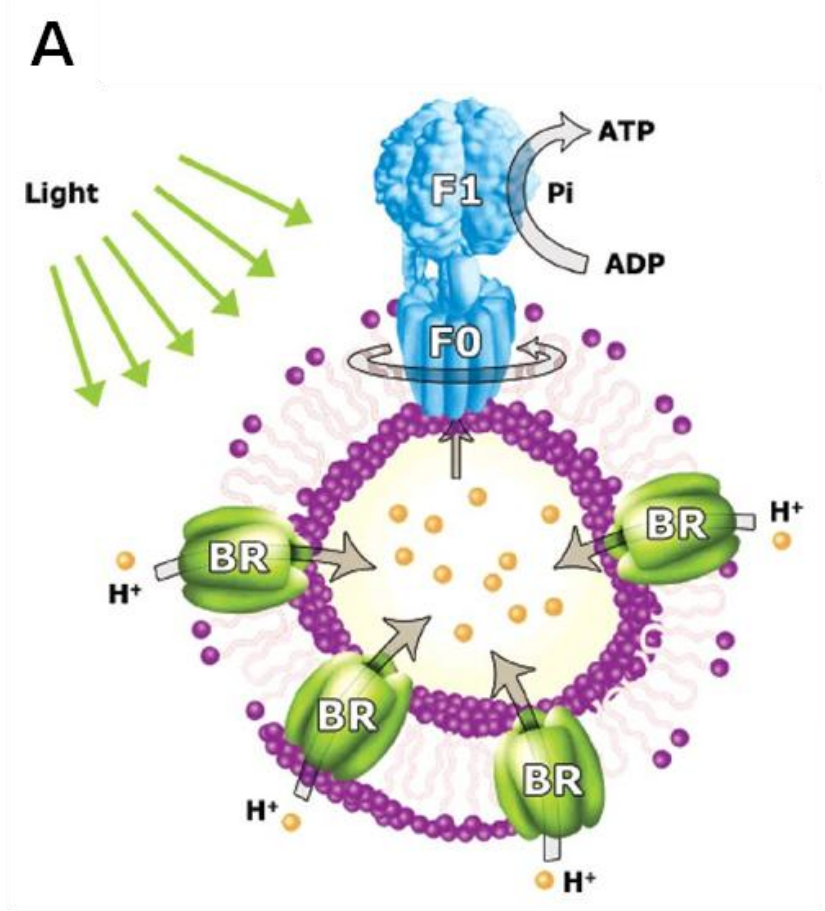

B

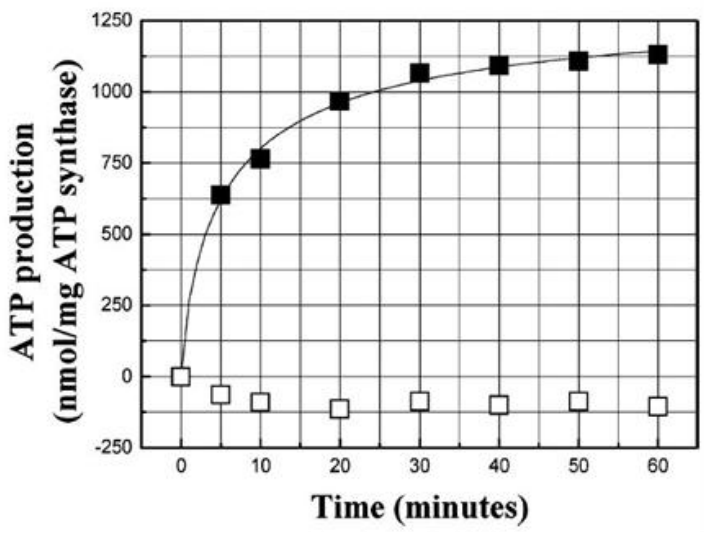

Abb. 1.17: A Schematische Darstellung der Energieumwandlung in einem Polymervesikel mit bR (grün) und ATPase (blau) insertiert. Bei Belichtung transportiert bR Protonen (gelb) über die Polymermembran ins Vesikelinnere und erzeugt so einen Protonengradienten. Die ATPase nutzt diesen Gradienten und erzeugt unter Rücktransport der Protonen ins Vesikeläußere ATP aus ADP und anorganischem Phosphat (Pi). B Zeitlicher Verlauf der Menge des bei Belichtung (ロ) bzw. ohne Belichtung ( $\square$ ) einer Lösung von Proteo-Polymerosomen (A) gebildeten ATP. Abbildungen nach Choi und Montemagno. ${ }^{[132]}$

Eine weitere Eigenschaft von bR, welche es besonders interessant für technische Anwendungen macht, ist die Möglichkeit es durch gezielte Mutationen in seiner Funktion zu manipulieren. Während andere Proteine oftmals anfällig gegenüber einem Austausch einzelner Aminosäuren sind und ihre Struktur verändern oder ihre Funktionalität dadurch 
verlieren, weist bR eine hohe Stabilität und Toleranz gegenüber Mutationen auf. Patil et al. zeigten, dass sich durch Austausch einer Aminosäure (M163C) bR effektiv an Elektrodenoberflächen binden lässt und konnten dabei eine deutliche Erhöhung des Photostromsignals nachweisen. ${ }^{[133]}$ Durch Austausch der für den Protonenpumpmechanismus wichtigen Aminosäure Aspartat-85 gegen die Aminosäure Threonin kann bR sogar von einer Protonenpumpe in eine Chloridionenpumpe umgewandelt werden. ${ }^{[134,135]}$ 
1 Einleitung 


\section{Zielsetzung}

Elektrochemische Gradienten über Membranen spielen eine wichtige Rolle bei zellulären Prozessen, wie dem Aufbau von Aktionspotentialen zur Reizweiterleitung, oder der Bildung des universellen Energieträgers ATP in Mitochondrien. Gebildet werden solche Gradienten durch Membranproteine, welche unter Verbrauch von Energie einen aktiven Transport von z. B. Ionen über Membranen verrichten. Zur Untersuchung von Membranproteinen und dem Aufbau elektrochemischer Gradienten werden häufig artifizielle Membransysteme eingesetzt.

Im Fokus dieser Arbeit steht die Entwicklung eines neuartigen Modellsystems auf Basis freistehender Membranen auf mikroporösen Substraten. Dabei wird die Bildung porenüberspannender Membranen untersucht und optimiert. Poren mit geschlossenen Böden bieten pikolitergroße Volumina, die einen gezielten Einschluss von wässriger Lösung mit definierter Zusammensetzung erlauben. Durch Einschluss eines pH-sensitiven Farbstoffs soll ein assay entwickelt werden, der die optische Untersuchung von in situ gebildeten elekrochemischen Gradienten ermöglicht.

Zur Bildung von Gradienten wird neben niedermolekularen Ionophoren das Membranprotein Bacteriorhodopsin (bR), eine lichtgetriebene Protonenpumpe, eingesetzt. Hierzu soll eine Strategie entwickelt werden, mit Hilfe derer bR funktionell in porenüberspannende Membranen rekonstituiert werden kann. Aktuelle Modellsysteme erlauben nur begrenzt die funktionelle Rekonstitution von Membranproteinen und beschränken sich häufig auf die Untersuchung wasserlöslicher Peptide und Proteine mit geringerer biologischer Relevanz.

Da der Transport durch Membranproteine oftmals sehr sensitiv an externe Reize (Licht, Potentialdifferenz, Temperatur) gekoppelt ist, wird ein Einsatz solcher Proteine als Biosensoren diskutiert. Weiterhin bilden Membranproteine den Großteil pharmazeutischer targets und es besteht ein großes Interesse an neuartigen Modellsystemen, welche ein schnelles screening potentieller Wirkstoffe ermöglichen. Ein im Rahmen dieser Arbeit entwickeltes Modellsystem soll auf mögliche Anwendungen in diesen Bereichen untersucht und gegebenenfalls optimiert werden. 
$2 \mathrm{Zielsetzung}$ 


\section{Materialien und Methoden}

\subsection{Verwendete Substanzen}

\subsubsection{Lipide}

In dieser Arbeit wurden unterschiedliche Phospholipide eingesetzt, um artifizielle Membranen auszubilden. Sie unterscheiden sich in der Struktur der Seitenketten und der Struktur der Kopfgruppe, was zu verschiedenen physikochemischen Eigenschaften der einzelnen Lipide führt. Im Folgenden sollen die Struktur und charakteristischen Merkmale der Lipide kurz vorgestellt werden. Ihre allgemeine Struktur ist in Abb. 3.1 dargestellt. Eine genaue Spezifizierung der Fettsäurereste und der Kopfgruppe, sowie die molare Masse sind in Tabelle 3.1 aufgeführt.<smiles>[R]OC([R])=O</smiles>

Abb. 3.1: Allgemeine Strukturformel von Phospholipiden.

\section{Phosphatidylcholine}

Die folgenden Phosphatidylcholine sind synthetische Lipide, bestehend aus einem Glyceringrundgerüst, an welches ein Phosphocholinrest und zwei Fettsäuren über Esterbindungen geknüpft sind.

1,2-Diphytanoyl-sn-glycero-3-phosphocholin (DPhPC) besitzt zwei $\mathrm{C}_{16}$-Seitenketten, welche Verzweigungen in Form von Methylgruppen aufweisen. Dadurch zeigt dieses Lipid in einem Temperaturbereich von -120 bis $+120{ }^{\circ} \mathrm{C}$ keinen Phasenübergang. ${ }^{[136]}$ Aus DPhPC aufgebaute Membranen zeigen gute elektrisch isolierende Eigenschaften und eignen sich dadurch zum Aufbau elektrochemischer Gradienten. ${ }^{[137]}$ Außerdem kommt das Lipid natürlicherweise in aus Halobacterium salinarum isolierten Purpurmembranen (PM) vor, weshalb es sich als potentielles Matrixlipid zur Rekonstitution von Bacteriorhodopsin (bR) anbietet. ${ }^{[38]}$ Im 
Rahmen dieser Arbeit wurde DPhPC zur Ausbildung von Lipiddoppelschichten nach der painting-Technik verwendet (Kapitel 3.2.9).

1-Palmitoyl-2-oleoyl-sn-glycero-3-phosphocholin (POPC) weist eine gesättigte $\mathrm{C}_{16}$-Seitenkette und eine an Position 9 (Z)-ungesättigte $\mathrm{C}_{18}$-Seitenkette auf. Das Lipid ist Bestandteil vieler biologischer Membranen. ${ }^{[139]}$ POPC wurde zur Elektroformation mikrometergroßer unilamellarer Vesikel (giant unilamellar vesicles, GUVs) eingesetzt (Kapitel 3.2.5), da es im Vergleich mit anderen Lipiden eine hohe Zahl sehr großer und stabiler Vesikel lieferte.

Neben POPC wurde auch 1,2-Dioleoyl-sn-glycero-3-phosphocholin (DOPC) in ersten Versuchen zur Bildung von GUVs eingesetzt, im weiteren Verlauf der Arbeit jedoch aufgrund der höheren Qualität der erhaltenen Vesikel durch ersteres Lipid ersetzt. Es weist zwei ungesättigte $\mathrm{C}_{18}$-Seitenketten auf, die durch ihren erhöhten sterischen Anspruch die Fluidität von Membranen steigern, jedoch auch potentiell anfällig für (photo-)chemische Reaktionen sind.

1-Stearoyl-2-oleoyl-sn-glycero-3-phosphocholin (SOPC) wurde ebenfalls zur Bildung von GUVs eingesetzt. Es besitzt zwei $\mathrm{C}_{18}$-Seitenketten, von denen eine an Position 9 (Z)-ungesättigt ist. Seine Phasenumwandlungstemperatur beträgt $6{ }^{\circ} \mathrm{C}$, wodurch sowohl Gelphase, als auch flüssig-kristalline Phase leicht experimentell zugängig sind. ${ }^{[140]}$ SOPC Vesikel wurden eingesetzt, um den Einfluss der Lipidphase auf das Spreitverhalten von GUVs zu untersuchen (Kapitel 4.1.2).

\section{Phosphatidsäuren}

Phosphatidsäuren sind aufgebaut wie Phosphatidylcholine, allerdings besitzen sie als Kopfgruppe keinen Cholinrest, sondern Phosphomonoester, welche unter physiologischen Bedingungen eine negative Gesamtladung tragen. Sie kommen nur in kleinen Mengen in biologischen Membranen vor, werden aber in Modellmembranen häufig anteilig als negativ geladene Lipide verwendet, um einen Ladungseinfluss zu untersuchen. ${ }^{[141]}$

In dieser Arbeit wurde 1,2-Dipalmitoyl-sn-glycero-3-phosphat (DPPA) in Kombination mit $\mathrm{DPhPC}$ als Matrixlipid für lösungsmittelhaltige Membranen (painted membranes) eingesetzt (Kapitel 3.2.9). Es besitzt zwei gesättigte $\mathrm{C}_{16}$-Seitenketten und die Phosphatgruppe besitzt $\mathrm{pK}_{\mathrm{S}}$-Werte von $\mathrm{pK}_{\mathrm{S}, 1}=3,5$ und $\mathrm{pK}_{\mathrm{S}, 2}=8,0$ (bestimmt in Monoschichten ${ }^{[142]}$ ). Es wurde eingesetzt, da PM-Fragmente ebenfalls einen erhöhten Anteil negativ geladener Lipide aufweisen und DPPA sich somit gut als Modelllipid zur Nachbildung PM-fragmenthaltiger Membranen eignet. ${ }^{[143]}$ Des Weiteren soll der Einsatz negativ geladener Lipide eine Akkumulation des wasserlöslichen Farbstoffs Pyranin an der Membran, welcher bei physiologischen Bedingungen dreifach negativ geladen vorliegt, verhindern. 


\section{Phosphatidylserine}

Eine weitere Spezies von unter physiologischen Bedingungen negativ geladenen Lipiden bilden Phosphatidylserine. Sie teilen die Grundstruktur mit den Phosphatidylcholinen, besitzen statt des Cholinrestes allerdings einen L-Serinrest, der mit der kopfständigen Phosphatgruppe verestert ist. Der $\mathrm{pK}_{\mathrm{S}}$-Wert der Carboxygruppe beträgt 3,6. ${ }^{[144]}$ Auch diese Lipide sind in vielen biologischen Membranen zu finden. ${ }^{[139]}$

Um GUVs zu präparieren, wurde 1-Palmitoyl-2-oleoyl-sn-glycero-3-phospho-L-serin (POPS) anteilig als Matrixlipid eingesetzt. Es wurde bereits gezeigt, dass aus POPS in Kombination mit anderen, neutralen Lipiden, GUVs in hoher Anzahl und Größe durch Elektroformation gebildet werden können. ${ }^{[145]}$

\section{Phosphatidylethanolamine}

Eine weitere Lipidspezies mit biologischer Relevanz bilden die Phosphatidylethanolamine. Aufgebaut wie Phosphatidylcholine besitzen sie eine sterisch weniger anspruchsvolle Kopfgruppe, da statt eines Cholinrestes mit drei Methylgruppen am terminalen Stickstoff ein Ethanolaminrest vorliegt.

In dieser Arbeit wurde 1,2-Dioleoyl-sn-glycero-3-phosphoethanolamin (DOPE) verwendet, um GUVs zu präparieren. Durch die relativ kleine Kopfgruppe und zwei sterisch anspruchsvolle an Position $9(Z)$-ungesättigte $\mathrm{C}_{18}$-Seitenketten, induziert DOPE in Membranen eine starke negative Krümmung und kann so die Fusion DOPE-haltiger Vesikel begünstigen. ${ }^{[146]}$ Ein Einsatz von DOPE sollte dementsprechend zu einem verbesserten Spreiten von GUVs auf porösen Substraten führen (Kapitel 4.1.2).

\section{Funktionalisierte Lipide}

Um Vesikel für mikroskopische Untersuchungen auf einem planaren Substrat zu fixieren, wurde ein mit Biotin funktionalisiertes Lipid anteilig in die Vesikel rekonstituiert. Dazu wurde 1,2-Dipalmitoyl-sn-glycero-3-phosphoethanolamin- $N$-capronsäure-biotin (Bio-CapPE) verwendet, welches eine Phosphoethanolamin Grundstruktur besitzt, an dessen Kopfgruppe über eine Amidbindung 6-Aminocapronsäure gebunden ist, welche wiederum über eine Amidbindung mit einer Biotineinheit verknüpft ist. Die starke Biotin-AvidinWechselwirkung erlaubt die Fixierung der Vesikel über den Biotinrest auf mit Avidin beschichteten Oberflächen (Kapitel 3.2.6). ${ }^{[145]}$

Als weiteres funktionalisiertes Lipid wurde das Thiolipid 1,2-Dipalmitoyl-sn-glycero-3phosphothioethanol (DPPTE) eingesetzt, welches aufgrund seiner Funktion näher unter dem Abschnitt 3.1.2 (Thiole) erläutert wird. 
Tabelle 3.1: Struktur der Seitenketten und Kopfgruppen, sowie molare Massen aller vorgestellten Lipide.

\begin{tabular}{|c|c|c|c|}
\hline Lipid & Seitenketten & Kopfgruppe $\left(\mathbf{R}^{\mathbf{3}}\right)$ & $M / \mathrm{g} \cdot \mathrm{mol}^{-1}$ \\
\hline DPhPC & $\begin{array}{l}\mathrm{R}^{1}= \\
\mathrm{R}^{2}=\end{array}$ & & 846,25 \\
\hline POPC & $\begin{array}{l}\mathrm{R}^{1}= \\
\mathrm{R}^{2}=\end{array}$ & & 760,08 \\
\hline DOPC & $\begin{array}{l}\mathrm{R}^{1}= \\
\mathrm{R}^{2}=\end{array}$ & & 786,11 \\
\hline SOPC & $\begin{array}{l}\mathrm{R}^{1}= \\
\mathrm{R}^{2}=\end{array}$ & & 788,13 \\
\hline $\begin{array}{l}\mathrm{Na} \\
\text { DPPA }\end{array}$ & $\begin{array}{l}\mathrm{R}^{1}= \\
\mathrm{R}^{2}=\end{array}$ & $\mathrm{H}$ & 670,87 \\
\hline $\begin{array}{l}\mathrm{Na} \\
\text { POPS }\end{array}$ & $\begin{array}{l}\mathrm{R}^{1}= \\
\mathrm{R}^{2}=\end{array}$ & & 783,99 \\
\hline DOPE & $\begin{array}{l}\mathrm{R}^{1}= \\
\mathrm{R}^{2}=\end{array}$ & & 744,03 \\
\hline $\begin{array}{l}\text { Na Bio- } \\
\text { Cap-PE }\end{array}$ & $\begin{array}{l}\mathrm{R}^{1}= \\
\mathrm{R}^{2}=\end{array}$ & $\mathrm{C}_{\mathrm{NH}}$ & 1053,39 \\
\hline DPPTE & $\begin{array}{l}\mathrm{R}^{1}= \\
\mathrm{R}^{2}=\end{array}$ & & 730,99 \\
\hline
\end{tabular}

\subsubsection{Thiole}

Eine weitere wichtige Substanzklasse, welche in dieser Arbeit vermehrt Verwendung gefunden hat, sind Thiole. Über die enthaltene SH-Gruppe können Thiole an Goldoberflächen chemisorbieren und dadurch quasi kovalent gebunden werden, wobei sich sogenannte selbstorganisierende Monoschichten (self assembled monolayer, SAM) bilden. Je nach Charakter des Restes können so hydrophil oder hydrophob funktionalisierte Oberflächen gebildet 
werden. Da im weiteren Verlauf der Arbeit gezeigt werden wird, dass eine geeignete Funktionalisierung entscheidenden Einfluss auf das Spreitverhalten von GUVs und somit die Bildung lösungsmittelfreier Membranen hat, sollen die wichtigsten verwendeten Thiole im Folgenden kurz vorgestellt werden. Strukturen und molare Massen der Thiole sind in Tabelle 3.2 aufgeführt.

\section{Hydrophobe Thiole}

Cholesterylpolyethylenoxythiol $(\mathrm{CPEO} 3)^{[147]}$ besteht aus einem hydrophoben Cholesteringrundgerüst, welches als Carbamidsäureester mit einem aus zwei Ethylenoxy-Einheiten bestehenden spacer verbunden und schließlich an eine dritte C2-Einheit mit terminaler SHGruppe gebunden ist. CPEO3 funktionalisierte Oberflächen wurden im Rahmen dieser Arbeit verwendet, um lösungsmittelhaltige Membranen durch Anwendung der painting-Technik auszubilden (Kapitel 3.2.9). Neben CPEO3 wurden teilweise andere hydrophobe Thiole, namentlich 1-Tetradekanthiol (TDT) und 1,2-Dipalmitoyl-sn-glycero-3-phosphothioethanol (DPPTE, Tabelle 3.1), ein Lipid mit Thiolfunktionalität im Bereich der Kopfgruppe, eingesetzt.

\section{Hydrophile Thiole}

Um hydrophil funktionalisierte Oberflächen für die Präparation lösungsmittelfreier Membranen zu bilden, wurde hauptsächlich 11-Amino-1-undekanthiol eingesetzt. Dieses Thiol besitzt als Rest eine terminale Aminofunktion, mit der es über eine $\mathrm{C}_{11}$-Alkankette verbunden ist. Der $\mathrm{pK}_{\mathrm{S}}$-Wert der terminalen Aminofunktion eines 11-Amino-1-undekanthiolSAM wird von Campiña et al. auf 7,5 geschätzt, was bedeutet, dass rund $60 \%$ bei pHBedingungen, wie sie für die meisten in dieser Arbeit verwendeten Puffer gelten $(7,3)$, protoniert und somit positiv geladen vorliegt. ${ }^{[148]}$ Weitere hydrophile Thiole die ergänzend Verwendung gefunden haben, sind die Carbonsäurederivate Mercaptoessigsäure, 3-Mercaptopropionsäure und 11-Carboxy-1-undekanthiol, welche bei Bildung von goldunterstützten Monolagen $\mathrm{pK}_{\mathrm{S}}$-Werte von 6,1, 5,3 und 7,3 aufweisen und somit bei physiologischem $\mathrm{pH}$ netto negativ geladen sind. ${ }^{[149]}$ Außerdem wurden die Alkohole Mercaptoethanol und Mercaptohexanol zur Oberflächenfunktionalisierung eingesetzt, welche ebenfalls hydrophile, jedoch ungeladene Monolagen ausbilden. 
Tabelle 3.2: Struktur und molare Masse aller vorgestellten Thiole.

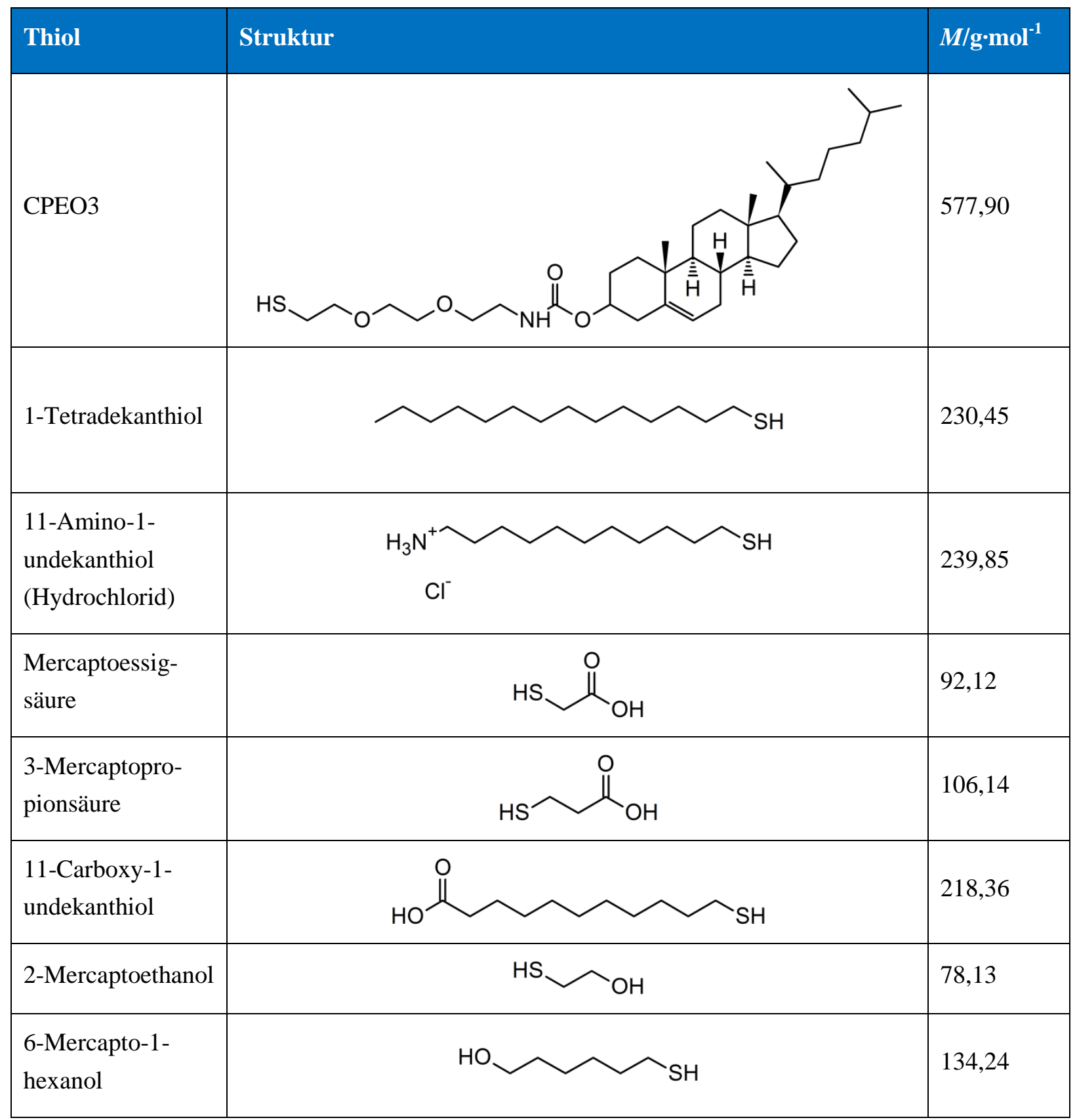

\subsubsection{Fluoreszenzfarbstoffe}

Um artifizielle Membranen, sowie darin rekonstituierte Proteine fluoreszenzmikroskopisch visualisieren zu können, wurden verschiedene Fluoreszenzfarbstoffe eingesetzt. Darüber hinaus wurde ein wasserlöslicher, $\mathrm{pH}$-sensitiver Farbstoff verwendet, um Protonengradienten fluoreszenzmikroskopisch sichtbar zu machen und wässrige Kompartimente zu markieren. Die Strukturen, sowie spektrale Eigenschaften und molare Massen der Farbstoffe sind in Tabelle 3.3 zusammengefasst. 


\section{Lipidgebundene Fluorophore}

Im Rahmen dieser Arbeit wurde auf zwei spektral voneinander getrennte Fluoreszenzfarbstoffe zurückgegriffen, mit denen Membranen nach ihrer Präparation visualisiert werden konnten. Zum einen wurde $\beta$-BODIPY® 500/510 $\mathrm{C}_{12}$ HPC (Bodipy PC) verwendet, ein Phosphatidylcholin, welches an einer Seitenkette eine heterozyklische Fluoreszenzeinheit trägt. Bodipy PC lässt sich bei befriedigender Photostabilität dennoch mit hoher Laserleistung gut bleichen, weshalb es hauptsächlich für fluorescence recovery after photobleaching (FRAP-) Experimente eingesetzt wurde (Kapitel 3.5.1), um so die Mobilität der Lipide innerhalb der Membranen zu untersuchen. Da es spektral mit dem wasserlöslichen Farbstoff Pyranin überlappt, wurde für Experimente, in denen Lipidphase und wässrige Phase parallel abgebildet werden sollten, auf den spektral weitgehend von Pyranin getrennten Farbstoff Texas Red® DHPE zurückgegriffen.

Texas Red DHPE besitzt zwar ebenfalls eine Phosphatidylcholin Grundstruktur, im Gegensatz zu Bodipy PC ist die fluorophore Einheit jedoch über eine Sulfonamidbindung an die Kopfgruppe gebunden. Es zeichnet sich durch eine sehr hohe Photostabilität aus und eignet sich daher gut für Messungen, bei denen die Probe über einen langen Zeitraum abgebildet wird, wie Zeitserien oder dreidimensionale Aufnahmen (z-stacks, Kapitel 3.5).

\section{Fluoreszenzmarker für Proteine}

Um membranständige Proteine nach ihrer Rekonstitution fluoreszenzmikroskopisch abbilden zu können, wurden diese zuvor mit Fluoreszenzfarbstoffen markiert (labeling). Als Marker wurden dabei stets $\mathrm{N}$-Hydroxysuccinimidester (NHS Ester) Derivate der Farbstoffe eingesetzt, welche üblicherweise kovalent durch einen nukleophilen Angriff terminaler Amine (z. B. Lysin-Seitenketten) innerhalb des Proteins gebunden werden können (Kapitel 3.2.2). Hierfür eingesetzte Farbstoffe sind Texas Red® NHS Ester $\left(\varepsilon_{595}=80000 \mathrm{M}^{-1} \cdot \mathrm{cm}^{-1[150]}\right), \quad$ der $\quad$ Cyanin-Farbstoff $\quad$ Cy3 $3 H S$ Ester $\left(\varepsilon_{550}=150000 \mathrm{M}^{-1} \cdot \mathrm{cm}^{-1[151]}\right)$, sowie Alexa Fluor ${ }^{\circledR} 488$ NHS Ester $\left(\varepsilon_{496}=71000 \mathrm{M}^{-1} \cdot \mathrm{cm}^{-1[152]}\right)$. Alle drei Fluorophore zeichnen sich durch eine sehr hohe Photostabilität aus, besonders die letzten beiden lassen sich bei hoher Laserleistung dennoch exzellent bleichen und eignen sich somit zur Beobachtung des Diffusionsverhaltens des markierten Proteins mittels FRAP (Kapitel 4.3.4). 
pH sensitive Fluorophore

Wesentlicher Teil dieser Arbeit war die Ausbildung elektrochemischer Gradienten über Membranen und die Entwicklung einer visuellen Methode, um den Aufbau dieser Gradienten qualitativ und wenn möglich auch quantitativ verfolgen zu können. Zu diesem Zweck wurde der wasserlösliche und pH-sensitive Farbstoff 8-Hydroxypyren-1,3,6-Trisulfonsäure (Pyranin) eingesetzt. Durch die drei Sulfonatgruppen ist Pyranin sehr gut wasserlöslich und praktisch nicht membrangängig. Die Hydroxygruppe in 8-Position besitzt einen $\mathrm{pK}_{\mathrm{S}}$-Wert von 7,2, was einem unter physiologischen Bedingungen gut zugänglichem $\mathrm{pH}-$ Wert entspricht. ${ }^{[153]}$ Protonierung bzw. Deprotonierung der Hydroxygruppe führt zu einer starken Verschiebung des Absorptionsmaximums $\left(\lambda_{\text {max,protoniert }}=404 \mathrm{~nm}, \lambda_{\text {max,deprotoniert }}=455 \mathrm{~nm}\right),($ Abb. $4.18, A)$. Pyranin besitzt einen isosbestischen Punkt bei $415 \mathrm{~nm}$. Ein Vorteil des Absorptionsverhaltens von Pyranin ist, dass die Maxima der protonierten wie der deprotonierten Form genau im Bereich gängiger Laserwellenlängen, wie sie standardmäßig in kommerziellen Fluoreszenzmikroskopen vertrieben werden, liegen (z. B. $405 \mathrm{~nm}$ Diodenlaser, $458 \mathrm{~nm}$ ArgonIonenlaser). Im Rahmen dieser Arbeit wurde üblicherweise die deprotonierte Form des Pyranins fluoreszenzmikroskopisch untersucht, da bei einer Anregung mit $405 \mathrm{~nm}$ ein sehr starkes Photobleichen auftrat (Abb. 4.18, C). 
Tabelle 3.3: Struktur, Absorptions- und Emmisionsmaxima, sowie molare Masse aller vorgestellten Fluoreszenzfarbstoffe.

\begin{tabular}{|c|c|c|c|c|}
\hline Farbstoff & Struktur & $\begin{array}{l}\lambda_{\mathrm{Abs}} \\
/ \mathrm{nm}\end{array}$ & $\begin{array}{l}\lambda_{\mathrm{Em}} \\
/ \mathrm{nm}\end{array}$ & $M / \mathrm{g} \cdot \mathrm{mol}^{-1}$ \\
\hline Bodipy PC & & 500 & 510 & 881,92 \\
\hline $\begin{array}{l}\text { Texas Red } \\
\text { DHPE }\end{array}$ & & 584 & 607 & 1381,85 \\
\hline $\begin{array}{l}\text { Texas Red } \\
\text { NHS Ester }\end{array}$ & & 582 & 600 & 816,94 \\
\hline $\begin{array}{l}\text { Cy3 NHS } \\
\text { Ester }\end{array}$ & & 555 & 570 & 590,15 \\
\hline $\begin{array}{l}\text { Alexa Fluor } \\
488 \text { NHS } \\
\text { Ester }\end{array}$ & & 493 & 517 & 643,41 \\
\hline Pyranin & & $404 /$ & 513 & 524,39 \\
\hline
\end{tabular}




\subsection{Präparative Methoden}

\subsubsection{Isolierung von Purpurmembranfragmenten aus Halobacterium salinarum}

\section{Kultivierung}

BR wurde in Form von PM-Fragmenten nach einer optimierten Vorschrift des Instituts für Biochemie der Westfälischen Wilhelms-Universität Münster aus Halobacterium salinarum (Stamm S9) isoliert. Dabei wurden unterschiedliche Nährmedien getestet, deren Zusammensetzungen in Tabelle 3.4 aufgeführt sind. Zunächst wurde jeweils eine Vorkultur $(30 \mathrm{~mL})$ in einem $100 \mathrm{~mL}$ Schüttelkolben angesetzt und für $10-12 \mathrm{~d}$ bei $100 \mathrm{U} \cdot \mathrm{min}^{-1}$ und $37^{\circ} \mathrm{C}$ lichtgeschützt inkubiert. Der Schüttelkolben wurde dabei mit einem Schaumstoffdeckel verschlossen, um semi-anaerobe Bedingungen zu schaffen, da zu hohe Sauerstoffkonzentrationen die bR-Biosynthese reprimieren. ${ }^{[105]}$ Aus der Vorkultur wurden dann $6 \mathrm{~mL}$ in $500 \mathrm{~mL}$ Medium überführt und in einem $1 \mathrm{~L}$ Schüttelkolben für $10-14 \mathrm{~d}$ bei $100 \mathrm{U} \cdot \mathrm{min}^{-1}$ und $37^{\circ} \mathrm{C}$ lichtgeschützt inkubiert.

Tabelle 3.4: Zusammensetzung der für die Kultivierung der Halobakterien verwendeten Nährmedien.

\begin{tabular}{|c|c|c|c|}
\hline \multicolumn{2}{|c|}{ Normalmedium } & \multicolumn{2}{|c|}{ Medium 97} \\
\hline $\mathrm{NaCl}$ & $250 \mathrm{~g} \cdot \mathrm{L}^{-1}$ & $\mathrm{NaCl}$ & $250 \mathrm{~g} \cdot \mathrm{L}^{-1}$ \\
\hline $\mathrm{Na}_{3}$ Citrat & $3 \mathrm{~g} \cdot \mathrm{L}^{-1}$ & $\mathrm{Na}_{3}$ Citrat & $3 \mathrm{~g} \cdot \mathrm{L}^{-1}$ \\
\hline $\mathrm{KCl}$ & $2 \mathrm{~g} \cdot \mathrm{L}^{-1}$ & $\mathrm{KCl}$ & $2 \mathrm{~g} \cdot \mathrm{L}^{-1}$ \\
\hline $\mathrm{MgSO}_{4} \cdot 6 \mathrm{H}_{2} \mathrm{O}$ & $18,5 \mathrm{~g} \cdot \mathrm{L}^{-1}$ & $\mathrm{MgSO}_{4} \cdot 6 \mathrm{H}_{2} \mathrm{O}$ & $18,5 \mathrm{~g} \cdot \mathrm{L}^{-1}$ \\
\hline \multirow[t]{4}{*}{$\begin{array}{l}\text { Pepton (L 34, Oxoid, } \\
\text { Hampshire, UK) }\end{array}$} & $10 \mathrm{~g} \cdot \mathrm{L}^{-1}$ & Hefeextrakt & $10 \mathrm{~g} \cdot \mathrm{L}^{-1}$ \\
\hline & & Casaminosäuren & $7,5 \mathrm{~g} \cdot \mathrm{L}^{-1}$ \\
\hline & & $\mathrm{FeSO}_{4} \cdot 7 \mathrm{H}_{2} \mathrm{O}$ & $0,05 \mathrm{~g} \cdot \mathrm{L}^{-1}$ \\
\hline & & $\mathrm{MnSO}_{4} \cdot \mathrm{H}_{2} \mathrm{O}$ & $0,02 \mathrm{~g} \cdot \mathrm{L}^{-1}$ \\
\hline $\mathrm{pH} 7,0$ & & $\mathrm{pH} 7,4$ & \\
\hline
\end{tabular}




\section{Fraktionierung der Zellmembranen}

Die Kulturlösung wurde zunächst für $15 \mathrm{~min}$ bei $3900 \mathrm{~g}$ und $4{ }^{\circ} \mathrm{C}$ zentrifugiert $\left(4250 \mathrm{U} \cdot \mathrm{min}^{-1}\right.$, Allegra X-22R, SX 4255 Rotor, Beckman, Krefeld). Das Zellpellet wurde in $6 \mathrm{~mL}$ frisch angesetzter Basalsalzlösung (250 $\left.\mathrm{g} \cdot \mathrm{L}^{-1} \mathrm{NaCl}, 18,5 \mathrm{~g} \cdot \mathrm{L}^{-1} \mathrm{MgSO}_{4}, 2 \mathrm{~g} \cdot \mathrm{L}^{-1} \mathrm{KCl}\right)$ resuspendiert und mit einer Spatelspitze DNAse I (Grade II, Roche, Mannheim) versetzt. Zur Lyse der Zellen wurde die Lösung mit Reinstwasser auf $50 \mathrm{~mL}$ aufgefüllt und für $2 \mathrm{~h}$ bei Raumtemperatur inkubiert, bevor die Zellmembranfragmente für $1 \mathrm{~h}$ bei $186000 \mathrm{~g}$ und $4{ }^{\circ} \mathrm{C}$ in der Zentrifuge (43000 U· $\min ^{-1}$, TI 70 Rotor, Beckman, Krefeld) sedimentiert wurden. Das so erhaltene Pellet wurde in 1,5 mL Pufferlösung (50 mM TRIS, pH 7,5-8,0) aufgenommen und durch Pottern resuspendiert. Zur Fraktionierung der Membranbestandteile per Dichtegradientenzentrifugation, wurde ein kontinuierlicher Sucrosegradient hergestellt. Dazu wurden $16 \mathrm{~mL}$ einer $45 \%$ (w/v) Lösung und $18 \mathrm{~mL}$ einer $20 \%$ (w/v) Lösung von Sucrose in Reinstwasser in einem Gradientenmischer (Auftragsanfertigung, Glasgerätebau Ochs e. K., Bovenden) vermengt. Auf diese Lösung wurden bis zu $2 \mathrm{~mL}$ Membransuspension aufgetragen und die Probe anschließend für $14 \mathrm{~h}$ bei $80000 \mathrm{~g}$ und $15^{\circ} \mathrm{C}$ zentrifugiert $\left(16500 \mathrm{U} \cdot \mathrm{min}^{-1}\right.$, SW 28 Rotor, Beckman, Krefeld). Dabei wurde darauf geachtet, den Rotor ungebremst ausschwingen zu lassen. Es resultierten drei separierte farbige Banden (von oben nach unten, siehe auch Sumper $\left.{ }^{[105]}\right)$ : orange-rot (membranständige Pigmente wie Lycopin), gelb-braun (Cytochrom b und monomeres bR) und violett (Purpurmembranen). Die violette Bande wurde mit einer Pasteurpipette isoliert und zweimal mit Reinstwasser gewaschen. Dazu wurde je für $1 \mathrm{~h}$ bei $186000 \mathrm{~g}$ und $4{ }^{\circ} \mathrm{C}$ zentrifugiert (43000 U.min ${ }^{-1}$, TI 70 Rotor). Schließlich wurde das erhaltene Pellet in wenig (1-3 mL) $50 \mathrm{mM}$ TRIS-Puffer ( $\mathrm{pH} \mathrm{7,5-8,0)} \mathrm{oder} \mathrm{Reinstwasser}$ aufgenommen und durch Pottern homogenisiert. Die bR-Konzentration in den isolierten PMFragmenten wurde UV-Vis spektroskopisch bestimmt $\left(\varepsilon(\mathrm{bR})_{568 \mathrm{~nm}}=63000 \mathrm{M}^{-1} \cdot \mathrm{cm}^{-1[154]}\right.$, V650 Spectrophotometer, Jasco, Gross-Umstadt) und die Suspension bei $-21{ }^{\circ} \mathrm{C}$ lichtgeschützt gelagert.

\subsubsection{Fluoreszenzmarkierung von Bacteriorhodopsin}

Um bR für fluoreszenzmikroskopische Untersuchungen zugänglich zu machen, wurde es kovalent mit einem Fluoreszenzfarbstoff ( $d y e$ ) über NHS Ester markiert. NHS Ester werden üblicherweise verwendet, um terminale Aminogruppen des Proteins zu markieren, insbesondere den N-Terminus oder Lysin-Seitenketten. Im Fall von bR ist lediglich die $\varepsilon$-Aminofunktion der Aminosäure Lysin-129 zugänglich, weshalb jeweils nur ein Farbstoffmolekül an ein bR-Molekül gebunden werden kann. ${ }^{[155]}$ Die Reaktion ist in Gl. 3.1 dargestellt und besteht aus einem nukleophilen Angriff der Aminogruppe an die Esterfunktionalität des Farbstoffs. Dabei wird unter Abspaltung des Hydroxysuccinimids eine stabile Amidbindung gebildet. Die Reaktion wird bei leicht basischem $\mathrm{pH}$ durchgeführt $(8,3)$, da zum einen die Amino- 
funktionen für den nukleophilen Angriff deprotoniert vorliegen müssen, was nur im basischen Bereich in signifikantem Maße der Fall ist (der $\mathrm{pK}_{\mathrm{S}}\left(\varepsilon-\mathrm{NH}_{2}\right)$ von freiem Lysin beträgt etwa 10,3). Zum anderen darf der $\mathrm{pH}$-Wert nicht zu hoch eingestellt werden, da Hydroxidionen ebenfalls nukleophil am Farbstoffester angreifen und diesen so hydrolysieren können. Weiterhin dürfen keine anderen Substanzen mit primären Aminogruppen (z. B. TRIS-Puffer) vorliegen, da diese die Markierungsrate durch Konkurrenzreaktionen drastisch senken.<smiles>Cc1ccccc1C(=O)NNC(=O)C(=O)ON1C(=O)CCC1=O</smiles>

\section{Durchführung}

Eine grundsätzliche Vorschrift zur Durchführung der Markierungsreaktion findet sich bei den meisten kommerziellen Vertreibern entsprechender Farbstoffe und wurde hier modifiziert eingesetzt. ${ }^{[156]}$ Bei jeglichen Arbeiten mit bR oder Farbstoffen wurde darauf geachtet, die Probe vor Belichtung zu schützen. Zunächst wurde der entsprechende Farbstoff langsam aufgetaut und in über Molsieb (4 A, Carl Roth, Karlsruhe) getrocknetem DMF bei einer Konzentration von $10 \mathrm{mg} \cdot \mathrm{mL}^{-1}$ gelöst. Parallel wurden PM-Fragmente aufgetaut, Natriumhydrogencarbonat zugefügt, sodass eine $0,1 \mathrm{M}$ Lösung mit $\mathrm{pH}$ 8,3 erhalten wurde und die bR-Konzentration UV-Vis spektroskopisch bestimmt. Für eine hohe Markierungsrate sollte die Konzentration des zu markierenden $\mathrm{bR}$ zwischen 5 und $10 \mathrm{mg} \cdot \mathrm{mL}^{-1}$ liegen und ein fünfbis sechsfacher molarer Überschuss des Farbstoffs eingesetzt werden. Um die Lysin-Seitenketten möglichst gut zugänglich zu machen, wurden die PM-Fragmente (je nach Konzentration des bR 1-2,5 mL) in einen $5 \mathrm{~mL}$ Spitzkolben überführt und für 2 min mit Hilfe eines tip sonifiers (cycle $40 \%$, power $70 \%$, Bandelin electronic, Berlin) bei Eiskühlung beschallt. Nun wurde der Farbstoff gelöst in DMF (üblicherweise $100 \mu \mathrm{L}$ ) unter Rühren zugegeben. Die Reaktion wurde $1 \mathrm{~h}$ bei Raumtemperatur und mindestens für weitere $3 \mathrm{~h}$ bei $4{ }^{\circ} \mathrm{C}$ gerührt. Zur Trennung der PM-Fragmente vom freien, nicht gebundenen Farbstoff, wurde die Reaktionslösung für $20 \mathrm{~min}$ bei $80000 \mathrm{~g}$ und $4{ }^{\circ} \mathrm{C}$ zentrifugiert (30500 U.min ${ }^{-1}$, TI 90 Rotor, Beckman, Krefeld). Der Überstand wurde verworfen und das Pellet zweimal mit $0,1 \mathrm{M} \mathrm{NaHCO}_{3}$-Lösung gewaschen und einmal mit Reinstwasser. Dazu wurde je für $20 \mathrm{~min}$ bei $80000 \mathrm{~g}$ und $4{ }^{\circ} \mathrm{C}$ zentrifugiert (30500 U $\cdot \mathrm{min}^{-1}$, TI 90 Rotor). Das fluoreszenzmarkierte Protein wurde in wenig Reinstwasser (1-2 mL) aufgenommen, in ein Eppendorf-Gefäß überführt und bei $-21^{\circ} \mathrm{C}$ gelagert. 


\section{Bestimmung der Markierungsrate}

Der Anteil fluoreszenzmarkierten Proteins, wie auch die bR-Konzentration, wurde nach der Markierungsreaktion UV-Vis spektroskopisch bestimmt. Abhängig vom Fluorophor wurde dazu folgendermaßen vorgegangen: Sind Fluorophor (Alexa Fluor 488) und bR spektral so weit voneinander getrennt, dass die Farbstoffabsorption und das Absorptionsmaximums des bR nicht überlappen, wurde zusätzlich ein Spektrum unmarkierter PM-Fragmente aufgenommen und daraus Absorptionswerte bei $\lambda_{\max , \mathrm{bR}}$ und $\lambda_{\max \text {,Farbstoff }}$ abgelesen. Die Markierungsrate (degree of labeling, DOL) wurde dann gemäß Gl. 3.2 bestimmt:

$$
D O L=\frac{\left(E_{\text {Probe }, \lambda \max , F a r b s t o f f}-\frac{E_{b R, \lambda \max , \text { Farbstoff }}}{E_{b R, \lambda \max , b R}} \cdot E_{\text {Probe }, \lambda \max , b R}\right) \cdot \varepsilon_{b R}}{\varepsilon_{\text {Farbstoff }} \cdot E_{\text {Probe }, \lambda \max , b R}},
$$

wobei $E_{\text {Probe }}$ die Absorption der Protein-Farbstoff-Lösung und $E_{\mathrm{bR}}$ die Absorption der Referenzlösung mit reinen PM-Fragmenten bei den jeweils im Index angegebenen Wellenlängen (Absorptionsmaximum des bR bzw. des Farbstoffs) bezeichnet, sowie $\varepsilon$ den molaren dekadischen Extinktionskoeffizienten von bR bzw. dem Farbstoff für die Wellenlänge des jeweiligen Absorptionsmaximums.

Für den Fall, dass Fluorophor (Texas Red, Cy3) und bR spektral stark überlappen, wurde die Lösung mit 1-2\% (v/v) Natriumdodecylsulfat (SDS) versetzt, geschüttelt und $1 \mathrm{~h}$ inkubiert, bevor ein Spektrum aufgenommen wurde. Dadurch verschiebt sich das Absorptionsmaximum des bR zu niedrigeren Wellenlängen $\left(\lambda_{\max ^{\star}, \mathrm{bR}}=392 \mathrm{~nm}\right)$ und kann so spektral von dem des gekoppelten Fluorophors vollständig getrennt werden, weshalb auf eine Korrektur, wie in Gl. 3.2 verzichtet werden kann. Die Markierungsrate berechnet sich dann gemäß Gl. 3.3:

$$
D O L=\frac{E_{\text {Probe }, \lambda \max , \text { Farbstoff }} \cdot \varepsilon_{\lambda \max ,, b R}}{\varepsilon_{\text {Farbstoff }} \cdot E_{\text {Probe }, \lambda \max , b R}}
$$

wobei Absorption $E$ und molarer dekadischer Extinktionskoeffizient $\varepsilon$ von bR bei $\lambda_{\max }=392 \mathrm{~nm}$ eingesetzt werden müssen. $\varepsilon_{\lambda \max ^{\natural}, \mathrm{bR}}$ wurde experimentell $\mathrm{zu} 30460 \mathrm{M}^{-1} \cdot \mathrm{cm}^{-1}$ bestimmt.

\subsubsection{Präparation goldunterstützter lösungsmittelhaltiger Membranen}

Um bR auf seine Funktion, bei Belichtung Protonen zu pumpen, durch Messung von Photoströmen (Kapitel 3.3.1) zu testen, wurden bR-haltige Proben auf goldunterstützten painted membranes angebunden. Solche Membranen werden durch Auftragen von Lipidlösungen in organischem Lösungsmittel (z. B. n-Dekan) auf selbstorganisierte Monoschichten und anschließendem Ausdünnen des Lösungsmittels generiert und weisen durch Spuren in der Membran verbleibenden Lösungsmittels exzellente Stabilität und elektrisch isolierende Eigen- 
schaften auf. ${ }^{[157]}$ Der Aufbau einer Messkammer, in welcher goldunterstützte lösungsmittelhaltige Membranen präpariert wurden, ist in Abb. 3.2 schematisch dargestellt.

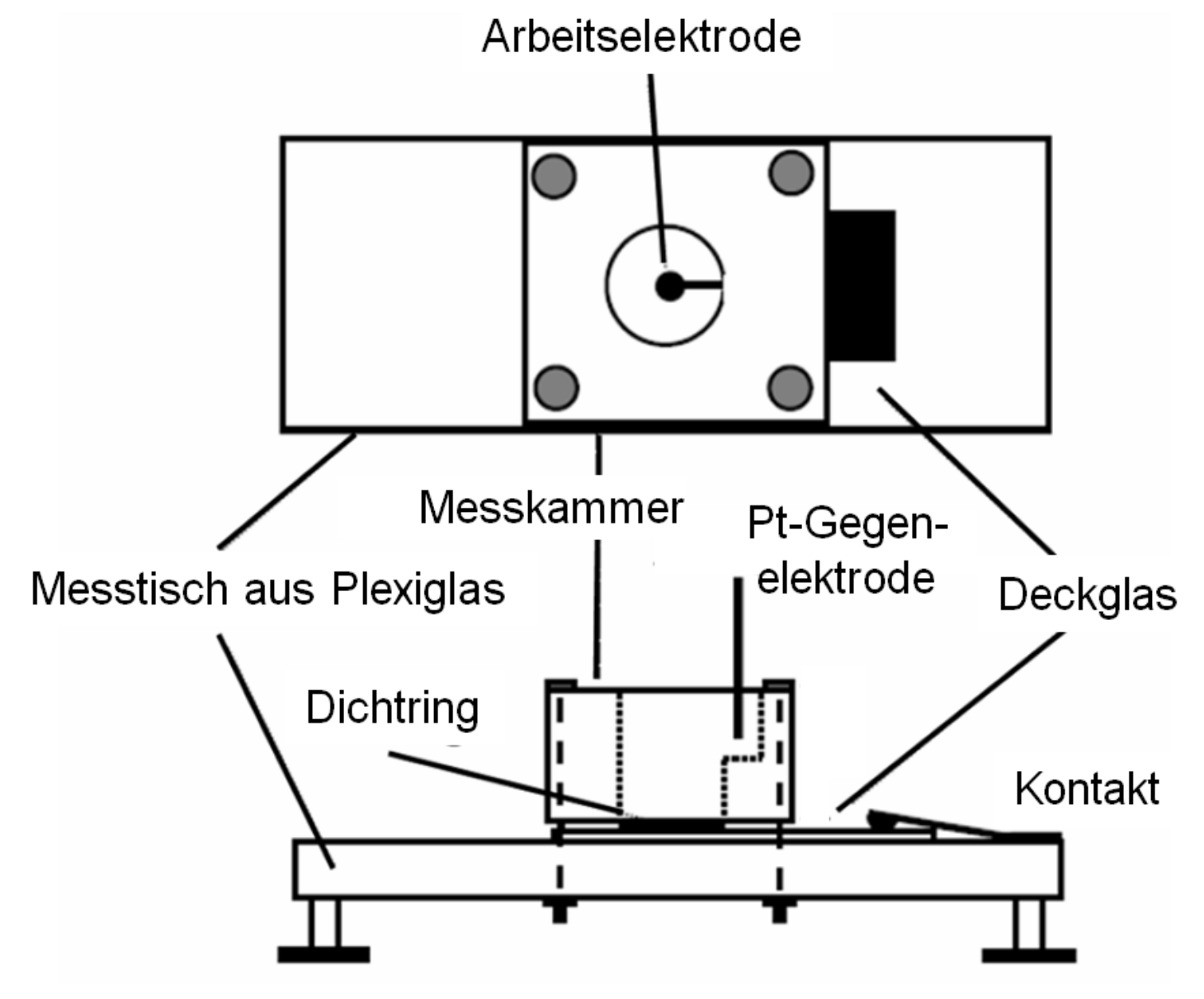

Abb. 3.2: Schematische Darstellung der Messkammer, in welcher goldunterstützte lösungsmittelhaltige Membranen präpariert wurden. ${ }^{[158]}$ Der gezeigte Aufbau diente für Impedanz- und Photostrommessungen (Kapitel 3.3.1). Die Fläche der Goldelektrode beträgt $0,0452 \mathrm{~cm}^{2}$.

\section{Durchführung}

Eine auf einem Deckglas aufgedampfte Goldelektrode wurde in Piranha-Lösung (konz. $\mathrm{H}_{2} \mathrm{SO}_{4}, 30 \% \mathrm{H}_{2} \mathrm{O}_{2}, 2: 1$ (v/v)) für 1 min gereinigt und gründlich mit Reinstwasser und Ethanol gespült. Im Argonplasma (5 min, PDC 32 G-2, Harrick, Ithaca, NY, USA) wurden letzte Verunreinigungen entfernt und die Elektrode mit einem Dichtring (Kalrez ${ }^{\circledR}$ O-Ring, DuPont Dow Elast., Newark, NJ, USA) abgedichtet und in eine Kunststoff-Kammer eingesetzt. Die Kammer wurde mit $400 \mu \mathrm{L}$ Thiollösung (0,1 M CPEO3 in $n$-Propanol) gefüllt, abgedichtet und für mindestens $1 \mathrm{~h}$ bei Raumtemperatur inkubiert. Die Elektrode wurde anschließend mehrfach mit $n$-Propanol und Pufferlösung gespült und mit Pufferlösung aufgefüllt. Die so präparierte CPEO3-Monoschicht wurde impedanzspektroskopisch vermessen (SI 1260, Solartron Instruments, Farnborough, GB). ${ }^{[147]}$ Für die Bildung einer Doppelschicht wurde die Monoschicht zunächst im Stickstoffstrom trocken geblasen und für $30 \mathrm{~s}$ mit $20 \mu \mathrm{L}$ einer 
Lösung von DPhPC $(2 \%(\mathrm{w} / \mathrm{v}))$ und Octadecylamin $(0,05$ oder $0,1 \%(\mathrm{w} / \mathrm{v}))$ in $n$-Dekan inkubiert. Anschließend wurde die Probe mehrfach mit Pufferlösung gespült, bis keine Spuren organischen Lösungsmittels in Form von „Schlieren“ mehr erkennbar waren, wobei darauf geachtet wurde, die Elektrode stets benetzt zu lassen. Die Doppelschicht wurde schließlich analog zur Monoschicht impedanzspektroskopisch vermessen.

\subsubsection{Präparation unilamellarer Vesikel zur funktionellen Rekonstitution von Bacteriorhodopsin}

\section{Präparation von Vesikeln nach der reverse phase Methode}

Bei der reverse phase Methode zur Präparation unilamellarer Vesikel wird ein ZweiphasenGemisch aus Lipid in organischem Lösungsmittel (Diethylether) und einer wässrigen Phase durch Ultraschallbehandlung gemischt. Dabei bilden die Lipide inverse Mizellen, in denen die unpolaren Seitenketten nach außen und die Kopfgruppen nach innen zum eingeschlossenen, wässrigen Medium weisen. Durch langsames Entfernen des Lösungsmittels lagern sich die Mizellen zusammen und bilden schließlich doppelschichtige Vesikel aus. Liegt dabei bR in dem Gemisch vor, so wird es in die sich bildenden Liposomen inkorporiert.

\section{Durchführung}

Reverse phase Vesikel wurden modifiziert nach einer Vorschrift von Rigaud et al. präpariert. ${ }^{[87]}$ Dazu wurde zunächst ein Lipidfilm hergestellt, indem definierte Mengen der gewünschten Lipide und Fluorophore $(0,2-2 \mathrm{mg})$ gelöst in $\mathrm{CHCl}_{3}$ in ein Reagenzglas überführt, mit $200 \mu \mathrm{L} \mathrm{CHCl}_{3}$ aufgefüllt und das Lösungsmittel bei $30{ }^{\circ} \mathrm{C}$ im Stickstoffstrom für 30 min und anschließend im Vakuum für mindestens $3 \mathrm{~h}$ entfernt wurde. Die fertigen Filme konnten bis zu ihrer Verwendung mit Parafilm versiegelt mehrere Wochen bei $4{ }^{\circ} \mathrm{C}$ dunkel gelagert werden. Ein Film wurde mit $500 \mu \mathrm{L}$ Diethylether versetzt, das Lipid durch mehrfaches Pipettieren gelöst und die Lösung in einen auf Eis gelagerten Spitzkolben überführt. Es wurden $500 \mu \mathrm{L}$ der gewünschten wässrigen Pufferlösung und optional PMFragmente zugegeben. Die Probe wurde für 2 min mit Hilfe eines tip sonifiers (cycle $40 \%$, power $70 \%$ ) beschallt, wodurch sich das bR aus den PM-Fragmenten löste und sich die Probe von violett zu gelb verfärbte. Bei kontinuierlich reduziertem Druck wurde der Diethylether langsam am Rotationsverdampfer entfernt, bis die Mischung eine gelartige Konsistenz annahm. Dabei färbte sich die Suspension nach violett zurück, was auf eine erfolgreiche Inkorporation des bR in die Vesikel deutete. An diesem Punkt wurde Pufferlösung zugegeben, um die gewünschte Endkonzentration einzustellen und restliches Lösungsmittel bei reduziertem Druck für mindestens 15 min vollständig entfernt. Bei der Zusammensetzung der 
Pufferlösung dürfen keine Calciumionen zugegen sein, da diese zu einem Verklumpen und dadurch Ausfallen der PM-Fragmente führen können (Abb. 4.31). Die Vesikelpopulation konnte nun entweder durch 31-fache Extrusion durch eine Polycarbonatmembran mit definierter Porengröße in eine geringe Lamellarität und enge Größenverteilung überführt werden (Miniextruder LiposoFast, Avestin, Ottawa, Kanada), oder direkt in ein EppendorfGefäß überführt und bei $4{ }^{\circ} \mathrm{C}$ lichtgeschützt bis zur Weiterverwendung gelagert werden.

\section{Rekonstitution von Bacteriorhodopsin in Vesikel durch Detergensentzug}

Eine weitere, gängige Methode, um Transmembranproteine in Liposomen zu rekonstituieren, besteht in der Verwendung von Detergentien. Detergentien sind amphiphile Moleküle, welche oberhalb einer sogenannten kritischen Mizellbildungskonzentration (critical micelle concentration, CMC) in wässrigen Lösungen Mizellen ausbilden. Abhängig von Parametern wie Temperatur oder der Art der eingesetzten Detergentien, bilden diese mit vorgeformten Liposomen bei steigender Detergenskonzentration zunächst detergensgesättigte Liposomen, bevor sich schließlich gemischte Mizellen bilden. Solch detergensgesättigte Liposomen ermöglichen die spontane Inkorporation von Membranproteinen und können anschließend durch Entzug des Detergens per Dialyse oder Adsorption an BioBeads ${ }^{\circledR}$ in funktionelle Proteoliposomen überführt werden. ${ }^{[61]}$ Im Folgenden werden zwei Varianten der detergensmediierten Rekonstitution von bR in Lipidvesikeln vorgestellt:

1) Die Rekonstitution nach einer mofizierten Vorschrift von Girard et al. unter Verwendung von Triton-X-100 als Detergens. ${ }^{[117]}$

2) Die Rekonstitution nach einer Vorschrift von Björklund et al. unter Einsatz von $n$-Octyl- $\beta$-D-glucopyranosid (n-OG) als Detergens. ${ }^{[10]}$

\section{Durchführung}

1) Ein Lipidfilm (POPC/POPS/Texas Red DHPE, 89,8:10,0:0,2) wurde mit Pufferlösung ( $2 \mathrm{mM}$ MOPS, pH 7,3 (TRIS)) zu einer Konzentration von $4 \mathrm{mg} \cdot \mathrm{mL}^{-1}$ Lipid versetzt und für 30 min quellen gelassen. Die Probe wurde in fünf Minuten Abständen dreimal für je $30 \mathrm{~s}$ in einem Vortex-Schüttler geschüttelt. Anschließend wurde die Suspension für zweimal $30 \mathrm{~min}$ im Ultraschallbad behandelt (cycle $40 \%$, power $60 \%$ ). Die dadurch erhaltene, klare Lösung wurde in ein Eppendorf-Gefäß überführt, mit Triton-X-100 versetzt bis ein Detergens-zuLipid-Verhältnis von 2 (w/w) erreicht war und nach kräftigem Durchmischen für 30 min bei Raumtemperatur lichtgeschützt inkubiert. Für die Rekonstitution von bR wurden über Nacht mit Triton-X-100 bei einem Detergens-zu-Protein-Verhältnis von 5 (w/w) in Puffer $(20 \mathrm{mM}$ HEPES, pH 6,8 (TRIS)) inkubierte PM-Fragmente zugegeben und die Probe für $2 \mathrm{~h}$ bei Raumtemperatur lichtgeschützt geschwenkt. Um im Anschluss das Detergens zu entfernen, 
wurden zweimal im Abstand von je einer Stunde $10 \mathrm{mg}$ BioBeads pro mg Detergens zur Probe zugefügt und weiter geschwenkt. Bei einer dritten Zugabe wurden $20 \mathrm{mg}$ BioBeads pro mg Detergens eingesetzt, für eine weitere Stunde geschwenkt, der Überstand durch vorsichtiges Pipettieren von den BioBeads abgetrennt und in ein Eppendorf-Gefäß überführt. Die Vesikel wurden bei $4{ }^{\circ} \mathrm{C}$ lichtgeschützt bis zu ihrer Verwendung gelagert.

2) Ein Lipidfilm (POPC/POPS, 9:1) wurde mit KCl-Lösung (150 mM) auf eine Lipidkonzentration von $5 \mathrm{mM}$ aufgefüllt und für $30 \mathrm{~min}$ quellen gelassen. Die Probe wurd dreimal für je $30 \mathrm{~s}$ in einem Vortex-Schüttler geschüttelt mit fünfminütiger Ruhezeit zwischendurch. Um die Multilamellarität der gebildeten Vesikel zu reduzieren, wurde die Probe mehrmals abwechselnd in flüssigem Stickstoff eingefroren und dann in einem $40{ }^{\circ} \mathrm{C}$ warmen Wasserbad wieder aufgetaut (freeze-thaw), bis die Suspension klar wurde. Die so erhaltenen Vesikel wurden 31 mal durch eine Polycarbonatmembran (nomineller Porendurchmesser $100 \mathrm{~nm}$ ) extrudiert, mit $n$-OG $(29 \mu \mathrm{M})$ versetzt und für 10 min inkubiert. Anschließend wurde eine Lösung von PM-Fragmenten in 1,5\% $n$-OG zu der Vesikellösung gegeben und dabei eine finale bR-Konzentration von $1,5 \mu \mathrm{M}$ (etwa $0,03 \mathrm{~mol} \%$ ) eingestellt. Die Probe wurde geschüttelt, für $5 \mathrm{~min}$ inkubiert, zur Entfernung des Detergens $80 \mathrm{mg}$ BioBeads pro $\mathrm{mL}$ zugefügt und für $3 \mathrm{~h}$ geschwenkt. Nach einer weiteren Zugabe von $80 \mathrm{mg}$ BioBeads pro $\mathrm{mL}$ wurde die Probe für mindestens weitere $2 \mathrm{~h}$ geschwenkt und der Überstand vorsichtig mit einer Pipette abgezogen. Reste von Detergens wurden durch Filtration der Lösung über eine G-25 Sephadex-Säule (GE Healthcare, Freiburg) entfernt und die erhaltenen Vesikel bei $4{ }^{\circ} \mathrm{C}$ lichtgeschützt bis zu ihrer Verwendung gelagert.

\subsubsection{Präparation mikrometergroßer unilamellarer Vesikel}

Im Rahmen dieser Arbeit wurden GUVs zum einen verwendet, um den Transport von Protonen über Membranen, induziert durch bR (Kapitelt 3.3.3) oder Nigericin (Kapitel 3.4.2), $\mathrm{zu}$ untersuchen, zum anderen, um durch Spreiten solcher GUVs auf porösen Substraten porenüberspannende Membranen zu generieren (Kapitel 3.2.11). Zur Präparation von GUVs wurde die Methode der Elektroformation (electro-swelling, e-swelling) nach Angelova et al. eingesetzt ${ }^{[159]}$, modifiziert von Mathivet et al. ${ }^{[160]}$ Es wird ein Lipidfilm auf elektrisch leitende Indium-Zinn-Oxid beschichtete Deckgläser aufgetragen, wässrige Lösung zugegeben und durch Anlegen einer Wechselspannung ein alternierendes elektrisches Feld erzeugt, welches die quellenden Lipidschichten in eine mikrometergroße, sphärische Form überführt. Je nachdem, ob Protein dabei rekonstituiert werden sollte und welche Ionenstärke die Lösung bei der Elektroformation haben sollte, wurde das Protokoll entsprechend angepasst, wie im folgenden Teil beschrieben. 


\section{Durchführung}

Indium-Zinn-Oxid beschichtete Deckgläser (indium tin oxide, ITO, $\left(\operatorname{In}_{2} \mathrm{O}_{3}\right)_{0,9} \cdot\left(\mathrm{SnO}_{2}\right)_{0,1}$, Präzisions Glas \& Optik GmbH, Iserlohn) wurden mit Ethanol und Reinstwasser sorgfältig gereinigt und eine Lösung von Lipid in Chloroform $\left(3 \mathrm{mg} \cdot \mathrm{mL}^{-1}\right.$, je $25 \mu \mathrm{L}$ pro Glas) wurde mit einer Mikroliterspritze (Hamilton AG, Bonaduz, Schweiz) aufgetragen. Die Lipidlösung wurde gleichmäßig über die Glasfläche verteilt und das Lösungsmittel über Nacht im Vakuum entfernt. Die Gläser wurden am Rand mit Kupferklebeband versehen (Abb. 3.3, A), bei jedem zweiten Glas ein Silikonring um den lipidbedeckten Bereich aufgelegt und jeweils zwei Gläser mit der beschichteten Seite nach innen zu einer Kammer zusammengefügt (Abb. 3.3, B, C). Die Kammern wurden durch Anlegen von Foldback-Klammern fixiert und der Innenraum zwischen beiden Gläsern mit filtrierter (Filterfeinheit 0,2 $\mu \mathrm{m}$ ) und entgaster Sucroselösung (0,3 M) aufgefüllt. Über das Kupferklebeband wurde die Kammer elektrisch mit einem Frequenzgenerator (Agilent Technologies, Santa Clara, CA, USA) kontaktiert und soweit nicht anders vermerkt eine sinusförmige Wechselspannung von $3 \mathrm{~V}$ (peak-to-peak) und $5 \mathrm{~Hz}$ für $2 \mathrm{~h}$ angelegt. Anschließend wurde die GUV-Suspension mittels Pipette aus der Kammer in zwei Eppendorf-Gefäße überführt. Hierbei wurde darauf geachtet, eine $1000 \mu \mathrm{L}$ Pipette zu benutzen, da die entsprechenden Spitzen eine relativ große Öffnung besitzen und somit eventuell auftretende Scherkräfte auf die Vesikel minimiert werden. Weiterhin wurde zunächst nur die Hälfte des in der Kammer befindlichen Volumens entnommen und in das erste Eppendorf-Gefäß überführt. Die zweite Hälfte wurde mehrfach an den Glaswänden entlang gespült, bevor sie in das zweite Eppendorf-Gefäß überführt wurde, um noch nicht abgelöste Vesikel möglichst vollständig zu entfernen, was sich positiv auf die Anzahl der isolierten Vesikel auswirkte. Die so erhaltenen GUV-Suspensionen wurden bis zu ihrer Verwendung bei $4{ }^{\circ} \mathrm{C}$ lichtgeschützt gelagert. 

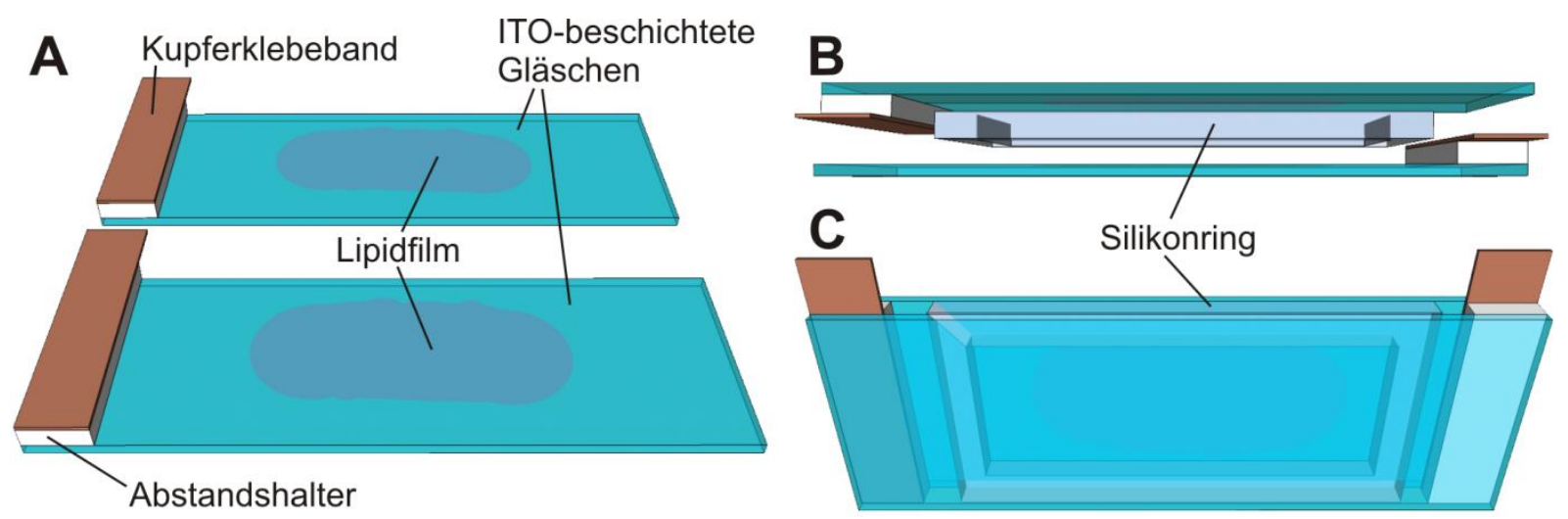

Abb. 3.3: Schematische Darstellung der Zusammensetzung zweier ITO-beschichteter Gläser zu einer Kammer für die GUV-Präparation. ${ }^{[161]}$ A zeigt zwei ITO-beschichtete Deckgläser nach Auftragen eines Lipidfilms. Zur elektrischen Kontaktierung wurde der am Rand jeden Glases aufgebrachte Abstandshalter aus Teflonfolie mit Kupferklebeband beschichtet. B Aufsicht der Zusammensetzung zweier Gläser. Nach Einsetzen eines Silikonrings um den lipidbedeckten Bereich eines Glases wurden beide Gläser mit der beschichteten Seite nach innen zusammengesetzt. C Seitenansicht der fertig zusammengesetzten Kammer. Der vom Silikonring eingeschlossene Bereich kann mit Sucroselösung gefüllt werden. Zur zusätzlichen Stabilisierung wurden Foldback-Klammern angebracht (hier nicht gezeigt).

\section{Präparation von Proteo-GUVs}

Die Funktionalität von Membranproteinen wie bR kann negativ beeinflusst werden, wenn sie dem in der GUV-Bildung beschriebenem Vakuum ausgesetzt und so dehydratisiert werden. ${ }^{[162]}$ Eine direkte Applikation von bR zusammen mit den Lipiden ist aufgrund des Kontaktes mit organischem Lösungsmittel, was zur Denaturierung des Proteins führen würde, nicht möglich. Es wurden folgende Strategien angewendet, um bR möglichst funktionell in GUVs zu rekonstituieren:

1) Statt des Auftragens eines Lipidfilms auf die ITO-beschichteten Gläschen, wurde eine Suspension vorgeformter Proteoliposomen aufgetragen, wie sie nach einer der in Kapitel 3.2.4 beschriebenen Methoden präpariert worden waren. Dazu wurden insgesamt etwa $200 \mu \mathrm{L}$ einer Suspension von Proteoliposomen (Lipidkonzentration soweit nicht anders vermerkt $1 \mathrm{mg} \cdot \mathrm{mL}^{-1}$ ) als $2 \mu \mathrm{L}$ Tropfen auf zwei beschichtete Gläser verteilt. Hiervon ausgehend wurde nach verschiedenen Ansätzen partiell dehydratisiert:

1-1) Trocknen der Lösung über Nacht im Exsikkator über gesättigter NaClLösung. ${ }^{[117]}$

1-2) Vor Auftragen der $2 \mu \mathrm{L}$-Tropfen wurde der Vesikelsuspension Glycerin $(1 \%(\mathrm{v} / \mathrm{v}))^{[163]}$, Sucrose $(0,2 \mathrm{~g} \text { pro g Lipid })^{[162]}$ oder Trehalose $(20 \mathrm{mM})^{[164]}$ beigefügt. Die tropfenbedeckten Gläschen wurden dann unter Vakuum getrocknet. 
2) PM-Fragmente wurden mit Pufferlösung auf ein Volumen von $20 \mu \mathrm{L}$ aufgefüllt (Endkonzentration bR ca. $2,5 \mathrm{mg} \cdot \mathrm{mL}^{-1}$ ) und für $1 \mathrm{~min}$ im Ultraschallbad behandelt. Nach Trocknen der auf die Gläschen aufgebrachten Lipidfilme im Vakuum, wurden je $10 \mu \mathrm{L}$ der PM-Suspension gleichmäßig auf den vorgetrockneten Lipidfilmen zweier ITO-Gläser verteilt und die Proben im Exsikkator über gesättigter NaCl-Lösung partiell dehydratisiert.

Die zugefügten Stoffe unter 1-2 sollen durch Bildung von Wasserstoffbrücken die Struktur des Proteins bei der Dehydratisierung konservieren. Nach Trocknung der Probe über Nacht wurde analog zur Vorgehensweise bei der Bildung proteinfreier GUVs die Kammer zusammengesetzt, wässrige Lösung zugegeben und eine Sinusspannung angelegt.

\section{Präparation von GUVs unter physiologischen Bedingungen}

Der Prozess der Elektroformation toleriert nur geringe Ionenstärken in der Rehydratationslösung, typischerweise bis zu $10 \mathrm{mM}$ monovalente Ionen und sogar geringere Werte für divalente Ionen. ${ }^{[165]}$ Für fluoreszenzmikroskopische Studien zum Transport von Protonen über Membranen wurde im Rahmen dieser Arbeit der dreifach negativ geladene Farbstoff Pyranin bis zu $1 \mathrm{mM}$ in GUVs eingeschlossen. Weiterhin sollten GUVs mit einer Füllung von $160 \mathrm{mM} \mathrm{KCl}$ und $10 \mathrm{mM}$ MOPS gebildet werden, was in diesen Fällen eine Abweichung vom Standard-Elektroformationsprotokoll erforderte. Um unter diesen Bedingungen dennoch GUVs bilden zu können, wurde nach einer Vorschrift von Pott et al. vorgegangen, bei der im Wesentlichen lediglich angelegte Spannung und Frequenz verändert wurden. ${ }^{[166]}$

\section{Durchführung}

Ausgehend von einem beliebigen der bisher oben beschriebenen Protokolle wird zu einer zusammengesetzten Kammer aus zwei Gläsern ein gewünschter Hochsalzpuffer gegeben. Statt einer Spannung von $3 \mathrm{~V}$ und $5 \mathrm{~Hz}$ wurde eine Startspannung von $50 \mathrm{mV}$ (peak-to-peak) bei einer Frequenz von $500 \mathrm{~Hz}$ angelegt. Die Spannung wurde innerhalb von 30 min langsam auf $3 \mathrm{~V}$ erhöht und die Probe unter diesen Bedingungen für mindestens 90 min belassen. Anschließend wurde die Frequenz von $500 \mathrm{~Hz}$ sukzessive innerhalb von $30 \mathrm{~min}$ auf $50 \mathrm{~Hz}$ reduziert und die GUV-Suspension nach weiteren $30 \mathrm{~min}$ wie bereits oben beschrieben in zwei Eppendorf-Gefäße überführt.

\subsubsection{Fixierung von GUVs auf Siliziumwafern}

Um GUVs über einen längeren Zeitraum fluoreszenzmikroskopisch untersuchen zu können, war es notwendig, diese auf einem Substrat zu immobilisieren. Hierzu wurden Siliziumwafer hydrophilisiert und in Avidin inkubiert. Durch die starke Avidin-Biotin-Wechselwirkung 
konnten Vesikel, welche mit dem Biotin-funktionalisierten Lipid Bio-Cap-PE (Kapitel 3.1.1) dotiert worden waren, nach Zugabe auf dem Substrat fixiert werden. ${ }^{[145]}$

\section{Durchführung}

Ein Siliziumwafer (Dicke: $625 \mu \mathrm{m}$, Orientierung: (100), Dotierung: p-Typ, Bor, Widerstand: 1-20 $\Omega \cdot \mathrm{cm}$, CrysTec, Berlin) mit einer Siliziumdioxidschicht von $100 \mathrm{~nm}$ Dicke, wurde zunächst mit Hilfe eines Diamantschneiders in Stücke mit Kantenlängen von $2 \mathrm{~cm}$ und $0,5 \mathrm{~cm}$ geschnitten. Die Stücke wurden mit Isopropanol und Reinstwasser gespült und dann für 20 min bei $70{ }^{\circ} \mathrm{C}$ in einem Gemisch aus Reinstwasser, wässriger Ammoniaklösung (25\%) und Wasserstoffperoxidlösung (30\%) im Volumenverhältnis von 5:1:1 inkubiert. Die WaferStücke wurden erneut mit Reinstwasser gespült und in einer Messkammer aus Delrin oder einer Plastikpetrischale fixiert. Die Kammern wurden mit einer Avidinlösung $(50 \mathrm{nM})$ in Puffer (100 mM NaCl, 20 mM TRIS, pH 7,4 ( HCl)) aufgefüllt, für 1,5 h bei Raumtemperatur inkubiert und anschließend mit Puffer (wenn nicht anders vermerkt $160 \mathrm{mM} \mathrm{KCl}, 10 \mathrm{mM}$ MOPS, pH 7,3 (KOH)) gespült. Auf die mit Avidin funktionalisierten, pufferbedeckten Wafer konnten schließlich mit Bio-Cap-PE dotierte GUVs gegeben werden. Für die Untersuchung des nigericininduzierten $\mathrm{K}^{+} / \mathrm{H}^{+}$-Antiports wurden GUVs $(100 \mu \mathrm{L})$ der Zusammensetzung DPhPC/DOPC/Bio-Cap-PE/Texas Red DHPE, 59,4:39,4:1:0,2 (Elektroformation (Hochfrequenz) in $320 \mathrm{mM}$ Sucrose, $10 \mathrm{mM}$ MOPS, 0,5 mM Pyranin, pH 7,3 (TRIS)) verwendet. Im Fall des bR-induzierten, lichtgetriebenen Protonentransports besaßen die GUVs $(10 \mu \mathrm{L})$ eine Zusammensetzung von POPC/Bio-Cap-PE/Texas Red DHPE, 98,8:1:0,2 (0,3 mol\% bR, rekonstituiert nach der reverse phase Methode nach Girard et al., Elektroformation (Hochfrequenz) in $320 \mathrm{mM}$ Sucrose, $10 \mathrm{mM}$ MOPS, $1 \mathrm{mM}$ Pyranin, pH 7,3 (TRIS)). Nach kurzem Absinken der GUVs konnte die Probe dann fluoreszenzmikroskopisch untersucht werden.

\subsubsection{Präparation poröser Siliziumsubstrate}

Porenüberspannende Membranen wurden durch Spreiten von Vesikeln oder Anwendung der painting-Technik präpariert und elektrochemische Gradienten über diese aufgebaut. Hierbei wurden neben Substraten von offenen Poren auf Siliziumnitridbasis mit Durchmessern von 450 bis $2000 \mathrm{~nm}$ (FluXXion, Eindhoven, Niederlande) vor allem Substrate von periodisch angeordneten Poren mit geschlossenen Böden und Durchmessern bzw. Kantenlängen von 1 bis $8 \mu \mathrm{m}$ sowie Tiefen bis $12 \mu \mathrm{m}$ eingesetzt. Die Poren bieten ein abgeschlossenes PikoliterVolumen, in welches wässrige Lösungen definierter Zusammensetzung durch Überspannen der Poren mittels einer Membran eingeschlossen werden können. Dies schafft die Voraussetzung, Ionengradienten aufbauen zu können. Substrate mit runden Poren und geschlossenen Porenböden (Durchmesser von 3,5 bis 5,5 $\mu \mathrm{m}$, Porositäten von 10 bis $40 \%$ ) wurden von Dr. Siegfried Steltenkamp (Micro System Technologies, Center of Advanced European Studies 
and Research, CAESAR, Bonn) erhalten. Rechteckige, Poren mit geschlossenen Porenböden (Durchmesser von 1 bis $8 \mu \mathrm{m}$, Porositäten von 58 bis $65 \%$ ) wurden großzügigerweise von Dr. Stefan Schweizer (Institut für Physik, Martin-Luther-Universität Halle-Wittenberg) zur Verfügung gestellt. Die rechteckigen Poren wurden dabei durch photo-elektrochemisches Ätzen mit HF von (100)-orientierten Siliziumscheiben, welche photolithographisch vorstrukturiert worden waren, gefertigt. ${ }^{[167]}$ Die Fertigung runder, poröser Siliziumsubstrate, wie sie von Dr. Siegfried Steltenkamp durchgeführt worden war, erfolgte nach ähnlichem Prinzip (Bosch deep silicon etching) ${ }^{[40]}$ und soll aufgrund ihrer prominenten Bedeutung für diese Arbeit im Folgenden kurz genauer erläutert werden (Abb. 3.4). Rasterelektronenmikroskopische Aufnahmen der verwendeten Substrate sind in Abb. 3.5 dargestellt.

\section{Durchführung}

Ein mit einer elektrisch isolierenden Schicht durchzogenes Siliziumsubstrat (Dicke der bearbeiteten Schicht: $8 \mu \mathrm{m}$, Dicke der unterliegenden, unbearbeiteten Schicht: $525 \mu \mathrm{m}$ silicon-on-insulator, SOI, Abb. 3.4, A) mit einer (100)-Orientierung wurde zunächst einer nassen thermischen Oxidation (wet thermal oxidation) unterzogen, um eine $1 \mu \mathrm{m}$ dicke Siliziumdioxidschicht aufzutragen (Abb. 3.4, B). Siliziumdioxid- und unterliegende Siliziumschicht wurden mittels UV-Lithographie (AZ1518, MicroChemicals GmbH, Ulm, Abb. 3.4, C und D), Plasmaätzen (reactive ion etching, Abb. 3.4, E) und reaktivem Ionentiefenätzen (deep reactive ion etching, Abb. 3.4, F) strukturiert. Dabei wurde abwechselnd mit $\mathrm{SF}_{6}$ geätzt $\left(65 \mathrm{sccm}, t_{\text {Ätzen }}=8 \mathrm{~s}, p_{\ddot{A ̈ t z e n ~}}=10 \mathrm{mTorr}\right)$ und mit $\mathrm{C}_{4} \mathrm{~F}_{8}$ passiviert $\left(55 \mathrm{sccm}, t_{\text {Passivierung }}=7,8 \mathrm{~s}\right.$, $p_{\text {Passivierung }}=10 \mathrm{mTorr}$ ) . Eine dünne $\mathrm{SiO}_{2}$-Schicht zwischen Siliziumschicht und Isolatorschicht bildete die Grenze des Ätzprozesses. Nach Entfernung des Photolacks (Abb. 3.4, G) wurde per thermischer Oxidation eine dünne Schicht Siliziumdioxid aufgebracht $(500 \mathrm{~nm})$, welche anschließend durch nasses Ätzen (wet etching, BHF, $35^{\circ} \mathrm{C}$ ) wieder entfernt wurde. Dadurch konnte die Rauhigkeit der Porenwände reduziert werden (Abb. 3.4, H). Um eine hydrophile Oberfläche zu generieren, wurde durch thermische Oxidation abschließend eine dünne Siliziumdioxidschicht $\left(500 \mathrm{~nm}\right.$ ) aufgetragen (Abb. 3.4, I), und das Substrat in $25 \mathrm{~mm}^{2}$ große Chips geschnitten. Ein weiterer Wafer wurde abschließend mit Siliziumnitrid (200 nm) statt mit Siliziumdioxid beschichtet. Zum Schutz vor Transportschäden wurden die Substrate mit einer dünnen Schicht Schutzlack versehen. 
A
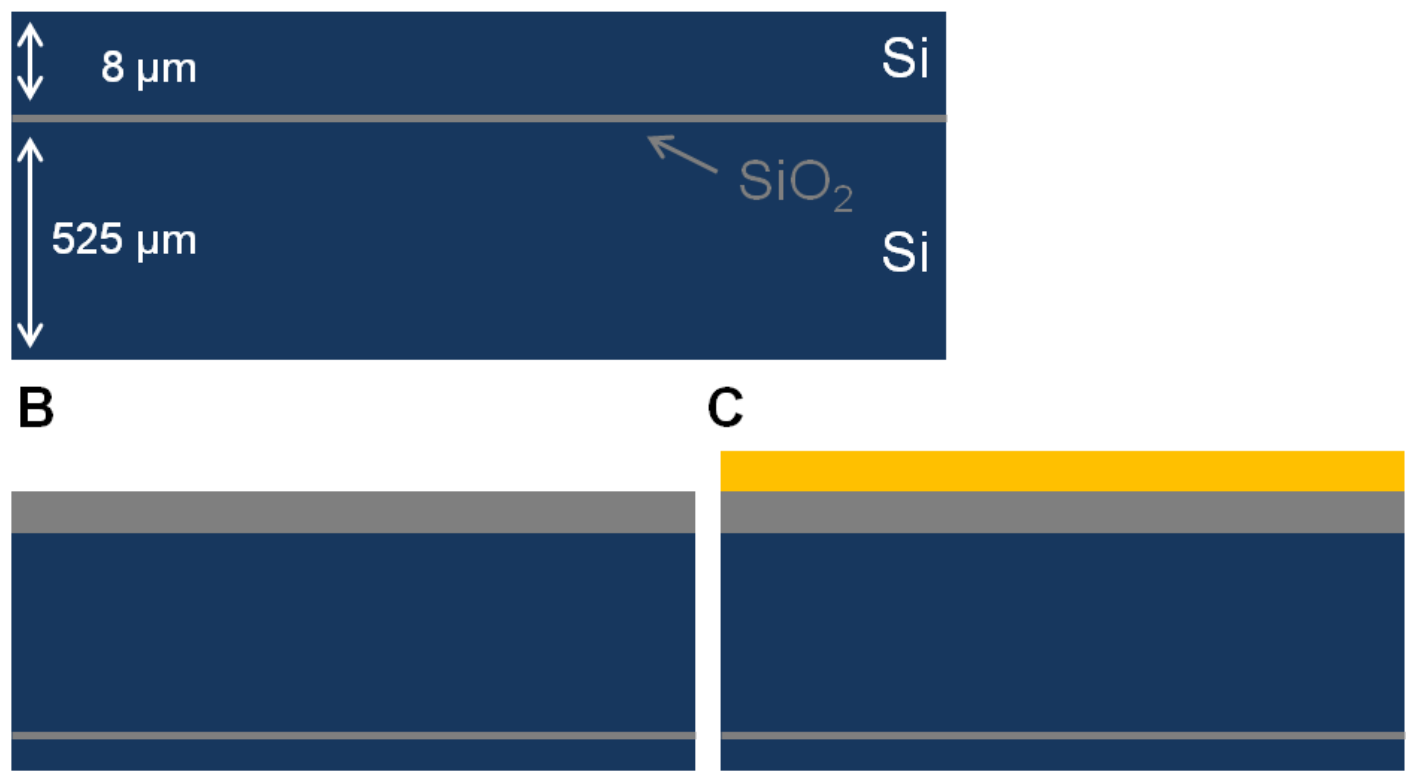

D

E
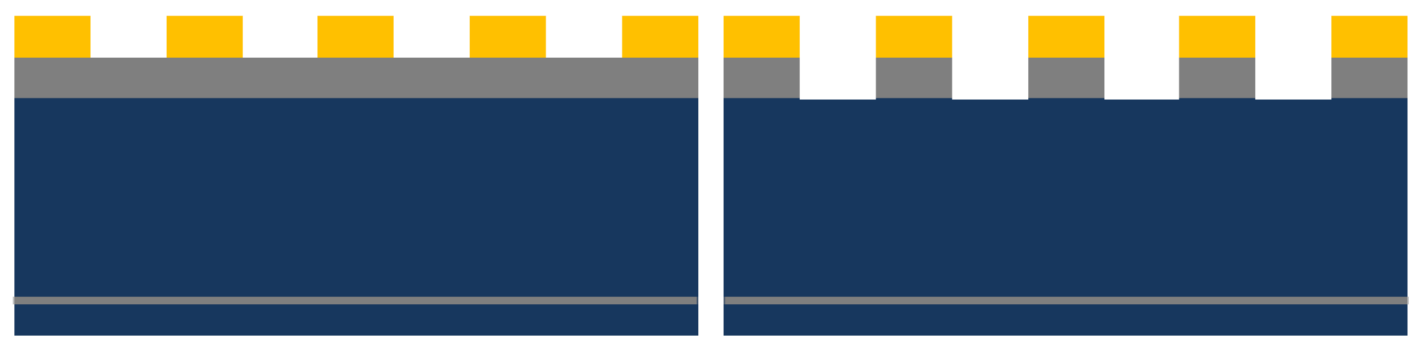

$\mathbf{F}$

G
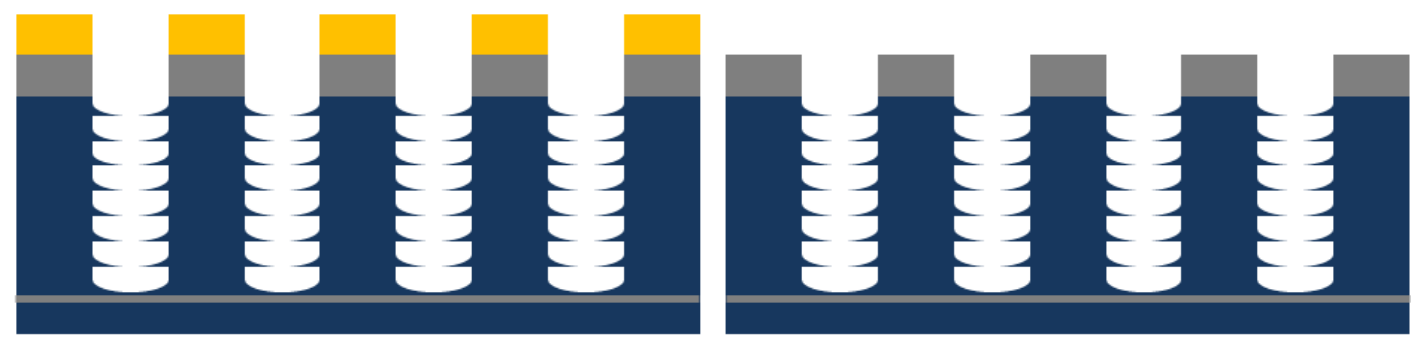

\section{$\mathrm{H}$}

I
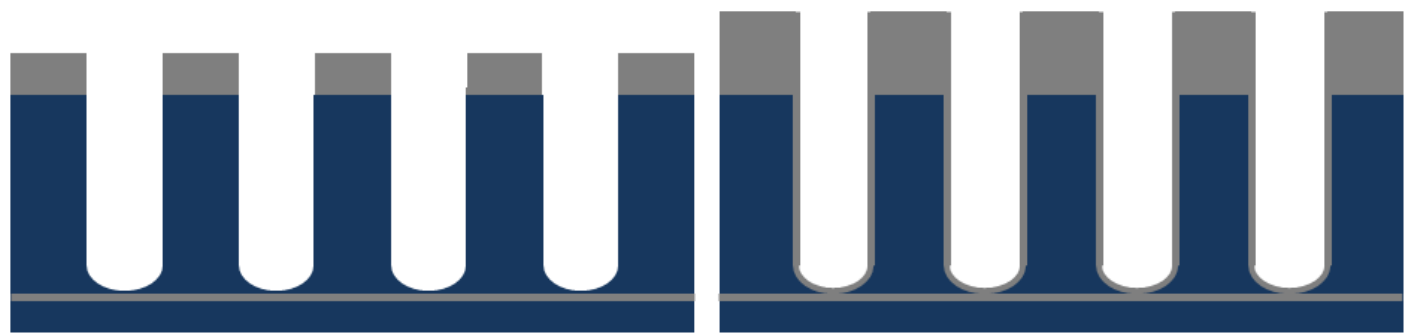

Abb. 3.4: Schematische Darstellung des Fertigungsprozesses poröser Substrate mit runden, geschlossenen Poren (nicht maßstabsgetreu). A zeigt einen SOI-Wafer, welcher zunächst mit einer Oxidschicht (B) und anschließend Photolack (C) bedeckt wird. D durch Photolithographie und anschließendem reaktiven Ionenätzen (E) wird das Substrat vorstrukturiert. F Reaktives Ionentiefenätzen bis zur isolierenden $\mathrm{SiO}_{2}$-Schicht bildet tiefe Poren. G Nach Entfernen des Photolacks werden durch Aufbringen und Ablösen einer $\mathrm{SiO}_{2}$-Schicht $(\mathbf{H})$ die Poreninnenwände geglättet. I zeigt das fertige Substrat mit hydrophiler Oxidschicht. Für eine bessere Übersicht wurde in den Abbildungen B bis I nur der oberer Teil des Substrates dargestellt. 

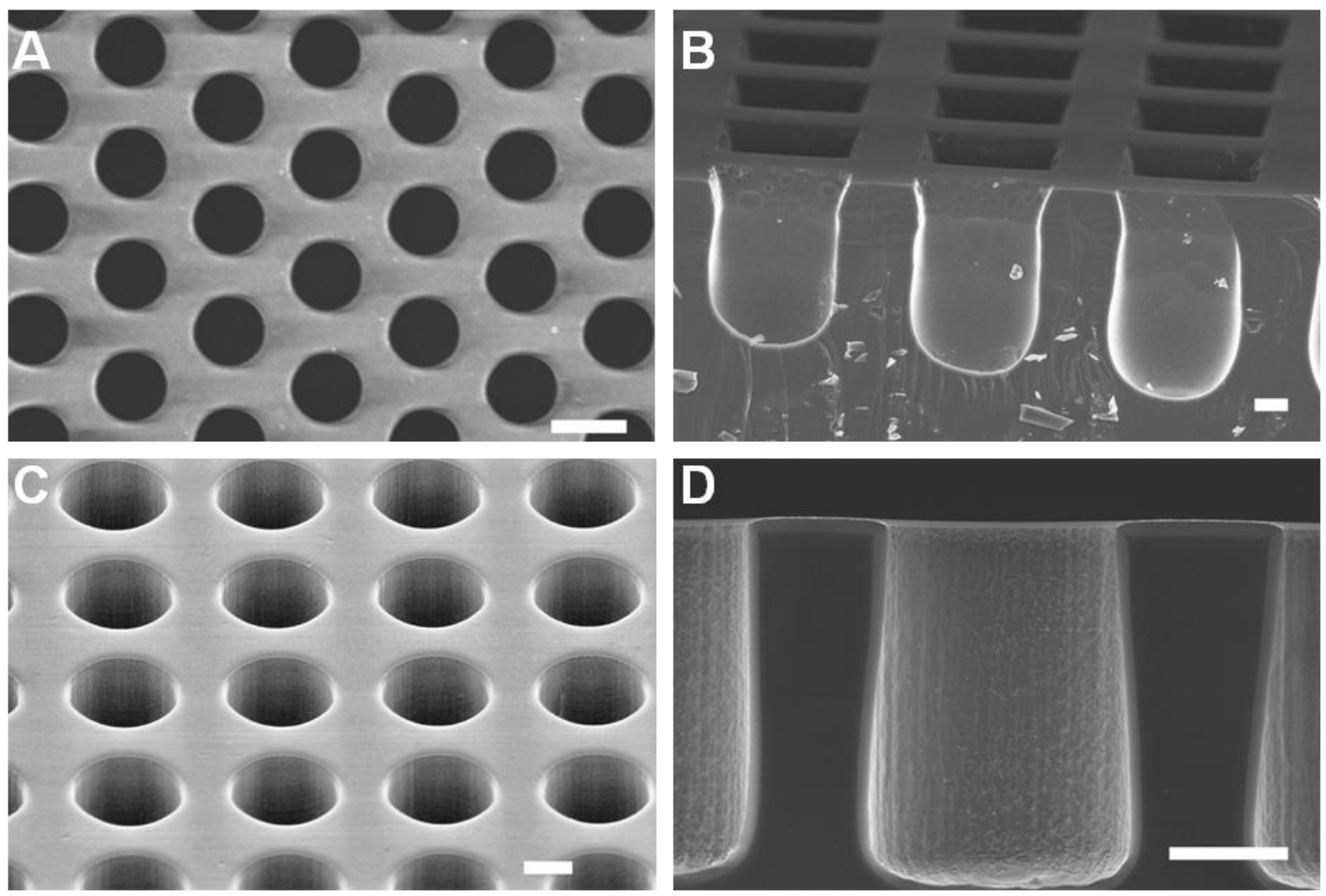

Abb. 3.5: Rasterelektronenmikroskopische Aufnahmen verschiedener poröser Siliziumsubstrate. A zeigt offene Poren mit einem Durchmesser von $2 \mu \mathrm{m}$ (FluXXion, aus ${ }^{[161]}$ ), B zeigt geschlossene, rechteckige Poren mit einer Kantenlänge von $8 \mu \mathrm{m}$ und einer Tiefe von etwa $12 \mu \mathrm{m}$ (Dr. Schweizer, Halle). C (Aufsicht) und D (Querschnitt) zeigen geschlossene, runde Poren mit einem Durchmesser von 4,5 $\mu \mathrm{m}$, einer Porosität von $30 \%$ und einer Tiefe von etwa $9 \mu \mathrm{m}$ (Dr. Steltenkamp, Bonn). Im Querschnitt lässt sich die im finalen Fertigungsschritt aufgebrachte $\mathrm{SiO}_{2}$-Schicht entlang der Porenwände gut erkennen (hellgraue Kante). Maßstabsbalken je $2 \mu \mathrm{m}$. Die Aufnahmen wurden mit einem Supra 55 VP SEM Instrument (Carl Zeiss, Jena) bei einer Beschleunigungsspannung von $5 \mathrm{kV}$ aufgenommen.

\subsubsection{Funktionalisierung poröser Substrate}

Um Membranen auf porösen Substraten auszubilden, wurden Lipidmischungen mittels painting-Technik aufgetragen oder GUVs gespreitet. Für eine erfolgreiche Bildung porenüberspannender Membranen spielte die Funktionalisierung der Substratoberfläche eine entscheidende Rolle. Es wurden unfunktionalisierte, plasmagereinigte Substrate verwendet, sowie goldbeschichtete und durch Inkubation in entsprechender Thiollösung hydrophob oder hydrophil funktionalisierte Substrate genutzt. Die jeweiligen Prozeduren sollen nachfolgend erläutert werden:

\section{Unfunktionalisierte Substrate}

GUVs wurden zum Teil auf unfunktionalisierten Poren mit offenen oder geschlossenen Porenböden gespreitet. Dabei wurden die Substrate mit Reinstwasser und Ethanol gespült, im Stickstoffstrom getrocknet und anschließend für mindestens 5 min im Argon- oder Sauerstoff- 
plasma behandelt. Die Substrate wurden in Messkammern oder Plastikpetrischalen fixiert, diese mit Pufferlösung aufgefüllt und bis zur weiteren Verwendung bei Raumtemperatur abgedeckt gelagert.

\section{Funktionalisierte Substrate}

Im Rahmen der Spreitexperimente von GUVs auf porösen Substraten, sowie beim Präparieren lösungsmittelhaltiger porenüberspannender Membranen, wurden die Substrate zunächst mit einem geeigneten Thiol funktionalisiert. Dafür wurde auf die Substrate eine dünne Goldschicht aufgetragen, was mittels Bedampfung (MED 020, Balzers AG, Liechtenstein) oder Kathodenzerstäubung (Sputter Coater 108 auto, Cressington Scientific Instruments, Watford, UK) erreicht werden konnte. Zunächst wurden die Substrate mit Reinstwasser und Ethanol gespült, im Stickstoffstrom getrocknet und für mindestens 5 min im Argonplasma gereinigt. Runde, geschlossene Poren mussten zuvor für zweimal 15 min in Aceton im Ultraschallbad behandelt werden, um den Schutzlack zu entfernen. Beim Bedampfen der Substrate wurde zunächst im Hochvakuum eine dünne Chromschicht $(2,5 \mathrm{~nm})$ als Haftvermittler und schließlich Gold $(30 \mathrm{~nm})$ aufgetragen. Bei der Kathodenzerstäubung wurde statt des Chroms zunächst eine dünne Schicht Titan $(2,5 \mathrm{~nm})$ aufgetragen und anschließend Gold (30 bis $60 \mathrm{~nm}$ ). Unmittelbar nach Aufbringen der Goldschicht wurden die Substrate in eine $n$-propanolische Thiollösung überführt und dort bei $4{ }^{\circ} \mathrm{C}$ für mindestens $3 \mathrm{~h}$ inkubiert. Für eine hydrophobe Funktionalisierung wurden die Substrate in CPEO3-Lösung (0,2 mM), TDTLösung $(0,2 \mathrm{mM})$ oder DPPTE-Lösung $(0,5 \mathrm{mM})$ inkubiert. Für eine hydrophile Funktionalisierung wurden Lösungen von Mercaptoethanol (in Ethanol), Mercaptohexanol, Mercaptoessigsäure, Mercaptopropionsäure, 11-Carboxy-1-undekanthiol oder 11-Amino1-undekanthiol (je $1 \mathrm{mM}$ ) verwendet.

\subsubsection{Präparation lösungsmittelhaltiger porenüberspannender Membranen (painting-Technik)}

Eine zuverlässige Methode zur Präparation porenüberspannender Membranen, ist das Auftragen eines Lipid-Lösungsmittelgemisches auf hydrophob funktionalisierten Substraten, bekannt als painting-Technik. ${ }^{[46,157,168]}$ Das Lösungsmittel sammelt sich nach einiger Zeit im Randbereich der einzelnen porenüberspannenden Membranen und bildet dort eine sogenannte Plateau-Gibbs-Grenze. ${ }^{[169]}$ Dieser Prozess wird auch als Ausdünnen der Membran bezeichnet.

\section{Durchführung}

Hydrophob funktionalisierte Substrate (Kapitel 3.2.8) wurden aus der Thiollösung entfernt und überschüssiges Thiol durch gründliches Spülen und anschließender Inkubation in 
$n$-Propanol entfernt. Inzwischen wurde eine Lösung von Lipid in $n$-Dekan $(20 \mathrm{mM})$ auf Eis gekühlt bereitgestellt und ein ausgedünnter Pinsel (da Vinci DEFET GmbH, Nürnberg) im Ultraschallbad für je 15 min in Mucasollösung und zweimal in Reinstwasser gereinigt. Der Pinsel wurde mit Ethanol gespült, in einem Becherglas mit Reinstwasser gelagert und zwischen den einzelnen painting-Schritten darin gespült. Die Substrate wurden im Stickstoffstrom getrocknet und zügig in einer Messkammer oder einer Plastikpetrischale fixiert. Um eine vollständige Benetzung hydrophob funktionalisierter Poren zu gewährleisten, wurde die Oberfläche der fixierten Substrate mit einem Tropfen $n$-Propanol bedeckt. Das Lösungsmittel verdrängt eingeschlossene Luft aus den Poren und hilft so, diese nachfolgend vollständig mit wässriger Pufferlösung zu füllen. Die Kammern wurden mit 3 bis $5 \mathrm{~mL}$ filtrierter (Filterfeinheit $0,2 \mu \mathrm{m}$ ), entgaster Pufferlösung gefüllt und diese anschließend zehnmal gegen ein gleiches Volumen frischer Lösung ausgetauscht, um Reste von $n$-Propanol vollständig zu entfernen. Vor Aufpinseln der Lipidlösung wurde das Volumen in den Kammern auf $3 \mathrm{~mL}$ reduziert. Proben, bei welchen Pyranin in die Poren eingeschlossen werden sollte, wurde an dieser Stelle Pyranin $(0,5 \mathrm{mM})$ beigemengt, der Farbstoff durch mehrfaches Pipettieren gleichmäßig verteilt und die Proben für mindestens 10 min inkubiert. Der Pinsel wurde vorsichtig mit einem nichtfasernden Tuch getrocknet, in die Lipidlösung eingetaucht und die Borsten benetzt. Anschließend wurde der Pinsel in die mit Pufferlösung gefüllte Kammer getaucht, an einer Seite des Substrates angesetzt und bei ständigem Kontakt gleichmäßig zur anderen Seite des Substrates geführt. Der Pinsel wurde im mit Reinstwasser gefüllten Becherglas gespült, das Substrat jeweils um $90^{\circ}$ gedreht und die Prozedur des Aufpinselns zwei weitere Male wiederholt. Üblicherweise genügte dies, um eine annähernd vollständige Bedeckung des Substrates zu erreichen. Die erfolgreiche Ausbildung porenüberspannender Membranen wurde fluoreszenzmikroskopisch überprüft und die Proben bis zur weiteren Verwendung bei $4{ }^{\circ} \mathrm{C}$ (Lagerung $>1 \mathrm{~d}$ ) oder Raumtemperatur (Lagerung $<1 \mathrm{~d}$ ) lichtgeschützt aufbewahrt. Optional konnte die Pufferlösung in den Kammern nach Aufpinseln einer Membran getauscht werden, um oberflächliche Spuren organischen Lösungsmittels zu entfernen. Der Pinsel wurde schließlich gründlich mit Reinstwasser und Ethanol gespült.

\subsubsection{Ausfrieren des remanenten Lösungsmittels in porenüberspannenden painted membranes}

Ein Teil des organischen Lösungsmittels bleibt auch nach dem Ausdünnen in der mittels painting-Technik aufgebrachten Membran zurück. Nach der painting-Technik präparierte Membranen weisen zwar exzellente elektrisch isolierende Eigenschaften auf und eignen sich dadurch für Einzelkanalmessungen, ${ }^{[7]}$ rückständiges Lösungsmittel kann bei Kontakt mit membranständigen Proteinen deren Struktur und dadurch auch deren Funktionalität jedoch negativ beeinflussen. ${ }^{[61]}$ Um den Anteil remanenten Lösungsmittels nach der Präparation porenüberspannender Membranen zu minimieren, wurde nach einer abgeänderten Vorschrift 
von Ding et al. vorgegangen. ${ }^{[170]}$ Hierbei wird die Probe nach Auftragen des Lipid-Lösungsmittelgemisches für 5 min bei -5 bis $-20{ }^{\circ} \mathrm{C}$ inkubiert und dadurch überschüssiges Lösungsmittel ausgefroren (solvent freeze-out), was in einer verringerten Dicke, Fluidität und höheren Dichte der Membran resultierte. Erstmals beschrieben wurde die solvent freeze-out Methode von White, welcher als Lösungsmittel allerdings $n$-Hexadekan eingesetzt hatte. ${ }^{[171]}$

\section{Durchführung}

Nach Auftragen des Lipid-Lösungsmittelgemisches auf hydrophob funktionalisierte Poren gemäß Kapitel 3.2.9, wurde das mit Pufferlösung bedeckte Substrat inklusive Kammer bzw. Petrischale für 15 min bei $-21^{\circ} \mathrm{C}$ im Eisfach inkubiert. Die Probe wurde anschließend lichtgeschützt auf Raumtemperatur erwärmt, bevor sie fluoreszenzmikroskopisch untersucht werden konnte. So konnten thermisch bedingte Schwankungen der Fokusebene bei optischen Untersuchungen vermieden werden.

\subsubsection{Präparation lösungsmittelfreier porenüberspannender Membranen durch Spreiten von GUVs}

Neben lösungsmittelhaltigen, durch die painting-Technik präparierte Membranen, wurden auch lösungsmittelfreie porenüberspannende Membranen präpariert. Hierzu wurden sucrosegefüllte GUVs auf poröse Substrate gegeben. Durch die höhere Dichte der Sucrosefüllung im Vergleich zur umgebenden, wässrigen Pufferlösung, sanken die GUVs zügig auf die Substratoberfläche ab und spreiteten dort. Im Gegensatz zu gepainteten Membranen lassen sich durch Spreiten von GUVs nur einzelne, definierte und meist kreisförmige Bereiche (patches) der porösen Fläche bedecken, statt einer durchgängigen porenüberspannenden Membran über die gesamte Substratfläche. Die Technik des Vesikelspreitens zur Ausbildung porenüberspannender Membranen konnte bereits für diverse Systeme erfolgreich angewendet werden. ${ }^{[43,48,172]}$ Ein großer Teil dieser Arbeit beschäftigt sich mit dem Spreiten von GUVs auf porösen Substraten mit geschlossenen Porenböden. Dabei wurden viele Parameter, wie Funktionalisierung, Zusammensetzung der GUVs, Temperatur, Spreitpuffer, Porengröße uvm. variiert, um das Ergebnis zu optimieren. Dementsprechend gibt es keine einheitliche Vorschrift für das Spreiten von GUVs auf porösen Substraten. Im Folgenden sollen daher eine

1) allgemeine Präparation beschrieben werden und eine

2) optimierte Präparation für den Aufbau nigericininduzierter Protonengradienten (Kapitel 3.4.3). 


\section{Durchführung}

1) Ein poröses Substrat, funktionalisiert oder unfunktionalisiert nach Kapitel 3.2.8, wurde in eine Plastikpetrischale oder Messkammer montiert. Funktionalisierte Substrate wurden zuvor gründlich mit $n$-Propanol gespült und im Stickstoffstrom getrocknet, um Reste von Thiol zu entfernen. Hydrophob funktionalisierte Substrate wurden mit einem Tropfen $n$-Propanol bedeckt. Die fixierten Substrate wurden mit filtrierter (Filterfeinheit 0,2 $\mu \mathrm{m}$ ), entgaster Pufferlösung überschichtet $(5 \mathrm{~mL})$ und die Lösung mehrfach gegen ein gleiches Volumen frischer Lösung ausgetauscht. Ein Volumen von $3 \mathrm{~mL}$ in der Kammer wurde eingestellt und eine GUV-Suspension (Kapitel 3.2.5) mittels einer Pipette langsam über der Substratoberfläche in die Lösung gegeben. Nach Inkubation für wenige Minuten wurde die Kammer mit Pufferlösung gespült, um nicht gespreitete GUVs zu entfernen. Die Probe konnte nun fluoreszenzmikroskopisch auf membranbedeckte Bereiche untersucht werden.

2) Runde Poren mit geschlossenem Porenboden und einem Durchmesser von 4,5 oder $5,5 \mu \mathrm{m}$ wurden zunächst mit $30 \mathrm{~nm}$ Gold bedampft und mit 11-Amino-1-undekanthiol funktionalisiert. Das Substrat wurde mit $n$-Propanol gespült, im Stickstoffstrom getrocknet und auf einem doppelseitigen Klebestreifen in einer Plastikpetrischale fixiert. Hydrophil funktionalisierte Substrate lassen sich gut mit wässrigen Lösungen benetzen. Um einen Einschluss von Luft in den Poren jedoch ausschließen zu können, wurden die fixierten Substrate mit einem Tropfen $n$-Propanol bedeckt. Die Petrischale wurde mit $5 \mathrm{~mL}$ filtrierter (Filterfeinheit $0,2 \mu \mathrm{m}$ ), entgaster Pufferlösung aufgefüllt und diese zehnmal gegen ein gleiches Volumen frischer Pufferlösung getauscht, um restliches n-Propanol möglichst vollständig zu entfernen. Um Pyranin in die Poren einzuschließen, wurde das Volumen der Kammer auf $3 \mathrm{~mL}$ reduziert und Pyranin $(0,5 \mathrm{mM})$ zugegeben, welches gleichmäßig über dem Substrat verteilt wurde. Nach kurzer Inkubation bei Raumtemperatur, wurde mittels einer Pipette vorsichtig etwas GUV-Suspension (10 $\mu \mathrm{L}$, POPC/POPS, 9:1 mit 0,2 mol\% Texas Red DHPE) direkt über der Substratoberfläche in die Lösung gegeben. Dabei wurde die Spitze der Pipette abgeschnitten, um den Durchmesser der Öffnung zu erhöhen und so eventuell auftretende Scherkräfte für die GUVs zu minimieren. Der Spreitvorgang war üblicherweise nach 30 min abgeschlossen und die Probe wurde mit Pufferlösung vorsichtig gespült, um restliche Vesikel und nicht eingeschlossenes Pyranin zu entfernen.

\subsubsection{Wiederverwertung goldbeschichteter Siliziumsubstrate}

Nach Beendigung eines Experiments mit goldbeschichteten, porösen Substraten, konnten diese für eine Neubeschichtung regeneriert werden. Hierzu wurden die Substrate zunächst mit Reinstwasser und Ethanol gespült, im Stickstoffstrom getrocknet und mit Königswasser behandelt. Durch das darin gebildete Nitrosylchlorid sowie naszierendes Chlor, wird die 
Goldbeschichtung oxidiert und dadurch abgelöst. Beim Einsatz von Titan als Haftvermittler wird dieses durch eine Passivierung nicht durch die Behandlung mit Königswasser abgelöst. Die Siliziumsubstrate mit ihrer Siliziumdioxidbeschichtung sind aufgrund der deutlich höheren Stabilität der Si-O-Bindung im Vergleich zur Si-Cl-Bindung ebenfalls inert gegenüber einer Behandlung mit Königswasser.

\section{Durchführung}

Goldbeschichtete Substrate wurden mit Reinstwasser und Ethanol gespült und im Stickstoffstrom getrocknet. Salzsäure (37 \%ig) und Salpetersäure (65 \%ig) wurden in einem Volumenverhältnis von 3:1 in einem Becherglas vermischt (Gesamtvolumen etwa $10 \mathrm{~mL}$. Vorsicht! Es bilden sich nitrose Gase. Unbedingt im Abzug arbeiten!). Die Substrate wurden mit der goldbeschichteten Seite nach oben in das Säuregemisch getaucht und im Königswasser belassen, bis die Goldfärbung auf der Oberfläche komplett verschwunden war, was typischerweise innerhalb von 15 min der Fall war. Die Substrate wurden aus der Lösung genommen, direkt in ein mit Reinstwasser gefülltes Becherglas getaucht und anschließend mit Reinstwasser und Ethanol gespült. Nach Trocknung im Stickstoffstrom wurden die Substrate in Petrischalen bis zur erneuten Verwendung gelagert. Das Königswasser wurde auf Eis gekühlt, unter Zugabe von Natronlauge $(4 \mathrm{M})$ vorsichtig neutralisiert und konnte dann im Abfallbehälter für wässrige Schwermetalllösungen entsorgt werden.

\subsection{Messung der Protonenpumpaktivität von Bacteriorhodopsin}

Die lichtgetriebene Protonenpumpe bR wurde in Form von PM-Fragmenten isoliert (Kapitel 3.2.1) und in Proteoliposomen rekonstituiert (Kapitel 3.2.4). Um die Funktionalität des Proteins zu untersuchen, wurden Photostrommessungen, Messungen des pH-Wertes mittels pH-Elektrode und fluoreszenzspektroskopische Messungen der Intensität eines pHsensitiven Farbstoffs durchgeführt.

\subsubsection{Photostrommessungen an bR-haltigen Membranen}

Als Grundlage für die Messung bR-induzierter Photoströme dienten lösungsmittelhaltige Membranen auf Goldelektroden (Kapitel 3.2.3). PM-Fragmente oder bR-haltige Vesikel wurden auf den vorgeformten Membranen immobilisiert und diese, eingebaut in eine Messkammer, in einen abgedunkelten Faraday-Käfig eingebracht. Über einen Lichtleiter (Opto Sonderbedarf, München) konnte das Licht einer $250 \mathrm{~W}$ Halogenlampe (KL 2500, Opto Sonderbedarf, München) auf die Probe geleitet werden. Dabei passierte es einen Kantenfilter (515 nm, AHF Analysetechnik, Tübingen), wodurch Wellenlängen zur Anregung des Proteins selektiert werden konnten. Durch einen zwischengeschalteten mechanischen Blendverschluss 
(Voigtländer, Fürth) konnte die Belichtung der Probe während der Messung gesteuert werden. Das Photostromsignal wurde über einen Kontakt zur membranbedeckten Goldelektrode, sowie einer in der überstehenden Lösung befindlichen Platinelektrode an einen StromSpannungswandler (428 Current Amplifier, Keithley, Germering) geleitet. Dort konnte es um einen Faktor $10^{3}$ bis $10^{11}$ verstärkt, sowie durch ein Dämpfungsglied mit einer Zeitkonstanten von $100 \mathrm{~ms}$ gefiltert werden. Über eine A/D-Wandlerkarte (National Instruments, München) wurde das Signal an einen Computer übertragen und von dort aus die Messung über ein Labview-Programm angesteuert. Ein schematischer Aufbau der Apparatur ist in Abb. 3.6 dargestellt.

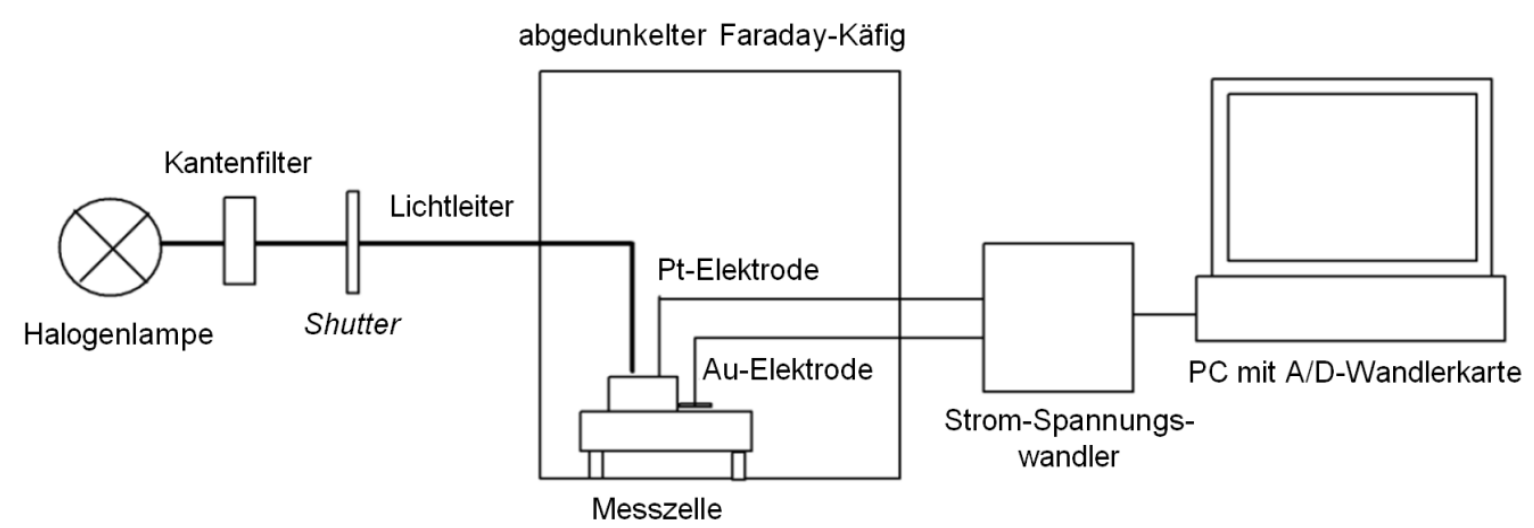

Abb. 3.6: Schematischer Aufbau einer Apparatur zur Messung von Photoströmen. ${ }^{[173]}$

\section{Durchführung}

Die in Kapitel 3.2.3 beschriebenen membranbedeckten Goldelektroden wurden in den Kammern mit Pufferlösung $(400 \mu \mathrm{L})$ überschichtet. Sollten PM-Fragmente auf ihre Aktivität getestet werden, so wurden diese zuvor bei einer Konzentration von $0,1 \mathrm{mg} \cdot \mathrm{mL}^{-1}$ (bezogen auf bR, Gesamtvolumen $400 \mu \mathrm{L}$ ) in Puffer gelöst und für 2 min unter Eiskühlung mit einem tip sonifier (cycle $40 \%$, power $70 \%$ ) beschallt. Die Pufferlösung wurde bis auf einen kleinen Überstand aus den Kammern entfernt und PM-Fragmentsuspension (400 $\mu \mathrm{L})$ bzw. bR-haltige Vesikel $\left(100 \mu \mathrm{L}, 0,17 \mathrm{mg} \cdot \mathrm{mL}^{-1}\right.$ bezogen auf die Lipidmasse mit $\left.1 \mathrm{~mol} \% \mathrm{bR}\right)$ zugegeben. Nach mindestens einstündiger Inkubation im Dunkeln wurden die Proben vorsichtig mit Pufferlösung gespült, auf ein Volumen von $1 \mathrm{~mL}$ aufgefüllt und in einen Faraday-Käfig platziert. Die membranbedeckte Goldelektrode wurde mit einer zweiten Goldelektrode kontaktiert und eine Platinelektrode wurde als Gegenelektrode in die Lösung getaucht. Am Spannungswandler wurde der Verstärkungsfaktor auf $10^{9}$ geregelt und der Lichtleiter senkrecht und nächstmöglich über der Probe platziert. Über das Labview-Programm wurde die Messung gestartet, nach etwa $3 \mathrm{~s}$ durch manuelle Betätigung des shutters die Probe belichtet, durch erneutes Betätigen die Belichtung nach etwa $8 \mathrm{~s}$ gestoppt und die 
Aufzeichnung nach insgesamt 10 bis $15 \mathrm{~s}$ beendet. Zwischen zwei Messungen wurden die Proben jeweils für mindestens 10 min dunkeladaptiert.

\subsubsection{Messung der Protonenpumpaktivität von in Vesikeln rekonstituiertem bR mittels pH-Elektrode}

Eine weitere Methode, um die Protonenpumpaktivität von in Vesikeln rekonstituiertem bR zu testen, ist die Messung des $\mathrm{pH}$-Wertes einer proteoliposomenhaltigen wässrigen Lösung mittels pH-Elektrode. Dabei wurde nach einer modifizierten Praktikumsvorschrift der TU Darmstadt vorgegangen und bR-haltige Vesikel in einem kleinen Rundkolben mit wässriger Lösung versetzt. ${ }^{[174]}$ In die Lösung wurde eine kleine pH-Elektrode eingetaucht (Mikro-pHEinstabmesskette Typ N 6000 A, SI-Analytics GmbH, Mainz), welche an ein pH-Meter (Pro Lab 2000, SI-Analytics GmbH, Mainz) angeschlossen und über USB mit einem Computer verbunden war. Über die Software Multilab Pilot konnte der zeitliche Verlauf des pH-Wertes der Vesikelsuspension digital aufgezeichnet werden. Die Probe wurde für die Messung in einem Faraday-Käfig abgedunkelt gerührt. Aufgrund der hohen Hitzeentwicklung bei längerer Belichtung mit der Halogenlampe, wurde zur Belichtung der Probe auf einen individuell gefertigten LED-Ring (light-emitting diode-Ring, institutseigene Werkstatt, IOBC, Universität Göttingen), welcher über einen externen Schalter selektiv ein- und ausgeschaltet werden konnte, zurückgegriffen. Eine Skizze des Rings und eine Aufnahme bei angeschalteten LEDs ist in Abb. 3.7 dargestellt. 

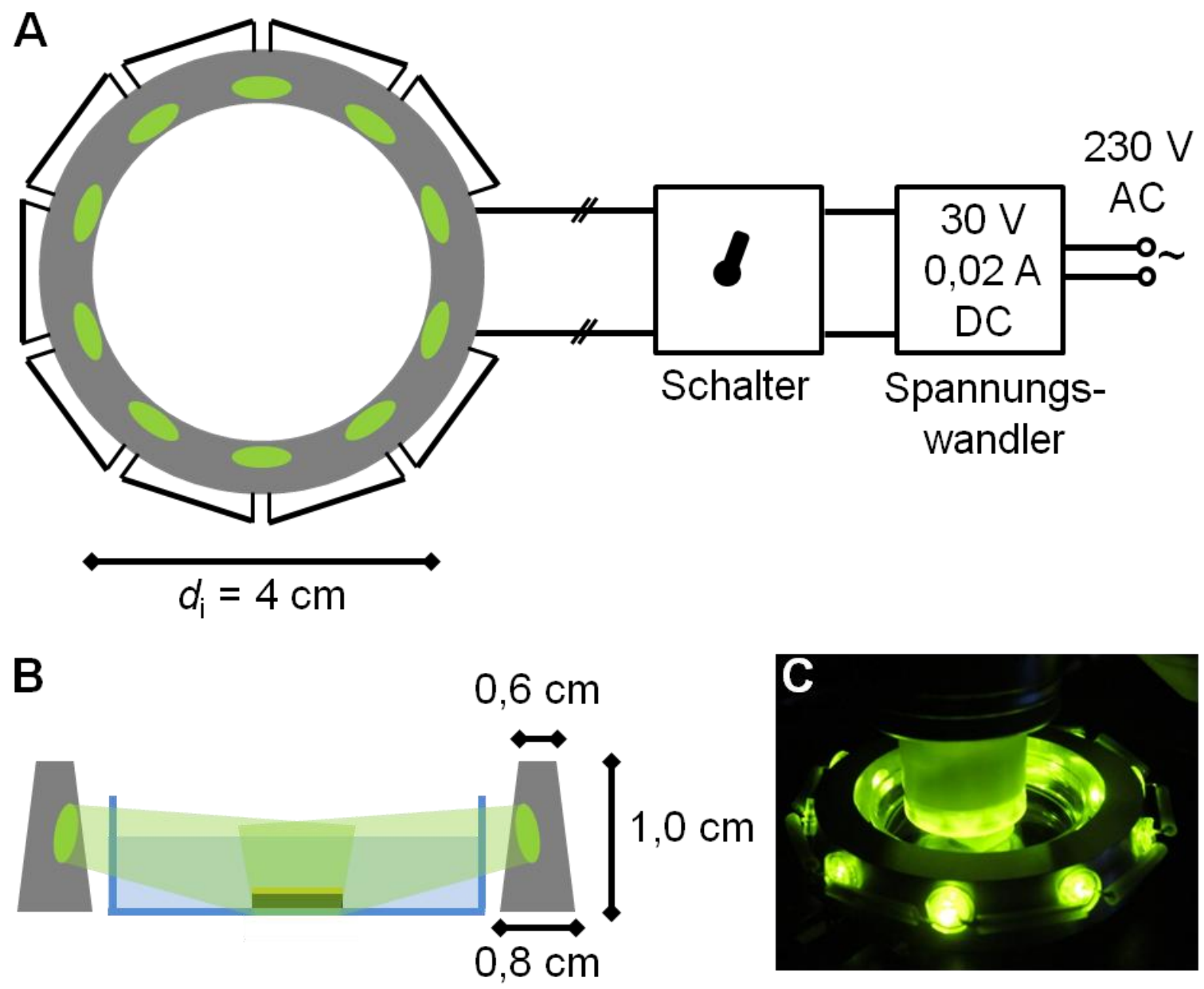

Abb. 3.7: A Schematische Darstellung des LED-Rings (Aufsicht). Der Ring (Innendurchmesser $4 \mathrm{~cm}$ ) ist aus Aluminium (grau) gefertig und insgesamt zehn LEDs (grün, dominante Wellenlänge $568 \mathrm{~nm}, I_{\mathrm{v}}=200 \mathrm{mcd}$, L-53SGC, Kingbright, Taipei, Taiwan) sind dort in Reihe geschaltet eingesetzt. Über einen Schalter ist der Ring an einen Spannungswandler (Voltcraft DPS-4005 PFC, Conrad Electronic SE, Hirschau) angeschlossen, welcher die Netzspannung in eine $30 \mathrm{~V}$ Gleichspannung mit einer Leistung von etwa 0,6 W umwandelt. B Schematische Darstellung des LED-Rings in der Seitenansicht bei Belichtung einer in einer Petrischale (blau) fixierten Probe (schwarz mit Goldoberfläche). Die Dioden sind leicht geneigt in den Ring eingelassen, sodass ihre Strahlen in der Mitte der im Ring platzierten Petrischale auf der Probe gebündelt werden. Zur besseren Übersichtlichkeit wurde der restliche Halbkreis des Rings in dieser Querschnittansicht weggelassen. C Fotografische Aufnahme des Rings bei Belichtung einer Probe. Der Aufbau wurde unter dem Objektiv eines konfokalen Fluoreszenzmikroskops, welches in der Mitte des Bildes zu erkennen ist, platziert. Darstellungen in A und B nicht maßstabsgetreu.

\section{Durchführung}

Eine Suspension von Vesikeln, wie sie nach einer unter Kapitel 3.2.4 beschriebenen Methode präpariert worden waren, wurde in einen $5 \mathrm{~mL}$ Rundkolben gegeben und mit wässriger Lösung soweit aufgefüllt, dass die Messeinheit der pH-Elektrode vollständig eintauchen konnte. Die Vesikelsuspension wurde dabei maximal um einen Faktor von fünf verdünnt. Ein kleiner Magnetrührstab aus Glas wurde in den Kolben gegeben und dieser in der Mitte eines LED-Rings auf einem Magnetrührer platziert. Der Aufbau fand dabei in einem abgedunkelten 
Faraday-Käfig statt. Die pH-Elektrode wurde in die Lösung getaucht und der zeitliche Verlauf des $\mathrm{pH}$-Wertes aufgezeichnet. Üblicherweise verlief eine solche Messung über einen Zeitraum von $2 \mathrm{~h}$ und die Probe wurde mittels LED-Ring mehrfach für einen jeweils mehrminütigen Zeitraum belichtet.

\subsubsection{Messung der Protonenpumpaktivität von in Vesikeln rekonstituiertem bR durch Einschluss eines pH-sensitiven Fluoreszenzfarbstoffs}

Neben der Messung bR-induzierter Änderungen des pH-Wertes der umgebenden Lösung per pH-Elektrode, wurde auch die pH-Wertänderung im Vesikelinneren adressiert. Hierfür wurden GUVs in Anwesenheit des pH-sensitiven Fluoreszenzfarbstoffs Pyranin präpariert, sodass dieser im Vesikelinneren eingeschlossen wurde. Fixierung der GUVs auf planaren, mit Avidin funktionalisierten Siliziumwafern erlaubte ihre fluoreszenzmikroskopische Untersuchung. Lichtinduzierte Änderungen des pH-Wertes konnten anschließend qualitativ durch Änderungen der Pyraninintensität im Vesikelinneren verfolgt werden.

\section{Durchführung}

BR-haltige, mit Bio-Cap-PE funktionalisierte und pyraningefüllte GUVs wurden auf avidinbedeckten, planaren Siliziumsubstraten immobilisiert (Kapitel 3.2.6). Die Substrate waren in einer Petrischale oder einer Messkammer fixiert und diese mit Pufferlösung gefüllt. Die Probe wurde im konfokalen Laserrastermikroskop (LSM 710 Examiner, Carl Zeiss GmbH, Jena) in den Probenhalter montiert. Um die Probe herum wurde der in Kapitel 3.3.2 beschriebene LED-Ring platziert, oder die im Aufbau der Photostromapparatur erwähnte Halogenlampe mit $515 \mathrm{~nm}$ Kantenfilter und Lichtleiter (Kapitel 3.3.1) mit Hilfe eines Stativs mit Klemme auf die Probe gerichtet. Eine dritte Möglichkeit der Belichtung bestand in der Verwendung des mikroskopinternen diodenlasergepumpten Festkörperlasers (diode-pumped solid state-Laser, DPPS-Laser, $561 \mathrm{~nm}, 20 \mathrm{~mW}$ ).

Eine Zeitserie der Pyraninfluoreszenz ( $\lambda_{\mathrm{ex}}=458 \mathrm{~nm}$, Detektionsbereich 500 bis $580 \mathrm{~nm}$ ) mit Bildabständen von $\Delta t<5 \mathrm{~s}$ über typischerweise mehrere Minuten wurde aufgenommen und die Probe zwischendurch für einige Sekunden bis Minuten durch Einschalten des LED-Rings oder der Halogenlampe belichtet. Der Intensitätsverlauf innerhalb eines manuell gesetzten Bildausschnitts (region of interest, ROI) wurde mittels Software (ZEN 2008, Carl Zeiss, Jena oder ImageJ, V. 1.41, http://rsb.info.nih.gov/ij/) ausgelesen. 


\subsubsection{Messung der Protonenpumpaktivität von in porenüberspannenden Membranen rekonstituiertem bR durch Einschluss eines pH-sensitiven Fluoreszenzfarbstoffs}

Nach erfolgreicher Bildung bR-haltiger, porenüberspannender Membranen auf funktionalisierten Substraten mit geschlossenen Poren, konnte auch hier durch den Einschluss von Pyranin die Protonenpumpaktivität des bR getestet werden.

\section{Durchführung}

Es wurden bR-haltige GUVs gemäß Kapitel 3.2.11 in Anwesenheit von Pyranin $\left(c_{\text {Pyranin }}=0,5 \mathrm{mM}\right)$ gespreitet. Überstehendes Pyranin wurde durch mehrfaches Spülen mit Pufferlösung entfernt. Die Probe wurde wie in Kapitel 3.3.3 beschrieben in das Konfokalmikroskop eingesetzt und entweder durch Belichtung mit einer Halogenlampe, einem LEDRing oder dem mikroskopeigenen DPSS-Laser angeregt. Eine Zeitserie wurde analog zu der Beschreibung unter Kapitel 3.3.3 aufgenommen und die Intensität sogenannter ROIs mit dort erwähnter Software ausgelesen. Jede einzelne Pore im Bildausschnitt wurde individuell mit einer eigenen ROI manuell versehen, sodass das Intensitätsprofil einer jeden Pore einzeln ausgelesen werden konnte.

\subsection{Untersuchung nigericininduzierter elektrochemischer Gradienten}

Neben der Verwendung des Membranproteins bR wurde auch der Kaliumionen-ProtonenAntiporter Nigericin im Rahmen dieser Arbeit eingesetzt, um elektrochemische Gradienten zu erzeugen. Gleiche Voraussetzung bei jedem untersuchten System war das Vorliegen eines Kaliumionengradienten zwischen zwei wässrigen, durch eine Lipidmembran voneinander separierten Kompartimenten. Durch Zugabe von Nigericin wurde der $\mathrm{K}^{+}$-Gradient abgebaut, während gleichzeitig ein $\mathrm{H}^{+}$-Gradient mit entgegengesetztem Vorzeichen aufgebaut wurde. Die Anreicherung von Protonen in einem der beiden Kompartimente konnte wie in Kapitel 3.3.3 bzw. 3.3.4 beschrieben durch den Einschluss des pH-sensitiven Fluoreszenzfarbstoffs Pyranin untersucht werden. Dabei wurden Gradienten entlang der Membran submikrometergroßer Vesikel fluoreszenzspektrometrisch und solche entlang GUVs und porenüberspannender Membranen konfokalmikroskopisch untersucht. 


\subsubsection{Fluoreszenzspektrometrische Untersuchung des nigericininduzierten Protonen-Kaliumionen-Antiports an großen unilamellaren Vesikeln}

Der nigericininduzierte Antiport wurde zunächst am Modellsystem sub-mikrometergroßer, unilamellarer Lipidvesikel (large unilamellar vesicles, LUVs) nach einer abgeänderten Vorschrift von Hell et al. getestet. ${ }^{[85]}$ Hierzu wurden LUVs in pyraninhaltiger Pufferlösung präpariert und anschließend säulenchromatografisch vom restlichen freien Farbstoff abgetrennt. In einer Küvette wurden Vesikel in eine Pufferlösung gegeben. Die Probe wurde in ein Fluorimeter eingesetzt, gerührt und mit Hilfe eines Kältethermostats konstant temperiert. Der zeitliche Verlauf der Pyraninemission bei konstanter Wellenlänge wurde aufgezeichnet. Durch die Zugabe von Nigericin zu einem definierten Zeitpunkt wurde der $\mathrm{K}^{+} / \mathrm{H}^{+}$-Antiport induziert. Mittels Variation der Pufferzusammensetzung im inneren der Vesikel sowie der umgebenden Lösung konnte sowohl ein Influx als auch ein Efflux von Protonen adressiert werden.

\section{Durchführung}

Ein Lipidfilm (2 mg DPhPC) wurde durch Pipettieren einer entsprechenden Menge Lipids gelöst in Chloroform in ein Reagenzglas, anschließendem Verblasen des Lösungsmittels im Stickstoffstrom und Trocknung im Vakuumtrockenschrank $\left(3 \mathrm{~h}, 30^{\circ} \mathrm{C}\right)$ präpariert. Für das Hervorrufen eines Intensitätsanstiegs wurde entgaste, filtrierte (Filterfeinheit 0,2 $\mu \mathrm{m}$ ) Pufferlösung (320 mM Sucrose, $10 \mathrm{mM}$ MOPS, $1 \mathrm{mM}$ Pyranin, pH 7,3 (TRIS)) zugefügt und eine Lipidkonzentration von $4 \mathrm{mg} \cdot \mathrm{mL}^{-1}$ eingestellt. Sollten Intensitätsabfälle untersucht werden, wurde eine Pufferlösung anderer Zusammensetzung (160 mM KCl, $10 \mathrm{mM} \mathrm{MOPS,} 1 \mathrm{mM}$ Pyranin, pH 7,3 (KOH)) eingesetzt. Die Probe wurde für 20 min quellen gelassen, für 1 min kräftig geschüttelt, weitere 10 min inkubiert und erneut kräftig geschüttelt (3 mal $30 \mathrm{~s}$ ). Die Vesikelsuspension wurde mit Hilfe eines Miniextruders 31 mal durch eine Polycarbonatmembran (nomineller Porendurchmesser 1000 nm) gepresst. Freier Farbstoff wurde über eine G-25 Sephadex-Säule abgetrennt. Hierzu wurde die Säule zuvor mit dem zum Vesikelinneren komplementären Puffer äquilibriert (Intensitätsanstieg: $160 \mathrm{mM} \mathrm{KCl}, 10 \mathrm{mM} \mathrm{MOPS}, \mathrm{pH}$ 7,3 (KOH); Intensitätsabfall: $320 \mathrm{mM}$ Sucrose, $10 \mathrm{mM}$ MOPS, pH 7,3 (TRIS), je fünffaches Säulenvolumen), sodass direkt ein Kaliumionengradient zwischen Vesikelinnerem und Umgebungslösung erzeugt wurde. Je nach Signalintensität wurde die Vesikelsuspension unverdünnt oder mit Umgebungspuffer verdünnt $(1: 1(\mathrm{v} / \mathrm{v}))$ in eine Glasküvette (28F/Q/10/MS, Starna GmbH, Pfungstedt) überführt und ein Magnetrührstab beigefügt. Eventuell freier Restfarbstoff kann durch Zugabe des Fluoreszenzlöschers $p$-Xylolbispyridiniumbromid (DPX) gelöscht werden, was aber üblicherweise nach säulenchromatografischer Abtrennung des freien Farbstoffs nicht nötig war. Die Küvette wurde in einem Fluoreszenzspektrometer (FP-6500 Spectrofluorimeter, Jasco, Gross-Umstadt) platziert, die 
Probentemperatur mittels Kältethermostats (1162A, VWR International GmbH, Darmstadt) auf $22{ }^{\circ} \mathrm{C}$ geregelt und die Suspension langsam gerührt. Um den zeitlichen Verlauf der Intensität der Pyraninfluoreszenz aufzuzeichnen, wurde die Probe mit Licht einer Wellenlänge von $458 \mathrm{~nm}$ bestrahlt und parallel in einem rechten Winkel die Emission bei einer Wellenlänge von $515 \mathrm{~nm}$ detektiert. Nach einer definierten Zeit wurde Nigericin in Ethanol zu der Probe gegeben und in der Folge verschiedene Entkoppler (Kapitel 1.2.1). Nach Ende der Messung wurde die Glasküvette gründlich mit Reinstwasser und Ethanol gespült und im Stickstoffstrom getrocknet.

\subsubsection{Fluoreszenzmikroskopische Untersuchung des nigericininduzierten Protonen-Kaliumionen-Antiports an GUVs}

Pyraningefüllte GUVs (Kapitel 3.2.5) wurden wie in Kapitel 3.2.6 beschrieben auf einem planaren Siliziumwafer fixiert und die Intensität der Pyraninfluoreszenz aus konfokalmikroskopischen Aufnahmen vor und nach Zugabe von Nigericin ausgelesen.

\section{Durchführung}

Mit Bio-Cap-PE funktionalisierte GUVs (DPhPC/DOPC/Bio-Cap-PE/TR, 59,4:39,4:1:0,2) wurden in pyranin- und sucrosehaltigem Puffer (320 mM Sucrose, $10 \mathrm{mM}$ MOPS, 0,5 mM Pyranin, pH 7,3 (TRIS)) unter Hochfrequenzbedingungen gebildet (Kapitel 3.2.5) und in $\mathrm{KCl}$ haltigem Puffer (160 mM KCl, $10 \mathrm{mM}$ MOPS, pH 7,3 (KOH)) auf einem Siliziumwafer immobilisiert (Kapitel 3.2.6). Die Probe wurde auf einem Probenhalter im konfokalen Laserrastermikroskop fixiert. In fluoreszenzmikroskopischen Aufnahmen der immobilisierten GUVs $\left(\lambda_{\mathrm{ex}}=458 \mathrm{~nm}\right.$, Detektionsbereich je 500 bis $580 \mathrm{~nm}$ ) wurde die Intensität der Pyraninfluoreszenz innerhalb der GUVs durch manuelle Zuordnung von ROIs ausgelesen. Darauf wurde Nigericin $\left(10 \mu \mathrm{L}\right.$ einer $1 \mathrm{mg} \cdot \mathrm{mL}^{-1}$ Lösung in Ethanol, finale Konzentration $\left.2,7 \mu \mathrm{M}\right)$ zugegeben, erneut Aufnahmen gemacht und die Intensitäten manuell gelegter ROIs ausgelesen. Weiterhin konnten GUVs vor ihrer Fixierung auf einem mit Avidin funktionalisiertem Substrat mit Nigericin (finale Konzentration etwa 12,3 $\mu \mathrm{M}$ ) über Nacht inkubiert werden und anschließend in KCl-haltigem Puffer immobilisiert werden. Dabei ausgelesene Intensitäten konnten mit denen von GUVs, welche nicht mit Nigericin inkubiert worden waren, verglichen werden.

\subsubsection{Fluoreszenzmikroskopische Untersuchung des nigericininduzierten Protonen-Kaliumionen-Antiports an porenüberspannenden Membranen}

Porenüberspannende Membranen wurden in Anwesenheit von Pyranin präpariert und die Probe konfokalmikroskopisch auf Änderungen der Pyraninfluoreszenz untersucht. Wie bei 
den zuvor beschriebenen beiden Systemen, sollten auch hier Entkopplersubstanzen eingesetzt werden, um zuvor aufgebaute Gradienten wieder abzubauen.

\section{Durchführung}

Porenüberspannende Membranen wurden wie unter Punkt 2) in Kapitel 3.2.11 (lösungsmittelfrei) bzw. Kapitel 3.2.9 (lösungsmittelhaltig) beschrieben auf Substraten mit geschlossenen Poren präpariert und dabei der pH-sensitive Farbstoff Pyranin eingeschlossen. Dabei wurde für die Detektion eines Anstiegs der Pyraninfluoreszenz in kaliumionenfreiem Puffer präpariert (10 mM MOPS, 0,5 mM Pyranin, pH 7,3 (TRIS), dazu bei painted membranes $320 \mathrm{mM}$ Sucrose bzw. beim Spreiten von GUVs $107 \mathrm{mM} \mathrm{CaCl}_{2}$ ). Zur Detektion von Intensitätsabfällen wurde in kaliumionenhaltigem Puffer präpariert $(160 \mathrm{mM} \mathrm{KCl}, 10 \mathrm{mM}$ MOPS, 0,5 mM Pyranin, pH 7,3 (KOH)). Nach Entfernen nicht eingeschlossenen Farbstoffs durch gründliches Spülen mit Pufferlösung (Zusammensetzung, in welcher auch präpariert worden war, jedoch ohne Pyranin), wurde die Probe auf einem Probenhalter im konfokalen Laserrastermikroskop platziert. Überspannte Poren konnten durch Korrelation der Fluoreszenz von Texas Red DHPE innerhalb der überspannenden Membran sowie von Pyranin innerhalb der Poren von nicht überspannten Poren unterschieden werden. Nachdem ein Bildausschnitt mit mehreren überspannten Poren gefunden worden war, wurde die Probe aus dem Probenhalter entfernt und für den Aufbau eines Kaliumionengradienten die Pufferlösung mehrmals gründlich gegen eine Pufferlösung entgegengesetzter Zusammensetzung getauscht (wurde in sucrose- bzw. calciumionenhaltigem Puffer präpariert, so wurde mit $160 \mathrm{mM} \mathrm{KCl,} 10 \mathrm{mM}$ MOPS, pH 7,3 (KOH) gespült; wurde in kaliumionenhaltigem Puffer präpariert, so wurde mit $320 \mathrm{mM}$ Sucrose, $10 \mathrm{mM}$ MOPS, pH 7,3 (TRIS) gespült). Alle verwendeten Pufferlösungen wurden osmometrisch (Gefrierpunktosmometer Osmomat 030, Gonotec $\mathrm{GmbH}$, Berlin) vermessen, um Unterschiede in der Osmolalität und daraus resultierende osmotische Drücke auf die porenüberspannenden Membranen zu minimieren. Nach dem Puffertausch wurde die Probe rasch wieder in den Probenhalter des Mikroskops eingesetzt, wobei zusätzlich ein kleiner Magnetrührer (Variomag Einzel-Magnetrührsystem MINI, H+P Labortechnik GmbH, Oberschleißheim) unterhalb der Probe montiert und ein Magnetrührstab in die Petrischale neben das Siliziumsubstrat gegeben wurde. Ein Bereich mit überspannten Poren wurde aufgenommen und der Fokus leicht aus der Ebene der Substratoberfläche ins Poreninnere verschoben, bis die Pyraninfluoreszenz mit maximaler Intensität detektiert werden konnte (Abb. 4.5, B). Unter moderatem Rühren wurde eine Zeitserie aufgenommen, in deren Verlauf Nigericin, sowie Entkopplersubstanzen zugegeben wurden. Der zeitliche Verlauf der Intensität einzelner Poren wurde durch manuelles Einfügen von ROIs ausgelesen. Die Pyraninfluoreszenz wurde bei einer Anregungswellenlänge von $458 \mathrm{~nm}$ in einem Bereich von 500 bis $580 \mathrm{~nm}$ detektiert. 


\section{Datenauswertung}

Um gebildete Protonengradienten in Form von $\mathrm{pH}$-Wertänderungen im Poreninneren quantifizieren zu können, wurde der Verlauf der Intensität des eingeschlossenen Pyranins in einen $\mathrm{pH}-$ Verlauf umgerechnet. Der $\mathrm{pH}-$ Wert einer pyraninhaltigen Lösung errechnet sich gemäß:

$$
p H=p K_{S}-\lg \left(\frac{[\mathrm{Py}]^{0}}{\left[\mathrm{Py}^{-}\right]}-1\right)
$$

Der $\mathrm{pK}_{\mathrm{S}^{-}}$Wert von Pyranin beträgt 7,22, ${ }^{[175]}[\mathrm{Py}]^{0}$ entspricht der Gesamtkonzentration des eingesetzten Pyranins $(0,5 \mathrm{mM})$ und $\left[\mathrm{Py}^{-}\right]$der Konzentration der deprotonierten Form von Pyranin. Eine lineare Proportionalität zwischen den gemessenen Intensitätswerten und der Konzentration deprotonierten Pyranins wurde angenommen. Es wurde ein $\mathrm{pH}-$ Wert zu Beginn der Messung von $\mathrm{pH}=7,3$ angenommen, da dieser dem $\mathrm{pH}$-Wert der verwendeten Pufferlösungen entspricht. Durch Einsetzen dieses Start-pH-Wertes in Gl. 3.4 und Auflösen nach $\left[\mathrm{Py}^{-}\right]$, ergibt sich eine Anfangskonzentration deprotonierten Pyranins von $\left[\mathrm{Py}^{-}\right](\mathrm{pH}=7,3)=\left[\mathrm{Py}^{-}\right]_{t=0}=0,273 \mathrm{mM}$. Die Konzentration deprotonierten Pyranins im Verlauf der Zeitserie $\left[\mathrm{Py}^{-}\right]_{t}$ wurde für jede Intensität $I_{\mathrm{t}}$ durch Multiplikation mit dem Quotienten aus $\left[\mathrm{Py}^{-}\right]_{t=0}$ und zugehöriger Startintensität $I_{0}$ bestimmt:

$$
\left[P y^{-}\right]_{t}=I_{t} \cdot \frac{\left[\mathrm{Py}^{-}\right]_{0}}{\mathrm{I}_{0}}
$$

Neben der pH-Differenz nach der nigericininduzierten Bildung eines Protonengradienten, wurde die initiale Transportrate für Protonen über porenüberspannende Membranen ermittelt. Hierzu wurde die Initialsteigung der pH-Anstiege bzw. -Abfälle nach Nigericinzugabe mittels linearer Anpassung bestimmt, analog $\mathrm{zu}$ bereits für bR-induziertes Protonenpumpen beschriebenen Systemen. ${ }^{[107]}$ Unter Umstellung von Gl. 3.4 und Ersetzen der Konzentrationen durch absolute Teilchenzahlen $N$, ergibt sich für die Anzahl deprotonierter Pufferteilchen innerhalb einer Pore:

$$
N\left(B^{-}\right)=V \cdot N_{A} \cdot \frac{[\mathrm{B}]^{0}}{1+10^{\left(\mathrm{pK}_{\mathrm{S}}-\mathrm{pH}\right)}}
$$

$[\mathrm{B}]^{0}$ entspricht dabei der Gesamtkonzentration der eingesetzten Pufferteilchen (Pyranin und MOPS, 10,5 mM) in der Pore, $\mathrm{N}_{\mathrm{A}}$ der Avogadro-Konstanten $\left(6,022 \cdot 10^{23} \mathrm{~mol}^{-1}\right)$ und $V$ dem Porenvolumen. Unter der Annahme, dass jedes in die Pore hinein gepumpte Proton mit einem deprotonierten Basenteilchen reagiert, lassen sich Differenzen in der Zahl deprotonierter Basenteilchen gleichsetzen mit der Differenz der Zahl an Protonen innerhalb einer Pore $\left(\Delta N\left(\mathrm{~B}^{-}\right)=\Delta N\left(\mathrm{H}^{+}\right)\right)$. Anhand der zuvor bestimmten Initialsteigung (m in $\left.\mathrm{pH} \cdot \mathrm{s}^{-1}\right)$ lässt sich die Zahl an Protonen innerhalb einer Pore bei $t=0 \mathrm{~s}\left(\mathrm{pH}=\mathrm{pH}^{0}=7,3\right)$ und $t=1 \mathrm{~s}(\mathrm{pH}=7,3+\mathrm{m})$ 
errechnen. Die Differenz beider Werte, $\Delta N\left(\mathrm{H}^{+}\right)$, entspricht der Zahl der transportierten Protonen pro Sekunde und wird beschrieben durch:

$$
\Delta N\left(H^{+}\right)=V \cdot N_{A} \cdot[\mathrm{B}]^{0} \cdot\left(\frac{1}{1+10^{\left(\mathrm{pK}_{\mathrm{S}}-\mathrm{pH}^{0}\right)}}-\frac{1}{1+10^{\left(\mathrm{pK}_{\mathrm{S}}-\mathrm{pH}^{0}+\mathrm{m}\right)}}\right)
$$

Da Poren mit unterschiedlichen Durchmessern verwendet wurden und sich dadurch unterschiedliche Flächen der porenüberspannenden Membranen ergaben, wurde die Zahl der über die Membran transportierten Protonen pro Sekunde durch die Porenfläche in $\mathrm{cm}^{-2}$ geteilt. Die Transportrate wurde so auf die zum Übertreten der Protonen verfügbare Membranfläche normiert.

\subsection{Fluoreszenzmikroskopie}

Das gezielte Einsetzen von Fluoreszenzfarbstoffen im Rahmen dieser Arbeit ermöglichte die Visualisierung von Strukturen im Mikrometerbereich und von elektrochemischen Gradienten. Hierzu wurde das Prinzip der Fluoreszenz genutzt, also der Anregung von Fluorophoren mittels elektromagnetischer Strahlung im Bereich des sichtbaren Lichts und deren rotverschobener Emission von Strahlung, welche detektiert wurde. Eine Rotverschiebung kommt dabei durch Prozesse wie innerer Konversion zu Stande und ermöglicht eine spektrale Trennung von Anregungslicht und emittierter Strahlung. Kommerziell verfügbare Fluoreszenzmikroskope unterteilen sich klassischerweise in Weitfeld-Fluoreszenzmikroskope und hochsowie superauflösende Fluoreszenzmikroskope.

\section{Aufbau}

Im Folgenden sollen Prinzip und Aufbau des konfokalen Laserrastermikroskops (confocal laser scanning microscope, CLSM) näher beschrieben werden. Das Konfokalmikroskop wurde bereits in den 1950er Jahren von Minsky entwickelt. ${ }^{[176]}$ Eine schematische Darstellung des Strahlengangs eines CLSM ist in Abb. 3.8 dargestellt. Dabei wird monochromatisches Licht eines Lasers (grün) durch einen Kollimator auf einen dichroitischen Spiegel gelenkt und von dort auf einen beweglichen Scanspiegel reflektiert. Der Scanspiegel ermöglicht ein Abrastern der Probenoberfläche. Das Licht trifft von dort auf ein Objektiv, durch welches es auf die Probe fokussiert wird. Fluorophore werden durch das eintreffende Licht angeregt und emittieren Licht einer größeren Wellenlänge (rot, gemeinsamer Weg von ein- und austretender Strahlung ist in orange dargestellt). Dieses tritt durch den Strahlenteiler, ohne reflektiert zu werden und wird mit Hilfe einer Linse so gebündelt, dass nur Licht, welches innerhalb der fokalen Ebene emittiert wurde, durch die nachfolgende Lochblende treten kann. Strahlung aus Ebenen ober- oder unterhalb der fokalen Ebene wird dort gestreut und kann somit nicht zum Detektionssignal beitragen. Hinter der Lochblende durchläuft das Licht einen 
Emissionsfilter und wird schließlich durch einen Sekundärelektronenvervielfacher (photomultiplier tube, PMT) detektiert.

Im Gegensatz zum CLSM besitzt ein klassisches Epifluoreszenzmikroskop, wie es ebenfalls stellenweise im Rahmen dieser Arbeit eingesetzt wurde, keine Lochblende und keinen Scanspiegel. Die Probe wird hierbei durch eine Quecksilberdampflampe belichtet, aus deren Spektrum Licht einer bestimmten Wellenlänge zur Anregung gefiltert wird. Hauptnachteil gegenüber dem CLSM ist die Überlagerung der Fluoreszenz mehrere Ebenen, die zum detektierten Signal beitragen, woraus ein unschärferes Bild und eine geringere laterale wie axiale Auflösung resultiert.



Abb. 3.8: Schematische Darstellung des Strahlengangs eines konfokalen Laserrastermikroskops (CLSM). 


\section{Auflösungsvermögen}

Das Auflösungsvermögen eines konventionellen Fluoreszenzmikroskops hängt vom Brechungsindex des Mediums ( $n$ ), dem halben Öffnungswinkel des Objektivs $(\alpha)$, sowie der Wellenlänge des Lichts $\mathrm{ab}(\lambda)$. Die ersten beiden Faktoren sind für kommerziell vertriebene Objektive in Form der numerischen Apertur (NA) angegeben (Gl. 3.8).

$$
N A=n \cdot \sin \alpha
$$

Laterale wie axiale Auflösungen von konventionellem Epifluoreszenz- sowie konfokalem Laserrastermikroskop bei unterschiedlicher Öffnungsgröße der Lochblende (pinhole, $\mathrm{PH}$ ) sind in Tabelle 3.5 aufgeführt. Eine airy unit (AU) dient dabei der Normalisierung des PH-Durchmessers und ist abhängig von numerischer Apertur und mittlerer Wellenlänge $(\bar{\lambda})$ (Gl. 3.9).

$$
1 A U=\frac{1,22 \cdot \bar{\lambda}}{N A}
$$

Die mittlere Wellenlänge wiederum kann näherungsweise als Quadratwurzel aus dem Produkt von Anregungs- und Emissionswellenlänge errechnet werden (Gl. 3.10).

$$
\bar{\lambda} \approx \sqrt{2} \frac{\lambda_{e m} \cdot \lambda_{e x}}{\sqrt{\lambda_{e x}^{2}+\lambda_{e m}^{2}}} \approx \sqrt{\lambda_{e m} \cdot \lambda_{e x}}
$$


Tabelle 3.5: Laterales und axiales Auflösungsvermögen von konventionellen sowie konfokalen Mikroskopen unterschiedlicher pinhole Größe nach S. Wilhelm, Firma Zeiss. ${ }^{[177]}$ Neben der allgemeinen Formel wurden jeweils die im Rahmen dieser Arbeit verwendeten Parameter für die Membranfarbstoffe Bodipy PC und Texas Red DHPE errechnet. Absorptions- und Emissionsmaxima wurden aus Tabelle 3.3 übernommen, $N A$ betrug für das am konventionellen Mikroskop verwendete Objektiv 0,8, für das konfokale Mikroskop 1,0. Es wurde der Brechungsindex von Wasser eingesetzt $(1,33)$, da in wässrigen Lösungen gemessen wurde.

\begin{tabular}{|c|c|c|c|c|c|c|}
\hline Auflösung $d$ & \multicolumn{2}{|c|}{$\begin{array}{l}\text { Konventionelles } \\
\text { Mikroskop }\end{array}$} & \multicolumn{2}{|c|}{$\begin{array}{l}\text { Konfokales } \\
\text { Mikroskop } \\
(1 \text { AU }<\text { PH < }<\text { ) }\end{array}$} & \multicolumn{2}{|c|}{$\begin{array}{l}\text { Konfokales } \\
\text { Mikroskop } \\
(\text { PH }<0,25 \text { AU) }\end{array}$} \\
\hline$d_{\text {lateral }}($ theoretisch) & \multicolumn{2}{|c|}{$\frac{0,51 \cdot \lambda_{e m}}{N A}$} & \multicolumn{2}{|c|}{$\frac{0,51 \cdot \lambda_{e x}}{N A}$} & \multicolumn{2}{|c|}{$\frac{0,37 \cdot \bar{\lambda}}{N A}$} \\
\hline $\begin{array}{l}d_{\text {lateral }} / \mathrm{nm}, \text { Bodipy PC } \mid \text { Texas } \\
\text { Red DHPE }\end{array}$ & 325 & 387 & 249 & 286 & 184 & 216 \\
\hline$d_{\text {axial }}($ theoretisch) & \multicolumn{2}{|c|}{$\frac{n \cdot \lambda_{e m}}{N A^{2}}$} & \multicolumn{2}{|c|}{$\frac{0,88 \cdot \lambda_{e x}}{\left(n-\sqrt{n^{2}-N A^{2}}\right)}$} & \multicolumn{2}{|c|}{$\frac{0,64 \cdot \bar{\lambda}}{\left(n-\sqrt{n^{2}-N A^{2}}\right)}$} \\
\hline $\begin{array}{l}d_{\text {axial }} / \mathrm{nm} \text {, Bodipy PC } \mid \text { Texas } \\
\text { Red DHPE }\end{array}$ & 1060 & 1261 & 948 & 1089 & 704 & 823 \\
\hline
\end{tabular}

\section{Eindringtiefe}

Ein weiterer interessanter Parameter in Hinblick auf hier durchgeführten Experimente, ist die Tiefe, bis zu welcher in Poren befindlicher Farbstoff detektiert werden kann. Ausgehend von einfachen geometrischen Überlegungen, lässt sich die Eindringtiefe $h$ des Lichtkegels als Funktion des halben Öffnungswinkels des Objektivs $\alpha$ und des Porendurchmessers $d$ gemäß Gl. 3.11 bestimmen:

$$
h=\frac{d}{2 \cdot \tan \alpha}
$$

Setzt man Gl.3.8 ein, so ergibt sich für eine numerische Apertur von 1,0 und einem Brechungsindex von 1,33 ein Zusammenhang von Eindringtiefe und Porendurchmesser von:

$$
h=\frac{d}{2,28} \text {. }
$$

Unter Berücksichtigung eines axialen Auflösungsvermögens von etwa $1 \mu \mathrm{m}$, sind Membranfluoreszenz und Fluoreszenz eines in den Poren eingeschlossenen Farbstoffs also ab einem Porendurchmesser von $d>2 \mu \mathrm{m}$ unterscheidbar. Einen Überblick über gemäß Gl. 3.12 
berechneter Eindringtiefe und Durchmesser der gängigsten in dieser Arbeit verwendeten Porengeometrien ist in Tabelle 3.6 dargestellt.

Tabelle 3.6: Gemäß Gl. 3.12 berechnete Eindringtiefe für Poren verschiedener Durchmesser und Geometrien.

\begin{tabular}{|l|c|c|}
\hline Porentyp, -durchmesser & Eindringtiefe (CLSM) $\boldsymbol{h} / \boldsymbol{\mu m}$ & Porentiefe $/ \boldsymbol{\mu m}$ \\
\hline Runde Poren, $3,5 \mu \mathrm{m}$ & 1,54 & 9 \\
\hline Runde Poren, $4,5 \mu \mathrm{m}$ & 1,97 & 9 \\
\hline Runde Poren, $5,5 \mu \mathrm{m}$ & 2,41 & 9 \\
\hline Eckige Poren, $8,0 \mu \mathrm{m}$ & 4,96 (diagonal) & 12 \\
\hline
\end{tabular}

\section{Durchführung}

Es wurde das Konfokalmikroskop LSM 710 mit der Software ZEN 2008 verwendet. Alle Aufnahmen wurden mit einem Wasserimmersionsobjektiv (W Plan-Apochromat 63x/1.0 M27, Carl Zeiss GmbH, Jena) durchgeführt. Das Gerät ist mit verschiedenen Lasern ausgestattet, welche zur Anregung verschiedener Farbstoffe verwendet wurden. Ein Überblick hierzu findet sich in Tabelle 3.7.

Tabelle 3.7: Überblick der zur Anregung der angegebenen Farbstoffe verwendeten Laser und des detektierten Emissionsbereichs.

\begin{tabular}{|l|c|c|}
\hline Laser & Fluorophor & Detekionsbereich \\
\hline Diode $(405 \mathrm{~nm}), 30 \mathrm{~mW}$ & Pyranin (Protoniert) & $500-580 \mathrm{~nm}$ \\
\hline Ar-Ionen $(458 \mathrm{~nm}), 25 \mathrm{~mW}$ & Pyranin (Deprotoniert) & $500-580 \mathrm{~nm}$ \\
\hline Ar-Ionen $(488 \mathrm{~nm}), 25 \mathrm{~mW}$ & Bodipy PC, Alexa Fluor 488 & $500-580 \mathrm{~nm}$ \\
\hline DPSS $(561 \mathrm{~nm}), 20 \mathrm{~mW}$ & Texas Red, Cy3 & $600-700 \mathrm{~nm}$ \\
\hline
\end{tabular}

Die Bilder wurden mit einer Farbtiefe von 8 Bit aufgenommen und Aufnahmen, bei denen weder stark photobleichende Fluorophore (Pyranin, protonierte Form), noch eine hohe zeitliche Auflösung nötig waren, wurden mit bis zu achtfach gemittelten Scanlinien durchgeführt, um die Bildqualität zu verbessern. Bei gleichzeitiger Aufnahme mehrerer Fluorophore 
in einem Bild, wurden die einzelnen Laserlinien nacheinander eingestrahlt und die Emission dabei detektiert (track scanning). Wurden mehrere Fokusebenen nacheinander aufgenommen (z-stack, Abb. 3.9, A), so wurden hierfür höchste und tiefste Ebene festgelegt und ein Abstand in $z$-Richtung der Ebenen voneinander im Bereich des axialen Auflösungsvermögens (etwa 700 bis $900 \mathrm{~nm}$ ) gewählt. Dreidimensionale Anordnungen solcher gestapelten fokalen Ebenen wurden in Ortho-Ansicht dargestellt (Abb. 3.9, B) Eine Nachbearbeitung der Bilder sowie das Auslesen von Intensitäten manuell gelegter ROIs erfolgte mit Hilfe der Software ZEN 2008, ZEN 2009 LE und der Software ImageJ.

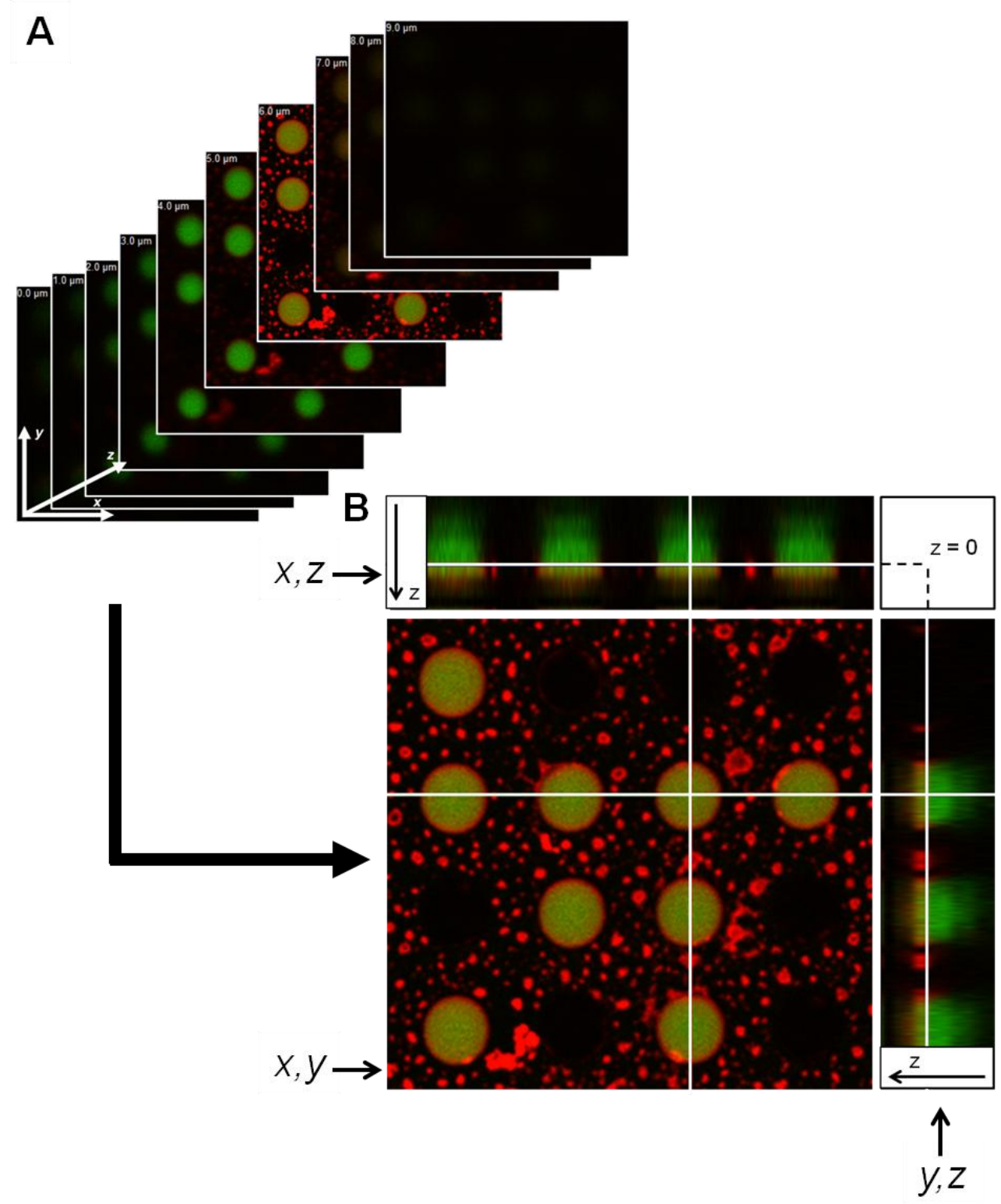

Abb. 3.9: Prinzip der Darstellung dreidimensionaler konfokalmikroskopischer Fluoreszenzaufnahmen. A zeigt eine Folge von zehn Einzelbildern, welche denselben Bildausschnitt in $x, y$-Richtung zeigen. Zwischen den Bildern wurde der Fokus in $z$-Richtung je um $\Delta z=1 \mu \mathrm{m}$ verändert (z-stack). B In der Ortho-Darstellung eines $z$-stacks werden neben der $x, y$-Ebene auch die Fluoreszenz in $x, z$-Ebene (oben) und $y, z$-Ebene (rechts) dargestellt. Die Auswahl der beiden $z$-Ebenen erfolgt dabei durch Verschieben zweier Linien (weiß) im $x, y$-Ausschnitt. Zur besseren Übersichtlichkeit wird die Substratoberfläche hierbei als $z=0$ definiert und ist in den $z$-Ebenen durch eine weiße Linie gekennzeichnet. 
Bei Aufnahmen, welche nicht am Konfokalmikroskop gemacht worden waren, kam das Auflicht-Fluoreszenzmikroskop Axiotech Vario (Carl Zeiss GmbH, Jena) zum Einsatz. Es ist mit einem Wasserimmersionsobjektiv (Achroplan 40x/0.8 W) ausgestattet und wurde mit den Filtersätzen 44 (BP 475/40, FT500, BP 530/50) sowie 45 (BP 560/40, FT585, BP 630/75, beide Carl Zeiss GmbH, Jena) betrieben. Zur Bildnachbearbeitung und Bildanalyse wurde das Programm AxioVision LE (V. 4.8, Carl Zeiss GmbH, Jena) eingesetzt.

\subsubsection{Fluorescence Recovery After Photobleaching}

Um die Mobilität von Lipiden innerhalb lösungsmittelfreier und lösungsmittelhaltiger porenüberspannender Membranen adressieren zu können, wurde die Fluoreszenz membranintegrierter Farbstoffe innerhalb eines definierten Bereichs mit Hilfe eines starken Laserpulses irreversibel gelöscht. Sind die Bestandteile der Membran mobil, so steigt die Intensität der Fluoreszenz innerhalb des gebleichten Bereichs durch zweidimensionale Diffusion wieder an. Gebleichte Moleküle werden aus dem Bereich heraus, ungebleichte, fluoreszierende Moleküle in den Bereich hinein transportiert. Dieses Experiment ist als fluorescence recovery after photobleaching (FRAP) bekannt und wurde mit einem entsprechenden Modell zur Quantifizierung der Lipidmobilität in Form eines Diffusionskoeffizienten $D$ erstmals 1976 von Axelrod beschrieben. ${ }^{[178]}$ Ein beispielhafter Intensitätsverlauf einer gebleichten ROI ist in Abb. 3.10 dargestellt. Die Intesität einer ROI unmittelbar nach dem Bleichen als Anteil der

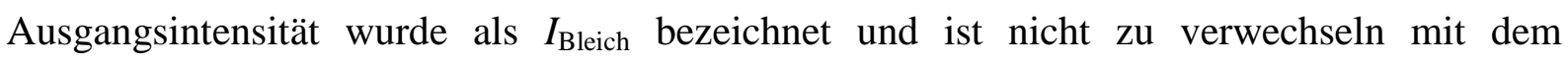
Parameter $I_{0}$, welcher erst nach Korrektur um unspezifisches Photobleichen und Normierung des Intensitätsverlaufs erhalten wurde. 


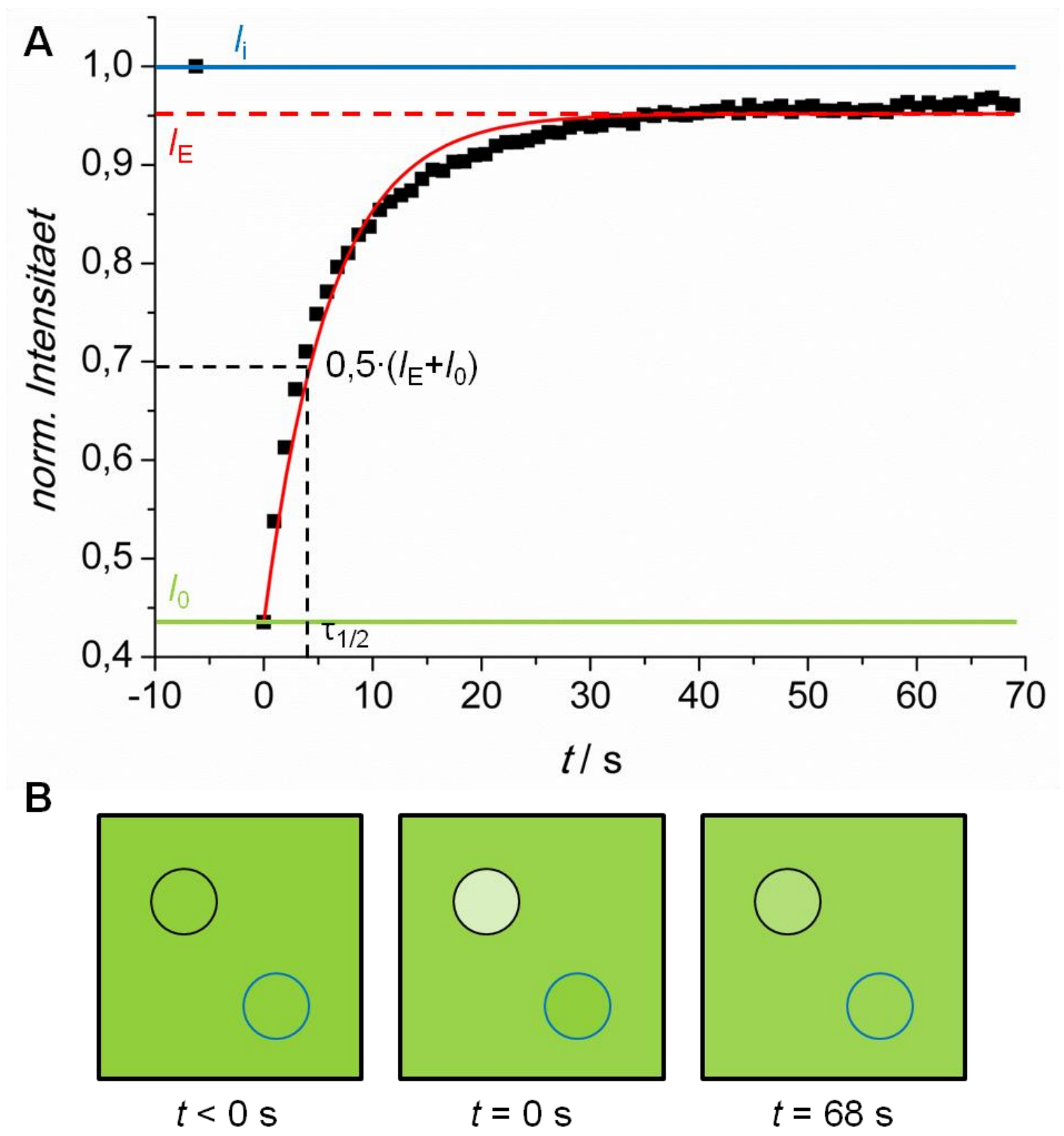

Abb. 3.10: A Intensitätsverlauf eines typischen fluorescence recovery after photobleaching (FRAP) Experiments. Die Intensität der ROI in einem Bild vor dem Bleichen ( $\mathbf{B}, t<0 \mathrm{~s}$, schwarzer Kreis) wird auf den Wert 1 normiert $\left(I_{\mathrm{i}}\right)$, die Intensitätswerte für die gebleichte ROI $(\mathbf{B}, t=0 \mathrm{~s})$ werden durch diejenigen einer ungebleichten ROI (B, blauer Kreis) im jeweils selben Bild geteilt, um unspezifisches Hintergrundbleichen zu berücksichtigen. Parameter wie $I_{\mathrm{i}}, I_{\mathrm{E}}, I_{0}$ und $\tau_{1 / 2}$ sind an entsprechender Stelle eingezeichnet. Für dieses Beispiel ergibt sich ein mobiler Anteil von 90,2\%. B Schematische Darstellung einer zweidimensionalen fluoreszenzmikroskopischen Aufnahme während eines FRAP-Experiments. Die Intensität der Fluoreszenz (grün) wird in zwei ROIs ausgelesen. Vor Bleichen einer der beiden ROIs (schwarz) bei $t=0 \mathrm{~s}$, weisen beide ROIs die gleiche Intensität auf. Durch zweidimensionale Diffusion gebleichter Moleküle aus der ROI heraus bzw. ungebleichter Moleküle in die ROI hinein, nimmt die Intensität innerhalb der gebleichten ROI im Verlauf der Zeitserie zu. Die Hintergrundintensität (berücksichtigt durch die in blau dargestellte ROI) nimmt im Verlauf des Experiments durch unspezifisches Photobleichen leicht ab. 
Die Auswertung eines FRAP-Experiments erfolgte mit Hilfe der Software ZEN 2008. Dabei wurden die Intensitätswerte einer ROI wie in Abb. 3.10 dargestellt normiert und angepasst (Gl. 3.13).

$$
I(t)=I_{E}-I_{1} \cdot \exp \left(\frac{-t}{T_{1}}\right)
$$

Dabei ist $I(t)$ der Intensitätswert zum Zeitpunkt $t, I_{\mathrm{E}}$ der Grenzwert für unendlich große $t$ und $I_{1}$ die Differenz zwischen den Intensitätswerten $I(t=\infty)\left(I_{\mathrm{E}}\right)$ und $I(t=0)\left(I_{0}\right)$. Der Parameter $T_{1}$ lässt sich gemäß Gl. 3.15 in die charakteristische Diffusionszeit $\tau_{1 / 2}$ umrechnen, bei welcher gilt:

$$
\begin{gathered}
I\left(\tau_{1 / 2}\right)=0,5 \cdot\left(I_{E}+I_{0}\right) . \\
\tau_{1 / 2}=\ln (0,5) \cdot\left(-T_{1}\right) .
\end{gathered}
$$

Aus diesen Werten kann der mobile Anteil der Lipide $(M)$ gemäß Gl. 3.16 berechnet werden:

$$
M=\frac{I_{1}}{I_{i}-I_{0}}
$$

Der Diffusionskoeffizient $D$ errechnet sich aus der charakteristischen Diffusionszeit $\tau_{1 / 2}$ und dem Radius $\omega$ des Bleichprofils gemäß:

$$
D=\frac{\omega^{2}}{4 \cdot \tau_{1 / 2}} .
$$

Als Radius des kreisförmigen gebleichten Bereichs $(\omega)$ wurde der Radius der entsprechenden ROI eingesetzt.

\section{Durchführung}

FRAP-Experimente wurden durchgeführt an mit Bodipy PC markierte, porenüberspannende Membranen, an mit Alexa Fluor 488 markiertem bR, welches in porenüberspannenden Membranen zuvor rekonstituiert worden war und an in Poren eingeschlossenem Pyranin, um $\mathrm{zu}$ testen, ob ein diffusionsbedingter Austausch von Pyranin zwischen benachbarten Poren möglich war. Bodipy PC und Alexa Fluor 488 wurden mit einem Puls des Argon-Ionenlasers (488 nm, $100 \%$ Power), Pyranin mit einem Puls des Diodenlasers (405 nm, $100 \%$ Power) gebleicht. Die Bleichdauer sollte dabei möglichst $<10 \%$ des Wertes von $\tau_{1 / 2}$ betragen, da sonst durch Diffusion von Fluorophormolekülen während des Bleichvorgangs ein unscharfes Bleichprofil erhalten wird, was zu einer fehlerhaften Quantifizierung der Mobilität führt. ${ }^{[178]}$ Um die Dauer des Bleichpulses möglichst kurz zu halten, dabei jedoch den Farbstoff 
innerhalb der ROI möglichst vollständig zu bleichen, wurde unter folgenden Bedingungen gebleicht: Zoom bleach aktiviert, eine Wiederholung (iteration =1) und eine deutlich niedrigere Rastergeschwindigkeit im Bereich der ROI als im Rest des Bildes (different scan speed $=1$ bis 2). So konnte bei Bleichzeiten von wenigen Sekunden ein Bleichgrad von üblicherweise $>50 \%$ realisiert werden. Zur Auswertung wurde eine zweite ROI vergleichbarer Größe und Startintensität wie die gebleichte ROI manuell in das Bild gefügt und diese in der Software als Referenz gewählt.

\subsection{Rasterionenleitfähigkeitsmikroskopie}

Mit der Rasterionenleitfähigkeitsmikroskopie (scanning ion conductance microscopy, SICM) ist es möglich, Aussagen über die Benetzung geschlossener Poren, sowie die Topografie porenüberspannender Membranen zu treffen. Diese noch relativ junge Technik zählt zur Familie der rastersondenmikroskopischen Techniken (scanning probe microscopy, SPM) und wurde von Hansma et al. erstmals 1989 beschrieben. ${ }^{[179]}$ Seitdem wurde die Technik weiterentwickelt (hopping mode ${ }^{[180]}$, SICM an porenüberspannenden Membranen ${ }^{[181,182]}$ ) und Geräte sind inzwischen kommerziell verfügbar. Das SICM misst Ionenströme, welche durch eine Glaspipette mit feiner Öffnung (einige zehn bis hundert Nanometer) fließen. Die Stromstärke ist dabei abhängig vom Abstand der Spitzenöffnung zur Probenoberfläche und wird durch Korrektur der Pipettenposition mittels Piezomotoren konstant gehalten. Die dabei nötige Auslenkung der Piezomotoren kann in ein Höhenprofil der Probenoberfläche übertragen werden.

\section{Aufbau und Funktionsprinzip}

Eine schematische Darstellung eines SICM-Aufbaus ist in Abb. 3.11 dargestellt. Das Funktionsprinzip des hier verwendete SICM (ICnano scanning ion conductance microscope, Ionscope, Melbourn, UK) ist nachfolgend erläutert. Eine mit wässriger Pufferlösung gefüllte Petrischale oder entsprechend große Messkammer wird in einen Faraday-Käfig platziert. Eine $\mathrm{Ag} / \mathrm{AgCl}-\mathrm{Gegenelektrode} \mathrm{wird} \mathrm{in} \mathrm{die} \mathrm{Lösung} \mathrm{getaucht} \mathrm{und} \mathrm{eine} \mathrm{zweite} \mathrm{Ag/AgCl-Elektrode}$ wird in eine mit identischem Puffer gefüllte Mikropipette eingeführt. Zwischen beiden Elektroden wird ein Potential von üblicherweise $200 \mathrm{mV}$ angelegt. Der Stromfluss ist dabei durch die Geometrie der Spitzenöffnung und dem damit einhergehenden Widerstand von typischerweise > $150 \mathrm{M} \Omega$ limitiert und liegt im Nanoamperebereich. Eine ausführliche Beschreibung des Zusammenhangs von Spitzengeometrie und Pipettenwiderstand kann bei Böcker gefunden werden. ${ }^{[183]}$ 


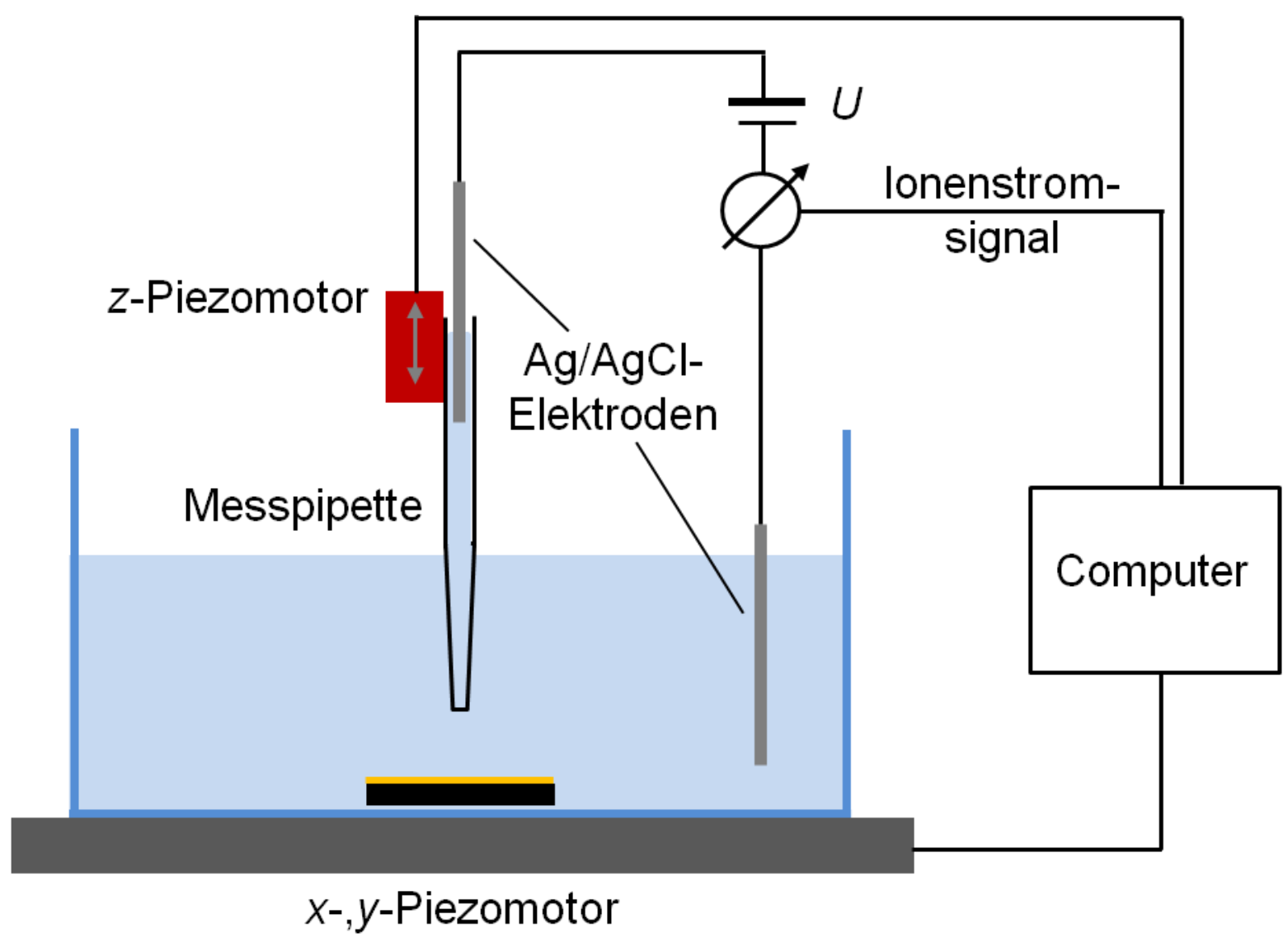

Abb. 3.11: Schematischer Aufbau eines Rasterionenleitfähigkeitsmikroskops (SICM). Zeichnung nicht maßstabsgetreu.

Die Spitze kann durch Piezomotoren in $z$-Richtung bewegt werden. In $x$ - und $y$-Richtung kann sie durch Bewegung der Probe mittels zweier weiterer Piezomotoren adjustiert werden. Nähert sich die Spitze mit ihrer Öffnung einer nicht-leitenden Oberfläche (z. B. einer Lipidmembran oder einer Luftschicht), so wird das Volumen, aus welchem Ionen aus der Lösung durch die Spitzenöffnung treten und zur Elektrode gelangen können, reduziert und es sinkt das Stromsignal (Abb. 3.12). Das Signal wird an einen Computer geleitet, an welchem ein Grenzwert (setpoint) eingestellt werden kann, bis zu welchem das Stromsignal abfallen darf, bevor die Annäherung der Pipette in z-Richtung gestoppt wird. Das hier beschriebene System wurde im hopping mode betrieben, also mit in z-Richtung oszillierender Pipette (Abb. 3.12, A). Zur Aufnahme eines Bildes wird die Pipette an die Probe angenähert und ein Ausschnitt einer Größe von bis zu 50.50 $\mu \mathrm{m}$ abgerastert. Die Pipette oszilliert mit definierter Amplitude (2-15 $\mu \mathrm{m})$ über einen Bildpunkt, bis das Stromsignal aufgrund der Nähe zur Probenoberfläche unter den zuvor festgelegten Grenzwert fällt (99,7 bis $98 \%$ des Maximalsignals), oder die Tiefstauslenkung der Oszillation erreicht ist. Die zugehörige $z$-Auslenkung des Piezomotors wird als Höhe an diesem Bildpunkt registriert und die Pipette rastert den nächsten Bildpunkt $\mathrm{ab}$. 

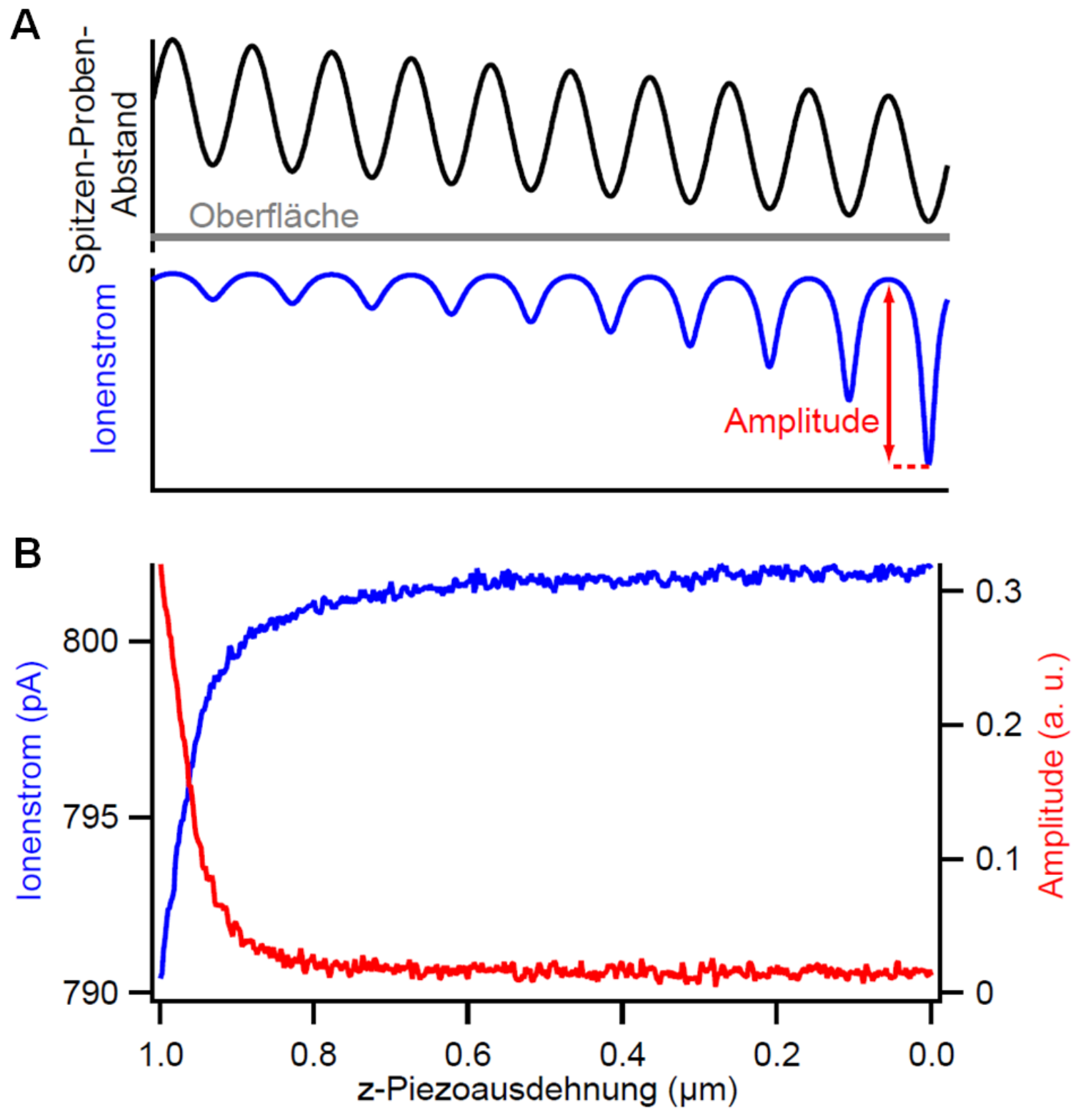

Abb. 3.12: Schematische Darstellung der Korrelation von Spitzen-Proben-Abstand (schwarz) und Ionenstrom (blau) sowie Amplitude des Ionenstroms (rot) eines SICM im hopping mode ${ }^{[183]}$ A Die Spitze oszilliert mit einer definierten Amplitude in z-Richtung und wird dabei der Oberfläche (grau) angenähert. Die Signalstärke des Ionenstroms oszilliert mit gleicher Frequenz und sinkt mit abnehmendem Spitzen-Proben-Abstand, wobei die Amplitude des Signals zunimmt. B Gemessener Ionenstrom und Amplitude in Abhängigkeit der z-Piezoausdehnung. Mit steigender Piezoausdehnung (sinkendem Spitzen-Proben-Abstand) nimmt der detektierte Ionenstrom zunächst sehr langsam, dann schnell ab. Fällt er unter einen zuvor festgelegten Grenzwert, so wird das z-Piezo zurückgefahren, bis das Ionenstromsignal das Ausgangsniveau erreicht. Die funktionelle Form des Ionenstroms und der Amplitude sind bis auf das Vorzeichen sehr ähnlich. Die Modulationsamplitude beträgt $120 \mathrm{~nm}$ bei einer Modulationsfrequenz von $800 \mathrm{~Hz}$.

\section{Auflösungsvermögen}

Das Auflösungsvermögen eines SICM wurde anhand kleinster Strukturen, wie Membranproteinen, Nanokristallen von biotinyliertem BSA, oder auch von Antikörpern experimentell 
bestimmt. ${ }^{[184]}$ Dabei ergaben sich Werte von $d_{\text {lateral }} \approx 100$ bis $200 \mathrm{~nm}$ (Durchmesser der Pipettenspitze) und $d_{\text {axial }} \approx 5 \mathrm{~nm}$. Das axiale Auflösungsvermögen ist also deutlich höher, als das laterale, welches nach Donnermeyer wie auch bei anderen SPM-Techniken üblich, durch den Durchmesser der Pipettenspitze limitiert ist. Es gilt zu beachten, dass diese Werte für ein Prototyp-SICM ermittelt wurden mit per Laser-Puller gezogenen Pipettenspitzen und einer optimierten elektrischen Isolierung. Durch Verwendung eines filamentgeheitzten Mikropipettenziehgeräts lassen sich Pipetten mit weniger isotroper Spitzengeometrie ziehen, was das Auflösungsvermögen des in dieser Arbeit verwendeten Aufbaus negativ beeinflusst. Strukturen mit axialen Dimensionen $d_{\text {axial }}<50 \mathrm{~nm}$ ließen sich praktisch nicht auflösen.

\section{Durchführung}

Die Probe (Siliziumsubstrat fixiert in Petrischale oder entsprechend großer Messkammer) wurde in einen Probenhalter im SICM platziert. Eine Messpipette wurde aus einer Glaskapillare (Borsilikatglas, Außendurchmesser 1,00 mm, Innendurchmesser 0,58 mm, Länge $80 \mathrm{~mm}$, mit Filament, NPI Electronic GmbH, Tamm) mit Hilfe eines Mikropipettenziehgeräts (P-1000 puller, Sutter Instruments, Novato, CA, USA, Parameter: Heat: Ramp, Pull: 150, Velocity: 75, Time: 250, Pressure: 500, Loops: 1, 2,5·2,5 mm Box Filament) gezogen und mit filtrierter, entgaster Pufferlösung (160 mM KCl, $10 \mathrm{mM}$ MOPS, pH 7,3 (KOH), Filterfeinheit 0,2 $\mu \mathrm{m})$ blasenfrei gefüllt. Eine $\mathrm{Ag} / \mathrm{AgCl}$-Elektrode wurde in die Pipette eingeführt, beides in das Gerät montiert und elektrisch kontaktiert. Eine Spannung von $200 \mathrm{mV}$ wurde am Gerät eingestellt und Elektrode und Gegenelektrode in die Probenlösung getaucht. Wurde an diesem Punkt kein Stromsignal im Nanoamperebereich angezeigt, so wurde die Pipette auf Luftblasen untersucht und bei Bedarf eine neue gezogen. Eine Oszillationsamplitude zwischen 2 und $15 \mu \mathrm{m}$ wurde eingestellt, der Grenzwert (setpoint) auf 0,3 bis $2 \%$ geregelt und die Pipettenspitze an die Substratoberfläche mit 15 bis $20 \mathrm{~nm} \cdot \mathrm{s}^{-1}$ angenähert. Ein Bildausschnitt definierter Größe wurde aufgenommen und nach Ende der Messung die Pipette aus der Lösung heraus in maximale $z$-Position gefahren. Die Bildnachbearbeitung sowie Bildanalyse erfolgte mit Hilfe der Software ScanIC (V 1.0, Ionscope, Melbourn, UK) und der Software Gwyddion (V. 2.20, http://gwyddion.net/).

Die Elektroden wurden regelmäßig neu chloridiert. Hierzu wurden die alte Chloridschicht mit Schmirgelpapier entfernt, die Elektrode mit Reinstwasser gespült und zusammen mit einer Platin-Gegenelektrode in eine 0,5 M KCl-Lösung getaucht. Die Elektroden wurden an ein Gleichspannungsnetzteil (PS280, Tektronix, Beaverton, OR, USA) angeschlossen und eine Spannung von $0,5 \mathrm{~V}$ angelegt, welche langsam auf bis zu $3 \mathrm{~V}$ erhöht wurde, wobei sich ein schwarzer Niedeschlag auf den Elektroden bildete. Nach mehrmaligem Umpolen wurde die fertig chloriderte Elektrode mit Reinstwasser gespült und ins SICM eingesetzt. 
3 Materialien und Methoden 


\section{Ergebnisse}

\subsection{Präparation und Charakterisierung porenüberspannender Membranen}

Voraussetzung für eine Kompartimentierung der Poreninnenräume von Siliziumsubstraten und damit der Möglichkeit, elektrochemische Gradienten zwischen Porenvolumen und überstehender Lösung aufzubauen, ist die Separation beider Bereiche durch eine Lipidmembran. Schrittweise wurden ausgehend von porösen Siliziumsubstraten Strategien entwickelt, welche die Bildung porenüberspannender Membranen und den Einschluss von Farbstoff im Poreninnenraum ermöglichten. Dabei wurde auf eine Präparation von lösungsmittelhaltigen Membranen mit Hilfe der painting-Technik, sowie auf die Bildung lösungsmittelfreier Membranen durch Vesikelspreiten zurückgegriffen. Optische (zwei- und dreidimensionale Konfokalmikroskopie) und sondenmikroskopische (Rasterionenleitfähigkeitsmikroskopie) Methoden wurden zur Charakterisierung des Systems eingesetzt.

\subsubsection{Lösungsmittelhaltige porenüberspannende Membranen (painted mem- branes)}

Siliziumsubstrate mit geschlossenen, mikrometergroßen Poren $\left(8 \cdot 8 \cdot 12 \mu \mathrm{m}^{3}\right.$, Abb. 3.5, B) wurden eingesetzt, um mit Hilfe der painting-Technik porenüberspannende Membranen zu bilden. Hierzu wurde zunächst eine dünne Schicht aus Gold (30 bis $60 \mathrm{~nm}$ ) auf den Stegbereich der porösen Siliziumsubstrate aufgebracht und durch Chemisorption eines Thiols (Cholesterylpolyethylenoxythiol, CPEO3) eine hydrophobe, selbstorganisierende Monolage (self assembled monolayer, SAM) gebildet. Auf CPEO3-funktionalisierten Substraten kann durch Aufbringen eines Lipid-Lösungsmittelgemisches nach Ausdünnen des Lösungsmittels eine planare Membran gebildet werden. ${ }^{[185]}$ Auftragen einer kleinen Menge $n$-Propanols und anschließendes Spülen mit Pufferlösung sollte eine vollständige Benetzung der Poren mit wässriger Lösung bewirken. Eine Lösung von Lipid (DPhPC bzw. DPhPC/DPPA, 9:1) in $n$-Dekan wurde mit Hilfe eines feinen Pinsels auf die funktionalisierte Substratoberfläche aufgetragen. Membranen aus DPhPC weisen hohe elektrische Widerstände auf und eignen sich zur Messung von Ionenströmen durch Kanalproteine auf Einzelkanalebene. ${ }^{[42]}$ In Hinblick auf den Aufbau stabiler Ionengradienten über Membranen wurde somit DPhPC zur Bildung porenüberspannender Membranen verwendet. Das bei $\mathrm{pH}$ 7,3 negativ geladene Lipid DPPA verhindert eine Akkumulation des wasserlöslichen, dreifach negativ geladenen 
Fluoreszenzfarbstoffs Pyranin im Bereich der Membran. Die Markierung der Membran mit dem Fluorophor Bodipy PC erlaubte die fluoreszenzmikroskopische Untersuchung der so gebildeten porenüberspannenden painted membranes. Eine konfokalmikroskopische Aufnahme mehrerer Ebenen in $z$-Richtung (z-stack, Kapitel 3.5) von einem lipidschichtüberspannten Bereich eines Substrates ist in Abb. 4.1, A dargestellt. Porenbereiche zeigen eine helle, grüne Fluoreszenz, was auf die erfolgreiche Ausbildung porenüberspannender Lipidschichten hindeutet. Der Stegbereich dazwischen hebt sich durch eine dunklere Fluoreszenz davon ab, da die Goldbeschichtung dort einen Teil der Fluoreszenz löscht. In diesem Ausschnitt einer Größe von etwa $94.94 \mu \mathrm{m}^{2}$ sind alle 64 sichtbaren Poren mit einer Lipidschicht bedeckt. Typischerweise konnten bei Anwendung der painting-Technik sehr große, zusammenhängende Bereiche des Substrates mit porenüberspannenden Lipidschichten bedeckt werden, bis hin zu $100 \%$. Die Ortho-Darstellung ermöglicht eine Aussage über die Verteilung der Fluoreszenz in $z$-Richtung. Hierbei zeigt sich, dass sich die Fluoreszenz nicht ausschließlich auf die Ebene der Substratoberfläche $(z=0)$ beschränkt, sondern Fluoreszenz noch 2,6 $\mu \mathrm{m}$ oberhalb der Substratoberfläche, sowie bis $\mathrm{zu} 4,4 \mu \mathrm{m}$ innerhalb der Poren detektierbar ist. Da das Auflösungsvermögen des Mikroskops etwa $1 \mu \mathrm{m}$ in $z$-Richtung und die Dicke einer Lipiddoppelschicht etwa $5 \mathrm{~nm}$ beträgt, deutet die über einen weiten Bereich in $z$-Richtung detektierbare Fluoreszenz nicht auf die Bildung einer definierten Membran hin. Vielmehr ist ein vielfacher Überschuss an Lösungsmittel vorhanden, so dass es sich um eine dreidimensionale Lipid-Lösungsmittelschicht handelt. Die hier abgebildete Aufnahme ist beispielhaft für große Bereiche vieler Substrate, es finden sich jedoch auch Bereiche mit in $z$-Richtung weniger breit oder weniger homogen verteilter Fluoreszenz (Abb. 4.2, E und F). Daher stellt sich der Verlauf der Fluoreszenz von durch painting-Technik präparierten porenüberspannenden Membranen auf kleine Bereiche bezogen als homogen, auf das gesamte Substrat bezogen jedoch als heterogen dar. 

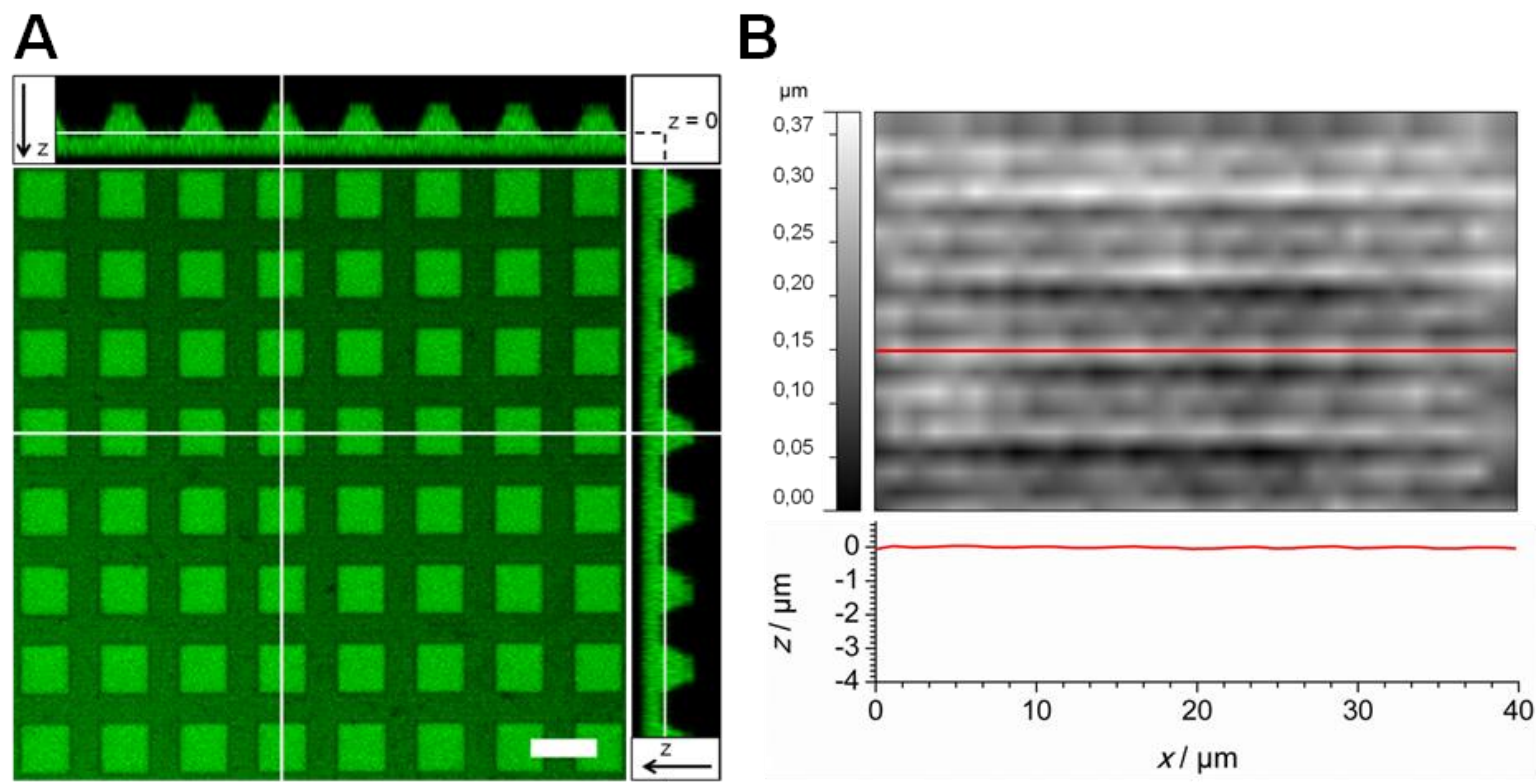

Abb. 4.1: A Ortho-Darstellung einer dreidimensionalen, konfokalmikroskopischen Aufnahme eines porösen Siliziumsubstrates (Porendimensionen: $8 \cdot 8 \cdot 12 \mu \mathrm{m}^{3}$ ) mit einer per painting-Technik präparierten porenüberspannenden Membran (DPhPC/DPPA/Bodipy PC, 89,8:10,0:0,2). Maßstabsbalken $10 \mu \mathrm{m}, z$-Dimension: 13,2 $\mu \mathrm{m}$ (16 Einzelbilder). Die Substratoberfläche ist definiert als $z=0 \mu \mathrm{m}$ (weiße Linie in $x, z-$ und $y, z$-Ebene, Punkte bei $z>0 \mu \mathrm{m}$ liegen in der Lösung oberhalb der Substratoberfläche, Punkte bei $z<0 \mu \mathrm{m}$ liegen im Poreninneren unterhalb der Substratoberfläche. Pufferlösung: $160 \mathrm{mM} \mathrm{KCl}, 10 \mathrm{mM} \mathrm{MOPS,} \mathrm{pH} \mathrm{7,3} \mathrm{(KOH).} \mathrm{B} \mathrm{SICM-}$ Aufnahme und Höhenprofil einer porenüberspannenden painted membrane (DPhPC/Bodipy PC, 99,5:0,5; Porendimension wie in A). Pufferlösung: $100 \mathrm{mM} \mathrm{KCl,} 20 \mathrm{mM}$ TRIS, $1 \mathrm{mM} \mathrm{CaCl}$, 0,5 mM Pyranin, pH 7,4 ( $\mathrm{HCl})$.

Rasterionenleitfähigkeitsmikroskopische Aufnahmen (scanning ion conductance microscopy, SICM-Aufnahmen) von painted membranes unterstützen dieses Modell (Abb. 4.1, B) und liefern dabei eine höhere Auflösung der Oberflächenstruktur in $z$-Richtung, als konfokalmikroskopische Aufnahmen (Kapitel 3.5 und 3.6, Auflösungsvermögen). Ein Ausschnitt von $40 \cdot 40 \mu \mathrm{m}^{2}$ (in Abb.4.1, B nicht vollständig abgebildet) zeigt eine Oberfläche mit einer maximalen Höhendifferenz von etwa $370 \mathrm{~nm}$. Dabei sind keine porenförmigen Strukturen erkennbar, sondern es ergibt sich eine planare Topografie. Ein Profil entlang der in rot eingezeichneten Linie verdeutlicht diesen Befund und entspricht dem Verlauf der in Abb. 4.1, A erkennbaren planaren Grenzschicht des fluoreszierenden Bereichs bei $z=+2,6 \mu \mathrm{m}$ in $x, z-$ und $y, z$-Ebene. Insgesamt zeigten SICM-Aufnahmen in den meisten Fällen planare Oberflächen mit Höhenunterschieden $<50 \mathrm{~nm}$ entlang einer scan-Linie. In seltenen Fällen konnten Poren- und Stegfläche durch geringe Höhendifferenzen voneinander strukturell unterschieden werden.

\section{Mobilität der Lipide}

Mittels fluorescence recovery after photobleaching (FRAP) Experimente wurde die Mobilität der Lipide innerhalb der porenüberspannenden Lösungsmittel-Lipidschicht adressiert. Der daraus ermittelte mobile Anteil $M$ innerhalb einer Lipidschicht kann Aufschluss darüber 
geben, ob ein Lipidaustausch zwischen benachbarten Poren möglich ist. Weiterhin sollte geprüft werden, ob durch FRAP-Experimente zwischen lösungsmittelreichen und lösungsmittelarmen Bereichen eines Substrates unterschieden werden kann. Hierzu wurde die Fluoreszenz in einem definierten Bereich (region of interest, ROI) durch einen Laserpuls hoher Intensität irreversibel gelöscht und der zeitliche Verlauf der Fluoreszenzintensität in diesem Bereich aufgenommen (Kapitel 3.5.1). Dabei ergab sich ein sehr inhomogenes Bild für verschiedene Bereiche bedeckter Poren. Exemplarisch sind die zeitlichen Verläufe der Fluoreszenzintensität während eines FRAP-Experiments, sowie die zugehörigen fluoreszenzmikroskopischen Aufnahmen direkt nach dem Bleichen und am Ende der Zeitserie zweier unterschiedlicher Stellen desselben Substrates in Abb. 4.2 dargestellt. Während Abb. 4.2, B und $\mathrm{C}$ eine Stelle mit homogener Bodipy PC Fluoreszenz zeigen, lassen sich in Abb. 4.2, E und F im Porenbereich teilweise Stellen verringerter Intensität ausmachen. Diese Unterschiede in der Bodipy PC Fluoreszenz spiegeln sich in den Verläufen der FRAP-Experimente wider. Abb. 4.2, A zeigt einen Abfall der Fluoreszenzintensität nach dem Bleichen auf einen Wert von $53 \%$ der Ausgangsintensität (im Folgenden als $I_{\text {Bleich }}$ bezeichnet). Die Intensität im gebleichten Bereich steigt rasch wieder an und ergibt einen mobilen Anteil von $M=97 \%$. In Abb. 4.2, D sinkt die Fluoreszenzintensität nach dem Bleichen bei ähnlicher Laserleistung und Bleichdauer auf $26 \%$ der Initialintensität ab und steigt im Folgenden nur sehr langsam und in geringem Maße wieder an. Es ergibt sich ein mobiler Anteil von $M=21 \%$. 

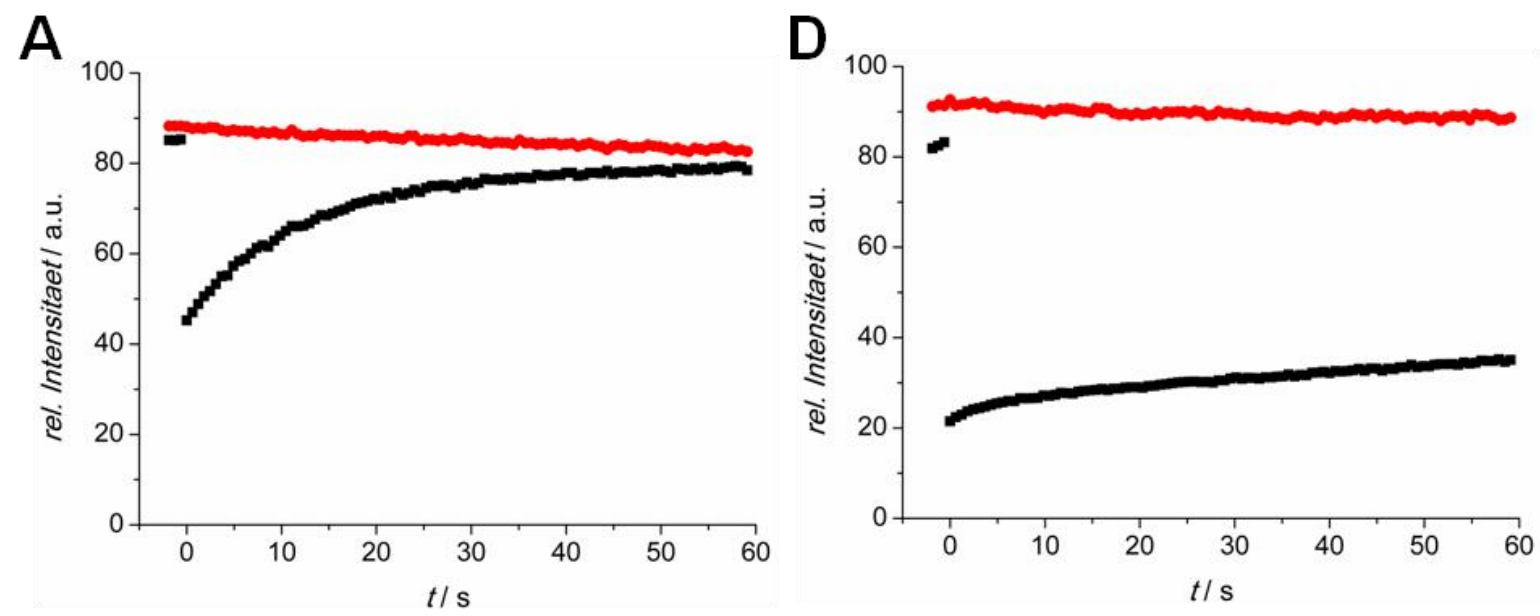

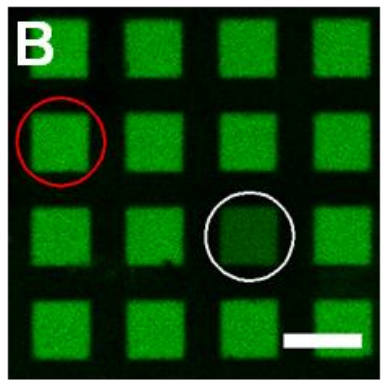

$t=0 \mathrm{~s}$

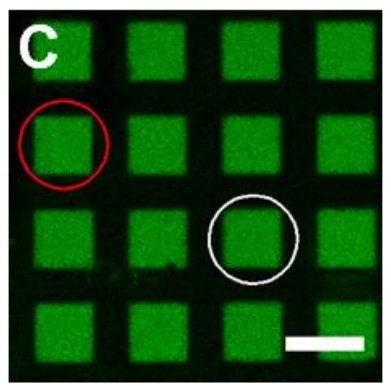

$t=60 \mathrm{~s}$

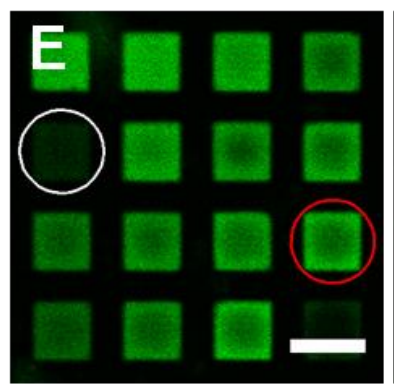

$t=0 \mathrm{~s}$

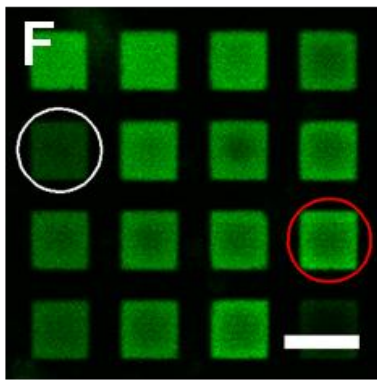

$t=60 \mathrm{~s}$

Abb. 4.2: FRAP-Experimente an lösungsmittelhaltigen porenüberspannenden Membranen. A und $\mathbf{D}$ zeigen den zeitlichen Verlauf der Bodipy PC Fluoreszenzintensität je zweier ROIs (rot entspricht der nicht gebleichten Referenz; schwarz entspricht dem gebleichten Bereich, in den Fluoreszenzbildern weiß dargestellt). Beide Zeitserien wurden an unterschiedlichen Stellen derselben Probe (Abb. 4.1, A) aufgenommen. Für A ergibt sich ein mobiler Anteil von $M=97 \%$, für D beträgt der Wert $M=21 \%$. B und $\mathbf{C}$, sowie $\mathbf{E}$ und $\mathbf{F}$ zeigen die zugehörigen fluoreszenzmikroskopischen Aufnahmen bei $t=0 \mathrm{~s}(\mathrm{~B}, \mathrm{E}$, direkt nach dem Bleichen) und bei $t=60 \mathrm{~s}(\mathrm{C}, \mathrm{F})$. Lipidzusammensetzung DPhPC/DPPA/Bodipy PC, 89,8:10:0,2, Pufferlösung: $160 \mathrm{mM} \mathrm{KCl,} 10 \mathrm{mM}$ MOPS, pH 7,3 (KOH). Maßstabsbalken $10 \mu \mathrm{m}$.

Diese Inhomogenität in Bezug auf die Mobilität der Lipide fand sich in allen betrachteten Proben, die mittels painting-Technik präpariert worden waren. Entweder wiesen die Membranen einen hohen mobilen Anteil auf und die Fluoreszenz innerhalb der gebleichten ROI konnte nur um rund die Hälfte des Ausgangswertes reduziert werden, oder die Fluoreszenz innerhalb der ROI zeigte kaum einen Anstieg und somit einen sehr geringen mobilen Anteil, wobei sich der Fluorophor deutlich stärker bleichen ließ. Zusammenfassend wurden für die FRAP-Experimente mobile Anteile von $M=65 \pm 40 \% \quad\left(M_{\max }=97 \%\right.$, $M_{\min }=7 \%$ ) erhalten. Nach dem Bleichen ergaben sich Fluoreszenzintensitäten von $I_{\text {Bleich }}=44 \pm 19 \% \quad\left(I_{\text {Bleich, } \max }=73 \%, I_{\text {Bleich,min }}=24 \%\right)$ der Ausgangsintensität. Die hohe Inhomogenität der Lipidmobilität wird starken Schwankungen im lokalen Gehalt von Lösungsmittel entlang des Substrates zugeordnet. 


\section{Ausfrieren des Lösungsmittels}

Das Aufbringen von Lipid gelöst in $n$-Dekan auf hydrophob funktionalisierten porösen Substrate resultierte wie oben gezeigt in einem porenüberspannenden Lipid-Lösungsmittelgemisch mit inhomogener Ausbreitung in $z$-Richtung und uneinheitlicher Lipidmobilität. Um den Lösungsmittelgehalt zu reduzieren und so die Struktur der Lipidschicht homogener zu gestalten, wurde remanentes Lösungsmittel ausgefroren. ${ }^{[170]}$ Hierzu wurde die fertig präparierte Probe für wenige Minuten bei $-21{ }^{\circ} \mathrm{C}$ gelagert ohne dabei einzufrieren (Kapitel 3.2.10). Nach Erwärmen der Probe auf Raumtemperatur, wurde diese erneut konfokalmikroskopisch und mittels SICM untersucht, wobei sich signifikante Unterschiede im Vegleich zur unbehandelten Probe ergaben (Abb. 4.3). Wie in Abb. 4.3, A zu erkennen, sind auch nach dem Prozess des Lösungsmittelausfrierens alle Poren im gezeigten Bildausschnitt überspannt (grüne Fluoreszenz). Allerdings ist die Fluoreszenz innerhalb der einzelnen Poren ungleichmäßiger verteilt, als dies vor dem Ausfrieren des Lösungsmittels der Fall war (Abb. 4.1, A). Im Zentrum einzelner Poren ist die Fluoreszenz schwächer ausgeprägt, als am Porenrand. Bei Betrachtung der Fluoreszenzverteilung in $z$-Richtung wird deutlich, dass die porenüberspannenden Membranen im Zentrum der Poren dünner erscheinen, als im Randbereich der Poren. Die Fluoreszenz erstreckt sich im Porenzentrum bis zu $z=-1,8 \mu \mathrm{m}$ tief in die Poren hinein, am Rand bis zu $z=-3,5 \mu \mathrm{m}$ tief ins Poreninnere. Diese Werte liegen deutlich unterhalb derjenigen für porenüberspannende painted membranes vor dem Ausfrieren des Lösungsmittels (überall bis $z=-4,4 \mu \mathrm{m}$ ). Auch die Fluoreszenz oberhalb der Substratebene verringerte sich von $z=+2,6 \mu \mathrm{m}$ vor Ausfrieren auf $z= \pm 0 \mu \mathrm{m}$ nach Ausfrieren des Lösungsmittels. Es ist also keine Fluoreszenz mehr oberhalb der Substratoberfläche detektierbar. Nach dem Ausfrieren des Lösungsmittels ergaben sich insgesamt $(N=136)$ für die Bodipy PC Fluoreszenz Ausdehnungen von 0 bis $-2,6 \mu \mathrm{m}$ für den überspannenden Bereich in der Mitte der Pore und von 0 bis $-4,4 \mu \mathrm{m}$ für den Porenrandbereich, was auf eine Abnahme des Gehalts remanenten Lösungsmittels hinweist.

Eine Veränderung der Topografie des Lipid-Lösungsmittelgemisches im porösen Bereich der Substrate wird durch SICM-Aufnahmen bestätigt (Abb. 4.3, B). Konnte vor Ausfrieren des Lösungsmittels nur in Einzelfällen die poröse Struktur des Substrates abgebildet werden (Abb. 4.1, B), so ergab sich danach ein Bild, in dem deutlich zwischen höherliegendem Stegbereich (hell) und tiefer im Poreninneren liegendem membranüberspannten Bereich (dunkel) unterschieden werden konnte. Das Profil entlang der in rot eingezeichneten Linie zeigt, dass die Poren erst in einer Tiefe von $z=-(3,1 \pm 0,3) \mu \mathrm{m}$ die Poren überspannen. Insgesamt ergab sich nach Ausfrieren eine Membrantiefe in überspannten Poren von $z=-(1,60 \pm 1,14) \mu \mathrm{m}(N=103)$. Dieser Wert weist eine recht große Standardabweichung auf, innerhalb einer Probe variierten die Tiefen der Membranen jedoch stets nur um bis zu $15 \%$. 

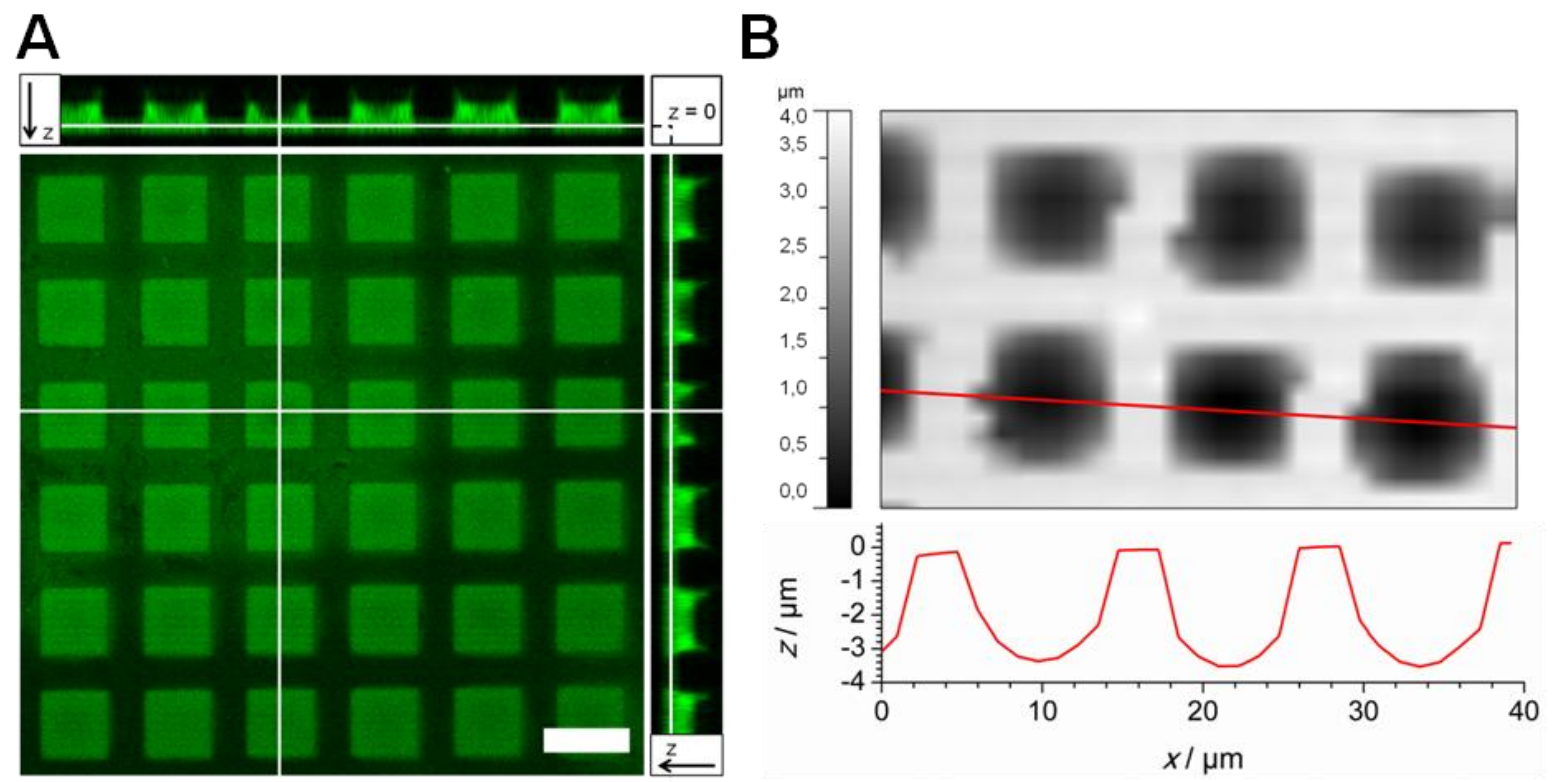

Abb. 4.3: A Ortho-Darstellung einer dreidimensionalen, konfokalmikroskopischen Aufnahme eines porösen Siliziumsubstrates $\left(8 \cdot 8 \cdot 12 \mu \mathrm{m}^{3}\right)$ mit einer mit Hilfer der painting-Technik präparierten porenüberspannenden Membran nach Ausfrieren des Lösungsmittels (DPhPC/DPPA/Bodipy PC, 89,8:10,0:0,2). Maßstabsbalken $10 \mu \mathrm{m}$, z-Dimension: 7,9 $\mu \mathrm{m}$ (10 Einzelbilder). Pufferlösung: $160 \mathrm{mM} \mathrm{KCl,} 10 \mathrm{mM} \mathrm{MOPS}, \mathrm{pH}$ 7,3 (KOH). B SICM-Aufnahme und Höhenprofil einer porenüberspannenden painted membrane nach Ausfrieren des Lösungsmittels (DPhPC/Bodipy PC, 99,5:0,5; Porendimension wie in A). Pufferlösung: $100 \mathrm{mM} \mathrm{KCl,} 20 \mathrm{mM}$ TRIS, $1 \mathrm{mM} \mathrm{CaCl} 2,0,5 \mathrm{mM}$ Pyranin, $\mathrm{pH}$ 7,4 $(\mathrm{HCl})$. Porenüberspannende Membranen bedecken die Poren in einer Tiefe von $z=-(3,1 \pm 0,3) \mu \mathrm{m}$.

Nachdem Unterschiede in der axialen Verteilung der Membranfluoreszenz und in der mittels SICM ermittelten Topografie der überspannten Poren nach Ausfrieren des Lösungsmittels festgestellt worden waren, wurde auch die Mobilität der Lipide innerhalb tieftemperaturbehandelter Proben untersucht (Abb. 4.4). Der Intensitätsverlauf der FRAP-Experimente nach Lösungsmittelausfrieren war einheitlicher, als bei solchen Proben, welche keinem solvent freeze-out unterzogen worden waren. Dies spiegelt sich in den ermittelten Werten von $M=85 \pm 20 \%\left(M_{\max }=98 \%, M_{\min }=41 \%\right)$ für den mobilen Anteil und $I_{\text {Bleich }}=51 \pm 8 \%$ $\left(I_{\text {Bleich,max }}=67 \%, I_{\text {Bleich,min }}=45 \%\right)$ für die Intensität nach dem Bleichen bezogen auf die Ausgangsintensität wider. Während der mobile Anteil und die Intensität nach dem Bleichen leicht stiegen, verringerten sich die Fehler beider Werte drastisch. Eine Zusammenfassung der Ergebnisse für die Charakterisierung porenüberspannender painted membranes vor und nach dem Ausfrieren des Lösungsmittels ist in Tabelle 4.1 aufgeführt. 


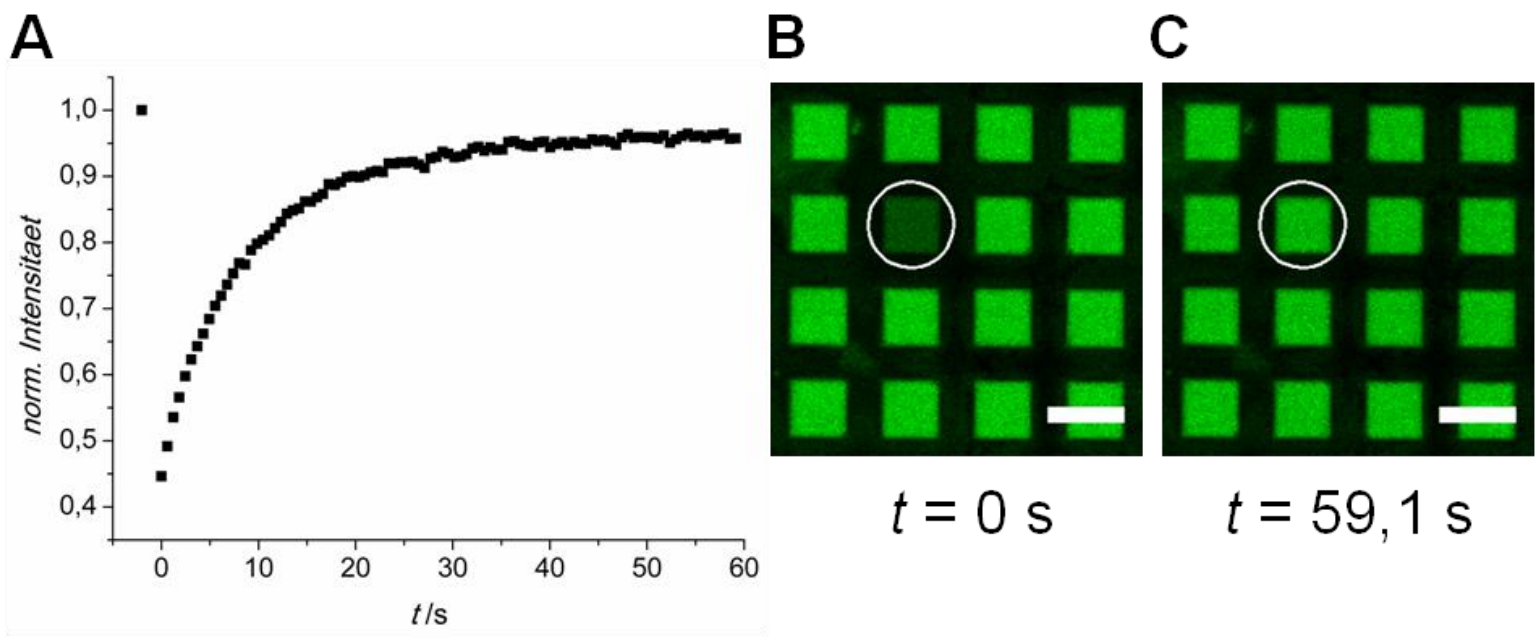

Abb. 4.4: A Intensitätsverlauf eines FRAP-Experiments an einem porösen Siliziumsubstrat $\left(8 \cdot 8 \cdot 12 \mu \mathrm{m}^{3}\right) \mathrm{mit}^{\mathrm{m}}$ einer per painting-Technik präparierten porenüberspannenden Membran nach Ausfrieren des Lösungsmittels (DPhPC/DPPA/Bodipy PC, 89,8:10,0:0,2). Pufferlösung: $160 \mathrm{mM} \mathrm{KCl,} 10 \mathrm{mM}$ MOPS, pH 7,3 (KOH). B und C zeigen die zugehörigen Fluoreszenzaufnahmen bei $t=0 \mathrm{~s}$ (unmittelbar nach dem Bleichen) und $t=59,1 \mathrm{~s}$ (Ende der Zeitserie). Maßstabsbalken $10 \mu \mathrm{m}$. Gebleicht wurde der in weiß eingezeichnete Bereich, dessen Intensitätsverlauf in A in normierter Form aufgetragen ist. Es ergibt sich ein mobiler Anteil von $M=94 \%$.

Tabelle 4.1: Vergleich der Ausdehnung der Membranfluoreszenz in Porenmitte und Porenrand in $z$-Richtung ( $\Delta z_{\text {Porenmitte }}, \Delta z_{\text {Porenrand }}$ ), der Tiefe, in welcher Membranen eine Pore überspannen $(z)$, sowie des mobilen Anteils $(M)$ und der Intensität nach Bleichen in Bezug auf die Ausgangsintensität ( $\left.I_{\text {Bleich }}\right)$ je mit Maximal- und Minimalwerten. Die Werte wurden ermittelt für porenüberspannende Membranen präpariert nach der paintingTechnik vor und nach Ausfrieren des Lösungsmittels. Die angegebenen Fehler entsprechen jeweils der Standardabweichung. Die Anzahl der berücksichtigten Experimente bzw. Aufnahmen ist als $N$ angegeben.

\begin{tabular}{|c|c|c|c|}
\hline & \multicolumn{2}{|c|}{ Vor solvent freeze-out } & Nach solvent freeze-out \\
\hline \multicolumn{4}{|l|}{ CLSM: } \\
\hline$\Delta z_{\text {Porenmitte }} / \mu \mathrm{m}$ & \multirow{2}{*}{\multicolumn{2}{|c|}{$+2,6$ bis $-4,4$}} & \pm 0 bis $-2,6$ \\
\hline$\Delta z_{\text {Porenrand }} / \mu \mathrm{m}$ & & & \pm 0 bis $-4,4$ \\
\hline SICM: & $N=6$ & $N=2(9$ Poren $)$ & $N=20(103$ Poren $)$ \\
\hline$z / \mu \mathrm{m}$ & $<0,05$ & $0,22 \pm 0,03$ & $1,60 \pm 1,14$ \\
\hline FRAP: & \multicolumn{2}{|c|}{$N=6$} & $N=7$ \\
\hline$M / \%\left(M_{\max }, M_{\min }\right)$ & \multicolumn{2}{|c|}{$65 \pm 40(97,7)$} & $85 \pm 20(98,41)$ \\
\hline$I_{\text {Bleich }} 1 \%\left(I_{\text {Bleich,max }}, I_{\text {Bleich,min }}\right)$ & \multicolumn{2}{|c|}{$44 \pm 19(73,24)$} & $51 \pm 8(67,45)$ \\
\hline
\end{tabular}




\section{Farbstoffeinschluss}

Nachdem erste Ergebnisse gezeigt hatten, dass sich durch Auftragen eines Lipid-Lösungsmittelgemisches porenüberspannende Membranen erzeugen ließen und durch Ausfrieren der Gehalt remanenten Lösungsmittels reduziert werden konnte, wurde untersucht, ob sich diese Membranen zur Abgrenzung eines wässrigen Volumens im Poreninneren gegenüber der überstehenden Lösung eignen. Hierzu wurde der wasserlösliche, pH-sensitive Fluoreszenzfarbstoff Pyranin in den Poren eingeschlossen und die Membranen nach Tausch der überstehenden Pufferlösung gegen pyraninfreien Puffer auf ihre Dichtigkeit getestet. Um die Pyraninfluoreszenz spektral von der Membranfluoreszenz abheben zu können, wurde statt des im gleichen Bereich emittierenden Bodipy PC im Folgenden der Fluorophor Texas Red DHPE zur Markierung der Membran eingesetzt. In Abb. 4.5, A ist eine konfokalmikroskopische Aufnahme porenüberspannender Membranen dargestellt, welche in Gegenwart von Pyranin mit Hilfe der painting-Technik gebildet worden waren. Dabei lässt sich erkennen, dass sich die grüne Fluoreszenz des wasserlöslichen Farbstoffs Pyranin nach Bildung der Membranen und anschließendem Spülen nur auf das Volumen im Poreninneren beschränkt. Die Ortho-Darstellung zeigt, dass der Farbstoff Texas Red DHPE im Gegensatz zum bisher verwendeten Bodipy PC (Abb. 4.3, A) nur am Porenrand detektiert werden kann, während der Bereich in der Porenmitte unmarkiert erscheint. Dass die abgebildeten Poren dennoch mit einer Membran überspannt sind, lässt sich aus der Tatsache ableiten, dass der wasserlösliche Farbstoff Pyranin auch nach wiederholtem Spülen der überstehenden Pufferlösung noch in den Poren detektiert werden kann.

In Abb. 4.5, B ist die Verteilung der Membranfluoreszenz (rot), sowie der Pyraninfluoreszenz (grün) in $z$-Richtung exemplarisch für eine der Poren dargestellt. Die Intensität der membranständigen Texas Red DHPE Fluoreszenz ist etwa Faktor sechs geringer, als die der Pyraninfluoreszenz, da die Intensität über die gesamte Porenfläche ausgelesen wurde, sich die Texas Red DHPE Fluoreszenz jedoch wie in Abb. 4.5, A zu erkennen im Wesentlichen auf den Randbereich der Poren beschränkt. Dennoch lässt sich mit hohem Bestimmtheitsmaß $\left(R^{2}=0,989\right)$ eine Gauss-Funktion anpassen, welche ein Maximum bei $z=-0,87 \mu \mathrm{m}$ und eine Halbwertsbreite (full width at half maximum, FWHM) von $F W H M=2,7 \mu \mathrm{m}$ aufweist. Die Membranfluoreszenz beschränkt sich demnach auf einen in $z$-Richtung rund 2,7 $\mu \mathrm{m}$ weiten Bereich mit Zentrum bei $-0,87 \mu \mathrm{m}$ unterhalb der Substratoberfläche. Die Pyraninfluoreszenz wird über einen weiteren Bereich in $z$-Richtung detektiert. Der Maximalwert für die Intensität der Pyraninfluoreszenz liegt etwa bei $z=-3,0 \mu \mathrm{m}$. Im Gegensatz zur Texas Red DHPE Fluoreszenz wurde an die Verteilung der Pyraninfluoreszenz keine Gauss-Funktion angepasst. Eine Abnahme der Fluoreszenzintensität in größerer Porentiefe ist aufgrund der limitierten Eindringtiefe des Lichtes (Tabelle 3.6) zu erwarten. Das Maximum der Pyraninfluoreszenz fällt in $z$-Richtung auf einen Bereich rund $2 \mu \mathrm{m}$ unterhalb des Maximums der Texas Red DHPE Fluoreszenz. Pyranin wird demnach nur im Poreninneren unterhalb der porenüberspan- 
nenden Membran detektiert. Das hohe Bestimmtheitsmaß der angepassten Gauss-Funktion bei einem Unterschied der Maxima beider Fluoreszenzsignale von $\Delta z=2,1 \mu \mathrm{m}$ erlaubt eine klare Differenzierung zwischen Membranfluoreszenz und der Fluoreszenz eingeschlossenen Farbstoffs. Es lässt sich weiterhin feststellen, dass die Pyraninfluoreszenz über einen größeren Bereich in $z$-Richtung detektiert werden kann, als diejenige der mit Texas Red DHPE markierten Membran. Einmal eingeschlossen, konnte die Pyraninfluoreszenz über Tage ohne merklichen Intensitätsabfall im Poreninneren beobachtet werden.

Der Verlauf der Fluoreszenzintensitäten in z-Richtung entlang einer einzelnen pyraningefüllten und membranüberspannten Pore ist in Abb.4.5, C dargestellt. Eine OrthoDarstellung in $y$-z-Ebene einer konfokalmikroskopischen Aufnahme und die maßstabsgetreue Darstellung des Verlaufs der Pyranin- und Texas Red DHPE Fluoreszenzintensität in einer ROI innerhalb der Porenfläche verdeutlichen den Einschluss von Pyranin unter der porenüberspannenden Membran im Poreninneren.

Um zu überprüfen, ob die einzelnen Poren des Substrates durch die Bildung porenüberspannender painted membranes und anschließendem Ausfrieren des Lösungsmittels voneinander abgetrennt werden konnten, wurde der eingeschlossene Farbstoff in einer Pore durch einen starken Laserpuls gebleicht. Bei einer Verbindung zwischen dem Volumen der Pore und demjenigen umliegender Poren würde ein Austausch zwischen gebleichtem und umliegendem ungebleichten Farbstoff möglich sein. Dadurch würde die Fluoreszenzintensität im Innern der gebleichten Pore im Verlauf einer Zeitserie wieder ansteigen. In Abb. 4.5, D ist der zeitliche Verlauf der Pyraninintensität einer gebleichten Pore im Rahmen eines solchen Experiments dargestellt. Die Fluoreszenz wurde auf den Wert der Ausgangsintensität normiert. Nach laserinduziertem Löschen der Pyraninfluoreszenz einer Einzelpore blieb der Intensitätswert über einen Zeitraum von 31 min unverändert. Eine konfokalmikroskopische Aufnahme der Probe vor dem Bleichen ( $t=0 \mathrm{~min})$ und am Ende der Zeitserie $(t=31 \mathrm{~min})$ ist oberhalb des zeitlichen Verlaufs in Abb. 4.5, D abgebildet. Der gebleichte Bereich ist dabei durch einen weißen Kreis markiert. Aufgrund dieses Befundes kann davon ausgegangen werden, dass die wässrigen Kompartimente innerhalb überspannter Poren räumlich voneinander isoliert sind. 
A

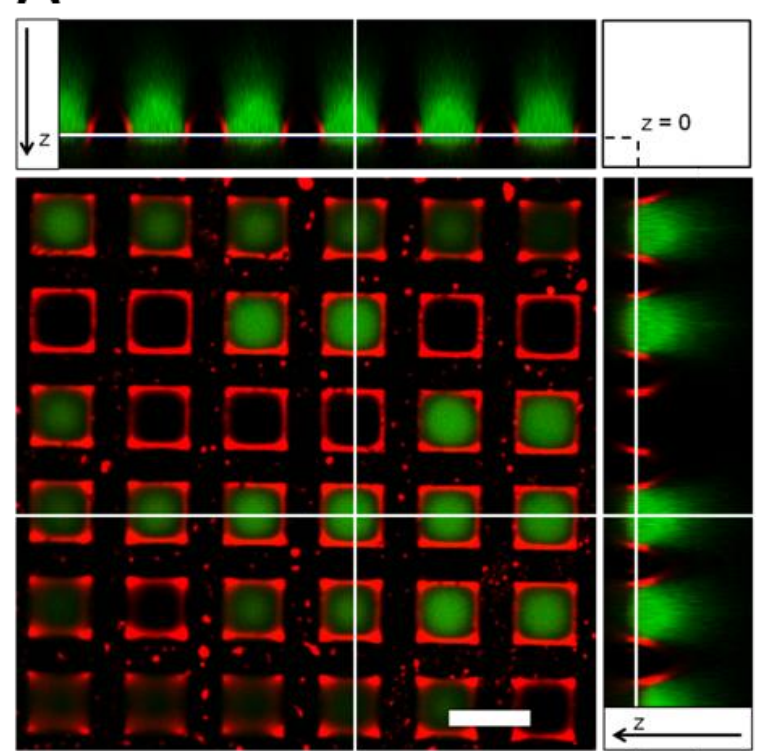

B

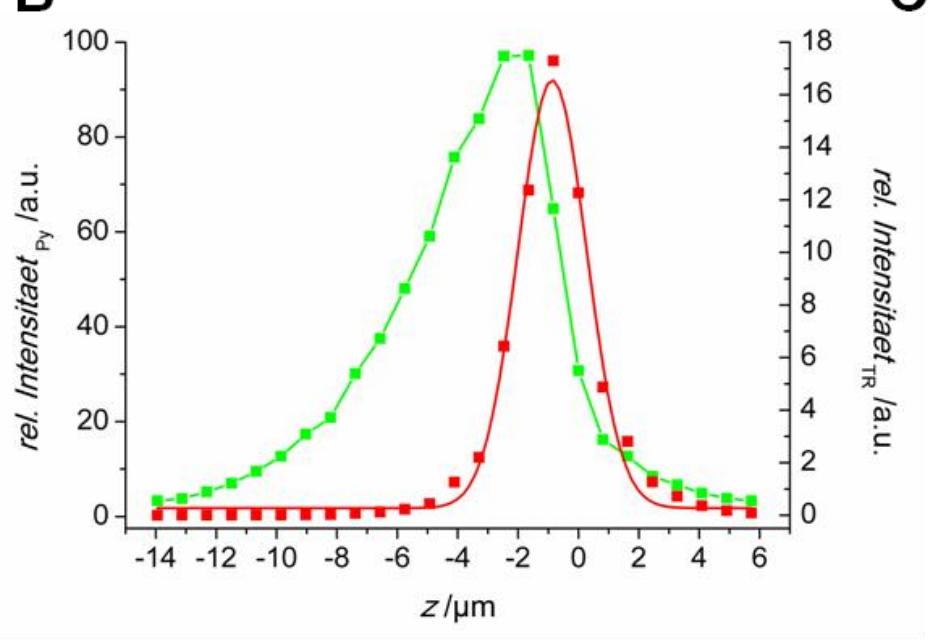

D

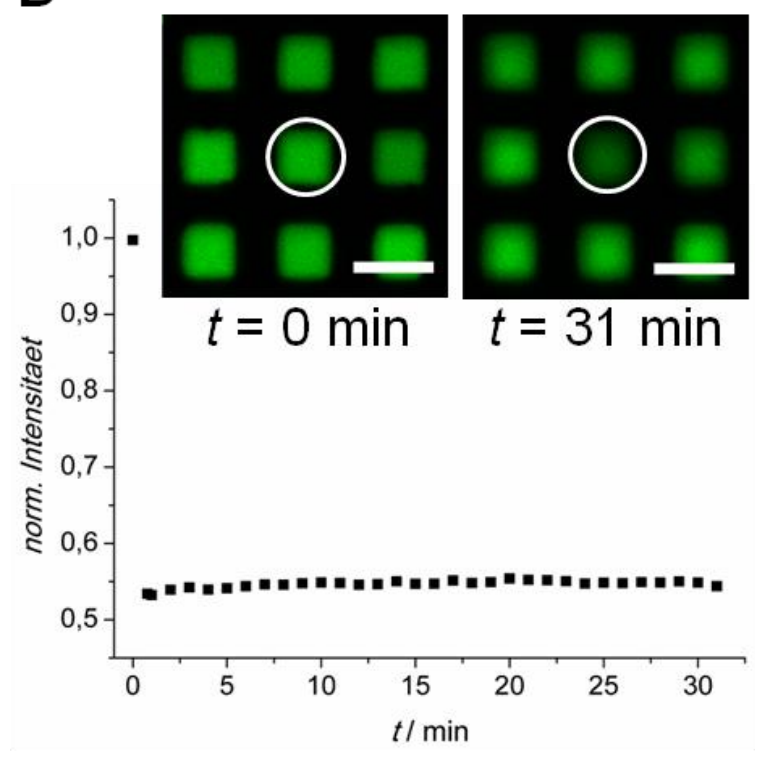

C

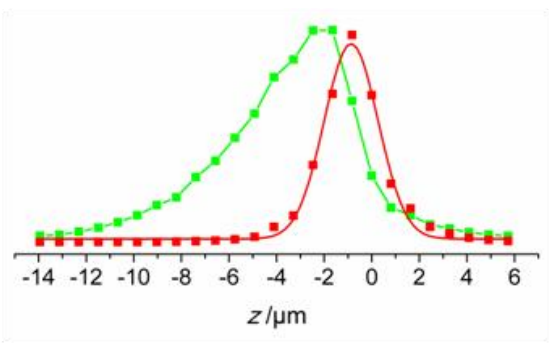

Abb. 4.5: A Ortho-Darstellung einer dreidimensionalen, konfokalmikroskopischen Aufnahme eines porösen Siliziumsubstrates $\left(8 \cdot 8 \cdot 12 \mu \mathrm{m}^{3}\right)$ mit einer per painting-Technik präparierten porenüberspannenden Membran nach Ausfrieren des Lösungsmittels (DPhPC/DPPA/Texas Red DHPE, 89,8:10,0:0,2, rot). Maßstabsbalken $10 \mu \mathrm{m}$, z-Dimension: 18,1 $\mu \mathrm{m}$ (23 Einzelbilder). Pufferlösung: $160 \mathrm{mM} \mathrm{KCl,} 10 \mathrm{mM}$ MOPS, 0,5 mM Pyranin (grün), pH 7,3 (KOH). B Intensitätsverlauf der Texas Red DHPE Fluoreszenz der Membran (rot, rechte Achse) und der Pyraninfluoreszenz unterhalb der Membran (grün, linke Achse) einer überspannten Pore. An den Verlauf der Texas Red DHPE Fluoreszenz ist eine Gauss-Funktion angepasst worden, wobei sich ein Maximum bei $z=-0,87 \mu \mathrm{m}$ und eine Halbwertsbreite von $F W H M=2,7 \mu \mathrm{m}$ ergab. C Ortho-Darstellung in $y$ - $z$-Ebene einer dreidimensionalen, konfokalmikroskopischen Aufnahme einer einzelnen Pore (Porenmaße, Membranzusammensetzung und Pufferlösung wie in A). Unterhalb der Fluoreszenzaufnahme ist der Verlauf von Pyranin- (grün) und Texas Red DHPE (rot, mit angepasster Gauss-Funktion) Intensität innerhalb der durch ein weiß gestricheltes Rechteck markierten ROI dargestellt (siehe B). Für eine bessere Übersichtlichkeit wurde auf eine Darstellung der $y$-Achsen verzichtet. Die Skalierung der $z$-Achse gilt ebenfalls für die Fluoreszenzaufnahme. D Verlauf der Fluoreszenzintensität von in einer Pore eingeschlossenem Pyranin nach Bleichen $\left(\lambda_{\text {Bleich }}=405 \mathrm{~nm}, 100 \%\right.$ Laserleistung). Die entsprechenden Fluoreszenzaufnahmen vor dem Bleichen $(t=0 \mathrm{~min})$ und am Ende der Zeitserie $(t=31 \mathrm{~min})$ sind über dem Verlauf eingefügt. Die gebleichte ROI ist in weiß dargestellt, Maßstabsbalken $10 \mu \mathrm{m}$. Die Probe ist dieselbe, wie in A. 


\subsubsection{Lösungsmittelfreie porenüberspannende Membranen}

Um eine vollständig lösungsmittelfreie Präparation von Membranen und dadurch eine funktionelle Rekonstitution lösungsmittelempfindlicher, membranständiger Proteine zu ermöglichen, wurde ein Protokoll entwickelt zur Bildung porenüberspannender Membranen durch Spreiten mikrometergroßer unilamellarer Vesikel (GUVs). Dazu wurden verschiedene Typen der Funktionalisierung poröser Substrate und das Spreitverhalten von GUVs darauf untersucht. Im Rahmen dieser Arbeit wurden hauptsächlich Experimente an Poren mit geschlossenen Böden $(h=9 \mu \mathrm{m})$ und Porendurchmessern im Bereich von $3,5 \mu \mathrm{m} \leq d \leq 5,5 \mu \mathrm{m}$ durchgeführt. Um hier entwickelte Protokolle mit Ergebnissen für poröse Substrate anderer Geometrie besser vergleichen zu können, wurden teilweise auch Substrate mit offenen Poren ohne Böden mit Durchmessern von $d=2 \mu \mathrm{m}$ verwendet.

\section{Größenverteilung der GUVS}

Für alle im Folgenden beschriebenen Funktionalisierungen wurden GUVs gespreitet, um lösungsmittelfreie planare Membranen zu bilden. GUVs wurden durch Elektroformation rehydratisierter Lipidfilme gebildet (Kapitel 3.2.5). Dabei bildeten sich Vesikel mit einer mehreren zehn Mikrometer breiten Größenverteilung. Um die Größe der gebildeten GUVs mit der Porengröße der Substrate vergleichen zu können, wurden GUVs auf einem planaren Siliziumwafer fixiert (Kapitel 3.2.6) und ihr Durchmesser anhand konfokalmikroskopischer Aufnahmen bestimmt. Eine Verteilung der ermittelten Vesikeldurchmesser ist in Abb. 4.6 aufgeführt. 


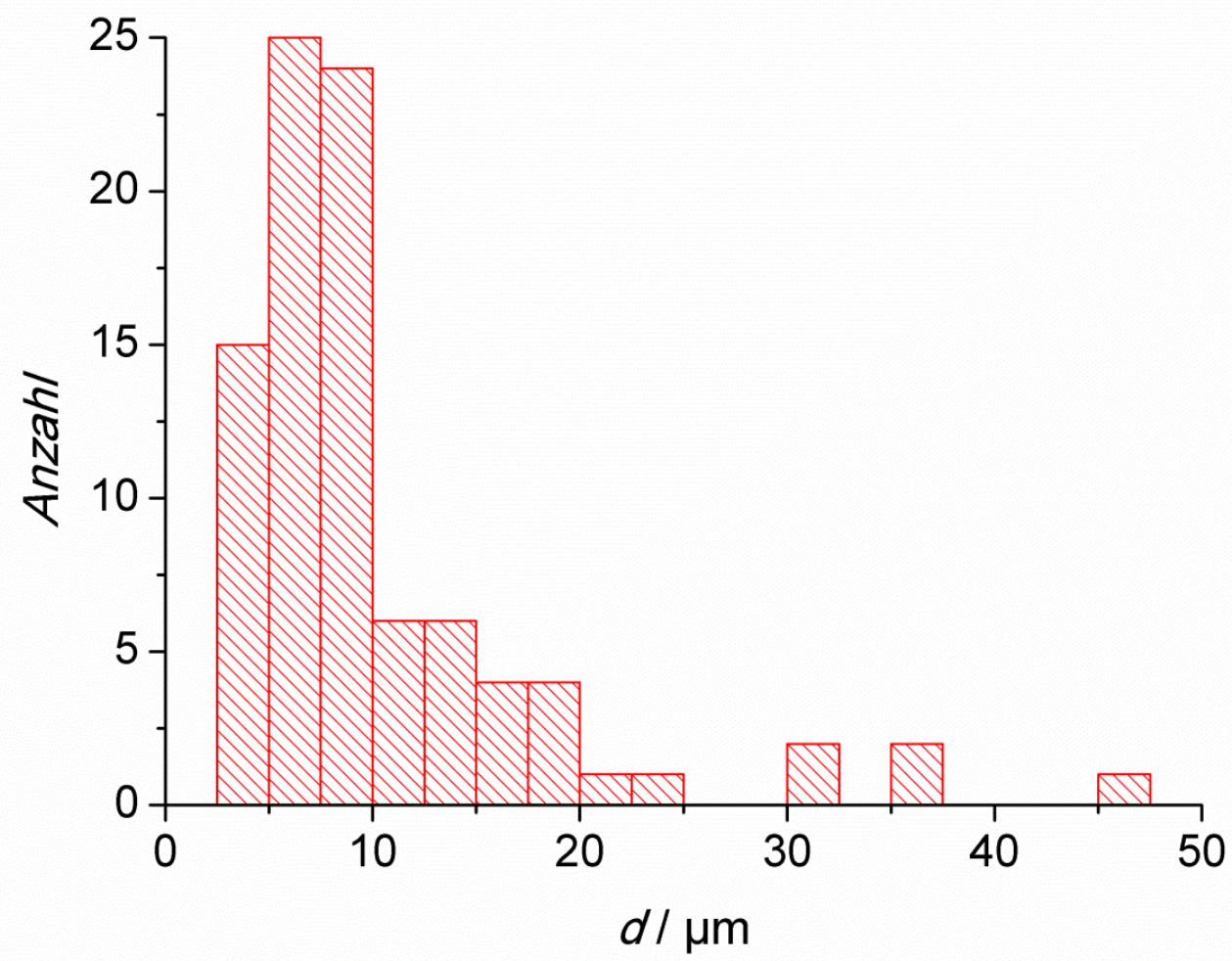

Abb. 4.6: Verteilung der Durchmesser von GUVs (DPhPC/DOPC/Bio-Cap-PE/Texas Red DHPE, 59,4:39,4:1,0:0,2). Die GUVs wurden unter Hochsalzbedingungen präpariert (Pufferlösung: $320 \mathrm{mM}$ Sucrose, $10 \mathrm{mM}$ MOPS, 0,5 mM Pyranin, pH 7,3 (TRIS)) und auf einem mit Avidin funktionalisierten planaren Siliziumsubstrat immobilisiert. Pufferlösung: $160 \mathrm{mM} \mathrm{KCl,} 10 \mathrm{mM}$ MOPS, pH 7,3 (KOH). Die Gesamtzahl der vermessenen GUVs beträgt $N=91$. Vesikel mit Durchmessern $d<2,5 \mu \mathrm{m}$ wurden nicht berücksichtigt.

Der Mittelwert aller gemessenen Durchmesser beträgt $d=10,3 \mu \mathrm{m}$. GUVs mit Durchmessern $d<2,5 \mu \mathrm{m}$ wurden nicht berücksichtigt. Die porösen Substrate, auf denen GUVs gespreitet wurden, wiesen Poren mit geschlossenen Böden und Durchmessern von $d=3,5,4,5$ und 5,5 $\mu \mathrm{m}$ auf. Aus der Größenverteilung der GUVs geht hervor, dass $78 \%$ der GUVs einen Durchmesser $d \geq 5,5 \mu \mathrm{m}$ besitzen. Für 4,5 $\mu \mathrm{m}$ sind es bereits $87 \%$ und für 3,5 $\mu \mathrm{m} 98 \%$ aller GUVs. Damit weist der Großteil der mittels Elektroformation gebildeten GUVs einen größeren Durchmesser auf, als die durch Spreiten zu überspannenden Poren, was für Poren mit Durchmessern bis $200 \mathrm{~nm}$ als Voraussetzung zur Bildung porenüberspannender Membranen bestimmt wurde. ${ }^{[52]}$

\section{Spreiten auf unfunktionalisierten porösen Substraten}

Für die Präparation lösungsmittelhaltiger porenüberspannender Membranen ist eine hydrophobe Funktionalisierung der Substratoberfläche in Form von auf einer Goldschicht chemisorbiertem CPEO3 verwendet worden. Lösungsmittelfreie Membranen, welche durch Vesikelspreiten generiert werden können, stellen eine Alternative zu diesem System dar und 
wurden bereits auf einer Vielzahl von Substraten erzeugt. So konnten Vesikel sowohl auf hydrophob funktionalisierten ${ }^{[186,187]}$ als auch auf hydrophil funktionalisierten Oberflächen ${ }^{[38,48]}$ und sogar auf völlig unfunktionalisiertem Siliziumdioxid ${ }^{[187,188]}$ gespreitet werden. Dementsprechend wurde zunächst auf unfunktionalisierten, geschlossenen Siliziumsubstraten gespreitet (runde Poren, Porendurchmesser 3,5 bis 5,5 $\mu \mathrm{m}$, Porosität 10 bis $40 \%$ ), welche mit einer Schicht aus Siliziumdioxid $(500 \mathrm{~nm})$ bedeckt waren. Eine dreidimensionale, konfokalmikroskopische Aufnahme eines Substrates nach Zugabe von GUVs und anschließendem Spülen ist in Abb. 4.7, A dargestellt. Da die Stegbereiche des Substrates nicht mit Gold funktionalisiert wurden, wird die Fluoreszenz dort nicht gelöscht und kann detektiert werden. Ein großer Teil des abgebildeten Substrates ist mit einer Lipidmembran bedeckt, wie die rote Texas Red DHPE Fluoreszenz zeigt. Im Randbereich einzelner Poren ist die Intensität der Texas Red DHPE Fluoreszenz deutlich erhöht, innerhalb der Porenfläche fällt die Intensität jedoch auf den für unbedeckte Bereiche detektierten Wert ab. Die $x, z-$ und $y, z$-Ebenen weisen eine Texas Red DHPE Fluoreszenz entlang der Porenränder für Bereiche von $-4 \mu \mathrm{m}<z<0 \mu \mathrm{m}$ auf. Auch hier ist keine Fluoreszenz im Zentrum der Poren erkennbar, welche auf eine Überspannung durch eine Membran hinweisen würde. Vielmehr scheinen die Poren durch die beim Spreiten der Vesikel gebildete Membran ausgekleidet und diese in ihrem Verlauf der Kontur der Substratoberfläche zu folgen. Diese Interpretation wird auch durch die Tatsache unterstützt, dass nach Zugabe von Pyranin $(0,5 \mathrm{mM})$ nach Spreiten der Vesikel dieses innerhalb der Poren mit gleicher Intensität wie oberhalb der Substratoberfläche detektiert werden konnte. In der Aufsicht in $x, y$-Ebene wurde die Pyraninfluoreszenz für eine bessere Übersichtlichkeit nicht dargestellt, in den beiden $z$-Ebenen ist jedoch zu erkennen, dass sich Pyranin gleichmäßig in den Poren wie in der überstehenden Lösung verteilt.

SICM-Aufnahmen unfunktionalisierter Poren nach dem Spreiten von GUVs zeigten eine Tiefe der Poren von $8 \mu \mathrm{m}$ (Abb. 4.7, B). Überspannte Poren wiesen bei Anwendung der painting-Technik nach Ausfrieren des Lösungsmittels Tiefen der Membran in den Poren von $z=-(1,60 \pm 1,14) \mu \mathrm{m}$ auf mit maximalen Tiefen von $-5,1 \mu \mathrm{m}$ (Kapitel 4.1.1). Demnach ließen sich keine überspannten Poren nach Spreiten von GUVs auf unfunktionalisierten Substraten mittels SICM abbilden. Die Tatsache, dass sich unfunktionalisierte Substrate mit hydrophiler $\mathrm{SiO}_{2}$-Oberfläche problemlos mittels $\mathrm{SICM}$ abbilden ließen, unterstützt die Hypothese der Auskleidung der Poren durch eine Membran. Unbedeckte Substrate mit Siliziumdioxidoberfläche ließen sich nur sehr schlecht mittels SICM abbilden, was auf starke Wechselwirkungen zwischen der aus Borsilikatglas bestehenden Spitze der Messsonde und der mit $\mathrm{SiO}_{2}$-Gruppen bedeckten Oberfläche zurückzuführen ist. Dies äußerte sich dadurch, dass bereits nach wenigen Sekunden während der Messung die Spitze beschädigt wurde und das Stromsignal über einen Wert von $20 \mathrm{nA}$ (entspricht dem Maximum bei den gewählten Verstärkungseinstellungen) anstieg, was zu einem Abbruch der Messung und einem Austausch der Spitze führte. 
Als weitere Methode zur Charakterisierung unfunktionalisierter Siliziumsubstrate mit geschlossenen Poren nach dem Spreiten von GUVs, wurden FRAP-Experimente durchgeführt (Abb. 4.7, C-E). Abb. 4.7 D und E zeigen die Fluoreszenz einer mit Bodipy PC dotierten Membran direkt nach dem Bleichen eines kreisförmigen Bereiches (weiß, D) und nach $t=120 \mathrm{~s}$ (E). Die Aufnahme unmittelbar nach dem Bleichen der ROI zeigt, dass sich der planare Stegbereich stärker bleichen lässt, als der runde Randbereich der vier zum Teil gebleichten Poren. Eine Auftragung der normierten Intensität der ROI (C) ergibt einen mobilen Anteil von $M=89 \%$, was vergleichbar ist mit porenüberspannenden painted membranes nach Ausfrieren des Lösungsmittels (Tabelle 4.1). Die Lipide sind demnach auch auf unfunktionalisierten Substraten in lösungsmittelfreien Membranen mobil. Für die charakteristische Diffusionszeit ergibt sich für den in $\mathrm{C}$ gezeigten Verlauf ein Wert von $\tau_{1 / 2}=20,8 \mathrm{~s}$. In einem FRAP-Experiment an derselben Probe, jedoch auf dem unporösen, planaren Randbereich des Substrates, wurden Werte von $M=87 \%$ und $\tau_{1 / 2}=10,6 \mathrm{~s}$ erhalten für eine ROI gleicher Größe. Die Lipide diffundieren dort also schneller bei praktisch gleichem mobilen Anteil. Dieses Diffusionsverhalten wird im Rahmen einer dreidimensionalen Diffusion entlang der Porenkanten näher unter Kapitel 5.1.2 diskutiert. 

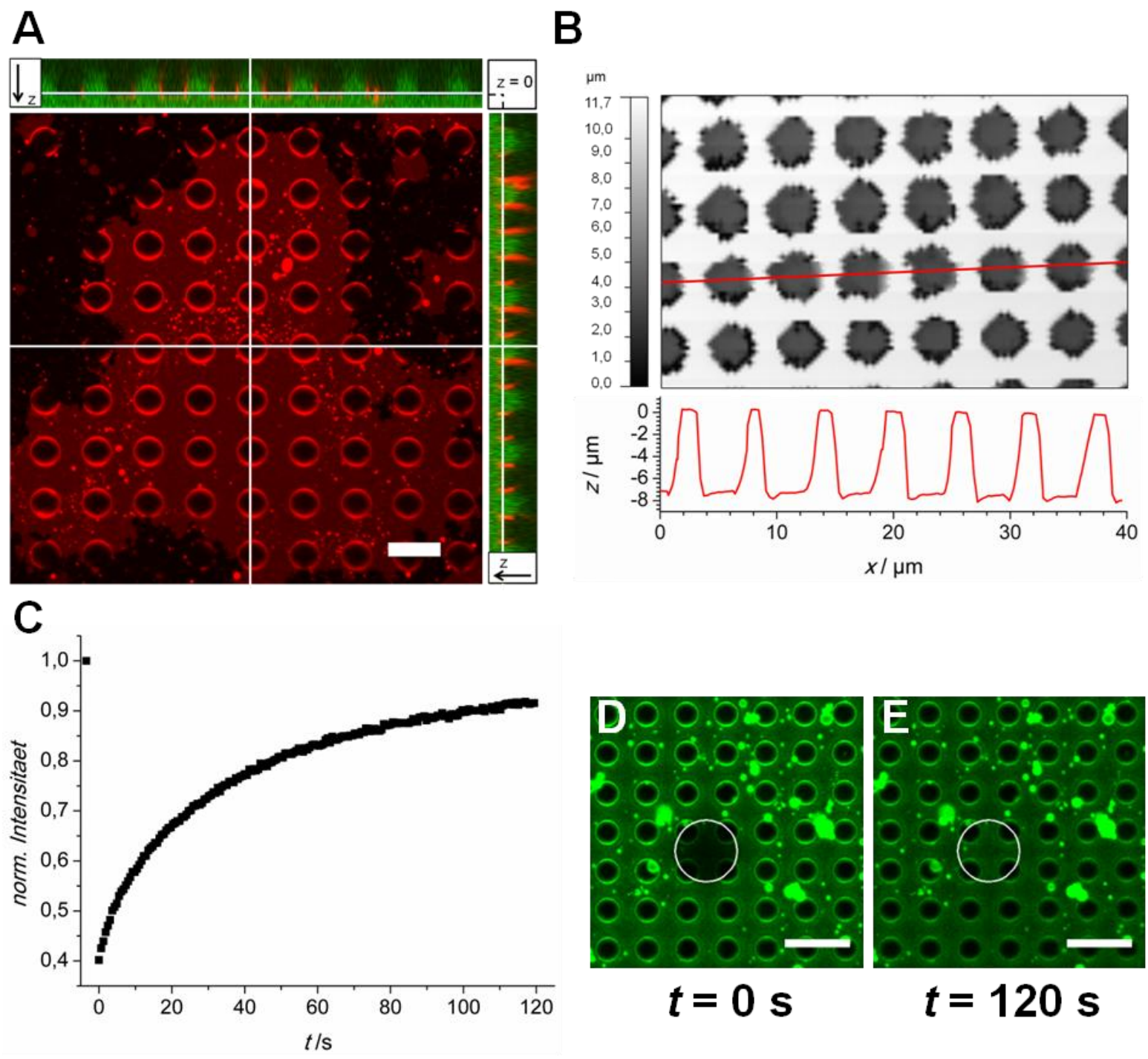

Abb. 4.7: A Ortho-Darstellung einer dreidimensionalen, konfokalmikroskopischen Aufnahme eines porösen Siliziumsubstrates $(d=5,5 \mu \mathrm{m}, h=9 \mu \mathrm{m})$ nach Spreiten von GUVs (POPC/POPS/Texas Red DHPE, 89,8:10,0:0,2, rot). Maßstabsbalken $10 \mu \mathrm{m}$, z-Dimension: 9,0 $\mu \mathrm{m}$ (10 Einzelbilder). Pufferlösung: $107 \mathrm{mM}$ $\mathrm{CaCl}_{2}, 10 \mathrm{mM}$ MOPS, pH 7,3 (TRIS). Nach Spreiten der GUVs und Spülen mit angegebener Pufferlösung, wurde Pyranin (grün, 0,5 mM) zugegeben. Zur besseren Übersichtlichkeit wurde die Pyraninfluoreszenz in der Aufsicht ( $x, y$-Ebene) ausgeblendet. B SICM-Aufnahme und Höhenprofil eines porösen Siliziumsubstrates ( $d=4,5 \mu \mathrm{m}, h=9 \mu \mathrm{m})$ nach Spreiten von GUVs (POPC/POPS/Texas Red DHPE, 89,8:10,0:0,2). Pufferlösung: $107 \mathrm{mM} \mathrm{CaCl}_{2}, 10 \mathrm{mM}$ MOPS, pH 7,3 (TRIS). Alle abgebildeten Poren weisen eine Tiefe von $8 \mu \mathrm{m}$ auf. Dunkel erscheinende Stellen am Porenrand sind ein Messartefakt und vermutlich auf eine anisotrope Spitzengeometrie zurückzuführen. C FRAP-Experiment an einem porösen Siliziumsubstrat $(d=3,5 \mu \mathrm{m}, h=9 \mu \mathrm{m})$ nach Spreiten von GUVs (DPhPC/DPPA/Bodipy PC, 89,5:10,0:0,5). Pufferlösung: $100 \mathrm{mM} \mathrm{KCl,} 20 \mathrm{mM}$ TRIS, 7,5 mM $\mathrm{CaCl}_{2}, \mathrm{pH} 7,4(\mathrm{HCl})$. D und $\mathbf{E}$ zeigen die zugehörigen Fluoreszenzaufnahmen bei $t=0 \mathrm{~s}$ (unmittelbar nach dem Bleichen) und $t=120 \mathrm{~s}$ (Ende der Zeitserie). Maßstabsbalken $10 \mu \mathrm{m}$. Gebleicht wurde der in weiß eingezeichnete Bereich, dessen Intensitätsverlauf auch in $\mathrm{C}$ in normierter Form aufgetragen ist. Es ergibt sich ein mobiler Anteil von $M=89 \%$. Alle gezeigten Substrate wurden vor Zugabe der GUVs für mindestens 5 min im Sauerstoffplasma behandelt. 
Spreiten auf hydrophob funktionalisierten porösen Substraten

Neben unfunktionalisierten Substraten wurden GUVs auch auf hydrophob funktionalisierten porösen Substrate gespreitet (Kapitel 3.2.8). Orth et al. beschreiben die Bildung porenüberspannender Membranen durch Spreiten von GUVs auf hydrophob (mit CPEO3) funktionalisierten Substraten mit offenen Poren bis $2 \mu \mathrm{m}$ Durchmesser. ${ }^{[172]}$ Im Rahmen dieser Arbeit wurde untersucht, inwiefern Membranen durch Spreiten von GUVs auf Poren mit geschlossenen Böden bis 5,5 $\mu \mathrm{m}$ Durchmesser und hydrophober Stegfunktionalisierung gebildet werden können. Experimente an porösen Substraten mit Geometrien, wie sie von Orth eingesetzt wurden, sollten denjenigen für geschlossene Poren vergleichend gegenübergestellt werden, um experimentelle Befunde vergleichen und richtig deuten zu können.

Dabei wurden gemäß Kapitel 3.2.11 vorgegangen. Zunächst wurden die Poren nicht mit $n$-Propanol benetzt, bevor die Messkammer mit Pufferlösung aufgefüllt wurde. Dadurch konnten bei Poren mit und ohne Porenböden weite Bereiche der Substratoberfläche mit porenüberspannenden Lipidschichten bedeckt werden (Abb. 4.8, A). Der hohe Grad der Belegung und die einheitliche Fluoreszenz über weite Teile des porösen Bereichs ähneln derjenigen, wie sie für porenüberspannende painted membranes erhalten worden war (Kapitel 4.1.1). Die $z$-stack Aufnahme zeigt, dass die Membranfluoreszenz bis zu $z=-1,8 \mu \mathrm{m}$ tief in den Poren detektiert werden kann. Dieser Wert stimmt gut mit dem für lösungsmittelhaltige porenüberspannende Membranen nach Ausfrieren des Lösungsmittels erhaltenen Wert von $z=-2,6 \mu \mathrm{m}$ überein (Abb. 4.3, A). Auffällig ist jedoch, dass keinerlei Pyraninfluoreszenz im Poreninneren detektiert werden konnte. Dies traf für alle Fälle zu, in denen eine porenüberspannende Membran fluoreszenzmikroskopisch nachgewiesen werden konnte. FRAP-Experimente an so präparierten, mit Bodipy PC dotierten Membranen auf geschlossenen Poren (rechteckige Geometrie, 2,6.3,3 $\mu \mathrm{m}^{2}$, etwa $4 \mu \mathrm{m}$ tief) lieferten einen mobilen Anteil von $M=88 \%(N=3)$ und zeigten so, dass die Lipide innerhalb der Membran mobil waren. Die Tatsache, dass kein Farbstoff (selbst vor Austausch der überstehenden Pufferlösung) im Poreninneren detektiert werden konnte, wurde näher untersucht, indem poröse Substrate vor Zugabe von GUVs per SICM abgebildet wurden. Eine Aufnahme von offenen Poren vor Zugabe von GUVs ist in Abb. 4.8, B dargestellt. Die Porenstruktur lässt sich deutlich erkennen, ein entsprechendes Höhenprofil zeigt eine Tiefe der leitenden Pufferlösung in den Poren von nur etwa $z=-120 \mathrm{~nm}$. Da diese Aufnahme vor Zugabe von GUVs erfolgte und fluoreszenzmikroskopische Aufnahmen keine Fluoreszenz im Porenbereich zeigten, kann es sich bei der in dieser Tiefe detektierten Grenzschicht um keine Membran handeln. Statt dessen kann die nicht-leitende Schicht Luft sein, welche aufgrund der hydrophoben Funktionalisierung der Poren im Poreninneren eingeschlossen wurde. Dies würde auch erklären, warum keine Pyraninfluoreszenz unterhalb der Membran detektierbar ist. Höhenprofile mit Grenzflächen in den Poren bei Tiefen von wenigen hundert Nanometern fanden sich bei allen untersuchten Substraten wieder. 


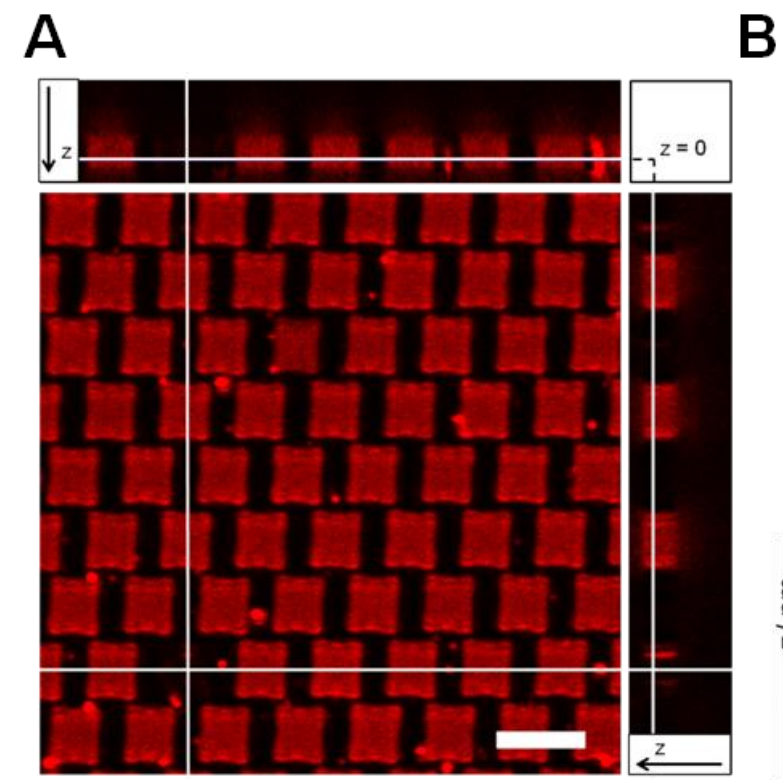

B

C

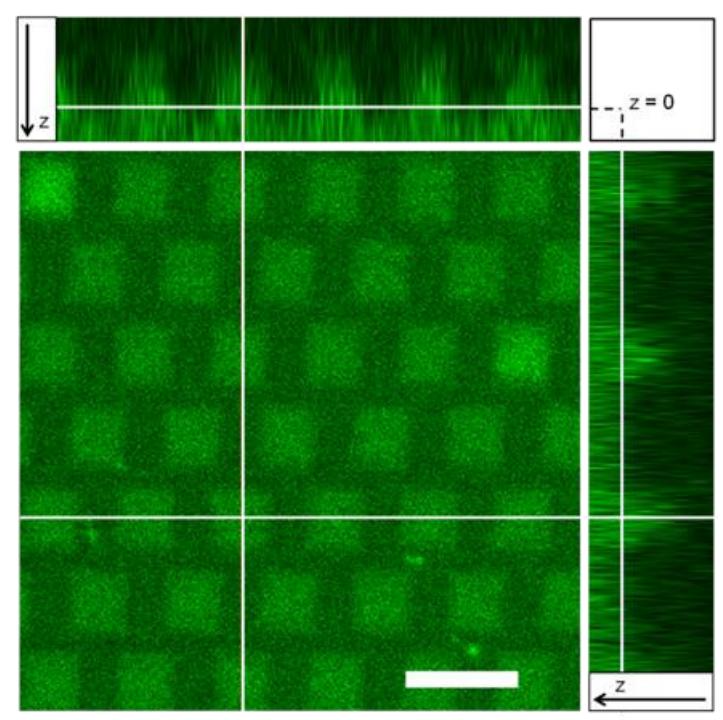

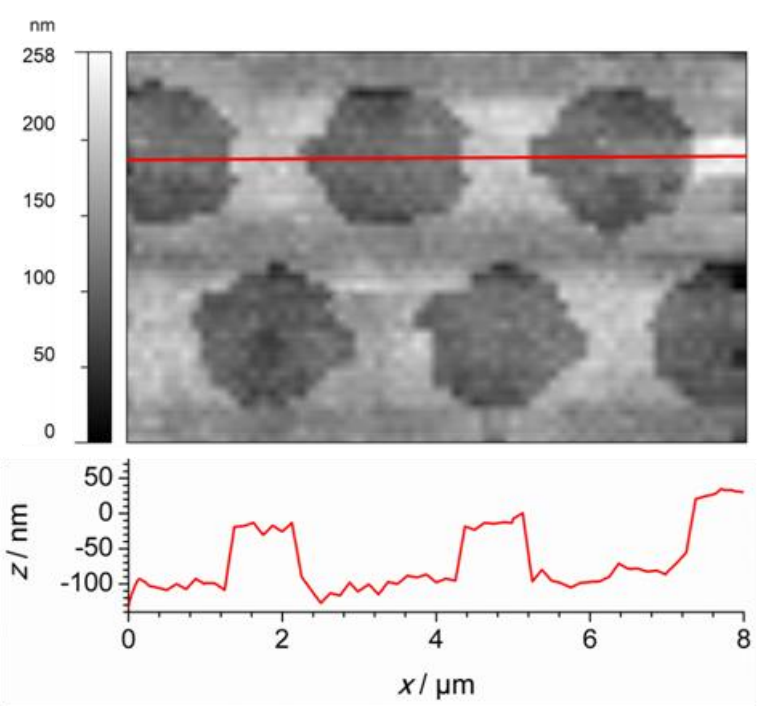

D

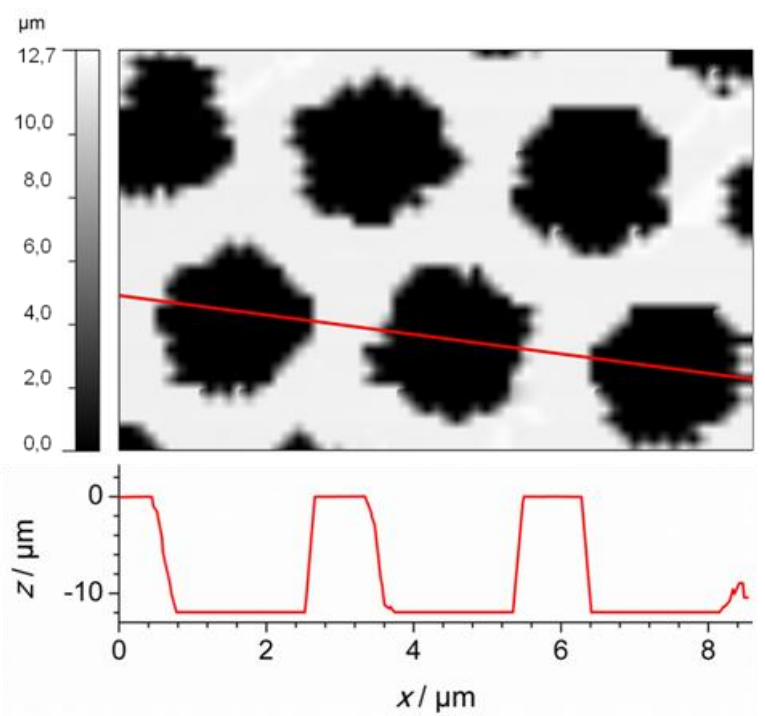

Abb. 4.8: A Ortho-Darstellung einer dreidimensionalen, konfokalmikroskopischen Aufnahme eines porösen Siliziumsubstrates $\left(2,6 \cdot 3,3 \cdot 4 \mu^{3}\right.$ ) nach Spreiten von GUVs (POPC/Texas Red DHPE, 99,8:0,2, rot; präpariert in $100 \mathrm{mM} \mathrm{KCl}, 100 \mathrm{mM}$ Sucrose, $20 \mathrm{mM}$ TRIS, $1 \mathrm{mM} \mathrm{CaCl}$, pH 7,4 ( $\mathrm{HCl}$ ) nach Hochfrequenz-Methode). Maßstabsbalken $5 \mu \mathrm{m}$, z-Dimension: 5,7 $\mu \mathrm{m}$ (30 Einzelbilder). Pufferlösung: $100 \mathrm{mM} \mathrm{KCl,} 100 \mathrm{mM}$ Glucose, $20 \mathrm{mM}$ TRIS, $1 \mathrm{mM} \mathrm{CaCl}$, 0,2 mM Pyranin (grün), pH 7,4 ( $\mathrm{HCl}$ ). B SICM-Aufnahme und Höhenprofil eines porösen Siliziumsubstrates $(d=2,0 \mu \mathrm{m}$, offene Poren) nach Spreiten von GUVs (DPhPC/DOPC/Texas Red DHPE, 59,9:40,0:0,1; präpariert in $2 \mathrm{mM} \mathrm{KCl,} 1 \mathrm{mM}$ MOPS, pH 7,4 (TRIS)). Pufferlösung: $2 \mathrm{mM} \mathrm{KCl,} 1 \mathrm{mM}$ MOPS, pH 7,4 (TRIS). Alle abgebildeten Poren weisen eine Tiefe von ca. $120 \mathrm{~nm}$ auf. Die Proben aus A und B wurden vor Zugabe der GUVs nicht mit $n$-Propanol benetzt. C Ortho-Darstellung einer dreidimensionalen, konfokalmikroskopischen Aufnahme eines porösen Siliziumsubstrates $\left(2,6 \cdot 3,3 \cdot 4 \mu \mathrm{m}^{3}\right)$ nach Spreiten von GUVs (DPhPC/DOPC/Texas Red DHPE, 59,9:40,0:0,1, rot; präpariert in $2 \mathrm{mM} \mathrm{KCl,} 1 \mathrm{mM}$ MOPS, pH 7,4 (TRIS)). Maßstabsbalken $5 \mu \mathrm{m}$, $z$-Dimension: 5,5 $\mu \mathrm{m}$ (8 Einzelbilder). Pufferlösung: $2 \mathrm{mM} \mathrm{KCl,} 1 \mathrm{mM}$ MOPS, 0,5 mM Pyranin (grün), pH 7,4 (TRIS). D SICM-Aufnahme und Höhenprofil eines porösen Siliziumsubstrates ( $d=2,0 \mu \mathrm{m}$, offene Poren) nach Spreiten von GUVs (DPhPC/DOPC/Texas Red DHPE, 59,9:40,0:0,1; präpariert in $2 \mathrm{mM} \mathrm{KCl}, 1 \mathrm{mM}$ MOPS, pH 7,4 (TRIS)). Pufferlösung: $100 \mathrm{mM} \mathrm{KCl,} 20 \mathrm{mM}$ TRIS, $1 \mathrm{mM} \mathrm{CaCl}, \mathrm{pH}_{7,4}$ (TRIS). Alle abgebildeten Poren weisen eine Tiefe von $12 \mu \mathrm{m}$ auf (maximale Auslenkung der Pipettenspitze in $z$-Richtung). Die Proben aus C und D wurden vor Zugabe der GUVs mit $n$-Propanol benetzt. 
Vergleichsexperimente an Substraten mit offenen Poren ohne Böden $(d=2 \mu \mathrm{m})$, analog zu denen, wie sie von Orth et al. in ihrer Studie eingesetzt wurden, ${ }^{[172]}$ wiesen ebenso Grenzflächen in wenigen hundert Nanometer Tiefe auf, wie Poren mit geschlossenen Böden $(d=3,5-5,5 \mu \mathrm{m})$. Es ist demnach davon auszugehen, dass ohne entsprechende Benetzung der Poren mit $n$-Propanol vor Zugabe der wässrigen Pufferlösung sowohl in Poren mit offenen als auch mit geschlossenen Böden bei hydrophober Funktionalisierung Luft im Poreninneren eingeschlossen wird.

Ein anderes Bild ergab sich, wenn die hydrophob funktionalisierten Poren vor Zugabe einer pyraninhaltigen Pufferlösung mit $n$-Propanol benetzt worden waren. Ein z-stack so präparierter Poren nach Zugabe von GUVs ist in Abb. 4.8, C gezeigt. Während keine Texas Red DHPE Fluoreszenz (Membranfarbstoff) zu erkennen ist, weisen alle Poren eine Pyraninfluoreszenz bis zu einer Tiefe von $z=-2,3 \mu \mathrm{m}$ auf. Konnte der wasserlösliche Farbstoff in den Poren detektiert werden, so ließ sich durch GUV-Zugabe keine porenüberspannende Membran ausbilden. In SICM-Aufnahmen von mit $n$-Propanol benetzten und puffergefüllten Substraten konnte keine Grenzschicht zwischen Stegbereich und Porenboden (bzw. für offene Poren der maximalen Piezoauslenkung in $z$-Richtung) detektiert werden. Eine Aufnahme offener Poren ist in Abb. 4.8, D gezeigt. Die Poren heben sich deutlich vom Stegbereich ab und bis zu einer Tiefe von $z=-12 \mu \mathrm{m}$, was hier der maximalen $z$-Auslenkung der Pipettenspitze entspricht, wird keine Grenzschicht in Form von Luft oder einer Membran detektiert.

Waren Poren einmal mit $n$-Propanol benetzt und anschließend mit Pufferlösung gefüllt worden, so ließen sich durch Aufbringen von Luft mittels einer Pipette sehr einfach große Teile des Substrates erneut mit Luft füllen. Nach Blasenerzeugung in der überstehenden Pufferlösung waren geschlossene Poren nicht länger mit Fluoreszenzfarbstoff gefüllt und anschließend applizierte GUVs spreiteten sofort unter Bildung porenüberspannender Lipidmono- oder doppelschichten (eine nähere Diskussion der Struktur der porenüberspannenden Lipidschichten folgt unter Kapitel 5.1.2).

Zusammengefasst zeigten hydrophob funktionalisierte, poröse Substrate Lufteinschlüsse. Diese erlaubten die Bildung porenüberspannender Lipidschichten mit mobilen Lipiden, jedoch keinen Farbstoffeinschluss im Poreninneren. Lufteinschlüsse ließen sich durch Benetzung der Poren mit $n$-Propanol vermeiden. Dann war der Einschluss wasserlöslichen Farbstoffs möglich, es bildeten sich jedoch keine Lipidschichten bei Zugabe von GUVs aus.

Vergleichsexperimente an offenen Poren mit Durchmessern bis $2 \mu \mathrm{m}$ wiesen ohne Benetzung der Poren mit $n$-Propanol und anschließendem Spülen mit wässriger Pufferlösung ebenso Lufteinschlüsse auf, wie Poren mit geschlossenen Böden. Für offene Poren auf Siliziumbasis mit Durchmessern von bis zu $2 \mu \mathrm{m}$ konnten nach erfolgreicher Benetzung der hydrophob funktionalisierten Poren durch Optimierung der Goldbeschichtung schließlich porenüberspannende Membranen präpariert werden. Gleisner und Kuhlmann konnten durch elektronen- 
mikroskopische Aufnahmen beschichteter Substrate zeigen, dass die aufgebrachte Goldschicht die Poreninnenwände zum Teil auskleidete und die Bildung porenüberspannender Membranen verhinderte. ${ }^{[99]}$ Durch Aufbringen einer durchgängigen, homogenen Goldschicht von etwa $30 \mathrm{~nm}$ Dicke konnte die Goldbeschichtung der Poreninnenwände unterbunden und so die Bildung porenüberspannender Membranen durch Spreiten von GUVs forciert werden. ${ }^{[172]}$ Der Einfluss der Goldbeschichtung des Stegbereichs auf die Bildung porenüberspannender Membranen wird näher im Kapitel 5.1.2 (Spreiten auf hydrophob funktionalisierten Substraten) diskutiert. Eine konfokalmikroskopische Aufnahme eines CPEO3 funktionalisierten, mit Pufferlösung benetzten Substrates mit offenen Poren nach Zugabe von GUVs ist in Abb. 4.9, A und B gezeigt. Das Substrat wurde in Aufnahme A leicht schräg fixiert, sodass im linken Teil des Bildes $\left(z_{\text {fokal }}>0 \mu \mathrm{m}\right)$ GUVs mit vollem Durchmesser abgebildet sind und im rechten, tiefer gelegenen Teil des Bildes $\left(z_{\text {fokal }}=0 \mu \mathrm{m}\right)$ die Substratoberfläche abgebildet ist. Im linken Teil des Bildes bedecken GUVs einen Großteil der Substratoberfläche. Im rechten Teil bilden die GUVs kleine Kontaktflächen zum Substrat (ringförmige Fluoreszenzmuster). Nach wenigen Minuten wurde die Probe vorsichtig mit Pufferlösung gespült, woraufhin sich zeigte, dass Teile des Substrates mit einer porenüberspannenden Membran bedeckt waren (Abb. 4.9, B).

Eine hydrophobe Funktionalisierung poröser Substrate mit geschlossenen Porenböden wies nach Zugabe von GUVs gleicher Zusammensetzung vergleichbar große Kontaktflächen der Vesikel zum Substrat auf (Abb.4.9, C und D). Fluoreszenzmikroskopische Aufnahmen zeigen GUVs in vergleichbarer Anzahl und Größe auf dem Substrat (C). Die Kontaktflächen sind durch ringförmige Fluoreszenzmuster in Abbildung $\mathrm{D} \mathrm{zu}$ erkennen. Trotz dieser analogen Beobachtungen, ließ sich in keinem Fall nach Spülen der Substrate eine porenüberspannende Membran, wie sie für offen Poren häufig gefunden werden konnten, nachweisen. 

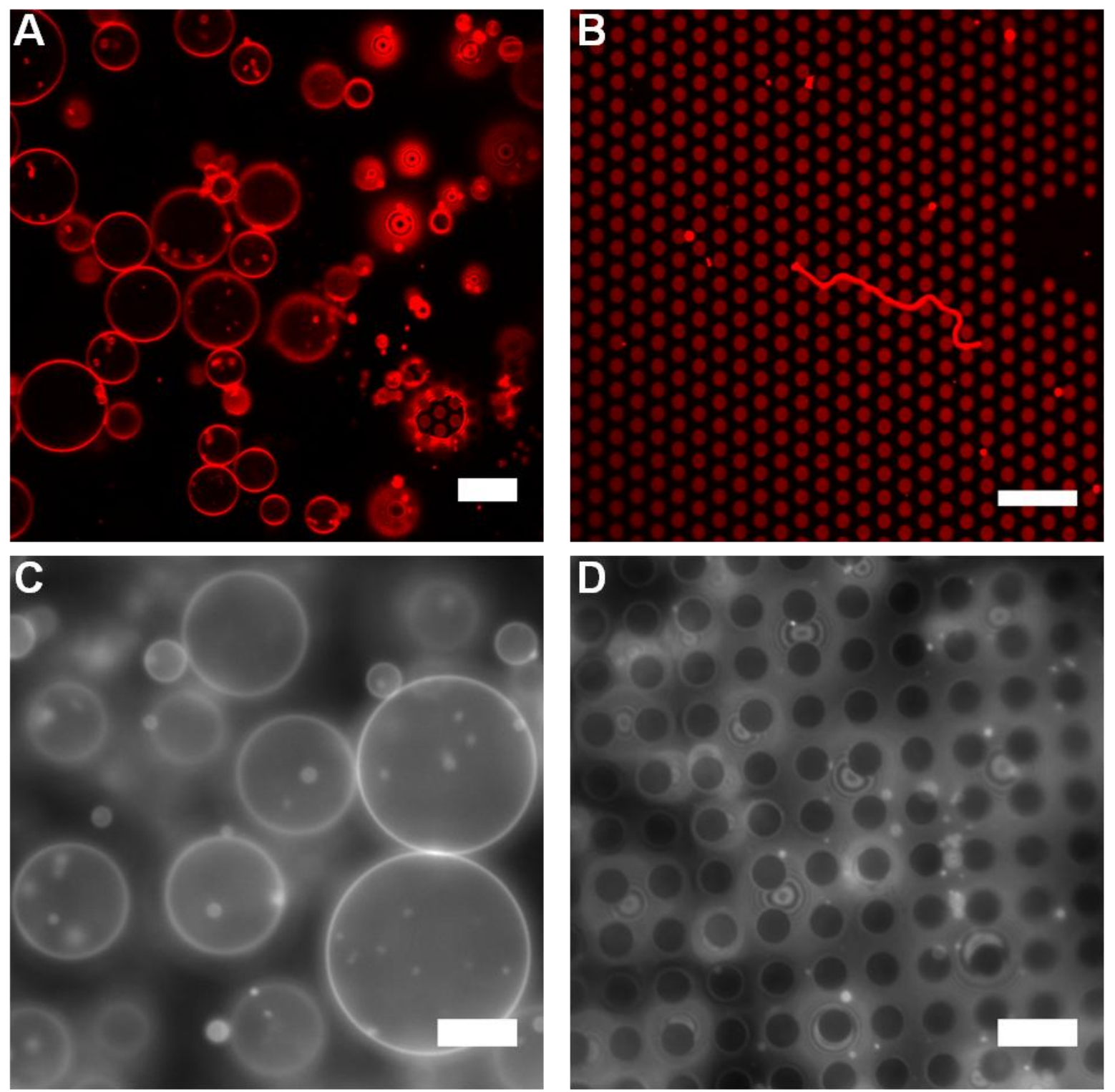

Abb. 4.9: A, B Konfokalmikroskopische Aufnahmen eines porösen Siliziumsubstrates (offene Poren, $d=2 \mu \mathrm{m}$, funktionalisiert mit CPEO3 nach optimierter Goldbeschichtung) nach Zugabe von GUVs (POPC/Texas Red DHPE, 99,8:0,2, rot). Pufferlösung: $107 \mathrm{mM} \mathrm{CaCl}_{2}, 10 \mathrm{mM}$ MOPS, pH 7,3 (TRIS). A zeigt die Substratoberfläche unmittelbar nach Zugabe von $10 \mu \mathrm{L}$ GUV-Suspension. B zeigt das Substrat nach Spülen mit Pufferlösung (160 mM KCl, $10 \mathrm{mM}$ MOPS, pH 7,3 (KOH)). C, D Weitfeldfluoreszenzmikroskopische Aufnahmen eines porösen Siliziumsubstrates (geschlossene Poren, $d=3,5 \mu \mathrm{m}, h=9 \mu \mathrm{m}$, funktionalisiert wie das Substrat aus A, B) nach Zugabe von GUVs (POPC/Texas Red DHPE, 99,8:0,2). Pufferlösung: $107 \mathrm{mM} \mathrm{CaCl}_{2}, 10 \mathrm{mM}$ MOPS, pH 7,3 (TRIS). C zeigt einen Bereich oberhalb der Substratoberfläche $(z>0 \mu \mathrm{m})$, D zeigt denselben Ausschnitt mit der Substratoberfläche im Fokus $(z=0 \mu \mathrm{m})$. Maßstabsbalken jeweils $10 \mu \mathrm{m}$.

Um auf den für einen Farbstoffeinschluss notwendigen Poren mit geschlossenen Böden dennoch lösungsmittelfreie porenüberspannende Membranen ausbilden zu können, wurden neben der Goldbeschichtung weitere Parameter variiert und optimiert:

Es wurde auf neuen, wie auf gemäß Kapitel 3.2.12 wiederverwerteten Substraten gespreitet. Die hydrophobe Funktionalisierung der Substratoberfläche wurde adressiert, indem statt CPEO3 1-Tetradekanthiol (TDT) und 1,2-Dipalmitoyl-sn-glycero-3-phosphothioethanol 
(DPPTE) zur hydrophoben Funktionalisierung der Substrate eingesetzt wurde. Spreittemperatur und Spreitdauer sind zwei weitere Parameter, welche die Bildung planarer Membranen aus GUVs beeinflussen können. Beim Spreiten der GUVs wurden die Substrate bei Temperaturen zwischen $4{ }^{\circ} \mathrm{C}$ und $40{ }^{\circ} \mathrm{C}$ für $1 \mathrm{~h}$ bis zu Tagen inkubiert, um ein Spreiten zu forcieren. Weiterhin wurde die Fusogenität der Vesikel erhöht, um die sphärische Form der GUVs zu destabilisieren und ein Spreiten zu bewirken. Aufgrund seiner fusogenen Wirkung wurde $\mathrm{CaCl}_{2}$ bei Zugabe der GUVs zugefügt in Konzentrationen von $1 \mathrm{mM}$ bis $107 \mathrm{mM} .^{[189]}$ Neben $\mathrm{CaCl}_{2}$ wurde als fusogen wirkende Komponente auch DOPE für die Bildung von GUVs verwendet. GUVs mit einem Anteil von 10 mol\% DOPE wurden per Elektroformation gebildet und auf hydrophob funktionalisierte Substrate gegeben. Auch membranständige Proteine können zur Destabilisierung von GUVs und dadurch zu einem verbesserten Spreiten beitragen, weshalb bR anteilig (1 mol\%) in GUVs rekonstituiert (Kapitel 3.2.5) und diese auf Substrate gegeben wurden. Neben dem Einsatz fusogen wirkender Komponenten wurde auch die Lipidphase der GUVs adressiert. Hierzu wurden GUVs aus dem Lipid SOPC gebildet und oberhalb der Phasenumwandlungstemperatur $\left(20^{\circ} \mathrm{C}\right)$ sowie unterhalb der Phasenumwandlungstemperatur $\left(4^{\circ} \mathrm{C}\right)$ auf porösen Substraten gespreitet. Ein weiterer Faktor, welcher das Spreitverhalten von GUVs auf funktionalisierten Substraten beeinflussen kann, ist eine chemische Umwandlung oder Zersetzung beteiligter Komponenten. Ungesättigte Lipide können in Gegenwart von Sauerstoff zu Peroxiden reagieren und dabei gespalten werden oder miteinander polymerisieren. ${ }^{[190,191]}$ Oxidierbare Komponenten (CPEO3, DOPC) wurden NMR-spektroskopisch auf strukturelle Änderungen nach mehrwöchiger Lagerung gelöst in Chloroform bei $-18{ }^{\circ} \mathrm{C}$ untersucht. ${ }^{1} \mathrm{H}$ - sowie ${ }^{13} \mathrm{C}$-Spektren unterschieden sich jedoch bei frisch angesetzten und gelagerten Lösungen nicht. Um eine ausreichende Bedeckung der Substratoberfläche mit GUVs sicherzustellen, wurde die Menge der zugegebenen GUVSuspension variiert (10 bis $200 \mu \mathrm{L}$ ). Der Belegungsgrad und die Zahl der Defektstellen des SAM auf der Substratoberfläche wurde durch Änderung der Temperatur und der Dauer, bei welcher die Substrate in der Thiollösung inkubiert wurden $\left(4^{\circ} \mathrm{C}\right.$ bis $25^{\circ} \mathrm{C}, 1 \mathrm{~h}$ bis $\geq$ 3 Monate) adressiert. Eine dichte Belegung mit hydrophoben Cholesterylresten sollte durch die erhöhte attraktive Wechselwirkung mit den GUVs deren Spreiten forcieren. Außerdem wurde die Osmolarität des Vesikelinneren und des umgebenden Spreitpuffers variiert und GUVs unter isoosmolaren, leicht und stark hypoosmolaren Bedingungen auf porösen Substraten inkubiert. Durch Applizieren osmotischer Drücke auf die GUVs sollten diese destabilisiert und dadurch die Bildung planarer Membranen initiiert werden. Unter Berücksichtigung der unterschiedlichen Stabilität freistehender Membranen in Abhängigkeit vom Porendurchmesser, ${ }^{[60]}$ wurden diese bei den porösen Substraten zwische 3,5 und $8 \mu \mathrm{m}$ variiert. Um die Wechselwirkung zwischen GUVs und hydrophober Funktionalisierung zu erhöhen und so ein Spreiten der Vesikel bewirken zu können, wurde der Anteil der Stegfläche erhöht in Form der Porosität $\left(10 \%\right.$ bis $65 \%$ ). Das Oberflächenmaterial $\left(\mathrm{SiO}_{2}\right.$ und $\left.\mathrm{Si}_{3} \mathrm{~N}_{4}\right)$ wurde variiert, um die Wechselwirkung zwischen GUVs und Poreninnenwänden zu 
modulieren und so dessen Einfluss auf die Bildung porenüberspannender Membranen zu untersuchen. Alle genannten Variationen führten zu keinem Spreiterfolg und nicht zur Bildung porenüberspannender Membranen.

Bei Zugabe von GUVs zu einem Substrat wurden konfokalmikroskopische Aufnahmen in kurzen zeitlichen Abständen gemacht, um den Spreitprozess zeitaufgelöst untersuchen zu können. Zwei dieser Zeitserien sind in Abb. 4.10 und Abb. 4.11 dargestellt. Abb. 4.10 zeigt einen Ausschnitt des zeitlichen Verlaufs der Membranfluoreszenz eines GUV von etwa $25 \mu \mathrm{m}$ Durchmesser. Nachdem der GUV nach Zugabe auf die Substratoberfläche absinkt, ist er dort lateral für einige Zeit beweglich. Dann wird er an der Substratoberfläche angebunden und in der fokalen Ebene der Substratoberfläche bildet sich eine durch ringförmige Fluoreszenz erkennbare Kontaktfläche aus (hier nicht gezeigt, siehe Abb. 4.9, A und D). Der Durchmesser des GUV nimmt über einen Zeitraum von $15 \mathrm{~s}$ kontinuierlich ab, bis seine Fluoreszenz in der fokussierten Ebene vollständig verschwunden ist $(t>14 \mathrm{~s})$.
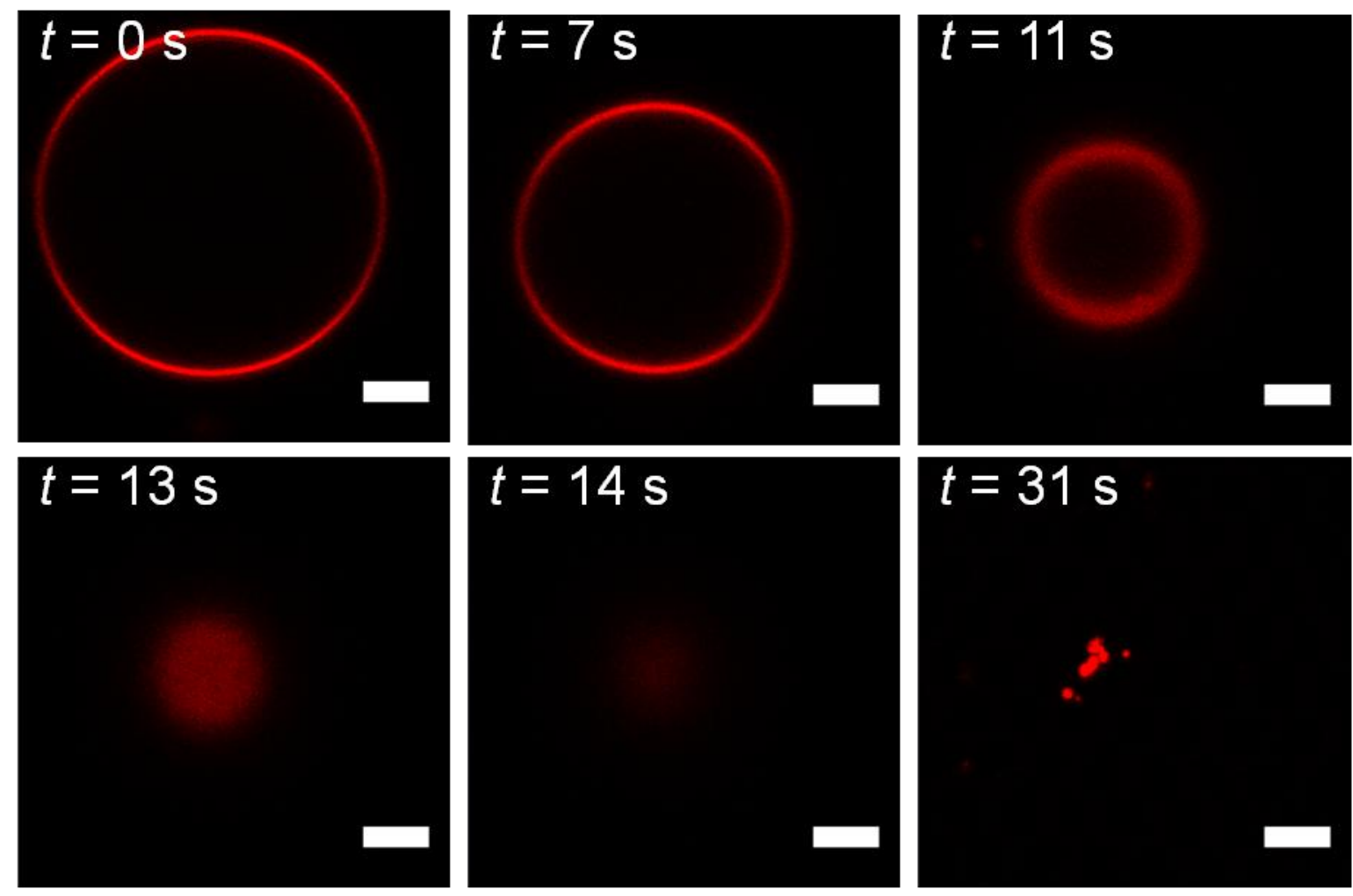

Abb. 4.10: Ausschnitt einer Zeitserie konfokalmikroskopischer Aufnahmen eines GUV (DOPC/DOPS/Texas Red DHPE, 89,8:10,0:0,2, rot) auf der Oberfläche eines mit CPEO3 funktionalisierten porösen Siliziumsubstrates $\left(2,6 \cdot 3,3 \cdot 4 \mu^{3}\right.$ ). Pufferlösung: $100 \mathrm{mM} \mathrm{KCl}, 20 \mathrm{mM}$ TRIS, $1 \mathrm{mM} \mathrm{CaCl}$, pH 7,4 (HCl). Die ersten fünf Bilder zeigen eine Ebene oberhalb der Substratoberfläche, in welcher der angebundenen GUV bei $t=0 \mathrm{~s}$ seinen maximalen Durchmesser hat $(z>0 \mu \mathrm{m})$, im Bild bei $t=31 \mathrm{~s}$ wurde auf die Substrateben fokussiert $(z=0 \mu \mathrm{m})$. Innerhalb von $15 \mathrm{~s}$ nach Absinken und Anbinden auf dem Substrat schrumpft der gezeigte GUV, bis letztlich nur noch wenig hell fluoreszierende punktförmige Materie auf dem Stegbereich zurückbleibt. Maßstabsbalken $5 \mu \mathrm{m}$. 
Bei Fokussierung der Substratoberfläche zeigten sich keinerlei membranüberspannte Poren. Es sind lediglich wenige hell fluoreszierende punktförmige Ablagerungen auf dem Stegbereich zu erkennen.

Abb. 4.11 zeigt eine Zeitserie eines solchen Vorgangs mit Fokus auf der Substratebene, sodass statt der zeitlichen Entwicklung der Fluoreszenz an der breitesten Stelle des GUV hier die Fluoreszenz der Kontaktfläche zwischen GUV und Substrat aufgezeichnet wird. Der abgebildete GUV hat mit $10 \mu \mathrm{m}$ einen geringeren Durchmesser, als der in Abb. 4.10 dargestellte GUV. Auch lässt sich keine langsame Reduzierung der fluoreszierenden Kontaktfläche erkennen. Vielmehr verschwindet die Membranfluoreszenz innerhalb von $2 \mathrm{~s}$ nachdem im Bereich der Kontaktfläche zum Substrat ein dunkler Defekt in der Fluoreszenz beobachtet werden konnte (weißer Pfeil, $t=2 \mathrm{~s}$ ). Dieses Verhalten abgesunkener GUVs konnte vielfach auf hydrophob funktionalisierten Substraten mit geschlossenen Porenböden beobachtet werden. Bei Zugabe einer die Substratoberfläche komplett füllenden Menge GUVs mit Durchmessern bis $80 \mu \mathrm{m}$ sanken diese zwar auf die Substratoberfläche ab, nach wenigen Minuten waren jedoch auf weiten Teilen des Substrates nur noch GUVs mit Durchmessern von 5 bis $10 \mu \mathrm{m}$ auszumachen. Wurden GUVs in Pufferlösungen mit höherer Osmolarität gespreitet (hypoosmotische Bedingungen), konnte auch ein lokales Reissen der Vesikelmembran und ein Austreten eingeschlossener kleiner Vesikel und Lösung beobachtet werden, wobei der GUV über einen Zeitraum von 2 min langsam schrumpfte. Auf mit CPEO3 funktionalisierten Substraten konnte weiterhin beobachtet werden, dass GUVs nach Absinken auf die Substratoberfläche eine Kontaktfläche zum Substrat hin ausbildeten, sich aber innerhalb weniger Sekunden wieder von diesem lösten und sich lateral weiter über das Substrat bewegten.

Zusammengefasst konnte kein Spreiten von GUVs auf hydrophob funktionalisierten porösen Substraten mit geschlossenen Porenböden beobachtet werden, welches zur Bildung porenüberspannender Membranen geführt hätte. Trotz gleicher Kontaktflächen wie bei offenen Poren, welche nach Optimierung der Goldbeschichtung erfolgreich mit einer Membran überspannt werden konnten, blieb nach Spreiten auf geschlossenen Poren keine detektierbare Fluoreszenz zurück. 

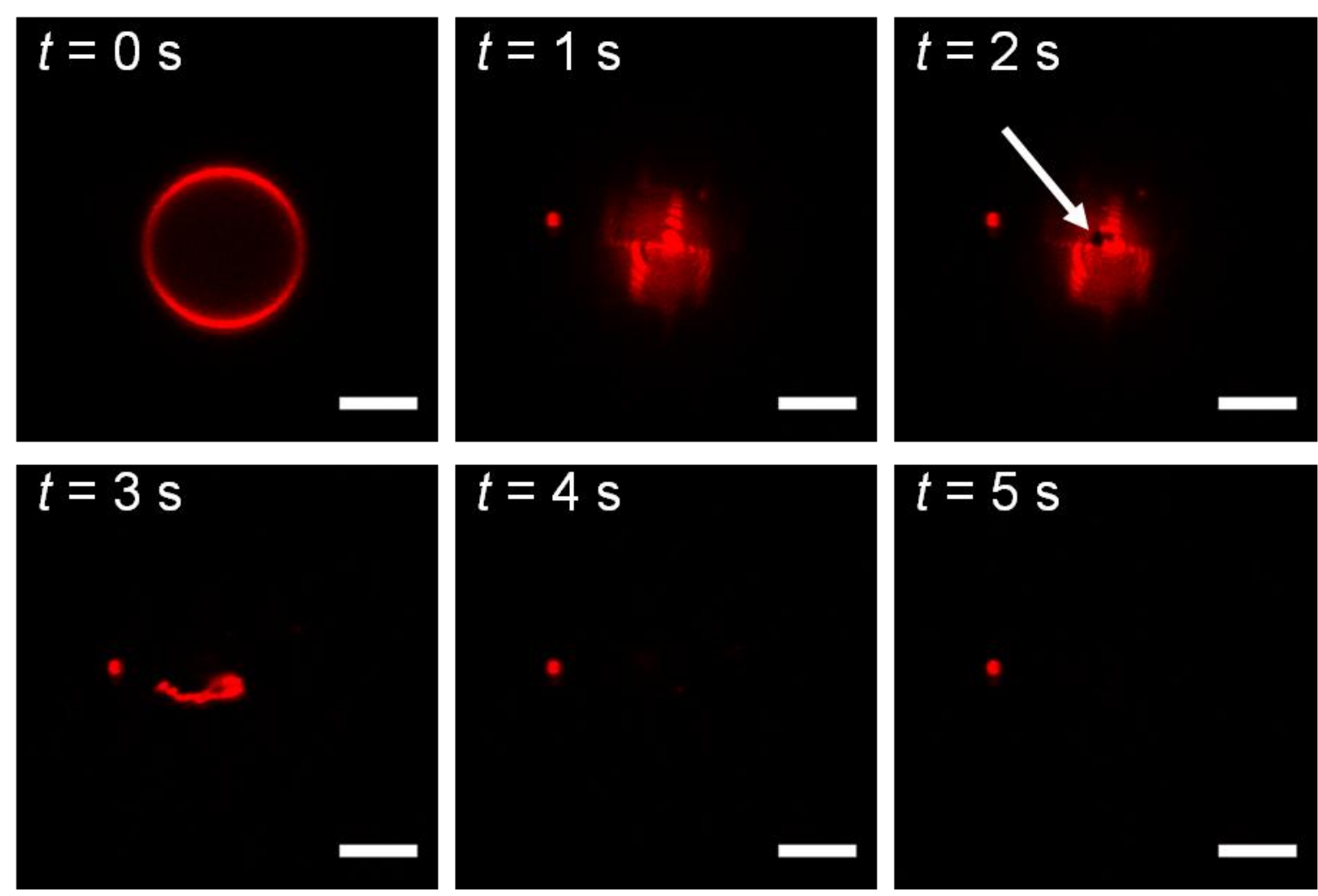

Abb. 4.11: Ausschnitt einer Zeitserie konfokalmikroskopischer Aufnahmen eines GUV (DOPC/DOPS/Texas Red DHPE, 89,8:10,0:0,2, rot) auf der Oberfläche eines mit CPEO3 funktionalisierten porösen Siliziumsubstrates (2,6·3,3·4 $\left.\mu \mathrm{m}^{3}\right)$. Pufferlösung: $100 \mathrm{mM} \mathrm{KCl,} 20 \mathrm{mM}$ TRIS, $1 \mathrm{mM} \mathrm{CaCl} 2, \mathrm{pH} \mathrm{7,4} \mathrm{(HCl).} \mathrm{Das} \mathrm{erste} \mathrm{Bild}$ zeigt eine Ebene oberhalb der Substratoberfläche, in welcher der angebundenen GUV bei $t=0 \mathrm{~s}$ seinen maximalen Durchmesser hat $(z>0 \mu \mathrm{m})$, die weiteren fünf Bilder wurden auf die Substrateben fokussiert $(z=0 \mu \mathrm{m})$. Während GUV und Substrat bei $t=1 \mathrm{~s}$ eine gemeinsame Kontaktfläche ausbilden (ringförmige Muster), zeigt die Fluoreszenz in diesem Bereich bei $t=2 \mathrm{~s}$ einen punktförmigen dunklen Bereich (weißer Pfeil). Innerhalb von $2 \mathrm{~s}$ verschwindet die Fluoreszenz im Bereich der Kontaktfläche schließlich und es bleibt keinerlei detektierbare Fluoreszenz an dieser Stelle zurück. Maßstabsbalken $5 \mu \mathrm{m}$.

\section{Spreiten auf hydrophil funktionalisierten porösen Substraten}

Da ein Spreiten von GUVs auf hydrophob funktionalisierten porösen Substraten zu keiner Bildung porenüberspannender Membranen bei gleichzeitigem Farbstoffeinschluss im Poreninneren führte, wurde der Charakter der Substratfunktionalisierung von hydrophob zu hydrophil geändert. Beispiele für die Ausbildung von Membranen auf hydrophil funktionalisierten, offenporigen Substraten mit Porendurchmessern bis $d=2,5 \mu \mathrm{m}$ finden sich bei Kocun und Heinemann. ${ }^{[48,49]}$ Dort konnte gezeigt werden, dass porenüberspannende Membranen auf hydrophil funktionalisierten Substraten geringere Membranspannungen aufweisen, als solche, die auf mit hydrophoben Monoschichten funktionalisierten Substraten gespreitet worden waren. ${ }^{[8]}$ Eine Verringerung der Membranspannung könnte ein Faktor sein, welcher die Bildung stabiler porenüberspannender Membranen durch Spreiten von GUVs favorisiert. 
Beim Spreiten von GUVs auf hydrophil funktionalisierten Substraten wurde nach einem Ansatz von Heinemann et al. vorgegangen, bei welchem poröse Oberflächen mit unter physiologischen Bedingungen positiv geladenen Aminosilanen funktionalisiert und darauf mit negativ geladenen Lipiden dotierte GUVs gespreitet wurden. ${ }^{[49]}$ Statt in wässriger Lösung Aminosilane kovalent an Si-OH-terminierte Substrate zu binden (Silane zersetzen sich rasch in wässrigen Lösungen), wurde ein Ansatz verfolgt, bei welchem eine dünne Goldschicht auf poröse Substrate aufgebracht und hydrophile Thiole chemisorbiert wurden. Zur Funktionalisierung poröser Substrate mit runden Poren und geschlossenen Böden wurden die Thiole Mercaptoessigsäure, 11-Carboxy-1-undekanthiol, 3-Mercaptopropionsäure und 11-Amino1-undekanthiol eingesetzt, von denen die ersten drei unter physiologischen Bedingungen negativ geladen und das vierte positiv geladen vorliegen. Zum Spreiten wurden GUVs der Zusammensetzungen DPhPC/DPPA, 9:1, POPC/POPS, 9:1, POPC/POPS, 8:2, POPC/POPS, 95:5 und POPC/ODA, 9:1 getestet (jeweils mit einem Anteil von 0,2 mol\% Texas Red DHPE). Die ersten vier aufgeführten Mischungen enthalten unter physiologischen Bedingungen negativ geladene Lipide, die letzte Mischung positiv geladenes Octadecylamin (ODA). Eine tabellarische Darstellung der getesteten Kombinationen ist in Tabelle 4.2 aufgeführt. Eine Phasenseparation innerhalb der GUVs wurde für keine der aufgeführten Lipidmischungen beobachtet, es sei jedoch darauf hingewiesen, dass DPPA eine Phasenumwandlungstemperatur von $T_{\mathrm{c}}=67^{\circ} \mathrm{C}^{[192]}$ und POPS einen Wert von $T_{\mathrm{c}}=13^{\circ} \mathrm{C}$ aufweist, wobei ein Überschuss metallischer Kationen die Phasenumwandlungstemperatur dramatisch erhöhen können. ${ }^{[193]}$ Eine genauere Charakterisierung des Einfluss von DPPA und POPS auf porenüberspannende Membranen wurde nicht im Rahmen dieser Arbeit behandelt.

Von allen getesteten Varianten lieferte die Kombination 11-Amino-1-undekanthiol funktionalisierter Substrate mit GUVs der Zusammensetzung POPC/POPS, 9:1 die höchste Anzahl porenüberspannender Membranen nach kürzester Inkubationszeit. Eine Zeitserie des Spreitprozesses eines entsprechenden GUV auf einem mit 11-Amino-1-undekanthiol funktionalisierten porösen Substrat ist in Abb. 4.12 dargestellt. 
Tabelle 4.2: Darstellung der Kombinationen aus Oberflächenfunktionalisierung der porösen Substrate und Lipidzusammensetzung der GUVs, welche in Spreitexperimenten untersucht wurden. Es wurden jeweils runde Poren mit Durchmessern von 3,5-5,5 $\mu \mathrm{m}$ mit geschlossenen Böden $(h=9 \mu \mathrm{m})$ in den angegebenen Thiollösungen inkubiert ( $c=1 \mathrm{mM}$ in $n$-Propanol). GUVs wurden mit den angegebenen Lipidzusammensetzungen und jeweils 0,2 mol\% Texas Red DHPE in 0,3 M Sucrose mittels Elektroformation gebildet. $10 \mu \mathrm{L}$ GUVSuspension wurden jeweils zum Spreiten auf ein funktionalisiertes Substrat gegeben. Puffer: $160 \mathrm{mM} \mathrm{KCl}$, $10 \mathrm{mM}$ MOPS, pH 7,3 (KOH). Getestete Kombinationen sind durch ein Symbol in der jeweiligen Spalte gekennzeichnet. Dabei wird unterschieden zwischen einer Bildung porenüberspannender Membranen $(+)$ und keiner Bildung porenüberspannender Membranen (-) nach Zugabe von GUVs.

\begin{tabular}{|l|l|l|l|l|}
\hline & $\begin{array}{l}\text { 11-Carboxy- } \\
1 \text {-undekanthiol }\end{array}$ & $\begin{array}{l}\text { 3-Mercapto- } \\
\text { propionsäure }\end{array}$ & $\begin{array}{l}\text { Mercaptoessig- } \\
\text { säure }\end{array}$ & $\begin{array}{l}\text { 11-Amino- } \\
\text { 1-undekanthiol }\end{array}$ \\
\hline DPhPC/DPPA, 9:1 & + & & & + \\
\hline POPC/POPS, 8:2 & & & & + \\
\hline POPC/POPS, 9:1 & & - & & + \\
\hline POPC/POPS, 95:5 & & & & + \\
\hline POPC/ODA, 9:1 & - & & - & \\
\hline
\end{tabular}

GUVs bildeten nach dem Absinken auf die Substratoberfläche innerhalb weniger Sekunden große Kontaktflächen aus. Behielten GUVs nach Absinken auf hydrophob funktionalisierten Substraten ihre sphärische Form und bildeten kleine Kontaktflächen (Abb. 4.10), so flachten die Vesikel auf hydrophil funktionalisierten Substraten rasch ab, sodass Substratoberfläche und die Stelle des GUV mit größtem Durchmesser in eine fokale Ebene fielen $(t=0 \mathrm{~s})$. Über den exakten Abstand zwischen Vesikelboden und Substratoberfläche kann anhand der Fluoreszenzaufnahmen keine sichere Aussage getroffen werden. Die bekannten ringförmigen Muster an der Kontaktfläche zwischen GUV und Substrat lassen sich jedoch erst nach Ausbildung eines Defektes (unten links, $t=13 \mathrm{~s}$ ) beobachten. Der Defekt wächst innerhalb von $24 \mathrm{~s}$ kreisförmig an und die zuvor im Stegbereich hell zu erkennende Fluoreszenz verschwindet. Nach Ende des Spreitvorgangs bleibt am Rand der ursprünglichen Kontaktfläche zwischen GUV und Substrat ein schmaler Bereich heller Fluoreszenz auf dem Stegbereich zurück. Die Poren, welche innerhalb der zu Beginn bedeckten Fläche lagen, weisen eine etwas höhere Fluoreszenzintensität auf, als umliegende, nicht bedeckte Poren. Eine genauere fluoreszenzmikroskopische Charakterisierung der potentiell membranüberspannten Poren ließ sich erst nach Entfernung überschüssiger GUVs und kleiner auf dem Substrat gebundener Vesikel durch Spülen durchführen. 

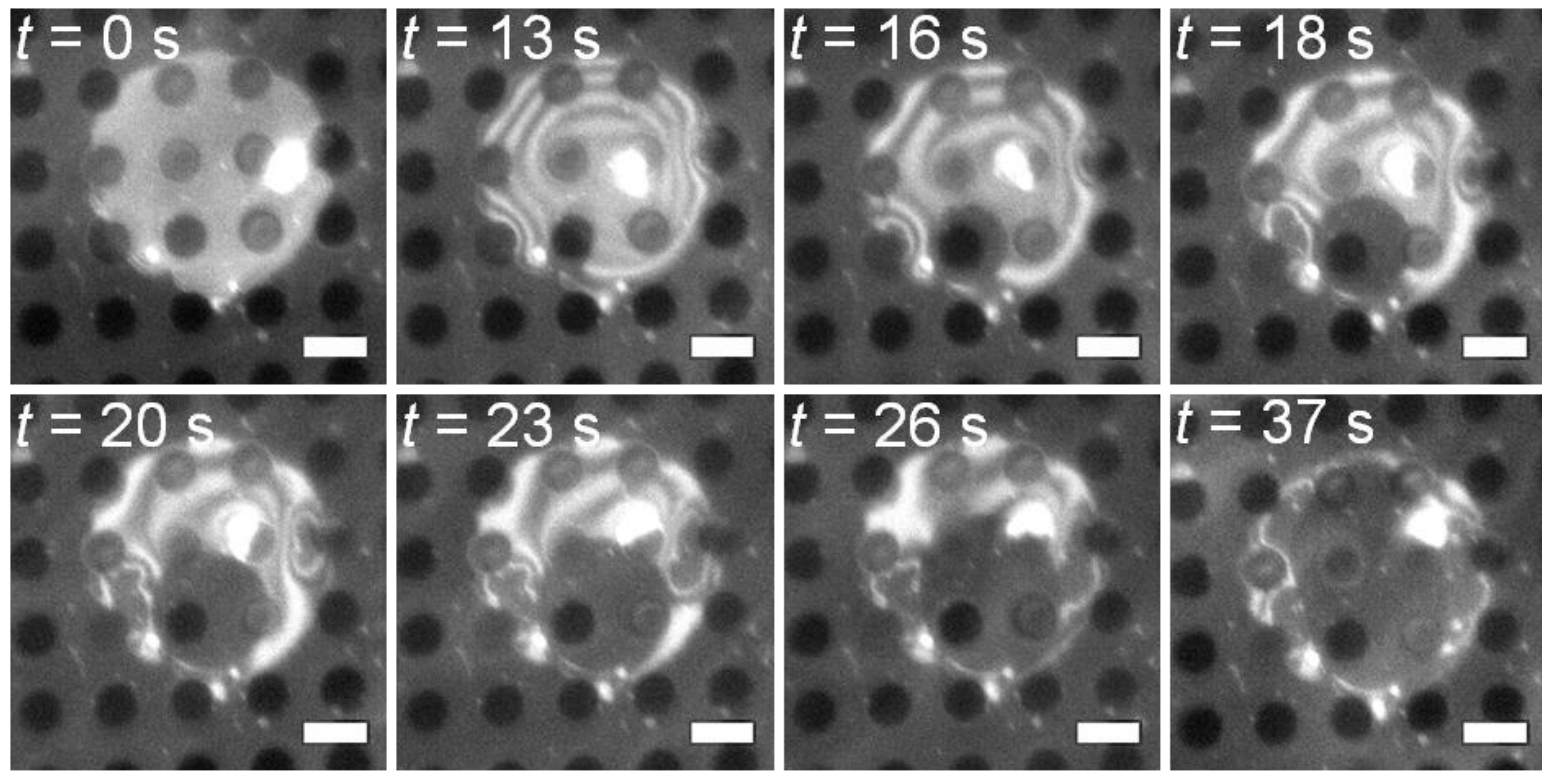

Abb. 4.12: Ausschnitt einer Zeitserie fluoreszenzmikroskopischer Aufnahmen des Spreitvorgangs eines GUV (POPC/POPS/Texas Red DHPE, 89,8:10,0:0,2) auf der Oberfläche eines mit 11-Amino-1-undekanthiol funktionalisierten porösen Siliziumsubstrates $(d=5,5 \mu \mathrm{m}, h=9 \mu \mathrm{m})$. Pufferlösung: $160 \mathrm{mM} \mathrm{KCl}, 10 \mathrm{mM}$ MOPS, pH 7,3 (KOH). Maßstabsbalken $10 \mu \mathrm{m}$.

Bei dem Versuch, GUVs (POPC/POPS, 9:1) auf mit 11-Amino-1-undekanthiol funktionalisierten porösen Substraten in einer Pufferlösung anderer Zusammensetzung als unter Abb. 4.12 angegeben zu spreiten, konnten zum Teil keine porenüberspannenden Membranen gebildet und kein Vesikelspreiten beobachtet werden. Um den Einfluss der Pufferzusammensetzung zu überprüfen und für Spreitzwecke zu optimieren, wurden die funktionalisierten Substrate in verschiedenen Pufferlösungen mit GUVs aus derselben Suspension versetzt und das Verhalten der GUVs auf der Substratoberfläche beobachtet. Die Ergebnisse dieser Studie sind in Tabelle 4.3 gezeigt.

Demnach lassen sich Osmolaritätsunterschiede zwischen dem Innenvolumen der GUVs und der Umgebungslösung, ihre Dichte, der pH-Wert der Umgebungslösung, das Vorliegen von Chloridionen, Kaliumionen, MOPS, TRIS und Zuckern als limitierende Faktoren für das Spreiten von GUVs auf den beschriebenen Substraten ausschließen. Vielmehr spreiten mit negativ geladenen Lipiden dotierte GUVs nur auf positiv geladenen porösen Oberflächen, wenn metallische Kationen vorliegen. In Bezug auf Vollständigkeit und Geschwindigkeit des Spreitprozesses wurde dabei beobachtet, dass einwertige Kationen ein Spreiten weniger gut forcieren, als zweiwertige Kationen $\left(\mathrm{Na}^{+}<\mathrm{K}^{+}<<\mathrm{Ca}^{2+}\right)$. In Anwesenheit von $\mathrm{Na}^{+}$wurden nur kleine Kontaktflächen zwischen GUVs und Substratoberfläche beobachtet. Erst nach einstündiger Inkubation wurden nach Spülen der Probe einige Zehn membranüberspannte Poren gefunden (Tabelle 4.3, ja, langsam). In kaliumionenhaltiger Lösung bildeten sich nach dem Absinken der GUVs auf die Substratoberfläche größere Kontaktflächen und es kam zu einer Verformung der GUVs von einer sphärischen Kugelform zu einer abgeflachten Halbkugel. In einem Zeitraum von Minuten konnte ein Spreiten der angebundenen GUVs und 
die Bildung porenüberspannender Membranen beobachtet werden. In Gegenwart von $\mathrm{Ca}^{2+}$ bildeten sich instantan bei Kontakt der GUVs mit der Oberfläche des Substrates Kontaktflächen in Größe der GUV-Durchmesser aus. Häufig konnte binnen Sekunden ein Spreiten der GUVs beobachtet werden. Dabei bildeten sich über die gesamte Substratfläche verteilt mehrere Dutzend patches mit porenüberspannenden Membranen (Tabelle 4.3, ja, vollständig und schnell). Ausgehend von diesem Resultat wurden zur Präparation porenüberspannender Membranen auf hydrophil funktionalisierten Substraten im Folgenden stets calciumionenoder kaliumionenhaltige Pufferlösung verwendet.

Tabelle 4.3: Studie zum Einfluss der Zusammensetzung der Pufferlösung auf das Spreitverhalten von GUVs (POPC/POPS/Texas Red DHPE, 89,8:10,0:0,2, formiert in 0,3 M Sucroselösung) auf porösen Substraten (geschlossene Porenböden, $d=4,5$ und $5,5 \mu \mathrm{m}, h=9 \mu \mathrm{m}$ ) mit hydrophiler Funktionalisierung (11-Amino1-undekanthiol).

\begin{tabular}{|c|c|}
\hline Zusammensetzung der Pufferlösung & $\begin{array}{l}\text { Bildung planarer Membranen } \\
\text { durch Spreiten von GUVs }\end{array}$ \\
\hline 160 mM KCl, 10 mM MOPS, pH 7,3 (KOH) & ja \\
\hline 320 mM Sucrose, 10 mM MOPS, pH 7,3 (TRIS) & nein \\
\hline 300 mM Glucose, 10 mM MOPS, pH 7,3 (TRIS) & nein \\
\hline 267 mM Glucose, 10 mM MOPS, pH 7,3 (TRIS) & nein \\
\hline 10 mM MOPS, pH 7,3 (TRIS) & nein \\
\hline Reinstwasser & nein \\
\hline Reinstwasser, nach KCl-Zugabe $\left(c_{\mathrm{KCl}} \approx 250 \mathrm{mM}\right)$ & ja \\
\hline $160 \mathrm{mM} \mathrm{NaCl}, 10 \mathrm{mM}$ MOPS, pH 7,3 (NaOH) & ja, langsam \\
\hline $107 \mathrm{mM} \mathrm{CaCl}_{2}, 10 \mathrm{mM}$ MOPS, pH 7,3 (TRIS) & ja, vollständig und schnell \\
\hline 160 mM KI, 10 mM MOPS, pH 7,3 (KOH) & ja \\
\hline
\end{tabular}

Lösungsmittelfreie, durch Spreiten von GUVs erzeugte porenüberspannende Membranen wurden analog zu lösungsmittelhaltigen Membranen (Kapitel 4.1.1) konfokalmikroskopisch und mittels SICM untersucht (Abb. 4.13). In Abb. 4.13, A ist eine konfokalmikroskopische z-stack Aufnahme planarer porenüberspannender Membranen dargestellt. Bedeckte Poren sind durch die rote Membranfluoreszenz von unbedeckten, dunklen Poren zu unterscheiden. Pyranin ließ sich in den Poren einschließen und auch nach gründlichem Spülen und 
Austausch der überstehenden Pufferlösung konnte Pyraninfluoreszenz innerhalb der Poren detektiert werden. Unbedeckte Poren enthielten nach dem Spülen kein detektierbares Pyranin mehr (Pore ganz rechts ( $x, z$-Ebene) bzw. ganz oben ( $y, z$-Ebene) im $z$-stack). Anpassen einer Gauss-Funktion an die Intensitätswerte der Texas Red DHPE Fluoreszenz im Bereich einer Pore über alle z-Ebenen (Abb. 4.13, B) ähnelt dem für painted membranes angepassten Profil nach Ausfrieren des Lösungsmittels (Abb. 4.5, B). Dabei wurden Werte von $R^{2}=0,993$ für das Bestimmtheitsmaß der angepassten Funktion mit einem Maximum bei $z=-1,29 \mu \mathrm{m}$ und eine Halbwertsbreite von $F W H M=2,6 \mu \mathrm{m}$ erhalten. Die Pyraninfluoreszenz weist ein Maximum bei etwa $z=-2,9 \mu \mathrm{m}$ auf. Im Gegensatz zu painted membranes nach Ausfrieren des Lösungsmittels (Abb. 4.5, A), zeigte sich die Membranfluoreszenz bei durch Spreiten von GUVs präparierten porenüberspannenden Membranen homogen über die gesamte Fläche einer Pore verteilt. Es wurde keine erhöhte Fluoreszenzintensität oder Ausdehnung der Fluoreszenz in $z$-Richtung am Rand der Porenfläche festgestellt.

Eine Kombination aus Ortho-Darstellung in $y$-z-Ebene einer konfokalmikroskopischen Aufnahme und der maßstabsgetreuen Darstellung des Verlaufs der Pyranin- und Texas Red DHPE Fluoreszenzintensität in einer ROI innerhalb der Porenfläche zeigen, dass Pyranin unterhalb der porenüberspannenden Membran im Poreninneren eingeschlossen ist (Abb. 4.13, C).

SICM-Aufnahmen eines Substrates nach Spreiten von GUVs zeigten zwischen unbedeckten, etwa $8 \mu \mathrm{m}$ tiefen Poren häufig zusammenhängende Bereiche bedeckter Poren. In Abb. 4.13, D sind vier benachbarte Poren mit einer Membran (DPhPC/DPPA, 9:1) bedeckt, welche eine Tiefe von lediglich $z=-120 \mathrm{~nm}$ aufweisen. Für planare, lösungsmittelfreie porenüberspannende Membranen der Zusammensetzung POPC/POPS, 9:1 wurde eine Position der Membran in den Poren von $z=-(1,3 \pm 1,1) \mu \mathrm{m}$ ermittelt mit Werten in einem Bereich von $z_{\max }=-3,56 \mu \mathrm{m}$ und $z_{\min }=-0,32 \mu \mathrm{m}$. Dieser Wert ähnelt dem für lösungsmittelhaltige porenüberspannende Membranen erhaltenen Wert nach Ausfrieren des Lösungsmittels (Kapitel 4.1.1). Die Position der Membran veränderte sich nicht nach Zugabe von z. B. Nigericin.

Der in den Poren eingeschlossene Farbstoff konnte mittels eines starken Laserpulses irreversibel gebleicht werden (analog zu Abb. 4.5, C). Auf einer Zeitskala von 30 min blieb die Fluoreszenzintensität innerhalb der gebleichten Pore auf einem konstant niedrigen Niveau, sodass ein Farbstoffaustausch zwischen benachbarten überspannten Poren auch für lösungsmittelfreie, durch Spreiten von GUVs präparierte Membranen ausgeschlossen werden konnte. 

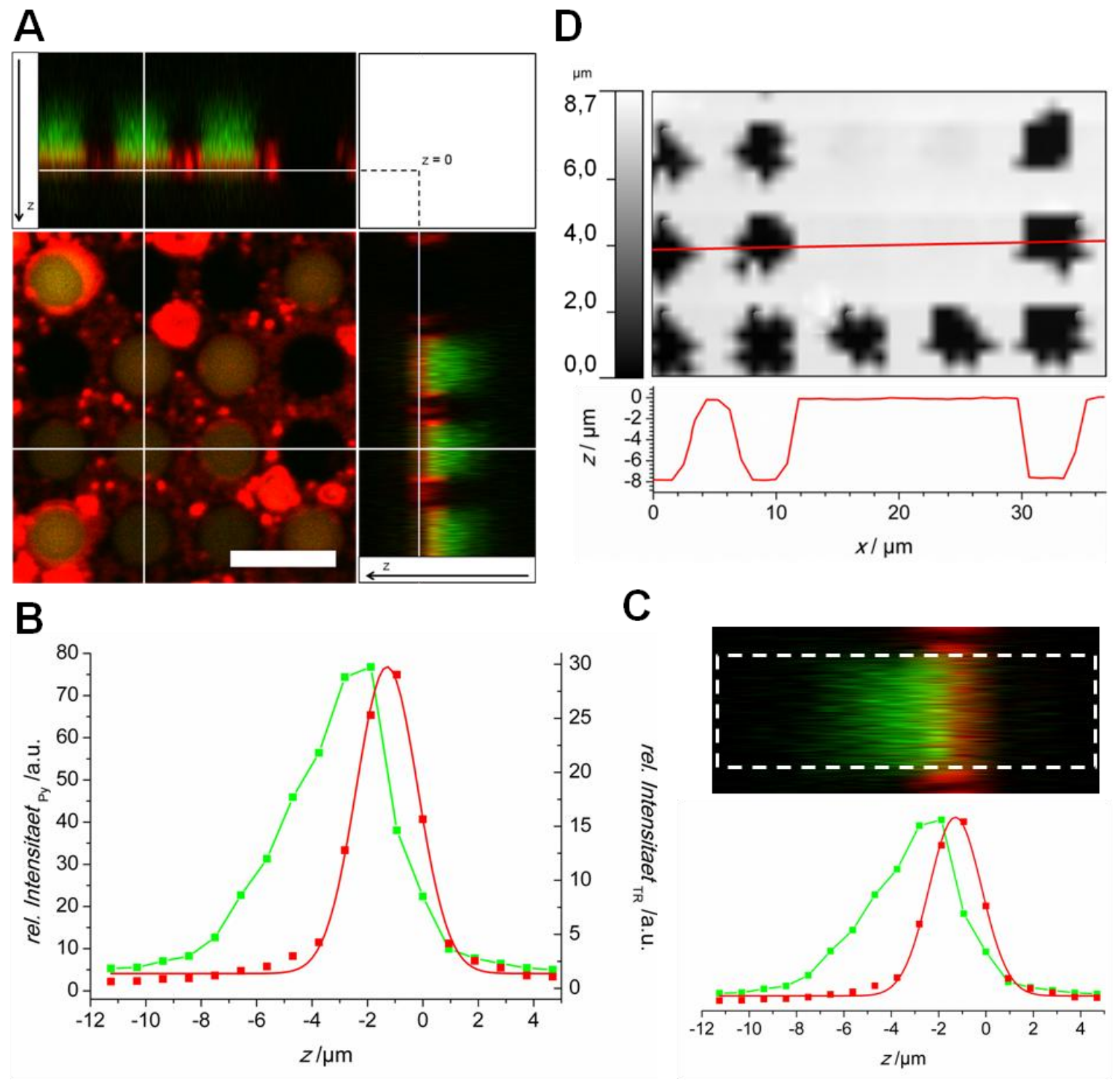

Abb. 4.13: A Ortho-Darstellung einer dreidimensionalen, konfokalmikroskopischen Aufnahme eines mit 11-Amino-1-undekanthiol funktionalisierten porösen Siliziumsubstrates $(d=5,5 \mu \mathrm{m}, h=9 \mu \mathrm{m})$ nach Spreiten von GUVs (POPC/POPS/Texas Red DHPE, 89,8:10,0:0,2, rot). Maßstabsbalken $10 \mu \mathrm{m}, z$-Dimension: 16,0 $\mu \mathrm{m}$ (18 Einzelbilder). Pufferlösung: $107 \mathrm{mM} \mathrm{CaCl}_{2}, 10 \mathrm{mM}$ MOPS, 0,5 mM Pyranin (grün), pH 7,3 (TRIS). B Intensitätsverlauf der Texas Red DHPE Fluoreszenz der Membran (rot, rechte Achse) und der Pyranin Fluoreszenz unterhalb der Membran (grün, linke Achse) einer überspannten Pore aus A. An den Verlauf der Texas Red DHPE Fluoreszenz ist eine Gauss-Funktion angepasst worden, wobei sich ein Maximum bei $z=-1,29 \mu \mathrm{m}$ und eine Halbwertsbreite von $F W H M=2,6 \mu \mathrm{m}$ ergab. C Ortho-Darstellung in $y$-z-Ebene einer dreidimensionalen, konfokalmikroskopischen Aufnahme einer einzelnen Pore (2. Reihe von oben, 2. Spalte von rechts in A). Unterhalb der Fluoreszenzaufnahme ist der Verlauf von Pyranin- (grün) und Texas Red DHPE (rot) Intensität innerhalb der durch ein weiß gestricheltes Rechteck markierten ROI dargestellt (siehe B). Für eine bessere Übersichtlichkeit wurde auf eine Darstellung der $y$-Achsen verzichtet. Die Skalierung der $z$-Achse gilt ebenfalls für die Fluoreszenzaufnahme. D SICM-Aufnahme und Höhenprofil eines mit 11-Amino-1-undekanthiol funktionalisierten porösen Siliziumsubstrates $(d=5,5 \mu \mathrm{m}, \quad h=9 \mu \mathrm{m})$ nach Spreiten von GUVs (DPhPC/DPPA/Texas Red DHPE, 89,8:10,0:0,2). Pufferlösung: 107 mM CaCl, $10 \mathrm{mM} \mathrm{MOPS,} \mathrm{pH} \mathrm{7,3} \mathrm{(TRIS).}$ Unbedeckte Poren weisen eine Tiefe von $8 \mu \mathrm{m}$ auf, in überspannten Poren wurde die Membran in einer Tiefe von $120 \mathrm{~nm}$ detektiert. 
Mit Bodipy PC dotierte porenüberspannende Membranen wurden in FRAP-Experimenten eingesetzt, um die Mobilität der Lipide in lösungsmittelfreien Membranen zu untersuchen. Der Intensitätsverlauf, sowie konfokalmikroskopische Aufnahmen einer gebleichten Membran sind in Abb. 4.14 dargestellt. Nach Bleichen der Bodipy PC Fluoreszenz innerhalb einer ROI (Abb. 4.14, B, weißer Bereich) auf einen Wert von $I_{\text {Bleich }}=39 \%$, stieg die Fluoreszenzintensität innerhalb der ROI binnen $37 \mathrm{~s}$ auf einen Wert von $80 \%$ der normierten Ausgangsintensität an (Abb. 4.14, C). Der Verlauf der Intensität der Fluoreszenz innerhalb der ROI (Abb. 4.14, A) bedingt eine laterale Mobilität der Lipide innerhalb durch Spreiten von GUVs präparierter porenüberspannender Membranen und ähnelt demjenigen, wie er für painted membranes nach Ausfrieren des Lösungsmittels beobachtet wurde (Abb. 4.4, A). Von einer Quantifizierung der Mobilität in Form von Parametern wie mobilem Anteil $M$ oder charakteristischer Diffusionszeit $t_{1 / 2}$ wurde abgesehen, da die durch Spreiten von GUVs erzeugten patches nur eine kleine Fläche zusammenhängender Membran aufwiesen (in den für FRAP-Experimente gebleichten Bereichen drei bis fünf zusammenhängende porenüberspannende Membranen). Bei Löschung der Fluoreszenz in der Fläche einer Pore ergibt sich dabei unter Berücksichtigung des eingeschlossenen Stegbereichs ein Anteil gebleichter Fläche an der Gesamtfläche des patches von 6-11\%. Somit ist die Näherung einer in Bezug auf die Größe des gebleichten Bereichs unendlich großen Fläche ungebleichter Membran, wie sie von Axelrod in seiner Theorie zur Quantifizierung der Lipidmobilität angenommen wird, nicht gegeben. ${ }^{[178]}$ Der hohe Anteil gebleichter Lipide in der Membran verfälscht den Verlauf der Intensität und die daraus extrahierten Werte und es kann lediglich qualitativ eine Aussage über die Mobilität der Lipide gemacht werden. Wertet man die FRAP-Experimente dennoch aus (Kapitel 3.5.1), so ergeben sich Werte für den mobilen Anteil von $M=55 \pm 5 \%$ und ein Diffusionskoeffizient von $D=0,6 \pm 0,1 \mu \mathrm{m}^{2} \cdot \mathrm{s}^{-1}(N=3)$. Diese Werte erlauben lediglich eine Abschätzung der Größenordnung der Lipidmobilität. Die Intensität unmittelbar nach dem Bleichen der ROI ist unabhängig von der Größe der Membranfläche und konnte auf $I_{\text {Bleich }}=41 \pm 4 \% \quad(N=3)$ bestimmt werden, was im Bereich der für lösungsmittelhaltige porenüberspannende Membranen erhaltenen Werte liegt (Tabelle 4.1). 
A

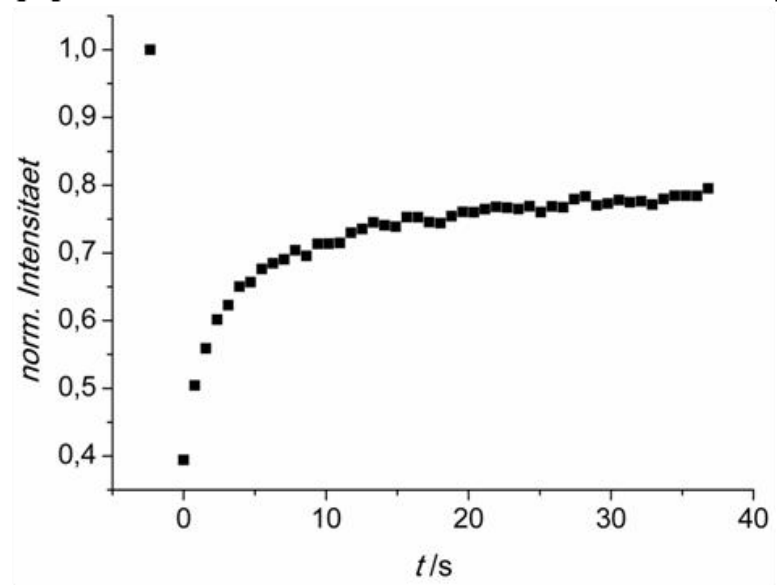

B

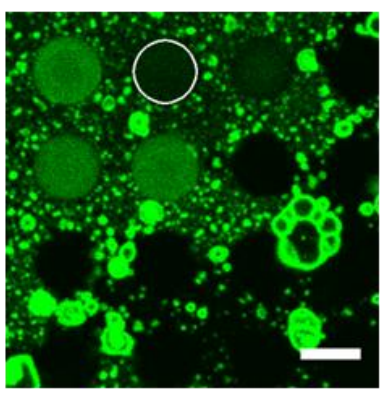

$t=0 \mathrm{~s}$
C

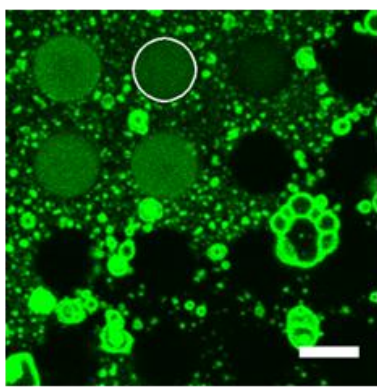

$t=36,8 \mathrm{~s}$

Abb. 4.14: A Intensitätsverlauf eines FRAP-Experiments an einem porösen Siliziumsubstrat $(d=5,5 \mu \mathrm{m}$, $h=9 \mu \mathrm{m}$ ) nach Spreiten von GUVs (POPC/POPS/Bodipy PC, 89,5:10,0:0,5). Pufferlösung: $107 \mathrm{mM} \mathrm{CaCl}_{2}$, $10 \mathrm{mM}$ MOPS, pH 7,3 (TRIS). B und $\mathbf{C}$ zeigen die zugehörigen Fluoreszenzaufnahmen bei $t=0 \mathrm{~s}$ (unmittelbar nach dem Bleichen) und $t=36,8 \mathrm{~s}$ (Ende der Zeitserie). Maßstabsbalken $5 \mu \mathrm{m}$. Gebleicht wurde der in weiß eingezeichnete Bereich, dessen Intensitätsverlauf in A in normierter Form aufgetragen ist.

\section{Hemisphärische porenüberspannende Membranen}

Ein in der Literatur bisher nicht beschriebenes Phänomen, welches bei der Bildung lösungsmittelfreier porenüberspannender Membranen durch Spreiten von GUVs auf hydrophil funktionalisierten porösen Substraten mit Porenböden beobachtet werden konnte, ist die Bildung hemisphärischer Ausstülpungen der Membran im Bereich der Poren. Neben den oben beschriebenen planaren porenüberspannenden Membranen bildeten sich auch immer Bereiche mit nicht-planaren, halbkugelförmig in die überstehende Pufferlösung ragenden porenüberspannenden Membranen. Eine dreidimensionale konfokalmikroskopische Aufnahme eines Bereiches mit planaren wie ausgestülpten porenüberspannenden Membranen ist in Abb. 4.15, A dargestellt. Eine planare Membran mit ungekrümmtem Verlauf der Texas Red DHPE Fluoreszenz und in der Pore eingeschlossenem Pyranin ist durch Pfeil 1 gekennzeichnet. Eine einzelne Pore, welche mit einer stark gewölbten Membran überspannt ist, ist durch Pfeil 2 gekennzeichnet. In der Aufsicht ( $x, y$-Ebene) ist diese Membran kaum von planaren Membranen zu unterscheiden. Erst bei Betrachtung der $z$-Richtung wird die halbkugelartige Struktur der Membran deutlich, welche etwa $4 \mu \mathrm{m}$ weit in die überstehende Lösung ragt. Trotz des zum Teil hohen Abstands der Membranen zum unterliegenden Substrats ist auch nach Spülen der Probe mit pyraninfreier Pufferlösung ein Farbstoffeinschluss innerhalb der Pore unter der Membran auszumachen. Die Pyraninfluoreszenz erstreckt sich dabei über die Substratoberfläche hinaus bis zum Rand der Membranhalbkugel. Ein patch aus mehreren hemisphärischen porenüberspannenden Membranen ist durch Pfeil 3 markiert. Hier ragen die Membranen etwa $3 \mu \mathrm{m}$ weit über die Substratoberfläche hinaus. 
Die SICM-Aufnahme eines analog zu A präparierten Substrates mit Höhenprofil ist in Abb. 4.15, B dargestellt. Der Umriss eines durch Spreiten eines GUV überspannten Bereichs ist durch eine weiße Linie angedeutet. SICM-Aufnahmen und konfokalmikroskopische Aufnahmen zeigten, dass sich hemisphärisch ausgestülpte Membranen zumeist im Zentrum eines patches bildeten, während planar überspannte Poren häufig im Randbereich eines patches auftraten. In der gezeigten SICM-Aufnahme treten die in Aufnahme A durch Pfeile markierten Membrantypen ebenfalls auf. Dabei kann zwischen unüberspannten Poren $(z<-6 \mu \mathrm{m})$, planar überspannten Poren $(-3,56 \mu \mathrm{m}<z<-0,32 \mu \mathrm{m})$ und hemisphärischen porenüberspannenden Membranen $(+2 \mu \mathrm{m}<z)$ unterschieden werden. Der Radius der gebildeten Membranhalbkugeln übertraf zum Teil den Durchmesser der unterliegenden überspannten Poren (Höhenprofil in B, erste und zweite überspannte Pore von links: $z=+5,2 \mu \mathrm{m}$, $d=4,5 \mu \mathrm{m})$.

A

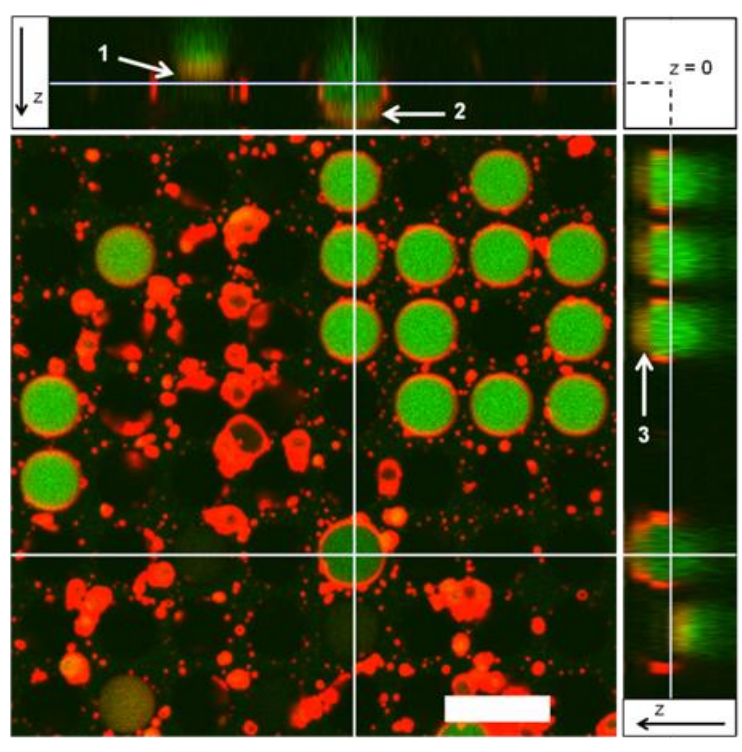

B
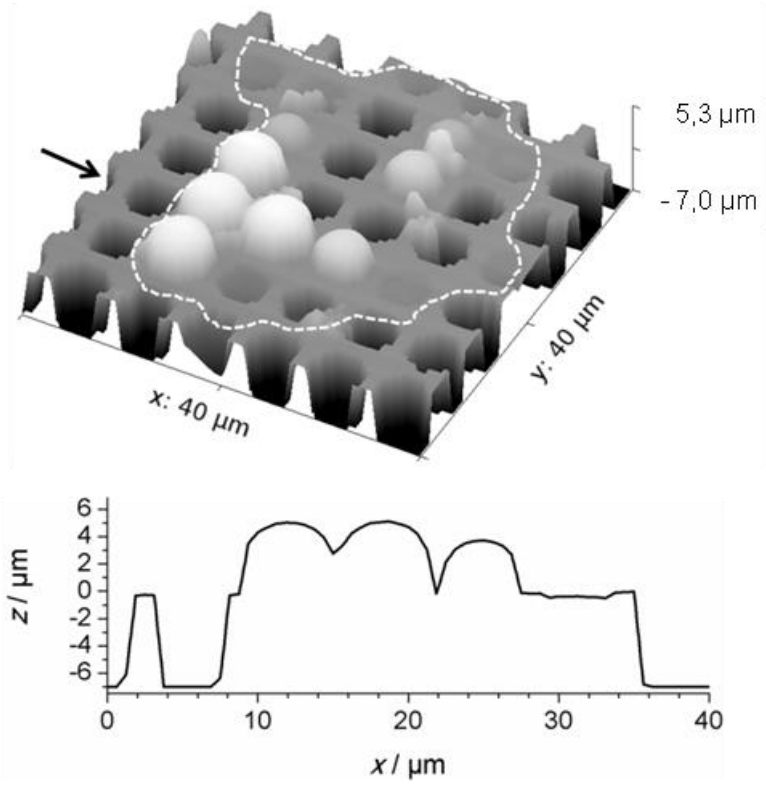

Abb. 4.15: A Ortho-Darstellung einer dreidimensionalen, konfokalmikroskopischen Aufnahme eines mit 11-Amino-1-undekanthiol funktionalisierten porösen Siliziumsubstrates $(d=5,5 \mu \mathrm{m}, h=9 \mu \mathrm{m})$ nach Spreiten von GUVs (POPC/POPS/Texas Red DHPE, 89,8:10,0:0,2, rot). Maßstabsbalken $10 \mu \mathrm{m}, z$-Dimension: 10,0 $\mu \mathrm{m}$ (12 Einzelbilder). Pufferlösung: $107 \mathrm{mM} \mathrm{CaCl}$, $10 \mathrm{mM}$ MOPS, 0,5 mM Pyranin (grün), pH 7,3 (TRIS). Pfeile markieren eine planare porenüberspannende Membran (1), eine stark ausgewölbte porenüberspannende Membran (2) und einen Bereich mehrerer weniger stark ausgewölbter porenüberspannender Membranen (3). B SICM-Aufnahme und Höhenprofil eines mit 11-Amino-1-undekanthiol funktionalisierten porösen Siliziumsubstrates $(d=4,5 \mu \mathrm{m}, h=9 \mu \mathrm{m})$ nach Spreiten von GUVs (DPhPC/DPPA/Texas Red DHPE, 89,8:10,0:0,2). Pufferlösung: $160 \mathrm{mM} \mathrm{KCl,} 10 \mathrm{mM}$ MOPS, pH 7,3 (KOH). Unbedeckte Poren weisen eine Tiefe von $z<-6 \mu \mathrm{m}$ auf, in der planar überspannten Pore wurde die Membran in einer Tiefe von $z=-320 \mathrm{~nm}$ detektiert. Ausstülpungen reichen bis $\mathrm{zu} z=+5,2 \mu \mathrm{m}$ weit in die überstehende Pufferlösung hinein. Die weiße gestrichelte Linie markiert den Umriss des durch das Spreiten eines GUV geformten membranüberspannten Bereichs (patch). Das Höhenprofil ist entlang des schwarze Pfeils in der 3D-Darstellung dargestellt.

Insgesamt überspannten planare, lösungsmittelfreie Membranen Poren mit geschlossenen Böden in einer Tiefe von $z=-(1,25 \pm 1,05) \mu \mathrm{m}(N=13)$. Dieser Wert stimmt gut mit dem für 
per painting-Technik präparierte porenüberspannende Membranen nach Ausfrieren des Lösungsmittels überein (Tabelle 4.1).

Wie in planaren porenüberspannenden Membranen, waren Lipide innerhalb hemisphärischer porenüberspannender Membranen lateral mobil (Abb.4.16). FRAP-Experimente wurden dabei an mit Mercaptohexanol funktionalisierten Substraten durchgeführt mit einer veränderten Lipidmischung (DOPC/Gb3/Bodipy PC, 94,5:5,0:0,5) in PBS-Pufferlösung. Mercaptoalkohole wurden teilweise neben geladenen Thiolen zur hydrophilen Funktionalisierung von Substraten eingesetzt (Kapitel 3.1.2), um Vergleiche der Ergebnisse mit porenüberspannenden Membranen auf offenen, mit Mercaptoalkohol funktionalisierten Substraten mit Porendurchmessern bis $2 \mu \mathrm{m}$ zu ermöglichen, wie sie von Kocun et al. präpariert wurden. ${ }^{[48]}$ Proben mit der unter Abb. 4.16 beschriebenen Zusammensetzung zeigten weiterhin besonders viele zusammenhängende, ausgeprägte Membranausstülpungen und eigneten sich daher besonders gut zur Untersuchung eines diffusionsbedingten Lipidaustausches zwischen benachbarten hemisphärischen Membranen. Auf eine Quantifizierung der zweidimensionalen Lipidmobilität wurde aufgrund der sphärischen Struktur der Membran verzichtet. Durch die dreidimensionale Struktur der Membran würde eine Auswertung gemäß Kapitel 3.5.1, wie sie für zweidimensionale Systeme entwickelt wurde, verfälschte Diffusionskoeffizienten liefern. Besonders das Intensitätsprofil des gebleichten Bereichs wäre aufgrund des Verlaufs der Membran in z-Richtung nicht kreisförmig und ein Radius $\omega$ kann nicht abgeschätzt werden. Bestimmt man dennoch einen mobilen Anteil, so ergibt sich ein Wert von $M=89 \pm 6 \% \quad(N=5)$. Qualitativ konnte demnach gezeigt werden, dass ungebleichte Fluorophormoleküle von benachbarten, halbkugelförmigen porenüberspannenden Membranen in die gebleichte ROI hineindiffundieren können, was auf die Ausbildung einer durchgängigen Membran hindeutet und das Vorliegen einzelner, voneinander isolierter Membranhemisphären über jeder Pore ausschließt. Dass dieser Befund auch für porenüberspannende Membranen mit anderer Lipidzusammensetzung (POPC/POPS, 9:1) und anderer Funktionalisierung gilt, muss in weiteren Experimenten noch bewiesen werden. Da allerdings planare porenüberspannende Membranen mit unterschiedlicher Zusammensetzung auch auf mit 11-Amino-1-undekanthiol funktionalisierten Substraten mobile Lipide aufwiesen (Abb. 4.14), ist es wahrscheinlich, dass auch hemisphärisch strukturierte Membranen eine zweidimensionale Lipiddiffusion ermöglichen. 


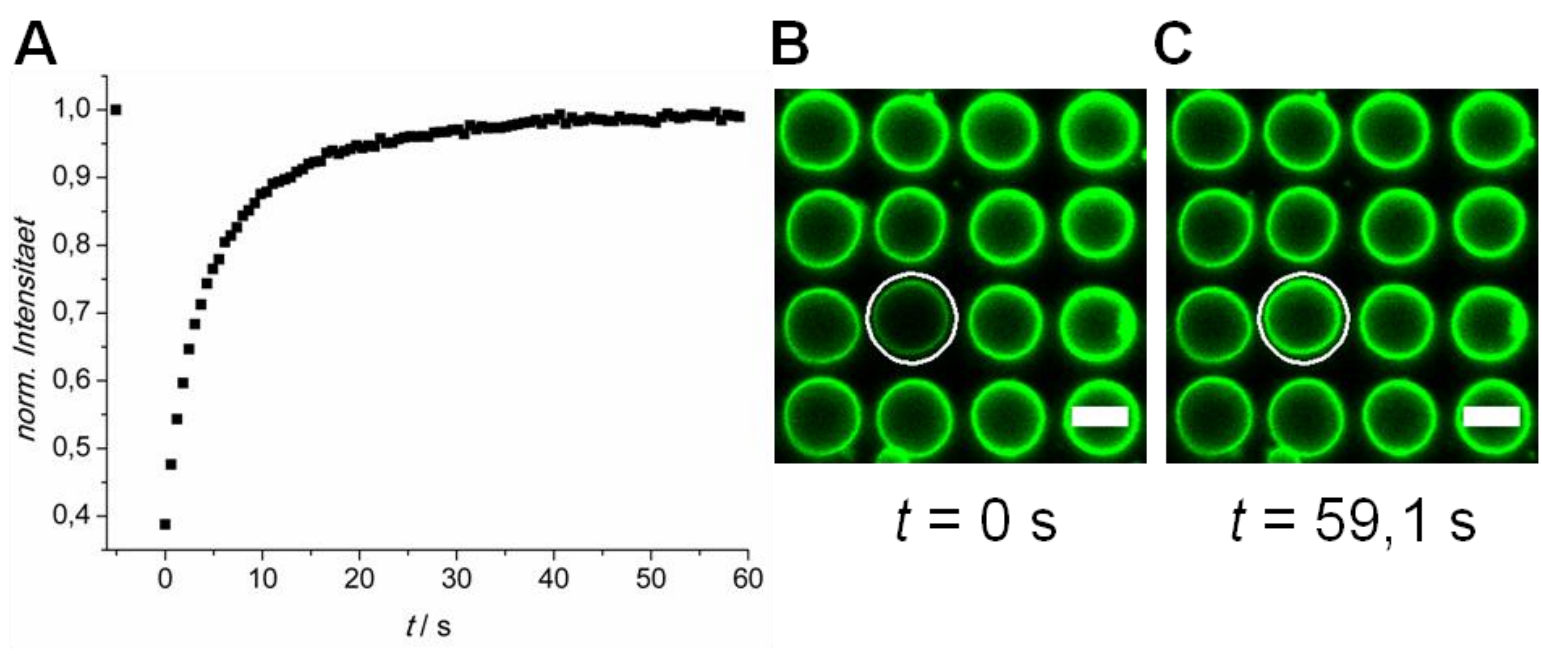

Abb. 4.16: A Intensitätsverlauf eines FRAP-Experiments an einem mit Mercaptohexanol funktionalisierten porösen Siliziumsubstrat $(d=5,5 \mu \mathrm{m}, h=9 \mu \mathrm{m})$ nach Spreiten von GUVs (DOPC/Globotriaosylceramid $\left(\mathrm{Gb}_{3}\right)$ /Bodipy PC, 94,5:5,0:0,5). Pufferlösung: PBS-Puffer (137 mM NaCl, 2,7 mM KCl, $10 \mathrm{mM} \mathrm{Na}_{2} \mathrm{HPO}_{4}$, $\left.2 \mathrm{mM} \mathrm{KH} \mathrm{PO}_{4}, \mathrm{pH} 7,4\right)$. B und $\mathbf{C}$ zeigen die zugehörigen Fluoreszenzaufnahmen bei $t=0 \mathrm{~s}$ (unmittelbar nach dem Bleichen) und $t=59,1 \mathrm{~s}$ (Ende der Zeitserie). Maßstabsbalken $5 \mu \mathrm{m}$. Gebleicht wurde der in weiß eingezeichnete Bereich, dessen Intensitätsverlauf in A in normierter Form aufgetragen ist.

Um zu untersuchen, inwiefern osmotische Effekte die Bildung und Größe solcher Ausstülpungen beeinflussen, wurden GUVs in Sucroselösungen verschiedener Konzentration präpariert. Nach Spreiten in Pufferlösung konstanter Zusammensetzung wurde die $z$-Position porenüberspannender Membranen relativ zur Substratoberfläche aus dreidimensionalen konfokalmikroskopischen Aufnahmen bestimmt. Die Verteilung der $z$-Position der drei Proben (hypo-, iso- und hyperosmolare Bedingungen) ist in Abb. 4.17 aufgeführt. Die Anzahl porenüberspannender Membranen ist für hypoosmotische GUV-Suspensionen (A) wesentlich geringer, als für iso- und hyperosmotische (B und C). Es wurden Gauss-Funktionen an die Verteilungen angepasst, deren Maxima mit steigender Sucrosekonzentration in den GUVs von $z=0,55 \mu \mathrm{m}$ (A) über $z=2,37 \mu \mathrm{m}$ (B) auf $z=2,71 \mu \mathrm{m}$ (C) zunehmen. Die engste Verteilung bei genauester Anpassung lieferten dabei die isoosmolaren Bedingungen (B, $F W H M=1,5 \mu \mathrm{m}$, $\left.R^{2}=0,907\right)$. 
A

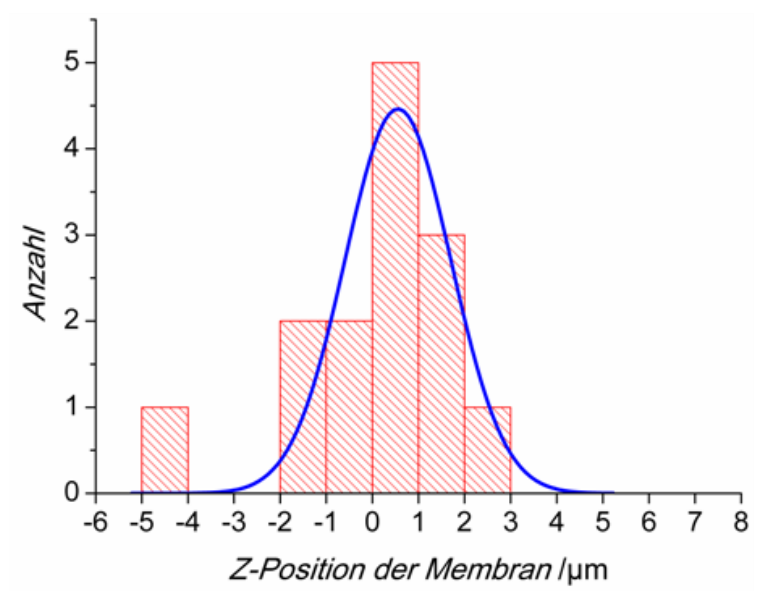

C

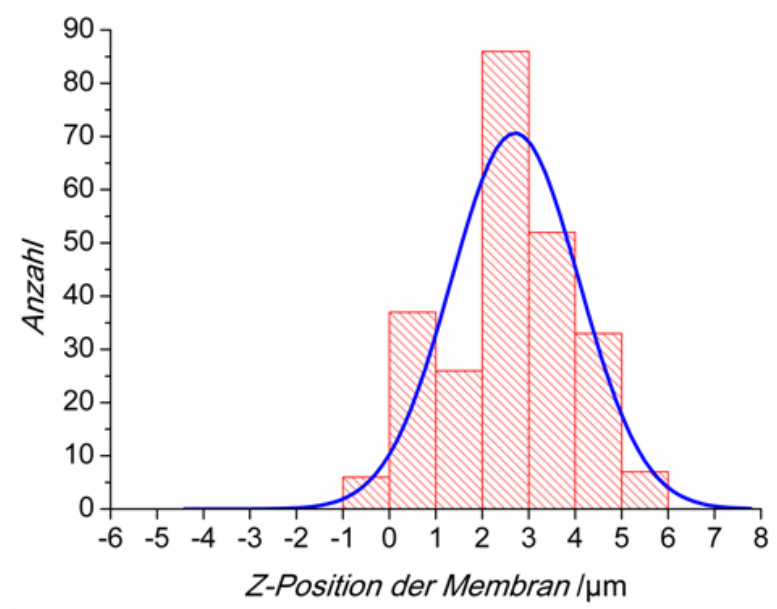

B

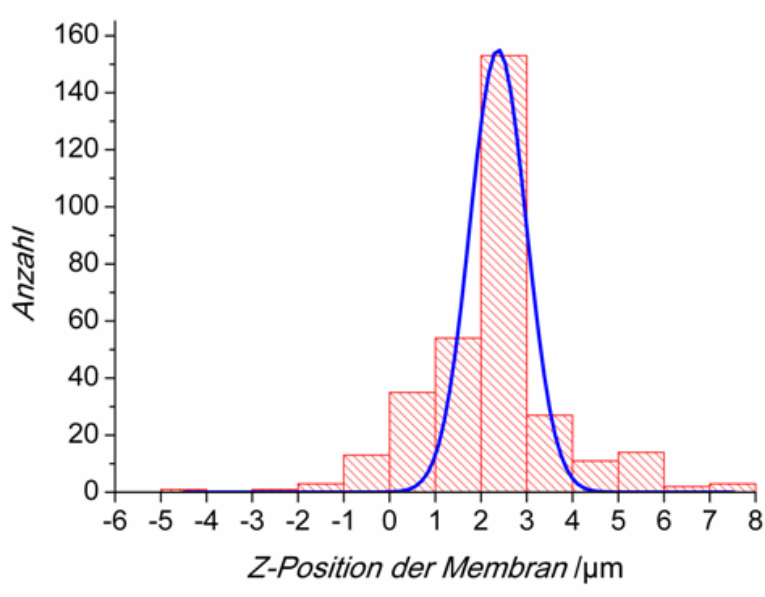

Abb. 4.17: Verteilung der z-Position lösungsmittelfreier porenüberspannender Membranen nach Spreiten von GUVs (POPC/POPS/Texas Red DHPE, 89,8:10,0:0,2), präpariert in Sucroselösungen unterschiedlicher Konzentration (A: $\left.0,15 \mathrm{M}\left(0,163 \mathrm{Osmol} \cdot \mathrm{Kg}^{-1}\right), \mathbf{B}: 0,22 \mathrm{M}\left(0,306 \mathrm{Osmol} \cdot \mathrm{Kg}^{-1}\right), \mathbf{C}: 0,5 \mathrm{M}\left(0,606 \mathrm{Osmol} \cdot \mathrm{Kg}^{-1}\right)\right)$ auf mit 11-Amino-1-undekanthiol funktionalisierten porösen Substraten $(d=5,5 \mu \mathrm{m}, h=9 \mu \mathrm{m})$. Pufferlösung: $107 \mathrm{mM}$ $\mathrm{CaCl}_{2}, 10 \mathrm{mM}$ MOPS, pH 7,3 (TRIS, 0,303 Osmol $\cdot \mathrm{Kg}^{-1}$ ). Die Position der Membranen wurde aus konfokalmikroskopischen Aufnahmen extrahiert. Bei gewölbten Membranen wurde die z-Position über der Porenmitte bestimmt. An die Verteilungen wurde jeweils eine Gauss-Funktion angepasst mit Maxima bei A: 0,55 $\mu \mathrm{m}$ $\left(F W H M=2,7 \mu \mathrm{m}, R^{2}=0,806\right), N=14, \mathrm{~B}: 2,37 \mu \mathrm{m}\left(F W H M=1,5 \mu \mathrm{m}, R^{2}=0,907\right), N=317$ und C: $2,71 \mu \mathrm{m}$ $\left(F W H M=3,3 \mu \mathrm{m}, R^{2}=0,632\right), N=247$.

In Tabelle 4.4 sind die Ergebnisse zusammengefasst und es wird zwischen planaren $(z \leq 0 \mu \mathrm{m})$ und gewölbten $(z>0 \mu \mathrm{m})$ porenüberspannenden Membranen differenziert. Der Anteil gewölbter Membranen steigt mit zunehmender Sucrosekonzentration innerhalb der Poren von $50 \%$ auf $91 \%$. Die Höhe der Ausstülpungen nimmt von hypoosmotischen zu iso-

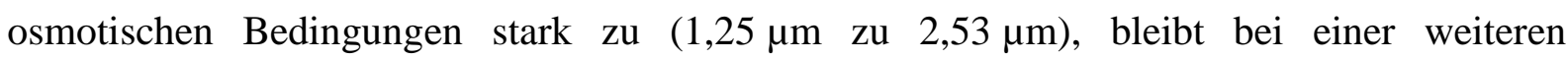
Verdopplung der Osmolalität der GUV-Suspension jedoch annähernd unverändert $(2,82 \mu \mathrm{m})$. Die Position planarer Membranen innerhalb der Poren variiert stark. Die Standardabweichung der Position ist jeweils größer als der Wert der $z$-Position. Tendenziell ist zu erkennen, dass mit abnehmender Sucrosekonzentration die Poren in größerer Tiefe membranüberspannt sind. 
Tabelle 4.4: Zusammenfassung der Ergebnisse zur Verteilung der z-Positionen lösungsmittelfreier Membranen (Experimentelle Bedingungen gemäß Abb. 4.17). Aufgeführt sind der Anteil $(N)$ sowie die mittlere Position $(z)$ planarer $(z \leq 0 \mu \mathrm{m})$ und gewölbter $(z>0 \mu \mathrm{m})$ porenüberspannender Membranen.

\begin{tabular}{|c|c|c|c|}
\hline $\begin{array}{l}\text { Sucrosekonzentration in den } \\
\text { GUVs (Osmolalität) }\end{array}$ & $\begin{array}{l}0,15 \mathrm{M} \\
\left(0,163 \mathrm{Osmol} \cdot \mathrm{Kg}^{-1}\right)\end{array}$ & $\begin{array}{l}0,22 \mathrm{M} \\
\left(0,306 \mathrm{Osmol} \cdot \mathrm{Kg}^{-1}\right)\end{array}$ & $\begin{array}{l}0,5 \mathrm{M} \\
\left(0,606 \mathrm{Osmol} \cdot \mathrm{Kg}^{-1}\right)\end{array}$ \\
\hline$N(z>0 \mu \mathrm{m})$ & $7(50 \%)$ & $275(87 \%)$ & $224(91 \%)$ \\
\hline$N(z \leq 0 \mu \mathrm{m})$ & $7(50 \%)$ & $42(13 \%)$ & $23(9 \%)$ \\
\hline$z(z>0 \mu \mathrm{m})$ & $1,25 \pm 0,75 \mu \mathrm{m}$ & $2,53 \pm 1,26 \mu \mathrm{m}$ & $2,82 \pm 1,17 \mu \mathrm{m}$ \\
\hline$z(z \leq 0 \mu \mathrm{m})$ & $-1,21 \pm 1,65 \mu \mathrm{m}$ & $-0,46 \pm 0,78 \mu \mathrm{m}$ & $-0,17 \pm 0,29 \mu \mathrm{m}$ \\
\hline
\end{tabular}

Eine Zusammenfassung der Ergebnisse zur Charakterisierung lösungsmittelfreier porenüberspannender Membranen ist analog zu derjenigen für lösungsmittelhaltige Membranen (Tabelle 4.1) in Tabelle 4.5 dargestellt.

Tabelle 4.5: Vergleich der ermittelten Werte für die Ausdehnung der Membranfluoreszenz im Porenbereich in $z$-Dimension $(\Delta z)$, die Tiefe (planare Membranen) bzw. Höhe (gewölbte Membranen), in welcher Membranen eine Pore überspannen $(z)$, sowie die Intensität nach Bleichen in Bezug auf die Ausgangsintensität $\left(I_{\text {Bleich }}\right)$ je mit Maximal- und Minimalwerten für lösungsmittelfreie, porenüberspannende Membranen präpariert durch Spreiten von GUVs auf hydrophil funktionalisierten Substraten. Die angegebenen Fehler entsprechen jeweils der Standardabweichung. Die Anzahl der berücksichtigten Experimente bzw. Aufnahmen ist als $N$ angegeben.

\section{CLSM:}

\begin{tabular}{|l|c|c|}
\hline \multirow{2}{*}{$z / \mu \mathrm{m}$} & \multicolumn{2}{|c|}{1,4 bis $2,6 \mu \mathrm{m}$} \\
\hline$z / \mu \mathrm{m}$ & \pm 0 bis $-4,8$ & \pm 0 bis $+7,5$ \\
\hline SICM: & $N=2(13$ Poren $)$ & $N=3$ (21 Poren) \\
\hline$z / \mu \mathrm{m}$ & $-1,25 \pm 1,05$ & $N=5$ \\
\hline FRAP: & $N=3$ & $45 \pm 4(50,39)$ \\
\hline$I_{\text {Bleich }} \%\left(I_{\text {Bleich,max }}, I_{\text {Bleich,min }}\right)$ & $41 \pm 4(46,38)$ & \\
\hline
\end{tabular}




\subsection{Bildung nigericininduzierter elektrochemischer Gradienten}

Es konnte gezeigt werden, dass sich lösungsmittelhaltige, wie auch lösungsmittelfreie porenüberspannende Membranen auf porösen Siliziumsubstraten bilden lassen. In Poren mit geschlossenen Böden konnte der pH-sensitive Farbstoff Pyranin stabil eingeschlossen werden und dabei die Impermeabilität der porenüberspannenden Membranen gegenüber dem dreifach geladenen Molekül gezeigt werden. Weiterhin sollte überprüft werden, ob lösungsmittelhaltige und -freie Membranen auch gegenüber kleinen, einfach geladenen Teilchen, wie Kaliumionen oder Protonen ausreichend impermeabel sind, um mit Hilfe eines $\mathrm{K}^{+} / \mathrm{H}^{+}$-Antiporters elektrochemische Gradienten aufbauen zu können. Dies ist eine Voraussetzung für die Untersuchung von Transportprozessen, wie sie von membranständigen Kanalproteinen und Protonenpumpen verrichtet werden und somit auch Voraussetzung für biotechnologische und pharmazeutische Anwendungen des beschriebenen Systems (Kapitel 1.2).

\section{Pyranin als $p H$-sensitiver Farbstoff}

Um zu untersuchen, inwiefern Pyranin sich als pH-sensitiver Farbstoff zum Nachweis von Protonengradienten eignet, wurden zunächst Absorptions- und Emissionsspektren einer wässrigen Pufferlösung von Pyranin bei verschiedenen pH-Werten UV-Vis spektroskopisch bzw. spektrofluorimetrisch aufgenommen (Abb. 4.18, A und B). Es konnte gezeigt werden, dass eine Protonierung bzw. Deprotonierung des Pyranins zu einer Verschiebung des Absorptionsmaximums führt $\left(\lambda_{\text {max,protoniert }}=404 \mathrm{~nm}, \lambda_{\text {max, deprotoniert }}=455 \mathrm{~nm}\right)$, wobei sich das Emissionsmaximum $(513 \mathrm{~nm})$ nicht verändert. Die Intensität der emittierten Strahlung bei konstanter Anregung korreliert dabei mit dem eingestellten pH-Wert. Pyranin weist zwei isosbestische Punkte bei $\lambda=415 \mathrm{~nm}$ und $\lambda=332 \mathrm{~nm}$ auf. An eine Auftragung der integrierten Emission des Pyranins in Abhängigkeit des $\mathrm{pH}-$ Wertes der Lösung ließ sich ein Verlauf gemäß Gl. 3.4 mit einen $\mathrm{pK}_{\mathrm{S}}-\mathrm{Wert}$ von 7,2 anpassen (Abb. 4.18, C). 

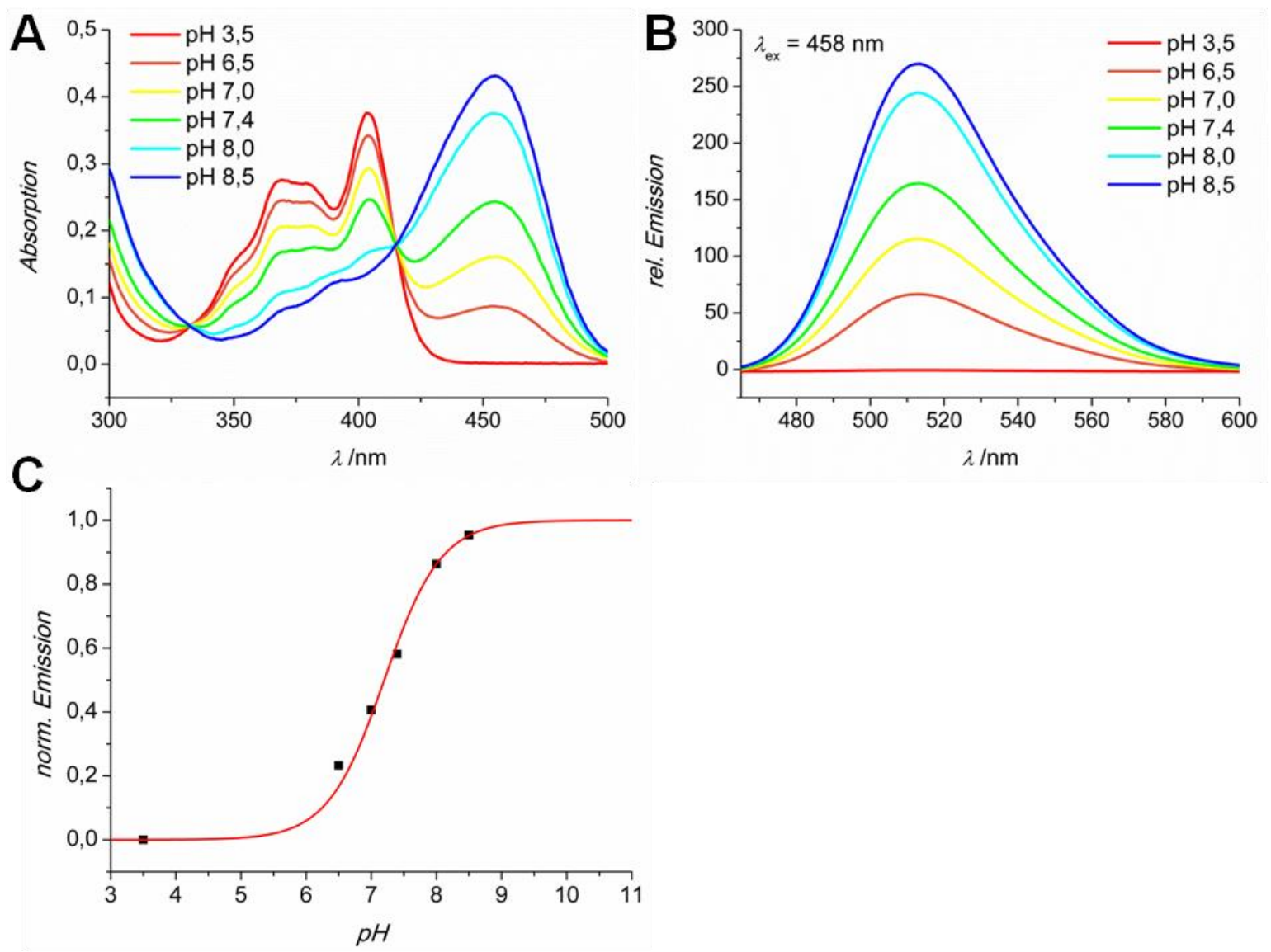

Abb. 4.18: A Absorptionsspektren von Pyranin in $100 \mathrm{mM} \mathrm{KCl}, 10 \mathrm{mM}$ TRIS (pH-Werte mit HCl bzw. KOH eingestellt, $c_{\text {Pyranin }}=0,2 \mathrm{mM}$ ). B Emissionsspektren derselben Lösungen bei einer Anregung mit Licht einer Wellenlänge von $458 \mathrm{~nm}$. C Verlauf der Emission von Pyranin in Abhängigkeit des pH-Wertes. An die Daten wurde ein Verlauf gemäß Gl. 3.4, umgestellt nach [Py $\left.{ }^{-}\right]$mit einem $\mathrm{pK}_{\mathrm{s}}-$ Wert von 7,2 und einer normierten Gesamtpyraninkonzentration von $[\mathrm{Py}]^{0}=1$ angepasst (rot). Die Emissionsspektren aus B wurden integriert und die Integrale auf den Maximalwert der angepassten Funktion normiert.

Eine konfokalmikroskopische Zeitserie von in Poren eingeschlossenem Pyranin zeigte bei Anregung mit Licht einer Wellenlänge von $458 \mathrm{~nm}$ einen konstanten Intensitätsverlauf der Pyraninfluoreszenz (Abb. 4.19). Wurde der Farbstoff hingegen bei 405 nm angeregt, konnte ein Abfall der Pyraninintensität beobachtet werden durch ein Photobleichen des Farbstoffs.

Die Intensitätsänderung der Pyraninfluoreszenz bei einer Anregung der deprotonierten Spezies eignete sich demnach zum Nachweis von $\mathrm{pH}$-Wertänderungen und wurde zur Untersuchung der Bildung elektrochemischer Gradienten eingesetzt. 


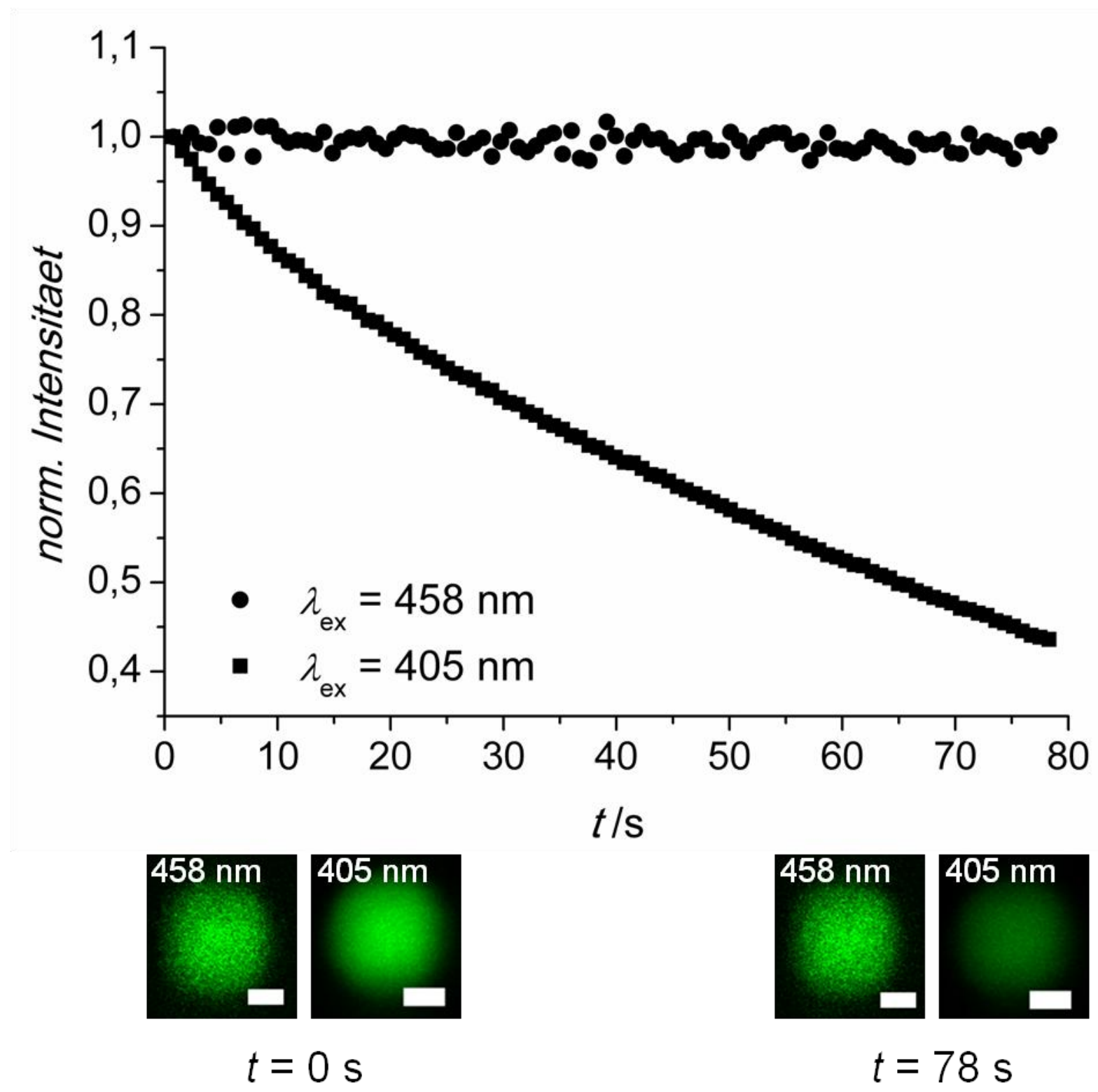

Abb. 4.19: Zeitlicher Verlauf der Fluoreszenzintensität von in $8 \cdot 8 \cdot 12 \mu \mathrm{m}^{3}$ großen Poren eingeschlossenem Pyranin (0,5 mM in $160 \mathrm{mM} \mathrm{KCl}, 10 \mathrm{mM}$ MOPS, pH 7,3 (KOH)) unter einer painted membrane aus DPhPC und DPPA (9:1) nach Ausfrieren des Lösungmittels ( $n$-Dekan, $10 \mathrm{~min},-2{ }^{\circ} \mathrm{C}$ ). Während die Intensität der Pyraninfluoreszenz bei einer Anregungswellenlänge von $458 \mathrm{~nm}$ annähernd konstant bleibt (匹), nimmt die Intensität bei einer Anregungswellenlänge von $405 \mathrm{~nm}$ rapide in einer nicht-linearen Weise ab (•), was auf eine hohe Photobleichrate hindeutet. Die Fluoreszenz wurde jeweils in einem Bereich von 500-580 nm detektiert bei Laserintensitäten von $5 \%(405 \mathrm{~nm})$ und $7 \%(458 \mathrm{~nm})$. Unterhalb des Verlaufs sind die entsprechenden konfokalmikroskopischen Aufnahmen der jeweiligen pyraningefüllten Pore zu Beginn der Messung $(t=0 \mathrm{~s})$ und $\mathrm{zu}$ Ende der Messung $(t=78 \mathrm{~s})$ dargestellt.

\subsubsection{Bildung elektrochemischer Gradienten in Liposomen}

Ein Ionophor, welche den entgegengesetzten Transport von Kaliumionen und Protonen über Lipidmembranen ausführt, ist der Antiporter Nigericin (Kapitel 1.2.1). Hell et al. konnten Nigericin bereits erfolgreich einsetzen, um einen vorhandenen Kaliumionengradienten in 
Lipidvesikeln mit Durchmessern kleiner $1 \mu \mathrm{m}$ in einen Protonengradienten umzuwandeln. ${ }^{[85]}$ Dessen Bildung verfolgten sie qualitativ UV-Vis spektroskopisch durch Zugabe des $\mathrm{pH}$ sensitiven Farbstoffs Acridinorange.

In Versuchen an unilamellaren Lipidvesikeln sollte getestet werden, ob sich auch Pyranin als pH-sensitiver Farbstoff eignet, um den nigericininduzierten Aufbau eines Protonengradienten zu verfolgen. Der Farbstoff wurde hierzu im Vesikelinneren bei deren Bildung eingeschlossen und äußerer Farbstoff säulenchromatografisch abgetrennt (Kapitel 3.4.1). Statt der Absorption des Farbstoffs wurde die Veränderung der Fluoreszenzintensität fluoreszenzspektrometrisch detektiert.

Der Verlauf der detektierten Intensität der emittierten Strahlung während eines Experiments mit in situ Bildung eines elektrochemischen Gradienten ist in Abb. 4.20 und Abb. 4.21 dargestellt. In Abb. 4.20, A wurden die Vesikel in kaliumionenhaltigem Puffer präpariert und in kaliumionenfreie Pufferlösung überführt. Bei Zugabe von Nigericin sank die Intensität der Pyraninfluoreszenz innerhalb weniger Sekunden auf einen Wert von 4 Einheiten ab. Daraus lässt sich schließen, dass der pH-Wert innerhalb der Vesikel durch den Transport von Protonen in die Vesikel hinein und von Kaliumionen aus diesen heraus abnimmt. Eine Zugabe von Ammoniumsulfat, einer Substanz, welche Protonengradienten durch Eintritt ins Vesikelinnere wieder abbauen kann (Entkoppler), führte zu einem leichten Anstieg der Fluoreszenzintensität. Durch Zugabe von Entkopplern können Änderungen in der Intensität eindeutig einem Protonengradienten zugeordnet werden.

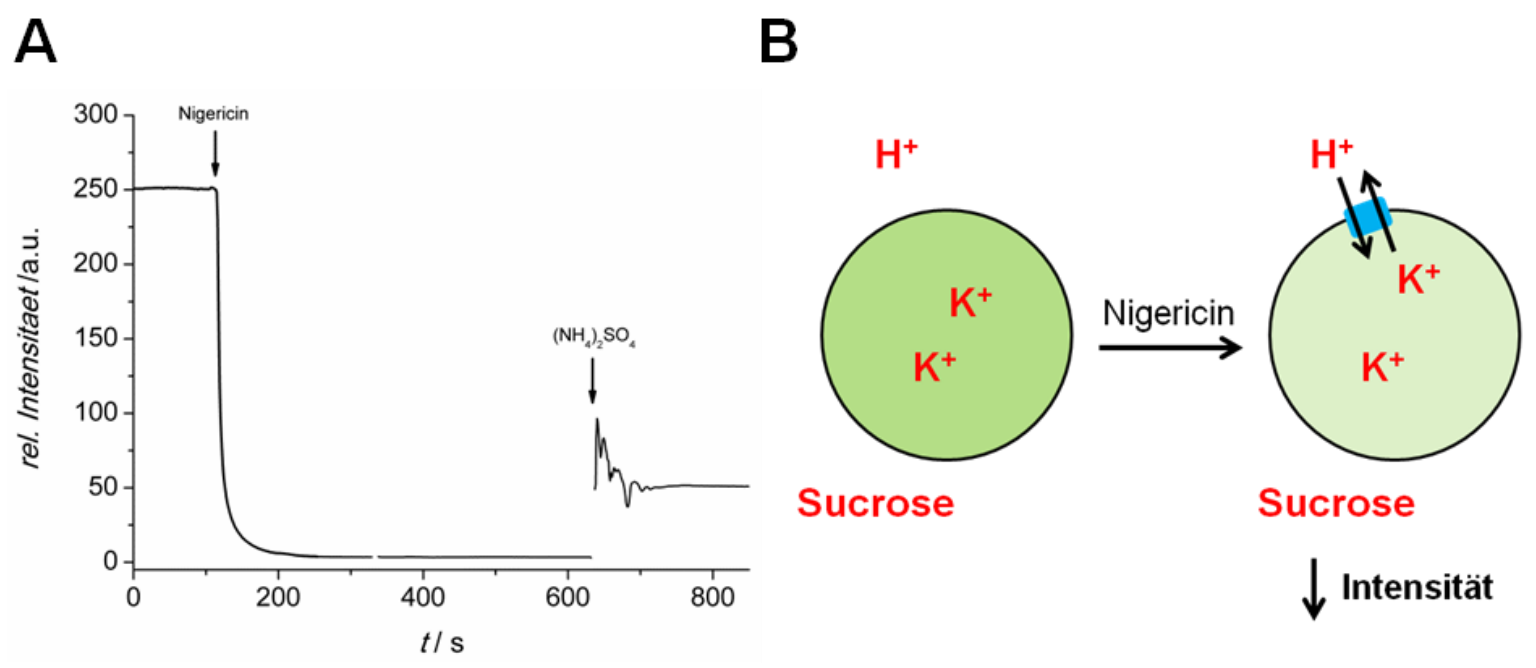

Abb. 4.20: A Fluoreszenzspektrometrisch detektierter Verlauf der Pyraninfluoreszenz in unilamellaren Lipidvesikeln (DPhPC, nomineller Porendurchmesser bei Extrusion $1000 \mathrm{~nm}$ ) bei Aufbau eines elektrochemischen Gradienten. Pufferlösung in den Vesikeln: $160 \mathrm{mM} \mathrm{KCl,} 10 \mathrm{mM}$ MOPS, $1 \mathrm{mM}$ Pyranin, pH 7,3 (KOH). Umgebende Pufferlösung $320 \mathrm{mM}$ Sucrose, $10 \mathrm{mM}$ MOPS, pH 7,3 (TRIS). Die Zugabe von Nigericin $\left(1 \mathrm{mg} \cdot \mathrm{mL}^{-1}\right.$ in Ethanol, $\left.c_{\text {final }}=4,2 \mu \mathrm{M}\right)$ und Ammoniumsulfat $\left(0,4 \mathrm{M}, c_{\text {final }}=24 \mathrm{mM}\right)$ ist jeweils mit Pfeilen gekennzeichnet. Anregungswellenlänge $\lambda_{\mathrm{ex}}=458 \mathrm{~nm}$, Emissionswellenlänge $\lambda_{\mathrm{em}}=515 \mathrm{~nm}$. B Schematische Darstellung des nigericininduzierten Kaliumionen-Protonen-Antiports. Der pH-Sensitive Farbstoff Pyranin (grün) ist in Vesikeln eingeschlossen. Bei Änderung des pH-Wertes im Vesikelinneren verändert sich die Intensität der Pyraninfluoreszenz. 
In Abb. 4.21, A wurde der vorgelegte Kaliumionengradient vertauscht, sodass im Vesikelinneren keine Kaliumionen vorlagen, jedoch in der umgebenden Pufferlösung. Bei Zugabe von Nigericin konnte in diesem Fall ein Anstieg der Fluoreszenzintensität von 35 auf 115 Einheiten beobachtet werden. Es wurden also Kaliumionen in die Vesikel hinein und Protonen aus den Vesikeln heraus transportiert, was einen Anstieg des pH-Wertes im Vesikelinneren zur Folge hatte. Eine Zugabe von reinem Ethanol statt einer Lösung von Nigericin in Ethanol bei vorgeformten Kaliumionengradienten hatte keinen Einfluss auf die Pyraninfluoreszenz. Wurde kein Kaliumionengradient vorgelegt und Vesikel in einer Pufferlösung vermessen mit gleicher Zusammensetzung, in welcher sie präpariert worden waren (abzüglich des Pyranins), so konnten nur geringe Intensitätsunterschiede bei Zugabe von Nigericin detektiert werden. Wurden die Vesikel nach Aufbau eines Protonengradienten durch Zugabe von Detergens (Triton-X-100) lysiert, konnte ein Rückgang der Fluoreszenzintensität auf das Anfangsniveau beobachtet werden. Die gezeigten Verläufe der Pyraninintensität lassen sich demnach eindeutig auf einen nigericininduzierten Kaliumionen-Protonen-Antiport zurückführen und belegen den Aufbau eines stabilen elektrochemischen Gradienten.

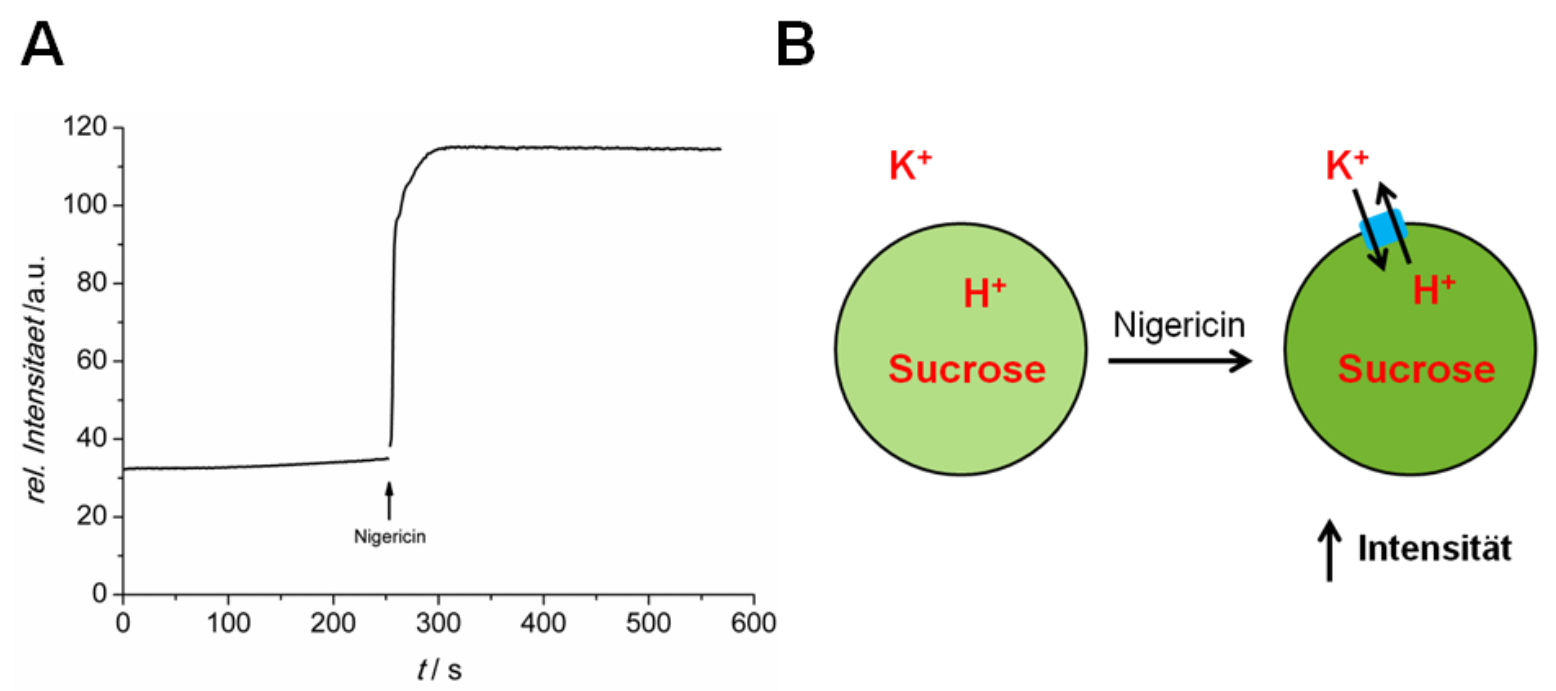

Abb. 4.21: Fluoreszenzspektrometrisch detektierter Verlauf der Pyraninfluoreszenz in unilamellaren Lipidvesikeln (DPhPC, nomineller Porendurchmesser bei Extrusion $1000 \mathrm{~nm}$ ) bei Aufbau eines elektrochemischen Gradienten. Pufferlösung in den Vesikeln: $320 \mathrm{mM}$ Sucrose, $10 \mathrm{mM}$ MOPS, $1 \mathrm{mM}$ Pyranin, pH 7,3 (TRIS). Umgebende Pufferlösung $160 \mathrm{mM} \mathrm{KCl,} 10 \mathrm{mM}$ MOPS, pH 7,3 (KOH). Die Zugabe von Nigericin $\left(1 \mathrm{mg} \cdot \mathrm{mL}^{-1} \mathrm{in}\right.$ Ethanol, $c_{\text {final }}=8,4 \mu \mathrm{M}$ ) ist mit einem Pfeil gekennzeichnet. Anregungswellenlänge $\lambda_{\mathrm{ex}}=458 \mathrm{~nm}$, Emissionswellenlänge $\lambda_{\mathrm{em}}=515 \mathrm{~nm}$. B Schematische Darstellung des nigericininduzierten Kaliumionen-ProtonenAntiports. Der pH-Sensitive Farbstoff Pyranin (grün) ist in Vesikeln eingeschlossen. Bei Änderung des pH-Wertes im Vesikelinneren verändert sich die Intensität der Pyraninfluoreszenz.

\subsubsection{Bildung elektrochemischer Gradienten in GUVs}

Pyraningefüllte GUVs wurden gemäß Kapitel 3.4.2 präpariert und auf mit Avidin funktionalisierten planaren Siliziumsubstraten immobilisiert. Um zu untersuchen, ob der nigericininduzierte Aufbau eines elektrochemischen Gradienten auch bei mikrometergroßen Vesikeln 
möglich ist und mittels konfokalmikroskopischer Aufnahmen nachgewiesen werden kann, wurden immobilisierte GUVs vor und nach Zugabe von Nigericin abgebildet. In Abb. 4.22, A und B ist eine konfokalmikroskopische Aufnahme eines fixierten GUV, gefüllt mit kaliumionenfreier Pufferlösung und von kaliumionenhaltiger Pufferlösung umgeben, dargestellt. Der GUV weist einen Durchmesser von etwa $85 \mu \mathrm{m}$ auf und eine homogene Texas Red DHPE Fluoreszenz im Membranbereich (A). Der gesamte membranumschlossene Bereich innerhalb des GUV zeigt eine homogene Pyraninfluoreszenz mit einer mittleren Intensität von $I=183$ Einheiten und hebt sich klar vom Hintergrund ab (B). Nach Zugabe von Nigericin nahm die Intensität der Pyraninfluoreszenz im Inneren der immobilisierten Vesikel innerhalb weniger Minuten deutlich zu. Dies zeigen Abb. 4.22, C und D anhand eines GUV nach Inkubation mit Nigericin. Die Membranfluoreszenz erscheint unverändert homogen und durchgängig (C), die Pyraninfluoreszenz im Vesikelinneren ist jedoch angestiegen und weist eine mittlere Intensität von $I=237$ Einheiten auf (D). Durch die Darstellung der Pyraninfluoreszenz in Form des range indicator Modus, bei welchem rote Pixel solchen mit Intensitätswerten größer dem Detektionslimit von 255 Einheiten entsprechen, lässt sich der Anstieg der Fluoreszenzintensität gut erkennen.

Wurden mit kaliumionenfreier Pufferlösung gefüllte GUVs in ebenfalls kaliumionenfreier Pufferlösung immobilisiert, so blieb die Intensität der Pyraninfluoreszenz im Vesikelinneren nach Zugabe von Nigericin unverändert. Diese Ergebnisse lassen darauf schließen, dass die Intensitätsunterschiede auf einen $\mathrm{K}^{+} / \mathrm{H}^{+}$-Antiport, induziert durch Nigericin und somit einer Alkalisierung des Inneren der GUVs zurückzuführen sind. 

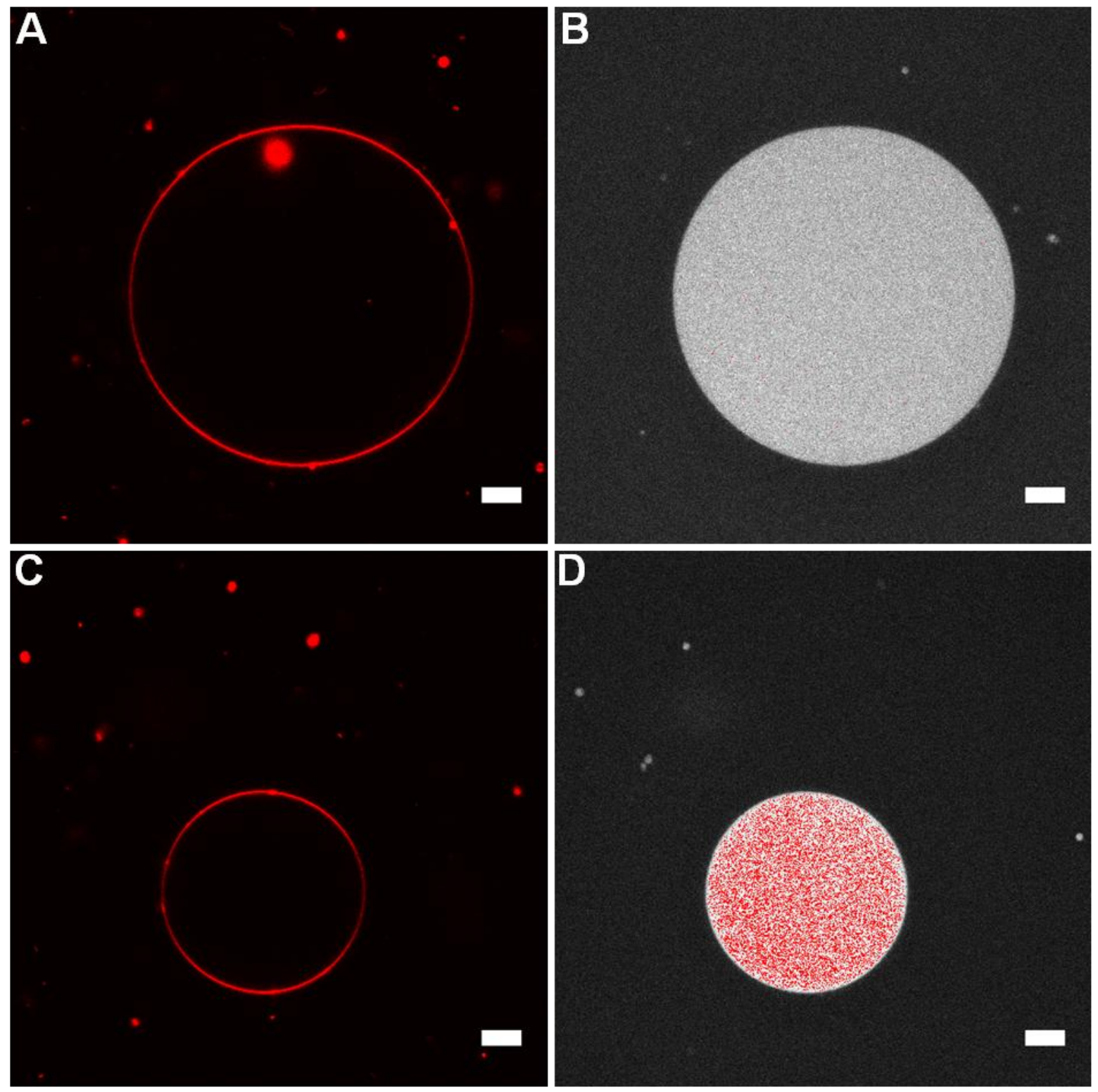

Abb. 4.22: Konfokalmikroskopische Aufnahmen von GUVs (DPhPC/DOPC/Bio-Cap-PE/Texas Red DHPE, 59,4:39,4:1,0:0,2, rot). Die GUVs wurden unter Hochsalzbedingungen präpariert (Pufferlösung: $320 \mathrm{mM}$ Sucrose, $10 \mathrm{mM}$ MOPS, 0,5 mM Pyranin, $\mathrm{pH}$ 7,3 (TRIS)) und auf einem mit Avidin funktionalisierten planaren Siliziumsubstrat immobilisiert. Pufferlösung: $160 \mathrm{mM} \mathrm{KCl}, 10 \mathrm{mM}$ MOPS, pH 7,3 (KOH). A und $\mathbf{C}$ zeigen jeweils die Texas Red DHPE Fluoreszenz der Membran eines GUV, B und D die Fluoreszenz des eingeschlossenen Pyranins. Die Pyraninfluoreszenz ist hier nicht in grün dargestellt, sondern zur besseren Unterscheidung der Intensitätswerte im range indicator Modus angezeigt. Pixel mit einer Intensität $I \geq 255$ Einheiten werden dabei rot abgebildet, Pixel mit einer Intensität $0<I<255$ in Grautönen und Pixel mit einer Intensität $I=0$ in blau dargestellt. A und $\mathbf{B}$ zeigen einen GUV vor Zugabe von Nigericin, $\mathbf{C}$ und $\mathbf{D}$ einen anderen GUV nach Zugabe von Nigericin $\left(c_{\text {final }}=2,7 \mu \mathrm{M}\right)$. Maßstabsbalken $10 \mu \mathrm{m}$.

Insgesamt wurde die Intensität der Pyraninfluoreszenz in $N=210$ GUVs vor Zugabe von Nigericin (blau) und in $N=139$ GUVs nach Nigericinzugabe (rot) ausgelesen und in Abb. 4.23 aufgetragen. An beide Verteilungen wurde eine Gauss-Funktion angepasst. Für die Intensitätsverteilung von Pyranin in GUVs vor Nigericinzugabe ergaben sich dabei Werte für das Bestimmtheitsmaß von $R^{2}=0,907$ bei einer maximalen Intensität von $I=153$ Einheiten 
und einer Halbwertsbreite von $F W H M=52$ Einheiten. Nach Nigericinzugabe wurden Werte ermittelt von $R^{2}=0,934, I=250$ Einheiten und $F W H M=41$ Einheiten. Das Intensitätsmaximum der Verteilungen verschiebt sich nach Zugabe von Nigericin somit um 97 Einheiten. Die Verteilungen überlappen lediglich in einem Intensitätsbereich von 190 bis 200 Einheiten und sind somit weitgehend voneinander getrennt. Es gilt zu beachten, dass der maximal detektierbare Wert der Pyraninintensität (Detektorsättigung) 255 Einheiten beträgt und dadurch der Intensitätsanstieg nach Nigericinzugabe nicht vollständig dargestellt werden kann. Die Verteilung nach Nigericinzugabe kann somit nicht exakt angepasst werden und der Wert für das Intensitätsmaximum der Verteilung wird dabei unterschätzt, sodass sich eine größere Verschiebung des Maximums als von 97 Einheiten ergibt. Qualitativ behält die Verteilung ihre Aussagekraft und verdeutlicht den nigericininduzierten Anstieg der Pyraninfluoreszenz innerhalb der GUVs und somit den Aufbau eines elektrochemischen Gradienten.

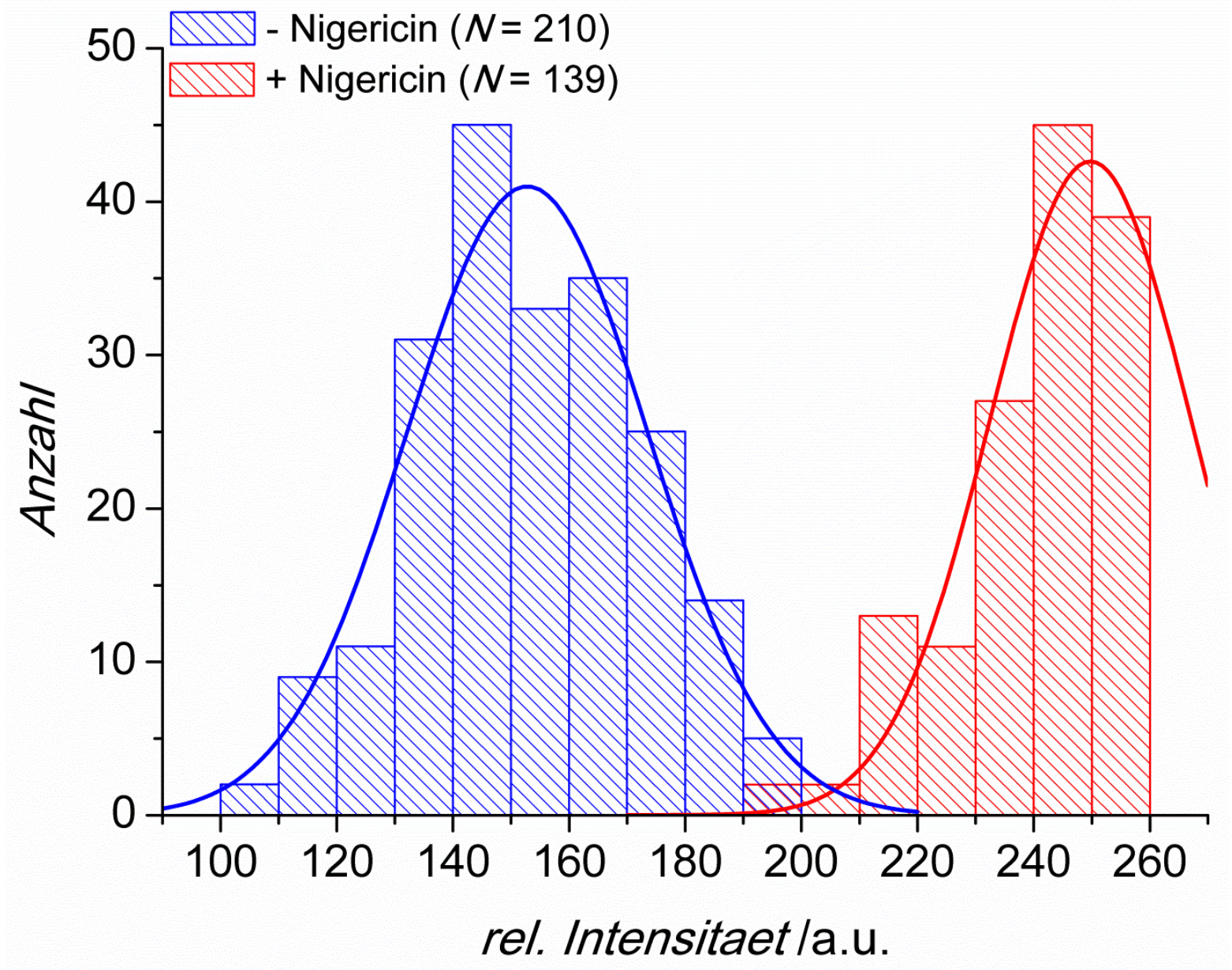

\begin{abstract}
Abb. 4.23: Verteilung der Fluoreszenzintensität des in GUVs eingeschlossenen Pyranins vor (blau) und nach (rot) Zugabe von Nigericin. Zusammensetzungen der Pufferlösungen und GUVs analog zu Abb. 4.22. Die experimentellen Bedingungen sind identisch mit den unter Abb. 4.22 erwähnten. An beide Verteilungen wurde jeweils eine Gauss-Funktion angepasst (durchgezogene Linie) mit Parametern von $R^{2}=0,907, I=153$ Einheiten und $F W H M=52$ Einheiten vor Nigericinzugabe und $R^{2}=0,934, I=250$ Einheiten und $F W H M=41$ Einheiten nach Zugabe von Nigericin. Die Anzahl der berücksichtigten GUVs ist jeweils mit $N$ gekennzeichnet.
\end{abstract}




\subsubsection{Bildung elektrochemischer Gradienten in porenüberspannenden Membranen}

Der für Modellsysteme auf Basis von Liposomen verschiedener Größe etablierte Assay zur in situ Bildung nigericininduzierter elektrochemischer Gradienten wurde auf das System der porenüberspannenden Membranen übertragen. Hierzu wurde Pyranin in Poren mit geschlossenen Böden unter lösungsmittelfreien und -haltigen porenüberspannenden Membranen eingeschlossen und durch Austausch der überstehenden Pufferlösung ein Kaliumionengradient erzeugt (Kapitel 3.4.3). Die Änderung der Fluoreszenzintensität eingeschlossenen Pyranins bei Zugabe von Nigericin wurde zeitaufgelöst konfokalmikroskopisch verfolgt.

Während GUVs eine breite Größenverteilung aufweisen und Maßnahmen zur (selektiven) Fixierung der Vesikel nötig sind, welche die Stabilität und Undurchlässigkeit der Membran beeinträchtigen können, ${ }^{[194,195]}$ bieten die im Rahmen dieser Arbeit verwendeten Substrate periodisch angeordnete Poren mit identischem Volumen und ermöglichen somit theoretisch ein vollautomatisches Auslesen einzelner Kavitäten, was Voraussetzung für eine Anwendung im Bereich des Screenings ist (z. B. high throughput screenings).

\section{Lösungsmittelhaltige porenüberspannende Membranen}

Der Verlauf der Fluoreszenzintensität eingeschlossenen Pyranins für eine Pore bei Zugabe von Nigericin für porenüberspannende painted membranes nach Ausfrieren des Lösungsmittels ist in Abb. 4.24 dargestellt. Bei Einschluss einer kaliumionenhaltigen Pufferlösung im Poreninneren und Vorliegen einer kaliumionenfreien überstehenden Pufferlösung, kann $13 \mathrm{~s}$ nach Zugabe von Nigericin ein Abfall der Intensität von 50 auf 10 Einheiten beobachtet werden (A). Dieser Abfall entspricht einer Änderung des $\mathrm{pH}$-Wertes um $\Delta \mathrm{pH}=-0,94$ Einheiten (zur Berechnung der pH-Wertänderungen siehe Kapitel 3.4.3, Datenauswertung). Im weiteren Verlauf bleibt die Intensität konstant, bis sie bei Zugabe von Ammoniumsulfat um zehn und bei erneuter Zugabe um weitere sechs Einheiten ansteigt $(\Delta \mathrm{pH}=+0,30$ bzw. $+0,12$ Einheiten). Dieser Intensitätsverlauf deutet auf einen nigericininduzierten Protonentransport in die Poren hinein und einem damit verbundenen Sinken der Intensität der Pyraninfluoreszenz hin. Ammoniumionen stehen mit ihrer deprotonierten Form, dem Ammoniak, im Gleichgewicht. Dieser kann als ungeladenes, kleines Molekül durch die Membranen in die Poren hinein gelangen, dort protoniert werden und so bei Zugabe den $\mathrm{pH}-$ Wert und die Intensität der Pyraninfluoreszenz partiell anheben. Exemplarisch sind unter Abb. 4.24, B CLSM-Aufnahmen der Pyraninfluoreszenz in den Poren zu ausgewählten Zeitpunkten der Zeitserie aufgeführt. Die Aufnahmen belegen, dass die Position des Substrates im Verlauf der Zeitserie konstant bleibt und Änderungen im Verlauf eindeutig der Pyraninfluoreszenz im Poreninneren zugeordnet werden können. 


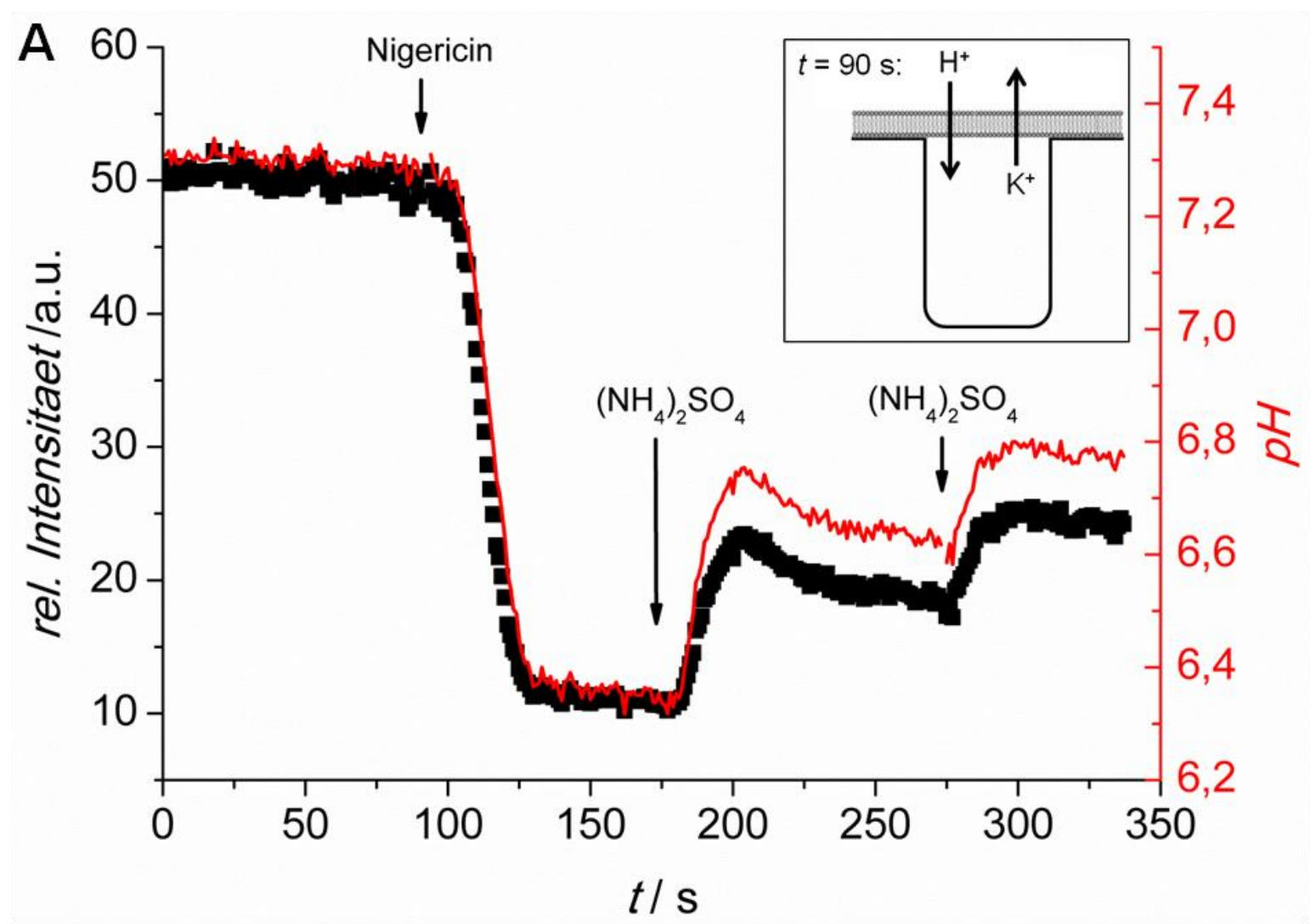

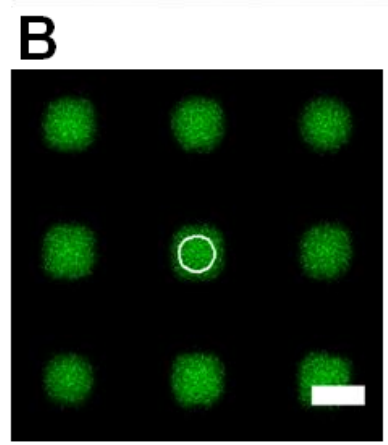

$t=0 \mathrm{~s}$

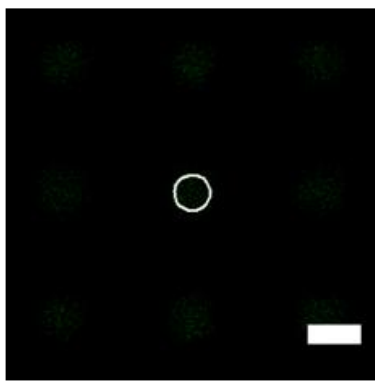

$150 \mathrm{~s}$

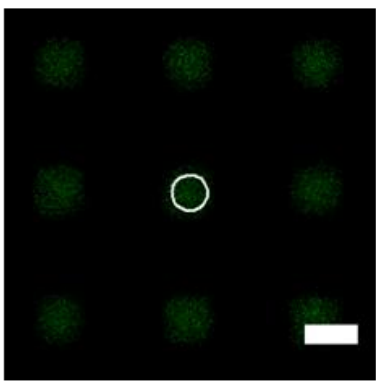

$273 \mathrm{~s}$

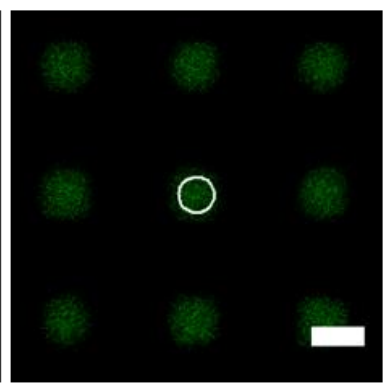

$337 \mathrm{~s}$

Abb. 4.24: A Zeitlicher Verlauf der Fluoreszenzintensität (schwarze Achse, ø), sowie des daraus errechneten pH-Wertes (rot) in einer Pore eingeschlossenen Pyranins. Poren mit geschlossenen Böden $\left(8 \cdot 8 \cdot 12 \mu \mathrm{m}^{3}\right)$ wurden mittels painting-Technik mit einer Membran überspannt (DPhPC/DPPA, 9:1) und nach Ausfrieren des Lösungsmittels ein Kaliumionengradient erzeugt. Pufferlösung in den Poren: $160 \mathrm{mM} \mathrm{KCl,} 10 \mathrm{mM}$ MOPS, 0,5 mM Pyranin, pH 7,3 (KOH). Überstehende Pufferlösung: 320 mM Sucrose, 10 mM MOPS, pH 7,3 (TRIS). 3,3 $\mu$ M Nigericin $\left(1 \mathrm{mg} \cdot \mathrm{mL}^{-1}\right.$ in EtOH) wurden zugegeben. Nach Aufbau eines Protonengradienten wurden $15 \mathrm{mM}$ Ammoniumsulfat (3 M) zugefügt. Die Zeitpunkte der Zugaben sind jeweils durch einen Pfeil markiert. Schematische Darstellungen der Richtung des Ionentransports sind jeweils in der oberen rechten Ecke eingefügt. B CLSM-Aufnahmen der Probe zu ausgewählten Zeitpunkten. Die ROI, in welcher die Fluoreszenzintensität von Pyranin ausgelesen wurde, welche in A aufgetragen ist, ist durch einen weißen Kreis markiert. Maßstabsbalken $5 \mu \mathrm{m}$.

Bei Umkehr des vorgelegten Kaliumionengradienten nimmt die Fluoreszenzintensität unmittelbar nach Nigericinzugabe von 90 Einheiten auf einen Maximalwert von 190 Einheiten $\mathrm{zu}$ (Abb. 4.25). Das entspricht einem Anstieg des pH-Wertes von 
$\Delta \mathrm{pH}=+1,80$ Einheiten. Dieser Verlauf lässt sich durch einen nigericininduzierten Eintritt von Kaliumionen und einem parallel verlaufenden Austritt von Protonen aus den Poren erklären. Dadurch steigt der $\mathrm{pH}-$ Wert im Poreninneren und die Intensität der Pyraninfluoreszenz nimmt zu. Es ist bereits vor Nigericinzugabe eine leichte, lineare Verringerung der Pyraninfluoreszenz (8 Einheiten $\cdot \mathrm{min}^{-1}$, entspricht $0,065 \mathrm{pH} \cdot \mathrm{min}^{-1}$ ) $\mathrm{zu}$ erkennen, welche auf ein Photobleichen des Pyranins zurückzuführen ist. Nach Zugabe von Carbonylcyanid- $p$-(trifluormethoxy)phenylhydrazon (FCCP) fällt die Intensität zunächst von 175 auf 40 Einheiten ab (entspricht $\Delta \mathrm{pH}=-1,74$ Einheiten) und nimmt schließlich bei $t=370 \mathrm{~s}$ einen Wert von drei Einheiten an. FCCP kann durch seine mesomeriestabilisierte Struktur Protonen über die Membran transportieren und den zuvor aufgebauten Protonengradienten so wieder abbauen (Kapitel 1.2.1).

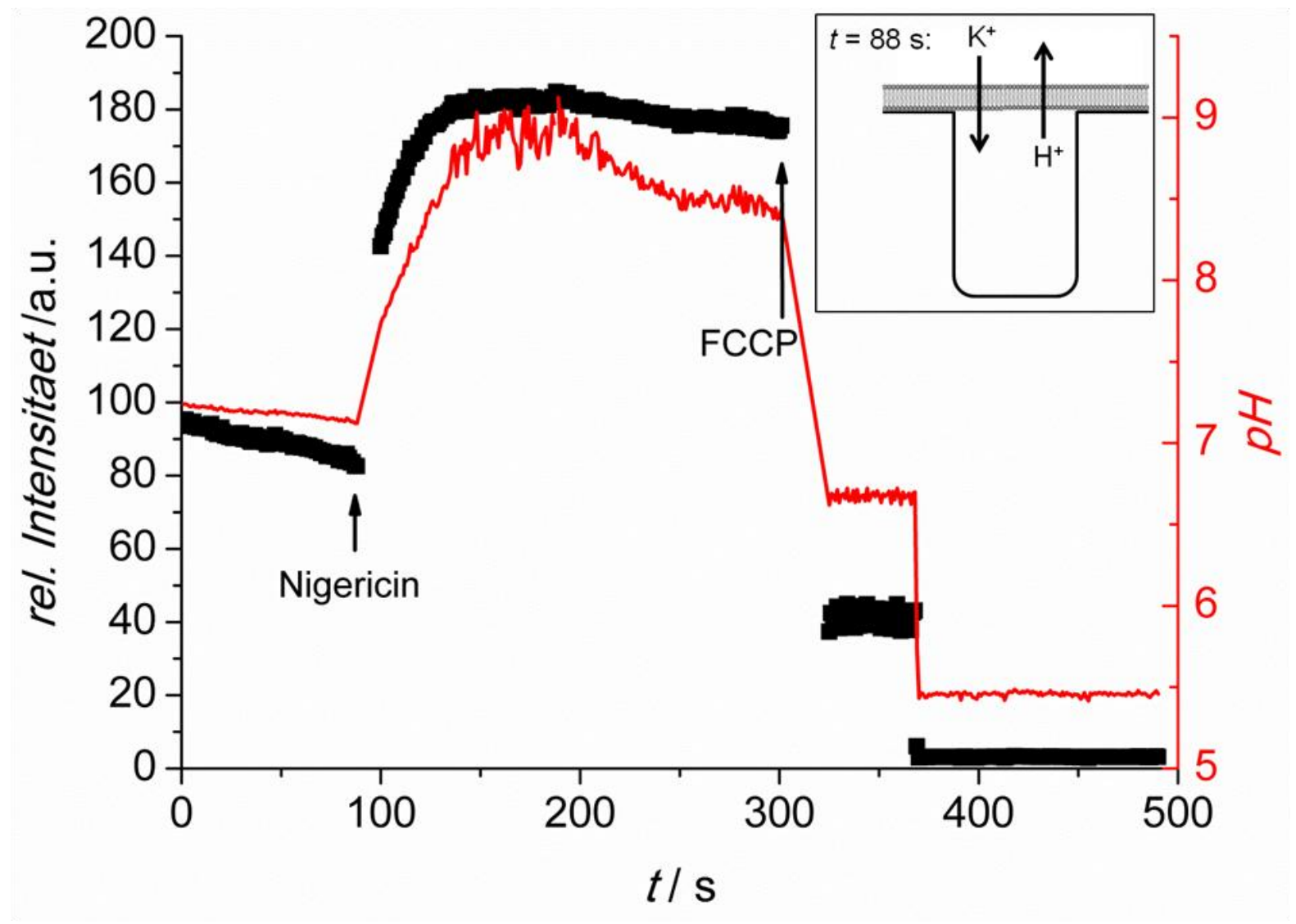

Abb. 4.25: Zeitlicher Verlauf der Fluoreszenzintensität (schwarze Achse, a), sowie des daraus errechneten pH-Wertes (rot) in einer Pore eingeschlossenen Pyranins. Poren mit geschlossenen Böden $\left(8 \cdot 8 \cdot 12 \mu \mathrm{m}^{3}\right)$ wurden mittels painting-Technik mit einer Membran überspannt (DPhPC/DPPA, 9:1) und nach Ausfrieren des Lösungsmittels ein Kaliumionengradient erzeugt. Pufferlösung in den Poren: $320 \mathrm{mM}$ Sucrose, $10 \mathrm{mM}$ MOPS, 0,5 mM Pyranin, pH 7,3 (TRIS). Überstehende Pufferlösung: $160 \mathrm{mM} \mathrm{KCl,} 10 \mathrm{mM}$ MOPS, pH 7,3 (KOH). 3,3 $\mu \mathrm{M}$ Nigericin $\left(1 \mathrm{mg} \cdot \mathrm{mL}^{-1}\right.$ in EtOH) wurden zugegeben. Nach Aufbau eines Protonengradienten wurden $10 \mu \mathrm{M}$ FCCP $\left(1 \mathrm{mg} \cdot \mathrm{mL}^{-1}\right.$ in EtOH $)$ zugefügt. Zum Zeitpunkt $t=370 \mathrm{~s}$ konnte ein Reissen der Membran und dadurch ein Freisetzen von Pyranin beobachtet werden und die Intensität fällt auf einen Wert von rund Null. Die Zeitpunkte der Zugaben sind jeweils durch einen Pfeil markiert. Schematische Darstellungen der Richtung des Ionentransports sind jeweils in der oberen rechten Ecke eingefügt. 
Unter Berücksichtigung des linearen Abfalls der Pyraninfluoreszenz zu Beginn des Experiments fällt die Intensität nach Zugabe von FCCP auf den Ausgangswert zurück, bevor bei $t=370 \mathrm{~s}$ die Membran reisst und Pyranin aus der Pore austritt. Dabei fällt die Fluoreszenzintensität auf das Hintergrundniveau ab.

Über mittels painting-Technik präparierten porenüberspannenden Membranen gebildete Protonengradienten waren für mehrere Tage stabil $(>45 \mathrm{~h})$. Dies äußerte sich in einer unveränderten Fluoreszenzintensität sowohl der protonierten $\left(\lambda_{\mathrm{ex}}=405 \mathrm{~nm}\right)$ als auch der deprotonierten Form $\left(\lambda_{\mathrm{ex}}=458 \mathrm{~nm}\right)$ von Pyranin nach Aufbau eines nigericininduzierten Gradienten. Kontrollexperimente wurden durchgeführt, bei denen statt einer Lösung von Nigericin in Ethanol reines Ethanol zu einer Probe mit vorgelegtem Kaliumionengradienten gegeben wurde. Weiterhin wurde Nigericin zu Proben gegeben, welche dieselbe Pufferlösung im Poreninneren wie im überstehenden Medium aufwiesen, wodurch kein Kaliumionengradient vorlag. In beiden Fällen änderte sich die Intensität der Pyraninfluoreszenz in den Poren nicht oder nur geringfügig, sodass Änderungen in der Pyraninfluoreszenz eindeutig der Bildung eines Protonengradienten zugeordnet werden konnten. Vor Zugabe von Nigericin, sowie nach Einstellen des Protonengradienten verlief die Intensität der Pyraninfluoreszenz typischerweise linear auf einem konstanten Niveau. Lediglich in Ausnahmen konnte ein linearer Abfall bzw. Anstieg beobachtet werden.

Um eine Transportrate für den Protonenaustausch über porenüberspannende Membranen zu errechnen, wurde der $\mathrm{pH}$-Verlauf unmittelbar nach Nigericinzugabe linear angepasst und daraus die Steigung bestimmt (Initialsteigung, Kapitel 3.4.3). Der Verlauf des pH-Wertes innerhalb einer membranüberspannten Pore und eine lineare Anpassung daran nach Nigericinzugabe ist exemplarisch in Abb. 4.26 dargestellt. Anhand der ermittelten Initialsteigungen wurden für lösungsmittelhaltige porenüberspannende Membranen Transportraten im Bereich von $10^{14} \mathrm{H}^{+} \cdot \mathrm{cm}^{-2} \cdot \mathrm{s}^{-1}$ bestimmt. Dieser Wert wurde für Intensitätsanstiege und -abfälle für Nigericinkonzentrationen von 3,34 $\mu \mathrm{M}$ und 16,7 $\mu \mathrm{M}$ bestimmt. 


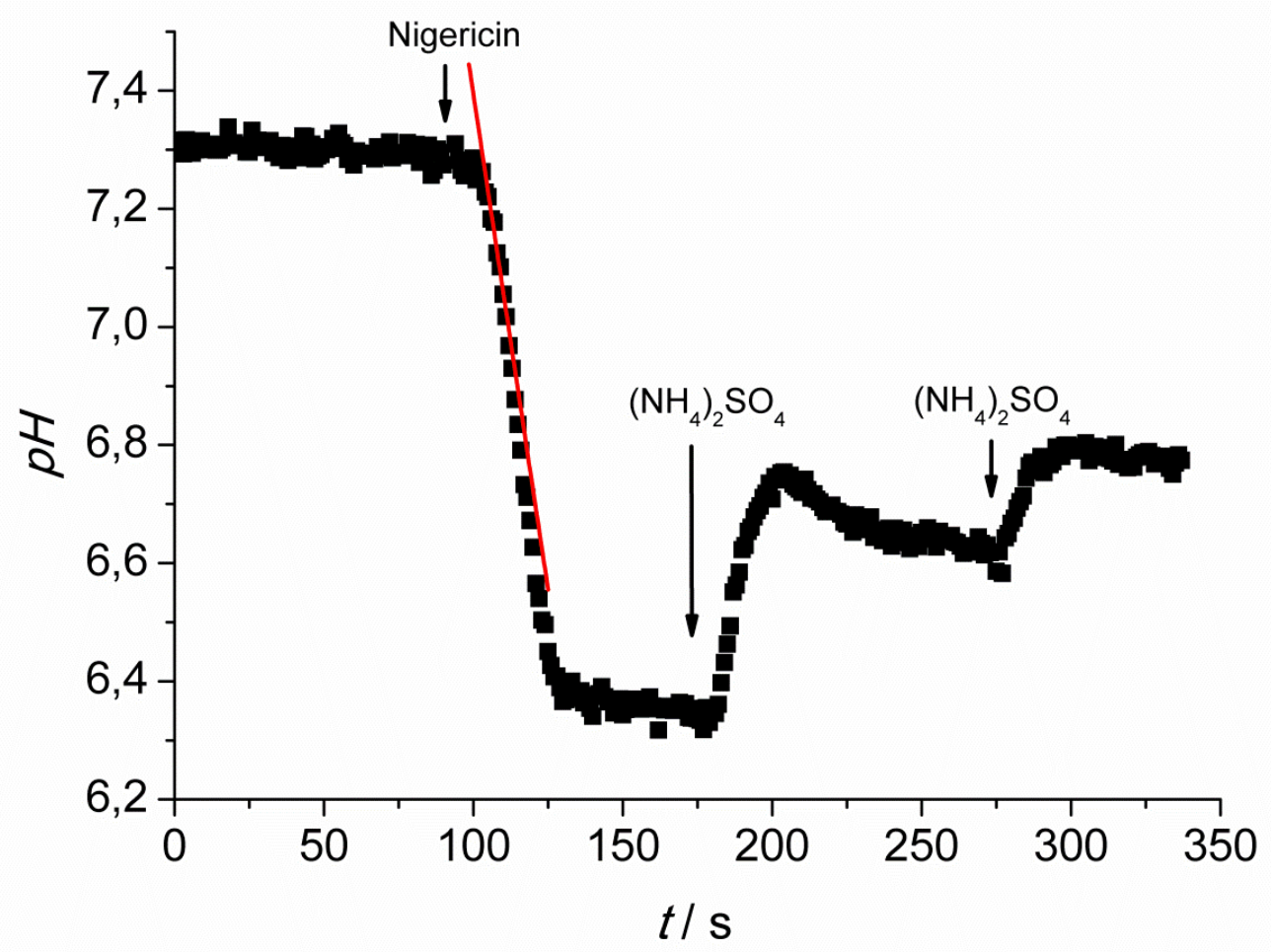

Abb. 4.26: Lineare Anpassung (rot) des pH-Verlaufs der Pyraninfluoreszenz innerhalb einer membranüberspannten Pore nach Zugabe von Nigericin. Der Verlauf entspricht dem unter Abb. 4.24, A dargestellten Verlauf (experimentelle Bedingungen siehe dort). Für den hier angepassten Geradenverlauf ergibt sich eine Steigung von $m=-0,033 \mathrm{pH} \cdot \mathrm{s}^{-1}$.

\section{Lösungsmittelfreie porenüberspannende Membranen}

Lösungsmittelfreie, durch Vesikelspreiten erzeugte porenüberspannende Membranen wurden nach Bildung eines Kaliumionengradienten mit Nigericin versetzt, um zu untersuchen, ob sich trotz Fehlen eines die Dichtigkeit erhöhenden Lösungsmittelkranzes (Plateau-Gibbs-Grenzschicht) stabile elektrochemische Gradienten aufbauen lassen. Der entsprechende Verlauf der Intensität der Pyraninfluoreszenz ist in Abb. 4.27 aufgeführt. Bei einem vorgegebenen Kaliumionengradienten $\mathrm{K}^{+}$innen $>\mathrm{K}^{+}$aussen (A) ähnelt der Intensitätsverlauf demjenigen, wie er für mit Hilfe der painting-Technik präparierte Membranen beobachtet wurde. Vor Nigericinzugabe nimmt die Intensität innerhalb von $30 \mathrm{~s}$ um 3 Einheiten ab und sinkt unmittelbar nach Zugabe von 47 auf 1 Einheit, was einer $\mathrm{pH}$-Wertänderung von $\Delta \mathrm{pH}=-1,94$ Einheiten entspricht. Wie schon in Abb. 4.24, A dargestellt, nimmt die Intensität nach Zugabe von Ammoniumsulfat um 12 Einheiten zu, wobei für den Verlauf lösungsmittelfreier Membranen die Intensität kurzzeitig um 30 Einheiten steigt und dann auf ein Niveau von 13 Einheiten absinkt (entspricht einem $\mathrm{pH}-$ Anstieg von $\Delta \mathrm{pH}=+1,12$ Einheiten). 

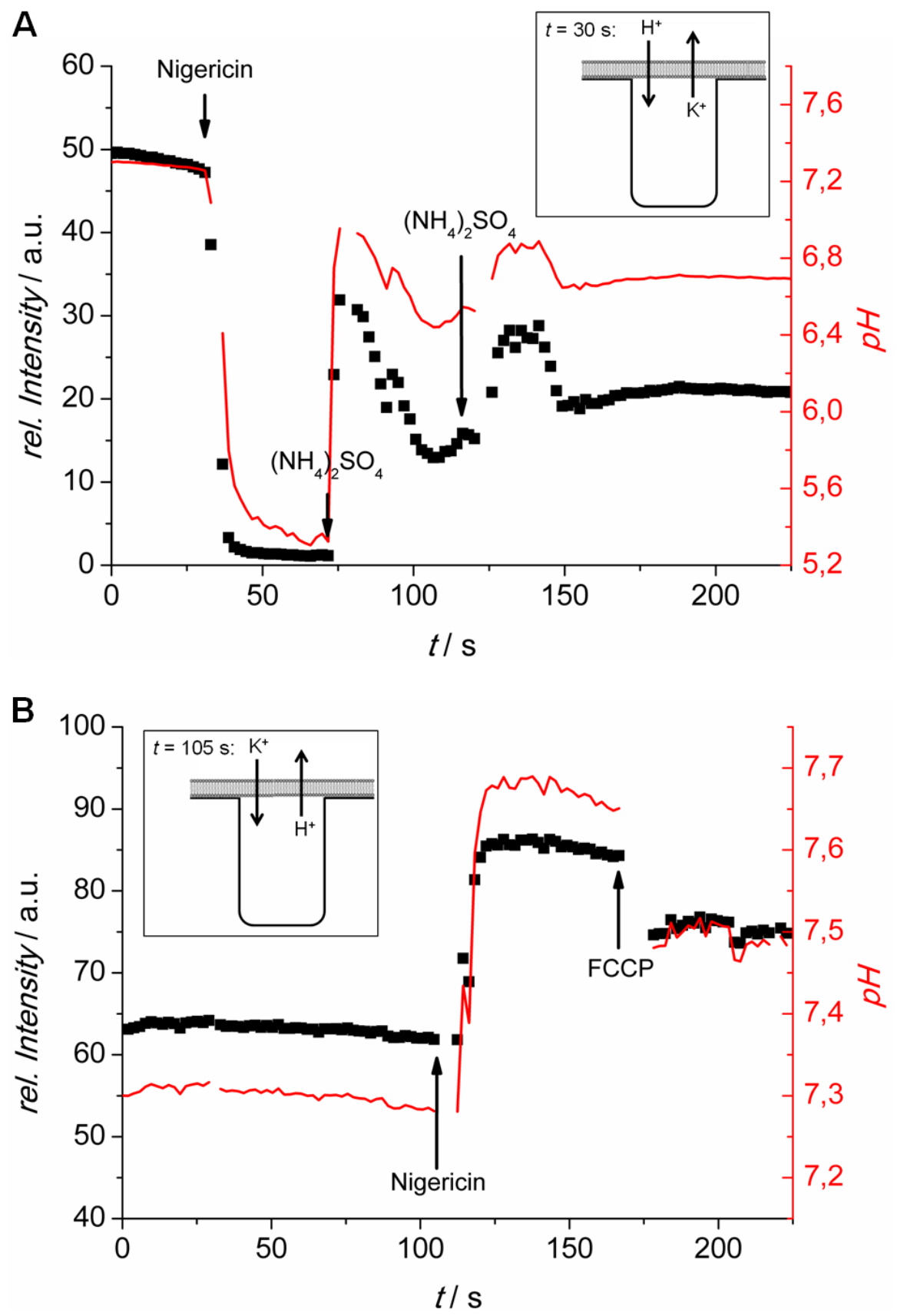

Abb. 4.27: Zeitlicher Verlauf der Fluoreszenzintensität (schwarze Achse, a) sowie des daraus errechneten $\mathrm{pH}-$ Wertes (rot) des in einer Pore eingeschlossenen Pyranins. Poren mit geschlossenen Böden $(d=5,5 \mu \mathrm{m}$, $h=9 \mu \mathrm{m}$ ) wurden durch Spreiten von GUVs (POPC/POPS/Texas Red DHPE, 89,8:10,0:0,2) mit einer Membran überspannt und ein Kaliumionengradient erzeugt. A Pufferlösung in den Poren: $160 \mathrm{mM} \mathrm{KCl,} 10 \mathrm{mM}$ MOPS, 0,5 mM Pyranin, pH 7,3 (KOH). Überstehende Pufferlösung: 320 mM Sucrose, $10 \mathrm{mM}$ MOPS, pH 7,3 (TRIS). $16,7 \mu \mathrm{M}$ Nigericin $\left(5 \mathrm{mg} \cdot \mathrm{mL}^{-1}\right.$ in EtOH) wurden zugegeben. Nach Aufbau eines Protonengradienten wurden $15 \mathrm{mM}$ Ammoniumsulfat (3 M) zugefügt. B Pufferlösung in den Poren: $107 \mathrm{mM} \mathrm{CaCl}, 10 \mathrm{mM} \mathrm{MOPS}, 0,5 \mathrm{mM}$ Pyranin, pH 7,3 (TRIS). Überstehende Pufferlösung: $160 \mathrm{mM} \mathrm{KCl,} 10$ mM MOPS, pH 7,3 (KOH). 16,7 $\mu \mathrm{M}$ Nigericin $\left(5 \mathrm{mg} \cdot \mathrm{mL}^{-1}\right.$ in EtOH) wurden zugegeben. Nach Aufbau eines Protonengradienten wurden $100 \mu \mathrm{M}$ FCCP $\left(10 \mathrm{mg} \cdot \mathrm{mL}^{-1}\right.$ in EtOH) zugefügt. Die Zeitpunkte der Zugaben sind jeweils durch einen Pfeil markiert. Schematische Darstellungen der Richtung des Ionentransports sind jeweils in der oberen rechten (A) bzw. linken (B) Ecke eingefügt. 
Eine erneute Zugabe von Ammoniumsulfat zeigt denselben Effekt und die Intensität stellt sich auf 21 Einheiten ein $(\Delta \mathrm{pH}=+0,25$ Einheiten). Der Aufbau nigericininduzierter elektrochemischer Gradienten wurde dabei nur an planaren porenüberspannenden Membranen untersucht.

Wird Nigericin $\mathrm{zu}$ einer Probe mit vertauschtem Kaliumionengradienten gegeben $\left(\mathrm{K}^{+}{ }_{\text {innen }}<\mathrm{K}^{+}{ }_{\text {aussen, }}\right.$ Abb. 4.27, B), kann 8 s nach Zugabe ein Anstieg der Intensität von 62 auf 86 Einheiten beobachtet werden, was einem Anstieg des $\mathrm{pH}$-Wertes im Poreninneren von $\Delta \mathrm{pH}=+0,41$ Einheiten entspricht. Über einen Zeitraum von $100 \mathrm{~s}$ vor der Zugabe bleibt die Pyraninfluoreszenz auf einem konstanten Niveau. Zugabe von FCCP senkt die Intensität auf einen Wert von 75 Einheiten ab $(\Delta \mathrm{pH}=-0,17$ Einheiten). Sowohl Anstieg als auch FCCPinduzierter Abfall der Intensität fielen bei lösungsmittelfreien porenüberspannenden Membranen generell geringer aus im Vergleich zu painted membranes.

Kontrollexperimente wurden analog zu den für lösungsmittelhaltige Membranen beschriebenen in Form von Zugabe reinen Ethanols und Nigericinzugabe ohne vorgelegten Kaliumionengradienten durchgeführt. Dabei wurden keine oder nur geringfügige Schwankungen in den Intensitätsverläufen beobachtet. Im Falle der Nigericinzugabe sind diese auf kleine Unterschiede in der Kaliumionenkonzentration zwischen dem Poreninneren und der überstehenden Lösung zurückzuführen. Diese können sich bilden, wenn beim Spreiten von GUVs deren Sucrosefüllung austritt und sich mit der Lösung im Poreninneren zum Teil vermischt. Die Pyraninfluoreszenz kann demnach eindeutig einer Bildung von Protonengradienten zugeordnet werden, was zeigt, dass sich lösungsmittelfreie, durch Spreiten von GUVs präparierte porenüberspannende Membranen zum Aufbau elektrochemischer Gradienten eignen.

Analog zu lösungsmittelhaltigen porenüberspannenden Membranen wurden auch für lösungsmittelfreie Membranen die Transportraten für den nigericininduzierten $\mathrm{K}^{+/} \mathrm{H}^{+}$-Austausch anhand der Initialsteigung bestimmt. Unabhängig von der Richtung des vorgelegten Kaliumionengradienten und für Nigericinkonzentrationen von $3,34 \mu \mathrm{M}$ und $16,7 \mu \mathrm{M}$ wurde eine Transportrate von $10^{14} \mathrm{H}^{+} \cdot \mathrm{cm}^{-2} \cdot \mathrm{s}^{-1}$ ermittelt. Diese Rate stimmt mit der für lösungsmittelhaltige Membranen bestimmten überein.

\subsection{Rekonstitution von Bacteriorhodopsin in Lipidmembranen}

Elektrochemische Gradienten konnten in verschiedenen Modellsystemen induziert durch den $\mathrm{K}^{+} / \mathrm{H}^{+}$-Antiporter Nigericin aufgebaut werden. Neben antibiotisch wirksamen Metaboliten wie Nigericin, sind vor allem Proteine in biologischen Systemen in der Lage, Ionengradienten aufzubauen. Um proteininduzierte elektrochemische Gradienten zu untersuchen, wurde das membranständige Protein Bacteriorhodopsin (bR) funktionell in Membranen rekonstituiert. Es ist in der Lage, bei Belichtung Protonen unidirektional über die Membran zu pumpen. 
Dadurch stellt es eine lichtgetriebene Alternative $\mathrm{zu}$ den nigericininduzierten Protonengradienten dar, für deren Bildung ein vorgegebener Kaliumionengradienten als Triebkraft benötigt wird. Es gilt als das am besten untersuchte Membranprotein und eignet sich daher als Prototyp für eine Rekonstitution in porenüberspannende Membranen, besonders in Hinblick auf potentielle biotechnologische Anwendungen (Kapitel 1.2.2). ${ }^{[119]}$

\subsubsection{Isolierung von Purpurmembranfragmenten aus Halobacterium salinarum}

Das Protein bR bildet den Hauptbestandteil (75 \%) der sogenannten Purpurmembran (PM) im halophilen Bakterium Halobacterium salinarum. ${ }^{[104]}$ Um bR für eine nachfolgende Rekonstitution in artifiziellen Membranen zu gewinnen, wurden Halobakterien des Stammes S9 kultiviert (Kapitel 3.2.1). Für die Kultivierung der Halobakterien wurden zwei unterschiedliche Nährmedien verwendet (Normalmedium, Medium 97). Beide Medien finden sich in Standardprotokollen ${ }^{[147,196]}$ und wurden im Rahmen dieser Arbeit in Bezug auf die Reinheit des isolierten bR gegenübergestellt. PM wurden als Fragmente isoliert und die bR-Konzentration UV-Vis spektroskopisch bestimmt. Absorptionsspektren der isolierten PM-Fragmente nach Kultivierung in beiden Medien sind in Abb. 4.28, A dargestellt.
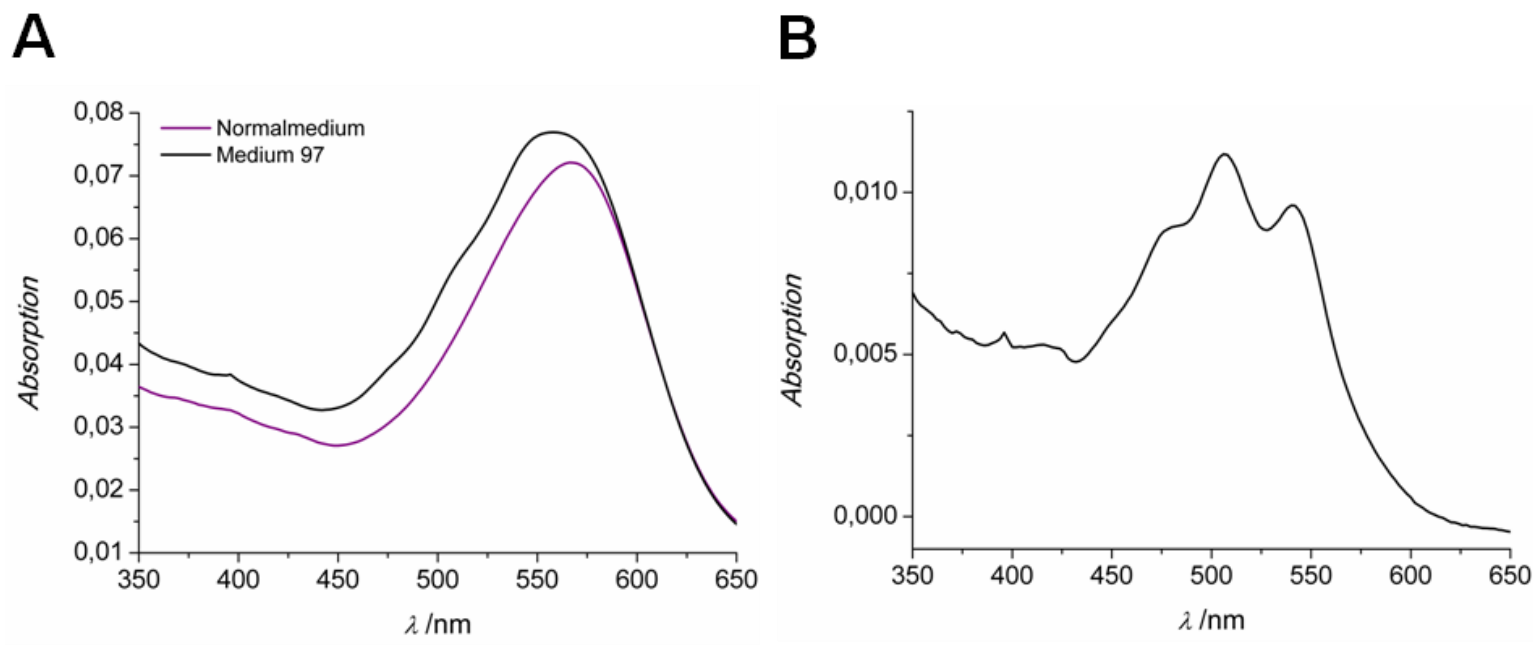

Abb. 4.28: A Absorptionsspektren der isolierten PM-Fragmente aus Halobakterien, kultiviert in Normalmedium (violett, $c_{\mathrm{bR}}=1,1 \mu \mathrm{M}$ ) und Medium 97 (schwarz, $c_{\mathrm{bR}}=1,2 \mu \mathrm{M}$ ). Während der Verlauf für Normalmedium ein Absorptionsmaximum bei $568 \mathrm{~nm}$ besitzt, ist das Maximum für Medium $97 \mathrm{zu} 558 \mathrm{~nm}$ verschoben und breiter. B Ein Differenzspektrum beider in A gezeigten Absorptionsspektren weist drei Absorptionsmaxima bei 541,506 und 479 nm auf. Pufferzusammensetzung: $160 \mathrm{mM} \mathrm{KCl,} 10 \mathrm{mM}$ MOPS, pH 7,3 (KOH).

Die aus dem Normalmedium isolierten PM-Fragmente weisen ein Absorptionsmaximum bei $568 \mathrm{~nm}$ auf, die aus dem Medium 97 isolierten Fragmente hingegen ein breiteres Maximum bei $558 \mathrm{~nm}$. Ein Differenzspektrum beider in A aufgeführten Absorptionsspektren weist drei Absorptionsmaxima auf (561, 506 und $479 \mathrm{~nm}, \mathrm{~B})$. Dementsprechend liegt in den aus Medium 97 isolierten PM-Fragmenten neben bR mindestens eine weitere UV-Vis aktive Spezies vor. Spektren, wie das in Abb. 4.28, B gezeigte, wurden den in Halobacterium 
salinarum vorkommenden carotinoiden Pigmenten Bacterioruberin und $\beta$-Carotin zugeordnet. $^{[197-199]}$ Die Struktur von Bacterioruberin ist in Abb. 4.29 dargestellt. Diese Komponenten wurden immer zusammen mit bR in Form von PM-Fragmenten isoliert, wenn zuvor in Medium 97 kultiviert worden war. Bei identischer Isolierungsvorschrift konnten diese Pigmente bei einer Kultivierung in Normalmedium nie nachgewiesen werden.

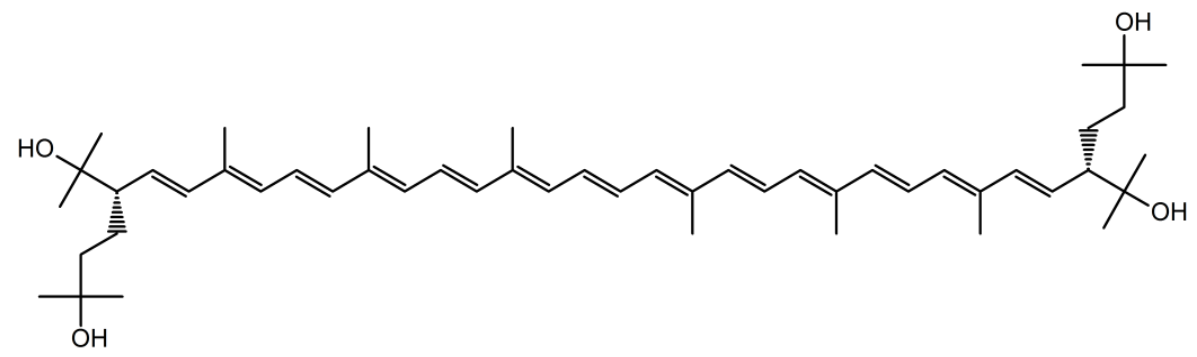

Abb. 4.29: Strukturformel des zusammen mit bR aus Halobakterien isolierten Bacterioruberin.

Die isolierten PM-Fragmente unterschieden sich neben ihrem Absorptionsverhalten auch in der Aktivität des bR, welche mittels Photostrommessungen (Kapitel 3.3.1) untersucht wurde (Abb. 4.30). Dabei wurden Photostrommessungen, wie insgesamt im Rahmen dieser Arbeit, lediglich qualitativ dazu vewendet, um eine prinzipielle Aktivität von bR in Form eines Protonentransports nachzuweisen. Eine quantitative Auswertung von bR-induzierten Photostrommessungen mit Bezug zu theoretischen Modellen findet sich bei Schmitt. ${ }^{[147]}$
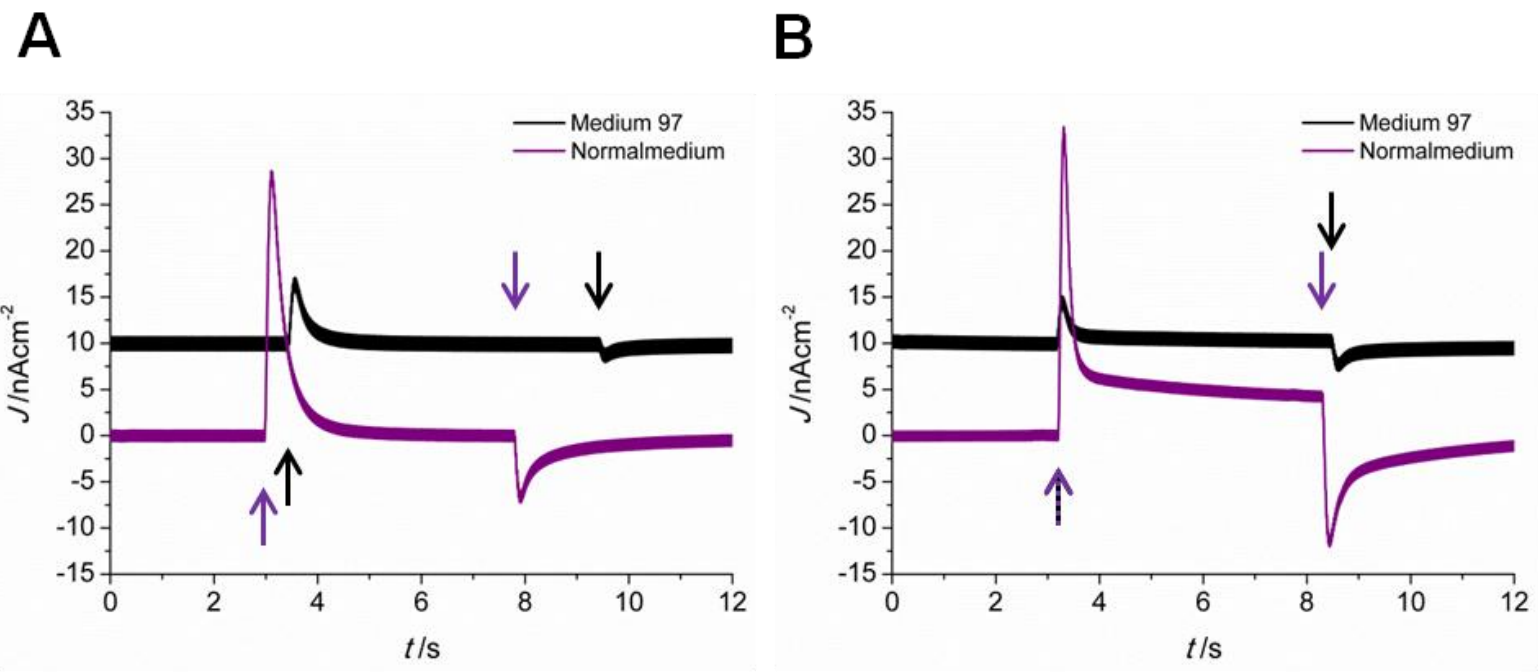

Abb. 4.30: Photostrommessungen der isolierten PM-Fragmente $\left(c_{\mathrm{bR}}=0,1 \mathrm{mg} \cdot \mathrm{mL}^{-1}\right)$ für Medium 97 (schwarz) und Normalmedium (violett). A zeigt den Verlauf des Photostromsignals vor, B den Verlauf nach Zugabe von Carbonylcyanid- $m$-chlorphenylhydrazon (CCCP, $24 \mu \mathrm{M})$. Start und Ende der Belichtung sind jeweils mit Pfeilen gekennzeichnet. Der Verlauf für das Medium 97 ist zwecks besserer Übersichtlichkeit jeweils um $+10 \mathrm{nA} \cdot \mathrm{cm}^{-2}$ verschoben. Pufferlösung: $160 \mathrm{mM} \mathrm{KCl,} 10 \mathrm{mM}$ MOPS, pH 7,3 (KOH).

PM-Fragmente wurden $\mathrm{zu}$ einer goldunterstützten (Arbeitselektrode), mittels paintingTechnik (2\%(w/v) DPhPC und $0,05 \%(\mathrm{w} / \mathrm{v})$ ODA in $n$-Dekan) präparierten Membran gegeben, eine Gegenelektrode in die überstehende Lösung gegeben und die Potentialdifferenz vor, während und nach Belichtung der Probe aufgenommen. Abb. 4.30, A (violetter Verlauf) 
zeigt für in Normalmedium kultivierte PM-Fragmente bei Belichtung der Probe einen Maximalwert (Amplitude) des gemessenen Photostromsignals von $J=29 \mathrm{nA} \cdot \mathrm{cm}^{-2}$. Das Signal sinkt exponentiell auf das Ausgangsniveau ab und zeigt bei Ende der Belichtung einen Minimalwert von $J=-7 \mathrm{nA} \cdot \mathrm{cm}^{-2}$, bevor erneut der Ausgangswert erreicht wird. Die Amplituden des Signals für aus Medium 97 isolierte PM-Fragmente (schwarzer Verlauf, um $+10 \mathrm{nA} \cdot \mathrm{cm}^{-2}$ versetzt) sind mit $J=7 \mathrm{nA} \cdot \mathrm{cm}^{-2}$ bzw. $J=-2 \mathrm{nA} \cdot \mathrm{cm}^{-2}$ etwa um ein Vierfaches geringer. Der Verlauf lässt sich bei Betrachtung der Membran als Kondensator mit einer Lade- bzw. Entladekurve vergleichen. Protonen werden durch bR in Richtung der Elektrode gepumpt und die Grenzschicht der Membran lädt sich kapazitiv auf, weshalb ein transienter Stromverlauf $\mathrm{zu}$ erkennen ist. Bei Ende der Belichtung fließen die gepumpten Protonen zurück, wobei Unterschiede in der Amplitude von Ein- und Ausschaltstrom auf unterschiedliche Geschwindigkeiten beider Prozesse hindeuten.

Ein Verlauf, wie er in Abb. 4.30 dargestellt ist, wurde qualitativ für sämtliche vermessenen PM-Fragmente aus den jeweiligen Medien erhalten. Von einer weiteren Quantifizierung der Belichtungsströme und stationären Ströme wurde abgesehen. Durch die painting-Technik präparierte unterstützende Membranen wiesen spezifische Kapazitäten in einem Bereich von 0,3 bis $0,5 \mu \mathrm{F} \cdot \mathrm{cm}^{-2}$ auf und liegen somit im Bereich literaturbekannter Werte. ${ }^{[173]}$ Diese Varianz in spezifischen Kapazitäten der unterstützenden Membranen kann die Menge der angebundenen PM-Fragmente beeinflussen und dadurch auch z. B. die Amplituden der gemessenen Photoströme.

Abb. 4.30, B, (violetter Verlauf) zeigt nach Zugabe von CCCP, einer entkoppelnd wirkenden Substanz, welche Membranen durchlässig für Protonen macht, für aus Normalmedium isolierte PM-Fragmente bei Belichtung einen stationärer Strom von $J=4 \mathrm{nA} \cdot \mathrm{cm}^{-2}$. Der Entkoppler bewirkt, dass Protonen durch die unterstützende Membran durchtreten können, statt an der Membranoberfläche akkumuliert zu werden. Es baut sich keine geladene Grenzschicht auf, welche dem weiteren Transport von Protonen durch bR entgegenwirkt. Dadurch wird ein kontinuierliches Protonenpumpen ermöglicht, welches in einem stationären Strom resultiert. CCCP verringert erkennbar die Asymmetrie des Photostromsignals. Der Minimalwert des Signals sinkt auf $J=-12 \mathrm{nA} \cdot \mathrm{cm}^{-2}$. Für aus Medium 97 isolierte PM-Fragmente (schwarzer Verlauf, um $+10 \mathrm{nA} \cdot \mathrm{cm}^{-2}$ versetzt) lässt sich kein stationärer Strom während der Belichtung ausmachen $\left(J<1 \mathrm{nA} \cdot \mathrm{cm}^{-2}\right)$ und der Minimalwert sinkt auf $J=-3 \mathrm{nA} \cdot \mathrm{cm}^{-2}$. Da kein stationärer Strom detektiert werden kann, muss die Anzahl kontinuierlich gepumpter Protonen deutlich geringer sein, als bei Photostrommessungen an aus Normalmedium isolierten PM-Fragmenten. Grund hierfür kann eine geringere Aktivität des bR sein oder eine verminderte Adsorption von PM-Fragmenten, die aus Medium 97 isoliert wurden. Eine detailierte Beschreibung und Ansätze zur Quantifizierung von an PM-Fragmenten gemessenen Photoströmen findet sich bei Bamberg et al. (PM-Fragmente adsorbiert an freistehenden Membranen) und Schmitt. ${ }^{[106,147]}$ 
Wurden keine PM-Fragmente zu der Probe gegeben, so verlief das Photostromsignal konstant und ohne Ausschläge $\left(J<1 \mathrm{nA} \cdot \mathrm{cm}^{-2}\right)$. Das gemessene Signal ist demnach auf die Protonenpumpaktivität des in Form von PM-Fragmenten isolierten bR zurückzuführen. Bei gleicher bR-Konzentration $\left(0,1 \mathrm{mg} \cdot \mathrm{mL}^{-1}\right)$ zeigten aus Normalmedium isolierte Fragmente ein deutlich höheres Photostromsignal, als aus Medium 97 isolierte Fragmente. Diese Differenzen in den Photostromsignalen können auf eine höhere Protonenpumpaktivität des aus Normalmedium isolierten bR, oder auf eine verminderte Anbindung der aus Medium 97 isolierten PM-Fragmente zurückgeführt werden. Die Funktionalität des isolierten bR als Protonenpumpe konnte somit nachgewiesen werden. Im Nachfolgenden wurde aufgrund des stärkeren Photostromsignals bR, welches aus in Normalmedium kultivierten Halobakterien isoliert worden war, verwendet.

\subsubsection{Rekonstitution von bR in Liposomen}

Verschiedene Methoden wurden eingesetzt, um bR funktionell in Liposomen zu rekonstituieren (Kapitel 3.2.4). Neben der reverse phase Methode, bei welcher Vesikel durch Zusammenlagerung inverser Mizellen bei Lösungsmittelentzug gebildet werden, wurden Detergentien (Triton-X-100, $n$-Octyl- $\beta$-D-glucopyranosid ( $n$-OG)) eingesetzt, um Protein in detergensgesättigte Vesikel einlagern zu können. Bei allen beschriebenen Methoden wurden calciumionenfreie Pufferlösungen verwendet, da Calciumionen $\mathrm{zu}$ einem Aggregieren und dadurch Ausfallen der PM-Fragmente führten (Abb. 4.31). Zugabe von $\mathrm{Ca}^{2+}$ nach abgeschlossener Bildung von Proteoliposomen führte in einem Zeitrahmen von $1 \mathrm{~h}$ zu keiner Bildung eines Niederschlags, was auf eine vollständige Inkorporation des Proteins in die gebildeten Vesikel hindeutet. Gebildeter Niederschlag ließ sich durch Zugabe von EDTA im Überschuss nicht auflösen. 


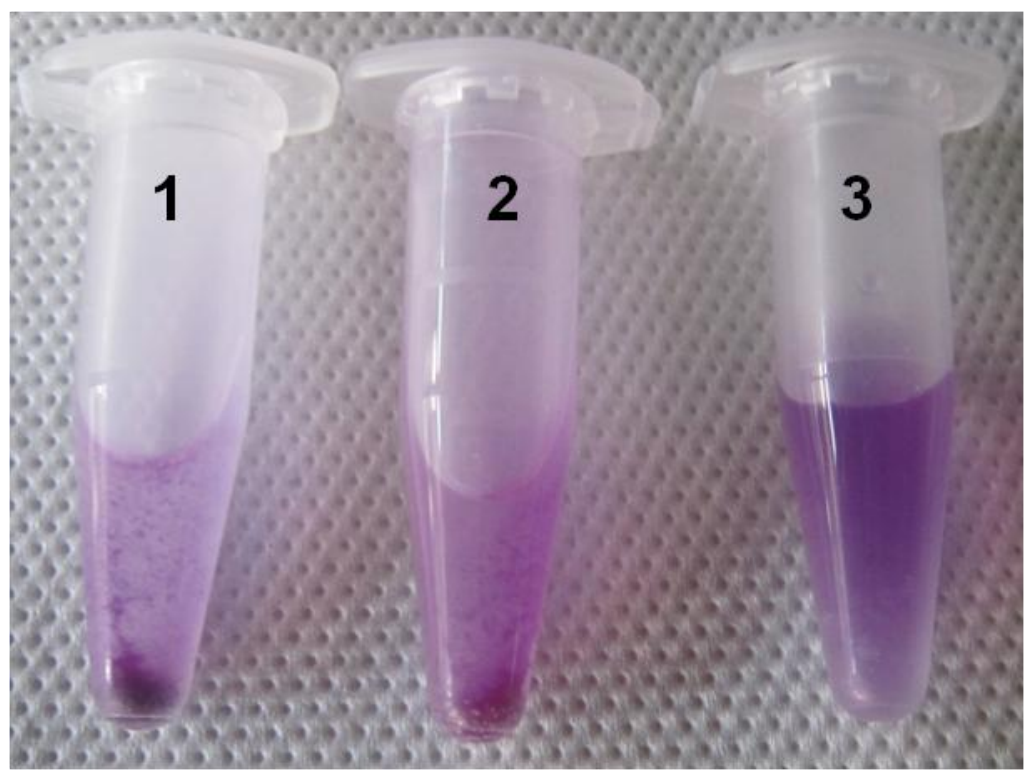

\begin{abstract}
Abb. 4.31: Eppendorf-Gefäß mit Vesikeln, die nach der reverse phase Methode hergestellt wurden. Als Lipide wurden DPhPC/DPPA (9:1) mit jeweils 1 mol\% bR eingesetzt. Gefäß 1 zeigt eine Vesikelsuspension mit einer Lipidkonzentration von $5 \mathrm{mg} \cdot \mathrm{mL}^{-1}$, Gefäß 2 eine mit einer Konzentration von $2 \mathrm{mg} \cdot \mathrm{mL}^{-1}$. Beide Proben wurden in einer Lösung von $80 \mathrm{mM} \mathrm{CaCl}_{2}, 50 \mathrm{mM} \mathrm{KCl}$ präpariert. Ein rötlich-violetter Niederschlag im Bodenbereich der Gefäße deutet auf eine Aggregation und ein Ausfallen der PM-Fragmente hin und somit eine unerfolgreiche Rekonstitution des Proteins. Gefäß 3 zeigt eine Vesikelsuspension mit einer Lipidkonzentration von $2 \mathrm{mg} \cdot \mathrm{mL}^{-1}$, welche in Reinstwasser präpariert wurde. Es ist kein Niederschlag zu erkennen, die gesamte Probe weist eine homogene violette Färbung auf.
\end{abstract}

Vesikelsuspensionen mit homogener, violetter Färbung konnten durch alle verwendeten Methoden (reverse phase, detergensmediiert) gebildet werden, was generell auf eine erfolgreiche Rekonstitution von bR in Vesikeln hindeutet. Um die Protonenpumpaktivität von bR nach dem Einbau in Vesikel zu untersuchen, wurden Photostrommessungen an Proteoliposomen durchgeführt (Kapitel 3.3.1). ${ }^{[147]}$ Die Stromantwort bei Belichtung von nach dem reverse phase Protokoll gebildeten Proteoliposomen in Gegenwart von CCCP ist in Abb. 4.32 dargestellt. Bei Start und Ende der Belichtung sind transiente Ströme zu erkennen mit Amplituden von $J=2,3 \mathrm{nA} \cdot \mathrm{cm}^{-2}$ und $J=-1,5 \mathrm{nA} \cdot \mathrm{cm}^{-2}$, wobei während der Belichtung ein stationärer Strom von $J=0,5 \mathrm{nA} \cdot \mathrm{cm}^{-2}$ gemessen wird. Die Vesikel wurden über elektrostatische Wechselwirkungen zwischen dem positiv geladenen ODA in der auf der Goldelektrode präparierten Membran und den in PM-Fragmenten und somit in den Vesikeln rekonstituierten negativ geladenen Lipiden angebunden. Der Verlauf zeigt, dass bR funktionell in Vesikeln rekonstituiert werden konnte. Fluoreszenzmarkierung von bR (Cy3/bR, 1:3, Texas Red/bR, 1:2,2, Alexa Fluor 488/bR, 1:4) hatte keinen Einfluss auf dessen Protonenpumpaktivität vor wie nach Rekonstitution in Vesikeln. Kontrollexperimente an bR-freien reverse phase Vesikeln zeigten bei Belichtung keine transienten Ströme und verliefen konstant bei $J=0 \mathrm{nA} \cdot \mathrm{cm}^{-2}$. 


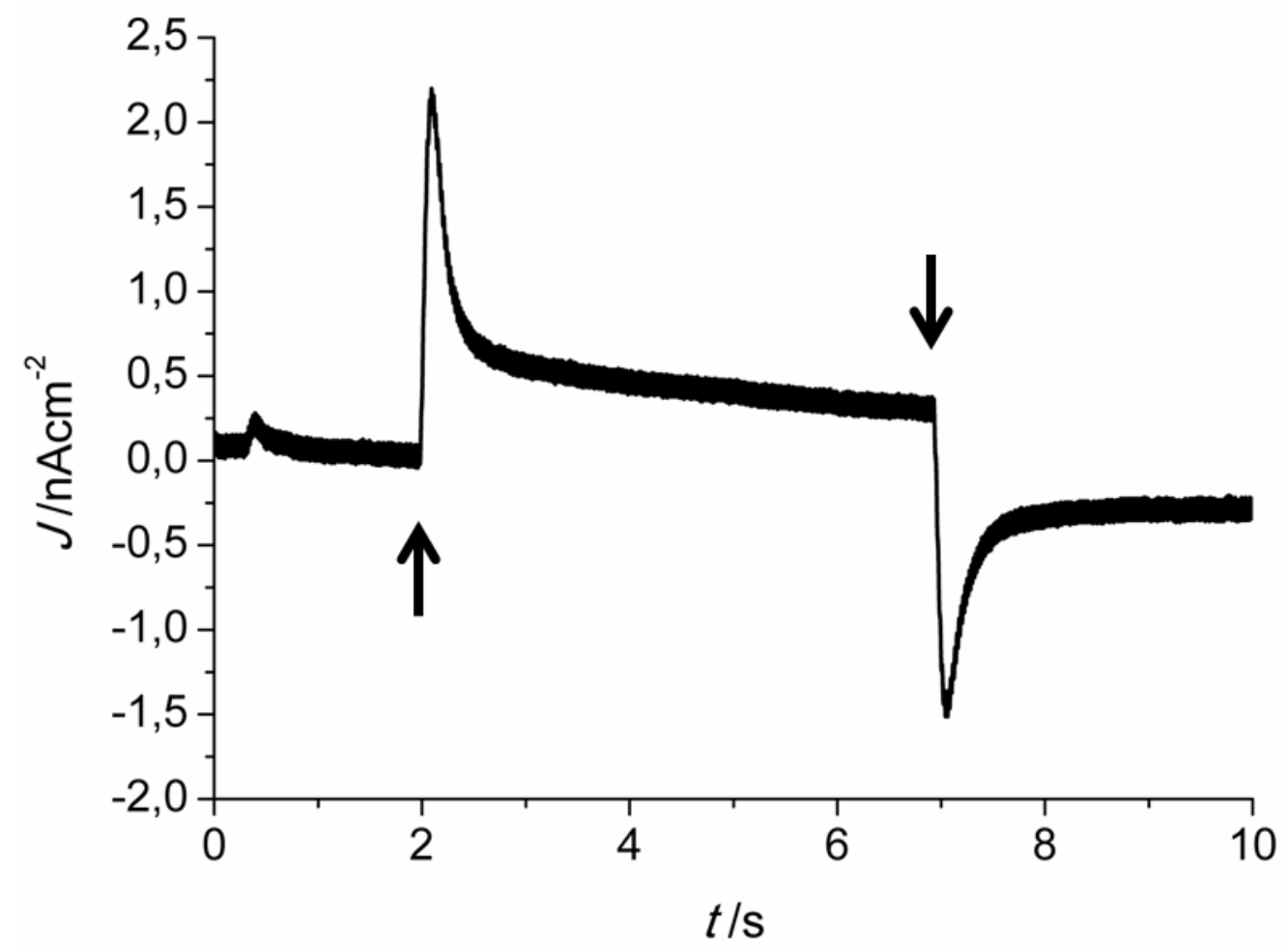

Abb. 4.32: Photostrommessung der Protonenpumpaktivität von per reverse phase Methode in Liposomen rekonstituiertem bR. Vesikel (DPhPC/DOPC, 6:4, 1 mol\% bR) wurden auf goldunterstützten painted membranes ( $2 \%(\mathrm{w} / \mathrm{v})$ DPhPC und 0,05\% (w/v) ODA in $n$-Dekan) elektrostatisch angebundenen durch die Wechselwirkung von positiv geladenem ODA und negativ geladenen Lipiden aus den PM-Fragmenten. Pufferlösung: 2 mM KOH, 1 mM MOPS, pH 7,4 (TRIS). Die Messung wurde nach Zugabe von $2 \mu \mathrm{M}$ CCCP durchgeführt.

Neben Photostrommessungen wurde der $\mathrm{pH}-$ Wert der Vesikelsuspensionen mittels pH-Elektrode gemessen und auf belichtungsinduzierte Änderungen untersucht (Kapitel 3.3.2). Der Verlauf in einer Suspension von reverse phase Vesikeln $(1,2 \mathrm{mg}$ Lipid $(600 \mu \mathrm{L}$ Vesikelsuspension) auf 3,0 mL KCl-Lösung (150 mM), 0,28 mol\% bR) ist in Abb. 4.33 abgebildet. Valinomycin wurde der Probe zugefügt, um den passiven Transport von Kaliumionen durch die Vesikelmembran zu ermöglichen und somit ein elektrisches Potential, welches den Transport von Protonen hemmen würde, abzubauen. Vor, während und nach Belichtung der Probe blieb der pH-Wert der Suspension konstant bei 6,19 \pm 0,01. Ein aktiver Transport von Protonen konnte weder aus den Vesikeln in die umgebende Lösung, noch in entgegengesetzter Richtung nachgewiesen werden. Lichtinduzierte Änderungen im pH-Wert des umgebenden Mediums konnten weder für reverse phase Vesikel, noch für durch Detergensentzug (Triton-X-100, n-OG) gebildete Vesikel detektiert werden, unabhängig von einer Zugabe von Valinomycin. Die Photostrommessungen zeigten ein aktives Protonenpumpen durch bR. Netto-pH-Wertänderungen konnten in der umgebenden, ungepufferten Lösung jedoch nicht induziert werden, was auf eine fehlende Vorzugsorientierung des rekonstituierten bR in den Vesikeln deutet und unter Kapitel 5.3.1 näher diskutiert werden wird. 


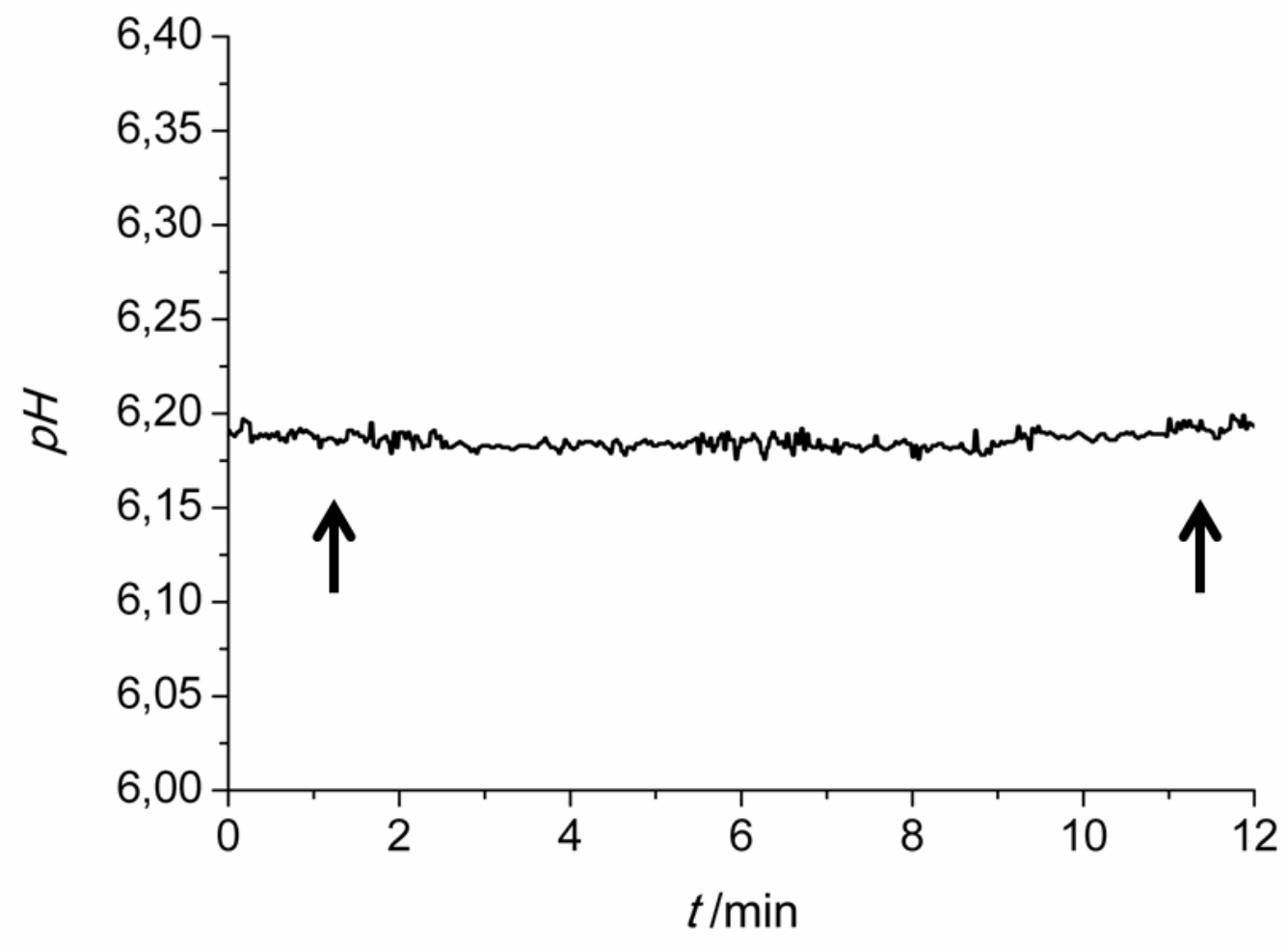

Abb. 4.33: Verlauf des pH-Wertes einer Suspension von Vesikeln (POPC/POPS, 9:1, 0,28 mol\% bR, extrudiert durch Polycarbonatmembranen mit nominellem Porendurchmesser von $400 \mathrm{~nm}$, dann $200 \mathrm{~nm}$ ) in $150 \mathrm{mM} \mathrm{KCl}$, gemessen mittels pH-Elektrode. Die Lösung wurde vor der Messung mit 3,0 $\mu \mathrm{M}$ Valinomycin $\left(1 \mathrm{mg} \cdot \mathrm{mL}^{-1}\right.$ in EtOH) versetzt. Beginn und Ende der Belichtung sind jeweils durch Pfeile markiert.

\subsubsection{Rekonstitution von bR in GUVs}

Um bR funktionell in porenüberspannenden Membranen rekonstituieren zu können, wurde das Protein zunächst ausgehend von PM-Fragmenten oder Proteoliposomen in GUVs inkorporiert (Kapitel 3.2.5). Fluoreszenzmarkiertes bR wurde konfokalmikroskopisch in GUVs nachgewiesen (Abb. 4.34) und dessen Funktionalität mittels Photostrommessungen untersucht, um eine erfolgreiche Rekonstitution des bR in GUVs nachzuweisen. 

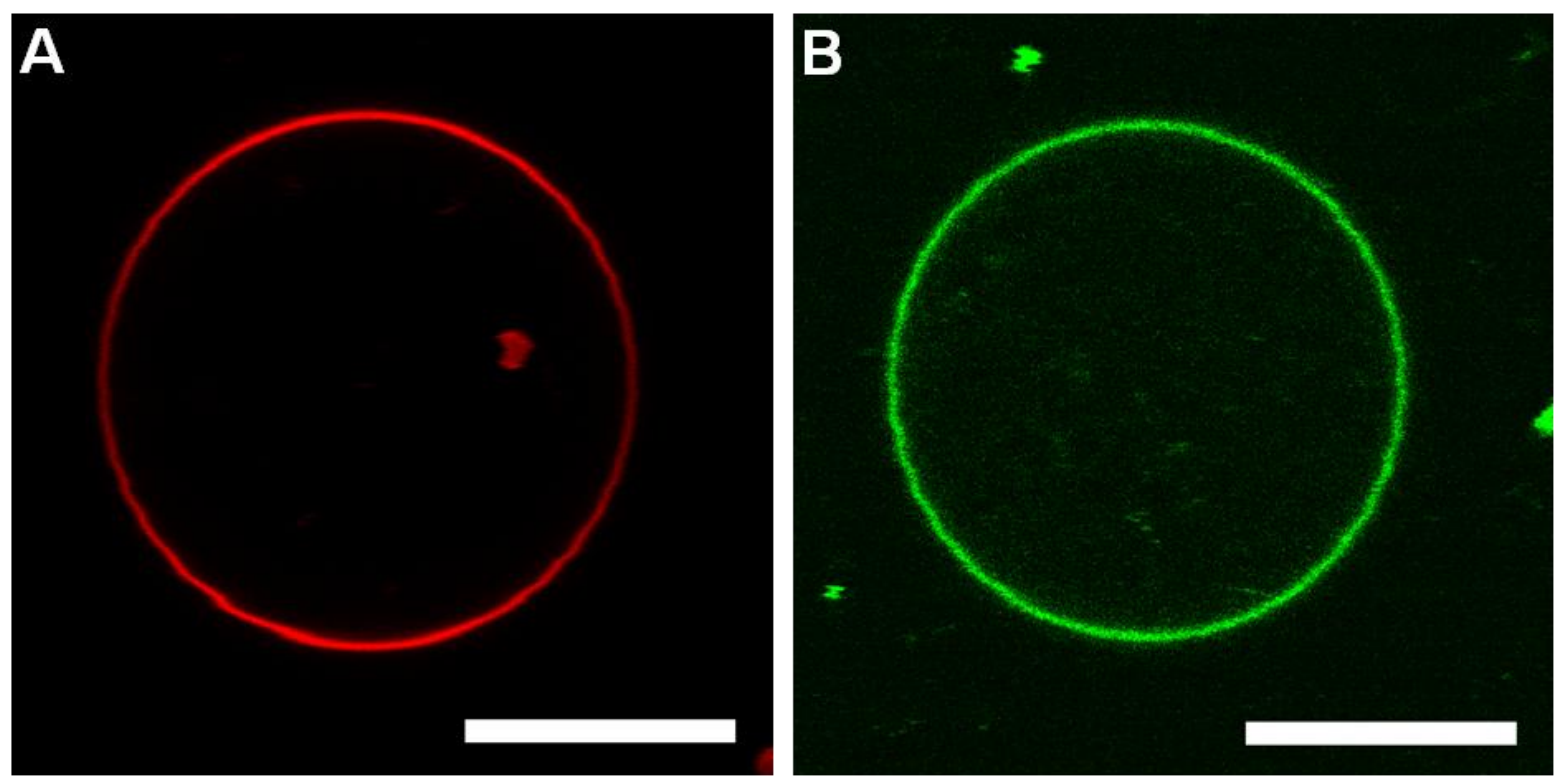

Abb. 4.34: Konfokalmikroskopische Aufnahme eines GUV (POPC/Texas Red DHPE, 99,8:0,2, rot, A, 0,7 mol\% Alexa Fluor 488 markiertes bR, grün, B, präpariert nach Kapitel 3.2.5, 2)). Pufferlösung: $160 \mathrm{mM}$ $\mathrm{KCl}, 10 \mathrm{mM}$ MOPS, pH 7,3 (KOH). Maßstabsbalken $10 \mu \mathrm{m}$.

Abb. 4.34, A zeigt die Texas Red DHPE Fluoreszenz, Abb. 4.34, B die Fluoreszenz des Alexa Fluor 488 markierten bR innerhalb eines GUV. Beide Fluoreszenzfarbstoffe sind homogen über den gesamten Membranbereich verteilt, was eine erfolgreiche Rekonstitution des markierten bR in die Vesikelmembran beweist. Der dargestellte GUV wurde durch partielle Dehydratisierung eines mit PM-Fragmenten versetzten Lipidfilms und anschließender Elektroformation gebildet. Durch diese Methode (Kapitel 3.2.5, 2)) konnten GUVs in großer Zahl mit deckungsgleicher Fluoreszenz von Texas Red und markiertem bR gebildet werden. Eine Anwendung der unter Kapitel 3.2.5, 1-1) und 1-2) beschriebenen Methoden zur Rekonstitution von bR in GUVs wies ebenfalls jeweils eine solche Überlagerung von Membran- und Proteinfluoreszenz auf (Abb. 4.35).

Alle untersuchten Methoden erlaubten demnach eine erfolgreiche Rekonstitution von bR in GUVs mit einem Anteil von 1 mol\% und unabhängig von den zur Markierung verwendeten Fluorophoren. 

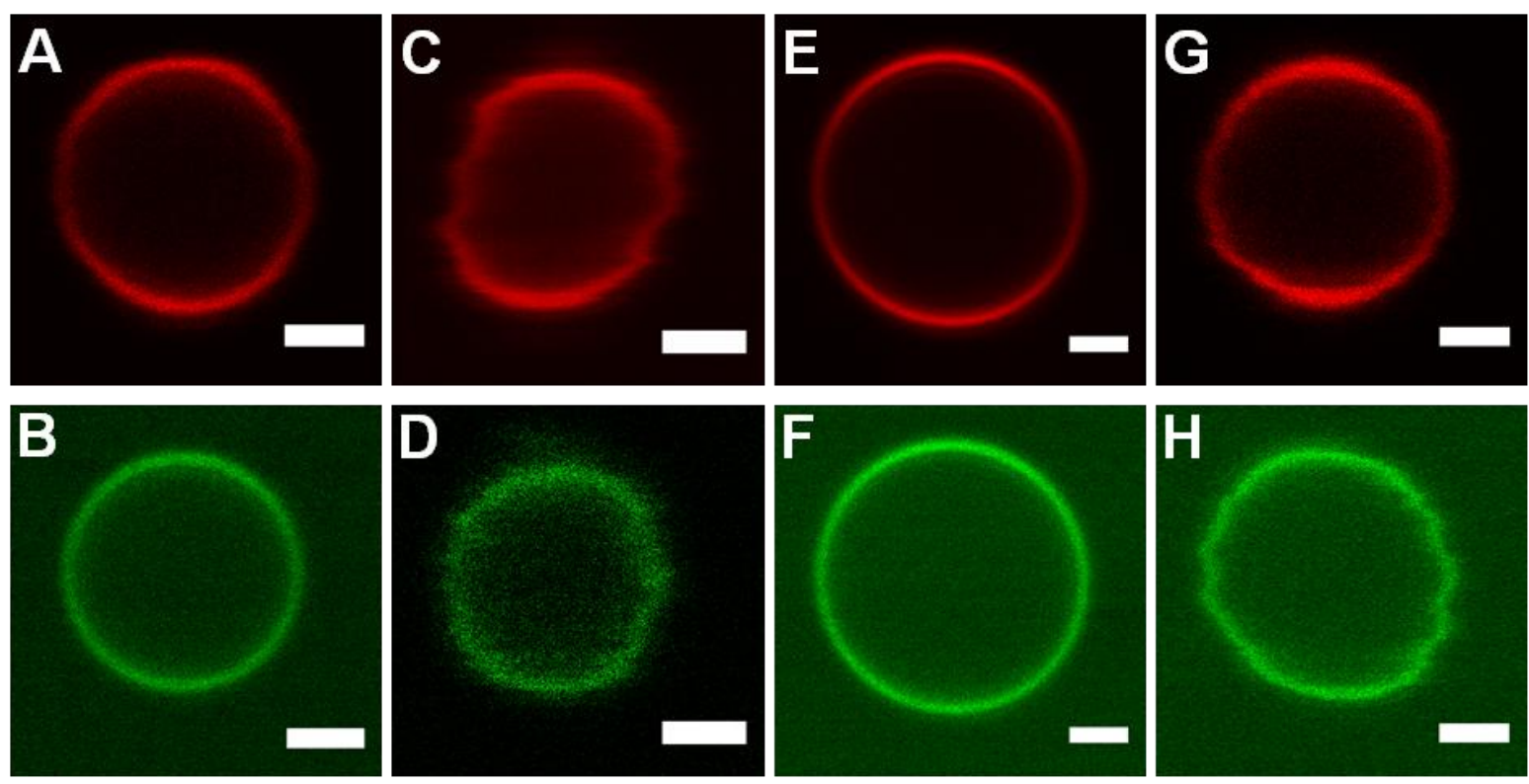

Abb. 4.35: Konfokalmikroskopische Aufnahmen von Proteo-GUVs (DPhPC/DOPC/Texas Red DHPE, 59,9:40,0:0,1, rot, 1,0 mol\% FITC-markiertes bR, grün), präpariert aus Proteoliposomen (Kapitel 3.2.4, reverse phase Methode) nach verschiedenen Methoden. A, C, E und G zeigen jeweils die Texas Red DHPE Fluoreszenz innerhalb der Vesikelmembran, B, D, F und $\mathbf{H}$ zeigen jeweils die Fluoreszenz des mit FITC markierten bR (zur Markierung von bR mit FITC siehe Frese ${ }^{[173]}$ ). A und B: Proteoliposomen wurden über gesättigter NaCl-Lösung dehydratisiert und in $100 \mathrm{mM} \mathrm{KCl}, 10 \mathrm{mM}$ TRIS, $100 \mathrm{mM}$ Sucrose, pH 7,4 (HCl) unter HochfrequenzBedingungen gebildet (Kapitel 3.2.5, Präparation von GUVs unter physiologischen Bedingungen). C und D: Proteoliposomen wurden mit $1 \%$ Glycerin (w/w) versetzt und im Vakuum dehydratisiert. Rehydratisierung erfolgte langsam in Pufferlösung wie unter A, B ohne Anlegen eines elektrischen Feldes (gentle hydration, Kapitel 3.2.5, 1-2)). E und F: Proteoliposomen wurden über gesättigter NaCl-Lösung dehydratisiert und in $1 \mathrm{mM}$ MOPS, 2 mM KCl, 100 mM Sucrose, pH 7,0 (TRIS) durch Elektroformation gebildet (Kapitel 3.2.5, 1-1)). G und H: Proteoliposomen mit Sucrose $\left(0,2 \mathrm{~g} \cdot \mathrm{g}^{-1}\right.$ Lipid) versetzt und im Vakuum dehydratisiert. Rehydratisierung und Elektroformation wie unter E und F. Pufferlösung je $100 \mathrm{mM} \mathrm{KCl,} 10$ mM TRIS, 100 mM Glucose, pH 7,4 (HCl). Maßstabsbalken je $2 \mu \mathrm{m}$.

Nachdem bR in GUVs eingebracht werden konnte, wurde mittels Photostrommessungen rein qualitativ untersucht, ob das Protein seine Funktionalität während der Bildung von GUVs konserviert hatte. Photostrommessungen an Proteoliposomen hatten eine Aktivität von rekonstituiertem bR nachgewiesen (Kapitel 4.3.2). Bei der Bildung von GUVs wird das Protein jedoch einer Dehydratation unterzogen, welche als kritischer Schritt in Bezug auf eine Konservierung der Struktur und Funktionalität von Proteinen gilt. ${ }^{[17,162]}$ Abb. 4.36 zeigt Verläufe des Photostromsignals von bR-haltigen (schwarz), sowie bR-freien (blau, Signal um $-3 \mathrm{nA} \cdot \mathrm{cm}^{-2}$ verschoben) GUVs vor (A) und nach (B) Inkubation mit CCCP. Bei Start der Belichtung ist für bR-haltige GUVs jeweils ein Stromsignal mit einer Amplitude von $J=15$ bzw. $14 \mathrm{nA} \cdot \mathrm{cm}^{-2}$ zu erkennen. Nach Inkubation mit CCCP lässt sich während der Belichtung ein stationärer Strom von $J=1 \mathrm{nA} \cdot \mathrm{cm}^{-2}$ und bei Ende der Belichtung eine Amplitude von $J=-10 \mathrm{nA} \cdot \mathrm{cm}^{-2}$ ablesen. Rekonstituiertes bR ist somit in der Lage bei Belichtung Protonen über die Membran von GUVs zu transportieren und bleibt demnach funktionell. Kontroll- 
experimente mit bR-freien GUVs zeigen keine lichtinduzierten Stromantworten und weisen lediglich teilweise Schwankungen im Bereich von $J=1 \mathrm{nA} \cdot \mathrm{cm}^{-2}$ auf.
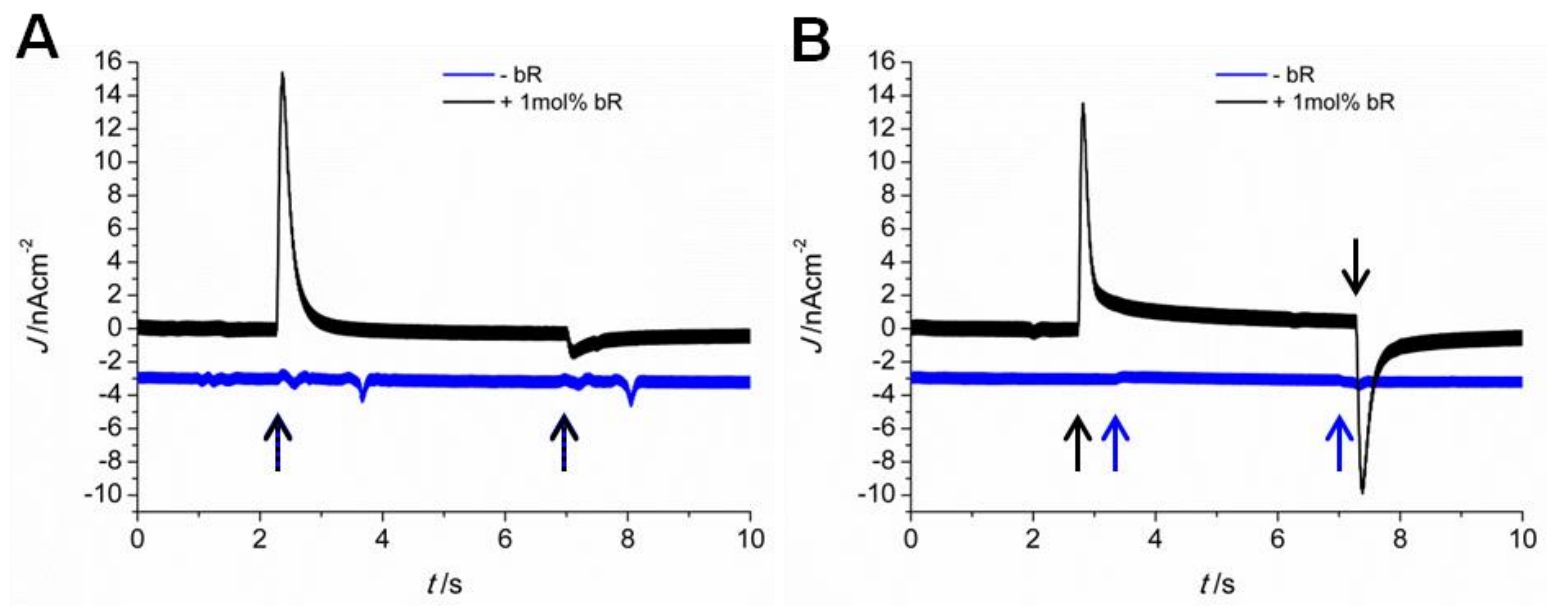

Abb. 4.36: Photostrommessungen an bR-haltigen GUVs (DPhPC/DOPC/Texas Red DHPE, 59,9:40,0:0,1, 1 mol\% bR, präpariert nach Kapitel 3.2.5, 1-1) in $100 \mathrm{mM}$ Sucrose, $2 \mathrm{mM} \mathrm{KCl}, 1 \mathrm{mM}$ MOPS, pH 7,4 (TRIS)). Entsprechen GUVs aus Abb. 4.35, E und F. Pufferlösung: $100 \mathrm{mM} \mathrm{KCl,} 20 \mathrm{mM}$ TRIS, pH 7,4 (HCl). A zeigt den Verlauf des Photostromsignals vor Zugabe von CCCP, B den Verlauf nach Zugabe von $2 \mu$ M CCCP. GUVs mit einem bR-Anteil von $1 \mathrm{~mol} \%$ sind in schwarz dargestellt, solche gleicher Zusammensetzung, jedoch ohne bR in blau dargestellt. Beginn und Ende der Belichtung der Probe sind jeweils mit Pfeilen markiert. Zur besseren Übersichtlichkeit sind die Verläufe für bR-freie GUVs um $J=-3 \mathrm{nA} \cdot \mathrm{cm}^{-2}$ versetzt. Durch die höhere Dichte der Sucroselösung in den GUVs sanken diese auf die mittels painting-Technik (2\% (w/v) DPhPC und 0,05\% (w/v) ODA in $n$-Dekan) auf eine Goldelektrode aufgetragene Membran ab und konnten zusätzlich über eine elektrostatische Wechselwirkung zwischen negativ geladenen Lipiden aus den PM-Fragmenten in der Vesikelmembran und dem positiv geladenen ODA in der goldunterstützten Membran angebunden werden.

Die abgebildeten Photostrommessungen wurden an GUVs durchgeführt, welche aus über gesättigter $\mathrm{NaCl}$-Lösung dehydratisierten reverse phase Proteoliposomen gebildet worden waren. Analoge Verläufe, welche auf eine funktionelle Rekonstituiton von bR in GUVs schließen ließen, wurden für sämtliche unter Kapitel 3.2.5, 1-1) und 1-2) beschriebenen Methoden erhalten, unabhängig von einer Fluoreszenzmarkierung des Proteins Abb. 4.37. An nach Methode 2) präparierte GUVs wurden keine Photostrommessungen durchgeführt. Somit konnte eine Auswahl an Methoden etabliert werden, welche eine mittels Fluoreszenzmikroskopie nachgewiesene Rekonstitution von bR unter Konservierung der Protonenpumpaktivität des Proteins erlaubten. 
A

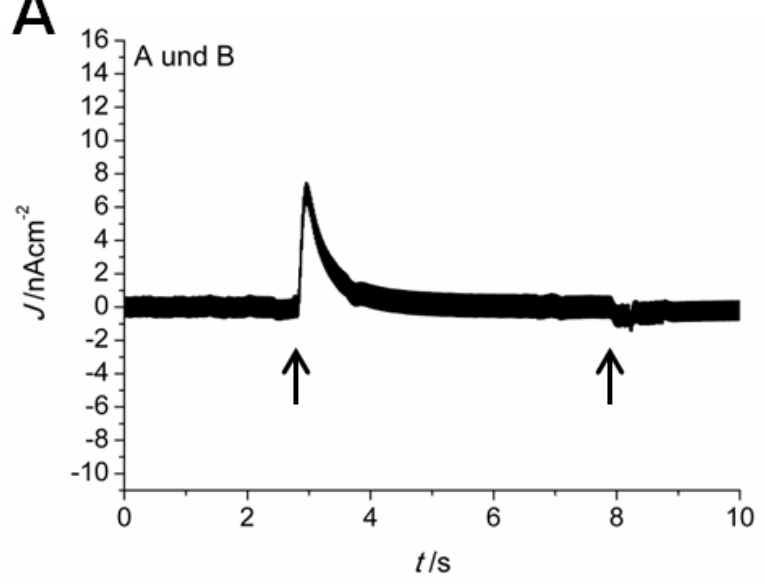

B

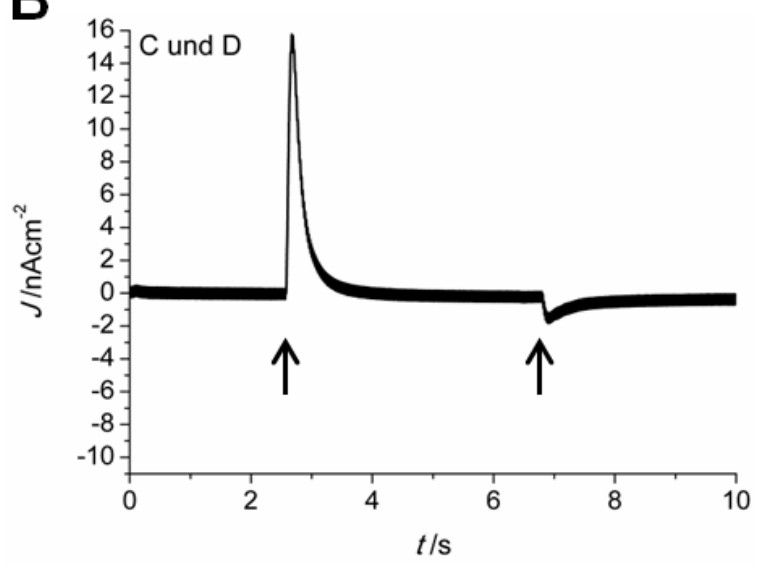

C

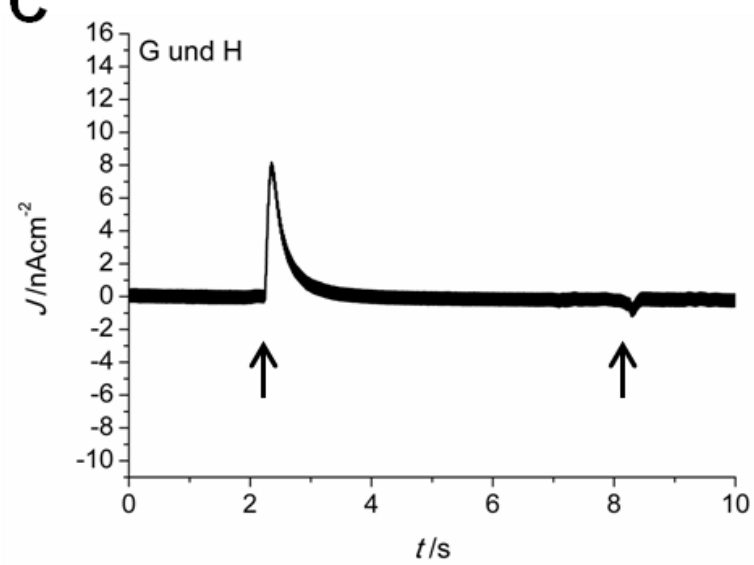

D

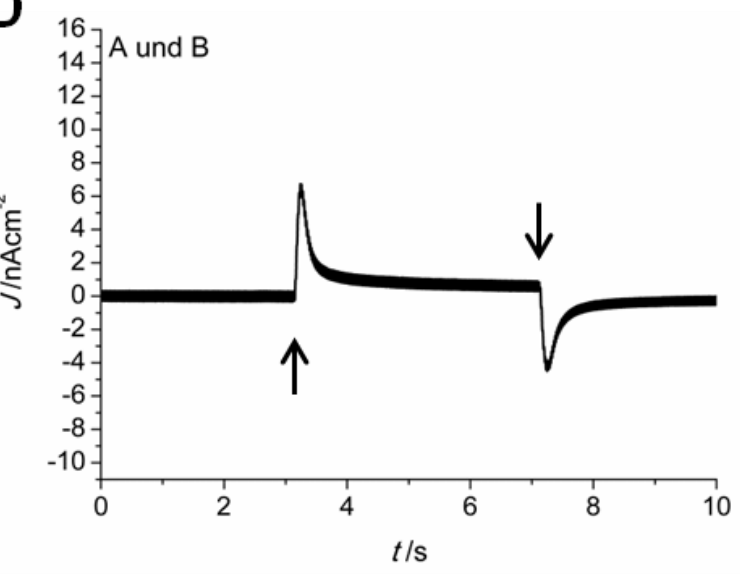

E

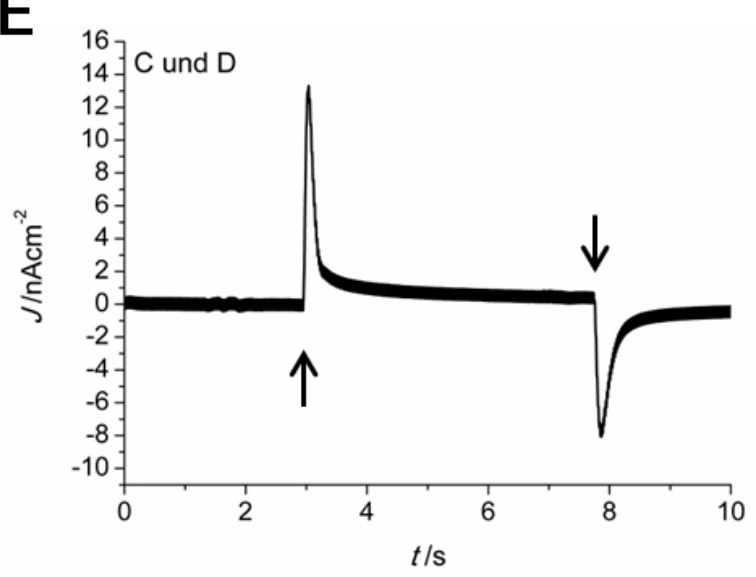

$\mathbf{F}$

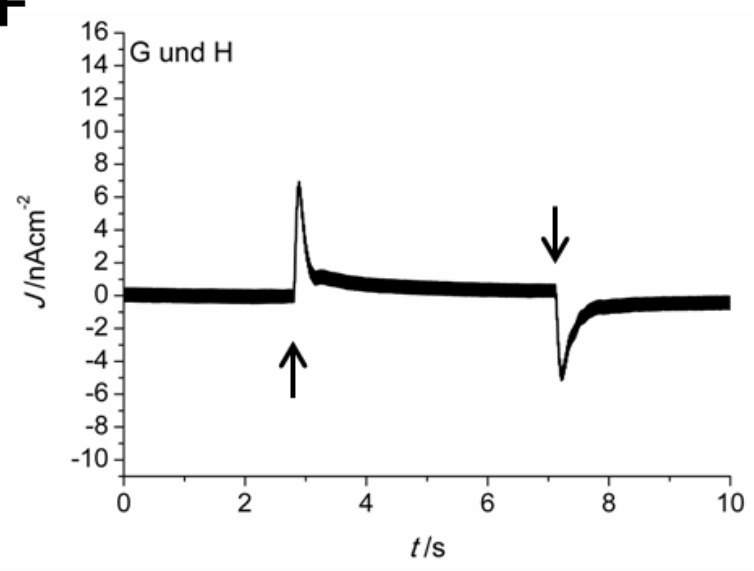

Abb. 4.37: Photostrommessungen an bR-haltigen GUVs (DPhPC/DOPC/Texas Red DHPE, 59,9:40,0:0,1, $1 \mathrm{~mol} \% \mathrm{bR}$ ), präpariert nach verschiedenen Methoden. Die Zusammensetzung und Präparation der vermessenen GUVs (A und B bis $\mathrm{G}$ und $\mathrm{H}$ ) stimmen mit den entsprechend benannten GUVs unter Abb. 4.35 überein. Pufferlösung: $100 \mathrm{mM} \mathrm{KCl}, 20 \mathrm{mM}$ TRIS, pH 7,4 ( $\mathrm{HCl})$. A, B und $\mathbf{C}$ zeigt die Verläufe der Photostromsignale vor Zugabe von CCCP, D, E und $\mathbf{F}$ die Verläufe nach Zugabe von $2 \mu \mathrm{M} \mathrm{CCCP.} \mathrm{Beginn} \mathrm{und} \mathrm{Ende} \mathrm{der} \mathrm{Belichtung} \mathrm{der}$ Probe sind jeweils mit Pfeilen markiert. 


\section{Bildung eines lichtinduzierten Protonengradienten}

Um zu untersuchen, ob ein gerichteter Protonentransport durch rekonstituiertes bR in GUVs und dadurch eine Veränderung des pH-Wertes im Vesikelinneren durch Belichtung erzeugt werden konnte, wurden pyraningefüllte GUVs präpariert und auf avidinbedeckten Substraten immobilisiert (Kapitel 3.3.3). Der pH-sensitive Farbstoff ließ sich unabhängig von der Methode der GUV-Präparation stabil in bR-haltige GUVs einschließen (Kapitel 3.2.5). Lediglich bei Verwendung von Triton-X-100 konnte ein Austritt des Farbstoffs sowohl aus den GUVs als auch aus durch Spreiten von GUVs membranüberspannten Poren festgestellt werden. Abb. 4.38, A zeigt eine dreidimensionale Darstellung der Texas Red DHPE Fluoreszenz eines porösen Substrates nach Spreiten von GUVs, welche aus Liposomen geformt wurden, die in Anwesenheit von Triton-X-100 und anschließendem Entzug des Detergens durch BioBeads gebildet wurden. Der Ausschnitt zeigt mehrere planare membranüberspannte Poren und keine hemisphärisch überspannten Poren.

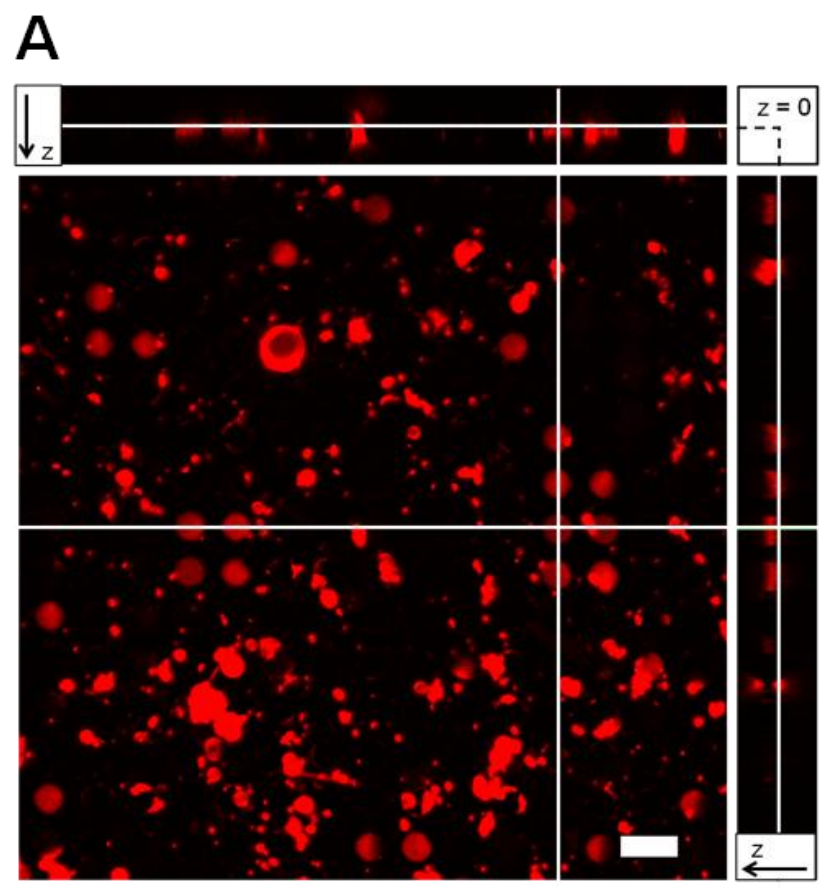

Abb. 4.38: A Ortho-Darstellung einer dreidimensionalen, konfokalmikroskopischen Aufnahme eines mit 11-Amino-1-undekanthiol funktionalisierten porösen Siliziumsubstrates $(d=4,5 \mu \mathrm{m}, h=9 \mu \mathrm{m})$ nach Spreiten von GUVs (POPC/POPS/Texas Red DHPE, 89,8:10,0:0,2, rot). Die GUVs wurden durch partielle Dehydratisierung von Liposomen (Kapitel 3.2.4, 1)) über gesättigter NaCl-Lösung, anschließender Rehydratisierung mit 0,24 M Sucrose, $2 \mathrm{mM} \mathrm{KCl,} 1 \mathrm{mM}$ MOPS, pH 7,3 (TRIS) und Elektroformation bei $3 \mathrm{~V}$ und $5 \mathrm{~Hz}$ gebildet. Die Liposomen wurden durch 30 minütiges Quellen eines Lipidfilms (2 mg) in Pufferlösung (2 mM MOPS, pH 7,3 (TRIS)) und anschließender Ultraschallbehandlung gebildet und mit Triton-X-100 (Lipidzu-Detergens Verhältnis $0,5 \%(w / w))$ versetzt. Nach 30 minütiger Inkubation bei Raumtemperatur wurde weiteres Triton-X-100 in $20 \mathrm{mM}$ HEPES, pH 6,8 (TRIS) zugegeben (Finales Lipid-zu-Detergens Verhältnis $0,51 \%(w / w)$ und das Detergens durch Zugabe von BioBeads (2x $54 \mathrm{mg}+109 \mathrm{mg}$ ) unter Rühren (12 h) entfernt. Z-Dimension: 14,0 $\mu \mathrm{m}$ (18 Einzelbilder). Pufferlösung: $107 \mathrm{mM} \mathrm{CaCl} 2,10 \mathrm{mM}$ MOPS, 0,5 mM Pyranin, pH 7,3 (TRIS). B Zweidimensionale konfokalmikroskopische Aufnahme der Pyraninfluoreszenz des in A gezeigten Ausschnitts. Maßstabsbalken je $10 \mu \mathrm{m}$. 
Eine zweidimensionale Aufnahme der Pyraninfluoreszenz derselben Stelle (Abb. 4.38, B) zeigt keine pyraningefüllten Poren. Das Fehlen hemisphärisch überspannter Poren in Kombination mit keinem Einschluss von Pyranin in membranüberspannten Poren weist auf eine Durchlässigkeit der Membranen gegenüber Pyranin, Sucrose und Ionen hin. Da Triton-X-100 mit $200 \mu \mathrm{M}$ eine geringe CMC aufweist und bekannt ist, dass es zu einem Farbstoffaustritt aus Lipidvesikeln führen kann, ${ }^{[200]}$ erklärt sich die erhöhte Durchlässigkeit porenüberspannender Membranen und von GUVs durch eine unvollständige Entfernung von Triton-X-100 im Verlauf der Vesikelbildung (Kapitel 3.2.4, 1)).

Bei Überführung pyraninfreier GUVs (gebildet in 0,3 M Sucrose) in eine pyraninhaltige Pufferlösung (160 mM KCl, 10 mM MOPS, $1 \mu \mathrm{M}$ Pyranin, pH 7,3 (KOH)) konnte beobachtet werden, dass GUVs direkt nach Zugabe mit Farbstoff gefüllt waren und sich die Intensitäten des Farbstoffs innerhalb und ausserhalb der GUVs angeglichen hatten (Abb. 4.39, B). Dieses Phänomen konnte nicht beobachtet werden, wenn Pyranin zu einer vorgelegten Suspension pyraninfreier GUVs gegeben wurde (Abb. 4.39, A). Bei Überführung von GUVs in eine Lösung anderer Zusammensetzung als im Innenvolumen der GUVs könnten geringe Unterschiede in der Osmolarität beider Volumina zu einer temporären Permeabilisierung der Membran und dadurch zu einem Eintritt des umgebenden Fluoreszenzfarbstoffs führen. Dass die Membranen nur temporär permeabel wurden, danach jedoch eingetretenen Farbstoff stabil einschliessen konnten, zeigte sich bei Belichtung des eingeschlossenen Pyranins über einen längeren Zeitraum, bei welchem selektiv im Inneren des beobachteten GUV ein Photobleichen des Pyranins auftrat (Abb. 4.39, C). Ein nachträglicher Austausch zwischen Vesikelinnerem und umgebender Lösung schließt sich somit aus.
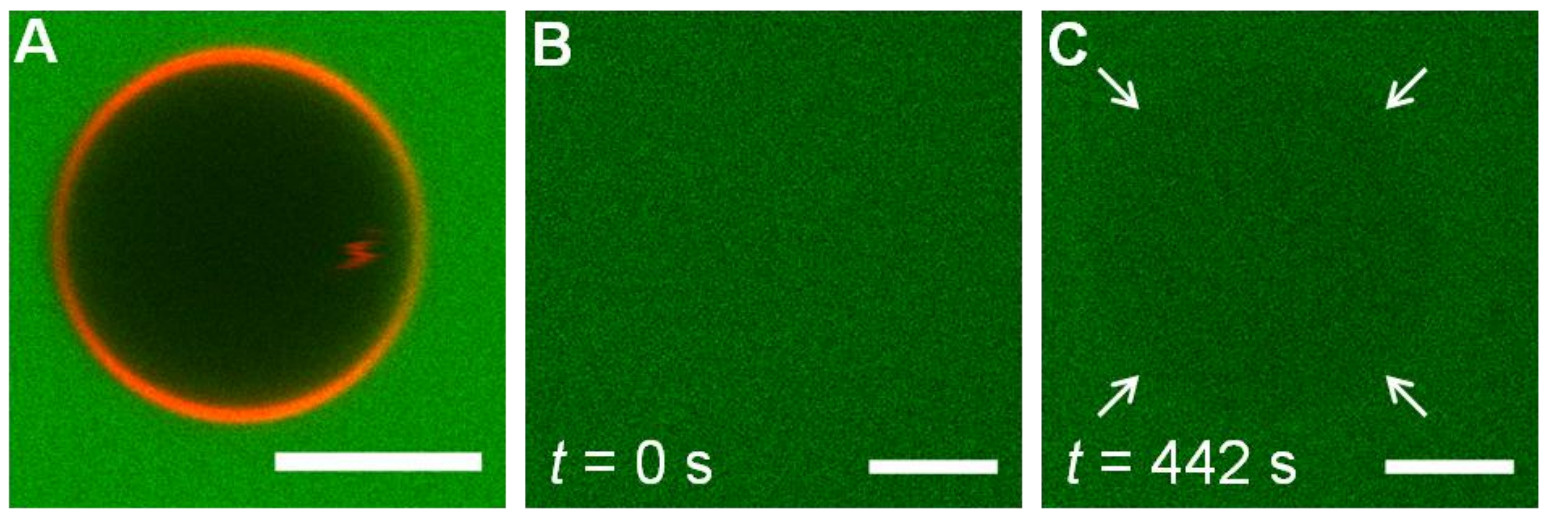

Abb. 4.39: Konfokalmikroskopische Aufnahmen von GUVs (POPC/POPS/Texas Red DHPE, 89,8:10,0:0,2, rot, mit $0,7 \mathrm{~mol} \%$ bR, Elektroformation in $0,3 \mathrm{M}$ Sucroselösung). Pufferlösung: $160 \mathrm{mM} \mathrm{KCl}, 10 \mathrm{mM}$ MOPS, $\mathrm{pH} 7,3(\mathrm{KOH})$. Zugabe von $1 \mu \mathrm{M}$ Pyranin (grün) nach $(\mathbf{A})$ bzw. vor $(\mathbf{B}, \mathbf{C})$ Überführung von GUVs in KClhaltige Pufferlösung. Maßstabsbalken $5 \mu \mathrm{m}$. B und C zeigen die Pyraninfluoreszenz im Verlauf einer Zeitserie konfokalmikroskopischer Aufnahmen, wobei der Farbstoff im Inneren eines GUV (Membranfluoreszenz nicht abgebildet) stärker photobleicht, als im umgebenden Medium (C). Pfeile deuten den Umriss des pyraningefüllten GUV am Ende der Zeitserie an (C). 
Temporäre Erhöhungen der Permeabilität von GUVs und ein daraus resultierender Austausch der wässrigen Lösung im Vesikelinneren mit der umgebenden Lösung wurden bereits durch elektrische Impulse erreicht. ${ }^{[201]}$ Daher ist es plausibel, dass ein osmotischer Schock der GUVs durch Überführung in ein Medium mit verändertem Elektrolytgehalt einen gleichen Effekt verursachen kann.

Der zeitliche Verlauf der Pyraninfluoreszenz innerhalb eines GUV bei Belichtung mit Hilfe eines LED-Rings (Abb. 3.7) ist in Abb. 4.40, A dargestellt. Die Intensität sinkt von 55 Einheiten zu Beginn der Zeitserie durch unspezifisches Photobleichen auf einen Wert von 39 Einheiten ab. Ein geringfügiges Bleichen der Hintergrundfluoreszenz (B, C) ist auf eine leichte Verschiebung der Fokusebene des Mikroskops zurückzuführen. Bei Belichtung der Probe (markiert durch Pfeile) kann in einem Zeitraum von $62 \mathrm{~s}$ keine Veränderung im Verlauf der Pyraninfluoreszenz, verglichen mit dem Gesamtverlauf beobachtet werden. Eine Anreicherung von Protonen oder Hydroxidionen im Vesikelinneren, induziert durch ein gerichtetes Pumpen des rekonstituierten bR lässt sich nicht feststellen. Ein Verlauf, wie er exemplarisch in Abb.4.40, A gezeigt ist, wurde für auf Siliziumsubstraten fixierten, bR-haltige GUVs beobachtet, unabhängig von deren Präparationsmethode. In keinem Fall konnte reproduzierbar ein Netto-Protonenpumpen, welches auf eine Vorzugsorientierung des rekonstituierten bR deuten würde, beobachtet werden.

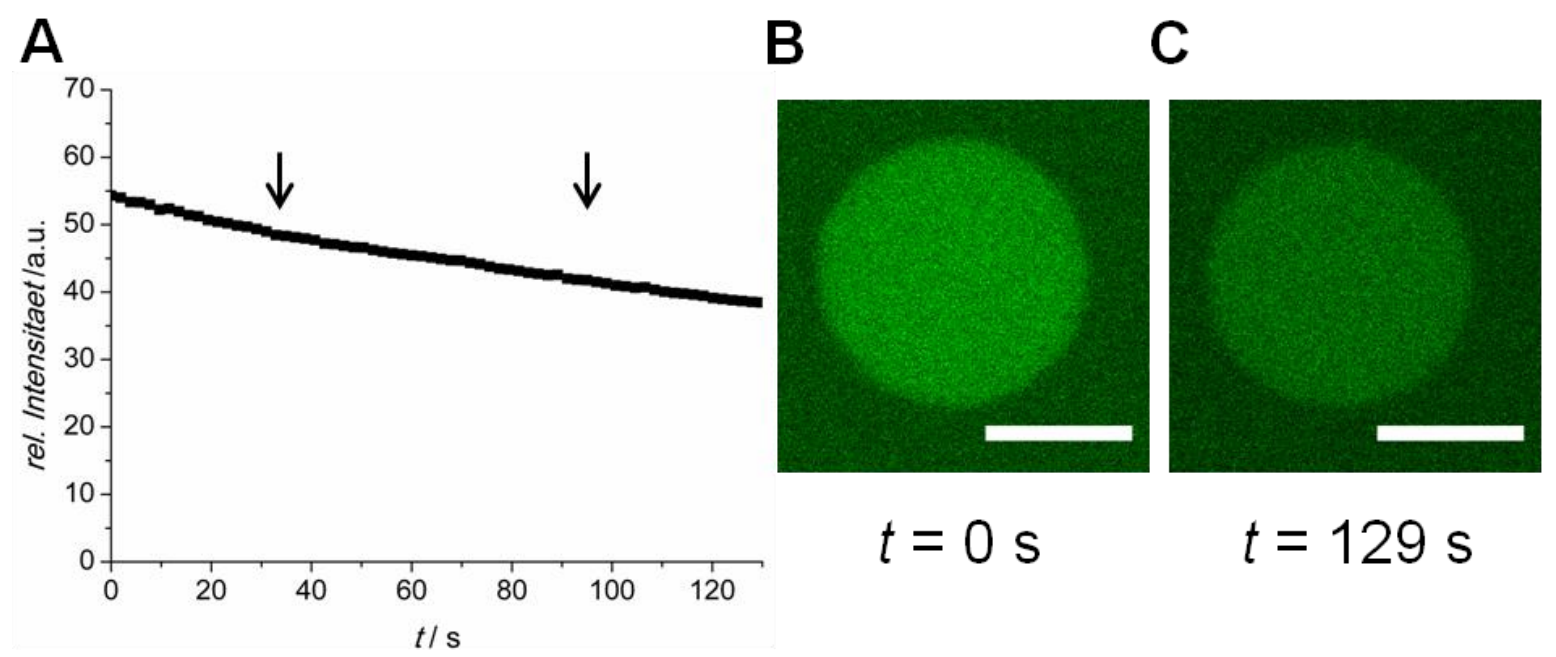

Abb. 4.40: A Zeitlicher Verlauf der Fluoreszenzintensität von in einem GUV (POPC/Bio-Cap-PE/Texas Red DHPE, 98,8:1,0:0,2, mit 0,3 mol\% bR) eingeschlossenem Pyranin (1 mM in $320 \mathrm{mM}$ Sucrose, $10 \mathrm{mM}$ MOPS, pH 7,3 (TRIS)). Pufferlösung: $160 \mathrm{mM} \mathrm{KCl,} 10 \mathrm{mM}$ MOPS, pH 7,3 (KOH). Beginn und Ende der Belichtung sind mit Pfeilen markiert. B und $\mathbf{C}$ zeigen die entsprechenden konfokalmikroskopischen Aufnahmen bei $t=0 \mathrm{~s}$ und $t=129 \mathrm{~s}$. Maßstabsbalken $5 \mu \mathrm{m}$.

Eine mögliche Erklärung für diesen Befund ist eine fehlende Vorzugsoritentierung des bR innerhalb der GUV-Membran. Die rekonstituierten bR-Moleküle sind demnach je zur Hälfte mit dem C-Terminus ins Vesikelinnere und zur umgebenden Lösung gerichtet, sodass bei Belichtung eine gleiche Zahl Protonen in den Vesikel hinein wie aus dem Vesikel hinaus 
transportiert werden. Ein Netto-Transport von Protonen und der Aufbau eines Protonengradienten über die Vesikelmembran wäre dadurch nicht möglich. Eine nähere Betrachtung hierzu findet sich in Kapitel 5.3.1.

\subsubsection{Rekonstitution von $\mathrm{bR}$ in porenüberspannende Membranen}

Um bR funktionell in porenüberspannende Membranen rekonstituieren zu können, wurden unterschiedliche Methoden untersucht. Zunächst wurde fluoreszenzmarkiertes Protein eingesetzt, um eine erfolgreiche Einlagerung von bR in porenüberspannende Membranen fluoreszenzmikroskopisch nachweisen zu können. Bei der Zugabe von fluoreszenzmarkierten PM-Fragmenten $\mathrm{zu}$ lösungsmittelfreien oder -haltigen porenüberspannenden Membranen, wurde eine inverse Verteilung von Membranfluoreszenz und Proteinfluoreszenz auf porösen Substraten beobachtet. Eine spontane Inkorporation von bR in die Membranen, was sich durch eine Deckungsgleichheit der Fluoreszenzen des markierten bR und des Membranfarbstoffs äußern würde, konnte in keinem Fall beobachtet werden. Auch die Zugabe bR-haltiger Vesikel (Kapitel 3.2.4) zu porenüberspannenden Membranen führte nach Spülen der Probe zu keiner deckungsgleichen Fluoreszenz, woraus geschlossen werden kann, dass keine Rekonstitution durch Fusion bR-haltiger Vesikel mit planaren porenüberspannenden Membranen stattfand. Eine Möglichkeit bR erfolgreich in porenüberspannende Membranen zu rekonstituieren, bot das Spreiten bR-haltiger GUVs auf hydrophil funktionalisierten porösen Substraten (Kapitel 3.2.11). Eine Ortho-Darstellung konfokalmikroskopischer Aufnahmen eines membranüberspannten Bereichs mit deckungsgleicher Membran- und Proteinfluoreszenz ist in Abb. 4.41 dargestellt. Ein Bereich von vier überspannten Poren, von denen die beiden unteren leicht gewölbt überspannt erscheinen und die beiden oberen Membranen planar und tiefer in den Poren verlaufen, ist in beiden Aufnahmen zu erkennen. Sowohl Texas Red DHPE (rot, A), als auch Alexa Fluor 488 Fluoreszenz (grün, B) erlauben dabei eine klare Unterscheidung zwischen bedeckten und leeren Poren. Generell konnte für bR-haltige porenüberspannende Membranen sowohl bei planaren, als auch bei ausgestülpten Membranen stets eine Kolokalisation beider Fluoreszenzen beobachtet werden. 


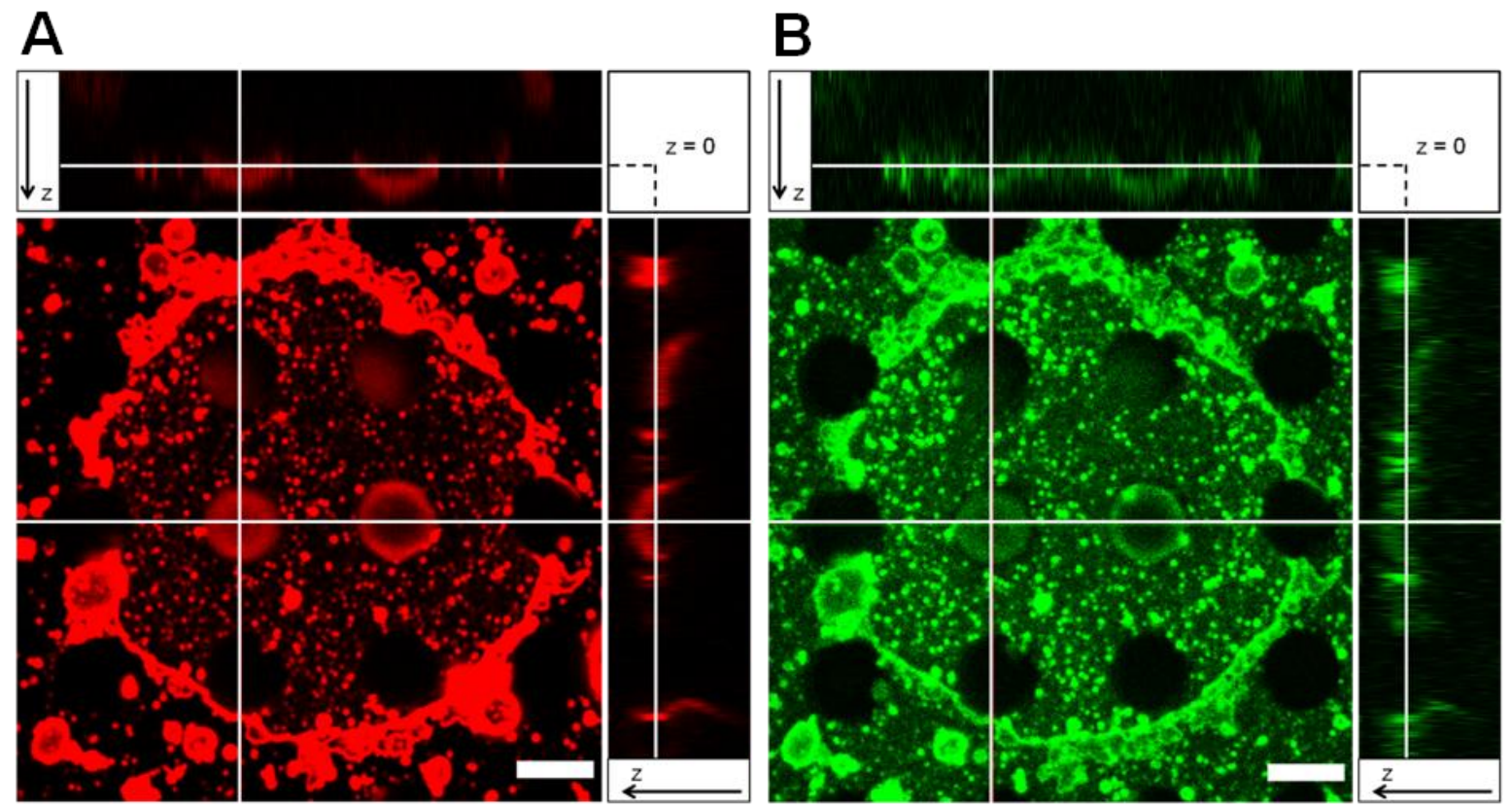

Abb. 4.41: Ortho-Darstellung einer dreidimensionalen, konfokalmikroskopischen Aufnahme eines mit 6-Mercapto-1-hexanol funktionalisierten porösen Siliziumsubstrates $(d=5,5 \mu \mathrm{m}, h=9 \mu \mathrm{m})$ nach Spreiten von GUVs (POPC/Texas Red DHPE, 99,8:0,2, rot, A, 0,7 mol\% Alexa Fluor 488 markiertes bR, grün, B). Maßstabsbalken $5 \mu \mathrm{m}$, z-Dimension: 8,6 $\mu \mathrm{m}$ (12 Einzelbilder). Pufferlösung: $160 \mathrm{mM} \mathrm{KCl,} 10 \mathrm{mM} \mathrm{MOPS}$, pH 7,3 $(\mathrm{KOH})$.

\section{Mobilität von bR in porenüberspannenden Membranen}

FRAP-Experimente wurden an bR-haltigen porenüberspannenden Membranen durchgeführt, um die Mobilität des fluoreszenzmarkierten Proteins zu untersuchen. Der Verlauf der Fluoreszenzintensität von an bR gebundenem Alexa Fluor 488 ist in Abb. 4.42, A dargestellt. Die Fluoreszenz fällt nach dem Bleichen auf einen Wert von 0,38 ab und steigt innerhalb von $116 \mathrm{~s}$ auf einen Wert von 0,86 an. Konfokalmikroskopische Aufnahmen (B, C) verdeutlichen den Intensitätsanstieg. Insgesamt wurden aus $N=6$ Experimenten Werte für planare Membranen bestimmt von $I_{\text {Bleich }}=38 \pm 13 \%$ und $M=68 \pm 16 \%$, wobei der mobile Anteil aufgrund der geringen Membranfläche fehlerbehaftet ist und somit unterbestimmt wird (Kapitel 4.1.2, Spreiten auf hydrophil funktionalisierten Substraten). Die geringe Gesamtfläche eines patches verfälscht ebenfalls den anhand von FRAP-Experimenten bestimmten Diffusionskoeffizienten von bR. Um die Größenordnung des Diffusionskoeffizienten abschätzen zu können, wurde dieser dennoch gemäß Gl. 3.17 in planaren porenüberspannenden Membranen zu $D=0,21 \pm 0,10 \mu \mathrm{m}^{2} \cdot \mathrm{s}^{-1}$ bestimmt $(N=6)$. Das Protein war sowohl in planaren, als auch in ausgestülpten Membranbereichen mobil. Für hemisphärische porenüberspannende Membranen wurde aufgrund des dreidimensionalen Membranverlaufs von einer Quantifizierung, wie sie für zweidimensionale Diffusion angewendet wurde, abgesehen (Kapitel 4.1.2, Hemisphärische porenüberspannende Membranen). 


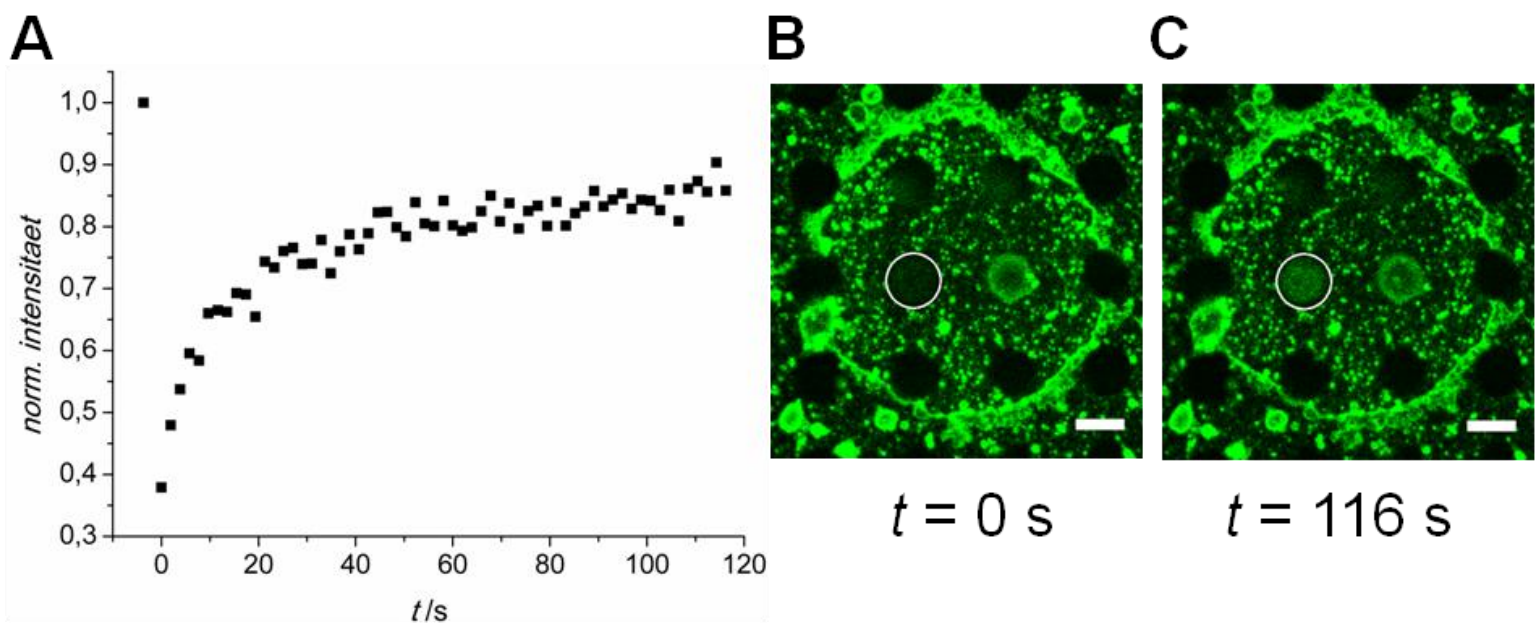

Abb. 4.42: A Intensitätsverlauf eines FRAP-Experiments an fluoreszenzmarkiertem bR auf einem porösen Siliziumsubstrat nach Spreiten von Proteo-GUVs (Probe aus Abb.4.41). B und C zeigen die zugehörigen Fluoreszenzaufnahmen bei $t=0 \mathrm{~s}$ (unmittelbar nach dem Bleichen) und $t=116 \mathrm{~s}$ (Ende der Zeitserie). Maßstabsbalken $5 \mu \mathrm{m}$. Gebleicht wurde der in weiß eingezeichnete Bereich, dessen Intensitätsverlauf in A in normierter Form aufgetragen ist.

\section{Bildung eines lichtinduzierten Protonengradienten}

Nach erfolgreicher Rekonstitution von bR in porenüberspannenden Membranen, wurde untersucht, ob durch Belichtung ein Protonengradient aufgebaut werden konnte (Kapitel 3.3.4). Hierzu wurde die Probe mit Hilfe eines LED-Rings belichtet und der zeitliche Verlauf der Fluoreszenzintensität eingeschlossenen Pyranins aufgezeichnet (Abb. 4.43). Wie zuvor bei in GUVs eingeschlossenem Pyranin, konnte auch bei in Poren eingeschlossenem Pyranin keine lichtinduzierte Änderung der Fluoreszenzintensität beobachtet werden. Dies war unabhängig davon, ob Valinomycin $(c=0-3 \mu \mathrm{M})$ oder Membranfarbstoff (Texas Red DHPE, 0-0,2 mol\%) oder eine puffernde Substanz (0-10 mM MOPS) zur Probe hinzugefügt wurden. Es konnte somit trotz Inkorporation von bR in porenüberspannende Membranen kein mittels Pyraninfluoreszenz nachweisbarer Protonengradient gebildet werden.

Lanthanchlorid wurde zu der überstehenden Lösung gegeben, um den bR-induzierten Transport von Protonen aus den Poren heraus selektiv zu hemmen und so einen NettoProtonentransport in die Poren hinein und den Aufbau eines Protonengradienten zu ermöglichen. ${ }^{[15]}$ Mit Lanthanionen behandelte Proben zeigten bei Belichtung jedoch keinen veränderten Intensitätsverlauf der Pyraninfluoreszenz. Statt dessen konnte bei Konzentrationen von 0,5 mM (Seigneuret et al. setzten Konzentrationen bis zu $10 \mathrm{mM}$ ein) die Bildung eines kristallförmigen Belags über dem gesamten Substrat verteilt beobachtet werden. Dieser besteht vermutlich aus Lanthanhydroxid, welches bereits im neutralen $\mathrm{pH}-$ Bereich präzipitiert. ${ }^{[202]}$ 


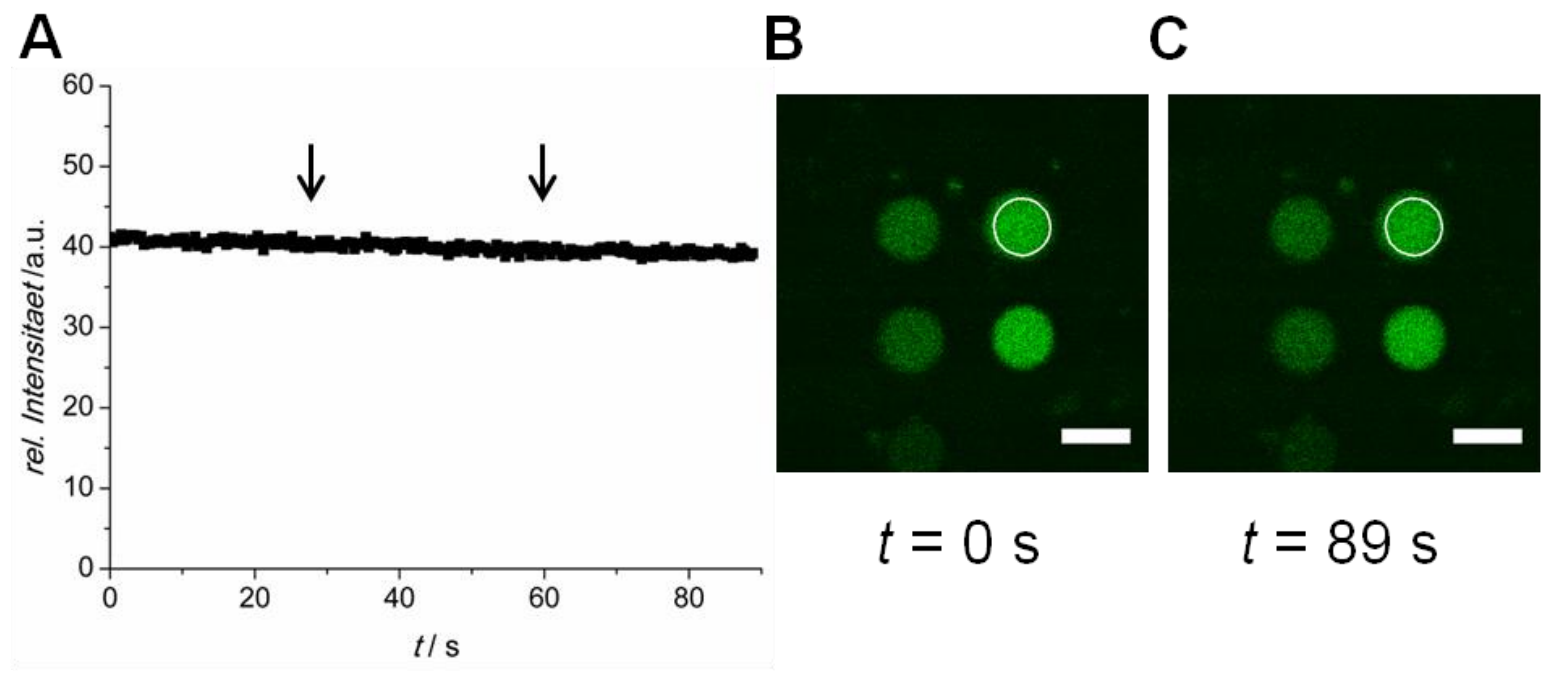

Abb. 4.43: A Zeitlicher Verlauf der Fluoreszenzintensität in einer Pore eingeschlossenen Pyranins. Mit 11-Amino-1-Undekanthiol funktionalisierte Poren mit geschlossenen Böden $(d=4,5 \mu \mathrm{m}, h=9 \mu \mathrm{m})$ wurden durch Spreiten von GUVs (DPhPC/DPPA, 9:1, 1 mol\% bR) mit einer Membran überspannt. Lösung: $80 \mathrm{mM}$ $\mathrm{CaCl}_{2}, 50 \mathrm{mM} \mathrm{KCl}, 0,5 \mathrm{mM}$ Pyranin, pH 7,8 (KOH). Beginn und Ende der Belichtung sind mit Pfeilen markiert. $\mathbf{B}$ und $\mathbf{C}$ zeigen die entsprechenden konfokalmikroskopischen Aufnahmen bei $t=0 \mathrm{~s}$ und $t=89 \mathrm{~s}$ (ROI weißer Kreis). Maßstabsbalken $5 \mu \mathrm{m}$.

Wurden die Proben im Rahmen der Zeitserien statt mit Hilfe eines LED-Rings oder des mikroskopeigenen DPSS-Lasers mit einer Halogenlampe (Kapitel 3.3.1) belichtet, ergab sich ein veränderter Intensitätsverlauf. In Abb. 4.44, A ist der Verlauf für zwei Poren im selben Bildausschnitt (B, C) dargestellt. Nach Beginn der Belichtung steigt die Pyraninintensität in der in weiß markierten Pore von 29 auf 42 Einheiten, nach Ende der Belichtung sinkt sie auf einen Wert von 34 Einheiten ab. Im Gegensatz dazu sinkt die Intensität in der rot markierten Pore nach Belichtung von 21 auf 12 Einheiten und steigt nach Ende der Belichtung auf 14 Einheiten an. Der Verlauf der Pyraninfluoreszenz ähnelt in seiner Form den Verläufen, wie sie für ein aktives Protonenpumpen von in Vesikeln rekonstituiertem bR beschrieben wurden. ${ }^{[87,111,115,127]}$ Eine Umrechnung der Fluoreszenzintensitäten in pH-Werte nach Gl. 3.4 und Gl. 3.5 ergab maximale $\mathrm{pH}-$ Wertänderungen bei Belichtung von $\Delta \mathrm{pH}=0,52$ Einheiten für den grauen Verlauf und $\Delta \mathrm{pH}=0,42$ Einheiten für den blassroten Verlauf. 


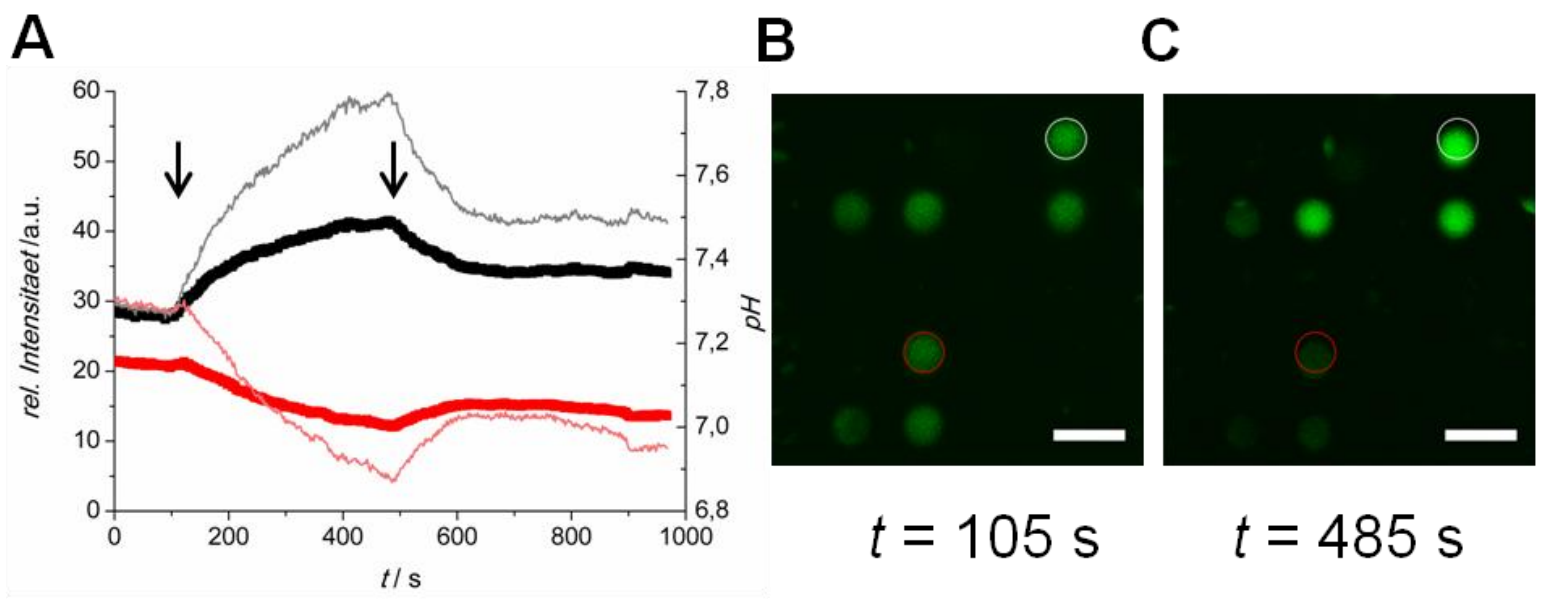

Abb. 4.44: A Zeitlicher Verlauf der Fluoreszenzintensitäten in Poren eingeschlossenen Pyranins. Mit 11-Amino1-Undekanthiol funktionalisierte Poren mit geschlossenen Böden $(d=5,5 \mu \mathrm{m}, h=9 \mu \mathrm{m})$ wurden durch Spreiten von GUVs (POPC/POPS, 9:1, 0,3 mol\% bR) mit einer Membran überspannt. Pufferlösung: $107 \mathrm{mM} \mathrm{CaCl}_{2}$, $10 \mathrm{mM}$ MOPS, 0,5 mM Pyranin, 0,2 $\mu \mathrm{M}$ Valinomycin, pH 7,3 (TRIS). Der Verlauf der Fluoreszenzintensität des Pyranins innerhalb zweier unterschiedlicher Poren ist in rot bzw. schwarz dargestellt. Die daraus errechneten Verläufer des jeweiligen pH-Wertes sind in blassrot bzw. grau dargestellt. Beginn und Ende der Belichtung sind mit Pfeilen markiert. B und $\mathbf{C}$ zeigen die entsprechenden konfokalmikroskopischen Aufnahmen bei $t=105 \mathrm{~s}$ (Beginn der Belichtung) und $t=485 \mathrm{~s}$ (Ende der Belichtung). ROIs sind in rot (roter Verlauf in A) und weiß (schwarzer Verlauf in A) markiert. Maßstabsbalken $10 \mu \mathrm{m}$.

Die Verschiebung der pyraningefüllten Poren zwischen Abb. 4.44, B und C lässt sich durch thermisch induzierte Änderung der Fokusebene sowie der Substratposition während der Belichtung erklären (Thermodrift, Abb.4.45) und nicht durch einen lichtinduzierten Protonentransport des bR. Bei Belichtung der Probe mit einer Halogenlampe erwärmt sich die Probe so stark, dass der Temperaturanstieg vermutlich eine thermische Ausdehnung entweder in der Probe oder im Mikroskopaufbau induziert, was eine Veränderung des Abstands zwischen Objektiv und fokussierter Substratebene bewirkt. Dadurch verschiebt sich die Ebene innerhalb des Substrates, auf welche der Anregungskegel des Laserlichtes fokussiert ist. Es wird eine veränderte Menge Pyranins angeregt, was die detektierte Intensität beeinflusst und $\mathrm{zu}$ einem Anstieg (Abb. 4.45, rechte Pore) oder Abfall (Abb. 4.45, linke Pore) der Fluoreszenzintensität führen kann. 
A

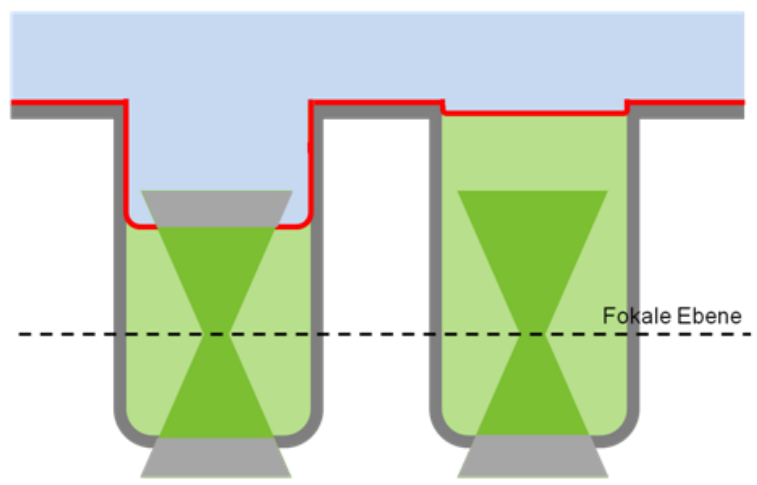

B

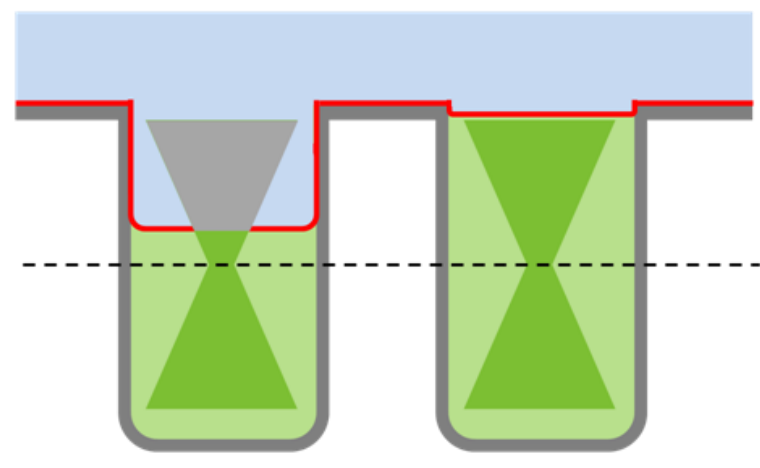

Abb. 4.45: Schematische Darstellung der thermisch bedingten Änderung der Pyraninintensität in membranüberspannten Poren bei Belichtung mit einer Halogenlampe. Es sind zwei Poren mit geschlossenen Böden dargestellt (grau), in welche unterhalb einer porenüberspannenden Membran (rot) Pyranin (blassgrün) eingeschlossen ist. Beide Membranen überspannen die jeweilige Pore in unterschiedlicher Tiefe. Das fokale Volumen, in welchem Pyranin angeregt wird, ist in grün dargestellt, der Teil des fokalen Volumens, welcher ausserhalb des Poreninneren liegt und dadurch kein Pyranin zur Fluoreszenz anregen kann, ist in hellgrau dargestellt. Das Zentrum des Kegelförmigen fokalen Volumens liegt in der fokalen Ebene (schwarze gestrichelte Linie). A Vor Start der Belichtung wird in der linken Pore weniger Pyranin im Bereich des fokalen Kegels angeregt, als in der rechten Pore (grüne Fläche kleiner, hellgraue größer). Die rechte pore erscheint dadurch heller. B Während der Belichtung der Probe mit einer Halogenlampe kommt es zu einer thermisch bedingten Verschiebung der fokalen Ebene (Thermodrift). Dadurch verschiebt sich jeweils das fokale Volumen in beiden Poren und in der linken Pore wird weniger Pyranin angeregt, als vor Belichtung (A). Die Intensität des Pyranins innerhalb der Pore nimmt dadurch ab. In der rechten Pore wird mehr Pyranin angeregt, als vor der Belichtung (A). Das gesamte fokale Volumen kann zur Anregung genutzt werden (gesamter Kegel grün) und es wird ein Intensitätsanstieg des Pyranins in dieser Pore detektiert. Zeichnung nicht maßstabsgetreu.

Die hier schematisch dargestellten Verläufe lassen sich auf die beiden in Abb. 4.44 berücksichtigten Poren übertragen. Die Intensitätsänderungen sind demnach thermisch bedingt und es kommt nicht $\mathrm{zu}$ einem bR-induzierten Netto-Protonentransport über die Membranen. Eine Bestätigung für diese Deutung liefert der Intensitätsverlauf der Pyraninfluoreszenz in membranüberspannten Poren ohne rekonstituiertes bR (Abb. 4.46). Abb. 4.46, A zeigt, dass auch ohne eine Rekonstitution der Protonenpumpe bR eine Intensitätsveränderung der Pyraninfluoreszenz im Poreninneren bei Belichtung der Probe mit einer Halogenlampe auftritt, welche dem in der Literatur als Protonentransport gedeuteten Verlauf bR-haltiger Membransysteme, sowie dem in Abb. 4.44, A dargestellten Verlauf ähnelt. Eine Änderung der Fluoreszenzintensität eingeschlossenen Pyranins ist demnach wahrscheinlich auf einen thermisch bedingten Drift der Fokusebene zurückzuführen und nicht auf Proteinaktivität. 


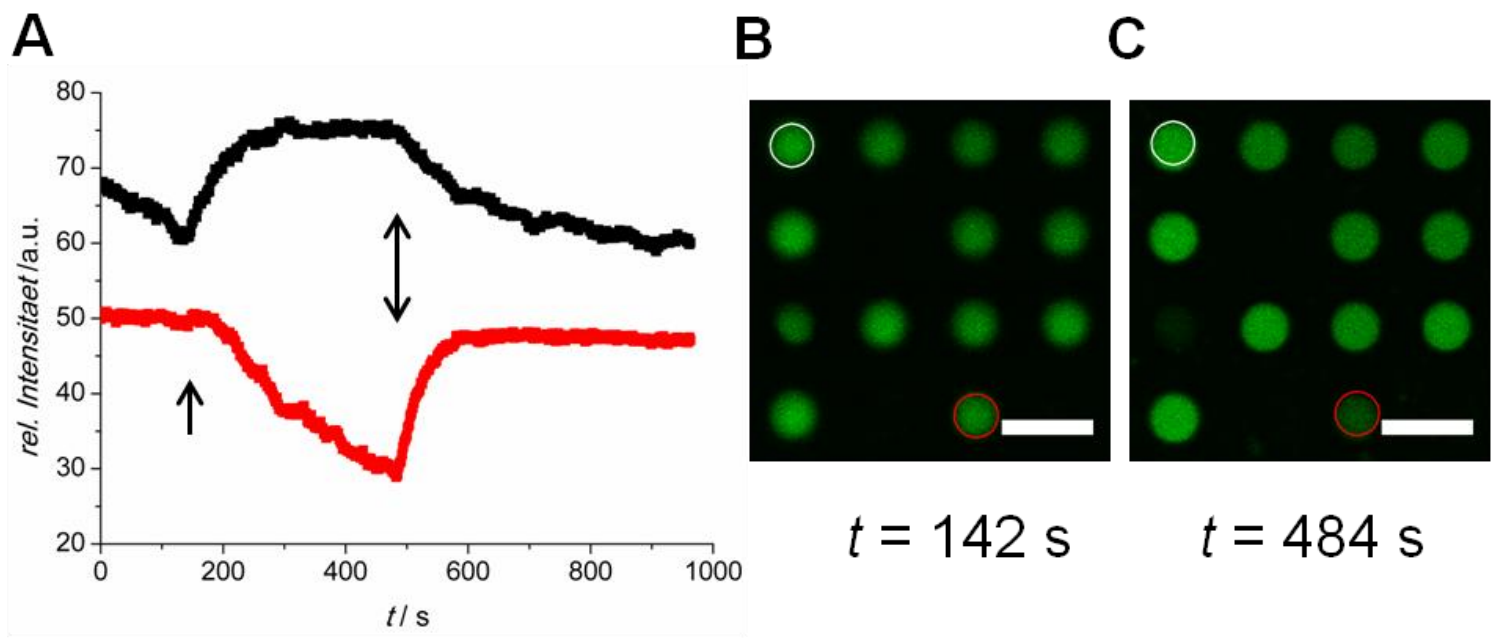

Abb. 4.46: A Zeitlicher Verlauf der Fluoreszenzintensitäten in Poren eingeschlossenen Pyranins. Mit 11-Amino1-Undekanthiol funktionalisierte Poren mit geschlossenen Böden $(d=5,5 \mu \mathrm{m}, h=9 \mu \mathrm{m})$ wurden durch Spreiten von GUVs (POPC/POPS, 9:1) mit einer Membran überspannt. Pufferlösung: $160 \mathrm{mM} \mathrm{KCl,} 10 \mathrm{mM} \mathrm{MOPS}$, 0,5 mM Pyranin, 0,2 $\mu \mathrm{M}$ Valinomycin, pH 7,3 (TRIS). Der Verlauf der Fluoreszenzintensität des Pyranins innerhalb zweier unterschiedlicher Poren ist in rot bzw. schwarz dargestellt. Beginn und Ende der Belichtung sind mit Pfeilen markiert. B und $\mathbf{C}$ zeigen die entsprechenden konfokalmikroskopischen Aufnahmen bei $t=142 \mathrm{~s}$ (Beginn der Belichtung) und $t=484 \mathrm{~s}$ (Ende der Belichtung). ROIs sind in rot (roter Verlauf in A) und weiß (schwarzer Verlauf in A) markiert. Maßstabsbalken $10 \mu \mathrm{m}$. 


\section{Diskussion}

\subsection{Präparation und Charakterisierung von Membranen auf porösen Substraten}

Porenüberspannende Membranen wurden mittels zweier verschiedener Techniken präpariert: Lösungsmittelhaltige Membranen wurden durch Auftragen eines Lipid-Lösungsmittelgemisches auf hydrophob funktionalisierten Substraten gebildet (Kapitel 4.1.1). Der Restgehalt an Lösungsmittel wurde mittels solvent freeze-out reduziert, einem bisher wenig untersuchten Prozess, welcher näher diskutiert werden soll. Lösungsmittelfreie Membranen wurden durch Spreiten mikrometergroßer Vesikel (GUVs) gebildet (Kapitel 4.1.2). Neben porenüberspannenden Membranen konnten durch Anpassung der Funktionalisierung auch porenauskleidende Membranen gebildet oder Lufteinschlüsse in den Poren forciert werden. Im Folgenden sollen Topografie und Mobilität der Lipide der gebildeten Membrantypen vergleichend gegenübergestellt werden.

\subsubsection{Ausfrieren remanenten Lösungsmittels in porenüberspannenden painted membranes}

Die painting-Technik ist in verschiedenen Variationen die meistverwendete Methode, um freistehende Lipiddoppelschichten zu bilden. ${ }^{[7]}$ Eine allgemeine schematische Darstellung der Bildung einer sogenannten black lipid membrane (BLM) durch die painting-Technik ist in Abb. 5.1 gezeigt. Dabei wird eine Lipid-Lösungsmittelschicht aufgetragen und durch spontanes Ausdünnen, ${ }^{[23,30,42,47,58,59,62,63,65,69]}$ Ausdünnen induziert durch Kontakt zu Luft, ${ }^{[22,23,47]}$ Abstreifen mit einem Kunststoffschlauch, ${ }^{[68]}$ oder druckinduziert ${ }^{[18,66]}$ bildet sich eine Lipiddoppelschicht umgeben von einer Lösungsmittelrandschicht, der sogenannten Plateau-Gibbs-Grenzschicht, aus. 


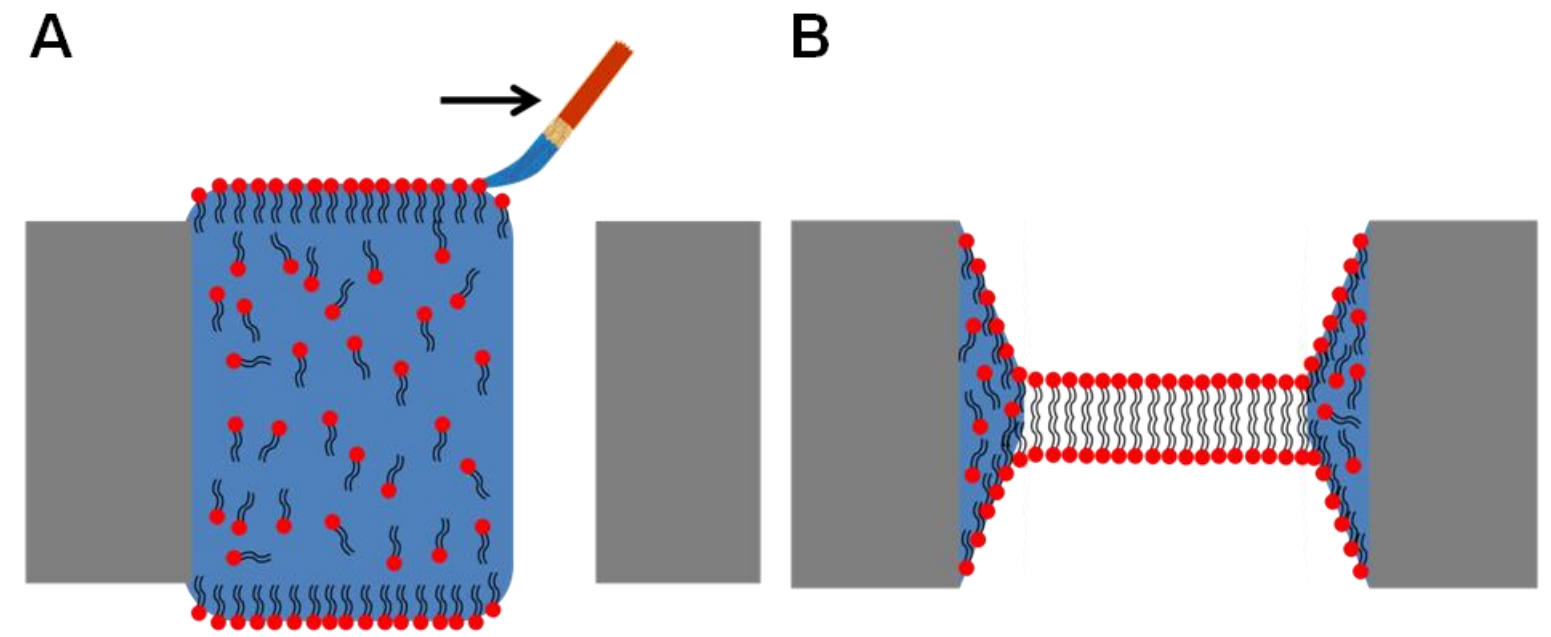

Abb. 5.1: Schematische Darstellung der Bildung einer lösungsmittelhaltigen porenüberspannenden Membran mittels painting-Technik. A Lipid (rot) gelöst in Lösungsmittel (blau) wird mit einem ausgedünnten Pinsel über einer einzelnen Pore aufgetragen. Der Stegbereich ist jeweils in grau dargestellt. B Durch spontanes oder induziertes Ausdünnen des Lösungsmittels bildet sich eine weitgehend lösungsmittelfreie Lipiddoppelschicht in der Porenmitte. Restliches Lösungsmittel sammelt sich an der Grenzfläche zum Substrat und bildet dort die sogenannte Plateau-Gibbs-Grenzschicht. Nicht Maßstabsgetreu.

Spontanes Ausdünnen des Lösungsmittels tritt nur auf hydrophoben Substraten (z. B. Polydimethylsiloxan (PDMS), Teflonfolie) auf, da sich das Lösungsmittel dort entlang der Substratfläche verteilt. ${ }^{[203]}$ Bei einzelnen Poren mit großer umgebender Stegfläche lässt sich restliches Lösungsmittel so effektiv aus der Membran entfernen. Bei Substraten mit einer Vielzahl periodisch angeordneter Poren und dabei einer hohen Porosität ist diese Methode weniger effektiv aufgrund des geringeren Steg-zu-Porenfläche Verhältnisses.

Poren mit geschlossenen Böden, wie sie im Rahmen dieser Arbeit zur Bildung lösungsmittelhaltiger porenüberspannender Membranen eingesetzt wurden, wiesen hohe Porositäten (bis $65 \%$ ) auf. Ein Austausch der Pufferlösung ist aufgrund der Porenböden nur einseitig möglich und hydrostatischer Druck lässt sich dadurch ebenfalls nicht direkt aufbauen. Anwendung von Luft führt zu Lufteinschlüssen im Poreninneren (Kapitel 4.1.2, Spreiten auf hydrophob funktionalisierten porösen Substraten), sodass zur Reduzierung der Menge remanenten Lösungsmittels auf die Methode des solvent freeze-out zurückgegriffen wurde. Ding et al. führten elektrochemische Messungen an painted membranes (Phosphatidylcholin in $n$-Dekan, $20 \mathrm{mg} \cdot \mathrm{mL}^{-1}$ ) durch, stellten dabei nach solvent freeze-out eine erhöhte Membrankapazität, sowie einen erhöhten Membranwiderstand fest und postulierten die Bildung lösungsmittelfreier Membranen. ${ }^{[170]}$ Die Idee des Ausfrierens remanenten Lösungsmittels aus durch painting-Technik präparierte Membranen geht auf White zurück. ${ }^{[171]}$ Dieser beobachtetete für freistehende Membranen aus Glycerylmonooleat (gebildet aus $n$-Hexadekan) bei Erniedrigung der Temperatur unterhalb der Schmelztemperatur von $n$-Hexadekan eine Bildung von Lösungsmittel-Mikrotropfen in Verbindung mit einem sprunghaften Anstieg der Membrankapazität. Er postulierte die Bildung großer Bereiche lösungsmittelfreier 
Membranen durch Verdichtung des Lösungsmittels in Form von Mikrotropfen und deren Akkumulation im Bereich der Plateau-Gibbs-Grenzschicht.

Mit einer Schmelztemperatur von $-29,7{ }^{\circ} \mathrm{C}^{[204]}$ wird der Schmelzpunkt des in dieser Arbeit sowie bei Ding verwendeten $n$-Dekans beim Prozess des Ausfrierens $\left(T \geq-21{ }^{\circ} \mathrm{C}\right)$ nicht erreicht. Der Mechanismus des Ausfrierens kann sich daher bei beiden Lösungsmitteln unterscheiden und wird von Ding et al. nicht näher erläutert. Einen Hinweis zum genauen Mechanismus des Ausfrierens von Lösungsmittel und dessen Verbleib könnten Experimente an superhydrophoben, mikrostrukturierten Oberflächen liefern. Rykaczewski et al. imprägnierten solche Präparate mit einem Schmierölfilm und testeten die eisabweisende Wirkung der Proben (Abb. 5.2). ${ }^{[205]}$ Mittels elektronenmikroskopischer Aufnahmen stellten sie fest, dass das Öl, welches zuvor entlang der mikrostrukturierten Oberfläche verlief (Abb. 5.2, A), bei Gefrieren aufliegender Wassertröpfchen aus den Kavitäten entlang der Tropfenoberfläche gezogen wurde (Abb. 5.2, B, C). Grund hierfür seien Kapillarkräfte, welche ein Ausbreiten des Ölfilms entlang der rauhen Eisoberfläche forcieren. Nach Auftauen der Probe und erneutem Gefrieren, war ein Großteil des Ölfilms aus den Mikrostrukturen verschwunden (Abb. 5.2, D).
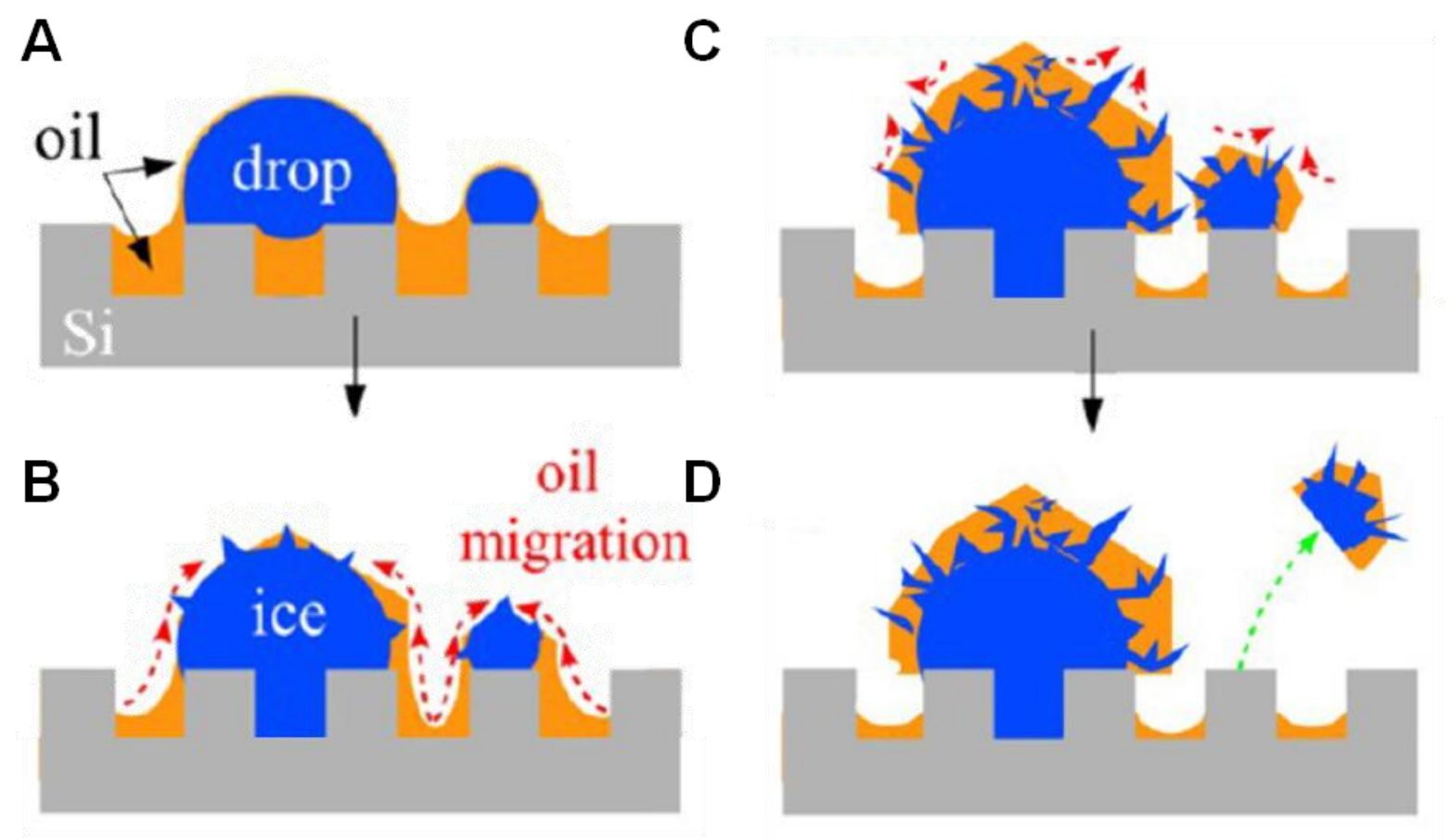

B

Abb. 5.2: Schematische Darstellung der Entfernung von Öl (gelb) aus mikrostrukturierten Siliziumoberflächen (grau) durch Gefrieren von aufliegenden Wassertropfen (blau). A Tropfen wässriger Lösung liegen auf einem mikroporösen, hydrophob funktionalisierten Siliziumsubstrat auf. B Beim Gefrieren der Tröpfchen verteilt sich das Öl entlang der Eisoberfläche auf den gefrorenen Tröpfchen. C Dabei wird ein Großteil des Öls aus den Poren entfernt. Getrieben wird der Prozess durch Kapillarkräfte. D Die ölbeschichteten Wassertröpfchen können von der Substratoberfläche abgelöst werden (vor oder nach Auftauen der Lösung, z. B. durch Vibration oder Spülen). Abbildung modifiziert nach Rykaczewski et al. ${ }^{[205]}$ 
Beim in dieser Arbeit beschriebenen Prozess des Lösungsmittelausfrierens wurde eine Mischung aus $n$-Dekan und Lipid auf mikrostrukturierte Oberflächen aufgetragen und statt einzelner Tropfen das ganze Substrat mit wässriger Lösung bedeckt. Die überstehende Lösung der Probe wurde nie komplett eingefroren. Dennoch ist es denkbar, dass sich auch hier Kleinstkristalle in Kontakt zu den mittels painting-Technik aufgebrachten Membranen bilden und überschüssiges Lösungsmittel durch Kapillarkräfte aus dem Porenbereich auf solche Kristallisationskeime übergeht. Dass die Oberflächenstruktur die Kristallbildung beim Abkühlen einer wässrigen Lösung beeinflussen kann, belegen Rykaczewski et al. durch Unterschiede in der Zeit, welche bis zum vollständigen Gefrieren der aufgebrachten Lösung verging. Der Lösungsmittelgehalt könnte dabei soweit reduziert werden, dass die beiden Lipid-Monoschichten zwischen organischer und wässriger Phase (Abb. 5.1, A) in eine räumliche Distanz gebracht werden, welche eine Zusammenlagerung beider Monoschichten zu einer Doppelschicht durch Van-der-Waals-Wechselwirkungen begünstigt. ${ }^{[206]}$ Ein Erwärmen der Probe auf Raumtemperatur und somit eine Auflösung der Kleinstkristalle oder ein Spülen der Oberfläche mit wässriger Lösung, entfernt das Lösungsmittel schließlich irreversibel aus dem Membranbereich.

Bei Ding et al., wie auch in dieser Arbeit, lässt sich eine Reduzierung remanenten Lösungsmittels nach Abkühlung der Probe feststellen. ${ }^{[170]}$ Während vor Ausfrieren des Lösungsmittels keine Plateau-Gibbs-Grenzschicht beobachtet werden konnte (Abb. 4.1, A), war dies nach dem Ausfrieren möglich (Abb.4.3, A). Die Ausdehnung der Membranfluoreszenz in $z$-Richtung verringerte sich insgesamt, was auf eine Abnahme der Lipid-Lösungsmittelschichtdicke hindeutet, wobei sich im Porenzentrum eine Ausdehnung von bis zu $\Delta z=2,6 \mu \mathrm{m}$ und am Porenrand, also im Bereich der Plateau-Gibbs-Grenzschicht eine Ausdehnung von bis zu $\Delta z=4,4 \mu \mathrm{m}$ ergab.

Die Topografie freistehender Membranen wurde bisher kaum mit Hilfe dreidimensionaler konfokalmikroskopischer (CLSM)-Aufnahmen untersucht. Beispiele von Asolectinmembranen, aufgetragen in $n$-Dekan auf ein vierporiges Substrat aus Polymethylmethacrylat (PMMA, Porendurchmesser $d=100 \mu \mathrm{m}),{ }^{[66]}$ sowie Membranen aus Sojalipiden, aufgetragen in $n$-Dekan auf eine poröse Polycarbonatfolie $(d=5 \mu \mathrm{m}$ bzw. $d=70 \mu \mathrm{m}),{ }^{[62]}$ oder solchen aus DPhPC, aufgetragen in $n$-Dekan auf eine mit einer Pore $(d=50 \mu \mathrm{m})$ versehenen Teflonfolie ${ }^{[30]}$ weisen eine ähnliche Struktur auf. Wie in Abb. 4.5, A gezeigt, wurde auch in den hier aufgeführten Beispielen eine Akkumulation von Membranfarbstoffen in der Plateau-GibbsGrenzsschicht beobachtet.

Erstmals wurden neben fluoreszenzmikroskopischen Aufnahmen auch rasterionenleitfähigkeitsmikroskopische (SICM)-Aufnahmen zur Charakterisierung freistehender Membranen vor (Abb. 4.1, B) bzw. nach (Abb. 4.3, B) Ausfrieren des Lösungsmittels verwendet. Hierbei konnte eine Verschiebung der Grenzfläche zwischen Membran bzw. Lipid-Lösungsmittelgemisch und überstehender wässriger Pufferlösung von oberhalb der Substratoberfläche 
$(z>0 \mu \mathrm{m})$ ins Poreninnere hinein $(z=-1,60 \pm 1,14 \mu \mathrm{m})$ beobachtet werden. Die Tiefe, in welcher Membranen nach Ausfrieren des Lösungsmittels die Poren überspannten, schwankte innerhalb einer Aufnahme um maximal 15\%, zwischen verschiedenen Proben jedoch um mehrere Mikrometer. Diese Beobachtung lässt sich durch ein ungleichmäßiges Auftragen des Lipid-Lösungsmittelgemisches auf die Substratoberfläche erklären. Die Menge an Lösung, welche mit dem feinen Pinsel auf das Substrat aufgebracht wird, variiert von Probe zu Probe und lässt sich nicht normieren. Nach Ausfrieren des Lösungsmittels bilden sich jeweils Lipiddoppelschichten im Porenbereich, wobei die Fläche der Poren mit $8.8 \mu \mathrm{m}^{2}$ konstant ist, die Menge aufgetragenen Lipids jedoch stark schwanken kann. Poren, auf welche vergleichsweise wenig Lipidmaterial aufgebracht worden war, waren nach Ausfrieren des Lösungsmittels in geringer Tiefe überspannt (Abb. 5.3, A und C). Poren, auf welche vergleichsweise viel Lipidmaterial aufgebracht worden war, wiesen Membranen in größeren Tiefen auf (Abb. 5.3, B und D). Die überschüssige Lipidmenge wird dabei durch eine Vergrößerung der Membranfläche in $z$-Richtung ausgeglichen. Eine solche Vertiefung porenüberspannender Membranen durch Einführen zusätzlichen Lipidmaterials konnte ebenfalls durch SICMAufnahmen von Höfer et al. bei Fusion von Vesikeln mit porenüberspannenden Membranen beobachtet werden. ${ }^{[182]}$

Neben der Topografie der porenüberspannenden Membranen wurde auch die Mobilität der Lipide mittels fluorescence recovery after photobleaching (FRAP) adressiert. FRAP-Experimente bestätigten die heterogene Verteilung restlichen Lösungsmittels innerhalb der Lipidschichten vor solvent freeze-out in Form von stark schwankenden Werten für den mobilen Anteil $\left(M=65 \pm 40 \%, M_{\max }=97 \%, M_{\min }=7 \%\right)$ und die Intensität nach Bleichen $\left(I_{\text {Bleich }}=44 \pm 19 \%, I_{\text {Bleich,max }}=73 \%, I_{\text {Bleich,min }}=24 \%\right)$. Abb. 4.2, A-C zeigt, dass hohe mobile

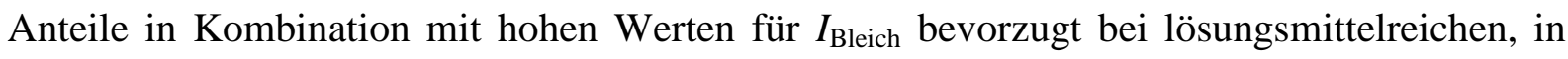
Fluoreszenzaufnahmen homogen erscheinenden Lipidschichten beobachtet werden. Ein hoher Lösungsmittelanteil erhöht den Diffusionskoeffizienten der Lipide in Membranen, sowie den mobilen Anteil. ${ }^{[46,207]} \mathrm{Da}$ durch die hohe Ausdehnung der Lösungsmittel-Lipidschicht in $z$-Richtung (Abb.5.3, B) keine planare Lipidschicht vorliegt, können Lipide nicht nur zweidimensional sondern dreidimensional diffundieren. Durch den schnellen Austausch von Lipiden in allen drei Raumdimensionen ergibt sich eine hohe Intensität nach dem Bleichen, da innerhalb der region of interest (ROI) gebleichte Lipide kontinuierlich gegen ungebleichte Lipide ausgetauscht werden können. Die Fluorophormoleküle liegen im lösungsmittelreichen Gemisch weiterhin weniger dicht gepackt vor, als in einer definierten zweidimensionalen Membran, was sich negativ auf die Bleicheffizienz auswirkt. Ein unscharfer Übergang zwischen der Fluoreszenz innerhalb der gebleichten ROI und der umgebenden Lipidschicht würder diese Erklärungen untermauern. Da der Randbereich der gebleichten ROI jedoch auf dem Stegbereich verläuft und die Fluoreszenz dort vom unterliegenden Gold gelöscht wird, lässt sich der Übergang zwischen gebleichtem und ungebleichtem Bereich nicht abbilden. 
A
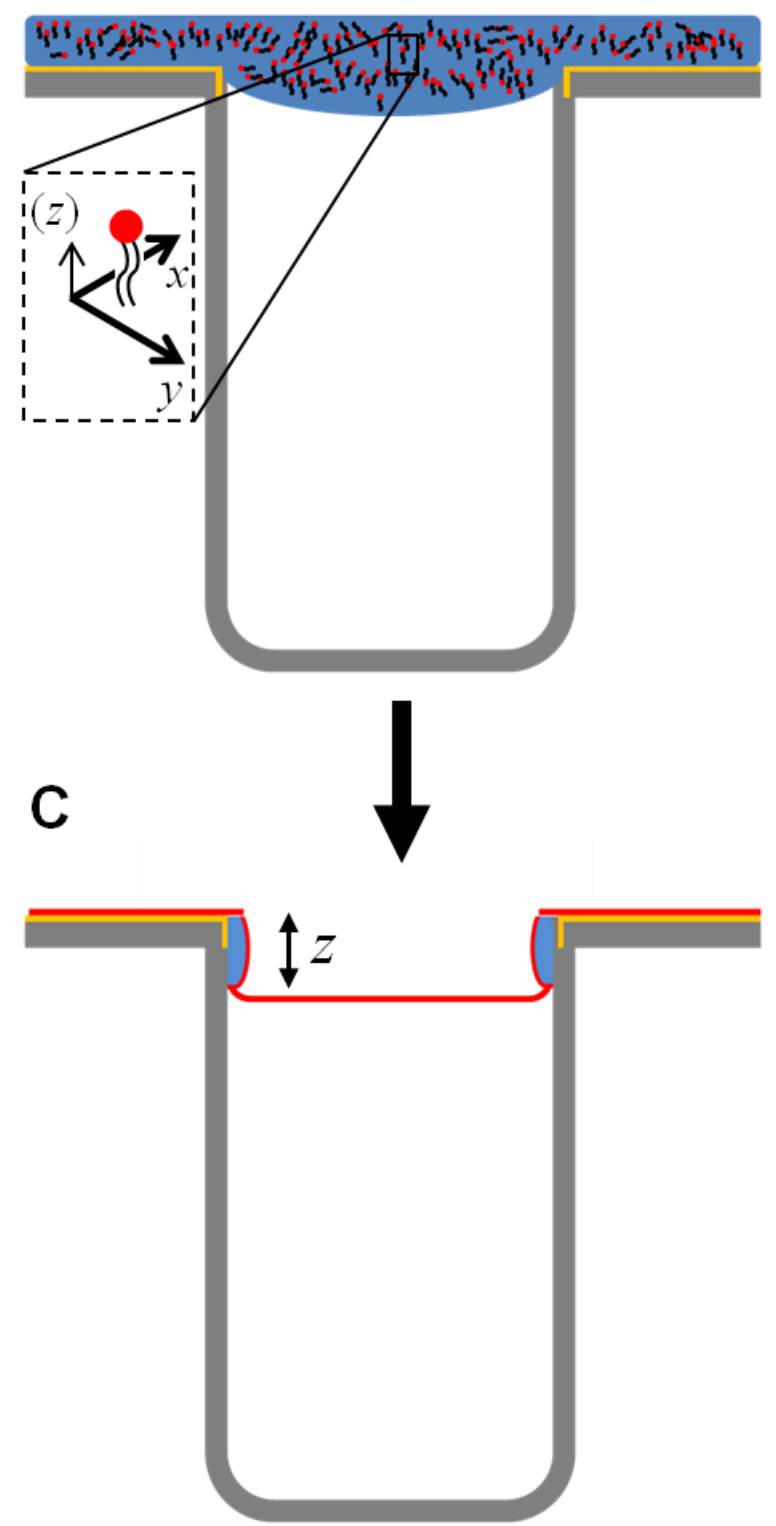

B


Abb. 5.3: Schematische Darstellung der Membranbildung nach Ausfrieren des Lösungsmittels für Substrate, auf welchen wenig (A, C) bzw. viel (B, D) Lipid-Lösungsmittelgemisch aufgetragen wurde. Ein Querschnitt einer Pore ist in grau dargestellt, die Goldbeschichtung in gelb, Lösungsmittel in blau und Lipide bzw. die Lipiddoppelschicht vereinfacht in rot. Sind Poren mit wenig Gemisch bedeckt (A), bildet sich nach Ausfrieren des Lösungsmittels eine Membran, welche die Pore in geringer Tiefe überspannt (C). Wird viel Gemisch aufgetragen (B), so bildet sich nach Ausfrieren des Lösungsmittels eine Membran mit größerer Fläche, welche die Pore in größerer Tiefe überspannt (D). In mit wenig Gemisch bedeckte Poren diffundieren Lipide hauptsächlich in einer Ebene, während eine Diffusion in $z$-Richtung aufgrund der geringen Schichtdicke nur eingeschränkt möglich ist (gestrichelter Kasten, A). Wird viel Gemisch aufgetragen, können Lipide frei in allen drei Raumrichtungen diffundieren (gestrichelter Kasten, D). Das unterschiedliche Diffusionsverhalten wirkt sich auf die mittels FRAP-Experimenten erzielten Ergebnisse aus (siehe folgenden Absatz). Darstellung nicht maßstabsgetreu.

Poröse Bereiche auf welche weniger Lipid-Lösungsmittelgemisch aufgetragen worden war, wiesen geringe mobile Anteile sowie niedrige Werte für $I_{\text {Bleich }}$ auf (Abb. 4.2, D-F). Die 
geringere Menge Lösungsmittel kann hier spontan entlang der hydrophoben Funktionalisierung ausdünnen, sodass sich schon vor dem Ausfrieren relativ lösungsmittelfreie Membranen bilden. Diese lassen sich aufgrund der dichteren Packung des Fluorophors und ihrer definierten zwiedimensionalen Struktur stärker Bleichen (Abb. 5.3, A). Der geringe mobile Anteil deutet auf eine Isolierung der Membranen innerhalb einzelner Poren voneinander hin. Ist die Membran nicht durchgängig entlang des porösen wie des Stegbereichs ausgebildet, so ist kein Austausch von gebleichten und ungebleichten Fluorophoren möglich und die Intensität innerhalb der ROI verläuft auf konstant niedrigem Niveau. Auch hier kann durch die gelöschte Fluoreszenz auf dem Stegbereich kein abschließender Beweis erbracht werden.

Nach Ausfrieren des Lösungsmittels wird eine einheitlichere Diffusion der Lipide innerhalb der porenüberspannenden Membranen beobachtet. Der mobile Anteil erhöht sich auf $M=85 \pm 20 \%$, wobei die Werte zwischen $M_{\max }=98 \%$ und $M_{\min }=41 \%$ schwanken und der Fehler sich halbiert. Analog dazu steigt die Intensität nach dem Bleichen leicht auf $I_{\text {Bleich }}=51 \pm 8 \%$ mit Werten zwischen $I_{\text {Bleich,max }}=67 \%$ und $I_{\text {Bleich,min }}=45 \%$. Die starke Abnahme der Standardabweichungen beider Werte deutet auf die Bildung einer durchgängigen, zweidimensionalen und weitgehend lösungsmittelfreien Membran hin. Der mobile Anteil von $M=85 \pm 20 \%$ impliziert, dass beide Monoschichten der Membran eine laterale Mobilität der Lipide ermöglichen. Es wird diskutiert, dass insertiertes CPEO3 die Diffusion von Lipiden in der unteren, dem Substrat zugewandten Monolage einschränkt bis hin zu einer völligen Immobilität. ${ }^{[161]}$ Mobile Anteile $>50 \%$ deuten somit auf eine unvollständige Belegung der goldbeschichteten Substratoberfläche mit CPEO3 hin. Da sich in SICMAufnahmen zeigte, dass die Tiefe der Membranen innerhalb der Poren zum Teil stark variierte, wurde von einer Quantifizierung des Diffusionskoeffizienten abgesehen. Unterschiedliche Diffusionslängen in $z$-Richtung entlang der Porenwände würden die anhand einer rein zweidimensionalen Diffusionstheorie errechneten Werte verfälschen.

Abschließend lässt sich bei einem Vergleich mit den für lösungsmittelfreie porenüberspannende Membranen bestimmten Werte (Tabelle 4.5) feststellen, dass der Gehalt remanenten Lösungsmittels in porenüberspannenden painted membranes durch Ausfrieren deutlich reduziert werden konnte, sodass diese anschließend vergleichbare Breiten der Membranfluoreszenz in $z$-Richtung, sowie Intensitäten nach Bleichen aufwiesen. Es wurde erstmalig gezeigt, dass sich dreidimensionale Konfokalmikroskopie in Kombination mit FRAPExperimenten und SICM-Aufnahmen dazu eignen, den Lösungsmittelgehalt freistehender painted membranes qualitativ zu bestimmen. 


\title{
5.1.2 Spreiten von GUVs auf porösen Substraten
}

Neben mittels painting-Technik präparierten lösungsmittelhaltigen porenüberspannenden Membranen ließen sich durch Spreiten von GUVs lösungsmittelfreie Membranen auf porösen Substraten präparieren. Je nach Funktionalisierung der Substrate wurden dabei verschiedene Membrantypen gebildet.

\section{Unfunktionalisierte poröse Substrate}

Zugabe von GUVs auf unfunktionalisierte poröse Siliziumsubstrate mit einer Siliziumdioxidschicht $(500 \mathrm{~nm})$ führte zur Bildung porenauskleidender Membranen (Abb. 4.7). Ein Modell dieses Membrantyps ist schematisch in Abb. 5.4 dargestellt.

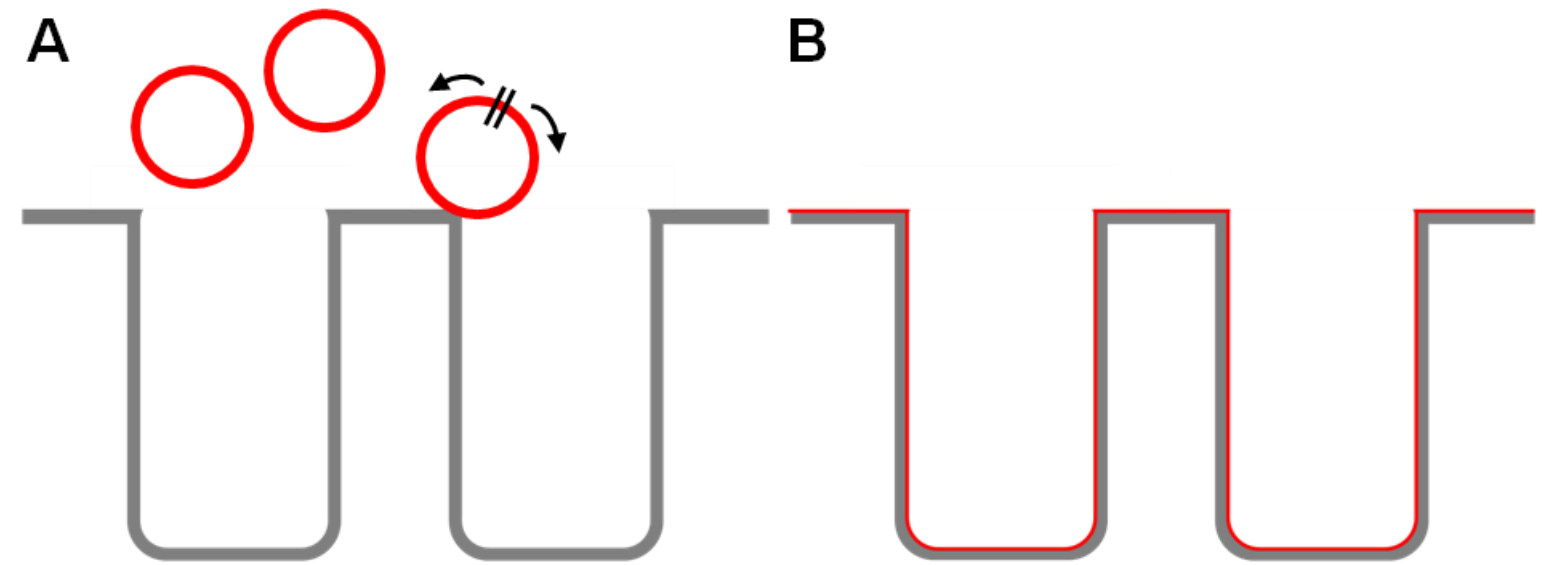

\begin{abstract}
Abb. 5.4: A Schematische Darstellung des Spreitprozesses von GUVs (rot) auf unfunktionalisierten, hydrophilen siliziumdioxidbeschichteten Substraten mit geschlossenen Poren (grau). Das Aufreissen der Membran (schwarze Striche) und ein seitliches Umklappen zum Substrat hin ist mit Pfeilen exemplarisch an einem GUV gezeigt. B Nach Spreiten der GUVs kleidet eine lösungsmittelfreie Membran (rot) die Poren vollständig aus. Nicht maßstabsgetreu.
\end{abstract}

Dabei folgt die Membran in porösen wie in Stegbereichen in ihrem Verlauf der Kontur des Substrates und bedeckt die gesamte Substratoberfläche, ohne jedoch porenüberspannende Membranen zu bilden. Die Membranfluoreszenz verläuft entlang der Poreninnenwände bis zu $z=-4 \mu \mathrm{m}$ in die Pore hinein. Anschließend zugegebener wasserlöslicher Farbstoff lässt sich im Poreninneren detektieren, was eine Bildung porenüberspannender Membranen oder eine Einlagerung von Luft ausschließt.

SICM-Aufnahmen zeigen Poren, welche bis zum Porenboden vollständig mit wässriger Pufferlösung gefüllt sind und über keine Grenzschicht im Porenbereich z. B. in Form einer Membran verfügen. Blanke Substrate ohne Membran zeigten eine starke Interaktion mit der aus Borsilikatglas gefertigten Messpipette im SICM-Aufbau, was auf elektrostatische Anziehung zwischen der mit mobilen Ionen (z. B. $\mathrm{Na}^{+}$) dotierten Glaspipette und der Siliziumdioxidoberfläche zurückzuführen ist. Unter Anlegen einer Spannung verstärkt sich der Effekt und bei hohen Spannungen und Temperaturen können Borsilikatglas und Silizium- 
substrate sogar dauerhaft fest miteinander verbunden werden. ${ }^{[208]}$ Diese attraktive Wechselwirkung äußerte sich im Verlauf einer Messung durch das Abbrechen der Pipettenspitze und erschwerte somit SICM-Aufnahmen. Dass dieser Effekt bei unfunktionalisierten Substraten nach Spreiten von GUVs nicht auftrat, deutet auf eine vollständige Auskleidung der Poren durch eine Membran hin, wodurch die attraktive Wechselwirkung abgeschwächt wird.

FRAP-Experimente an porenauskleidenden Membranen zeigten, dass die Lipide innerhalb der Membranen mobil sind. Die charakteristische Diffusionszeit $\tau_{1 / 2}$ ist im planaren Stegbereich geringer $\left(\tau_{1 / 2}=10,6 \mathrm{~s}\right)$, als im porösen Bereich $\left(\tau_{1 / 2}=20,8 \mathrm{~s}\right)$. In Letzterem benötigen die Lipide somit länger, um die ROI zu verlassen (gebleichte) bzw. es gelangen weniger Lipide pro Zeit in die ROI hinein (ungebleichte). Diese Beobachtung lässt sich durch den längeren Diffusionsweg in $z$-Richtung im porösen Bereich und der dadurch effektiv größeren gebleichten Fläche erklären (Abb. 5.4, B). Für das unter Abb. 4.7, C-E gezeigte Beispiel (Porendurchmesser $d=3,5 \mu \mathrm{m}$, Porentiefe $h=9 \mu \mathrm{m}$, Porosität $P=20 \%$ ) ergibt sich bei vollständiger Auskleidung der Poren eine 3,06 mal größere Membranfläche im porösen Bereich im Vergleich zum planaren Stegbereich. Generell gilt für das Verhältnis der Oberfläche poröser Bereiche $\left(A_{3 \mathrm{~d}}\right)$ zu derjenigen planarer Stegbereiche $\left(A_{2 \mathrm{~d}}\right)$ bei runden Poren:

$$
\frac{A_{3 d}}{A_{2 d}}=1+\frac{4 \cdot h \cdot P}{d}
$$

Eine Herleitung von Gl. 5.1 findet sich im Anhang.

Ein partielles Auskleiden von Kavitäten $(d=2 \mu \mathrm{m}, h=0,7 \mu \mathrm{m})$ in einem mit Siliziumdioxid bedeckten Siliziumsubstrat beim Ausbreiten eines Lipidfilms über die Substratoberfläche, wurde bereits von Suzuki et al. beschrieben. ${ }^{[09]}$ Dort wird eine energetische Betrachtung dieses Systems unter Berücksichtigung von Biegeenergien der Membran an der Porenkante und Adhäsionsenergien zwischen Membran und Siliziumdioxidoberfläche beschrieben. Dabei kommen die Autoren zu dem Schluss, dass im Falle einer einzelnen Lipiddoppelschicht die Adhäsionsenergie überwiegt und ein Überspannen der Poren für weitere Lipidschichten erst nach „Passivierung“ der Poreninnenwand durch vorheriges Auskleiden mit einer Lipiddoppelschicht möglich ist.

Eine genauere Untersuchung der Bildung sowohl porenüberspannender als auch porenauskleidender Membranen (POPC/POPS, 7:3) durch Spreiten von Vesikeln (mittlerer Durchmesser $d=75$ bis $130 \mathrm{~nm}$ ) in Gegenwart von Calciumionen auf porösen, mit Siliziumnitrid beschichteten Glassubstraten (Porendurchmesser $d=40$ bis $500 \mathrm{~nm}$, Porentiefe $h=350 \mathrm{~nm}$ ) wurde von Kumar et al. vorgestellt. ${ }^{[52]}$ Mittels hochauflösender stimulated emission depletion (STED)-Mikroskopie, sowie theoretischer Überlegungen analog zu solchen wie von Suzuki beschrieben, wurden dabei die Krümmung des Porenrands, die Oberflächenfunktionalisierung und damit einhergehend die Adhäsionsenergie, sowie das Verhältnis von Vesikel- zu Poren- 
durchmesser als kritische Parameter in Hinblick auf Auskleidung oder Überspannung der Poren bestimmt. Eine steile Porenkante (starke Krümmung des Porenrands) und Vesikel mit einem Durchmesser größer dem Porendurchmesser begünstigten die Bildung porenüberspannender Membranen. Im Rahmen von FRAP-Experimenten wurden mobile Anteile von $M=91 \pm 5 \%$ ermittelt, welche mit den im Rahmen dieser Arbeit bestimmten Werten von $M=89$ bzw. $87 \%$ für Membranen auf unfunktionalisierten porösen Substraten übereinstimmen. Auf Poren mit Durchmessern $d \geq 200 \mathrm{~nm}$ konnten Kumar et al. keine porenüberspannenden Membranen bilden.

In einer anderen Studie untersuchten Pfeiffer et al. mittels quartz crystal microbalance with dissipation monitoring (QCM-D) und Rasterkraftmikroskopie (atomic force microscopy, AFM) das Spreitverhalten von POPC Vesikeln mit einem nominellen Durchmesser von $d=100 \mathrm{~nm}$ auf nanostrukturierten Oberflächen aus auf Gold aufgebrachtem Siliziumdioxid. ${ }^{[210]}$ Dabei konnte ein schnelles Adsorbieren und Spreiten der Vesikel auf den Stegbereichen aus Siliziumdioxid beobachtet werden und ein langsames Adsorbieren der Vesikel an die den Boden von Poren $(d=100 \mathrm{~nm}, h=25 \mathrm{~nm})$ bildende Goldoberfläche. Durch Passivierung der goldenen Porenböden mittels mit Biotinamidocapryl markiertem Rinderalbumin (bovine serum albumin, BSA) konnte eine Adsorption von Vesikeln an die Porenböden unterbunden und die Bildung porenüberspannender Membranen erreicht werden.

Es gibt Beispiele für die Bildung porenüberspannender Membranen auf unfunktionalisierten, $\mathrm{SiO}_{2}$-terminalisierten Substraten. ${ }^{[50,51,55,60]}$ Voraussetzung hierfür ist dabei in jedem Fall eine Porengeometrie mit großem Volumen-zu-Öffnung Verhältnis. Es wurde jeweils ein Hohlraum unter den Stegbereich geätzt, sodass dieser die unterliegende Pore größtenteils bedeckt und nur eine im Verhältnis zum Gesamtdurchmesser der Pore sehr kleine Öffnung bleibt. Dadurch wird eine effektiv $180^{\circ}$ steile Porenkante erzeugt und wie oben diskutiert die Bildung porenüberspannender Membranen gegenüber derjenigen porenauskleidender Membranen bevorzugt.

\section{Hydrophob funktionalisierte Substrate}

Neben unfunktionalisierten porösen Substraten, wurden GUVs auf hydrophob funktionalisierten Substraten gespreitet. Eine hydrophobe Oberfläche wurde duch Chemisorption von Cholesterylpolyethylenoxythiol (CPEO3) auf einer Goldbeschichtung erzeugt. Auf offenen mit CPEO3 funktionalisierten Poren mit Durchmessern bis $\mathrm{zu} d=2 \mu \mathrm{m}$ wurden bereits erfolgreich porenüberspannende Membranen durch Spreiten von Vesikeln gebildet. ${ }^{\text {[43,172] }}{ }^{\text {Der }}$ Mechanismus unterscheidet sich dabei zwischen Spreiten von Vesikeln auf hydrophil oder hydrophob funktionalisierten Substraten. Wie in Abb. 5.4, A illustriert, spreiten Vesikel auf hydrophilen Oberflächen, nachdem sie dort zunächst adsorbieren, indem sich nach Bildung eines Defektes in der Vesikelmembran diese in Richtung Substrat umklappt und sich eine 
planare Membran bildet, bei welcher die zuvor zum Vesikeläußeren gerichtete Monolage nun die untere, substratkontaktierende Monolage darstellt. ${ }^{\text {[211] }}$

Auf mit einem hydrophoben self assembled monolayer (SAM) bedeckten Substrat wird hingegen ein Aufreissen der Vesikel an der Kontaktfläche zum Substrat, gefolgt von einem Ausbreiten beider Lipidmonolagen in der Form berichtet, dass sich eine gemischte Doppelschicht aus SAM und Vesikelmembran bildet. ${ }^{[186]}$ Bei Defekten im SAM bildet sich die Doppelschicht dabei so aus, dass die vormals zum Vesikeläußeren gerichtete Monolage schließlich die obere, zur überstehenden Lösung gerichtete Monolage bildet. Einen energetischen Beitrag zur Bildung planarer Membranen liefert für CPEO3-funktionalisierte Substrate weniger eine elektrostatische Wechselwirkung zwischen Oberfläche und Vesikelmembran, als die Einlagerung einzelner Cholesterylreste in die untere Monolage der sich bildenden planaren Membran. Sheikh et al. stellten mittels colloidal probe Rasterkraftmikroskopie eine attraktive Wechselwirkung zwischen gemischten 2-Mercaptoethanol/CPEO3-SAMs im Bereich eines CPEO3-Anteils von 1-29\% mit planaren Lipid/SAM-Hybridmembranen fest und ordneten diese einer Insertion der Cholesterylreste in die anliegende Monolage zu. ${ }^{[212]}$

GUVs wurden im Rahmen dieser Arbeit erstmals auf hydrophob funktionalisierten Poren mit geschlossenen Böden gespreitet. Wurden die Poren (offene wie geschlossene) vor Zugabe der GUV-Suspension nicht durch Auftragen von $n$-Propanol gefolgt von Pufferlösung benetzt, konnte zuverlässig Luft im Poreninneren eingeschlossen werden (Abb. 4.8, A und B). SICMAufnahmen zeigen eine Grenzfläche von Pufferlösung und Luft bei $z=-120 \mathrm{~nm}$ im Poreninneren. Bei Zugabe von Pyranin ließ sich kein Farbstoff in den Poren detektieren. Die CPEO3-funktionalisierten, geschlossenen Poren blieben auch nach Lösungsaustausch, Vibration oder Spülen luftgefüllt, sodass CPEO3 effektiv die Bildung eines Cassie-Zustands der eines Wenzel-Zustands der Benetzung begünstigt (für weiterführende Literatur zu Modellbetrachtungen von Benetzung siehe ${ }^{[213-215]}$ ).

Spreiten von GUVs auf luftgefüllten Poren führte zur Bildung weiter zusammenhängender Flächen mit homogener Fluoreszenz im Porenbereich (Abb. 4.8, A). FRAP-Experimente zeigten, dass sich eine mobile Lipidschicht gebildet hatte. Jedoch lässt sich durch die hier angewendeten Methoden nicht bestimmen, ob es sich dabei um porenüberspannende Lipiddoppelschichten oder Lipidmonoschichten handelt. Eine schematische Darstellung beider möglicher Membrantypen ist in Abb. 5.5 aufgeführt. Um feststellen zu können, welcher der beiden vorgeschlagenen Membrantypen vorliegt, könnte eine wasserlösliche fluoreszenzlöschende Substanz (quencher) in die überstehende wässrige Lösung gegeben werden. Wird die Membranfluoreszenz vollständig gelöscht und fällt im Porenbereich auf den Wert der Hintergrundfluoreszenz $a b$, so würde es sich um eine Monoschicht handeln. Sinkt die Fluoreszenzintensität innerhalb der Membran um die Hälfte, wäre dies ein Hinweis für das 
Vorliegen einer Lipiddoppelschicht, da die Fluoreszenz aus der unteren Monolage ungelöscht bliebe.

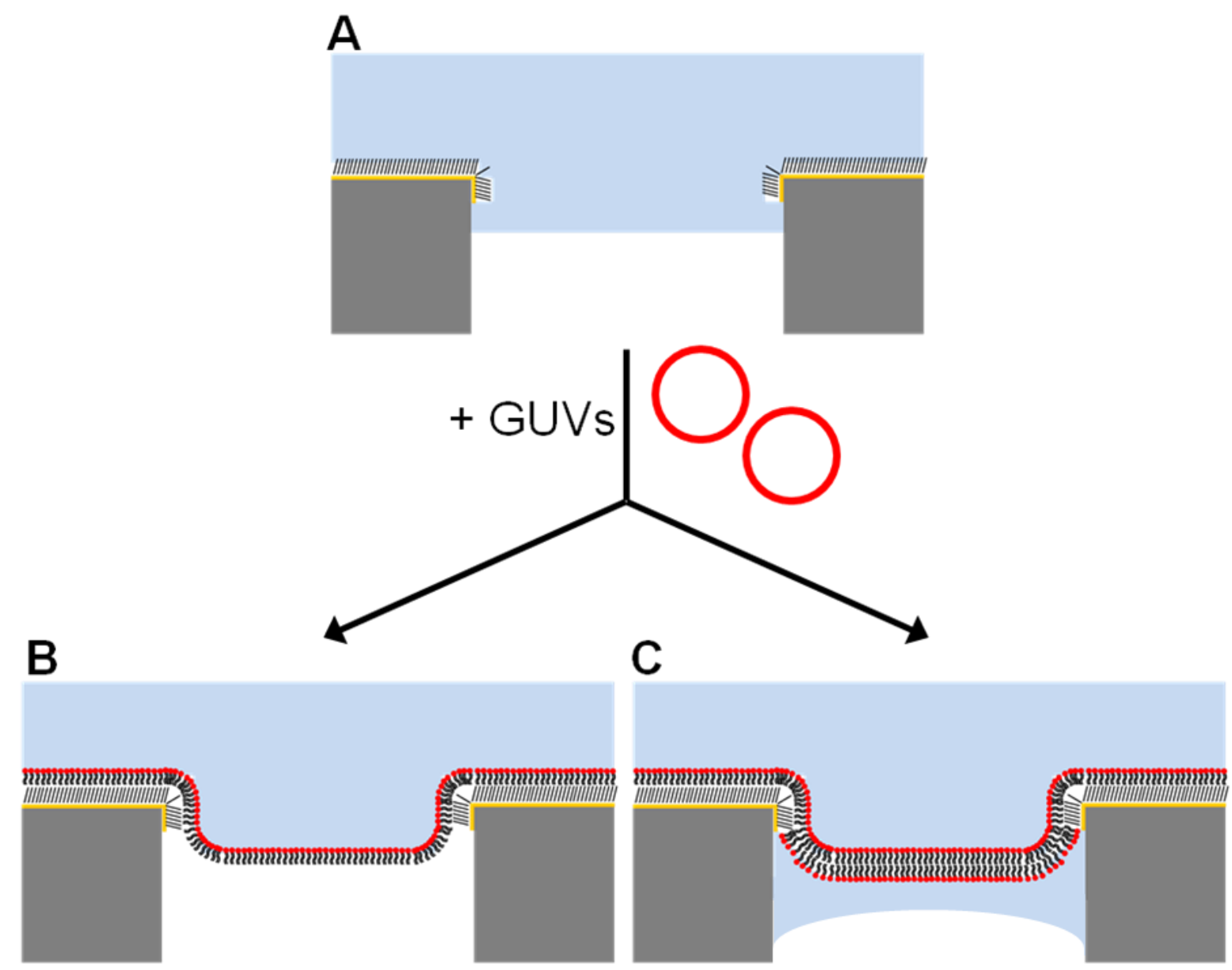

Abb. 5.5: Schematische Darstellung des Spreitens von GUVs auf luftgefüllten porösen Substraten. A Ein goldbeschichtetes poröses Siliziumsubstrat (grau) mit hydrophober CPEO3-SAM (schwarze Striche), bedeckt mit wässriger Lösung (blau). Im Poreninneren ist Luft (weiß) eingeschlossen. Nach Zugabe und Spreiten von GUVs (rot) bilden sich porenüberspannende Lipidschichten. Dabei ist die Bildung porenüberspannender Lipidmonoschichten auf Luft denkbar (B), sowie die Bildung porenüberspannender Lipiddoppelschichten mit einem dünnen Film wässriger Lösung an der dem Poreninneren zugewandten Seite (C). Darstellung nicht maßstabsgetreu.

Eingeschlossene Luft ließ sich durch Benetzung der Poren mit $n$-Propanol und anschließendem Spülen mit Pufferlösung vollständig aus den Poren entfernen (Abb. 4.8, C und D). Offene Poren mit Durchmessern bis zu $d=2 \mu \mathrm{m}$ konnten durch Spreiten von GUVs mit lösungsmittelfreien Membranen überspannt werden (Abb. 4.9, B). Gleisner und Kuhlmann konnten zeigen, dass eine Optimierung der Goldbeschichtung dabei eine entscheidende Rolle spielt. ${ }^{[99,216]}$ Ist die Beschichtung und dadurch die hydrophobe CPEO3-Monolage nicht durchgängig, verringert sich der Betrag der durch Insertion der Cholesterylreste in die untere Monolage gewonnenen Energie bei Bildung einer planaren Membran. Schließt die Goldbeschichtung am Porenrand nicht glatt ab, sondern ragt in die Pore hinein, verringert sich 
dadurch die effektive Krümmung der Porenkante, was die Bildung porenüberspannender Membranen negativ beeinflusst.

Auf benetzten, hydrophob funktionalisierten Poren mit geschlossenen Böden bildeten sich keine porenüberspannenden Membranen nach Spreiten von GUVs. In Abb. 4.10 und Abb. 4.11 ist jeweils das Spreiten eines GUV auf der Substratoberfläche dargestellt. Nach abgeschlossenem Spreitvorgang ist keine Membranfluoreszenz im Bereich der Porenflächen detektierbar. Inwiefern sich eine planare Membran entlang des Stegbereichs bildet, ist aufgrund der fluoreszenzlöschenden Wirkung der Goldbeschichtung nicht sichtbar. Es ist jedoch wahrscheinlich, dass ein Spreiten der GUVs entlang des Stegbereichs stattfindet. Die Insertion von Teilen der hydrophoben SAM in die untere Monolage der GUV-Membran wird energetisch begünstigt und ein Verschwinden der Fluoreszenz ist am besten mit einem Löschen durch die Goldschicht zu erklären. In Abb. 4.10 sind nach Spreiten des GUV kleine punktförmige Fluoreszenzsignale auf dem Stegbereich zu erkennen. Dass hier die Fluoreszenz nicht vollständig gelöscht wird, deutet auf eine hohe lokale Konzentration des Fluorophors und somit von Lipidmaterial hin in Verbindung mit einem ausreichend großen Abstand zur Goldschicht, da die Effizienz des Fluoreszenzlöschens abstandsabhängig ist. Der wahrscheinlichste Ablauf des Spreitvorgangs ist somit die Bildung einer stegbedeckenden planaren Membran (möglicherweise auch Multischichten) in Kombination mit der Bildung kleiner multilamellarer Vesikel (z. B. durch Abschnürung), welche an die unterliegende Membran binden.

Um dennoch porenüberspannende Membranen bilden zu können, wurden fusogene Komponenten, wie Calciumionen in der Pufferlösung, oder Phosphatidylethanolamine (PE) und Protein (Bacteriorhodopsin, bR) in der Vesikelmembran eingesetzt. Ein osmotischer Gradient zwischen Vesikelinnerem und Umgebungslösung wurde aufgebaut, welcher die Bildung porenüberspannender Membranen genauso forcieren sollte, wie ein Spreiten bei erhöhter Temperatur. Beide Ansätze verstärkten die Bildung planarer Membranen beim Spreiten von Vesikeln mit Durchmessern $d \leq 200 \mathrm{~nm}$ auf verschiedenen hydrophilen Oberflächen. ${ }^{\text {[17] }}$ Poren mit reduzierter Porosität wurden verwendet, um durch eine größere Stegfläche die attraktive Wechselwirkung mit den GUVs zu verstärken und so ein Spreiten zu induzieren. Diese und weitere unter Kapitel 4.1.2 vorgestellte Ansätze führten jedoch nicht zu einer Bildung porenüberspannender Membranen auf hydrophob funktionalisierten Poren mit geschlossenen Böden.

Es stellt sich die Frage, warum offene Poren sich durch Spreiten von GUVs mit Membranen überspannen lassen, geschlossene jedoch nicht. Einziger Unterschied zwischen beiden Systemen ist der Porenboden bei geschlossenen Poren. Wie später diskutiert wird, konnten auf hydrophil funktionalisierten geschlossenen Poren gleicher Geometrie porenüberspannende Membranen gebildet werden. Der Porenboden allein kann also nicht Grund sein für die Unmöglichkeit der Bildung porenüberspannender Membranen auf hydrophob funktio- 
nalisierten Poren, sondern eine Kombination aus hydrophober Funktionalisierung und dem Vorliegen eines Porenbodens. Mey et al. zeigten, dass die laterale Spannung für porenüberspannende Membranen auf hydrophob funktionalisierten Substraten höher ist, als für solche auf hydrophil funktionalisierten Substraten. ${ }^{[8]}$ Während bei Membranen auf hydrophilen Oberflächen bei mechanischer Deformation im Porenbereich Lipidmaterial vom Stegbereich „nachfließen“ kann, tendieren Membranen auf hydrophoben Monoschichten dazu zu reissen. Wirken bei der Bildung von Membranen mechanische Kräfte auf den porenüberspannenden Teil, würde dieser demnach auf hydrophoben Funktionalisierungen reissen.

Quellen für solche mechanischen Beanspruchungen der Membran können z. B. osmotische Drücke sein oder hydrodynamische Kräfte, welche beim Freiwerden des Innenvolumens von GUVs bei deren Spreiten entstehen. Ein deutliches Indiz für das Auftreten solcher Kräfte bei der Bildung porenüberspannender Membranen sind die Ausstülpungen, welche auf hydrophil funktionalisierten Substraten bei bis zu $91 \%$ der Poren auftraten (Tabelle 4.4). Für offene Poren wurden Ausstülpungen hingegen nie beobachtet. Durch die Verbindung des Poreninnenraums mit der umgebenden Pufferlösung können bei offenen Poren Druckunterschiede (osmotische wie hydrodynamische) zwischen Membranober- und unterseite ausgeglichen und so die mechanische Beanspruchung der porenüberspannenden Membranen minimiert werden. Bei Poren mit geschlossenen Böden ist dies nicht möglich und durch die hohe laterale Spannung bilden sich somit keine porenüberspannende Membranen.

\section{Hydrophil funktionalisierte Substrate}

Wurde die Oberfläche poröser Substrate mit OH-terminierten Thiolen, Aminothiolen oder Carboxythiolen hydrophil funktionalisiert, konnten porenüberspannende Membranen durch Spreiten von GUVs gebildet werden. Der Spreitverlauf eines GUV mit einem Anteil von $10 \%$ POPS auf einem mit 11-Amino-1-undekanthiol funktionalisierten Substrat ist in Abb. 4.12 aufgeführt. Durch elektrostatische Anziehung zwischen negativ geladenen Lipiden im GUV und positiven Ladungen der Oberflächenfunktionalisierung, bildete sich nach Absinken der GUVs auf die Oberfläche schnell eine große Kontaktfläche zwischen Vesikel und Substrat aus. Dabei ging die sphärische Form der GUVs verloren und ein Abflachen der Vesikel unter Vergrößerung der Kontaktfläche konnte beobachtet werden. GUVs auf hydrophob funktionalisierten Substraten bildeten kleine Kontaktflächen aus und behielten ihre sphärische Form (Abb.4.9). Die Bildung eines punktförmigen Defektes in der Vesikelmembran nahe der Substratoberfläche konnte als Ausgangspunkt des Spreitvorgangs identifiziert werden, in dessen Verlauf sich der Defekt kreisförmig ausbreitete und schließlich membranüberspannte Poren gebildet wurden. Der von Rädler diskutierte Mechanismus zum Spreiten von Vesikeln auf hydrophilen Oberflächen konnte somit bestätigt werden. ${ }^{\text {[211] }}$ 
Es konnte festgestellt werden, dass für ein Spreiten von GUVs mit Anteilen negativ geladener Lipide auf Substraten mit positiv geladener Funktionalisierung metallische Kationen vorliegen müssen (Tabelle 4.3). Dabei wurde beobachtet, dass die Kationen in der Reihenfolge $\mathrm{Na}^{+}<\mathrm{K}^{+}<<\mathrm{Ca}^{2+}$ die Zahl gespreiteter GUVs erhöhten und die Zeit, welche zum Spreiten benötigt wurde verringerten. Wurden entsprechende Salze durch Zucker (Glucose, Sucrose) ersetzt, oder in Reinstwasser gespreitet, fand kein Spreiten der GUVs statt. Für diesen Befund gibt es mehrere Erklärungsansätze.

Die Bindung mono- und divalenter Kationen wurde von Ohki et al. an Lipidmonoschichten und von Satoh an Lipiddoppelschichten sowohl negativ geladener als auch netto-neutraler Lipide untersucht. ${ }^{[218-220]}$ Divalente Kationen wie $\mathrm{Ca}^{2+}$ weisen deutlich höhere Bindungskonstanten auf, als monovalente Kationen wie $\mathrm{Na}^{+}$oder $\mathrm{K}^{+}$. Modelle zur theoretischen Beschreibung der Ionenverteilung an geladenen Oberflächen auf Basis der PoissonBoltzmann-Theorie und daraus resultierende Wechselwirkungen zwischen zwei geladenen Oberflächen mit Nanometerabständen wurden von Andelman et al. diskutiert. ${ }^{[21]}$ Ohki et al. beobachteten, dass bereits geringe Konzentrationen von $\mathrm{Ca}^{2+}(0.25 \mathrm{mM})$ die Fusion submikrometergroßer unilamellarer Vesikel aus Phosphatidsäure induzierten. ${ }^{[222]}$ Gleichzeitig konnten sie in Monoschichten des Lipids eine calciumioneninduzierte Erhöhung der Oberflächenspannung bei gleichen Konzentrationen feststellen. Neben der Oberflächenspannung verändert sich in Abhängigkeit der Calciumionenkonzentration auch das ZetaPotential $^{[223]}$ und das Biegemodul ${ }^{[224]}$ von Lipidmembranen. In Lipidmischungen aus Phosphatidylserin und netto-neutralen Lipiden konnte eine calciumioneninduzierte Phasentrennung beobachtet werden. ${ }^{[225]}$ Änderungen dieser Parameter können die Aktivierungsenergie, welche für den Übergang der sphärischen Vesikelstruktur hin zu planaren Membranen nötig ist, herabsetzen und so ein Spreiten begünstigen. Eine genauere Erklärung hierfür auf molekularer Ebene bleiben sämtliche im Absatz genannte Autoren dabei schuldig.

Das Spreiten von Vesikeln (nomineller Durchmesser $30 \mathrm{~nm}$ ) aus netto-neutralen sowie negativ geladenen Lipiden auf einem goldunterstützten SAM aus geladenen Thiolen (u. a. 11-Amino-1-undekanthiol) wurde mit Hilfe von FRAP von Cha et al. untersucht. ${ }^{[26]}$ Auch hier konnte ein Einfluss der Zusammensetzung der Pufferlösung auf das Spreitverhalten festgestellt werden, allerdings nur für netto-neutrale Lipide. Es wird argumentiert, dass die Größe der Gegenionen, welche sich an die geladenen Gruppen des SAM anlagern, das Spreiten beeinflussen. Beim Annähern der Vesikel an die geladene Oberfläche wird der Raum zwischen beiden Grenzflächen kleiner und die Gegenionen, welche für eine Ladungsneutralität sorgen, werden immer weiter aufkonzentriert, woraus eine entropische Abstoßung resultiert. Ein Einfluss von Gegenionen $\left(\mathrm{Cl}^{-}, \mathrm{I}^{-}\right)$konnte im Rahmen dieser Arbeit jedoch nicht beobachtet werden.

Ein ähnliches System, das Spreiten von GUVs (DPPC/POPS, 91:9) auf mit 3-Aminopropyldimethylethoxysilan (APS) funktionalisiertem Siliziumdioxid, wurde von Kim et al. 
untersucht. ${ }^{[227]}$ Während auf unfunktionalisierten Siliziumdioxidoberflächen $\mathrm{Ca}^{2+}$-Ionen für die Bildung einer planaren Membran durch Spreiten der GUVs nötig waren, konnte auf APSfunktionalisierten Substraten ein spontanes Spreiten der GUVs auch in Abwesenheit von Calciumionen beobachtet werden. Es wurde der Einfluss der Kaliumionenkonzentration auf das Spreitverhalten mittels Fluoreszenzmikroskopie und AFM untersucht und dabei festgestellt, dass hohe $\mathrm{K}^{+}$-Konzentrationen die Oberflächenbelegung mit planaren Membranen verringern. Begründet wird dieser Befund mit einer Verringerung der Dicke der elektrischen Doppelschichten von Vesikeln und Oberfläche bei steigender Elektrolytkonzentration gemäß der Theorie von Gouy-Chapman. Dadurch sinkt die attraktive elektrostatische Wechselwirkung zwischen beiden Schichten und es spreiten effektiv weniger GUVs. Dieser Effekt konnte im Rahmen dieser Arbeit nicht beobachtet werden.

Dass entgegen obiger Berichte kein spontanes Spreiten negativ geladener GUVs auf positiv geladenen Oberflächen in Abwesenheit metallischer Kationen beobachtet werden konnte, deutet auf eine unzureichende elektrostatische Wechselwirkung hin. Diese kann durch eine unzureichend hohe Belegung der Oberfläche mit postitiv geladenen Thiolen erklärt werden (für ein Spreiten von Vesikeln aus Phosphatidylcholinen wird ein Mindestwert von $N / A>3 \mathrm{~nm}^{-2}$ von $\mathrm{NH}_{3}{ }^{+}$auf der Oberfläche angegeben ${ }^{[228]}$ ). Die Bildung des SAM erfolgt durch spontane Chemisorption der Thiole an die Goldschicht. Der Grad der Belegung und damit die Oberflächenladungsdichte wurden nicht experimentell ermittelt und könnten unterhalb des für ein Spreiten kritischen Wertes liegen, insbesondere da durch die poröse Struktur der Substrate die effektive Oberfläche kleiner ist. Ein zweiter Erklärungsansatz ist eine Veränderung des $\mathrm{pK}_{\mathrm{S}}$-Wertes der Aminofunktion des SAM in Abhängigkeit der Zusammensetzung der Pufferlösung. Am Beispiel des Fluorophors Pyranin konnte eine starke Verschiebung des $\mathrm{pK}_{\mathrm{S}^{-}}$-Wertes der Hydroxygruppe durch Ionen gemäß der Hofmeister-Reihe beobachtet werden. ${ }^{[229]}$ Neben Ionen wurde ein solcher Effekt auch für ungeladene Teilchen mit hohem Wasserbindungsvermögen (Polyethylenglycol, PEG) festgestellt. Es ist denkbar, dass auch der $\mathrm{pK}_{\mathrm{S}}$-Wert des 11-Amino-1-undekanthiol SAM durch metallische Kationen so verändert wird, dass bei gleichem $\mathrm{pH}-$ Wert ein höherer Anteil protoniert vorliegt und sich somit die Oberflächenladungsdichte und dadurch die attraktive Wechselwirkung mit den GUVs erhöht.

Ein Modell, welches eine Erklärung für das Spreitverhalten von negativ geladenen GUVs auf positiv geladenen Oberflächen in Abhängigkeit der Zusammensetzung der Pufferlösung liefert, basiert auf Experimenten zur Zusammenlagerung entgegengesetzt geladener Makroionen (z. B. DNA) in wässriger Lösung. Studien zur Bindung von negativ geladener DNA an kationischen Liposomen zeigten, dass partiell gebundene Gegenionen frei werden und dabei einen entropischen Beitrag zur freien Enthalpie dieses Prozesses liefern. ${ }^{[230]}$ Eine schematische Darstellung dieses Modells für das Spreiten von mit POPS dotierten GUVs auf 
mit 11-Amino-1-undekanthiol funktionalisierten porösen Substraten ist in Abb.5.6 aufgeführt.

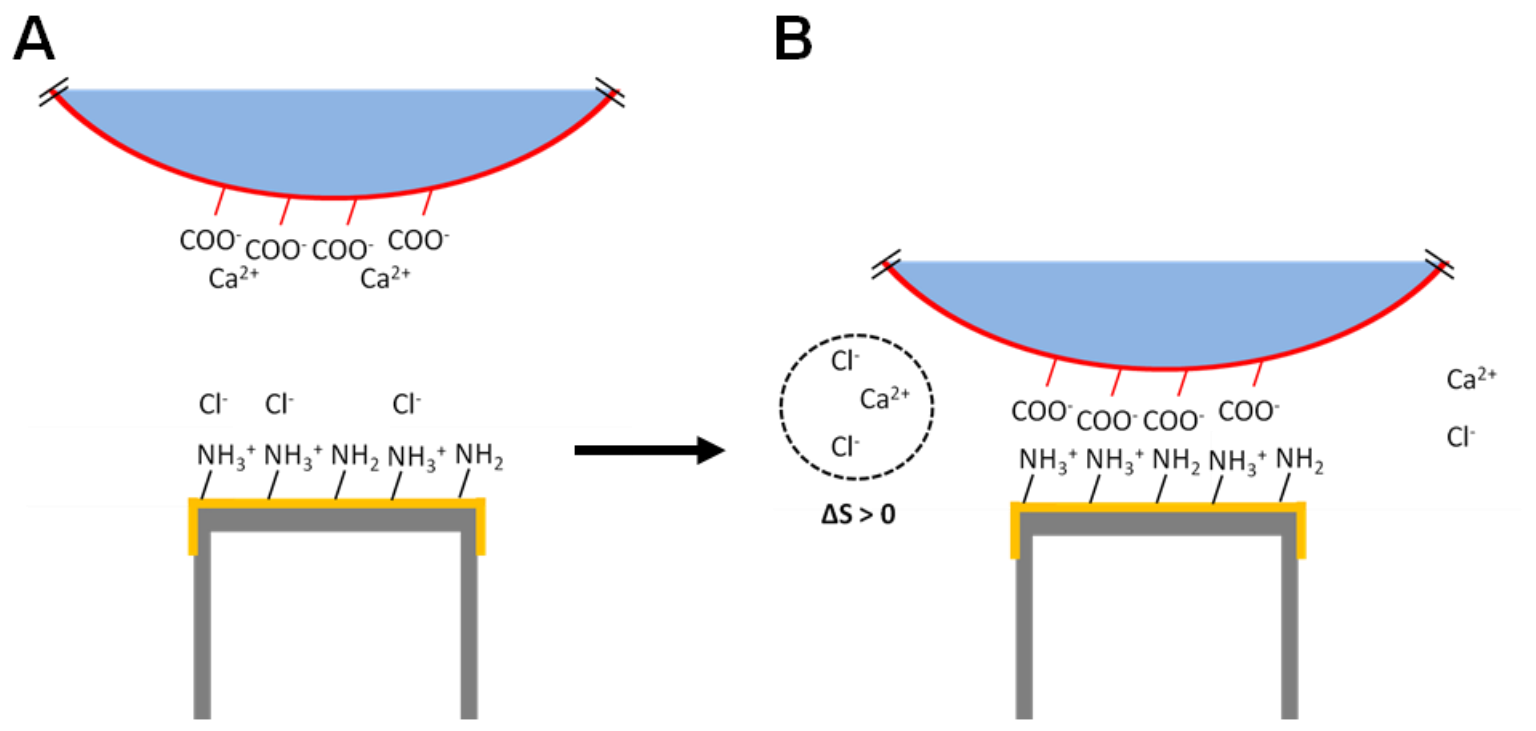

Abb. 5.6: Schematische Darstellung des ionenvermittelten Spreitens von negativ geladenen GUVs auf positiv geladenen porösen Substraten. A Mit POPS dotierte GUVs (rot, blaue Füllung) binden in der umgebenden Lösung vorhandene Calciumionen. Durch die höhere Dichte der in den GUVs befindlichen Sucroselösung sinken diese auf die Substratoberfläche ab, welche mit 11-Amino-1-undekanthiol funktionalisiert ist. Die positiven Ladungen auf der Oberfläche (ca. $60 \%$ der Aminogruppen bei $\mathrm{pH} 7,3$ ) werden von in der Lösung vorliegenden Chloridionen neutralisiert. B Nähern sich beide geladenen Oberfläche, werden gebundene Calcium- und Chloridionen aus dem Zwischenraum freigesetzt, was zu einem Anstieg der Entropie des Systems führt (gestrichelter Kreis). Negativ geladene Carboxylatgruppen des POPS und positiv geladene Aminogruppen des 11-Amino-1-undekanthiols ersetzen die jeweils frei gewordenen Bindungsstellen. Durch Vergrößerung der Kontaktfläche werden mehr Ionen freigesetzt und die Entropie steigt weiter, bis nach dem Spreiten der Vesikel planare Membranen mit maximaler Kontaktfläche gebildet werden. Darstellung nicht maßstabsgetreu.

Werden GUVs aus der Sucroselösung, in welcher sie gebildet wurden in ionenhaltige Pufferlösung überführt, binden metallische Kationen wie Calciumionen oder Kaliumionen an die negativ geladenen Phosphatidylseringruppen der äußeren Monolage der GUV-Membranen. Durch die höhere Dichte der Sucroselösung im Vergleich zur umgebenden Pufferlösung sinken diese auf die Substratoberfläche ab. Der poröse Stegbereich der Substrate ist mit einer Monolage aus 11-Amino-1-undekanthiol funktionalisiert, welche bei den verwendeten $\mathrm{pH}$ Bedingungen partiell positiv geladen vorliegt (60\% protoniert bei $\mathrm{pH} 7,3)$. An der positiv geladenen Monolage tritt eine Akkumulation von Anionen, z. B. Chloridionen auf. Nähern sich beide geladenen Oberflächen mit den jeweiligen umgebenden Ionenschichten an, so können gebundene Kationen bzw. Anionen durch elektrostatische Paarung von Amino- und Carboxygruppen freigesetzt werden und aus der Grenzschicht in die umgebende Pufferlösung übertreten. Bei diesem Prozess erhöht sich die Anzahl freier Teilchen im System, was zu einem Anstieg der Entropie führt. Dieser Entropieanstieg ist die treibende Kraft für die Vergrößerung der Kontaktfläche zwischen GUVs und Substrat bis hin zu einem Spreiten der GUVs und der damit einhergehenden Bildung planarer porenüberspannender Membranen. Ein 
entsprechender Mechanismus der „Gegenionen-Freisetzung“ wurde von Andelman, Safran et al. formuliert und als physikalische Ursache für eine anziehende Kraft zwischen zwei entgegengesetzt geladenen Oberflächen identifiziert. ${ }^{[231,232]}$

Für die Theorie eines entropiegetriebenen Vesikelspreitens spricht auch die Reihenfolge in welcher Kationen das Spreiten fördern $\left(\mathrm{Ca}^{2+}>>\mathrm{K}^{+}>\mathrm{Na}^{+}\right)$. Calciumionen weisen eine bis $\mathrm{zu}$ 50-fach höhere Bindungskonstante zu Phosphatidylserinen auf, als Kalium- oder Natriumionen (bestimmt an Phosphatidylserin-Monoschichten). ${ }^{[219]}$ Dementsprechend wird bei Vergrößerung der Kontaktfläche zwischen GUVs und Substratoberfläche eine größere Menge Calciumionen freigesetzt, als Kalium- oder Natriumionen, was zu einem höheren Entropiebeitrag führt. Monovalente Kationen zeigen nur sehr geringe Unterschiede in ihrer Bindung zu Phosphatidylserin, wobei Kaliumionen in dünnschichtchromatografischen Studien eine stärkere Bindung zeigten. ${ }^{[233]}$ Kaliumionen besitzen aufgrund ihrer geringeren Ladungsdichte eine kleinere Hydrathülle als Natriumionen. Werden während des Spreitprozesses also Natriumionen freigesetzt, so binden diese mehr Wasser in Form einer Hydrathülle als Kaliumionen. Der Beitrag der Entropie zur freien Enthalpie beim Spreitprozess nimmt durch die höhere Zahl der in Form einer Hydrathülle geordneten Wassermoleküle ab, weshalb Kaliumionen die Zahl der gespreiteten GUVs und die Geschwindigkeit des Spreitens im Vergleich zu Natriumionen erhöhen.

Auf hydrophil funktionalisierten Substraten konnten erstmals durch Spreiten von GUVs lösungsmittelfreie planare Membranen über Poren mit Durchmessern bis $d=5,5 \mu \mathrm{m}$ gebildet werden. Bei Poren mit offenen wie geschlossenen Böden gelang das Überspannen derart großer Kavitäten bisher nur mit lösungsmittelhaltigen Membranen, ${ }^{[47,76]}$ oder durch Einführung einer Verengung der Porenöffnung. ${ }^{[51]}$ Lösungsmittelfreie Membranen waren bisher auf Porendurchmesser bis $2,5 \mu \mathrm{m}$ beschränkt, was eine Untersuchung der Poreninnenräume mit optischen Methoden einschränkte. ${ }^{[49,172]}$

Lösungsmittelfreie porenüberspannende Membranen wurden konfokalmikroskopisch und mittels SICM untersucht (Abb. 4.13). Dabei wurden planare Membranen in den Poren in Tiefen von $z= \pm 0$ bis $-4,8 \mu \mathrm{m}$ (CLSM) bzw. $-1,25 \pm 1,05 \mu \mathrm{m}$ (SICM) detektiert (Tabelle 4.5). Diese Werte stimmen gut mit denjenigen für lösungsmittelhaltige porenüberspannende Membranen nach Ausfrieren des Lösungsmittels (Tabelle 4.1) überein. Die Halbwertsbreite $(F W H M)$ der an die Verteilung der Intensität des Membranfarbstoffs in $z$-Richtung entlang der Pore angepassten Gauss-Funktion stimmt ebenfalls für beide Präparationstechniken gut überein (lösungsmittelfrei: $F W H M=2,6 \mu \mathrm{m}$, lösungsmittelhaltig nach Ausfrieren: $F W H M=2,7 \mu \mathrm{m})$. Trotz des Fehlens einer Plateau-Gibbs-Grenzschicht im Porenrandbereich, welche als Lipidreservoir dient und eine mechanische Verformung und Ausdehnung der Membran unter Beibehaltung ihrer Impermeabilität für Elektrolyte erlaubt, ${ }^{[203]}$ konnte in mit lösungsmittelfreien Membranen überspannten geschlossenen Poren der wasserlösliche Farbstoff Pyranin über mindestens 30 min stabil eingeschlossen werden. FRAP-Experimente 
an lösungsmittelfreien porenüberspannenden Membranen zeigten, dass die Lipide innerhalb der Membranen mobil sind. Die Intensitäten der Fluoreszenz nach dem Bleichen wurde zu $I_{\text {Bleich }}=41 \pm 4 \%$ bestimmt mit Extremwerten von 46 bzw. $38 \%$, was im Rahmen der Fehlergrenzen mit den für lösungsmittelhaltige porenüberspannende Membranen nach Ausfrieren des Lösungsmittels bestimmten Werten übereinstimmt ( $I_{\text {Bleich }}=51 \pm 8 \%$, Extremwerte 67 bzw. $45 \%$ ). Von einer Quantifizierung des mobilen Anteils wurde aufgrund der geringen Größe der zusammenhängenden membranüberspannten Bereiche abgesehen (Kapitel 4.1.2, Spreiten auf hydrophil funktionalisierten Substraten). Eine Abschätzung ergab jedoch Werte von $M=55 \pm 5 \%$ und $D=0,6 \pm 0,1 \mu \mathrm{m}^{2} \cdot \mathrm{s}^{-1}$.

Die hohe Übereinstimmung der für lösungsmittelfreie und lösungsmittelhaltige porenüberspannende Membranen nach Ausfrieren des Lösungsmittels bestimmten Werte deutet auf einen geringen Restgehalt remanenten Lösungsmittels in letzteren Membranen hin. Befunde, welche durch den Lösungsmittelgehalt von Membranen erklärt wurden, können bei lösungsmittelfreien Membranen nicht auf diese Weise diskutiert werden. So lässt sich die mittels SICM ermittelte Tiefe der Membranen in den Poren bei $z=-1,25 \pm 1,05 \mu \mathrm{m}$ nicht mit dem Auftragen unterschiedlicher Mengen Lipidmaterials in Lösungsmittel erklären. Dass es trotz der Abwesenheit von Lösungsmittel zu großen Unterschieden in der z-Position porenüberspannender Membranen kommt, lässt sich auf die Freisetzung von Sucroselösung beim Spreiten von GUVs zurückführen. In diesem Zusammenhang soll zugleich die Bildung hemisphärischer Ausstülpungen von Membranen im Porenbereich diskutiert werden.

\section{Hemisphärische porenüberspannende Membranen}

Biologische Membranen weisen in Zellen verschiedenste Strukturen auf mit zum Teil hoher lokaler Krümmung. Für die Bildung von Membranausstülpungen und -invaginationen in Eukaryoten wurden Proteine als zentrale Regulatoren identifiziert und die Mechanismen der proteininduzierten Membranverformung für Proteine mit Bar (Bin-Amphiphysin-Rvs)Domänen $^{[234]}$ und weitere Proteine ${ }^{[235,236]}$ untersucht. Diese Proteine konnten sowohl in vivo als auch in vitro in artifiziellen Membransystemen wie GUVs Ausstülpungen bzw. Invaginationen bilden. Im Zusammenspiel mit Proteinen können auch das Zytoskelett und die Geometrie der Membranlipide Krümmungen von Membranen hervorrufen und stabilisieren. ${ }^{[237]}$

Für die Deformation artifizieller Lipidmembranen ohne Beteiligung von Proteinen finden sich nur wenige Beispiele. Darunter kurzlebige Verformungen von GUVs durch elektrische Pulse $^{[238]}$ und Internalisierungen von Vesikeln aus Invaginationen in GUVs, induziert durch osmotische Gradienten. ${ }^{[239]}$ Hemisphärische Ausstülpungen freistehender Membranen durch Anlegen eines hydrostatischen Drucks wurden bisher lediglich für lösungsmittelhaltige Membranen beschrieben. ${ }^{[18,203]}$ 
Im Rahmen dieser Arbeit wurde erstmals die Bildung stabiler lösungsmittelfreier, hemisphärischer Membranausstülpungen auf porösen Substraten mit geschlossenen Böden beschrieben. Die gewölbte Struktur der Membranen wurde konfokalmikroskopisch und mittels SICM abgebildet (Abb. 4.15). Der wasserlösliche Farbstoff Pyranin ließ sich homogen verteilt und stabil in hemisphärisch überspannten Poren einschließen und FRAP-Experimente an mit Bodipy-PC markierten Membranen bestätigten die Mobilität der Lipide und die Bildung einer durchgängigen Membran innerhalb eines patches (Abb. 4.16). Aufnahmen solcher patches zusammenhängender porenüberspannender Membranen zeigten, dass sich weit in die überstehende Lösung ausgestülpte Membranen bevorzugt nebeneinander im zentralen Bereich eines patches bildeten, während planare porenüberspannende Membranen häufig im Randbereich lokalisiert wurden (Abb. 4.15, B).

Um einen möglichen Einfluss eines osmotischen Gradienten zwischen membranbedecktem Poreninnenraum und überstehender Pufferlösung auf die Struktur der porenüberspannenden Membranen zu untersuchen, wurden GUVs mit unterschiedlicher Sucrosekonzentration im Inneren gespreitet (Abb. 4.17). Die Osmolarität der Lösung, in welcher gespreitet wurde, betrug jeweils $0,303 \mathrm{Osmol} \cdot \mathrm{Kg}^{-1}$. Unter hypo- $\left(0,163 \mathrm{Osmol} \cdot \mathrm{Kg}^{-1}\right)$, iso- $\left(0,306 \mathrm{Osmol} \cdot \mathrm{Kg}^{-1}\right)$ und hyperosmolaren $\left(0,606 \mathrm{Osmol} \cdot \mathrm{Kg}^{-1}\right)$ Bedingungen bildeten sich jeweils hemisphärische Membranen (Tabelle 4.4). Das Verhältnis hemisphärischer zu planaren Membranen, sowie die mittlere Membranposition relativ zur Substratebene nahm mit steigender Sucrosekonzentration in den gespreiteten GUVs zu. Die Anzahl membranüberspannter Poren verringerte sich bei Verwendung hypoosmolarer GUVs von $N=317$ bzw. $N=247$ auf $N=14$. Grund hierfür ist weniger eine Beeinflussung des Spreitverhaltens der GUVs, als vielmehr die Tatsache, dass sich in 0,15 M Sucroselösung weniger GUVs gebildet hatten und unter dem starken osmotischen Stress in der höher osmolaren wässrigen Lösung nur wenige GUVs intakt auf die Substratoberfläche absanken.

Mögliche Ursachen für die Bildung und die Stabilität solcher hemisphärischer Membranen neben planaren porenüberspannenden Membranen sollen nachfolgend diskutiert werden. Eine Bildung gewölbter Membranen konnte nur auf Poren mit geschlossenen Böden beobachtet werden und nur für lösungsmittelfreie Membranen. Bei der Präparation porenüberspannender Membranen mittels painting-Technik liegt lediglich eine definiert zusammengesetzte Pufferlösung vor, sodass sich keine Unterschiede zwischen Poreninnerem und überstehender Lösung nach Membranbildung ergeben. Zur Präparation lösungsmittelfreier Membranen wurden sucrosegefüllte GUVs in sucrosefreier, ionenhaltiger Pufferlösung gespreitet. Durch den Einsatz zweier unterschiedlicher wässriger Lösungen ist eine Ungleichverteilung zwischen Poreninnerem und überstehender Lösung möglich, welche Ursache für hemisphärisch ausgestülpte Membranen sein könnte. Offene Poren ohne Böden würden eine Mischung der Lösungen auf beiden Seiten der Membranen ermöglichen und so Differenzen in deren Zusammensetzung verhindern. Die Tatsache, dass auf offenen Poren keine gewölbten 
Membranbereiche beobachtet werden konnten, spricht für eine Ursache in der Ungleichverteilung von Teilchen zwischen Poreninnerem und überstehendem Volumen.

Differenzen in der Zusammensetzung beider wässriger membrangetrennter Bereiche würde einen osmotischen Druck und dadurch die Verformung der Membran zur Folge haben. Bei Angleichen der Osmolarität beider Lösungen (Füllung der GUVs und Umgebungslösung) traten dennoch hemisphärische Membranen in großer Zahl auf (Tabelle 4.4), sodass die Wölbung der Membranen nicht nur auf einem initialen osmotischen Gradienten zwischen Vesikelinnerem und umgebender Pufferlösung beruhen kann. Die inhomogene Verteilung von gewölbten und planaren porenüberspannenden Membranen innerhalb eines patches spricht dafür, dass ein osmotischer Gradient zwischen Poreninnerem und Umgebungslösung, welcher eine deformierende Kraft auf die Membranen ausübt, sich erst während des Spreitvorgangs der GUVs bildet.

Eine Erklärung für die Bildung ausgestülpter porenüberspannender Membranen soll anhand von Abb. 5.7 gegeben werden. Aufgrund der höheren Dichte der GUVs (0,3 M Sucroselösung bei $\left.20^{\circ} \mathrm{C}: \rho=1,0381 \mathrm{~g} \cdot \mathrm{cm}^{-3}\right)^{[240]}$ im Vergleich zur umgebenden wässrigen Pufferlösung (z. B. 0,16 M KCl-Lösung bei $\left.25^{\circ} \mathrm{C}: \rho=1,0046 \mathrm{~g} \cdot \mathrm{cm}^{-3}\right),{ }^{[241]}$ sinken GUVs auf die Substratoberfläche ab (Abb. 5.7, A). Es bilden sich Defekte in der Membran der Vesikel, welche Ausgangspunkte für ein Spreiten der GUVs in Form eines Ausbreitens der Membran entlang der Stegfläche sind (Abb. 4.12). Beim Ausbreiten der Membran wird die in den GUVs eingeschlossene Sucroselösung hin zur Substratoberfläche freigesetzt und es kann zu einer Vermischung mit der Elektrolytlösung im Poreninneren kommen. Ein Einschließen der Sucroselösung zwischen Membran und Poren ist nur dann möglich, wenn sich Defekte in der dem Substrat zugewandten Seite des GUV bilden und sich die Membran dann in der Form ausbreitet, dass die zuvor dem Inneren des GUV zugewandte Monolage der Membran schließlich die dem Substrat zugewandte Monolage der sich ausbreitenden Membran bildet. Rädler et al. beschrieben im Gegensatz dazu für ein Spreiten von Vesikeln auf hydrophilen Oberflächen die Bildung von Defekten in der vom Substrat abgewandten Hälfte des Vesikels und ein Ausbreiten der Membran, welches dazu führt, dass die vormals dem Vesikelinneren zugewandte Monolage schließlich die vom Substrat abgewandte Monolage bildet. Anhand von dissipative particle dynamics-Simulationen untersuchten Fuhrmans und Müller das Spreitverhalten von unilamellaren Vesikeln auf Oberflächen. ${ }^{[242]}$ Sie konnten zeigen, dass Vesikel je nach Stärke und Reichweite der attraktiven Wechselwirkung zwischen Substrat und Vesikelmembran und Substratrauhigkeit ein „receding-top“-Mechanismus, oder ein „parachute“-Mechanismus möglich ist. Beide Mechanismen unterscheiden sich in der Orientierung der beiden Monolagen der Vesikelmembran nach Bildung einer planaren Membran. 

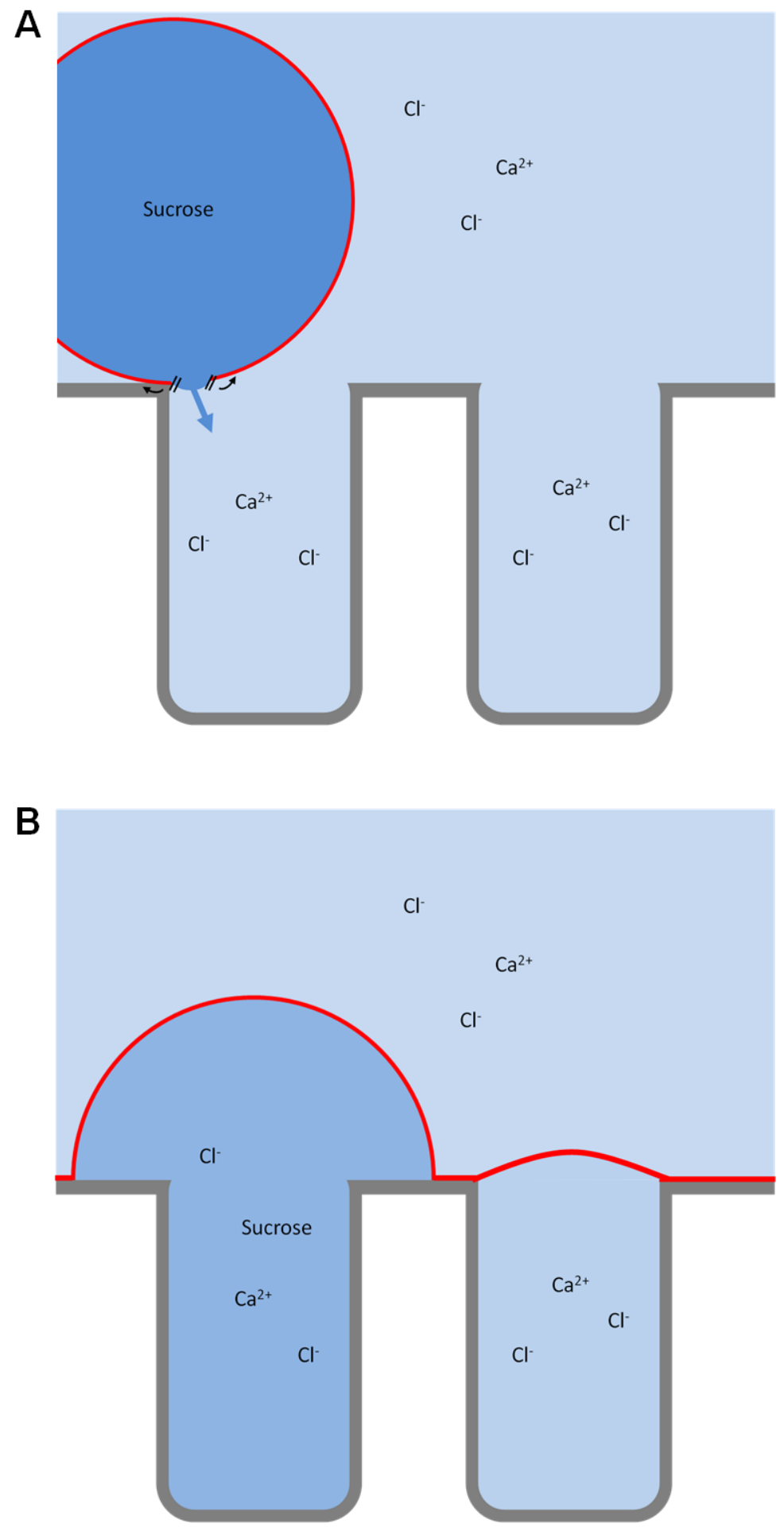

Abb. 5.7: Schematische Darstellung der Bildung hemisphärischer porenüberspannender Membranen durch Spreiten sucrosehaltiger GUVs (rot mit dunkelblauer Füllung) auf hydrophil funktionalisierten porösen Substraten (grau) mit geschlossenen Poren (für eine bessere Übersichtlichkeit wurde die Funktionalisierung der Substrate nicht dargestellt). A Nach dem Absinken auf die Substratoberfläche bildet sich in einem GUV ein Defekt im Bereich der Grenzfläche zum Substrat. Die Membran breitet sich entlang der Porenstege aus und bindet aufgrund der attraktiven Wechselwirkung an die Stegbereiche. B Poröse Flächen werden dabei überspannt. Der Inhalt des GUV vermischt sich mit der wässrigen Lösung im Poreninneren unterhalb der sich ausbreitenden Membran (Aufhellung des Blautons). Poren, welche weiter entfernt von der Defektstelle im GUV liegen, schließen weniger Sucroselösung ein und werden daher flacher überspannt. 
Die zwischen Membran und Substratoberfläche eingeschlossene Sucroselösung weist eine hohe Viskosität auf $\left(0,3 \mathrm{M}\right.$ Sucroselösung bei $\left.20^{\circ} \mathrm{C}: \eta=1,336 \mathrm{mPa} \cdot \mathrm{s}\right)$ bei gleichzeitig geringer Mobilität $\left(0,3 \mathrm{M}\right.$ Sucroselösung bei $\left.20^{\circ} \mathrm{C}: D=4,3 \cdot 10^{-10} \mathrm{~m}^{2} \cdot \mathrm{s}^{-1}\right) \cdot{ }^{[240]}$ Unter der Bedingung, dass der Prozess des Membranausbreitens beim Spreiten deutlich schneller verläuft, als die laterale Verteilung der vormals im GUV befindlichen Sucroselösung, ist der Einschluss dieser Lösung unterhalb hemisphärischer porenüberspannender Membranen möglich (Abb. 5.7, B). Anhand der in Abb. 4.12 dargestellten Aufnahmen eines spreitenden GUV ergibt sich eine Dauer des Spreitens von $24 \mathrm{~s}$ bis zum erreichen der entgültigen Form des patches. Der stabile Einschluss des wasserlöslichen Farbstoffs Pyranin zeigt, dass hemisphärische porenüberspannende Membranen das Poreninnere effektiv von der umgebenden Lösung abtrennen können. Durch die starke attraktive Wechselwirkung zwischen Membran und funktionalisiertem Stegbereich ist weiterhin kein Austausch der eingeschlossenen Lösung zwischen angrenzenden Membranen möglich, wie ein irreversibles Photobleichen eingeschlossenen Pyranins verdeutlichte (Kapitel 4.1.2). Ebenso ist ein stabiler Einschluss des Gemisches der wässrigen Lösungen aus GUV und Poren während des Spreitprozesses möglich.

Hat sich ein stabiler Kontakt zwischen der Membran und der die Pore umgebenden Stegfläche gebildet, wird das Gemisch aus Sucrose- und Pufferlösung permanent unterhalb der Membran eingeschlossen. Je nach Zusammensetzung der Sucroselösung innerhalb der GUVs können sich dabei osmotische Gradienten zwischen eingeschlossener Lösung und umgebender Pufferlösung bilden. Durch ein Ein- bzw. Ausströmen von Wasser kann dieser Gradient ausgeglichen werden und sich das eingeschlossene Volumen und somit die Form der Ausstülpung ändern. Da porenüberspannende Membranen auf hydrophil funktionalisierten Membranen schwächer adhäriert sind, was sich z. B. in einer geringeren lateralen Membranspannung äußert, als auf hydrophob funktionalisierten Substraten, kann die nötige Veränderung der Membranfläche der Ausstülpungen durch ein „Nachfließen“ der Membran vom Stegbereich oder dorthin stattfinden. ${ }^{[48]}$

Am Ende eines Spreitvorgangs (Abb. 5.7, B) liegt eine hemisphärisch gewölbte porenüberspannende Membran an der Stelle vor, wo durch die einen Spreitvorgang einleitende Defektbildung die vormals im Inneren des GUV eingeschlossene Sucroselösung in Richtung der Poren austritt. Weiter entfernt von der initialen Stelle der Membranausbreitung erreicht weniger bis keine Sucroselösung mehr die Poren. Durch die starke attraktive Wechselwirkung zwischen Substratoberfläche und Membran breitet sich die Membran entlang der Ebene der Substratoberfläche aus. Poren, welche durch diesen Ausbreitungsprozess überspannt werden, werden planar und dadurch in geringen Tiefen überspannt. Hierdurch wird die beobachtetet Ungleichverteilung von hemisphärischen und planaren porenüberspannenden Membranen innerhalb eines patches erklärt. 
Auf die gewölbten Membranen wirken nach Ende des Spreitprozesses weiterhin Kräfte, welche sich aufgrund der Stabilität der gebildeten hemisphärischen Strukturen in einem Gleichgewicht befinden müssen. Zum einen wirkt die attraktive elektrostatische wie entropiegetriebene Wechselwirkung zwischen Membran und Substratoberfläche. Eine Vergrößerung der Kontaktfläche in Form einer Abflachung der Ausstülpungen und einer damit verbundenen Vergrößerung der Fläche eines patches wäre energetisch begünstigt. Dagegen wirkt ein osmotischer Gadient zwischen der eingeschlossenen Lösung und der überstehenden Pufferlösung. Eine Abflachung der Ausstülpungen hätte eine Verkleinerung des eingeschlossenen Volumens und damit einhergehend eine Aufkonzentrierung zur Folge. Konzentrationsunterschiede zwischen den beiden membrangetrennten Lösungen würden zu einem osmotischen Druck führen, welcher die Membran nach außen wölbt. Durch ein Gleichgewicht zwischen dem osmotischen Druck auf die Membran und der attraktiven Wechselwirkung zwischen Membran und Substratoberfläche lässt sich die Stabilität der gebildeten hemisphärischen porenüberspannenden Membranen erklären.

In Abhängigkeit der Konzentration der Sucroselösung in den gespreiteten GUVs verändern sich Viskosität und dadurch Mobilität der Sucroselösung, sowie die Konzentration von Teilchen im eingeschlossenen Bereich, was wiederum einen Einfluss auf den osmotischen Druck auf die Membran hat. Eine höhere Startkonzentration von Sucrose in den GUVs führt demnach dazu, dass sich die Sucrose beim Freisetzen aus den GUVs langsamer verteilt und mehr Teilchen unterhalb der Membran eingeschlossen werden. Daraus resultiert ein höherer osmotischer Druck und somit eine höhere Ausstülpung, wie sie auch in Form einer erhöhten $z$-Position der Membran detektiert werden konnte (Tabelle 4.4).

Eine nähere Betrachtung und Quantifizierung von Parametern, welche die Form planarer Membranen beeinflussen und die Bildung gewölbter und tether-artiger Membranen fördern können, findet sich bei Arroyo et al. ${ }^{[243]}$ Dazu wurden planare Membranen auf einer flexiblen Schicht aus PDMS gebildet. Durch peristaltischen Druck konnte die unterliegende PDMSSchicht beliebig gewölbt und so die aufliegende Membran gebogen oder gedehnt werden. Änderungen in der Ionenkonzentration der umgebenden wässrigen Lösung wurden verwendet, um gezielt osmotischen Druck aufzubauen. Zusammenfassend konnten durch experimentelle Befunde und theoretische Überlegungen gezeigt werden, dass unter definierten Bedingungen sowohl planare als auch hemisphärisch gewölbte Membranen einen stabilen Zustand bilden können, was den im Rahmen dieser Arbeit beobachteten Befunden entspricht.

Anhand der hier geführten Argumentation lässt sich die hohe Schwankung der $z$-Position lösungsmittelfreier planarer Membranen in den Poren von $z=1,25 \pm 1,05 \mu \mathrm{m}$ durch Schwankungen in der Zusammensetzung der in den Poren eingeschlossenen Lösung erklären. Freigesetzte Sucroselösung verteilt sich ungleichmäßig entlang der angrenzenden Poren und es können Differenzen in der Osmolarität von Poreninnerem und umgebender Pufferlösung 
auftreten, welche durch Ein- bzw. Ausströmen von Wasser in die Pore und dadurch einer Verschiebung der $z$-Position der Membran ausgeglichen werden können.

Um das vorgeschlagene Modell zur Bildung hemisphärischer porenüberspannender Membranen zu testen, könnten Parameter, wie die Adhäsionsenergie in Form der Funktionalisierung der Substratoberfläche oder der osmotische Druck auf die Membranen in Form der Osmolaritäten der eingesetzten Lösungen variiert werden. Trifft die hier formulierte Beschreibung ihrer Bildung zu, würde sich die Höhe der Ausstülpungen dadurch verändern. Die Zusammensetzung der Lösung im Inneren der GUVs kann nur eingeschränkt modifiziert werden, da eine höhere Dichte der Vesikel zum Absinken auf die Substratoberfläche nötig ist und stark hypoosmolare Füllungen zu einer verringerten Stabilität der GUVs führen.

\subsection{Nigericininduzierte elektrochemische Gradienten}

Lösungsmittelfreie und -haltige porenüberspannende Membranen wurden verwendet, um wässrige Lösungen mit und ohne Kaliumionen voneinander $\mathrm{zu}$ trennen und so Kaliumionengradienten zu bilden. Durch Zugabe von Nigericin, einem $\mathrm{K}^{+} / \mathrm{H}^{+}$-Antiporter, konnten in situ Protonengradienten aufgebaut und deren Bildung anhand der Fluoreszenz des pH-sensitiven Farbstoffs Pyranin verfolgt werden. Neben Liposomen mit Durchmessern kleiner $1 \mu \mathrm{m}$ wurde der Aufbau nigericininduzierter Protonengradienten auch an GUVs und porenüberspannenden Membranen untersucht. Für Letztere wurden Kinetiken des Transportprozesses ermittelt und absolute $\mathrm{pH}$-Wertänderungen bestimmt, welche mit theoretischen Überlegungen in Zusammenhang gesetzt werden sollen.

\subsubsection{Bildung von Protonengradienten in Vesikeln}

Nach einem literaturbekannten Experiment von Hell et al. wurde der nigericininduzierte Aufbau eines Protonengradienten zunächst an Liposomen mit Durchmessern kleiner $1 \mu \mathrm{m}$ getestet. $^{[85]}$ In Hinblick auf Experimente an porenüberspannenden Membranen wurde untersucht, ob sich Pyranin prinzipiell als Fluoreszenzsonde zur Beobachtung von pH-Wertänderungen eignet. Abb. 4.20 zeigt den Verlauf der Intensität der Pyraninfluoreszenz bei Zugabe von Nigericin. Wie von Hell und anderen beschrieben, ${ }^{[97]}$ konnte qualitativ durch Anstiege bzw. Abfälle in der Pyraninfluoreszenz der Aufbau von Protonengradienten verfolgt werden.

Bei Experimenten an Liposomen wurden Änderungen der Pyraninfluoreszenz einer Suspension von Vesikeln in einer Küvette detektiert. Um zu ermitteln, inwiefern einzelne Volumina individuell und konfokalmikroskopisch auf Änderungen der Pyraninfluoreszenz untersucht werden können, wurden GUVs präpariert und Pyranin im Vesikelinneren eingeschlossen. Die Vesikel wurden auf einem planaren Substrat fixiert, ein Kaliumionen- 
gradient vorgelegt und ein nigericininduzierter Aufbau eines Protonengradienten beobachtet (Kapitel 4.2.2). Eine Fixierung durch Absinken und Anbinden der GUVs auf die Substratoberfläche ist nur möglich, wenn GUVs eine höhere Dichte, als die Umgebungslösung aufweisen. Für die im Rahmen dieser Arbeit verwendeten Pufferlösungen zum Aufbau eines Kaliumionengradienten trifft diese Voraussetzung nur auf GUVs mit kaliumionenfreier Sucroselösung zu. Bei Austausch der Umgebungslösung gegen kaliumionenhaltige Pufferlösung und anschließender Zugabe von Nigericin, konnte ein Anstieg der Pyraninintensität im Vesikelinneren beobachtet werden, was einem Anstieg des pH-Wertes durch einen nach aussen gerichteten Protonentransport entspricht. Eine Umkehr des Gradienten und eine daraus resultierende Azidifizierung des Vesikelinneren wurde nicht untersucht, da ein Absinken der GUVs in diesem Fall nur durch Änderung der Zusammensetzung der verwendeten Pufferlösungen möglich wäre.

Abb. 4.23 zeigt die Verteilung der Intensität von in GUVs eingeschlossenem Pyranin vor und nach Aufbau eines Protonengradienten durch Zugabe von Nigericin. Die Tatsache, dass Verteilungen mit einer Breite von $F W H M=52$ bzw. 41 Einheiten beobachtet wurden, deutet auf Unterschiede in der Pyraninkonzentration innerhalb der GUVs hin. Da die Vesikel in Gegenwart von 0,5 mM Pyranin gebildet wurden und als eine Suspension gelagert und schließlich zur Probe gegeben wurden, ist anzunehmen, dass Unterschiede der Pyraninkonzentration erst bei Fixierung der GUVs auftraten. Ursache hierfür kann die Bildung temporärer Defekte sein, verursacht durch geringfügige osmotische Unterschiede zwischen Innenraum der GUVs und äußerer Lösung, wie unter Kapite 4.3.3 (Bildung eines lichtinduzierten Protonengradienten) diskutiert. Nach erfolgter Fixierung veränderten sich die Intensitäten der Pyraninfluoreszenz innerhalb der GUVs nicht mehr, sodass permanente Defekte und ein Austausch zwischen Umgebungslösung und Innenvolumen der GUVs ausgeschlossen werden können.

Unter Verwendung von Gl. 3.4 kann ausgehend von einem Startwert von $\mathrm{pH}$ 7,3 die mittlere Änderung des pH-Wertes nach Nigericinzugabe innerhalb der beobachteten GUVs bestimmt werden. Der Mittelwert der an die Verteilungen angepassten Gauss-Funktionen verschiebt sich von $I=153$ Einheiten $\mathrm{zu} I=250$ Einheiten, was einer Konzentrationsänderung der deprotonierten Form des Pyranins von $c=0,273 \mathrm{mM}$ zu $c=0,446 \mathrm{mM}$ entspricht. Daraus errechnet sich eine $\mathrm{pH}-$ Wertänderung von 0,84 Einheiten auf $\mathrm{pH} \mathrm{8,14.} \mathrm{Die} \mathrm{errechnete}$ pH-Wertänderung ist als Mindeständerung zu bewerten, da wie unter Kapitel 4.2.2 beschrieben die Intensität der Pyraninfluoreszenz nach Nigericinzugabe nicht vollständig dargestellt werden kann. Die Intensität steigt über das Niveau des Detektorlimits hinaus an. Durch eine Veränderung der Laserleistung oder der Signalverstärkung kann die Signalintensität verringert werden, was eine Korrelation von Intensität und Konzentration deprotonierten Pyranins jedoch verhindern würde. 
Pyranin wurde qualitativ bereits für die Untersuchung von $\mathrm{pH}-$ Wertänderungen in GUVs verwendet. Darunter finden sich Beispiele für den lichtgetriebenen Transport von Protonen durch bR. ${ }^{[116-118]}$ Weitere Anwendungen beschränken sich auf fluorimetrische Messungen von GUV-Suspensionen. Der nigericininduzierte Antiport von Kaliumionen und Protonen wurde bisher nicht an GUVs untersucht.

\subsubsection{Bildung von Protonengradienten in porenüberspannenden Membranen}

Ein Nachteil fixierter GUVs in Hinblick auf die optische Untersuchung von Transportprozessen ist die inhomogene Größe der GUVs (Abb.4.6). Weiterhin binden die Vesikel unkontrolliert auf dem Substrat, was eine Automatisierung der Auslesung von Intensitäten innerhalb der GUVs erschwert. Substrate mit periodisch angeordneten Poren bieten im Gegensatz zu bisher beschriebenen Untersuchungen an GUVs ${ }^{[194,195]}$ Volumina von definierter, einheitlicher Größe, wodurch eine automatisierte Analyse von parallel ablaufenden Transportprozessen über eine große Anzahl von Membranen möglich ist. Weiterhin konnte gezeigt werden, dass planare porenüberspannende Membranen ein Rühren der überstehenden Probenlösung tolerieren, während fixierte GUVs deformiert, zerstört oder weggespült werden können. Bei Zugaben von z. B. Nigericin kann somit für porenüberspannende Membranen eine gleichmäßige Verteilung erreicht werden, während die Verteilung im Falle fixierter GUVs rein diffusionskontrolliert erfolgt.

Ein nigericininduzierter Aufbau eines Protonengradienten an lösungsmittelhaltigen porenüberspannenden Membranen ist in Abb. 4.24 dargestellt. Die Fluoreszenz des eingeschlossenen Pyranins zeigt jeweils innerhalb weniger Sekunden nach Zugabe von Nigericin einen starken Abfall bzw. Anstieg der Intensität. Die Intensität kann linear mit der Konzentration der deprotonierten Form von Pyranin in einer Pore korreliert werden, woraus sich gemäß Gl. 3.4 der pH-Wert berechnen lässt. Für pH-Abfälle bei lösungsmittelhaltigen Membranen wurden pH-Wertänderungen von -0,94 bis -1,97 Einheiten beobachtet. Unter Berücksichtigung der Porengeometrie $\left(V_{\text {Pore }}=7,7 \cdot 10^{-13} \mathrm{~L}\right)$ und der Zusammensetzung der Pufferlösung (10 mM MOPS, 0,5 mM Pyranin, $\mathrm{pK}_{\mathrm{S}}=7,2^{[244]}$ ) entspricht das einer Anzahl von 2,1 $10^{9} \mathrm{bzw}$. 2,6 $10^{9}$ transportierten Protonen. Daraus wird deutlich, dass bereits geringe Unterschiede in der Anzahl gepumpter Protonen (hier Faktor 0,8) zu Unterschieden der detektierten pH-Differenz von etwa 1 Einheit führen.

Unter der Annahme, dass ein $\mathrm{K}^{+} / \mathrm{H}^{+}$-Antiport so lange abläuft, bis der vorgelegte Kaliumionengradient so weit abgebaut ist, dass er dem entgegengesetzt aufgebauten Protonengradienten entspricht und somit gilt: 


$$
\frac{\left[K_{i}^{+}\right]}{\left[K_{a}^{+}\right]}=\frac{\left[H_{i}^{+}\right]}{\left[H_{a}^{+}\right]},
$$

lässt sich berechnen, wieviele Protonen bis zum Einstellen eines Gleichgewichts gepumpt werden. Dabei entsprechen $\left[\mathrm{K}^{+}{ }_{\mathrm{i}}\right]$ und $\left[\mathrm{H}^{+}{ }_{\mathrm{i}}\right]$ den Konzentrationen von Kaliumionen bzw. Protonen in der Pore und $\left[\mathrm{K}_{\mathrm{a}}^{+}\right]$und $\left[\mathrm{H}_{\mathrm{a}}^{+}\right]$den Konzentrationen in der überstehenden Pufferlösung. Eine doppelt logarithmische Auftragung der Quotienten von Kaliumionen (schwarz) bzw. Protonen (rot) in einer Pore und in der überstehenden Lösung als Funktion der Anzahl von in eine Pore hinein gepumpten Protonen $(N)$ ist in Abb. 5.8 dargestellt.

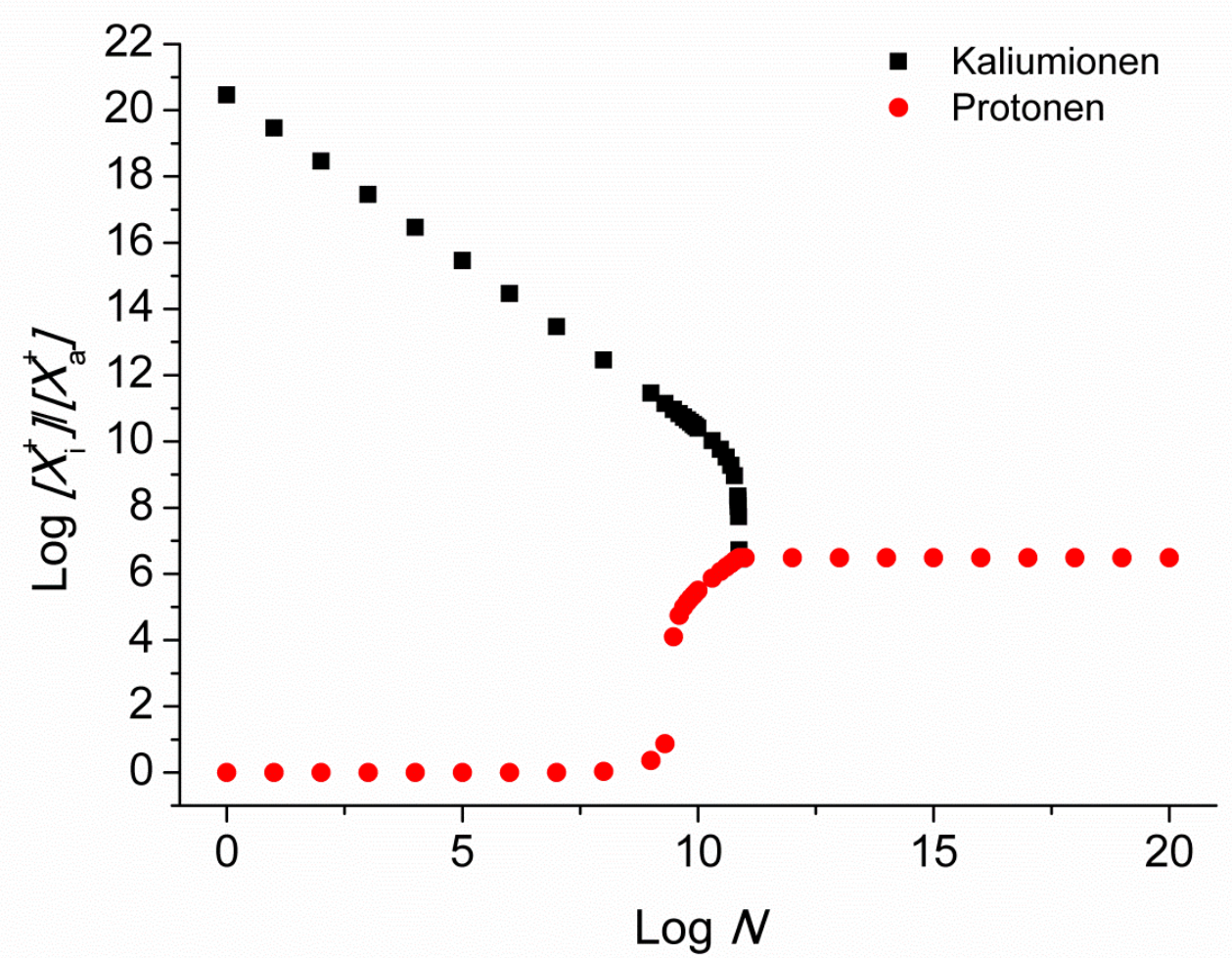

\begin{abstract}
Abb. 5.8: Doppelt logarithmische Auftragung des Quotienten aus Kaliumionenkonzentration (-) bzw. Protonenkonzentration $(\bullet)$ in den Poren und in der überstehenden Pufferlösung als Funktion der über eine porenüberspannende Membran transportierten Protonen $(N)$. Bei einem Wert größer 7,4 $10^{10}$ transportierter Protonen beträgt die Konzentration von Kaliumionen in einer Pore 0. Da der Logarithmus für Werte $=0$ nicht definiert ist, ist der Verlauf des Kaliumionengradienten nur bis zu diesem Wert dargestellt. Die Kurven wurden berechnet für Startbedingungen von $\mathrm{pH}=7,3, c($ Puffer $)=10,5 \mathrm{mM}, \mathrm{pK}_{\mathrm{S}}($ Puffer $)=7,2, \quad V($ Pore $)=7,68 \cdot 10^{-13} \mathrm{~L}, \quad$ Volumen der überstehenden Lösung $V$ (Probe) $=3 \mathrm{~mL}$, Anzahl der bedeckten Poren $N($ Poren $)=1$, Kaliumionenkonzentration in den Poren $\left[\mathrm{K}_{\mathrm{i}}^{+}\right]^{0}=160 \mathrm{mM}$, Kaliumionenkonzentration in der überstehenden Lösung $\left[\mathrm{K}_{\mathrm{a}}^{+}\right]^{0}=0 \mathrm{mM}$.
\end{abstract}

Die verwendeten Gleichungen zur Berechnung der Verläufe von Ionenkonzentrationen in den Poren und in der überstehenden Lösung sind im Anhang aufgeführt (Kapitel 8.4.2). Bis zum Erreichen eines Gleichgewichts zwischen Kaliumionen- und Protonengradienten werden theoretisch $7,39 \cdot 10^{10}$ Protonen in die Pore hinein bzw. Kaliumionen aus einer Pore hinaus 
transportiert (Schnittpunkt beider Kurven in Abb. 5.8). Eine Darstellung der Ausgangs- und Gleichgewichtskonzentrationen ist in Tabelle 5.1 aufgeführt.

Tabelle 5.1: Ausgangs- und Gleichgewichtskonzentrationen von Kaliumionen und Protonen in einer membranüberspannten Pore $(N($ Poren $)=1)$ und in der überstehenden Pufferlösung. Theoretische Betrachtung eines nigericininduzierten Protonentransports in eine Pore hinein. Bedingungen wie unter Abb. 5.8. Alle Konzentrationen sind in $\mathrm{mol} \cdot \mathrm{L}^{-1}$ angegeben.

\begin{tabular}{|l|c|c|}
\hline & Startwert & Gleichgewichtswert \\
\hline$\left[\mathrm{K}_{\mathrm{i}}^{+}\right]$ & 0,160 & $1,26 \cdot 10^{-4}$ \\
\hline$\left[\mathrm{K}_{\mathrm{a}}^{+}\right]$ & 0,0 & $4,09 \cdot 10^{-11}$ \\
\hline$\left[\mathrm{H}_{\mathrm{i}}^{+}\right]\left(\mathrm{pH}_{\mathrm{i}}\right)$ & $5,01 \cdot 10^{-8}(7,3)$ & $0,154(0,8)$ \\
\hline$\left[\mathrm{H}_{\mathrm{a}}^{+}\right]\left(\mathrm{pH}_{\mathrm{a}}\right)$ & $5,01 \cdot 10^{-8}(7,3)$ & $5,01 \cdot 10^{-8}(7,3)$ \\
\hline$N$ & 0 & $7,39 \cdot 10^{10}$ \\
\hline
\end{tabular}

Es wird deutlich, dass bis zum Erreichen des Gleichgewichtszustands annähernd sämtliche zu Beginn in der Pore eingeschlossenen Kaliumionen in die überstehende Pufferlösung transportiert werden. Lediglich $6 \cdot 10^{7}$ Kaliumionen verbleiben in der Pore. Umgekehrt erhöht sich die Protonenkonzentration in einer Pore fast auf den Startwert der Kaliumionenkonzentration, nämlich $154 \mathrm{mM}$ was einem $\mathrm{pH}-$ Wert von 0,8 entspricht.

Die Anzahl in die Pore hinein transportierter Teilchen ist bei dem hier beschriebenen theoretischen Ansatz um einen Faktor 28 größer, als der maximale experimentell ermittelte Wert für lösungsmittelhaltige porenüberspannende Membranen (2,6 $10^{9}$ Teilchen). Unter Berücksichtigung der Tatsache, dass bei der Präparation porenüberspannender Membranen nach der painting-Technik große Teile des Substrates mit einer Membran bedeckt vorliegen, verringert sich der errechnete Gleichgewichtswert. Auf einem Substrat der Größe 2,5 5, $0 \mathrm{~mm}^{2}$ mit einer Porosität von $65 \%$, wie sie im Rahmen dieser Arbeit verwendet wurden, finden etwa 126000 rechteckige Poren mit einer Kantenlänge von $8 \mu \mathrm{m}$ Platz. Wird statt von einer einzelnen membranüberspannten Poren von einer realistischen Anzahl überspannter Poren wie $N($ Poren $)=50000$ ausgegangen, so verringert sich die Zahl der in die Pore transportierten Protonen auf $N=1,2 \cdot 10^{10}$, einem Faktor 4,5 größeren Wert im Vergleich zum experimentell ermittelten Wert. In Abb. 5.9 ist der Verlauf des Kaliumionen- sowie des Protonengradienten in Abhängigkeit der transportierten Teilchen für 50000 überspannte Poren analog zu Abb. 5.8 aufgetragen. 


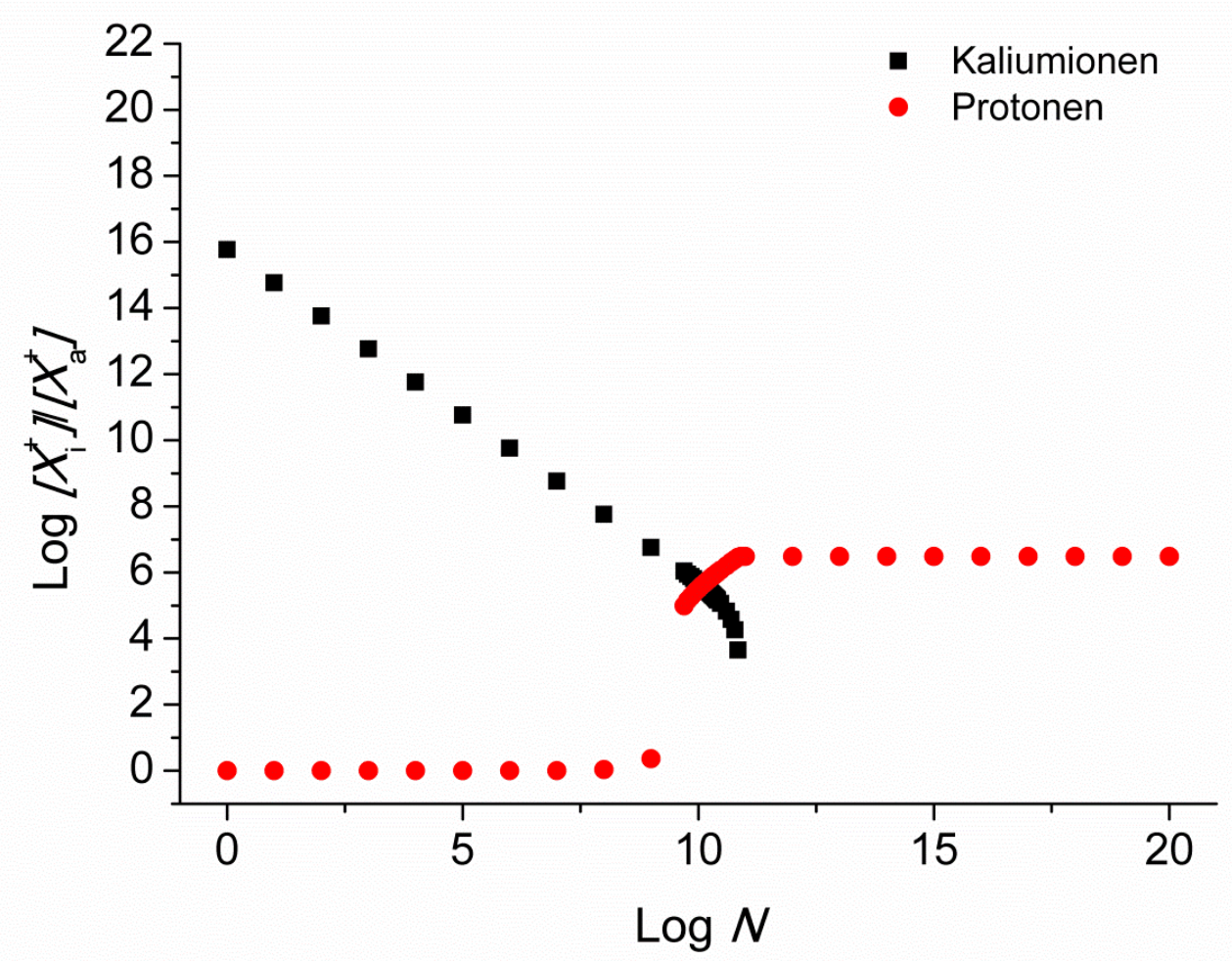

\begin{abstract}
Abb. 5.9: Doppelt logarithmische Auftragung des Quotienten aus Kaliumionenkonzentration (-) bzw. Protonenkonzentration $(\bullet)$ in den Poren und in der überstehenden Pufferlösung als Funktion der über eine porenüberspannende Membran transportierten Protonen $(N)$. Bei einem Wert größer 7,4 $\cdot 10^{10}$ transportierter Protonen beträgt die Konzentration von Kaliumionen in einer Pore 0. Da der Logarithmus für Werte $=0$ nicht definiert ist, ist der Verlauf des Kaliumionengradienten nur bis zu diesem Wert dargestellt. Die Kurven wurden berechnet für Startbedingungen von $\mathrm{pH}=7,3, c($ Puffer $)=10,5 \mathrm{mM}, \mathrm{pK}_{\mathrm{S}}($ Puffer $)=7,2, \quad V($ Pore $)=7,68 \cdot 10^{-13} \mathrm{~L}$, Volumen der überstehenden Lösung $V($ Probe $)=3 \mathrm{~mL}$, Anzahl der bedeckten Poren $N($ Poren $)=50000$, Kaliumionenkonzentration in den Poren $\left[\mathrm{K}_{\mathrm{i}}^{+}\right]^{0}=160 \mathrm{mM}$, Kaliumionenkonzentration in der überstehenden Lösung $\left[\mathrm{K}_{\mathrm{a}}^{+}\right]^{0}=0 \mathrm{mM}$.
\end{abstract}

Während der Quotient beider Protonenkonzentrationen näherungsweise unverändert bleibt im Vergleich zum Verlauf für $N($ Poren $)=1$ überspannte Poren, verschiebt sich der Verlauf des Quotienten aus den Kaliumionenkonzentrationen in den Poren und außerhalb zu niedrigeren Werten. Dadurch wird ein Gleichgewicht in Form eines Schnittpunktes beider Kurvenverläufe bereits bei nur $N=1,20 \cdot 10^{10}$ statt $N=7,39 \cdot 10^{10}$ erreicht. Tabelle 5.2 zeigt, inwiefern sich die Gleichgewichtskonzentrationen der Ionen dabei im Vergleich zum Ein-Poren-System verändern. 
Tabelle 5.2: Ausgangs- und Gleichgewichtskonzentrationen von Kaliumionen und Protonen in einer Vielzahl membranüberspannter Poren $(N($ Poren $)=50000)$ und in der überstehenden Pufferlösung. Theoretische Betrachtung eines nigericininduzierten Protonentransports in Poren hinein. Weitere Bedingungen wie unter Abb. 5.8. Alle Konzentrationen sind in $\mathrm{mol} \cdot \mathrm{L}^{-1}$ angegeben.

\begin{tabular}{|l|c|c|}
\hline & Startwert & Gleichgewichtswert \\
\hline$\left[\mathrm{K}_{\mathrm{i}}^{+}\right]$ & 0,160 & 0,134 \\
\hline$\left[\mathrm{K}_{\mathrm{a}}^{+}\right]$ & 0,0 & $3,32 \cdot 10^{-7}$ \\
\hline$\left[\mathrm{H}^{+} \mathrm{i}\right]\left(\mathrm{pH}_{\mathrm{i}}\right)$ & $5,01 \cdot 10^{-8}(7,3)$ & $2,01 \cdot 10^{-2}(1,7)$ \\
\hline$\left[\mathrm{H}_{\mathrm{a}}^{+}\right]\left(\mathrm{pH}_{\mathrm{a}}\right)$ & $5,01 \cdot 10^{-8}(7,3)$ & $5,01 \cdot 10^{-8}(7,3)$ \\
\hline$N$ & 0 & $1,20 \cdot 10^{10}$ \\
\hline
\end{tabular}

Die Gleichgewichtskonzentrationen der Protonen in der überstehenden Lösung bleibt weitgehend unverändert bei der Erhöhung der Anzahl überspannter Poren. Durch die Vielzahl an Poren, aus welchen Kaliumionen in die überstehende Lösung freigesetzt werden, erhöht sich die Kaliumionenkonzentration dort um vier Größenordnungen, während sie sich innerhalb der Poren lediglich um drei Größenordnungen erhöht. Der Quotient aus beiden Kaliumionenkonzentrationen im Gleichgewicht sinkt dadurch, weshalb eine geringere Protonenkonzentration in den Poren zum Erreichen des Gleichgewichtswertes genügt.

Theoretisch und experimentell ermittelte Werte liegen unter Berücksichtigung der erhöhten Anzahl bedeckter Poren in derselben Größenordnung. Weitere Faktoren, welche zu einer Überschätzung der Anzahl transportierter Teilchen führen, können Veränderungen in den $\mathrm{pK}_{\mathrm{S}}$-Werten der verwendeten Pufferlösungen sein. Dass Ionen den $\mathrm{pK}_{\mathrm{S}}$-Wert von puffernden Substanzen beeinflussen können, wurde bereits am Beispiel von Pyranin erläutert (Kapitel 5.1.2, hydrophil funktionalisierte Substrate). Eine lösungszusammensetzungs- oder auch temperaturbedingte Erhöhung des $\mathrm{pK}_{\mathrm{S}^{-}}$Wertes der puffernden Substanzen Pyranin oder MOPS würde eine Verringerung der Anzahl der bis zum Erreichen des Gleichgewichts in die Poren transportierten Protonen bewirken. Allerdings zeigt der $\mathrm{pK}_{\mathrm{S}}-$ Wert von MOPS nur eine geringe und dabei negative Temperaturabhängigkeit von $\Delta \mathrm{pK}_{\mathrm{S}} / \Delta T=-0,015 \mathrm{~K}^{-1} \cdot{ }^{[245]}$ Es gilt zu beachten, dass $\mathrm{pK}_{\mathrm{S}}$-Werte und $\mathrm{pH}$-Werte auch in die Berechnung der experimentell ermittelten $\mathrm{pH}$ - ̈̈nderungen einfließen und in die daraus extrahierte Zahl der transportierten Teilchen $N$. Änderungen in den $\mathrm{pK}_{\mathrm{S}}$-Werten der puffernden Substanzen eignen sich daher für einen Protonentransport in die Poren hinein nicht als Erklärung für größere Abweichungen zwischen theoretisch und experimentell ermittelten Gleichgewichtswerten. 
Weitere Faktoren, die die Lage des Gleichgewichts verschieben und die nötige Anzahl transportierter Teilchen verändern können, sind eine Abnahme des Volumens der überstehenden Lösung (z. B. durch thermische Verdampfung im Verlauf länger andauernder Bestrahlung mit Lasern während einer Messung), eine Verringerung des Porenvolumens (z. B. durch eine Überspannung mit Membranen in größeren Porentiefen, wie anhand von Abb. 5.3 diskutiert), sowie eine geringfügig verringerte Kaliumionenkonzentration in den Poren oder eine entsprechend geringfügig erhöhte Konzentration in der überstehende Lösung.

Zieht man von der nominellen Porentiefe von $12 \mu \mathrm{m}$ die mittlere Tiefe, in welcher Membranen nach Ausfrieren des Lösungsmittels die Poren überspannen (1,60 $\mu \mathrm{m}) \mathrm{ab}$, so erhält man eine Porentiefe von 10,4 $\mu \mathrm{m}$. In Kombination mit minimal veränderten Kaliumionenkonzentrationen von $0,154 \mathrm{mM}$ in den Poren, sowie $1,5 \cdot 10^{-3} \mathrm{M}$ im überstehenden Volumen (entspricht etwa dem kalkulierten Restwert nach fünffachem Puffertausch), ergibt sich ein Gleichgewichtswert von $N=2,65 \cdot 10^{9}$ in die Poren hinein transportierten Protonen. Durch das verringerte Porenvolumen aufgrund der geringeren Porentiefe ergibt sich daraus ein Gleichgewichtswert von $\mathrm{pH}_{\mathrm{i}}=5,3$.

Unter Berücksichtigung kleinster und dabei plausibler Änderungen sensitiver Parameter, kann demnach genau der experimentell ermittelte Wert simuliert werden. Die gute Übereinstimmung von experimentellem und kalkuliertem Wert in Kombination mit einer hohen Abhängigkeit der berechneten Gleichgewichtswerte von der Höhe des vorgelegten Kaliumionengradienten zeigt weiterhin, dass die mittels painting-Technik gebildeten porenüberspannenden Membranen sehr impermeabel gegenüber Kaliumionen sein müssen und den Aufbau eines stabilen Gradienten erlauben. Käme es bereits vor Aufnahme einer konfokalmikroskopischen Zeitserie und Zugabe von Nigericin zu einem passiven Transport von Kaliumionen über die Membranen aufgrund geringer Impermeabilitäten, so würde sich ein Gleichgewicht nach Zugabe von Nigericin nach deutlich weniger transportierten Teilchen einstellen. Der beobachtete Abfall des pH-Wertes wäre dann deutlich geringer, als die aus Abb. 4.24, A bestimmten 0,94 Einheiten.

Eine schematische Übersicht zum Einfluss einzelner Variablen auf das Gleichgewicht ist in Tabelle 5.3 dargestellt. Den stärksten Einfluss auf die bis zum Erreichen des Gleichgewichts nötige Anzahl transportierter Protonen bzw. Kaliumionen hat die Kaliumionenkonzentration in der überstehenden Pufferlösung. Schon geringe Konzentrationsänderungen können den Gradienten stark verkleinern und so die detektierten Änderungen in der Fluoreszenzintensität von Pyranin während eines Experiments zum nigericininduzierten Aufbau verringern. 
Tabelle 5.3: Schematische Übersicht zum Einfluss einzelner Startparameter auf die Anzahl von Protonen, welche bis zum Einstellen eines Gleichgewichts theoretisch in eine Pore hinein transportiert werden. Ausgangsbedingungen wie unter Abb. 5.9 aufgeführt. Der Index i steht für einen Wert im Poreninneren, a für einen Wert in der überstehenden Pufferlösung. Führt eine Erhöhung des Wertes eines Parameters zu einer Erhöhung der bis zum Gleichgewicht transportierten Protonen, ist dieser je nach Stärke des Effekts mit einem ++, + oder (+) gekennzeichnet (absteigend von sehr stark bis schwach). Analog dazu ist ein antiproportionaler Effekt mit --, oder (-) gekennzeichnet. Hat ein Parameter keinen erkennbaren Einfluss auf das Gleichgewicht, wird dieser mit 0 eingetragen. Dies gilt sowohl für lösungsmittelhaltige als auch lösungsmittelfreie porenüberspannende Membranen.

\begin{tabular}{|l|c|l|c|}
\hline Parameter & Effekt & Parameter & Effekt \\
\hline$\left[\mathrm{K}_{\mathrm{i}}^{+}\right]$ & + & $V_{\mathrm{i}}$ & + \\
\hline$\left[\mathrm{K}_{\mathrm{a}}^{+}\right]$ & -- & $V_{\mathrm{a}}$ & + \\
\hline $\mathrm{pH}_{\mathrm{i}}$ & $(+)$ & $\mathrm{pK}_{\mathrm{S}}$ & - \\
\hline $\mathrm{pH}_{\mathrm{a}}$ & - & $c(\text { Puffer })_{\mathrm{i}}$ & + \\
\hline$N($ Poren $)$ & - & $c(\text { Puffer })_{\mathrm{a}}$ & 0 \\
\hline
\end{tabular}

Neben den in der Lösung vorhandenen Puffern wie MOPS und Pyranin, können auch die Lipide der porenüberspannenden Membranen eine puffernde Wirkung haben und Protonen, welche in die Pore hinein transportiert werden, binden. Bei einer Porenfläche von $64 \mu \mathrm{m}^{2}$ und einer Fläche eines einzelnen Lipids von $0,32 \mathrm{~nm}^{2}$ für $\mathrm{DPPA}^{[246]}$ und $0,75 \mathrm{~nm}^{2}$ für DPhPC, ${ }^{[247]}$ befinden sich rund $9 \cdot 10^{6}$ Lipidmoleküle in der membranüberspannenden unteren Monolage. Dieser Wert ist vernachlässigbar klein im Vergleich mit etwa $5 \cdot 10^{9}$ Molekülen MOPS oder Pyranin in einer Pore $(c($ Puffer $)=10,5 \mathrm{mM})$ und 2,6 $10^{9}$ Protonen, welche zum Einstellen des Gleichgewichts in eine Pore eintreten, weshalb eine puffernde Wirkung der Lipide nicht näher berücksichtigt wurde.

Die absoluten Änderungen des detektierten pH-Wertes in den Poren durch einen nigericininduzierten $\mathrm{K}^{+} / \mathrm{H}^{+}$-Antiport, wie er in Abb. 4.24, A gezeigt ist, stimmen gut mit theoretisch bestimmten Werten überein. Ein weiterer Parameter, welcher anhand der aus konfokalmikroskopische Aufnahmen extrahierten Intensitätsverläufen bestimmt wurde, ist die Initialsteigung (Abb. 4.26). Daraus wurde eine initiale Transportrate von $10^{14} \mathrm{H}^{+} \cdot \mathrm{cm}^{-2} \cdot \mathrm{s}^{-1}$ errechnet. Initiale Transportraten des nigericininduzierten Antiports von Kaliumionen und Protonen wurden an planaren lösungsmittelhaltigen Membranen (BLMs) von Antonenko et al. bestimmt. ${ }^{[92,93]}$ Für vorgelegte Kaliumionenkonzentrationen von $10 \mathrm{mM}$ auf einer Seite und 0,3-1 $\mathrm{mM}$ auf der anderen Seite der Membran (jeweils $\mathrm{pH} \mathrm{7,0)} \mathrm{wurden} \mathrm{bei} \mathrm{Zugabe} \mathrm{von}$ $0,03 \mu \mathrm{M}$ Nigericin Transportraten von $30 \mathrm{pmol} \mathrm{H} \cdot \mathrm{cm}^{-2} \cdot \mathrm{s}^{-1}$ ermittelt, was einer Menge von 
$1,8 \cdot 10^{13} \mathrm{H}^{+} \cdot \mathrm{cm}^{-2} \cdot \mathrm{s}^{-1}$ entspricht. Dieser Wert stimmt in seiner Größenordnung gut mit dem im Rahmen dieser Arbeit ermittelten Wert überein.

Antonenko et al. zeigten in einem Konzentrationsbereich von (1-4) $10^{-8} \mathrm{M}$ eine lineare Abhängigkeit der initialen Transportrate von der Nigericinkonzentration. Die hier eingesetzten Konzentrationen sind Faktor 100 größer und ein Kaliumionengradient von $160 \mathrm{zu}$ $0 \mathrm{mM}$ statt $10 \mathrm{zu}$ 0,3 mM lag vor, wodurch sich der höhere experimentelle Wert erklärt. Eine lineare Extrapolation der Transportraten bis in den mikromolaren Konzentrationsbereich sollte kritisch betrachtet werden, da der Mechanismus des nigericininduzierten Antiports für Konzentrationen größer $10^{-6} \mathrm{M}$ von demjenigen in niedrigeren Konzentrationsbereichen abweichen kann. ${ }^{[90]}$

Wurden die Kaliumionenkonzentrationen im Poreninneren und in der überstehenden Lösung vertauscht, so wurde bei Zugabe von Nigericin ein Intensitätsanstieg der Fluoreszenz des in den Poren eingeschlossenen Pyranins beobachtet (Abb. 4.24, B). Ein maximaler Anstieg des $\mathrm{pH}$-Wertes um $\Delta \mathrm{pH}=1,80$ Einheiten kann analog zum Abfall des $\mathrm{pH}$-Wertes in eine Anzahl aus einer Pore heraus transportierter Protonen von $N=2,1 \cdot 10^{9}$ umgerechnet werden. Dieser Wert ist identisch mit dem für den in Abb. 4.24, A abgebildeten pH-Abfall ermittelten Wert.

Auch für einen $\mathrm{pH}$-Anstieg in membranüberspannten Poren durch Umkehr des $\mathrm{K}^{+} / \mathrm{H}^{+}$-Antiports wurden theoretische Berechnungen bezüglich eines Gleichgewichtswertes nach Gl. 5.2 durchgeführt. Eine doppelt logarithmische Auftragung der errechneten Quotienten aus Kaliumionen- bzw. Protonenkonzentrationen in den Poren und in der überstehenden Lösung in Abhängigkeit der Zahl von aus einer Pore transportierten Protonen ist in Abb. 5.10 dargestellt. 


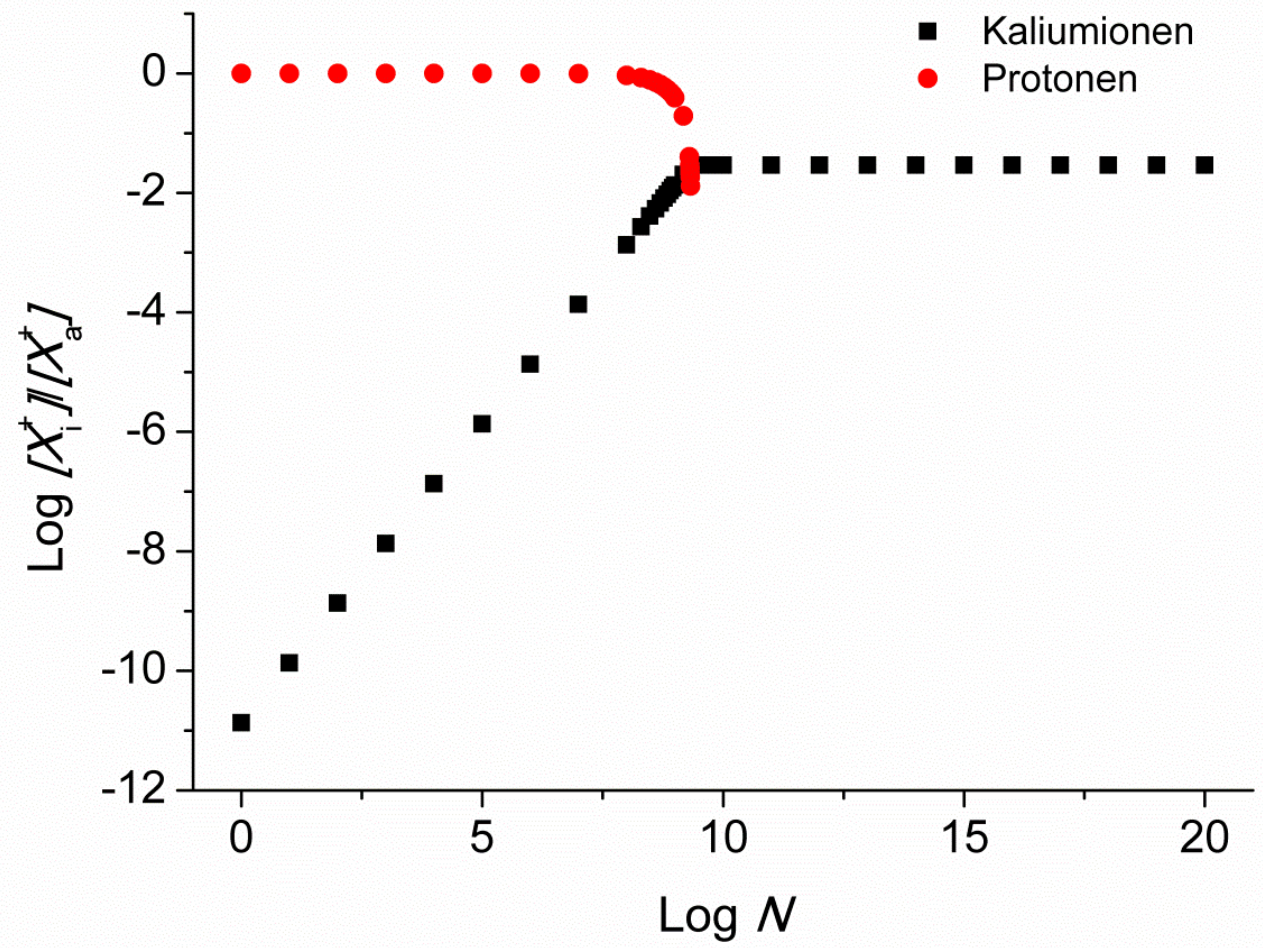

Abb. 5.10: Doppelt logarithmische Auftragung des Quotienten aus Kaliumionenkonzentration (a) bzw. Protonenkonzentration $(\bullet)$ in den Poren und in der überstehenden Pufferlösung als Funktion der über eine porenüberspannende Membran transportierten Protonen $(N)$. Bei einem Wert größer 2,2 $10^{9}$ transportierter Protonen beträgt die Konzentration von Protonen in einer Pore 0. Da der Logarithmus für Werte $=0$ nicht definiert ist, ist der Verlauf des Protonengradienten nur bis zu diesem Wert dargestellt. Die Kurven wurden berechnet für Startbedingungen von $\mathrm{pH}=7,3, c($ Puffer $)=10,5 \mathrm{mM}, \mathrm{pK}_{\mathrm{S}}($ Puffer $)=7,2, \quad V($ Pore $)=7,68 \cdot 10^{-13} \mathrm{~L}$, Volumen der überstehenden Lösung $V$ (Probe $)=3 \mathrm{~mL}$, Anzahl der bedeckten Poren $N($ Poren $)=50000$, Kaliumionenkonzentration in den Poren $\left[\mathrm{K}_{\mathrm{i}}^{+}\right]^{0}=0 \mathrm{mM}$, Kaliumionenkonzentration in der überstehenden Lösung $\left[\mathrm{K}_{\mathrm{a}}^{+}\right]^{0}=160 \mathrm{mM}$.

Die Verläufe beider Quotienten schneiden sich bei $N=2,05 \cdot 10^{9}$ transportierten Protonen. Dieser Wert stimmt mit dem experimentell ermittelten Gleichgewichtswert von $2,1 \cdot 10^{9}$ transportierten Teilchen exakt überein. Bis zu diesem Punkt steigt der Quotient beider Kaliumionenkonzentrationen linear an, während der Protonengradient aufgrund des vorliegenden Puffers konstant verläuft. Erst wenn die Grenze der Pufferkapazität innerhalb der Poren erreicht ist, nimmt der Quotient der Protonenkonzentrationen stark ab. Die Konzentrationen der jeweiligen Ionen im Gleichgewicht sind in Tabelle 5.4 aufgeführt.

Im Vergleich zu einem $\mathrm{pH}-$ Anstieg durch nigericininduzierten Protonentransport in membranüberspannte Poren hinein, werden bei vertauschtem Kaliumionengradienten Faktor 6 weniger Teilchen transportiert, bis sich ein Gleichgewicht einstellt (Tabelle 5.2). Die Konzentrationen beider Ionensorten in der überstehenden Pufferlösung bleiben dabei aufgrund des im Vergleich zu den Poren großen Volumens unverändert. 
Tabelle 5.4: Ausgangs- und Gleichgewichtskonzentrationen von Kaliumionen und Protonen in einer Vielzahl membranüberspannter Poren $(N($ Poren $)=50000)$ und in der überstehenden Pufferlösung. Theoretische Betrachtung eines nigericininduzierten Protonentransports aus den Poren hinaus. Weitere Bedingungen wie unter Abb. 5.10. Alle Konzentrationen sind in $\mathrm{mol} \cdot \mathrm{L}^{-1}$ angegeben.

\begin{tabular}{|l|c|c|}
\hline & Startwert & Gleichgewichtswert \\
\hline$\left[\mathrm{K}_{\mathrm{i}}^{+}\right]$ & 0,0 & $4,42 \cdot 10^{-3}$ \\
\hline$\left[\mathrm{K}_{\mathrm{a}}^{+}\right]$ & 0,160 & 0,160 \\
\hline$\left[\mathrm{H}_{\mathrm{i}}^{+}\right]\left(\mathrm{pH}_{\mathrm{i}}\right)$ & $5,01 \cdot 10^{-8}(7,3)$ & $1,38 \cdot 10^{-9}(8,9)$ \\
\hline$\left[\mathrm{H}_{\mathrm{a}}^{+}\right]\left(\mathrm{pH}_{\mathrm{a}}\right)$ & $5,01 \cdot 10^{-8}(7,3)$ & $5,01 \cdot 10^{-8}(7,3)$ \\
\hline$N$ & 0 & $2,05 \cdot 10^{9}$ \\
\hline
\end{tabular}

Wie für den Abfall des pH-Wertes in den Poren (Tabelle 5.3) wurde auch für den Anstieg des pH-Wertes eine schematische Übersicht zum Einfluss einzelner Faktoren auf die Lage des Gleichgewichts erstellt (Tabelle 5.5).

Tabelle 5.5: Schematische Übersicht zum Einfluss einzelner Startparameter auf die Anzahl von Protonen, welche bis zum Einstellen eines Gleichgewichts theoretisch aus einer Pore hinaus transportiert werden. Ausgangsbedingungen wie unter Abb. 5.10 aufgeführt. Der Index i steht für einen Wert im Poreninneren, a für einen Wert in der überstehenden Pufferlösung. Führt eine Erhöhung des Wertes eines Parameters zu einer Erhöhung der bis zum Gleichgewicht transportierten Protonen, ist dieser je nach Stärke des Effekts mit einem ,+++ oder (+) gekennzeichnet (absteigend von sehr stark bis schwach). Analog dazu ist ein antiproportionaler Effekt mit --, - oder (-) gekennzeichnet. Hat ein Parameter keinen erkennbaren Einfluss auf das Gleichgewicht, wird dieser mit 0 eingetragen. Dies gilt sowohl für lösungsmittelhaltige als auch lösungsmittelfreie porenüberspannende Membranen.

\begin{tabular}{|l|c|l|c|}
\hline Parameter & Effekt & Parameter & Effekt \\
\hline$\left[\mathrm{K}_{\mathrm{i}}^{+}\right]$ & - & $V_{\mathrm{i}}$ & + \\
\hline$\left[\mathrm{K}_{\mathrm{a}}^{+}\right]$ & + & $V_{\mathrm{a}}$ & 0 \\
\hline $\mathrm{pH}_{\mathrm{i}}$ & -- & $\mathrm{pK}_{\mathrm{S}}$ & + \\
\hline $\mathrm{pH}_{\mathrm{a}}$ & + & $c(\text { Puffer })_{\mathrm{i}}$ & + \\
\hline$N($ Poren $)$ & 0 & $c(\text { Puffer })_{\mathrm{a}}$ & 0 \\
\hline
\end{tabular}

Während bei einem Protonentransport in Poren hinein die Kaliumionenkonzentration der einflussreichste Faktor ist, zeigen Unterschiede im vorgelegten Kaliumionengradienten beim 
Transport von Protonen aus der Pore hinaus nur einen moderaten Einfluss auf das Gleichgewicht. Statt dessen bewirken bereits kleine Erhöhungen des $\mathrm{pH}$-Wertes und somit Verringerungen der Protonenkonzentration in den Poren vor Zugabe von Nigericin eine Verschiebung des Gleichgewichts hin zu weniger transportierten Teilchen. Aufgrund der um ein vielfaches geringeren Startkonzentration von Protonen in einer jeden Pore $\left(5 \cdot 10^{-8} \mathrm{M}\right)$ im Vergleich zu Kaliumionen für einen umgekehrten Gradienten $(0,160 \mathrm{M})$, müssen bis zum Erreichen des Gleichgewichts deutlich weniger Protonen aus den Poren hinaus und im Gegenzug Kaliumionen in die Poren hinein transportiert werden. Daher bleiben die entsprechenden Konzentrationen in der überstehenden Lösung weitgehend konstant im Verlauf des nigericininduzierten Antiports und eine Veränderung von Volumen und Pufferkonzentration der überstehenden Lösung hat keinen Einfluss auf das Gleichgewicht.

Zusammengefasst stimmen die experimentell bestimmten Änderungen der pH-Werte in den Poren und damit verbunden die Zahl der über eine porenüberspannende Membran transportierten Teilchen sehr gut mit den theoretisch errechneten Werten überein, unabhängig von der Richtung des vorgegebenen Kaliumionengradienten. Die gute Übereinstimmung belegt die hohe Impermeabilität porenüberspannender painted membranes nach Ausfrieren des Lösungsmittels, da bereits kleine Änderungen der Startkonzentrationen durch passiven Transport über die Membranen das Gleichgewicht und dadurch die detektierten pH-Wertänderungen stark verschieben würden. Geschwindigkeitsraten für den nigericininduzierten Antiport, bestimmt anhand der initialen Steigung der pH-Abfälle bzw. pH-Anstiege, liegen im Bereich literaturbekannter Werte für BLMs.

\section{Lösungsmittelfreie porenüberspannende Membranen}

Freistehende Membranen, welche mittels painting-Technik präprariert wurden, weisen hohe elektrische Widerstände auf und sind praktisch impermeabel für geladene Teilchen, wie Ionen. Lösungsmittelhaltige Membranen aus DPhPC, welche Poren mit Durchmessern im Mikrometerbereich überspannen, besitzen typischerweise Widerstände im Bereich von 20-30 G $\Omega$ und eignen sich dadurch für elektrische Messungen an Ionenkanälen auf Einzelkanalebene. ${ }^{[76]}$ Lösungsmittelfreie, durch Spreiten von GUVs präparierte Membranen wurden bisher selten für Einzekanalmessungen eingesetzt. Beispiele finden sich hauptsächlich für Poren mit Durchmessern $d<1 \mu \mathrm{m}$ und auf Substraten aus $\mathrm{Si}_{3} \mathrm{~N}_{4}{ }^{[57]}$ oder hydrophob funktionalisierten Substraten. ${ }^{[43]}$ Die dabei gemessenen Membranwiderstände lagen im Bereich von $\mathrm{M} \Omega$ bis $\mathrm{G} \Omega$ und somit leicht unterhalb der für lösungsmittelhaltige Membranen reproduzierbaren mehreren zehn G $\Omega$, was auf Defekte in der Membran zurückgeführt wird. Sich dadurch ergebende Durchlässigkeiten einer Membran für Ionen würden den nigericininduzierten Aufbau stabiler Ionengradienten verhindern. 
Abb. 4.27 zeigt, dass Kaliumionengradienten auch über lösungsmittelfreie porenüberspannende Membranen gebildet werden und durch einen nigericingetriebenen $\mathrm{K}^{+} / \mathrm{H}^{+}$-Antiport daraus ein stabiler Protonengradient aufgebaut werden konnte. Bei einem Transport von Protonen in die Poren hinein wurden Abfälle des pH-Wertes von 1,26 bis 1,94 Einheiten beobachtet. Bei einem Volumen der runden Poren, welche für die Bildung lösungsmittelfreier porenüberspannender Membranen verwendet wurden, von $2,1 \cdot 10^{-13} \mathrm{~L}$ und unter den für Abb. 4.27, A angegebenen experimentellen Bedingungen, entspricht der gemessene Abfall des $\mathrm{pH}$-Wertes einem Transport von $N=6,7 \cdot 10^{8}$ bzw. $N=7,3 \cdot 10^{8}$ Protonen in jede Pore hinein.

Theoretische Betrachtungen der bis zum Erreichen eines Gleichgewichts gemäß Gl. 5.2 nötigen Menge transportierter Protonen ergeben einen Wert von $N=2,06 \cdot 10^{10}$ für $N($ Pore $)=1$ bedeckte Poren. Dieser Wert ist Faktor 3,6 kleiner, als der für rechteckige Poren errechnete Gleichgewichtswert, was genau dem Volumenunterschied beider Poren entspricht. Unter Berücksichtigung einer realistischen Anzahl bedeckter Poren nach Spreiten von GUVs, wie $N($ Poren $)=500$, verschiebt sich das Gleichgewicht $\mathrm{zu} N=1,87 \cdot 10^{10}$ transportierten Protonen. Dieser Wert ist Faktor 26 größer, als der maximale experimentell ermittelte Wert. Am Verlauf der Konzentrationsquotienten von Kaliumionen und Protonen ändert sich qualitativ nichts im Vergleich zu den lösungsmittelhaltigen porenüberspannenden Membranen (Abb. 5.8). Durch das verringerte Porenvolumen ist die Kurve des Quotienten der Protonenkonzentrationen leicht nach links zu geringeren Mengen transportierter Teilchen verschoben, ebenso wie der Abfall des Quotienten der Kaliumionenkonzentrationen. Eine Zusammenfassung der errechneten Gleichgewichtskonzentrationen für $N($ Poren $)=500$ bedeckte Poren ist in Tabelle 5.6 aufgeführt.

Tabelle 5.6: Ausgangs- und Gleichgewichtskonzentrationen von Kaliumionen und Protonen in einer Vielzahl lösungsmittelfreier membranüberspannter Poren $(N($ Poren $)=500)$ und in der überstehenden Pufferlösung. Theoretische Betrachtung eines nigericininduzierten Protonentransports in die Poren hinein. Porenmaße: $d=5,5 \mu \mathrm{m}, h=9 \mu \mathrm{m}$. Alle Konzentrationen sind in $\mathrm{mol} \cdot \mathrm{L}^{-1}$ angegeben.

\begin{tabular}{|l|c|c|}
\hline & Startwert & Gleichgewichtswert \\
\hline$\left[\mathrm{K}_{\mathrm{i}}^{+}\right]$ & 0,160 & $1,45 \cdot 10^{-2}$ \\
\hline$\left[\mathrm{K}^{+}{ }_{\mathrm{a}}\right]$ & 0 & $5,19 \cdot 10^{-9}$ \\
\hline$\left[\mathrm{H}_{\mathrm{i}}^{+}\right]\left(\mathrm{pH}_{\mathrm{i}}\right)$ & $5,01 \cdot 10^{-8}(7,3)$ & $0,14(0,9)$ \\
\hline$\left[\mathrm{H}_{\mathrm{a}}^{+}\right]\left(\mathrm{pH}_{\mathrm{a}}\right)$ & $5,01 \cdot 10^{-8}(7,3)$ & $5,01 \cdot 10^{-8}(7,3)$ \\
\hline$N$ & 0 & $1,87 \cdot 10^{10}$ \\
\hline
\end{tabular}


Die Abweichung der theoretisch ermittelten Zahl transportierter Protonen bis zum Einstellen des Gleichgewichts von der experimentell bestimmten Zahl lässt sich vermutlich auf eine Veränderung der Zusammensetzung der Lösung im Poreninneren beim Spreiten von GUVs zurückführen. Wie in Abb. 5.4 dargestellt und dort diskutiert, wird beim Spreiten sucrosehaltiger GUVs ein Teil ihrer Füllung in den Poren unter den sich bildenden planaren und hemisphärischen Membranen eingeschlossen. Dadurch können puffernde Susbtanzen und Kaliumionen teilweise aus den Poren heraus gespült werden, wodurch sich die Zusammensetzung der eingeschlossenen Lösung verändert.

Auch bei lösungsmittelfreien porenüberspannenden Membranen ist es plausibel, eine Restkonzentration von Kaliumionen in der überstehenden Lösung im mikromolaren Bereich nach mehrfachem Austausch der Pufferlösung gegen kaliumionenfreie Lösung anzunehmen. Ausgehend von einer Verringerung der Kaliumionenkonzentration in den Poren von 0,16 auf 0,12 und einer Verringerung der Porentiefe um 1,25 $\mu \mathrm{m}$ (Mittelwert für planare lösungsmittelfreie Membranen, Tabelle 4.5), beträgt die Restkonzentration von Kaliumionen in der überstehenden Lösung rund $1 \mathrm{mM}$, um einen Gleichgewichtswert entsprechend dem experimentell ermittelten Wert zu erreichen. Dieser Wert ist höher, als ein zu erwartender Restwert nach mehrmaligem Spülen der Probe mit kaliumionenfreiem Puffer.

Grund für diese Diskrepanz kann eine geringere Impermeabilität lösungsmittelfreier Membranen für Ionen gegenüber lösungsmittelhaltigen sein. Aufgrund des fehlenden Lösungsmittelreservoirs in Form einer Plateau-Gibbs-Grenzschicht, bilden sich eher Defekte in lösungsmittelfreien Membranen, durch welche ein passiver Austausch von Ionen entlang eines Gradienten erfolgen kann. Dies würde mit den eingangs berichteten niedrigeren elektrischen Widerständen lösungsmittelfreier Membranen übereinstimmen.

Ein weiterer Faktor, welcher berücksichtigt werden muss, ist das Verhältnis von Protonen zu Kaliumionen, welche während eines Transportzyklus durch Nigericin in entgegengesetzte Richtung transportiert werden. Es ist bekannt, dass Nigericin in Konzentrationen ab etwa $10^{-5} \mathrm{M}$ vom bei Konzentrationen $<10^{-6} \mathrm{M}$ berichteten ladungsneutralen 1:1-Verhältnis transportierter $\mathrm{K}^{+}$und $\mathrm{H}^{+}$abweichen kann. ${ }^{[90,95]}$ Werden effektiv Ladungen beim Antiport transportiert, so bildet sich ein elektrisches Potential über der Membran, welches bei einer Berechnung eines Gleichgewichts zwischen beiden Ionenspezies neben den reinen Konzentrationen berücksichtigt werden muss. Im unter Abb. 4.27, A gezeigten Beispiel betrug die Nigericinkonzentration $16,7 \mu \mathrm{M}$ und war somit im Bereich des abweichenden Transportverhaltens von Nigericin. Die Konzentration von Kaliumionen lässt sich demnach nicht mehr mit derjenigen der Protonen in den Poren und in der überstehenden Lösung korrelieren und es kann anhand der gemessenen $\mathrm{pH}$-Wertänderung nicht mehr auf die Zahl transportierter Teilchen geschlossen werden. 
Bei einer Umkehr des vorgelegten Kaliumionengradienten konnten auch für lösungsmittelfreie porenüberspannende Membranen Anstiege des $\mathrm{pH}$-Wertes in den Poren detektiert werden (Abb. 4.27, B). Die pH-Änderungen lagen dabei im Bereich von $\Delta \mathrm{pH}=0,41$ bis 0,47 Einheiten. Das entspricht $N=2,8 \cdot 10^{8}$ bzw. $N=3,1 \cdot 10^{8}$ aus einer Pore heraus transportierten Protonen. Bei 500 membranbedeckten Poren ergibt sich ein theoretisch kalkulierter Wert von $N=5,7 \cdot 10^{8}$ transportierten Protonen. Weitere berechnete Gleichgewichtswerte sind in Tabelle 5.7 dargestellt.

Tabelle 5.7: Ausgangs- und Gleichgewichtskonzentrationen von Kaliumionen und Protonen in einer Vielzahl lösungsmittelfreier membranüberspannter Poren $(N($ Poren $)=500)$ und in der überstehenden Pufferlösung. Theoretische Betrachtung eines nigericininduzierten Protonentransports aus den Poren hinaus. Porenmaße: $d=5,5 \mu \mathrm{m}, h=9 \mu \mathrm{m}$. Alle Konzentrationen sind in $\mathrm{mol} \cdot \mathrm{L}^{-1}$ angegeben.

\begin{tabular}{|l|c|c|}
\hline & Startwert & Gleichgewichtswert \\
\hline$\left[\mathrm{K}_{\mathrm{i}}^{+}\right]$ & 0 & $4,42 \cdot 10^{-3}$ \\
\hline$\left[\mathrm{K}_{\mathrm{a}}^{+}\right]$ & 0,160 & 0,160 \\
\hline$\left[\mathrm{H}_{\mathrm{i}}^{+}\right]\left(\mathrm{pH}_{\mathrm{i}}\right)$ & $5,01 \cdot 10^{-8}(7,3)$ & $1,38 \cdot 10^{-9}(8,9)$ \\
\hline$\left[\mathrm{H}_{\mathrm{a}}^{+}\right]\left(\mathrm{pH}_{\mathrm{a}}\right)$ & $5,01 \cdot 10^{-8}(7,3)$ & $5,01 \cdot 10^{-8}(7,3)$ \\
\hline$N$ & 0 & $5,70 \cdot 10^{8}$ \\
\hline
\end{tabular}

Die errechneten Gleichgewichtswerte sind bis auf $N$ identisch mit den für einen nigericininduzierten Antiport von $\mathrm{K}^{+}$in die Poren hinein und $\mathrm{H}^{+}$aus den Poren hinaus ermittelten Werte bei einem Transport über lösungsmittelhaltige Membranen (Tabelle 5.4). Die verringerte Zahl transportierter Teilchen ist durch das kleinere Volumen der verwendeten Poren zu erklären. Die geringere Anzahl überspannter Poren hat, wie in Tabelle 5.5 dargestellt, keinen Einfluss. Der Verlauf der Ionenkonzentrationsquotienten in einer doppelt logarithmischen Auftragung ist qualitativ analog zu dem für lösungsmittelhaltige Membranen (Abb. 5.10). Aufgrund des geringeren Porenvolumens ist lediglich der Kaliumionengradient im Bereich $N<N_{\text {Gleichgewicht }} \mathrm{zu}$ niedrigeren Werten verschoben und der Protonengradient nimmt bereits bei geringeren Werten für $N$ stärker ab.

Der theoretisch und der experimentell ermittelte Wert für die Zahl transportierter Protonen stimmen gut überein. Eine Korrektur der Zusammensetzung des Poreninneren, bedingt durch einen Eintrag von Sucroselösung beim Spreiten von Vesikeln, ist in diesem Fall nicht notwendig, da in kaliumionenfreier Lösung gespreitet wurde. Diese Tatsache unterstützt die Argumentation über eine spreitbedingte Veränderung der Zusammensetzung der Lösung im Poreninneren bei umgekehrtem Kaliumionengradienten. Der einzige Parameter, welcher bei 
geringfügiger Anpassung eine genaue Übereinstimmung von experimentellem und theoretischem Wert bedingt, ist der $\mathrm{pK}_{\mathrm{S}}$-Wert des Puffers im Poreninneren. Alle weiteren Parameter ändern an der Lage des Gleichgewichts entweder nur wenig, oder beeinflussen den experimentell ermittelten Wert ebenfalls, so dass sich beide Werte nicht angleichen. Bei Annahme eines Wertes von $\mathrm{pK}_{\mathrm{S}}=6,95$ stimmen experimenteller Wert und theoretischer Wert genau überein. Eine Verschiebung des $\mathrm{pK}_{\mathrm{S}^{-}}$Wertes für einen nigericininduzierten $\mathrm{pH}$-Anstieg im Inneren lösungsmittelfreier membranüberspannter Poren ist durch die Anwesenheit von Calciumionen zu erklären. Avnir und Barenholz konnten zeigen, dass Ionen, insbesondere Calciumionen, den $\mathrm{pK}_{\mathrm{S}}-\mathrm{Wert}$ von Pyranin z. T. drastisch erniedrigen können (z. B. $\Delta \mathrm{pK}_{\mathrm{S}}=-0,727$ in $100 \mathrm{mM} \mathrm{CaCl} 2$ im Vergleich zu $20 \mathrm{mM}$ HEPES, pH 7,0). ${ }^{[229]}$ Für den korrigierten $\mathrm{pK}_{\mathrm{S}}-$ Wert ergibt sich ein korrigierter Anstieg von $\Delta \mathrm{pH}=1,71$ statt 0,47 Einheiten. Dieser Wert stimmt gut mit den beobachteten $\mathrm{pH}$-Wertänderungen für lösungsmittelhaltige Membranen und für entgegengesetzte Ionengradienten überein. Eine Übersicht der ermittelten Gleichgewichtswerte für einen veränderten $\mathrm{pK}_{\mathrm{S}}$-Wert im Inneren der Poren ist in Tabelle 5.8 aufgeführt.

Tabelle 5.8: Ausgangs- und Gleichgewichtskonzentrationen von Kaliumionen und Protonen in einer Vielzahl lösungsmittelfreier membranüberspannter Poren $(N($ Poren $)=500)$ und in der überstehenden Pufferlösung. Theoretische Betrachtung eines nigericininduzierten Protonentransports aus den Poren hinaus. Porenmaße: $d=5,5 \mu \mathrm{m}, h=9 \mu \mathrm{m}$. Der $\mathrm{pK}_{\mathrm{S}}$-Wert im Poreninneren wurde mit 6,95 statt 7,20 einberechnet. Alle Konzentrationen sind in $\mathrm{mol} \cdot \mathrm{L}^{-1}$ angegeben.

\begin{tabular}{|l|c|c|}
\hline & Startwert & Gleichgewichtswert \\
\hline$\left[\mathrm{K}_{\mathrm{i}}^{+}\right]$ & 0 & $3,14 \cdot 10^{-3}$ \\
\hline$\left[\mathrm{K}_{\mathrm{a}}^{+}\right]$ & 0,160 & 0,160 \\
\hline$\left[\mathrm{H}_{\mathrm{i}}^{+}\right]\left(\mathrm{pH}_{\mathrm{i}}\right)$ & $5,01 \cdot 10^{-8}(7,3)$ & $9,82 \cdot 10^{-10}(9,0)$ \\
\hline$\left[\mathrm{H}_{\mathrm{a}}^{+}\right]\left(\mathrm{pH}_{\mathrm{a}}\right)$ & $5,01 \cdot 10^{-8}(7,3)$ & $5,01 \cdot 10^{-8}(7,3)$ \\
\hline$N$ & 0 & $4,04 \cdot 10^{8}$ \\
\hline
\end{tabular}

Die gute Übereinstimmung experimenteller und theoretischer Werte für einen nigericininduzierten Transport von Protonen aus den Poren hinaus weicht vom weniger idealen Verhalten bei einem Transport von Protonen in die Poren hinein ab. In beiden Fällen wurden Nigericinkonzentrationen bis $16,7 \mu \mathrm{M}$ eingesetzt und die Membranen wurden lösungsmittelfrei präpariert. Eine Bildung von Defekten in den Membranen und damit einhergehend ein passiver Abbau der Ionengradienten ist somit unwahrscheinlich. Ein verändertes stöchiometrisches Verhältnis des $\mathrm{K}^{+} / \mathrm{H}^{+}$-Antiports aufgrund der hohen Nigericinkonzentrationen ist nur eine plausible Erklärung, wenn die Konzentration bei den Experimenten zum 
$\mathrm{pH}-$ Anstieg in den Poren bei geringeren Nigericinkonzentrationen, als 16,7 $\mu \mathrm{M}$ durchgeführt wurden, da die dort erzielten Ergebnisse sonst ebenfalls von den theoretisch bestimmten Werten abweichen müssten.

Kaliumionenfrei gefüllte Poren wurde durch Spreiten von GUVs in einer Pufferlösung mit 107 mM Calciumionen mit Membranen überspannt. In Gegenwart von Calciumionen bilden sich mehr porenüberspannende Membranen, als in Gegenwart von Kaliumionen (Kapitel 4.1.2, Spreiten auf hydrophil funktionalisierten Substraten). Dadurch vergrößert sich die Gesamtmembranfläche auf dem Substrat. Nigericin lagert sich aufgrund seines hydrophoben Charakters bevorzugt in die Membran ein. Bei vergrößerter Membranfläche nimmt bei Zugabe gleicher Mengen Nigericins die effektive Nigericinkonzentration innerhalb der Membran ab. Durch die erhöhte Membranfläche der calciumionenhaltigen Probe im Vergleich zur kaliumionenhaltigen Probe, kann die Konzentration von Nigericin in der Membran dadurch unterhalb eines kritischen Wertes absinken und so ein ladungsneutraler Transport statt finden. Ein Unterschied in der effektiven Nigericinkonzentration erklärt somit den Unterschied im Verhalten entgegengerichteter Ionengradienten. Die Tatsache, dass bei lösungsmittelhaltigen porenüberspannenden Membranen eine Erhöhung der Nigericinkonzentration keinen Einfluss zeigte, belegt diese Theorie, da bei per painting-Technik präparierten Membranen ein sehr hoher Belegungsgrad erzielt wurde.

Zusammengefasst konnte gezeigt werden, dass lösungsmittelfreie porenüberspannende Membranen trotz des Fehlens einer isolierenden Plateau-Gibbs-Grenzschicht geeignet sind, um nigericininduziert elektrochemische Gradienten aufzubauen. Die dabei erzielten $\mathrm{pH}$-Wertänderungen liegen im Bereich derjenigen, welche für lösungsmittelhaltige Membranen bestimmt wurden und stimmen mit theoretisch bestimmten Werten überein. Bei Nigericinkonzentrationen größer $10^{-5} \mathrm{M}$ und einer geringen Membranfläche (vereinzelte patches, Annahme von 500 membranüberspannten Poren auf 126000 Poren insgesamt) auf dem Substrat kann es zu einer literaturbekannten Abweichung des ladungsneutralen $\mathrm{K}^{+} / \mathrm{H}^{+}$-Antiports kommen. In Anwesenheit von Calciumionen muss eine mögliche Erniedrigung des $\mathrm{pK}_{\mathrm{S}}$-Wertes von Pyranin und weiteren puffernden Substanzen bei einer Bestimmung der $\mathrm{pH}-$ Wertänderung und der entsprechenden Berechnung eines theoretischen Wertes berücksichtigt werden. Die Transportgeschwindigkeit, welche sich als von der Menge eingesetzten Nigericins unabhängig gezeigt hat, betrug für lösungsmittelfreie wie lösungsmittelhaltige porenüberspannende Membranen unabhängig von der Richtung des Antiports $10^{14} \mathrm{H}^{+} \cdot \mathrm{cm}^{-2} \cdot \mathrm{s}^{-1}$.

\subsection{Rekonstitution von Bacteriorhodopsin in artifiziellen Membranen}

In verschiedenen artifiziellen Membransystemen, wie sub-mikrometergroßen und mikrometergroßen Vesikeln und porenüberspannenden Membranen, konnten in situ durch einen 
$\mathrm{K}^{+} / \mathrm{H}^{+}$-Antiport Protonengradienten aus Kaliumionengradienten aufgebaut werden. Neben der nigericininduzierten Umwandlung eines Kaliumionen- in einen Protonengradienten, sollte weiterhin der lichtgetriebene Aufbau eines Protonengradienten durch das membranständige Protein bR untersucht werden. Hierzu wurden verschiedene Methoden zur Rekonstitution von $\mathrm{bR}$ in Vesikel und porenüberspannende Membranen getestet. In porenüberspannenden Membranen rekonstituiertes bR wurde mittels FRAP-Experimenten auf seine Mobilität untersucht.

\subsubsection{Isolierung von bR und Rekonstitution in Vesikeln}

Einfluss des Kultivierungsmediums auf die Zusammensetzung von PM-Fragmenten

Für die Isolierung von bR in Form von PM-Fragmenten wurden Halobakterien in zwei unterschiedlichen Medien kultiviert. Je nach Zusammensetzung des Mediums unterschieden sich UV-Vis-Spektrum (Abb. 4.28) und Photostromsignal (Abb. 4.30) der isolierten PM-Fragmente. Das Differenzspektrum von PM-Fragmenten aus beiden Medien wies auf ein Vorhandensein der carotinoiden Pigmente Bacterioruberin und $\beta$-Carotin in aus Medium 97 isolierten Fragmenten hin. Diese Pigmente beeinflussen die Membranelastizität und bieten Schutz gegenüber UV Licht. ${ }^{[199]}$ Dummer et al. fanden einen Zusammenhang zwischen der Menge von Bacterioopsin, dem Apoprotein des bR, an welches noch kein Retinal als Cofaktor gebunden ist und der Menge an Bacterioruberin in Purpurmembranen aus Halobacterium salinarum. So konnte durch Entfernen des Genes bop, welches Bacterioopsin kodiert, eine Akkumulation von Bacterioruberin beobachtet werden. Licht und Sauerstoffkonzentration wurden ebenfalls als Faktoren zur Regulation der Menge gebildeter Pigmente identifiziert. $^{[105,197]}$

Carotinoide werden immer in Form von „roten“ und „braunen“ Membranfragmenten bei der Isolierung von PM-Fragmenten beobachtet. Jedoch lassen sich diese durch eine Dichtegradientenzentrifugation in der Regel sauber voneinander abtrennen. ${ }^{[105]}$ Dass bei Verwendung von Medium 97 unter den im Rahmen dieser Arbeit beschriebenen Kultivierungs- und Isolationsbedingungen (Kapitel 3.2.1) keine vollständige Trennung von Carotinoiden und PM-Fragmenten möglich war, kann neben einer stark erhöhten Carotinoidkonzentration an einer stärkeren Bindung der Carotinoide an bR liegen. Solche Phänomene wurden bisher für keines der verwendeten Medien beschrieben. Einziger Unterschied zwischen beiden Medien sind der pH-Wert (7,0 vs. 7,4) und die Zusetzung von Casaminosäuren, Eisen- und Manganionen im Medium 97. Eine abschließende Erklärung kann an dieser Stelle nicht gegeben werden. Es sei jedoch darauf hingewiesen, dass Eisen und Mangan redoxaktive Metalle sind und besonders Eisenionen in Enzymen an Radikalreaktionen beteiligt sind. ${ }^{[248]}$ Hohe Konzentrationen an Eisen im Kulturmedium könnten demnach die Bildung von reaktiven 
Radikalen bevorzugen. Eine erhöhte Bildung von Carotinoiden in den Bakterien zum Schutz vor solchen Radikalen wäre eine Erklärung für deren Vorkommen in PM-Fragmenten. Schäden am bR durch Radikalreaktionen würden die niedrigeren Photostromamplituden der aus Medium 97 isolierten PM-Fragmente im Vergleich $\mathrm{zu}$ den aus eisenfreiem Normalmedium isolierten Fragmenten erklären.

\section{Qualitative Bestimmung der Pumpaktivität von bR mittels Photostrom}

Um die Protonenpumpaktivität von $\mathrm{bR} \mathrm{zu}$ untersuchen, wurden Photostrommessungen durchgeführt (Kapitel 3.3.1). Die Aktivität von bR wurde in isolierten PM-Fragmenten (Abb. 4.30), wie auch in sub-mikrometergroßen (Abb. 4.32) und mikrometergroßen unilamellaren Vesikeln (Abb. 4.36) getestet. Bei Belichtung der bR-haltigen Proben wurde jeweils ein Photostromsignal in Form eines Einschaltstroms und eines Ausschaltstroms bei Start und Ende der Belichtung beobachtet. Bei Zugabe des Entkopplers CCCP wurde zusätzlich jeweils ein stationärer Strom während der Belichtung beobachtet. Vergleichsproben, die kein bR enthielten zeigten bei Belichtung keine Photostromantwort. Qualitativ wurde so die Aktivität von bR in Form eines lichtinduzierten Protonentransports in PM-Fragmenten, Proteoliposomen und Proteo-GUVs nachgewiesen.

Die Anbindung von PM-Fragmenten und Proteoliposomen erfolgt über eine elektrostatische Wechselwirkung der negativ geladenen Lipide, wie sie in PM-Fragmenten vorkommen und dort bis zu $80 \%$ der Lipide ausmachen können ${ }^{[143]}$ und dem positiv geladenen Octadecylamin (ODA), welches zu 0,05 bis $0,1 \%(\mathrm{w} / \mathrm{v})$ in $n$-Dekan zur Bildung von painted membranes eingesetzt wurde. Eine schematische Darstellung der Anbindung ist Abb. 5.11 in aufgeführt.
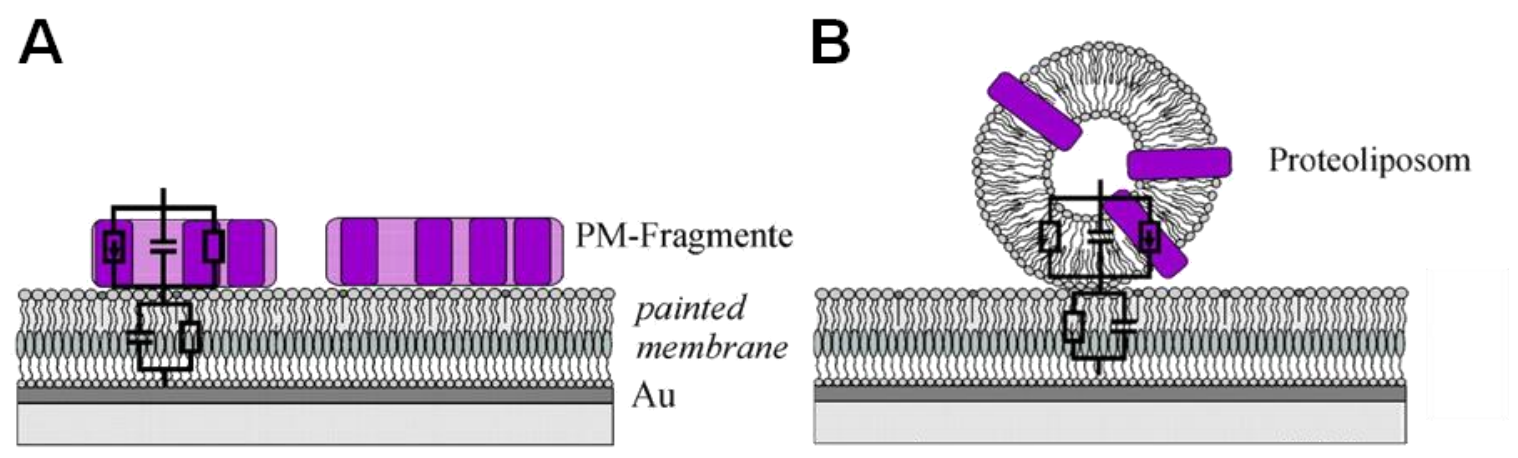

Abb. 5.11: Schematische Darstellung der Adsorption von PM-Fragmenten (A) und bR-haltiger Vesikel (B) an mit ODA dotierte painted membranes. ${ }^{[147]}$

Von einer Quantifizierung der Photostromsignale wurde abgesehen. Unterschiede in den Kapazitäten der unterstützenden painted membranes, an welche die PM-Fragmente bzw. bR-haltigen Vesikel elektrostatisch gebunden wurden, weisen auf mögliche Defekte in den Membranen hin, welche das Photostromsignal beeinflussen können. Ein theoretisches Modell zum lichtinduzierten Protonentransport von bR und die daraus bestimmten Verläufe des 
Photostromsignals wurden für verschiedene Membransysteme bereits beschrieben. Die Adsorption von PM-Fragmenten an planare, lösungsmittelhaltige Membranen wurde von Schmitt, ${ }^{[147]}$ Bamberg et al., ${ }^{[106]}$, Seifert et al. ${ }^{[249]}$ und Seta et al. ${ }^{[250]}$ ausführlich beschrieben. In allen drei Berichten wurden Photostromverläufe gezeigt, die den im Rahmen dieser Arbeit gemessenen Verläufen für PM-Fragmente qualitativ gleichen.

Seta et al. gehen weiterhin auf unterschiedliche Orientierungen der PM-Fragmente nach ihrer Adsorption ein. Da die negativ geladenen Lipide ungleichmäßig zwischen beiden Monolagen in den PM-Fragmenten verteilt sind, weisen die Monolagen unterschiedliche Ladungsdichten auf. Dadurch kann es zu einer bevorzugten Adsorption der Fragmente mit der insgesamt höher negativ geladenen Monolage an die positiv geladene Oberfläche der painted membrane kommen. Weil bR-Moleküle innerhalb eines PM-Fragments dieselbe Orientierung aufweisen, ergibt sich so eine Vorzugsorientierung der adsorbierten bR-Moleküle ( $N$-Terminus der Elektrode zugewandt) und Protonen werden bevorzugt in Richtung der membranbedeckten Elektrode transportiert.

Die Bindung von bR-haltigen Vesikeln an painted membranes wird bei Schmitt, ${ }^{[147]}$ Herrmann et al. ${ }^{[107]}$ und Mirsky et al. ${ }^{[109]}$ diskutiert. Auch hier gleichen die gemessenen und theoretisch beschriebenen Verläufe der Photoströme qualitativ den im Rahmen dieser Arbeit ermittelten. Die Argumentation von Seta et al., dass eine unterschiedliche Ladungsverteilung zwischen beiden Monolagen innerhalb der PM-Fragmente zu einer Vorzugsorientierung der adsorbierten Fragmente führt, lässt sich auf die Anbindung bR-haltiger Vesikel übertragen. BR-Moleküle können so orientiert in der Vesikelmembran vorliegen, dass der C-Terminus ins Vesikelinnere gerichtet ist (Protonentransport aus dem Vesikel heraus), oder anders herum mit dem C-Terminus nach aussen in die umgebende Pufferlösung (Protonentransport in den Vesikel hinein).

Negativ geladene Lipide aus den PM-Fragmenten sind stark an die bR-Moleküle gebunden, sodass sich selbst bei Behandlung von PM-Fragmenten mit Detergens nur rund $75 \%$ der Lipide entfernen lassen. ${ }^{[143]}$ Unter der Annahme, dass negativ geladene Lipide nach der Rekonstitution von bR ungleich verteilt sind zwischen beiden Monolagen der Proteoliposomen kommt es zu einer Akkumulation negativ geladener Lipide und von einseitig orientiertem bR an der Kontaktfläche zwischen Vesikeln und positiv geladener painted membrane. Selbst wenn auf den gesamten Vesikel gesehen beide möglichen Orientierungen des bR gleichhäufig vorliegen, kann es so an der Grenzschicht zwischen Vesikelmembran und painted membrane $\mathrm{zu}$ einem lichtinduzierten Netto-Protonentransport kommen und so ein Photostromsignal detektiert werden. 


\section{Aktivität von bR in Proteoliposomen}

Die Aktivität von in Vesikeln rekonstituiertem bR wurde neben Photostrommessungen anhand von $\mathrm{pH}-$ Wertmessungen mit Hilfe einer $\mathrm{pH}$-Elektrode untersucht (Abb. 4.33) und anhand von Intensitätsänderungen der Pyraninfluoreszenz in Proteo-GUVs (Abb. 4.40). Obwohl Photostrommessungen die Aktivität des rekonstituierten bR in Proteoliposomen belegten, ließ sich kein lichtinduzierter Protonentransport mit Hilfe einer $\mathrm{pH}$-Elektrode oder anhand der Pyraninfluoreszenz im Vesikelinneren nachweisen.

Grund hierfür kann eine fehlende Vorzugsorientierung des bR in den Vesikeln sein. BR kann mit dem C-Terminus ins Vesikelinnere gerichtet rekonstituiert werden, oder mit dem C-Terminus nach aussen zur umgebenden Pufferlösung. In beiden Fällen unterscheidet sich die Richtung des Protonentransports. Wie oben beschrieben, können selbst bei einer 1:1-Verteilung beider Orientierungen Photostromsignale durch an eine planare painted membrane adsorbierte bR-haltige Vesikel detektiert werden. Der $\mathrm{pH}-$ Wert der umgebenden Lösung ändert sich nur, wenn eine ungleiche Anzahl Protonen durch bR in die Vesikel hinein und aus ihnen heraus transportiert werden. Findet bei Belichtung kein Netto-Transport von Protonen statt, bleibt der pH-Wert der Umgebungslösung konstant. Ein solcher konstanter Verlauf des extravesikulären pH-Wertes wurde bei Belichtung von bR-haltigen Liposomen in einer Küvette beobachtet (Abb. 4.33).

Eine unzureichend hohe Vorzugsorientierung von bR in Modellmembranen oder anderen Systemen wird als Hauptgrund genannt dafür, dass die kurzzeitig nach seiner Entdeckung beschriebenen Anwendungen wie z.B. die Bildung von Adenosintriphosphat (ATP) aus Sonnenlicht noch immer nicht technisch umgesetzt werden konnten. ${ }^{[251]}$ Bemühungen, eine Vorzugsorientierung von bR auf Oberflächen oder in Lipidmembranen zu erreichen, resultierten bisher in einer Chemisorption von bR über eine durch gezielte Mutation eingeführte Cystein-Seitenkette an Goldoberflächen, ${ }^{[133]}$ oder einer elektrostatischen Bindung von bR auf negativ geladenen Oberflächen durch Einführung mehrerer positiver Ladungen am C-Terminus des Proteins durch Mutation. ${ }^{[251]}$ Weiterhin wäre eine Modifikation von bR in der Form möglich, dass entweder an $\mathrm{N}$ - oder C-Terminus selektiv Cystein eingefügt wird und daran über Chemisorption ein Gold-Nanopartikel angebunden wird. Durch den großen Partikel wird die Struktur des bR anisotroper gestaltet und eine selektive Insertion in submikrometergroße Vesikel mit dem Terminus, an welchem der Nanopartikel gebunden ist nach aussen wäre bevorzugt. Dass große aus der Membran hervortretende Teile eines Proteins eine selektive Orientierung des Proteins bei einer Rekonstitution in Vesikel bevorzugen können, zeigen Experimente an $\mathrm{F}_{\mathrm{O}} \mathrm{F}_{1}$ ATP Synthasen. Diese Proteine bestehen aus einem transmembranständigen $\mathrm{F}_{\mathrm{O}}$-Teil und einem 300 bis $400 \mathrm{kDa}$ großen, aus der Membran herausragenden $\mathrm{F}_{1}$-Teil. Richard et al. konnten in mittels reverse phase Methode präparierten Vesikeln detergensvermittelt eine $\mathrm{CF}_{\mathrm{O}} \mathrm{F}_{1}$ ATP Synthase mit praktisch unidirektionaler Orientierung rekonstituieren $\left(\mathrm{F}_{1}\right.$-Teil nach aussen gerichtet $) .{ }^{[252]}$ 
Anhand des in Abb. 4.33 gezeigten Beispiels soll theoretisch abgeschätzt werden, welche Änderungen des pH-Wertes in der Umgebungslösung zu erwarten wären bzw. welchen Einfluss die Orientierung der bR-Moleküle darauf hat. Unter Annahme eines Volumens der Lösung in einer Küvette von $5 \mathrm{~mL}$ und einem Start-pH-Wert von 6,2 müssten für eine $\mathrm{pH}$-Wertänderung von $\Delta \mathrm{pH}=0,1$ Einheiten auf $\mathrm{pH} 6,3$ in der Umgebungslösung $3,9 \cdot 10^{14}$ Protonen aus der umgebenden Lösung in die Vesikel hineingepumpt werden. Bei Veranschlagung von Flächen innerhalb einer Lipiddoppelschicht von 0,64 $\mathrm{nm}^{2}$ für ein Lipid und $8,75 \mathrm{~nm}^{2}$ für ein bR-Molekül enthält ein unilamellarer Vesikel bei einem Anteil von $0,28 \mathrm{~mol} \% \mathrm{bR}$ und einem nominellen Durchmesser von $200 \mathrm{~nm}$ (entspricht Bedingungen in Abb. 4.33) etwa 3090 Moleküle bR. Ausgehend von einem Lipidfilm (0,2 mg) erhält man auf $5 \mathrm{~mL}$ Küvettenvolumen maximal $2 \cdot 10^{11}$ Vesikel mit $200 \mathrm{~nm}$ Durchmesser. Pro Vesikel müssten demnach 1900 Protonen aus der umgebenden Lösung aufgenommen werden, um dort den pH-Wert um 0,1 Einheiten zu erhöhen. Bamberg et al. geben in ihren Berechnungen eine Rate von 100 Photozyklen pro bR und Sekunde an, was $100 \mathrm{H}^{+} \cdot \mathrm{s}^{-1}$ entspricht. $^{[106]}$ In 10 Minuten Belichtungszeit (analog zu Abb. 4.33) kann ein einziges bR-Molekül somit 60000 Protonen über eine Membran transportieren. Zusammengefasst würde es demnach genügen, wenn nur $3 \%$ aller Vesikel einen Überschuss von einem einzigen bR-Molekül mit einer Orientierung, welche einen Protonentransport aus der umgebenden Lösung ins Vesikelinnere hinein erlaubt, besitzen, um in einem Belichtungszeitraum von $10 \mathrm{~min}$ den $\mathrm{pH}$-Wert der umgebenden Lösung um 0,1 Einheiten auf pH 6,3 zu erhöhen. Diese Verteilung entspräche einem Verhältnis beider möglichen bR-Orientierungen innerhalb eines Vesikels von 49,97:50,03. Im Gegenzug würde sich der pH-Wert bei einer Aufnahme von 1900 Protonen in einem Vesikel allerdings von 6,2 auf 3,1 um über 3 Einheiten verringern. Bei einem so geringen $\mathrm{pH}$-Wert im Vesikelinneren können die Kopfgruppen von Lipiden protoniert werden ( $\mathrm{pK}_{\mathrm{S}}$ Carboxygruppe ca. 3-4), was die Vesikel instabil und für Ionen permeabel machen kann. PH-Wertänderungen von 3 Einheiten wurden für bR-induzierte Protonengradienten bei Rekonstitution in sub-mikrometergroße Vesikel bisher als maximal erreichte Werte beschrieben. ${ }^{[87]}$ Es ist daher denkbar, dass eine zu geringe Kapazität der Vesikel zur Protonenaufnahme, bedingt durch ihr kleines Volumen $\left(10^{-18} \mathrm{~L}\right)$, ein limitierender Faktor für die Änderung des pH-Wertes der umgebenden Lösung darstellt.

Weitere mögliche Ursachen für den beobachteten konstanten Verlauf des pH-Wertes der Lösung bei Belichtung können anders hervorgerufene Änderungen der Permeabilität der Vesikelmembranen sein. Preobraschenski beschreibt die Rekonstitution einer $\mathrm{F}_{\mathrm{O}} \mathrm{F}_{1}$ ATP Synthase in sub-mikrometergroße unilamellare Vesikel und den Aufbau eines Protonengradienten unter Verbrauch von ATP. ${ }^{[253]}$ Eine Zugabe von Valinomycin in mikromolaren Konzentrationen verhinderte den Aufbau eines Protonengradienten, was mit einer Erhöhung der Permeabilität der Membranen durch Valinomycin erklärt wurde. Durch die Zugabe von Valinomycin in mikromolaren Konzentrationen, wie sie im Rahmen dieser Arbeit eingesetzt 
wurden, könnten die Vesikel somit in einem Maße für Protonen durchlässig gemacht worden sein, dass trotz eines bR-induzierten Netto-Protonenpumpens aus den Vesikeln hinaus keine Änderung des pH-Wertes der umgebenden Lösung detektiert werden konnte.

In Abwesenheit von Valinomycin baut sich ein elektrisches Potential über der Vesikelmembran auf durch einen Netto-Ladungstransport bei einer Verschiebung von Protonen. Mit zunehmendem Potential verringert sich die Geschwindigkeit des Protonentransports durch bR und es bilden sich kleinere pH-Gradienten, als in Gegenwart von Valinomycin. Rigaud et al. zeigten solche Unterschiede durch Messungen des pH-Wertes einer Suspension von bR-haltigen Vesikeln mit einer pH-Elektrode bzw. durch Messungen der Fluoreszenzintensität des pH-sensitiven Farbstoffs 9-Aminoacridin. ${ }^{[87]}$ Ohne Valinomycin unterschieden sich die pH-Verläufe nicht von Verläufen in Gegenwart von Entkopplern wie FCCP, was bedeutet, dass sich kein detektierbarer $\mathrm{pH}$-Gradient aufbaut. Mit Valinomycin $(1 \mu \mathrm{M})$ wurden von Rigaud et al. bei Belichtung $\mathrm{pH}-$ Wertänderungen von bis $\mathrm{zu} \Delta \mathrm{pH}=3$ Einheiten gemessen (Vesikel Phosphatidylcholin/Phosphatidsäure 9:1, zweifach extrudiert bei nominellen Porendurchmessern von 400 und $200 \mathrm{~nm}$, Lipid/bR-Verhältnis von 80:1 (w/w), finale bR-Konzentration bei der Messung $50 \mu \mathrm{g} \cdot \mathrm{mL}^{-1}$ in $\left.150 \mathrm{mM} \mathrm{KCl}\right) .{ }^{[87]}$

Für Protokolle zur Bildung sub-mikrometergroßer bR-haltiger Vesikel, wie sie in dieser Arbeit ebenfalls verwendet wurden, werden Verhältnisse der bR-Orientierungen von 95:5 (Björklund, Kapitel 3.2.4, 2)), ${ }^{[110]}$ 75:25 (Girard, Kapitel 3.2.4, 1)) ${ }^{[117]}$ und 85:15 (reverse phase Methode, Kapitel 3.2.4) ${ }^{[15]}$ in den Vesikeln angegeben. Dabei wird eine Anordnung begünstigt, in welcher bR Protonen in die Vesikel hinein transportiert. Dabei konnten maximale $\mathrm{pH}-$ Wertänderungen bei Belichtung von $\Delta \mathrm{pH}=2$ Einheiten beobachtet werden. Björklund et al. beobachteten pH-Wertänderungen von 2 Einheiten in Abwesenheit von Valinomycin oder anderen Substanzen, die ein elektrisches Potential abbauen könnten, was den Ergebnissen von Rigaud widerspricht.

Die Literatur liefert somit widersprüchliche Ergebnisse in Bezug auf die bR-induzierte Bildung von Protonengradienten in unilamellaren Vesikeln und den Einfluss von Valinomycin. Warum im Rahmen dieser Arbeit Vesikel, die nach den oben erwähnten Protokollen präpariert wurden kein Netto-Protonentransport zeigten, kann nicht abschließend geklärt werden. Ein Faktor, welcher den Netto-Protonentransport beeinflussen könnte, ist die Größe der PM-Fragmente, welche für die Rekonstitution verwendet wurden. Innerhalb eines solchen Fragments besitzen alle enthaltenen bR-Moleküle dieselbe Orientierung. Werden bei einer Rekonstitution in Liposomen große PM-Fragmente eingesetzt, von denen nur eine kleine Zahl jeweils in einen Vesikel eingelagert wird, erhöht sich die Wahrscheinlichkeit einer ungleichen Verteilung beider Orientierungen des bR im Vesikel. Werden statt dessen kleine PM-Fragmente verwendet mit jeweils nur wenigen gleichorientierten bR-Molekülen, so werden in einen Vesikel mehr Fragmente eingelagert und die Wahrscheinlichkeit eine Vorzugsorientierung des bR in den Vesikeln zu erhalten sinkt. 
Die Größe der PM-Fragmente kann zwischen Durchmessern von wenigen hundert Nanometern bis zu $5 \mu \mathrm{m}$ variieren und übersteigt somit den Durchmesser der Vesikel, in welche bR rekonstituiert wurde. ${ }^{[251,254,255]}$ Durch Behandlung mit Diethylether (reverse phase Methode), Detergentien oder Ultraschall im Rahmen der Rekonstituion von bR in Vesikel, wird die zweidimensionale kristallartige Struktur des bR in Form der PM-Fragmente aufgelöst, sodass ein Einfluss der Größe der PM-Fragmente auf die Orientierung des bR in den gebildeten Vesikeln ausgeschlossen werden kann.

Zum Vergleich mit den errechneten Werten für sub-mikrometergroße Vesikel soll berechnet werden, welches Verhältnis beider bR-Orientierungen in einem GUV einen Abfall des pH-Wertes um 0,1 Einheiten verursachen würde. Für einen GUV mit einem Durchmesser von $10 \mu \mathrm{m}$, gefüllt mit einer Lösung von $320 \mathrm{mM}$ Sucrose, $10 \mathrm{mM}$ MOPS und $1 \mathrm{mM}$ Pyranin $\left(\mathrm{pK}_{\mathrm{S}}\right.$ je 7,2), $\mathrm{pH} 7,3$ (Bedingungen wie unter Abb. 4.40) müssten unter Verwendung der Henderson-Hasselbalch-Gleichung $2 \cdot 10^{8}$ Protonen in den GUV hinein transportiert werden. Bei einem Belichtungszeitraum von $60 \mathrm{~s}$ und einer Transportrate von $100 \mathrm{H}^{+} \cdot \mathrm{bR}^{-1} \cdot \mathrm{s}^{-1}$ müsste ein Überschuss von 3,3 $10^{4}$ bR-Moleküle einen Transport von Protonen in den Innenraum des GUV hinein durchführen. Für einen bR-Anteil von 0,3 mol\% errechnen sich 7,7·10 ${ }^{6}$ Moleküle bR pro GUV mit $10 \mu \mathrm{m}$ Durchmesser. 3,3·10 ${ }^{4}$ Moleküle ergeben davon einen Anteil von $0,43 \%$. Ein Überschuss von $0,43 \%$ aller im GUV rekonstituierten bR-Moleküle genügt demnach, um innerhalb von $60 \mathrm{~s}$ den $\mathrm{pH}$-Wert im GUV um 0,1 Einheit zu senken. Das entspricht einer Verteilung beider bR-Orientierungen von 50,2:49,8. Wie schon in der Berechnung für sub-mikrometergroße bR-haltige Vesikel gezeigt, müsste auch bei geringen Abweichungen von einer 50:50 Verteilung beider möglicher bR-Orientierungen ein Abfall des $\mathrm{pH}-$ Wertes innerhalb von GUVs binnen $60 \mathrm{~s}$ Belichtungszeitraum stattfinden. Ein solcher Abfall des $\mathrm{pH}$-Wertes in Form einer Verringerung der Fluoreszenzintensität von Pyranin konnte experimentell nicht nachgewiesen werden.

Eine Erklärung dafür, dass sich auch in bR-haltigen GUVs kein lichtinduzierter Protonengradient aufbauen ließ, kann eine erhöhte Durchlässigkeit der Membran für Protonen sein. Für die Untersuchung einer bR-induzierten $\mathrm{pH}$-Wertänderung in pyraningefüllten GUVs wurden diese über eine Biotin-Avidin-Wechselwirkung auf einem Siliziumsubstrat angebunden (Kapitel 3.3.3). Eine Dotierung der GUVs mit dem biotinfunktionalisierten Lipid Bio-Cap-PE könnte die Impermeabilität der Vesikelmembran beeinflussen. Weiterhin kann es durch die starke Wechselwirkung zwischen Avidin und Biotin bei Anbindung der Vesikel auf avidinfunktionalisierten Oberflächen zu einer Akkumulation von Bio-Cap-PE an der Kontaktfläche zwischen GUV und Oberfläche kommen und dadurch zu einer partiellen Entmischung der unterschiedlichen Lipide in der GUV-Membran. An den Grenzflächen zwischen Bio-CapPE-reichen Regionen und POPC-reichen Regionen kann es aufgrund geringer Unterschiede in der Länge der Seitenketten beider Lipide (Bio-Cap-PE: zweimal $\mathrm{C}_{16}$, POPC: $\mathrm{C}_{16}$ und einfach ungesättigt $\mathrm{C}_{18}$ ) zu einem hydrophobic mismatch kommen. ${ }^{[256]}$ Eine erhöhte Durchlässigkeit 
an der Grenzschicht zweier Bereiche mit unterschiedlichen hydrophoben Längen wäre plausibel.

Carnarius beobachtete teilweise ein Austreten von Pyranin aus mit Bio-Cap-PE dotierten GUVs nach Anbindung auf avidinfunktionalisierten Oberflächen (persönliche Mitteilung). Pyranin liegt in wässriger Lösung bei $\mathrm{pH}$ 7,3 drei- bis vierfach negativ geladen vor. Ein Austritt dieses Farbstoffs aus den GUVs ist aufgrund der hohen Ladungsdichte und der vielfach höheren Größe im Vergleich zu einem Proton gehindert. Demnach ist trotz eines konstanten Verlaufs der Fluoreszenzintensität von Pyranin in GUVs gleichzeitig ein passiver Transport von Protonen über die Vesikelmembran möglich und ein stabiler Farbstoffeinschluss kein Ausschlusskriterium für eine erhöhte Permeabilität der GUVs.

Girard et al. rekonstituierten bR in GUVs nach einem ebenfalls im Rahmen dieser Arbeit verwendeten Protokoll (Kapitel 3.2.5, 1-1)) und konnten bei Belichtung der Vesikel Änderungen der Intensität der Fluoreszenz von eingeschlossenem Pyranin beobachten. ${ }^{[117]}$ Dabei wurde in 2/3 aller GUVs ein Protonentransport ins Vesikelinnere hinein beobachtet und bei 1/3 ein nach aussen gerichteter Protonentransport. Es sei darauf hingewiesen, dass die beobachteten Änderungen in der Fluoreszenz gerade einmal 1 Einheit über einen Zeitraum von etwa 4,5 min beträgt, also langsam verläuft und dabei sehr gering ausfällt. Erst durch eine nicht nachvollziehbare Extrapolation der Werte und eine Korrektur des Photobleichens um 1 - 2 Einheiten (Faktor 2 der gemessenen Differenz!) wird ein Abfall der Fluoreszenzintensität erkennbar. Die Intensitätsänderungen wurden nicht in $\mathrm{pH}$-Einheiten umgerechnet. Eine Bildung der Proteo-GUVs fand unter Verwendung von Triton-X-100 statt, einem Detergens, welches sich im Rahmen dieser Arbeit nur schlecht aus der GUV-Suspension entfernen ließ und einen Einschluss von Farbstoff unmöglich machte (Kapitel 4.3.3, Bildung eines lichtinduzierten Protonengradienten). Die GUVs wurden von Girard et al. mit einer Xenon Lampe über einen Zeitraum mehrerer Minuten belichtet. Die Wärmeentwicklung dabei kann, wie in Abb. 4.45 gezeigt, zu einer Verschiebung des Fokus und somit einer Änderung der detektierten Fluoreszenzintensität führen. Anhand dieser Befunde stellt sich ein tatsächlicher Protonentransport bei Belichtung, induziert durch funktionell rekonstituiertes bR in den GUVs wie von Girard beschrieben als höchst unwahrscheinlich dar.

Kahya et al. rekonstituierten bR in GUVs durch Fusion von GUVs mit Proteoliposomen und wiesen eine Protonentransportaktivität von bR ebenfalls anhand von Änderungen der Pyraninfluoreszenz nach. ${ }^{[118]}$ Dabei wurde nicht eingeschlossenes Pyranin nicht aus der umgebenden Lösung entfernt. GUVs, welche sich nach Belichtung der Probe mit einer Xenon Lampe in ihrer Pyraninfluoreszenz von der Fluoreszenz in der umgebenden Lösung unterschieden, wurden als funktionelles bR enthaltend beschrieben. Ein Photobleichen als Grund für die Intensitätsabnahme im Vesikelinneren wurde mit dem Argument widerlegt, dass relative Änderungen zur Hintergrundfluoreszenz beobachtet wurden. Der Austausch von gebleichtem gegen ungebleichten Fluorophor ausserhalb der GUVs durch Diffusion wurde dabei offenbar 
nicht berücksichtigt. Auch dieser Aktivitätsnachweis von bR ist daher unter Vorbehalt zu betrachten.

In einer Studie aus dem Jahr 2013 weisen Dezi et al. anhand von Änderungen der Fluoreszenzintensität von in GUVs eingeschlossenem Pyranin den Protonentransport von rekonstituiertem bR bei Belichtung nach. ${ }^{[116]}$ Die Rekonstitution erfolgte dabei detergensvermittelt (mit $n$-Dodecyl- $\beta$-D-thiomaltopyranosid, DOTM). Dabei wurden $\mathrm{pH}$-Wertänderungen von bis $\mathrm{zu}$ 0,8 Einheiten innnerhalb von 40 min beobachtet, wobei Valinomycin $(0,01 \mu \mathrm{M})$ zugegeben wurde, um durch passiven $\mathrm{K}^{+}$-Transport den Aufbau eines elektrischen Potentials über die Vesikelmembran zu verhindern. Anhand der Fluoreszenzintensität von mit Texas Red markiertem bR in den GUVs wurde deren bR-Gehalt auf $1800 \pm 570$ Moleküle bR pro $\mu \mathrm{m}^{2}$ bestimmt. Aus diesen Werten errechnet sich für einen GUV mit einem Durchmesser von $d=10 \mu \mathrm{m}$ analog zu oben gezeigter Berechnung eine Pumprate von rekonstituiertem bR von $0,6 \mathrm{H}^{+} \cdot \mathrm{s}^{-1}$. Dieser Wert ist Faktor 170 geringer, als der von Bamberg in seiner Rechnung angenommene Wert von $100 \mathrm{H}^{+} \cdot \mathrm{s}^{-1} \cdot{ }^{[106]}$ Diese Diskrepanz wird von den Autoren nicht näher diskutiert. Die Zugabe von Casein $\left(5 \mathrm{mg} \cdot \mathrm{mL}^{-1}\right)$ sowie das Auftragen eines Mineralölfilms auf die Probe, wie von Dezi et al. durchgeführt, sind Faktoren, die die Funktionalität von bR sowie die Permeabilität von GUVs beeinflussen könnten und ebenfalls nicht näher erläutert werden. GUVs wurden in $400 \mathrm{mM}$ Sucrose gebildet und im Verhältnis 2:1 (v/v) mit detergenshaltiger Pufferlösung (u. a. $200 \mathrm{mM} \mathrm{K}_{2} \mathrm{SO}_{4}$ ) versetzt. Die genaue Zusammensetzung der GUVs nach Detergensentzug ist unklar und kann zwischen einzelnen GUVs variieren. GUVs wurden dann mehrfach in einer Lösung von $200 \mathrm{mM}$ Glucose und u. a. $100 \mathrm{mM} \mathrm{K}_{2} \mathrm{SO}_{4}$ verdünnt und nach Valinomycinzugabe belichtet. Liegt dabei ein Kaliumionengradient vor, kann dieser in einem langsamen Prozess durch einen passiven Transport mittels Valinomycin von Kaliumionen entlang des Gradienten und einem passiven Antiport zum Ladungsausgleich von Protonen als membranpermeabelste Teilchen ausgeglichen werden. Dabei würde sich ein Protonengradient aufbauen, welcher nicht lichtinduziert durch bR generiert wäre. Dass dieser Prozess so statt findet kann anhand der von Dezi beschriebenen Ergebnisse nicht ausgeschlossen werden, zumal in derselben Studie gezeigt wird, dass GUVs über einen Zeitraum von 40 min permeabel für Protonen sind. Ob die beobachteten Abnahmen der Fluoreszenzintensität von Pyranin tatsächlich auf einen ins Vesikelinnere gerichteten Protonentransport durch bR zurückzuführen sind, bleibt zweifelhaft und wird nicht ausreichend belegt.

Weitere Studien an in GUVs rekonstituiertem bR weisen eine Protonentransportaktivität indirekt durch Änderungen der Mobilität von bR in der Vesikelmembran ${ }^{[257]}$ oder einer Änderung der Membranspannug bei Belichtung nach. ${ }^{[258]}$ Eine direkte Messung der Änderung des $\mathrm{pH}$-Wertes in bR-haltigen GUVs mit verlässlichen Ergebnissen wurde bisher nicht berichtet. 


\subsubsection{Rekonstitution von $b R$ in porenüberspannenden Membranen}

Durch Spreiten bR-haltiger GUVs auf hydrophil funktionalisierten porösen Substraten mit geschlossenen Porenböden konnten bR-haltige porenüberspannende Membranen gebildet werden (Kapitel 4.3.4). Die Rekonstitution von bR in porenüberspannenden Membranen wurde durch CLSM-Aufnahmen von fluoreszenzmarkiertem bR visualisiert (Abb. 4.41). Eine Kolokalisation des Membranfarbstoffs Texas Red DHPE und des an bR gebundenen Farbstoffs Alexa Fluor 488 in allen Ebenen der Ortho-Darstellung von CLSM-Aufnahmen belegen die erfolgreiche Insertion von bR in die Membranen. Bisher sind nur wenige Transmembranproteine erfolgreich in porenüberspannende Membranen insertiert worden. Der allergrößte Teil entsprechender Studien berichtet die Rekonstitution von $\alpha$-Hämolysin. ${ }^{[259]}$ Dieses Protein ist als Monomer wasserlöslich und lagert sich spontan in Membranen ein unter Bildung einer heptameren Pore, was im Vergleich zu komplett wasserunlöslichen Transmembranproteinen die Rekonstitution vereinfach. Neben $\alpha$-Hämolysin wurde von der erfolgreichen Rekonstitution von Connexin $26^{[260]}$ und einem Glutamat-Rezeptor ${ }^{[63]}$ in multiporösen, membranüberspannten Systemen berichtet.

Mit Hilfe von FRAP-Experimenten wurde die Mobilität von rekonstituiertem bR untersucht. Dabei wurde in planaren porenüberspannenden Membranen ein mobiler Anteil von $M=68 \pm 16 \%$ bestimmt und ein apparenter Diffusionskoeffizient von $D=0,21 \pm 0,10 \mu \mathrm{m}^{2} \cdot \mathrm{s}^{-1}$ $(N=6)$. Anhand dieser Messungen wurde erstmals gezeigt, dass ein Transmembranprotein in porenüberspannenden Membranen über den Stegbereich hinweg beweglich ist. FRAPExperimente an in porenüberspannende Membranen rekonstituiertem antikörpermarkierten Connexon Cx26 (transmembranständiges Hexamer aus $26 \mathrm{kDa}$-Einheiten) zeigten, dass kein Proteinaustausch zwischen benachbarten Poren über den Porensteg hinweg möglich war. ${ }^{\text {[261] }}$ Die untersuchten porenüberspannenden Membranen wurden dabei auf mit Tetradekanthiol (TDT) hydrophob funktionalisierten Substraten mit offenen Porenböden gebildet. Weitere Studien, bei denen die Mobilität rekonstituierter Membranproteine in porenüberspannenden Membranen adressiert wurde sind nicht bekannt.

Ein Unterschied in der Struktur porenüberspannender Membranen auf hydrophob (TDT) funktionalisierten Substraten im Vergleich $\mathrm{zu}$ hydrophil (Thioalkohol) funktionalisierten Substraten, welcher die Diffusion von Membranproteinen beeinflussen kann, wird bei Kocun diskutiert. ${ }^{[262]}$ In AFM-Experimenten konnte dort beobachtet werden, dass lösungsmittelfreie porenüberspannende Membranen auf hydrophob funktionalisierten Substraten tiefer unterhalb der Stegoberfläche die Poren überspannen, als solche auf hydrophil funktionalisierten Substraten. Weiterhin wiesen Membranen auf hydrophob funktionalisierten Substraten eine höhere laterale Spannung auf, als Membranen auf hydrophil funktionalisierten Substraten. Ein anhand dieser Ergebnisse von Kocun entwickeltes Modell der jeweiligen Membranstrukturen ist in Abb. 5.12 gezeigt. Auf hydrophob funktionalisierten Stegbereichen insertieren die hydrophoben Reste des SAM in die untere Monolage der porenüberspannenden Membranen 
(Abb. 5.12, A). Um die attraktive Wechselwirkung dabei zu erhöhen, folgt die Membran der Goldbeschichtung und überspannt die Pore in einer $z$-Position unterhalb der Substratoberfläche. Durch die eingeschränkte Mobilität der Lipide innerhalb der substratzugewandten Monolage und die starken Krümmungen der Membran, welche beim Übergang zwischen Porenbereich und Goldoberfläche, sowie an der Kante der Goldbeschichtung auftreten, wird eine Diffusion von Transmembranproteinen aus einer Pore über den Stegbereich hinaus unterbunden. Ist die Oberfläche des Substrats hingegen hydrophil funktionalisiert, befindet sich eine dünne Schicht von Wasserteilchen zwischen unterer Monolage der Membran und dem Substrat (Abb. 5.12, B). Die attraktive Wechselwirkung zwischen Substrat und Membran ist geringer, weshalb die Membran nicht der Goldbeschichtung folgt und die Pore unterhalb der Substratoberfläche überspannt. Beide Monolagen weisen eine laterale Mobilität der Lipide auf und starke Krümmungen der Membran treten aufgrund der abgeschwächten Wechselwirkung mit dem Substrat nicht auf. Dadurch können auch membrandurchspannende Proteine aus dem Porenbereich heraus über die Stege hinweg in andere Poren diffundieren.
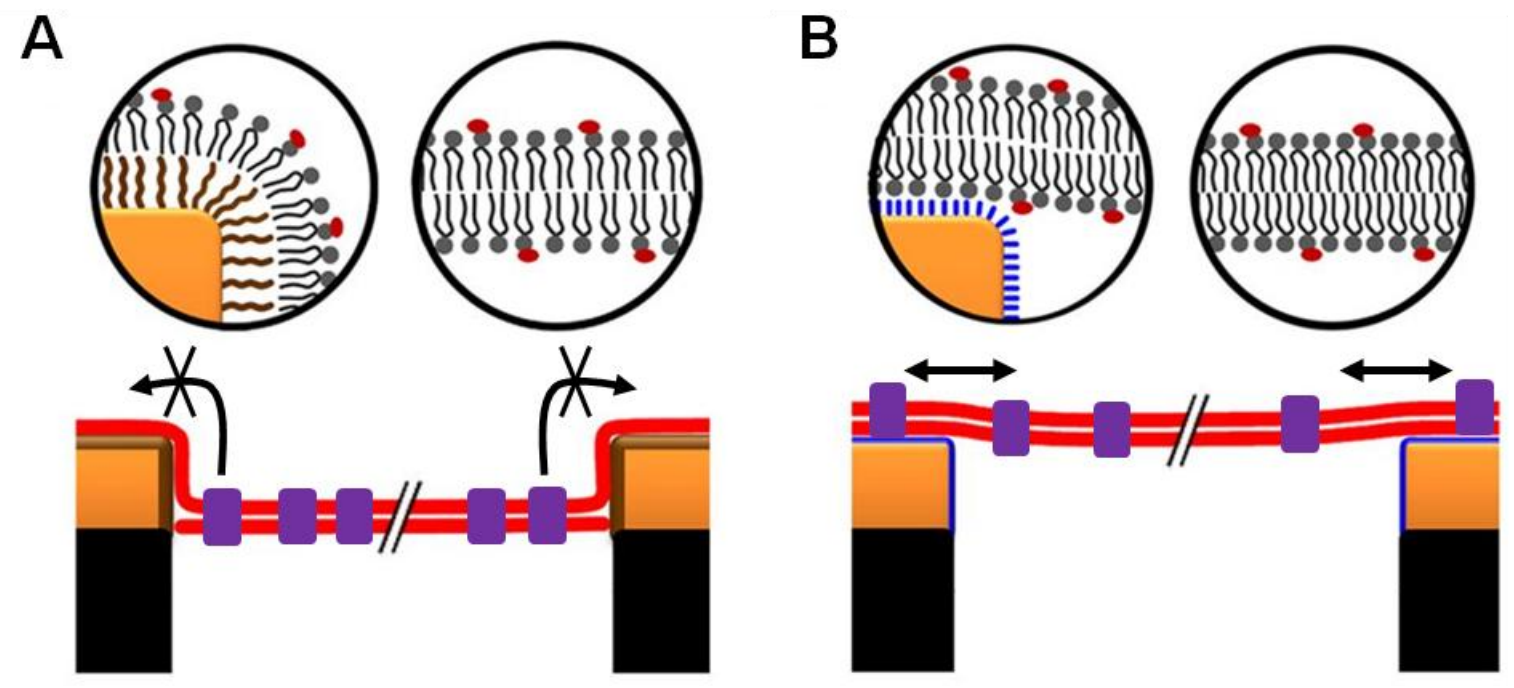

Abb. 5.12: Schematische Darstellung der Struktur porenüberspannender Membranen (rot) auf hydrophob (A) bzw. hydrophil (B) funktionalisierten Substraten. Das Substrat ist in schwarz dargestellt, die aufgebrachte Goldschicht in gold. Ein hydrophober SAM ist in braun dargestellt, ein hydrophiler mit Wasserschicht zwischen SAM und Membran in blau. Die Kreise zeigen jeweils einen vergrößerten Ausschnitt der Membran auf dem Stegbereich (links) und im Porenbereich (rechts). Durch die starken lokalen Krümmungen der Membran im Verlauf entlang der Goldbeschichtung, sowie die Immobilität der unteren Monolage der Membran, ist auf hydrophob funktionalisierten Substraten keine laterale Diffusion von Proteinen (z. B. bR, violett) möglich (A, angedeutet durch Pfeile). Porenüberspannende Membranen auf hydrophil funktionalisierten Substraten weisen keine starken Krümmungen auf und in beide Monolagen sind Lipide lateral beweglich. Dadurch können Membranproteine über den Stegbereich hinaus zwischen benachbarten Poren diffundieren (B, angedeutet durch Pfeile). Darstellung verändert nach Kocun. ${ }^{[262]}$

In glasunterstützten Membranen (DPhPC/DOPC, 6:4, 1 mol\% bR) wurden für die Mobilität von bR Werte von $M=70 \%$ und $D=0,6 \mu \mathrm{m}^{2} \cdot \mathrm{s}^{-1}$ bestimmt. ${ }^{[173]}$ Kahya et al. zeigten eine Verringerung des Diffusionskoeffizienten von bR bei Aktivierung des Proteins durch Belichtung. ${ }^{[257]}$ Für ein Protein/Lipid-Verhältnis von 1:130 (w/w) ergaben sich Koeffizienten 
von $D=1,0 \mu \mathrm{m}^{2} \cdot \mathrm{s}^{-1}$ vor Belichtung und $D=0,2 \mu \mathrm{m}^{2} \cdot \mathrm{s}^{-1}$ nach 2 min Belichtung (bestimmt mittels fluorescence correlation spectroscopy, FCS). Die Absorption von bR bei $\lambda=488 \mathrm{~nm}$, der für FRAP-Experimente im Rahmen dieser Arbeit verwendeten Wellenlänge, ist gering, so dass von einer nicht-aktivierten Form des bR innerhalb der Membranen und somit einer erhöhten Mobilität ausgegangen wird. Peters und Cherry bestimmten den Diffusionskoeffizient von bR in multilamellaren Vesikeln in Abhängigkeit von Temperatur, Lipidphase, Protein/Lipid-Verhältnis und Viskosität der wässrigen Phase. ${ }^{[263]}$ Für experimentelle Bedingungen, wie sie im Rahmen dieser Arbeit vorlagen, ergaben sich dabei Werte im Bereich von $0,2 \mu \mathrm{m}^{2} \cdot \mathrm{s}^{-1}$, welche gut mit den hier bestimmten Werten übereinstimmen. Eine ausführliche Diskussion zur Mobilität von bR in verschiedenen Modellmembranen findet sich bei Frese. ${ }^{[173]}$

CLSM-Aufnahmen unter Belichtung bR-haltiger porenüberspannender Membranen zeigten keine Änderungen der Fluoreszenzintensität eingeschlossenen Pyranins (Abb. 4.43). Wie bereits bei bR-haltigen sub-mikrometergroßen Vesikeln und GUVs konnte somit kein gerichteter Protonentransport durch bR beobachtet werden. Intensitätsverläufe, die in der Literatur beschriebenen Verläufen ähneln und welche dort einem bR-induzierten Protonentransport zugeordnet werden, konnten als thermisch bedingt identifiziert werden (Abb. 4.45). Dass porenüberspannende Membranen sich prinzipiell zum Aufbau stabiler elektrochemischer Gradienten eignen konnte durch den nigericininduzierten $\mathrm{K}^{+} / \mathrm{H}^{+}$-Antiport gezeigt werden (Kapitel 4.2.3).

Wie bereits für bR-haltige Vesikel diskutiert, könnte eine mangelnde Vorzugsorientierung des $\mathrm{bR}$ in den porenüberspannenden Membranen einen Netto-Protonentransport bei Belichtung verhindern. Um einen Netto-Protonentransport ins Poreninnere hinein zu forcieren, wurde Lanthanchlorid zu porenüberspannenden Membranen gegeben. Lanthanionen inhibieren einen Protonentransport von bR, wenn sie auf Seite des C-Terminus zugegeben werden. ${ }^{[15]}$ Zugabe von $\mathrm{LaCl}_{3}$ zur überstehenden Lösung bewirkte jedoch keine detektierbare Akkumulation von Protonen im Poreninneren.

Um einen möglichen Einfluss der Orientierung des bR besser abschätzen zu können, wurden für bR-haltige porenüberspannende Membranen theoretische Überlegungen anhand von Abb. 4.43 angestellt. Bei einem Start-pH-Wert von 7,8 in den Poren $(d=4,5 \mu \mathrm{m}, h=9 \mu \mathrm{m})$ und einer Pyraninkonzentration von $0,5 \mathrm{mM}\left(\mathrm{pK}_{\mathrm{S}}=7,2\right)$ müssten für einen $\mathrm{pH}$-Abfall um 0,1 Einheiten in der Pore $N=1,7 \cdot 10^{6}$ Protonen hinein transportiert werden. Ausgehend von einer bR-Dichte in den GUVs von $1800 \mathrm{bR} \cdot \mu_{\mathrm{m}}{ }^{-2}$, wie von Dezi et al. bestimmt und deutlich niedriger, als die für einen Anteil von $1 \mathrm{~mol} \%$ berechnete Dichte von $24700 \mathrm{bR} \cdot \mu \mathrm{m}^{-2}$, befinden sich im Bereich der porenüberspannenden Fläche einer Membran 28600 Moleküle bR. ${ }^{[116]}$ Um während der etwa $30 \mathrm{~s}$ langen Belichtungsdauer $1,7 \cdot 10^{6}$ Protonen in eine Pore zu transportieren, erfordert es bei einer Transportrate von $100 \mathrm{H}^{+} \cdot \mathrm{bR}^{-1} \cdot \mathrm{s}^{-1}$ einen Überschuss von 570 bR mit einer in die Pore hinein gerichteten Transportrichtung. Dies entspricht einer 
Verteilung beider bR-Orientierungen von 51,0:49,0, was immer noch an einer Gleichverteilung beider Orientierungen grenzt.

Während die prinzipielle Funktionsfähigkeit von bR nach Rekonstitution in Vesikel mit Hilfe von Photostrommessungen verifiziert werden konnte, war dies mit dem unter Kapitel 3.3 beschriebenen Versuchsaufbau nicht direkt möglich. Es ist demnach möglich, dass bR nicht funktionell in porenüberspannende Membranen rekonstituiert wurde. Als kritischster Schritt, dem bR ausgesetzt wurde, gilt die Dehydratisierung und anschließende Rehydratisierung unter Anlegen einer Wechselspannung mit einer Amplitude von $3 \mathrm{~V}$ bei der Bildung von Proteo-GUVs (Kapitel 3.2.5). ${ }^{[17]} \mathrm{Da}$ in bR-haltigen GUVs Proteinaktivität anhand von Photostrommessungen nachgewiesen werden konnte, ist es unwahrscheinlich, dass die Proteinaktivität nach Spreiten von Proteo-GUVs verloren geht, zumal bR als sehr robustes Protein gilt, das unempfindlich gegenüber Entfernung nativer Lipide, ${ }^{[143]}$ extremen pH-Werten $^{[264]}$ und hohen Temperaturen ist. ${ }^{[265]}$

Ein Faktor, welcher bei den theoretischen Überlegungen zum bR-induzierten Protonentransport bisher nicht berücksichtigt wurde, ist ein passiver Rücktransport von Protonen durch Membranen entlang des Gradienten. Dezi et al. zeigten in einem Experiment an GUVs (Ei-PC/Ei-PA, 9:1), dass ein pH-Gradient von 1,5 Einheiten ( $\mathrm{pH}$ 7,5 im Inneren der GUVs, pH 6,0 in der umgebenden Lösung) sich erst über einen Zeitraum von 40 min durch passiven Transport von Protonen über die Vesikelmembran ausglich. ${ }^{[116]}$ Anhand der dort angegebenen Daten lässt sich für eine $\mathrm{pH}-$ Wertdifferenz von 0,1 Einheiten ein passiver Transport in der Größenordnung von $10^{7} \mathrm{H}^{+} \cdot \mathrm{min}^{-1}$ für einen GUV mit einem Durchmesser von $10 \mu \mathrm{m}$ abschätzen. Das entspricht $3 \cdot 10^{4} \mathrm{H}^{+} \cdot \mathrm{min}^{-1} \cdot \mu \mathrm{m}^{-2}$ und übertragen auf die Fläche einer Pore mit Durchmesser $d=4,5 \mu \mathrm{m}$ einem Transport von $5 \cdot 10^{5} \mathrm{H}^{+} \cdot \mathrm{min}^{-1}$. Bezogen auf die Anzahl von Protonen, welche in $30 \mathrm{~s}$ in die Pore hinein transportiert werden müssten, um in diesem Zeitraum eine detektierbare $\mathrm{pH}$-Wertänderung von 0,1 Einheiten $\mathrm{zu}$ verursachen $\left(N=1,7 \cdot 10^{6} \mathrm{H}^{+}\right)$ist ein entgegengerichteter passiver Transport von Protonen von $N=2,5 \cdot 10^{5} \mathrm{H}^{+}$im selben Zeitraum vernachlässigbar klein. Unter Berücksichtigung dieses passiven Protonentransports ergäbe sich statt eines Verhältnisses beider bR-Orientierungen von 51,0:49,0, welches nötig wäre, um eine $\mathrm{pH}$-Wertänderung von 0,1 Einheiten in einem $30 \mathrm{~s}$ Belichtungszeitraum zu erreichen, nun ein Verhältnis von 51,1:48,9. Ein passiver Protonenrücktransport, welcher schneller verläuft, als der aktive durch $b R$ getriebene Protonentransport in die Poren hinein, lässt sich als Grund für den beobachteten konstanten $\mathrm{pH}-$ Verlauf bei Belichtung von bR-haltigen Poren somit ausschließen.

Warum bR trotz mit Hilfe von Photostrommessungen gemessener Aktivität nach Rekonstitution in artifizielle Membranen keinen Aufbau eines Protonengradienten zulässt, kann nicht abschließend geklärt werden. Es ist möglich, dass die Menge rekonstituierten Proteins deutlich von der Menge eingesetzten Proteins abweicht. Auch nach Rekonstitution ist z. B. in porenüberspannenden Membranen eine Verarmung der Porenfläche an bR denkbar 
durch Akkumulation von bR auf den Stegbereichen. Der aus der Membran hervorstehende Teil des Proteins könnte mit der Substratoberfläche bzw. der dort aufgebrachten hydrophilen Funktionalisierung wechselwirken und dadurch $\mathrm{zu}$ einer Verdichtung von bR auf den Stegbereichen führen. Durch die fluoreszenzlöschende Wirkung der Goldbeschichtung lässt sich anhand von CLSM-Aufnahmen über die Verteilung von bR zwischen Poren- und Stegbereich keine Aussage treffen. Eine stark verringerte Anzahl von bR-Molekülen im Porenbereich würde auch die theoretischen Überlegungen zur Orientierung von bR beeinflussen. Bei einer Verringerung der Anzahl von bR-Molekülen über einer Pore muss eine größere Ungleichverteilung zwischen beiden möglichen Orientierungen vorliegen, um in einem konstanten Zeitraum eine bestimmte Zahl an Protonen in die Pore hinein zu transportieren. Durch Änderungen der bR-Konzentration, z. B. durch Aggregation auf dem Stegbereich oder untereinander, durch Veränderung der Transportrate von bR oder andere Parameter, kann die Orientierung des Proteins demnach mehr Einfluss auf einen NettoProtonentransport gewinnen. 


\section{Zusammenfassung}

Im Fokus dieser Arbeit stand die Entwicklung eines artifiziellen Membransystems zur Bildung und Untersuchung elektrochemischer Gradienten. Hierzu wurden porenüberspannende Membranen (PSMs) auf mikroporösen Substraten mit geschlossenen Porenböden gebildet.

Lösungsmittelhaltige PSMs wurden mit Hilfe der painting-Technik hergestellt und der Gehalt remanenten Lösungsmittels durch Anwendung des solvent freeze-out reduziert. Die Struktur der PSMs vor bzw. nach Ausfrieren des Lösungsmittels wurde erstmals anhand dreidimensionaler konfokalmikroskopischer und rasterionenleitfähigkeitsmikroskopischer (SICM) Aufnahmen untersucht. In Kombination mit fluorescence recovery after photbleaching (FRAP-) Experimenten war eine Abschätzung des Gehaltes in der Membran verbleibenden Lösungsmittels möglich. Ein Mechanismus des Ausfrierprozesses von membranständigen Lösungsmittel wird anhand der Bildung von Mikrokristallen beim Abkühlen der Probe und einer durch Kapillarkräfte getriebenen Beschichtung dieser Kristalle durch das Lösungsmittel diskutiert.

Lösungsmittelfreie PSMs konnten durch Spreiten mikrometergroßer unilamellarer Vesikel (GUVs) auf hydrophil funktionalisierten Substraten erhalten werden. Dabei konnten Öffnungen mit Durchmessern $d>2,5 \mu \mathrm{m}$ reproduzierbar mit planaren Membranen überspannt werden, was bisher nicht oder nur durch Verengung der Porenöffnung auf Kosten eines verringerten Fläche-zu-Volumen Verhältnisses möglich war. Mit negativ geladenen Lipiden dotierte GUVs konnten nur in Anwesenheit metallischer Kationen auf positiv funktionalisierten Substraten gespreitet werden. Gemeinsam mit Prof. David Andelman (Tel Aviv University, Israel) wurde ein Modell für den Spreitmechanismums geladener GUVs auf entgegengesetzt geladenen Oberflächen entwickelt, welches die entropisch begünstigte Freisetzung von an den geladenen Grenzflächen gebundenen Gegenionen als treibende Kraft für die Bildung planarer PSMs beschreibt.

Neben planaren PSMs wurde beim Spreiten sucrosehaltiger GUVs auf hydrophil funktionalisierten porösen Substraten mit geschlossenen Böden erstmals die Bildung hemisphärischer PSMs beobachtet. Diskutiert wird die Bildung solch ausgestülpter Membranen anhand eines Einschlusses von Lösung aus dem Inneren der GUVs in unterliegenden Poren im Verlauf des Spreitvorgangs. Die Stabilität hemisphärischer PSMs wird anhand eines Gleichgewichts zwischen Adhäsion von Membran und Substrat und dem osmotischen Druck zwischen membranumschlossenem Volumen und überstehender wässriger Lösung erläutert. 
PSMs auf hydrophob wie hydrophil funktionalisierten porösen Substraten erlaubten den stabilen Einschluss des pH-sensitiven Fluorophors Pyranin. Über planare PSMs wurde durch nigericininduzierten $\mathrm{K}^{+} / \mathrm{H}^{+}$-Antiport in situ ein Protonengradient aufgebaut, dessen Bildung anhand des Verlaufs der Pyraninfluoreszenz quantitativ verfolgt werden konnte. Dabei wurden $\mathrm{pH}-$ Wertänderungen von bis $\mathrm{zu} \Delta \mathrm{pH}=2$ Einheiten beobachtet. Die experimentell ermittelten Werte stimmten mit Werten, welche anhand eines Modells für einen ladungsneutralen Antiport errechnet wurden, gut überein. Die Rate des Protonentransports wurde jeweils anhand der Initialsteigungen der $\mathrm{pH}-$ Wertverläufe $\mathrm{zu} 10^{14} \mathrm{H}^{+} \cdot \mathrm{cm}^{-2} \cdot \mathrm{s}^{-1}$ bestimmt. Neben der Bildung nigericininduzierter Protonengradienten aus Kaliumionengradienten sollte ein lichtinduzierter Protonengradient durch das Membranprotein Bacteriorhodopsin (bR) untersucht werden. Hierzu wurden verschiedene Methoden zur funktionellen Rekonstiution von bR in sub-mikrometergroße Vesikel (LUVs), GUVs und PSMs getestet. Photostrommessungen bestätigten dabei die Konservierung der Protonenpumpaktivität von rekonstituiertem bR in LUVs und GUVs. Durch eine Fluoreszenzmarkierung des Proteins konnte dessen Insertion jeweils konfokalmikroskopisch bestätigt werden. FRAP-Experimente an bR-dotierten PSMs zeigten, dass das Protein lateral mobil ist (Diffusionskoeffizient $D=0,21 \pm 0,10 \mu \mathrm{m}^{2} \cdot \mathrm{s}^{-1}$, mobiler Anteil $M=68 \pm 16 \%, N=6$ ) und über den Stegbereich hinaus zwischen benachbarten Poren diffundieren kann. Membranproteine in anderen porösen Modellmembransystemen waren bisher in ihrer Mobilität auf eine einzelne Pore beschränkt. Ein Netto-Protonentransport, welcher den lichtinduzierten Aufbau eines Protonengradienten durch bR verursachen würde, konnte für keines der Modellsysteme nachgewiesen werden, weder durch Messungen mit Hilfe einer pH-Elektrode, noch durch Verfolgung der Pyraninfluoreszenz. Änderungen der Pyraninfluoreszenz konnten einem thermischen Einfluss der Lichtquelle zugeordnet werden („Thermodrift"), welcher durch Entwicklung eines LEDRings zur Belichtung bR-haltiger Proben unterbunden werden konnte. 


\section{Literaturverzeichnis}

[1] E. T. Castellana, P. S. Cremer, Solid supported lipid bilayers: From biophysical studies to sensor design, Surf. Sci. Rep. 2006, 61, 429.

[2] Y. Cheng, S. D. Ogier, R. J. Bushby, S. D. Evans, Discrete membrane arrays, J. Biotechnol. 2000, 74, 159.

[3] M. Winterhalter, Black lipid membranes, Curr. Opin. Colloid Interface Sci. 2000, 5, 250 .

[4] P. Walde, K. Cosentino, H. Engel, P. Stano, Giant vesicles: preparations and applications, ChemBioChem 2010, 11, 848.

[5] E. Reimhult, K. Kumar, Membrane biosensor platforms using nano- and microporous supports, Trends Biotechnol. 2008, 26, 82.

[6] H. Suzuki, S. Takeuchi, Microtechnologies for membrane protein studies, Anal. Bioanal. Chem. 2008, 391, 2695.

[7] M. Zagnoni, Miniaturised technologies for the development of artificial lipid bilayer systems, Lab Chip 2012, 12, 1026.

[8] I. Mey, C. Steinem, A. Janshoff, Biomimetic functionalization of porous substrates: towards model systems for cellular membranes, J. Mater. Chem. 2012, 22, 19348.

[9] B. Zhu, J. Li, D. Xu, Porous biomimetic membranes: fabrication, properties and future applications, Phys Chem Chem Phys 2011, 13, 10584.

[10] M. E. Warkiani, A. A. S. Bhagat, B. L. Khoo, J. Han, C. T. Lim, H. Q. Gong, A. G. Fane, Isoporous micro/nanoengineered membranes, ACS Nano 2013, 7, 1882.

[11] A. Janshoff, C. Steinem, Transport across artificial membranes - an analytical perspective, Anal. Bioanal. Chem. 2006, 385, 433.

[12] R. Peters, Optical single transporter recording: transport kinetics in microarrays of membrane patches, Annu. Rev. Biophys. Biomol. Struct. 2003, 32, 47.

[13] S. Demarche, K. Sugihara, T. Zambelli, L. X. Tiefenauer, J. Vörös, Techniques for recording reconstituted ion channels, Analyst 2011, 136, 1077.

[14] Y. Arinaminpathy, E. Khurana, D. M. Engelman, M. B. Gerstein, Computational analysis of membrane proteins: the largest class of drug targets, Drug Discov. Today 2009, 14,1130 . 
[15] M. Bally, K. Bailey, K. Sugihara, D. Grieshaber, J. Vörös, B. Städler, Liposome and lipid bilayer arrays towards biosensing applications, Small 2010, 6, 2481.

[16] M. K. Jain, F. P. White, A. Strickholm, E. Williams, E. H. Cordes, Studies concerning the possible reconstitution of an active cation pump across an artificial membrane, J. Membr. Biol. 1972, 8, 363.

[17] E. N. Ervin, R. J. White, H. S. White, Sensitivity and signal complexity as a function of the number of ion channels in a stochastic sensor, Anal. Chem. 2009, 81, 533.

[18] A. E. P. Schibel, E. C. Heider, J. M. Harris, H. S. White, Fluorescence microscopy of the pressure-dependent structure of lipid bilayers suspended across conical nanopores, J. Am. Chem. Soc. 2011, 133, 7810.

[19] R. J. White, E. N. Ervin, T. Yang, X. Chen, S. Daniel, P. S. Cremer, H. S. White, Single ion-channel recordings using glass nanopore membranes, J. Am. Chem. Soc. 2007, 129, 11766.

[20] E. Gouaux, alpha-Hemolysin from Staphylococcus aureus: an archetype of beta-barrel, channel-forming toxins, J. Struct. Biol. 1998, 121, 110.

[21] G. A. Woolley, B. A. Wallace, Model ion channels: gramicidin and alamethicin, J. Membr. Biol. 1992, 129, 109.

[22] M. E. Sandison, M. Zagnoni, H. Morgan, Air-exposure technique for the formation of artificial lipid bilayers in microsystems, Langmuir 2007, 23, 8277.

[23] M. E. Sandison, M. Zagnoni, M. Abu-Hantash, H. Morgan, Micromachined glass apertures for artificial lipid bilayer formation in a microfluidic system, J. Micromech. Microeng. 2007, 17, S189.

[24] R. Kawano, T. Osaki, H. Sasaki, S. Takeuchi, A polymer-based nanopore-integrated microfluidic device for generating stable bilayer lipid membranes, Small 2010, 6, 2100.

[25] N. Malmstadt, M. A. Nash, R. F. Purnell, J. J. Schmidt, Automated formation of lipidbilayer membranes in a microfluidic device, Nano Lett. 2006, 6, 1961.

[26] M. Zagnoni, M. E. Sandison, P. Marius, A. G. Lee, H. Morgan, Controlled delivery of proteins into bilayer lipid membranes on chip, Lab Chip 2007, 7, 1176.

[27] C. Schmidt, M. Mayer, H. Vogel, A Chip-Based Biosensor for the Functional Analysis of Single Ion Channels, Angew. Chem. Int. Ed. 2000, 39, 3137.

[28] E. L. Kendall, C. Shao, D. L. DeVoe, Visualizing the Growth and Dynamics of Liquid-Ordered Domains During Lipid Bilayer Folding in a Microfluidic Chip, Small 2012, DOI: $10.1002 / \mathrm{smll} .201200831$. 
[29] C. Shao, E. L. Kendall, D. L. DeVoe, Electro-optical BLM chips enabling dynamic imaging of ordered lipid domains, Lab Chip 2012, 12, 3142.

[30] V. C. Stimberg, J. G. Bomer, I. van Uitert, A. van den Berg, S. Le Gac, High Yield, Reproducible and Quasi-Automated Bilayer Formation in a Microfluidic Format, Small 2012, DOI: $10.1002 / \mathrm{smll} .201201821$.

[31] M. R. Nussio, G. Oncins, I. Ridelis, E. Szili, J. G. Shapter, F. Sanz, N. H. Voelcker, Nanomechanical characterization of phospholipid bilayer islands on flat and porous substrates: a force spectroscopy study, J Phys Chem B 2009, 113, 10339.

[32] M. Claesson, R. Frost, S. Svedhem, M. Andersson, Pore spanning lipid bilayers on mesoporous silica having varying pore size, Langmuir 2011, 27, 8974.

[33] M. Roerdink Lander, S. Ibragimova, C. Rein, J. Vogel, K. Stibius, O. Geschke, M. Perry, C. Hélix-Nielsen, Biomimetic membrane arrays on cast hydrogel supports, Langmuir 2011, 27, 7002 .

[34] N. J. Wittenberg, H. Im, T. W. Johnson, X. Xu, A. E. Warrington, M. Rodriguez, S.-H. Oh, Facile assembly of micro- and nanoarrays for sensing with natural cell membranes, ACS Nano 2011, 5, 7555.

[35] R. Syeda, M. A. Holden, W. L. Hwang, H. Bayley, Screening blockers against a potassium channel with a droplet interface bilayer array, J. Am. Chem. Soc. 2008, 130, 15543.

[36] O. K. Castell, J. Berridge, M. I. Wallace, Quantification of membrane protein inhibition by optical ion flux in a droplet interface bilayer array, Angew. Chem. Int. Ed. 2012, 51,3134 .

[37] D. Morick, In Vitro Studies of Protein Interactions on Substrate Supported Artificial Membranes, Dissertation, Georg-August-Universität, Göttingen, 2013.

[38] T. D. Lazzara, C. Carnarius, M. Kocun, A. Janshoff, C. Steinem, Separating attolitersized compartments using fluid pore-spanning lipid bilayers, ACS Nano 2011, 5, 6935.

[39] C. Carnarius, Funktionelle Rekonstitution von Connexonen in artifizielle Membranen: Expression, Reinigung und Charakterisierung von Connexin 43, Dissertation, Georg-AugustUniversität, Göttingen, 2012.

[40] F. Laermer, A. Schilp, K. Funk, M. Offenberg in Twelfth IEEE International Conference on Micro Electro Mechanical Systems, Orlando, FL, USA, 1999, 211.

[41] E. K. Schmitt, C. Weichbrodt, C. Steinem, Impedance analysis of gramicidin D in pore-suspending membranes, Soft Matter 2009, 5, 3347.

[42] E. K. Schmitt, M. Vrouenraets, C. Steinem, Channel activity of OmpF monitored in nano-BLMs, Biophys. J. 2006, 91, 2163. 
[43] E. K. Schmitt, M. Nurnabi, R. J. Bushby, C. Steinem, Electrically insulating poresuspending membranes on highly ordered porous alumina obtained from vesicle spreading, Soft Matter 2008, 4, 250.

[44] H. Wang, T.-S. Chung, Y. W. Tong, W. P. Meier, Z. Chen, M. Hong, K. Jeyaseelan, A. Armugam, Preparation and characterization of pore-suspending biomimetic membranes embedded with Aquaporin $\mathrm{Z}$ on carboxylated polyethylene glycol polymer cushion, Soft Matter 2011, 7, 7274.

[45] H. Wang, T.-S. Chung, Y. W. Tong, K. Jeyaseelan, A. Armugam, Z. Chen, M. Hong, W. P. Meier, Highly permeable and selective pore-spanning biomimetic membrane embedded with aquaporin Z, Small 2012, 8, 1185-90, 1125.

[46] D. Weiskopf, E. K. Schmitt, M. H. Klühr, S. K. Dertinger, C. Steinem, Micro-BLMs on highly ordered porous silicon substrates: rupture process and lateral mobility, Langmuir 2007, 23, 9134.

[47] P. V. Ganesan, S. G. Boxer, A membrane interferometer, Proc. Natl. Acad. Sci. U. S. A. 2009, 106, 5627.

[48] M. Kocun, T. D. Lazzara, C. Steinem, A. Janshoff, Preparation of solvent-free, porespanning lipid bilayers: modeling the low tension of plasma membranes, Langmuir 2011, 27, 7672.

[49] F. Heinemann, P. Schwille, Preparation of micrometer-sized free-standing membranes, ChemPhysChem 2011, 12, 2568.

[50] K. Buchholz, A. Tinazli, A. Kleefen, D. Dorfner, D. Pedone, U. Rant, R. Tampé, G. Abstreiter, M. Tornow, Silicon-on-insulator based nanopore cavity arrays for lipid membrane investigation, Nanotechnology 2008, 19, 445305.

[51] K. Sumitomo, A. McAllister, Y. Tamba, Y. Kashimura, A. Tanaka, Y. Shinozaki, K. Torimitsu, $\mathrm{Ca} 2+$ ion transport through channels formed by $\alpha$-hemolysin analyzed using a microwell array on a Si substrate, Biosens. Bioelectron. 2012, 31, 445.

[52] K. Kumar, L. Isa, A. Egner, R. Schmidt, M. Textor, E. Reimhult, Formation of nanopore-spanning lipid bilayers through liposome fusion, Langmuir 2011, 27, 10920.

[53] H. Im, N. J. Wittenberg, A. Lesuffleur, N. C. Lindquist, S.-H. Oh, Membrane protein biosensing with plasmonic nanopore arrays and pore-spanning lipid membranes, Chem. Sci. 2010, 1,688 .

[54] P. Jönsson, M. P. Jonsson, F. Höök, Sealing of submicrometer wells by a shear-driven lipid bilayer, Nano Lett. 2010, 10, 1900.

[55] M. D. Mager, N. A. Melosh, Nanopore-Spanning Lipid Bilayers for Controlled Chemical Release, Adv. Mater. 2008, 20, 4423. 
[56] C. E. Korman, M. Megens, C. M. Ajo-Franklin, D. A. Horsley, Nanopore-Spanning Lipid Bilayers on Silicon Nitride Membranes That Seal and Selectively Transport Ions, Langmuir 2013, DOI: 10.1021/1a305064j.

[57] S. Kresák, T. Hianik, R. L. C. Naumann, Giga-seal solvent-free bilayer lipid membranes: from single nanopores to nanopore arrays, Soft Matter 2009, 5, 4021.

[58] W. Römer, Y. H. Lam, D. Fischer, A. Watts, W. B. Fischer, P. Göring, R. B. Wehrspohn, U. Gösele, C. Steinem, Channel activity of a viral transmembrane peptide in micro-BLMs: Vpu(1-32) from HIV-1, J. Am. Chem. Soc. 2004, 126, 16267.

[59] A. Studer, X. Han, F. K. Winkler, L. X. Tiefenauer, Formation of individual protein channels in lipid bilayers suspended in nanopores, Colloids Surf. B 2009, 73, 325.

[60] A. Kleefen, D. Pedone, C. Grunwald, R. Wei, M. Firnkes, G. Abstreiter, U. Rant, R. Tampé, Multiplexed Parallel Single Transport Recordings on Nanopore Arrays, Nano Lett. 2010, 10, 5080.

[61] A. M. Seddon, P. Curnow, P. J. Booth, Membrane proteins, lipids and detergents: not just a soap opera, Biochim. Biophys. Acta 2004, 1666, 105.

[62] R. Hemmler, G. Böse, R. Wagner, R. Peters, Nanopore unitary permeability measured by electrochemical and optical single transporter recording, Biophys. J. 2005, 88, 4000.

[63] G. Favero, L. Campanella, S. Cavallo, A. D'Annibale, M. Perrella, E. Mattei, T. Ferri, Glutamate receptor incorporated in a mixed hybrid bilayer lipid membrane array, as a sensing element of a biosensor working under flowing conditions, J. Am. Chem. Soc. 2005, 127, 8103.

[64] J. K. Rosenstein, S. Ramakrishnan, J. Roseman, K. L. Shepard, Single Ion Channel Recordings with CMOS-Anchored Lipid Membranes, Nano Lett. 2013, DOI: $10.1021 / \mathrm{nl} 400822$ r.

[65] B. Le Pioufle, H. Suzuki, K. V. Tabata, H. Noji, S. Takeuchi, Lipid bilayer microarray for parallel recording of transmembrane ion currents, Anal. Chem. 2008, 80, 328.

[66] H. Suzuki, K. V. Tabata, H. Noji, S. Takeuchi, Highly reproducible method of planar lipid bilayer reconstitution in polymethyl methacrylate microfluidic chip, Langmuir 2006, 22, 1937.

[67] T.-J. Jeon, J. L. Poulos, J. J. Schmidt, Long-term storable and shippable lipid bilayer membrane platform, Lab Chip 2008, 8, 1742.

[68] J. S. Hansen, M. Perry, J. Vogel, J. S. Groth, T. Vissing, M. S. Larsen, O. Geschke, J. Emneús, H. Bohr, C. H. Nielsen, Large scale biomimetic membrane arrays, Anal. Bioanal. Chem. 2009, 395, 719. 
[69] G. Baaken, M. Sondermann, C. Schlemmer, J. Rühe, J. C. Behrends, Planar microelectrode-cavity array for high-resolution and parallel electrical recording of membrane ionic currents, Lab Chip 2008, 8, 938.

[70] T. Osaki, H. Suzuki, B. Le Pioufle, S. Takeuchi, Multichannel simultaneous measurements of single-molecule translocation in alpha-hemolysin nanopore array, Anal. Chem. 2009, 81, 9866.

[71] T. Osaki, Y. Watanabe, R. Kawano, H. Sasaki, S. Takeuchi, Electrical Access to Lipid Bilayer Membrane Microchambers for Transmembrane Analysis, J. Microelectromech. Syst. 2011, 20, 797.

[72] S. Ota, H. Suzuki, S. Takeuchi, Microfluidic lipid membrane formation on microchamber arrays, Lab Chip 2011, 11, 2485.

[73] Y. Rondelez, G. Tresset, K. V. Tabata, H. Arata, H. Fujita, S. Takeuchi, H. Noji, Microfabricated arrays of femtoliter chambers allow single molecule enzymology, Nat. Biotechnol. 2005, 23, 361.

[74] T. Osaki, S. Yoshizawa, R. Kawano, H. Sasaki, S. Takeuchi, Lipid-coated microdroplet array for in vitro protein synthesis, Anal. Chem. 2011, 83, 3186.

[75] R. Kawano, T. Osaki, H. Sasaki, M. Takinoue, S. Yoshizawa, S. Takeuchi, Rapid detection of a cocaine-binding aptamer using biological nanopores on a chip, J. Am. Chem. Soc. 2011, 133, 8474.

[76] G. Baaken, N. Ankri, A.-K. Schuler, J. Rühe, J. C. Behrends, Nanopore-based singlemolecule mass spectrometry on a lipid membrane microarray, ACS Nano 2011, 5, 8080.

[77] P. Mitchell, Coupling of phosphorylation to electron and hydrogen transfer by a chemi-osmotic type of mechanism, Nature 1961, 191, 144.

[78] P. R. Rich, A perspective on Peter Mitchell and the chemiosmotic theory, J Bioenerg Biomembr 2008, 40, 407.

[79] B. C. Pressman, Biological applications of ionophores, Annu. Rev. Biochem. 1976, 45, 501.

[80] http://www.sigmaaldrich.com/catalog/product/sigma/94675?lang=de\&region=DE, abgerufen am 18.05.2013.

[81] W. L. Duax, H. Hauptman, C. M. Weeks, D. A. Norton, Valinomycin crystal structure determination by direct methods, Science 1972, 176, 911.

[82] http://www.sigmaaldrich.com/catalog/product/sigma/n7143?lang=de\&region=DE, abgerufen am 18.05.2013. 
[83] A. J. Geddes, B. Sheldrick, W. T. Stevenson, L. K. Steinrauf, The crystal structure of the potassium salt of nigericin, Biochem. Biophys. Res. Commun. 1974, 60, 1245.

[84] S. Ahmed, I. R. Booth, The use of valinomycin, nigericin and trichlorocarbanilide in control of the protonmotive force in Escherichia coli cells, Biochim. Biophys. Acta Bioenergetics 1983, 212, 105.

[85] J. W. Hell, L. Edelmann, J. Hartinger, R. Jahn, Functional reconstitution of the gamma-aminobutyric acid transporter from synaptic vesicles using artificial ion gradients, Biochemistry 1991, 30, 11795.

[86] B. Pitard, P. Richard, M. Duñach, J. L. Rigaud, ATP synthesis by the FOF1 ATP synthase from thermophilic Bacillus PS3 reconstituted into liposomes with bacteriorhodopsin. 2. Relationships between proton motive force and ATP synthesis, Eur. J. Biochem. 1996, 235, 779 .

[87] J. L. Rigaud, A. Bluzat, S. Buschlen, Incorporation of bacteriorhodopsin into large unilamellar liposomes by reverse phase evaporation, Biochem. Biophys. Res. Commun. 1983, $111,373$.

[88] H. J. Freisleben, K. Zwicker, P. Jezek, G. John, A. Bettin-Bogutzki, K. Ring, T. Nawroth, Reconstitution of bacteriorhodopsin and ATP synthase from Micrococcus luteus into liposomes of the purified main tetraether lipid from Thermoplasma acidophilum: proton conductance and light-driven ATP synthesis, Chem. Phys. Lipids 1995, 78, 137.

[89] F. Milano, M. Trotta, M. Dorogi, B. Fischer, L. Giotta, A. Agostiano, P. Maróti, L. Kálmán, L. Nagy, Light induced transmembrane proton gradient in artificial lipid vesicles reconstituted with photosynthetic reaction centers, J Bioenerg Biomembr 2012, 44, 373.

[90] M. Toro, C. Gómez-Lojero, M. Montal, S. Estrada-O, Charge transfer mediated by nigericin in black lipid membranes, J Bioenerg 1976, 8, 19.

[91] M. O. Bevensee, E. Bashi, W. F. Boron, Effect of trace levels of nigericin on intracellular $\mathrm{pH}$ and acid-base transport in rat renal mesangial cells, J Membrane Biol 1999, $169,131$.

[92] Y. N. Antonenko, L. S. Yaguzhinsky, A new method of the measurement of the electrically neutral fluxes of cations through lipid bilayer membranes induced by $\mathrm{Me}^{\mathrm{n}+} / \mathrm{nH}^{+}-$ exchangers, FEBS Lett. 1983, 163, 42.

[93] Y. N. Antonenko, L. S. Yaguzhinsky, The ion selectivity of nonelectrogenic ionophores measured on a bilayer lipid membrane: nigericin, monensin, A23187 and lasalocid A, Biochim. Biophys. Acta 1988, 938, 125. 
[94] O. N. Kovbasnjuk, Y. N. Antonenko, L. S. Yaguzhinsky, Proton dissociation from nigericin at the membrane-water interface, the rate-limiting step of $\mathrm{K}+\mathrm{H}+$ exchange on the bilayer lipid membrane, FEBS Lett. 1991, 289, 176.

[95] V. S. Markin, V. S. Sokolov, L. I. Bogulavsky, L. S. Jaguzhinsky, Nigericin-induced charge transfer across membranes, J. Membr. Biol. 1975, 25, 23.

[96] J. Barreto, L. M. Lichtenberger, Vesicle acidification driven by a millionfold proton gradient: a model for acid influx through gastric cell membranes, Am. J. Physiol. 1992, 262, G30-4.

[97] B. S. Prabhananda, M. M. Ugrankar, Nigericin-mediated H+, K+ and $\mathrm{Na}+$ transports across vesicular membrane: T-jump studies, Biochim. Biophys. Acta 1991, 1070, 481.

[98] F. G. Riddell, S. Arumugam, P. J. Brophy, B. G. Cox, M. C. H. Payne, T. E. Southon, The nigericin-mediated transport of sodium and potassium ions through phospholipid bilayers studied by $23 \mathrm{Na}$ and 39K NMR spectroscopy, J. Am. Chem. Soc. 1988, 110, 734.

[99] M. Gleisner, Untersuchung von Transportvorgängen an porenüberspannenden Membranen, Masterarbeit, Georg-August-Universität, Göttingen, 2012.

[100] J. K. Lanyi, Proton transfers in the bacteriorhodopsin photocycle, Biochim. Biophys. Acta 2006, 1757, 1012.

[101] J. K. Lanyi, B. Schobert, Structural changes in the L photointermediate of bacteriorhodopsin, J. Mol. Biol. 2007, 365, 1379.

[102] K. Edman, P. Nollert, A. Royant, H. Belrhali, E. Pebay-Peyroula, J. Hajdu, R. Neutze, E. M. Landau, High-resolution X-ray structure of an early intermediate in the bacteriorhodopsin photocycle, Nature 1999, 401, 822.

[103] A. Kawanabe, H. Kandori, Photoreactions and structural changes of anabaena sensory rhodopsin, Sensors 2009, 9, 9741.

[104] D. Oesterhelt, W. Stoeckenius, Rhodopsin-like protein from the purple membrane of Halobacterium halobium, Nature New Biol. 1971, 233, 149.

[105] M. Sumper, H. Reitmeier, D. Oesterhelt, Biosynthesis of the purple membrane of halobacteria, Angew. Chem. Int. Ed. 1976, 15, 187.

[106] E. Bamberg, H.-J. Apell, N. A. Dencher, W. Sperling, H. Stieve, P. Läuger, Photocurrents generated by bacteriorhodopsin on planar bilayer membranes, Biophys Struct Mechanism 1979, 5, 277.

[107] T. R. Herrmann, G. W. Rayfield, The electrical response to light of bacteriorhodopsin in planar membranes, Biophys. J. 1978, 21, 111. 
[108] M. Ikematsu, Y. Sugiyama, M. Iseki, E. Muneyuki, A. Mizukami, Direct reconstitution of bacteriorhodopsin into planar phospholipid bilayers--detergent effect, Biophys. Chem. 1995, 54, 155.

[109] V. M. Mirsky, V. S. Sokolov, A Study of Bacteriorhodsopsin-Containing Proteoliposome Incorporation into Bimolecular Lipid Membranes, Bioelectrochem Bioenerg 1983, 11, 327.

[110] J. Björklund, H. Biverståhl, A. Gräslund, L. Mäler, P. Brzezinski, Real-time transmembrane translocation of penetratin driven by light-generated proton pumping, Biophys. J. 2006, 91, L29.

[111] M. S. Braiman, L. J. Stern, B. H. Chao, H. G. Khorana, Structure-function studies on bacteriorhodopsin. IV. Purification and renaturation of bacterio-opsin polypeptide expressed in Escherichia coli, J. Biol. Chem. 1987, 262, 9271.

[112] L. A. Drachev, A. A. Jasaitis, A. D. Kaulen, A. A. Kondrashin, E. A. Liberman, I. B. Nemecek, S. A. Ostroumov, A. Y. Semenov, V. P. Skulachev, Direct measurement of electric current generation by cytochrome oxidase, H+-ATPase and bacteriorhodopsin, Nature 1974, $249,321$.

[113] F. Madani, A. Perálvarez-Marín, A. Gräslund, Liposome Model Systems to Study the Endosomal Escape of Cell-Penetrating Peptides: Transport across Phospholipid Membranes Induced by a Proton Gradient, J Drug Deliv 2011, 2011, 897592.

[114] J. L. Rigaud, M. T. Paternostre, A. Bluzat, Mechanisms of membrane protein insertion into liposomes during reconstitution procedures involving the use of detergents. 2 . Incorporation of the light-driven proton pump bacteriorhodopsin, Biochemistry 1988, 27, 2677.

[115] M. Seigneuret, J. L. Rigaud, Use of the fluorescent $\mathrm{pH}$ probe pyranine to detect heterogeneous directions of proton movement in bacteriorhodopsin reconstituted large liposomes, FEBS Lett. 1985, 188, 101.

[116] M. Dezi, A. Di Cicco, P. Bassereau, D. Lévy, Detergent-mediated incorporation of transmembrane proteins in giant unilamellar vesicles with controlled physiological contents, Proc. Natl. Acad. Sci. U.S.A. 2013, 110, 7276.

[117] P. Girard, J. Pécréaux, G. Lenoir, P. Falson, J. L. Rigaud, P. Bassereau, A new method for the reconstitution of membrane proteins into giant unilamellar vesicles, Biophys. J. 2004, $87,419$.

[118] N. Kahya, E. I. Pécheur, W. P. de Boeij, D. A. Wiersma, D. Hoekstra, Reconstitution of membrane proteins into giant unilamellar vesicles via peptide-induced fusion, Biophys. J. 2001, 81, 1464. 
[119] J. K. Lanyi, A. Pohorille, Proton pumps: mechanism of action and applications, Trends Biotechnol. 2001, 19, 140.

[120] A. Oren, Industrial and environmental applications of halophilic microorganisms, Environ Technol 2010, 31, 825.

[121] D. Bald, T. Amano, E. Muneyuki, B. Pitard, J. L. Rigaud, J. Kruip, T. Hisabori, M. Yoshida, M. Shibata, ATP synthesis by FOF1-ATP synthase independent of noncatalytic nucleotide binding sites and insensitive to azide inhibition, J. Biol. Chem. 1998, 273, 865.

[122] B. Deisinger, T. Nawroth, K. Zwicker, S. Matuschka, G. John, G. Zimmer, H. J. Freisleben, Purification of ATP synthase from beef heart mitochondria (FOF1) and coreconstitution with monomeric bacteriorhodopsin into liposomes capable of light-driven ATP synthesis, Eur. J. Biochem. 1993, 218, 377.

[123] G. Groth, J. E. Walker, ATP synthase from bovine heart mitochondria: reconstitution into unilamellar phospholipid vesicles of the pure enzyme in a functional state, Biochem. J. 1996, 318 ( Pt 1), 351.

[124] X. He, M. Miginiac-Maslow, C. Sigalat, E. Keryer, F. Haraux, Mechanism of activation of the chloroplast ATP synthase. A kinetic study of the thiol modulation of isolated ATPase and membrane-bound ATP synthase from spinach by ESCHERICIA COLI THIOREDOXIN, J. Biol. Chem. 2000, 275, 13250.

[125] P. Richard, B. Pitard, J. L. Rigaud, ATP synthesis by the FOF1-ATPase from the thermophilic Bacillus PS3 co-reconstituted with bacteriorhodopsin into liposomes. Evidence for stimulation of ATP synthesis by ATP bound to a noncatalytic binding site, J. Biol. Chem. 1995, 270, 21571.

[126] I. J. Ryrie, C. Critchley, J. E. Tillberg, Structure and energy-linked activities in reconstituted bacteriorhodopsin-yeast ATPase proteoliposomes, Arch. Biochem. Biophys. 1979, 198, 182.

[127] N. Sone, Y. Takeuchi, M. Yoshida, K. Ohno, Formations of electrochemical proton gradient and adenosine triphosphate in proteoliposomes containing purified adenosine triphosphatase and bacteriorhodopsin, J. Biochem. 1977, 82, 1751.

[128] R. L. van der Bend, J. B. W. J. Cornelissen, J. A. Berden, K. van Dam, Factors defining the functional coupling of bacteriorhodopsin and ATP synthase in liposomes, Biochim. Biophys. Acta - Bioenergetics 1984, 767, 87.

[129] M. Yoshida, N. Sone, H. Hirata, Y. Kagawa, ATP synthesis catalyzed by purified DCCD-sensitive ATPase incorporated into reconstituted purple membrane vesicles, Biochem. Biophys. Res. Commun. 1975, 67, 1295. 
[130] G. D. Winget, N. Kanner, E. Racker, Formation of ATP by the adenosine triphosphatase complex from spinach chloroplasts reconstituted together with bacteriorhodopsin, Biochim. Biophys. Acta 1977, 460, 490.

[131] T.-J. M. Luo, R. Soong, E. Lan, B. Dunn, C. D. Montemagno, Photo-induced proton gradients and ATP biosynthesis produced by vesicles encapsulated in a silica matrix, Nat Mater 2005, 4, 220.

[132] H.-J. Choi, C. D. Montemagno, Artificial organelle: ATP synthesis from cellular mimetic polymersomes, Nano Lett. 2005, 5, 2538.

[133] A. V. Patil, T. Premaruban, O. Berthoumieu, A. Watts, J. J. Davis, Enhanced photocurrent in engineered bacteriorhodopsin monolayer, J Phys Chem B 2012, 116, 683.

[134] J. Sasaki, L. S. Brown, Y. S. Chon, H. Kandori, A. Maeda, R. Needleman, J. K. Lanyi, Conversion of bacteriorhodopsin into a chloride ion pump, Science 1995, 269, 73.

[135] D. Rhinow, I. Chizhik, R.-P. Baumann, F. Noll, N. Hampp, Crystallinity of purple membranes comprising the chloride-pumping bacteriorhodopsin variant D85T and its modulation by $\mathrm{pH}$ and salinity, J Phys Chem B 2010, 114, 15424.

[136] H. Lindsey, N. O. Petersen, S. I. Chan, Physicochemical characterization of 1,2diphytanoyl-sn-glycero-3-phosphocholine in model membrane systems, Biochim. Biophys. Acta 1979, 555, 147.

[137] R. Coronado, Recent advances in planar phospholipid bilayer techniques for monitoring ion channels, Annu Rev Biophys Biophys Chem 1986, 15, 259.

[138] A. E. Blaurock, Bacteriorhodospin: a trans-membrane pump containing alpha-helix, $J$. Mol. Biol. 1975, 93, 139.

[139] R. Lipowsky, E. Sackmann (Eds.) Handbook of Biological Physics. Structure and Dynamics of Membranes, Elsevier Science B.V., 1995.

[140] P. J. Davis, B. D. Fleming, K. P. Coolbear, K. M. Keough, Gel to liquid-crystalline transition temperatures of water dispersions of two pairs of positional isomers of unsaturated mixed-acid phosphatidylcholines, Biochemistry 1981, 20, 3633.

[141] S. D. O'neill, A. C. Leopold, An assessment of phase transitions in soybean membranes, Plant Physiol. 1982, 70, 1405.

[142] G. S. Patil, N. J. Dorman, D. G. Cornwell, Effects of ionization and counterion binding on the surface areas of phosphatidic acids in monolayers, J. Lipid Res. 1979, 20, 663.

[143] C. D. Heyes, M. A. El-Sayed, The role of the native lipids and lattice structure in bacteriorhodopsin protein conformation and stability as studied by temperature-dependent Fourier transform-infrared spectroscopy, J. Biol. Chem. 2002, 277, 29437. 
[144] F. C. Tsui, D. M. Ojcius, W. L. Hubbell, The Intrinsic pKA Values for Phosphatidylserine and Phosphatidylethanolamine in Phosphatidylcholine Host Bilayers, Biophys. J. 1986, 49, 459.

[145] A. Boll, Das vollständige HIV-1 Tat-Protein überquert Lipidmembranen?, Dissertation, Georg-August-Universität, Göttingen, 2011.

[146] I. M. Hafez, P. R. Cullis, Roles of lipid polymorphism in intracellular delivery, $A d v$. Drug Deliv. Rev. 2001, 47, 139.

[147] E. K. Schmitt, Hochohmige porenüberspannende Lipidmembranen: Elektrochemische Untersuchungen zur Aktivität von Gramicidin und Bacteriorhodopsin, Dissertation, GeorgAugust-Universität, Göttingen, 2009.

[148] J. Campina, A. Martins, F. Silva, Selective Permeation of a Liquidlike Self-Assembled Monolayer of 11-Amino-1-undecanethiol on Polycrystalline Gold by Highly Charged Electroactive Probes, J Phys Chem C 2007, 111, 5351.

[149] Z. Dai, H. Ju, Effect of chain length on the surface properties of $\omega$-carboxy alkanethiol self-assembled monolayers, Phys Chem Chem Phys 2001, 3, 3769.

[150] M. A. Behlke, H. Lingyan, L. Bogh, S. Rose, E. J. Devor, Fluorescence and Fluorescence Applications, http://3979.voxcdn.com/Support/Technical/TechnicalBulletinPDF/Fluorescence_and_Fluores cence_Applications.pdf, 2005, abgerufen am 14.02.2013.

[151] R. B. Mujumdar, L. A. Ernst, S. R. Mujumdar, C. J. Lewis, A. S. Waggoner, Cyanine dye labeling reagents: sulfoindocyanine succinimidyl esters, Bioconjug. Chem. 1993, 4, 105.

[152] Molecular Probes, Alexa Fluor® Succinimidyl Esters (NHS esters) (MP10168), http://tools.invitrogen.com/content/sfs/manuals/mp10168.pdf, 2012, abgerufen am 14.02.2013.

[153] N. R. Clement, J. M. Gould, Pyranine (8-hydroxy-1,3,6-pyrenetrisulfonate) as a probe of internal aqueous hydrogen ion concentration in phospholipid vesicles, Biochemistry 1981, 20,1534 .

[154] D. Oesterhelt, B. Hess, Reversible photolysis of the purple complex in the purple membrane of Halobacterium halobium, Eur. J. Biochem. 1973, 37, 316.

[155] J. Heberle, N. A. Dencher, Surface-bound optical probes monitor protein translocation and surface potential changes during the bacteriorhodopsin photocycle, Proc. Natl. Acad. Sci. U.S.A. 1992, 89, 5996.

[156] Molecular Probes, Amine Reactive Probes (MP 00143), http://probes.invitrogen.com/media/pis/mp00143.pdf, 2009, abgerufen am 14.02.2013. 
[157] E. L. Florin, H. E. Gaub, Painted supported lipid membranes, Biophys. J. 1993, 64, 375.

[158] Christian Horn, Aktivität lichtaktivierter Proteine adsorbiert an funktionalisierten nanoporösen Aluminaten, Dissertation, Universität Regensburg, Regensburg, 2005.

[159] M. Angelova, S. Soléau, P. Méléard, F. Faucon, P. Bothorel, Preparation of giant vesicles by external AC electric fields. Kinetics and applications, Prog. Colloid Polym. Sci. 1992, 89, 127.

[160] L. Mathivet, S. Cribier, P. F. Devaux, Shape change and physical properties of giant phospholipid vesicles prepared in the presence of an AC electric field, Biophys. J. 1996, 70, 1112.

[161] A. Orth, Einfluss des Zellkortex auf die Plasmamembran: Modulation von Mikrodomänen in Modellmembranen, Dissertation, Georg-August-Universität, Göttingen, 2012.

[162] M. K. Doeven, J. H. A. Folgering, V. V. Krasnikov, E. R. Geertsma, G. van den Bogaart, B. Poolman, Distribution, lateral mobility and function of membrane proteins incorporated into giant unilamellar vesicles, Biophys. J. 2005, 88, 1134.

[163] M. Davidson, M. Karlsson, J. Sinclair, K. Sott, O. Orwar, Nanotube-vesicle networks with functionalized membranes and interiors, J. Am. Chem. Soc. 2003, 125, 374.

[164] N. Kahya, D. A. Brown, P. Schwille, Raft partitioning and dynamic behavior of human placental alkaline phosphatase in giant unilamellar vesicles, Biochemistry 2005, 44, 7479.

[165] K. Akashi, H. Miyata, H. Itoh, K. Kinosita, Preparation of giant liposomes in physiological conditions and their characterization under an optical microscope, Biophys. $J$. 1996, 71, 3242.

[166] T. Pott, H. Bouvrais, P. Méléard, Giant unilamellar vesicle formation under physiologically relevant conditions, Chem. Phys. Lipids 2008, 154, 115.

[167] T. Geppert, S. Schweizer, U. Gösele, R. Wehrspohn, Deep trench etching in macroporous silicon, Appl. Phys. A 2006, 84, 237.

[168] P. Mueller, D. O. Rudin, H. T. Tien, W. C. Wescott, Reconstitution of cell membrane structure in vitro and its transformation into an excitable system, Nature 1962, 194, 979.

[169] S. H. White, Analysis of the torus surrounding planar lipid bilayer membranes, Biophys. J. 1972, 12, 432. 
[170] L. Ding, J. Li, S. Dong, E. Wang, Supported phospholipid membranes: comparison among different deposition methods for a phospholipid monolayer, J. Electroanal. Chem. 1996, 416, 105.

[171] S. H. White, Temperature-dependent structural changes in planar bilayer membranes: solvent "freeze-out", Biochim. Biophys. Acta 1974, 356, 8.

[172] A. Orth, L. Johannes, W. Römer, C. Steinem, Creating and modulating microdomains in pore-spanning membranes, ChemPhysChem 2012, 13, 108.

[173] D. Frese, Rekonstitution von Bacteriorhodopsin in porenüberspannenden Membranen und dessen Einfluss auf die laterale Mobilität der Matrixlipide, Diplomarbeit, Georg-AugustUniversität, Göttingen, 2009.

[174] TU Darmstadt, Institut für Biochemie, Aktiver Transport von Protonen über natürliche und artifizielle biologische Membranen. Biochemisches Praktikum II, Physikalische Biochemie, Darmstadt, 2006.

[175] K. Kano, J. H. Fendler, Pyranine as a sensitive $\mathrm{pH}$ probe for liposome interiors and surfaces. pH gradients across phospholipid vesicles, Biochim. Biophys. Acta 1978, 509, 289.

[176] M. Minsky, Memoir on inventing the confocal scanning microscope, Scanning 1988, $10,128$.

[177] S. Wilhelm, Confocal Laser Scanning Microscopy, http://www.zeiss.de/C1256CFB00332E16/0/4A76BC11844F32F4C12578300048B58A/\$file/ 60-1-0030_confocal-principles.pdf, Jena, 2010, abgerufen am 14.08.2012.

[178] D. Axelrod, D. E. Koppel, J. Schlessinger, E. Elson, W. W. Webb, Mobility measurement by analysis of fluorescence photobleaching recovery kinetics, Biophys. J. 1976, $16,1055$.

[179] P. K. Hansma, B. Drake, O. Marti, S. A. Gould, C. B. Prater, The scanning ionconductance microscope, Science 1989, 243, 641.

[180] P. Novak, C. Li, A. I. Shevchuk, R. Stepanyan, M. Caldwell, S. Hughes, T. G. Smart, J. Gorelik, V. P. Ostanin, M. J. Lab et al., Nanoscale live-cell imaging using hopping probe ion conductance microscopy, Nat. Methods 2009, 6, 279.

[181] M. Böcker, S. Muschter, E. K. Schmitt, C. Steinem, T. E. Schäffer, Imaging and patterning of pore-suspending membranes with scanning ion conductance microscopy, Langmuir 2009, 25, 3022.

[182] I. Höfer, C. Steinem, A membrane fusion assay based on pore-spanning lipid bilayers, Soft Matter 2011, 7, 1644. 
[183] M. Böcker, Entwicklungen in der Rasterionenleitfähigkeitsmikroskopie und Untersuchungen von porenüberspannenden Lipidmembranen, Dissertation, FriedrichAlexander-Universität, Erlangen-Nürnberg, 2009.

[184] A. Donnermeyer, Scanning Ion--Conductance Microscopy, Dissertation, Universität Bielefeld, Bielefeld, 2007.

[185] I. Mey, M. Stephan, E. K. Schmitt, M. M. Müller, M. Ben Amar, C. Steinem, A. Janshoff, Local membrane mechanics of pore-spanning bilayers, J. Am. Chem. Soc. 2009, 131,7031 .

[186] S. Lingler, I. Rubinstein, W. Knoll, A. Offenhäusser, Fusion of Small Unilamellar Lipid Vesicles to Alkanethiol and Thiolipid Self-Assembled Monolayers on Gold, Langmuir 1997, 13, 7085 .

[187] J. Jass, T. Tjärnhage, G. Puu, From liposomes to supported, planar bilayer structures on hydrophilic and hydrophobic surfaces: an atomic force microscopy study, Biophys. $J$. 2000, 79, 3153.

[188] C. Hamai, P. S. Cremer, S. M. Musser, Single giant vesicle rupture events reveal multiple mechanisms of glass-supported bilayer formation, Biophys. J. 2007, 92, 1988.

[189] D. Papahadjopoulos, S. Nir, N. Düzgünes, Molecular mechanisms of calcium-induced membrane fusion, J. Bioenerg. Biomembr. 1990, 22, 157.

[190] W.-Y. Tai, Y.-C. Yang, H.-J. Lin, C.-P. Huang, Y.-L. Cheng, M.-F. Chen, H.-L. Yen, I. Liau, Interplay between structure and fluidity of model lipid membranes under oxidative attack, J Phys Chem B 2010, 114, 15642.

[191] J. Velasco, S. Marmesat, C. Dobarganes, G. Márquez-Ruiz, Heterogeneous aspects of lipid oxidation in dried microencapsulated oils, J. Agric. Food Chem. 2006, 54, 1722.

[192] K. Jacobson, D. Papahadjopoulos, Phase transitions and phase separations in phospholipid membranes induced by changes in temperature, $\mathrm{pH}$, and concentration of bivalent cations, Biochemistry 1975, 14, 152.

[193] H. Hauser, Effect of inorganic cations on phase transitions, Chem. Phys. Lipids 1991, $57,309$.

[194] A. Boll, A. Jatho, N. Czudnochowski, M. Geyer, C. Steinem, Mechanistic insights into the translocation of full length HIV-1 Tat across lipid membranes, Biochim. Biophys. Acta 2011, 1808, 2685.

[195] S. Bleicken, C. Wagner, A. J. García-Sáez, Mechanistic differences in the membrane activity of Bax and Bcl-xL correlate with their opposing roles in apoptosis, Biophys. J. 2013, $104,421$. 
[196] W. Stoeckenius, R. Rowen, A morphological study of Halobacterium halobium and its lysis in media of low salt concentration, J. Cell Biol. 1967, 34, 365.

[197] W. S. M. El-Sayed, S. Takaichi, H. Saida, M. Kamekura, M. Abu-Shady, H. Seki, T. Kuwabara, Effects of light and low oxygen tension on pigment biosynthesis in Halobacterium salinarum, revealed by a novel method to quantify both retinal and carotenoids, Plant Cell Physiol. 2002, 43, 379.

[198] K. Yoshimura, T. Kouyama, Structural role of bacterioruberin in the trimeric structure of archaerhodopsin-2, J. Mol. Biol. 2008, 375, 1267.

[199] A. M. Dummer, J. C. Bonsall, J. B. Cihla, S. M. Lawry, G. C. Johnson, R. F. Peck, Bacterioopsin-mediated regulation of bacterioruberin biosynthesis in Halobacterium salinarum, J. Bacteriol. 2011, 193, 5658.

[200] Y. Liu, S. L. Regen, Control over Vesicle Rupture and Leakage by Membrane Packing and by the Aggregation State of an Attacking Surfactant, J. Am. Chem. Soc. 1993, 115, 708.

[201] T. Portet, C. Mauroy, V. Démery, T. Houles, J.-M. Escoffre, D. S. Dean, M.-P. Rols, Destabilizing giant vesicles with electric fields: an overview of current applications, $J$. Membr. Biol. 2012, 245, 555.

[202] N. N. Soe, L. T. Shwe, K. T. Lwin, Study on Extraction of Lanthanum Oxide from Monazite Concentrate, World Academy of Science, Engineering and Technology 2008, 22, 142.

[203] V. F. Antonov, E. V. Shevchenko, Smirnova EYu, E. V. Yakovenko, A. V. Frolov, Stable cupola-shaped bilayer lipid membranes with mobile Plateau-Gibbs border: expansionshrinkage of membrane due to thermal transitions, Chem. Phys. Lipids 1992, 61, 219.

[204] L.-D. Naake, G. Wiegand, Franck Ernst Ulrich, The Viscosity of n-Decane to High Temperatures of 573K and High Pressures of 300MPa, Z Phys Chem 2002, 216, 1295.

[205] K. Rykaczewski, S. Anand, S. Bengaluru Subramanyam, K. K. Varanasi, Mechanism of Frost Formation on Lubricant-Impregnated Surfaces, Langmuir 2013, DOI: 10.1021/la400801s.

[206] H. Fujiwara, M. Fujihara, T. Ishiwata, Dynamics of the spontaneous formation of a planar phospholipid bilayer: A new approach by simultaneous electrical and optical measurements, J. Chem. Phys. 2003, 119, 6768.

[207] P. F. Fahey, W. W. Webb, Lateral diffusion in phospholipid bilayer membranes and multilamellar liquid crystals, Biochemistry 1978, 17, 3046.

[208] H. S. Kim, R. H. Blick, D. M. Kim, C. B. Eom, Bonding silicon-on-insulator to glass wafers for integrated bio-electronic circuits, Applied Physics Letters 2004, 85, 2370. 
[209] K. Suzuki, H. Masuhara, Groove-spanning behavior of lipid membranes on microfabricated silicon substrates, Langmuir 2005, 21, 6487.

[210] I. Pfeiffer, S. Petronis, I. Köper, B. Kasemo, M. Zäch, Vesicle adsorption and phospholipid bilayer formation on topographically and chemically nanostructured surfaces, $J$ Phys Chem B 2010, 114, 4623.

[211] J. Rädler, H. Strey, E. Sackmann, Phenomenology and Kinetics of Lipid Bilayer Spreading on Hydrophilic Surfaces, Langmuir 1995, 11, 4539.

[212] K. H. Sheikh, H. K. Christenson, R. J. Bushby, S. D. Evans, A model system to study the insertion of cholesterol into a phospholipid monolayer, J Phys Chem B 2007, 111, 379.

[213] V. Raspal, K. O. Awitor, C. Massard, E. Feschet-Chassot, R. S. P. Bokalawela, M. B. Johnson, Nanoporous surface wetting behavior: the line tension influence, Langmuir 2012, 28,11064 .

[214] E. Bormashenko, A. Musin, G. Whyman, M. Zinigrad, Wetting transitions and depinning of the triple line, Langmuir 2012, 28, 3460.

[215] B.-B. Ke, L.-S. Wan, Y. Li, M.-Y. Xu, Z.-K. Xu, Selective layer-by-layer selfassembly on patterned porous films modulated by Cassie-Wenzel transition, Phys Chem Chem Phys 2011, 13, 4881.

[216] J. Kuhlmann, Kraftspektroskopische Studien an porenüberspannenden Membranen, Masterarbeit, Georg-August-Universität, Göttingen, 2012.

[217] E. Reimhult, F. Höök, B. Kasemo, Intact Vesicle Adsorption and Supported Biomembrane Formation from Vesicles in Solution: Influence of Surface Chemistry, Vesicle Size, Temperature, and Osmotic Pressure, Langmuir 2003, 19, 1681.

[218] S. Ohki, R. Sauve, Surface potential of phosphatidylserine monolayers. I. Divalent ion binding effect, Biochim. Biophys. Acta 1978, 511, 377.

[219] S. Ohki, R. Kurland, Surface potential of phosphatidylserine monolayers. II. Divalent and monovalent ion binding, Biochim. Biophys. Acta 1981, 645, 170.

[220] K. Satoh, Determination of binding constants of $\mathrm{Ca} 2+, \mathrm{Na}+$, and $\mathrm{Cl}$ - ions to liposomal membranes of dipalmitoylphosphatidylcholine at gel phase by particle electrophoresis, Biochim. Biophys. Acta 1995, 1239, 239.

[221] N. Kampf, D. Ben-Yaakov, D. Andelman, S. A. Safran, J. Klein, Direct measurement of sub-Debye-length attraction between oppositely charged surfaces, Phys. Rev. Lett. 2009, 103, 118304.

[222] S. Ohki, H. Ohshima, Divalent cation-induced phosphatidic acid membrane fusion. Effect of ion binding and membrane surface tension, Biochim. Biophys. Acta 1985, 812, 147. 
[223] S. McLaughlin, N. Mulrine, T. Gresalfi, G. Vaio, A. McLaughlin, Adsorption of divalent cations to bilayer membranes containing phosphatidylserine, J. Gen. Physiol. 1981, 77,445 .

[224] I. Reviakine, A. Brisson, Formation of Supported Phospholipid Bilayers from Unilamellar Vesicles Investigated by Atomic Force Microscopy, Langmuir 2000, 16, 1806.

[225] S. Onishi, T. Ito, Calcium-induced phase separations in phosphatidylserine-phosphatidylcholine membranes, Biochemistry 1974, 13, 881.

[226] T. Cha, A. Guo, X.-Y. Zhu, Formation of supported phospholipid bilayers on molecular surfaces: role of surface charge density and electrostatic interaction, Biophys. $J$. 2006, $90,1270$.

[227] Y.-H. Kim, M. M. Rahman, Z.-L. Zhang, N. Misawa, R. Tero, T. Urisu, Supported lipid bilayer formation by the giant vesicle fusion induced by vesicle-surface electrostatic attractive interaction, Chemical Physics Letters 2006, 420, 569.

[228] R. Tero, H. Watanabe, T. Urisu, Supported phospholipid bilayer formation on hydrophilicity-controlled silicon dioxide surfaces, Phys Chem Chem Phys 2006, 8, 3885.

[229] Y. Avnir, Y. Barenholz, pH determination by pyranine: medium-related artifacts and their correction, Anal. Biochem. 2005, 347, 34.

[230] K. Wagner, D. Harries, S. May, V. Kahl, J. O. Rädler, A. Ben-Shaul, Direct Evidence for Counterion Release upon Cationic Lipid-DNA Condensation, Langmuir 2000, 16, 303.

[231] D. Ben-Yaakov, Y. Burak, D. Andelman, S. A. Safran, Electrostatic interactions of asymmetrically charged membranes, Europhys. Lett. 2007, 79, 48002.

[232] David Andelman, Need your help for discussion of my results in PhD thesis; Entropic attraction of oppositely charged surfaces. E-Mail, 15.04.-28.04.13.

[233] T. Cserháti, M. Szögyi, Interaction between phospholipids and monovalent cations studied by a new thin-layer chromatographic method, Chem. Phys. Lipids 1983, 34, 93.

[234] J. Saarikangas, H. Zhao, A. Pykäläinen, P. Laurinmäki, P. K. Mattila, P. K. J. Kinnunen, S. J. Butcher, P. Lappalainen, Molecular mechanisms of membrane deformation by I-BAR domain proteins, Curr. Biol. 2009, 19, 95.

[235] L. Johannes, W. Römer, Shiga toxins--from cell biology to biomedical applications, Nat. Rev. Microbiol. 2010, 8, 105.

[236] H. Barelli, B. Antonny, Cell biology: Detached membrane bending, Nature 2009, 458, 159.

[237] H. T. McMahon, J. L. Gallop, Membrane curvature and mechanisms of dynamic cell membrane remodelling, Nature 2005, 438, 590. 
[238] K. A. Riske, R. Dimova, Electro-Deformation and Poration of Giant Vesicles Viewed with High Temporal Resolution, Biophys. J. 2005, 88, 1143.

[239] K. Oglęcka, J. Sanborn, A. N. Parikh, R. S. Kraut, Osmotic gradients induce bioreminiscent morphological transformations in giant unilamellar vesicles, Front Physiol 2012, 3,120 .

[240] D. R. Lide, CRC handbook of chemistry and physics, 1998-1999, CRC Press, Boca Raton, 1998.

[241] Z. Hai-Lang, H. Shi-Jun, Viscosity and Density of Water + Sodium Chloride + Potassium Chloride Solutions at 298.15 K, J Chem Eng Data 1998, 41, 516.

[242] M. Fuhrmans, M. Müller, Mechanisms of vesicle spreading on surfaces: coarsegrained simulations, Langmuir 2013, 29, 4335.

[243] M. Staykova, M. Arroyo, M. Rahimi, H. A. Stone, Confined bilayers passively regulate shape and stress, Phys. Rev. Lett. 2013, 110, 28101.

[244] J. M. Thomas, M. E. Hodes, A new discontinuous buffer system for the electrophoresis of cationic proteins at near-neutral pH, Anal. Biochem. 1981, 118, 194.

[245] Sigma-Aldrich, MOPS sodium salt (M9381) - Product Information Sheet, http://www.sigmaaldrich.com/etc/medialib/docs/Sigma/Product_Information_Sheet/1/m9381 pis.Par.0001.File.tmp/m9381pis.pdf, 2000, abgerufen am 29.04.2013.

[246] P. Luckham, J. Wood, S. Froggatt, R. Swart, A Comparison of Directly Measured Forces and Monolayer Behavior of Dipalmitoylphosphatidic Acid, J Colloid Interface Sci 1992, 153, 368.

[247] T. Husslein, D. M. Newns, P. C. Pattnaik, Q. Zhong, P. B. Moore, M. L. Klein, Constant pressure and temperature molecular-dynamics simulation of the hydrated diphytanolphosphatidylcholine lipid bilayer, J. Chem. Phys. 1998, 109, 2826.

[248] E. Graf, J. R. Mahoney, R. G. Bryant, J. W. Eaton, Iron-catalyzed hydroxyl radical formation. Stringent requirement for free iron coordination site, J. Biol. Chem. 1984, 259, 3620.

[249] K. Seifert, K. Fendler, E. Bamberg, Charge transport by ion translocating membrane proteins on solid supported membranes, Biophys. J. 1993, 64, 384.

[250] P. Seta, P. Ormos, B. d'Epenoux, C. Gavach, Photocurrent response of bacteriorhodopsin adsorbed on bimolecular lipid membranes, Biochim. Biophys. Acta 1980, 591,37 . 
[251] R.-P. Baumann, A. P. Busch, B. Heidel, N. Hampp, A new class of purple membrane variants for the construction of highly oriented membrane assemblies on the basis of noncovalent interactions, $J$ Phys Chem B 2012, 116, 4134.

[252] P. Richard, J. L. Rigaud, P. Gräber, Reconstitution of CF0F1 into liposomes using a new reconstitution procedure, Eur. J. Biochem. 1990, 193, 921.

[253] J. Preobraschenski, Transport mechanisms of the vesicular glutamate transporter 1, Dissertation, Max Planck Institut für Biophysikalische Chemie, Göttingen, 2012.

[254] Y. Kimura, M. Fujiwara, A. Ikegami, Anisotropic electric properties of purple membrane and their change during the photoreaction cycle, Biophys. J. 1984, 45, 615.

[255] K. Barabás, A. Dér, Z. Dancsházy, P. Ormos, L. Keszthelyi, M. Marden, Electrooptical measurements on aqueous suspension of purple membrane from Halobacterium halobium, Biophys. J. 1983, 43, 5.

[256] K. Jørgensen, M. M. Sperotto, O. G. Mouritsen, J. H. Ipsen, M. J. Zuckermann, Phase equilibria and local structure in binary lipid bilayers, Biochim. Biophys. Acta 1993, 1152, 135.

[257] N. Kahya, D. A. Wiersma, B. Poolman, D. Hoekstra, Spatial organization of bacteriorhodopsin in model membranes. Light-induced mobility changes, J. Biol. Chem. 2002, 277, 39304.

[258] M. D. El Alaoui Faris, D. Lacoste, J. Pécréaux, J.-F. Joanny, J. Prost, P. Bassereau, Membrane tension lowering induced by protein activity, Phys. Rev. Lett. 2009, 102, 38102.

[259] A. de La Escosura-Muñiz, A. Merkoçi, Nanochannels preparation and application in biosensing, ACS Nano 2012, 6, 7556.

[260] O. Gassmann, M. Kreir, C. Ambrosi, J. Pranskevich, A. Oshima, C. Röling, G. Sosinsky, N. Fertig, C. Steinem, The M34A mutant of Connexin26 reveals active conductance states in pore-suspending membranes, J. Struct. Biol. 2009, 168, 168.

[261] H. A. O. Gaßmann, Integration von Connexonen in Lipidmembranen auf porösen Oberflächen, Dissertation, Georg-August-Universität, Göttingen, 2010.

[262] M. Kocun, Mechanical properties of pore-spanning membranes prepared from giant vesicles, Dissertation, Georg-August-Universität, Göttingen, 2011.

[263] R. Peters, R. J. Cherry, Lateral and rotational diffusion of bacteriorhodopsin in lipid bilayers: experimental test of the Saffman-Delbrück equations, Proc. Natl. Acad. Sci. U.S.A. 1982, 79, 4317.

[264] H. Li, D.-L. Chen, S. Zhong, B. Xu, B.-S. Han, K.-S. Hu, Structural changes of purple membrane and bacteriorhodopsin during its denaturation induced by high $\mathrm{pH}, J$ Phys Chem $B$ 2005, 109, 11273. 
[265] Y. Shen, C. R. Safinya, K. S. Liang, A. F. Ruppert, K. J. Rothschild, Stabilization of the membrane protein bacteriorhodopsin to $140{ }^{\circ} \mathrm{C}$ in two-dimensional films, Nature 1993, 366,48 . 
7 Literaturverzeichnis 


\section{Anhang}

\subsection{Symbolverzeichnis}

A

a.u.

AU

$c$

$d$

D

E

F

G

$g$

$\mathrm{h}$

$h$

I

$I_{\mathrm{V}}$

$J$

M

$\mathrm{m}$

$N$

$n$

$\mathrm{N}_{\mathrm{A}}$

$N A$

$P$
Fläche

arbitrary units, willkürliche Einheiten

airy unit

Konzentration

Durchmesser; Auflösung

Diffusionskoeffizient

Extinktion

Faraday Konstante $\left(96485 \mathrm{C} \cdot \mathrm{mol}^{-1}\right)$

Gibbs Energie, Freie Enthalpie

Erdbeschleunigung $\left(9,81 \mathrm{~m} \cdot \mathrm{s}^{-1}\right)$

Planksches Wirkungsquantum $\left(6,626 \cdot 10^{-34} \mathrm{~J} \cdot \mathrm{s}^{-1}\right)$

Tiefe

Fluoreszenzintensität

Lichtstärke

Stromdichte

molare Masse; mobile fraction, mobiler Anteil

Steigung

Teilchenzahl; Anzahl

Brechungsindex

Avogadro-Konstante $\left(6,022 \cdot 10^{23} \mathrm{~mol}^{-1}\right)$

Numerische Apertur

Porosität 


\begin{tabular}{|c|c|}
\hline $\mathrm{R}$ & Universelle Gaskonstante $\left(8,31451 \mathrm{~J} \cdot \mathrm{mol}^{-1} \cdot \mathrm{K}^{-1}\right)$ \\
\hline$R^{2}$ & Bestimmtheitsmaß \\
\hline$T$ & absolute Temperatur \\
\hline$t$ & Zeit \\
\hline$T_{1}$ & Zeitkonstante einer exponentiellen Anpassung \\
\hline$T_{\mathrm{c}}$ & Phasenumwandlungstemperatur \\
\hline$V$ & Volumen \\
\hline $\mathrm{v}$ & Volumen \\
\hline w & Gewicht \\
\hline$x$ & $\mathrm{x}$-Achse \\
\hline$y$ & $y$-Achse \\
\hline$z$ & Ladung; $z$-Achse \\
\hline$\alpha$ & Halber Öffnungswinkel eines Objektivs \\
\hline$\varepsilon$ & Molarer, dekadischer Extinktionskoeffizient \\
\hline$\eta$ & Viskosität \\
\hline$\lambda$ & Wellenlänge \\
\hline$v$ & Frequenz \\
\hline$\tau_{1 / 2}$ & charakteristische Diffusionszeit \\
\hline$\phi$ & elektrisches Potential \\
\hline$\omega$ & Radius eines Bleichprofils \\
\hline
\end{tabular}

\subsection{Abkürzungsverzeichnis}

A/D analog/digital

Abb. Abbildung

abs. absorption, Absorption

ABT Aminobenztropin

ADP Adenosin-5'-diphosphat 
AFM

APS

ATP

BAR

BHF

Bio-Cap-PE

BLM

Bodipy PC

bop

bR

bzw.

C

ca.

CCCP

CF

CLSM

CMC

CPEO3

DHPE

DMF

DNA

DOL

DOPC

DOPE

DOTM

DPhPC

DPPA

DPPS

DPPTE atomic force microscopy, Rasterkraftmikroskopie

3-Aminopropyldimethylethoxysilan

Adenosin-5'-triphosphat

Bin-Amphiphysin-Rvs

buffered $H F$, gepuffertes HF-Ätzen

1,2-Dipalmitoyl-sn-glycero-3-phosphoethanolamin- $N$-capronsäure-biotin black lipid membrane, freistehende Membran

$\beta$-BODIPY® 500/510 $\mathrm{C}_{12} \mathrm{HPC}$

Bacterioopsin-codierendes Gen

Bacteriorhodopsin

beziehungsweise

Cystein

circa

Carbonylcyanid-m-chlorphenylhydrazon

Carboxyfluorescein

confocal laser scanning microscope, konfokales Laserrastermikroskop

critical micelle concentration, kritische Mizellenbildungskonzentration

Cholesterylpolyethylenoxythiol

1,2-Dihexadekanoyl-sn-glycero-3-phosphoethanolamin

$N, N$-Dimethylformamid

Desoxyribonukleinsäure

degree of labeling, Markierungsrate

1,2-Dioleoyl-sn-glycero-3-phosphocholin

1,2-Dioleoyl-sn-glycero-3-phosphoethanolamin

$n$-Dodecyl- $\beta$-D-thiomaltopyranosid

1,2-Diphytanoyl-sn-glycero-3-phosphocholin

1,2-Dipalmitoyl-sn-glycero-3-phosphat

diode-pumped solid state

1,2-Dipalmitoyl-sn-glycero-3-phosphothioethanol 
DPX $\quad p$-Xylol-bispyridiniumbromid

em. emission, Emission

et al. et alii/aliae/alia, und andere

ETFE Ethylentetrafluorethylen

ex. excitation, Anregung

FCCP Carbonylcyanid- $p$-(trifluormethoxy)phenylhydrazon

FCS fluorescence correlation spectroscopy, Fluoreszenzkorrelationsspektroskopie

FITC Fluoresceinisothiocyanat

FomA fusobacterial outer membrane porin A, ein Porin

FRAP fluorescence recovery after photobleaching

FWHM full width at half maximum, Halbwertsbreite

$\mathrm{Gb}_{3} \quad$ Globotriaosylceramid

Gl. Gleichung

GUV giant unilamellar vesicle, mikrometergroßer Vesikel

HEPES 2-(4-(2-Hydroxyethyl)-1-piperazinyl)-ethansulfonsäure

ITO indium tin oxide, Indium-Zinn-Oxid

KcsA potassium crystallographically-sited activation channel, ein Kaliumkanal

Kcv viral potassium channel

LED light-emitting diode, Leuchtdiode

$\lg , \log \quad$ dekadischer Logarithmus

ln logarithmus naturalis, natürlicher Logarithmus

LUV large unilamellar vesicle, sub-mikrometergroßer unilamellarer Vesikel

M Methionin

max. $\quad$ maximum, Maximum

MOPS 3-(N-Morpholino)-Propansulfonsäure

NHS N-Hydroxysuccinimid

NMR nuclear magnetic resonance, Kernspinresonanz

n-OG n-Octyl- $\beta$-D-glucosid 
norm.

ODA

ODT

$\mathrm{OmpF}$

PBS

PDB (ID)

PDMS

PEG

PH

$\mathrm{Pi}$

PM

PMMA

PMT

POPC

POPS

Pyranin

QCM-D

rel.

ROI

$\mathrm{S} / \mathrm{N}$

SAM

$\mathrm{sccm}$

SDS

SEM

SICM

sog.

SOI normiert

Octadecylamin

Octadekanthiol

outer membrane protein $F$, ein Porin

phosphate buffered saline, phosphatgepufferte Salzlösung

protein data bank (identity document)

Polydimethylsiloxan

Polyethylenglycol

pinhole, Lochblende

anorganisches Phosphat

purple membrane, Purpurmembran

Polymethylmethacrylat

photomultiplier tube, Sekundärelektronenvervielfacher

1-Palmitoyl-2-oleoyl-sn-glycero-3-phosphocholin

1-Palmitoyl-2-oleoyl-sn-glycero-3-phospho-L-serin

8-Hydroxypyren-1,3,6-Trisulfonsäure

quartz crystal microbalance with dissipation monitoring,

Schwingquarzmikrowaage mit Dissipationsaufnahme

relativ

region of interest

signal-to-noise, Signal-zu-Rauschen

self assembled monolayer, selbstorganisierende Monoschicht

standard cubic centimeters per minute, Standardkubikzentimeter pro

Minute

Natriumdodecylsulfat

scanning electron microscopy, Rasterelektronenmikroskopie

scanning ion conductance microscopy,

Rasterionenleitfähigkeitsmikroskopie

sogenannt

silicon-on-insulator 


$\begin{array}{ll}\text { SOPC } & \text { 1-Stearoyl-2-oleoyl-sn-glycero-3-phosphocholin } \\ \text { SPM } & \text { scanning probe microscopy, Rastersondenmikroskopie } \\ \text { SPR } & \text { surface plasmon resonance, Oberflächenplasmonenresonanzspektroskopie } \\ \text { SSM } & \text { solid supported membrane, festkörperunterstützte Membran } \\ \text { TDT } & \text { 1-Tetradekanthiol } \\ \text { TIRF } & \text { total internal reflection fluorescence, interne } \\ \text { TRIS } & \text { Totalreflexionsfluoresezenzmikroskopie } \\ \text { u. a. } & \text { Tris(hydroxymethyl)-aminomethan } \\ \text { USB } & \text { unter anderem } \\ \text { UV } & \text { universal serial bus } \\ \text { uvm. } & \text { Ultraviolett } \\ \text { Vis } & \text { und vieles mehr } \\ \text { Vpu } & \text { visible, sichtbar } \\ \text { vs } & \text { viral protein unique, virales Porin } \\ \text { wt } & \text { zersus } \\ \text { z. B. } & \text { wild type } \\ \text { zum Beispiel }\end{array}$

\subsection{Chemikalien, Geräte, Materialien und Software}

\subsubsection{Chemikalien}

11-Amino-1-undekanthiol (Hydrochlorid) Dojindo EU GmbH (München)

11-Carboxy-1-undekanthiol Dojindo EU GmbH (München)

1-Tetradekanthiol Sigma-Aldrich (Taufkirchen)

2-Mercaptoethanol Sigma-Aldrich (Taufkirchen)

3-Mercaptopropionsäure Sigma-Aldrich (Taufkirchen) 
6-Mercapto-1-hexanol

Aceton

Alexa Fluor 488 NHS Ester (Dilithiumsalz)

Ammoniak

Ammoniumsulfat

Argon

Avidin

BioBeads SM-2

Bio-Cap-PE (Natriumsalz)

Bodipy-PC

BSA

Calciumchlorid

Casaminosäuren

CCCP

Chloroform

Chloroform-D1

Chrom

Cy3 NHS Ester

Diethylether

Dikaliumhydrogenphosphat

DMF

DMSO

DNAse I, Grade II

DOPC

DOPE

$\mathrm{DPhPC}$

DPPA (Natriumsalz)

DPPTE

D-Trehalose Dihydrat
Sigma-Aldrich (Taufkirchen)

VWR Internationa GmbH (Darmstadt)

Invitrogen $\mathrm{GmbH}$ (Karslruhe)

Sigma-Aldrich (Taufkirchen)

Carl Roth GmbH (Karlsruhe)

Air Liquide Deutschland GmbH (Düsseldorf)

Merck KGaA (Darmstadt)

Bio-Rad Laboratories GmbH (München)

Avanti Polar Lipid (Alabaster, USA)

Life Technologies GmbH (Darmstadt)

Carl Roth GmbH (Karlsruhe)

Merck KGaA (Darmstadt)

Otto Nordwald GmbH (Hamburg)

Sigma-Aldrich (Taufkirchen)

VWR Internationa GmbH (Darmstadt)

Deutero GmbH (Kastellaun)

Umicore Materials AG (Balzers, Liechtenstein)

GE Healthcare Europe GmbH (München)

VWR Internationa GmbH (Darmstadt)

Merck KGaA (Darmstadt)

Acros Organics b.v.b.a. (Geel, Belgien)

Carl Roth GmbH (Karlsruhe)

Roche GmbH (Mannheim)

Avanti Polar Lipid (Alabaster, USA)

Avanti Polar Lipid (Alabaster, USA)

Avanti Polar Lipid (Alabaster, USA)

Avanti Polar Lipid (Alabaster, USA)

Avanti Polar Lipid (Alabaster, USA)

Sigma-Aldrich (Taufkirchen) 
EDTA

Eisensulfat Heptahydrat

Ethanol

FCCP

FITC

$\mathrm{Gb}_{3}$

Glucose

Glycerin, $87 \%$

Hefeextrakt

Hellmanex-Lösung

HEPES

Isopropanol

Kaliumchlorid

Kaliumdihydrogenphosphat

Kaliumhydroxid

Kaliumiodid

Lanthanchlorid Heptahydrat

Magnesiumsulfat Hexahydrat

Mangansulfat Monohydrat

Mercaptoessigsäure

MES

Methanol

Molsieb

MOPS

Mucasol

Natriumchlorid

Natriumcitrat

Natriumdodecylsulfat

Natriumhydrogencarbonat
Sigma-Aldrich (Taufkirchen)

AppliChem GmbH (Darmstadt)

Carl Roth GmbH (Karlsruhe)

Santa Cruz Biotechnology Inc. (Heidelberg)

Invitrogen $\mathrm{GmbH}$ (Karslruhe)

Matreya LLC (Pleasant Gap, PA, USA)

VWR Internationa GmbH (Darmstadt)

Merck KGaA (Darmstadt)

Carl Roth GmbH (Karlsruhe)

Hellma GmbH (Müllheim)

Carl Roth GmbH (Karlsruhe)

Carl Roth GmbH (Karlsruhe)

Merck KGaA (Darmstadt)

Merck KGaA (Darmstadt)

Merck KGaA (Darmstadt)

Carl Roth GmbH (Karlsruhe)

Sigma-Aldrich (Taufkirchen)

Sigma-Aldrich (Taufkirchen)

Merck KGaA (Darmstadt)

ABCR GmbH (Karlsruhe)

Carl Roth GmbH (Karlsruhe)

Sigma-Aldrich (Taufkirchen)

Carl Roth GmbH (Karlsruhe)

Carl Roth GmbH (Karlsruhe)

Merck KGaA (Darmstadt)

Merck KGaA (Darmstadt)

Merck KGaA (Darmstadt)

AppliChem GmbH (Darmstadt)

Carl Roth GmbH (Karlsruhe) 
Natriumhydroxid

n-Dekan

n-Hexan

Nigericin

$n$-Octyl- $\beta$-D-glucopyranosid

$n$-Propanol

Octadecylamin

Pepton L34

POPC

POPS (Natriumsalz)

p-Xylol-bispyridiniumbromid

Pyranin (Trinatriumsalz)

Salpetersäure

Salzsäure

Sauerstoff

Schwefelsäure

SOPC

Stickstoff

Sucrose

Texas Red DHPE

Texas Red NHS Ester

TRIS

Triton-X-100

Valinomycin

Wasserstoffperoxid, $30 \%$
Merck KGaA (Darmstadt)

Sigma-Aldrich (Taufkirchen)

Carl Roth GmbH (Karlsruhe)

AppliChem GmbH (Darmstadt)

Carl Roth GmbH (Karlsruhe)

Carl Roth GmbH (Karlsruhe)

Sigma-Aldrich (Taufkirchen)

Oxoid Deutschland GmbH (Wesel)

Avanti Polar Lipid (Alabaster, USA)

Avanti Polar Lipid (Alabaster, USA)

Sigma-Aldrich (Taufkirchen)

Acros Organics b.v.b.a. (Geel, Belgien)

Sigma-Aldrich (Taufkirchen)

Merck KGaA (Darmstadt)

Linde AG (München)

Carl Roth GmbH (Karlsruhe)

Avanti Polar Lipid (Alabaster, USA)

Linde AG (München)

Carl Roth GmbH (Karlsruhe)

Santa Cruz Biotechnology Inc. (Heidelberg)

Invitrogen $\mathrm{GmbH}$ (Karslruhe)

Carl Roth GmbH (Karlsruhe)

Merck KGaA (Darmstadt)

Sigma-Aldrich (Taufkirchen)

Carl Roth GmbH (Karlsruhe)

\subsubsection{Geräte}




\section{Bedampfungsanlage}

Bal-Tec MED 020

Balzers AG (Liechtenstein)

\section{CLSM}

LSM 710 Examiner

Carl Zeiss GmbH (Jena)

Objektiv W Plan-Apochromat 63x/1.0 M27

Carl Zeiss GmbH (Jena)

\section{Elektronenmikroskop}

LEO Supra 55 VP SEM Instrument

Carl Zeiss GmbH (Jena)

\section{Feinwaagen}

Adventurer

OHAUS (Pine Brook, NJ, USA)

Sartorius CP55D

Sartorius (Göttingen)

\section{Fluoreszenzspektrometer}

FP-6500 Spectrofluorimeter

Jasco (Gross-Umstadt)

Thermostat $1162 \mathrm{~A}$

VWR International GmbH (Darmstadt)

\section{Impedanzspektrometer}

Impedance/Gain-Phase Analyser SI 1260

Solartron Instruments (Farnborough, UK)

I296 Dielectric Interface

Solartron Instruments (Farnborough, UK)

\section{Kathodenzerstäuber}

Sputter Coater 108 auto

Cressington Scientific Instruments (Watford, UK)

Thickness Controller MTM20

Cressington Scientific Instruments (Watford, UK)

\section{pH-Meter}

pH-Meter Calimatic 766

Knick (Berlin)

pH Meter Pro Lab 2000

SI-Analytics GmbH (Mainz)

Mikro-pH-Einstabmesskette Typ N 6000 A

SI-Analytics GmbH (Mainz)

\section{Photostromanlage}

428 Current Amplifier

Halogenlampe KL 2500

Kantenfilter
Keithley (Germering)

Opto Sonderbedarf (München)

AHF Analysetechnik (Tübingen) 
Lichtleiter

Blendverschluss

A/D-Wandlerkarte

\section{Plasma Cleaner}

PDC 32 G-2

\section{Reinstwasseranlage}

Milli-Q Elix 5

Milli-Q Gradient A10

Rotationsverdampfer

Laborota 4000

VAC control automatic

\section{SICM}

ICnano scanning ion conductance microscope

P-1000 puller

\section{UV-Vis Spektrometer}

V-650 Spectrophotometer

\section{Weitfeld-Fluoreszenzmikroskop}

Axiotech Vario

Filtersatz 44

Filtersatz 45

Objektiv Achroplan 40x/0,8 W

\section{Sonstige Geräte}

Frequenzgenerator Agilent 33220A

Gleichspannungsnetzteil PS280

LED-Ring

Magnetrührer MR $3001 \mathrm{~K}$

Miniextruder LiposoFast

Osmometer Osmomat 030
Opto Sonderbedarf (München)

Voigtländer (Fürth)

National Instruments (München)

Harrick Plasma (Ithaca, NY, USA)

Millipore (Eschborn)

Millipore (Eschborn)

Heidolph (Kelheim)

Heidolph (Kelheim)

Ionscope (Melbourn, UK)

Sutter Instruments (Novato, CA, USA)

Jasco (Gross-Umstadt)

Carl Zeiss GmbH (Jena)

Carl Zeiss GmbH (Jena)

Carl Zeiss GmbH (Jena)

Carl Zeiss GmbH (Jena)

Agilent Technologies (Santa Clara, USA)

Tektronix (Beaverton, OR, USA)

Werkstatt IOBC (Göttingen)

Heidolph (Schwabach)

Avestin (Ottawa, Kanada)

Gonotec GmbH (Berlin) 
Schüttler Reax Top

Tip Sonifier Sonoplus HD2070

Ultraschallbad Sonorex RK 255 H

Vakuumtrockenschrank VD 23

Variomag Einzel-Magnetrührsystem MINI

Vortexer

\subsubsection{Materialien}

Dialyseschläuche

Eppendorf-Gefäße

Eppendorf-Pipetten

Haftaufkleber

Glaskapillare

Glasküvette Fluorimeter

Gold-Target

Gradientenmischer

Indium-Zinnoxid-Gläschen

Kalrez O-Ringe

Kupferklebeband

Küvetten

Mikroliterspritze

Parafilm

Petrischalen

Pinsel (Painting)

Pipettenspitzen

Polycarbonatmembranen

Poröse Substrate, offene Böden
Heidolph (Schwabach)

Bandelin (Berlin)

Bandelin (Berlin)

Binder GmbH (Tuttlingen)

$\mathrm{H}+\mathrm{P}$ Labortechnik GmbH (Oberschleißheim)

Heidolph (Schwabach)

Carl Roth GmbH (Karlsruhe)

Eppendorf AG (Hamburg)

Eppendorf AG (Hamburg)

Plano GmbH (Wetzlar)

NPI Electronic GmbH (Tamm)

Hellma Optik (Halle)

Elektronen Optik Service GmbH (Dortmund)

Glasgerätebau Ochs e.K. (Bovenden)

Präzisions Glas \& Optik GmbH (Iserlohn)

DuPont Dow Elast. (Newark, NJ, USA)

Präzisions Glas \& Optik GmbH (Iserlohn)

Sarstedt (Nürnbrecht)

Hamilton AG (Bonaduz, Schweiz)

Pechiney Plastic Packaging (Chicago, IL, USA)

VWR International GmbH (Darmstadt)

daVinci DEFET GmbH (Nürnberg)

Sarstedt (Nürnbrecht)

Avestin (Ottawa, Kanada)

FluXXion b.V. (Eindhoven, Niederlande) 
Reagenzgläser

Schleifpapier P100

Schwingquartz für MTM20

Sephadex G25 Säulen

Silica-TLC-Platten für

Dünnschichtchromatografie)

Siliziumwafer

Spritzen BD Discardit II, $20 \mathrm{~mL}$

Spritzensterilfilter Minisart RC 25

Titan-Target

\subsubsection{Software}

VWR International GmbH (Darmstadt)

AEG (Frankfurt/Main)

Elektronen Optik Service GmbH (Dortmund)

GE Healthcare (Freiburg)

Merck KGaA (Darmstadt)

CrysTec (Berlin)

Becton Dickinson, BD (Heidelberg)

Sartorius (Göttingen)

Elektronen Optik Service GmbH (Dortmund)
AxioVision 4.8 LE

ChemSketch V 12.01

Citavi V 3.4.0

Gwyddion V. 2.20

ImageJ V. 1.41

LabView V 6.0.2

Microsoft Office 2007

Multilab Pilot V 5.04

OriginPro 8 SR0 V 8.0724

ScanIC V 1.0

ZEN 2008

ZEN 2009 LE

ZView V 3.0a
Carl Zeiss GmbH (Jena)

Advanced Chemistry Development Inc. (Toronto, Kanada)

Swiss Academic Software GmbH (Wädenswil, Schweiz)

http://gwyddion.net/

http://rsb.info.nih.gov/ij/

National Instruments (Austin, TX, USA)

Microsoft Corporation (Redmond, WA, USA)

SI-Analytics GmbH (Mainz)

Origin Lab Corporation (Northampton, MA, USA)

Ionscope (Melbourn, UK)

Carl Zeiss GmbH (Jena)

Carl Zeiss GmbH (Jena)

Scribner Associates Inc. (Southern Pines, NC, USA) 


\subsection{Mathematischer Anhang}

\subsubsection{Herleitung von Gl. 5.1 (Verhältnis der Oberflächen poröser und unporöser Substratbereiche)}

Die globale Porosität $P$ eines porösen Substrates ist definiert als das Verhältnis von Porenfläche $\left(A_{\text {Pore }}\right)$ zu Gesamtfläche $\left(A_{\text {Gesamt }}\right)$

$$
P=\frac{A_{\text {Pore }}}{A_{\text {Gesamt }}}
$$

Die Porenfläche entspricht dabei der Fläche der Pore in der Ebene der Substratoberfläche $\left(A_{\text {Pore,2d }}\right)$, also im Falle runder Poren einer Kreisfläche mit Porendurchmesser $d$

$$
A_{\text {Pore }, 2 d}=\pi \cdot\left(\frac{d}{2}\right)^{2}
$$

Unter Berücksichtigung der Porentiefe $h$ und somit der Fläche der Poreninnenwände ergibt sich für eine Pore eine Gesamtfläche $\left(A_{\text {Pore,3d }}\right)$ von

$$
A_{\text {Pore }, 3 d}=\pi \cdot\left(\frac{d}{2}\right)^{2}+\pi \cdot d \cdot h=A_{\text {Pore }, 2 d}+\pi \cdot d \cdot h .
$$

Mit Umstellung der ersten Gleichung zu

$$
A_{\text {Gesamt }}=\frac{A_{\text {Pore }}}{P},
$$

ergibt sich für die Gesamtfläche in Ebene der Substratoberfläche $\left(A_{\text {Gesamt,2d }}\right.$ oder kurz $\left.A_{2 \mathrm{~d}}\right)$

$$
A_{2 d}=\frac{A_{P o r e, 2 d}}{P}
$$

Für die Gesamtfläche unter Berücksichtigung der Poreninnenwände $\left(A_{\text {Gesamt,3d }}\right.$ oder kurz $\left.A_{3 \mathrm{~d}}\right)$ muss entsprechend $A_{\text {Pore, } 3 \mathrm{~d}}$ eingesetzt werden

$$
A_{3 d}=\frac{A_{P o r e, 3 d}}{P}=\frac{A_{P o r e, 2 d}+\pi \cdot d \cdot h}{P} .
$$

Das Verhältnis von poröser zu unporöser Oberfläche ergibt sich dann gemäß 


$$
\frac{A_{3 d}}{A_{2 d}}=\frac{\frac{A_{\text {Pore }, 2 d}+\pi \cdot d \cdot h}{P}}{\frac{A_{\text {Pore }, 2 d}}{P}}=1+\frac{\pi \cdot h \cdot d}{\frac{\pi \cdot\left(\frac{d}{2}\right)^{2}}{P}}
$$

und vereinfacht sich zu

$$
\frac{A_{3 d}}{A_{2 d}}=1+\frac{4 \cdot h \cdot P}{d}
$$

Gl. 5.1 


\subsubsection{Berechnung der Konzentrationen von Kaliumionen und Protonen im Verlauf eines nigericininduzierten Antiports}

Ein schematisches Modell des nigericin-vermittelten Antiports von Protonen und Kaliumionen über einen porenüberspannende Membran ist in Abb. 8.1 dargestellt.

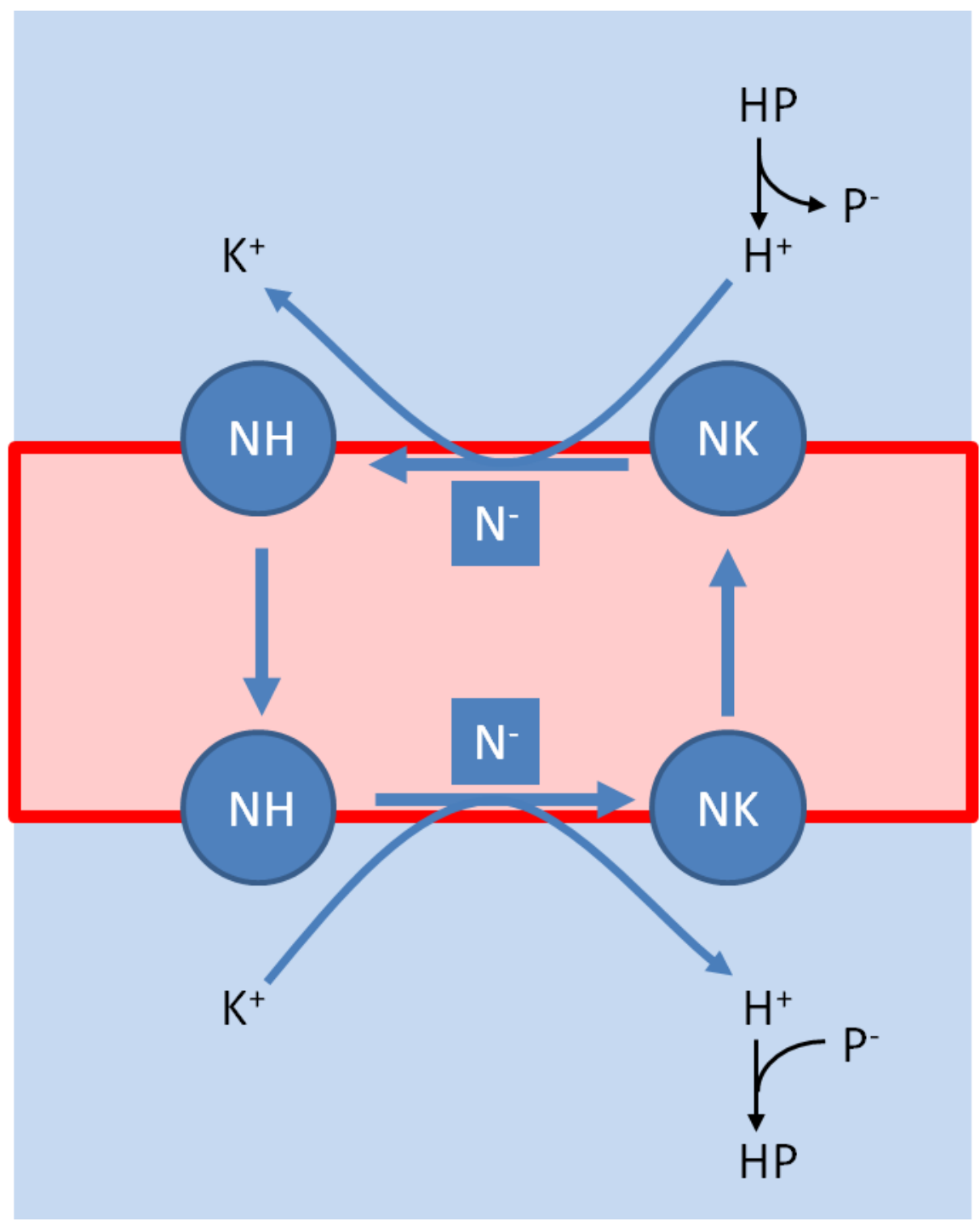

Abb. 8.1: Schematische Darstellung des nigericin-vermittelten Antiports von Protonen und Kaliumionen über eine porenüberspannende Membran (rot). Nigericin (blau) kann als Anion Kaliumionen aufnehmen, so einen ungeladenen Komplex bilden und das Ion entlang eines vorgelegten Gradienten über die Membran transportieren. Nach freisetzung des Kaliumions bindet das Nigericinanion ein Proton passiert erneut die Membran und setzt das Proton auf der anderen Seite der Membran frei. So wird netto ein Kaliumion gegen jeweils ein Proton transportiert in einem ladungsneutralen Prozess. Protonen könne in beiden membrangetrennten Lösungen durch Puffermoleküle HP freigesetzt, oder durch deprotonierte Puffermoleküle $\mathrm{P}^{-}$aufgenommen werden. Modell gemäß\{Antonenko 1988 \#405\}.

Unter der Annahme eines 1:1 Transportes von Protonen gegen Kaliumionen durch Nigericin über porenüberspannende Membranen, gilt für ein Gleichgewicht gemäß Gl. 5.2: 


$$
\frac{\left[K_{i}^{+}\right]}{\left[K_{a}^{+}\right]}=\frac{\left[H_{i}^{+}\right]}{\left[H_{a}^{+}\right]}
$$

Die Konzentrationen der einzelnen Ionen lassen sich unter Berücksichtigung verschiedener Parameter gemäß einfacher Gleichungen, wie der Henderson-Hasselbalch-Gleichung in Abhängigkeit der Anzahl von in die Pore hinein bzw. aus der Pore heraus transportierter Teilchen $N$ errechnen. Eine Tabelle für verschiedene Porengeometrien, entgegengesetzte Ionengradienten, sowie mit und ohne Berücksichtigung von puffernden Substanzen wurde in Microsoft ${ }^{\circledR}$ Office Excel® 2007 programmiert. Die zugrundeliegenden Gleichungen und entsprechende in Excel verwendete Gleichungen werden nachfolgend aufgeführt und erläutert.

Abb. 8.2 zeigt den ersten Teil der Excel-Tabelle. In Spalte A sind die jeweiligen Parameter (Abhängig von Porengeometrie oder Zusammensetzung der verwendeten Pufferlösungen) benannt und ihre Einheiten angegeben.

\begin{tabular}{|c|c|c|c|c|c|}
\hline 4 & A & B & C & D & E \\
\hline 1 & & Kalium innen & Kalium aussen & Kalium innen + Puffer & Kalium aussen + Puffer \\
\hline 2 & Durchmesser Poren $/ \mu \mathrm{m}$ & 5,5 & 5,5 & 5,5 & 5,5 \\
\hline 3 & Tiefe Poren $/ \mu \mathrm{m}$ & 9 & 9 & 9 & 9 \\
\hline 4 & Volumen Innen /L & $2,13825 \mathrm{E}-13$ & $2,13825 \mathrm{E}-13$ & $2,13825 \mathrm{E}-13$ & $2,13825 E-13$ \\
\hline 5 & Volumen Aussen / L & $3,00 \mathrm{E}-03$ & $3,00 \mathrm{E}-03$ & $3,00 E-03$ & $3,00 E-03$ \\
\hline 6 & Anzahl der bedeckten Poren & 1 & 1 & 1 & 500 \\
\hline 7 & pHo innen & 7,3 & 7,3 & 7,3 & 7,3 \\
\hline 8 & pHO aussen & 7,3 & 7,3 & 7,3 & 7,3 \\
\hline \multicolumn{6}{|l|}{9} \\
\hline 10 & Konzentration Puffer in Poren /mM & 0 & 0 & 10,5 & 10,5 \\
\hline 11 & pks Puffer & 7,2 & 7,2 & 7,2 & 7,2 \\
\hline 12 & Verhältnis [P-]/[HP] & 1,258925412 & 1,258925412 & 1,258925412 & 1,258925412 \\
\hline 13 & [HP] 0 in Pore / M & 0 & 0 & 0,004648228 & 0,004648228 \\
\hline 14 & [P-]0 in Pore / M & 0 & 0 & 0,005851772 & 0,005851772 \\
\hline \multicolumn{6}{|l|}{15} \\
\hline 16 & Konzentration $\mathrm{K}+0$ in Poren $/ \mathrm{M}$ & 0,16 & 0 & 0,16 & 0 \\
\hline \multicolumn{6}{|l|}{17} \\
\hline 18 & Konzentration $\mathrm{H}+0$ in Poren $/ \mathrm{M}$ & $5,01187 \mathrm{E}-08$ & $5,01187 \mathrm{E}-08$ & $5,01187 \mathrm{E}-08$ & $5,01187 \mathrm{E}-08$ \\
\hline \multicolumn{6}{|l|}{19} \\
\hline 20 & Konzentration Puffer aussen /mM & 0 & 0 & 10 & 10 \\
\hline 21 & pks Puffer & 7,2 & 7,2 & 7,2 & 7,2 \\
\hline 22 & Verhältnis [P-]/[HP] & 1,258925412 & 1,258925412 & 1,258925412 & 1,258925412 \\
\hline 23 & [HP] 0 aussen / M & 0 & 0 & 0,004426884 & 0,004426884 \\
\hline 24 & {$[\mathrm{P}-] 0$ aussen $/ \mathrm{M}$} & 0 & 0 & 0,005573116 & 0,005573116 \\
\hline \multicolumn{6}{|l|}{25} \\
\hline 26 & Konzentration $\mathrm{K}+0$ aussen $/ \mathrm{M}$ & 0 & 0,16 & 0 & 0,16 \\
\hline \multicolumn{6}{|c|}{27} \\
\hline 28 & Konzentration $\mathrm{H}+0$ aussen $/ \mathrm{M}$ & $5,01187 E-08$ & $5,01187 E-08$ & $5,01187 \mathrm{E}-08$ & $5,01187 \mathrm{E}-08$ \\
\hline
\end{tabular}

Abb. 8.2: Variablen und Startparameter zur Berechnung der Konzentrationen von Kaliumionen und Protonen im Verlauf eines nigericininduzierten Antiports.

In Zeile 1 sind die jeweiligen Randbedingungen eines Experimentes angegeben, namentlich die Richtung des vorgegebenen Kaliumionengradienten und ob Puffer berücksichtigt wurde oder nicht. Die Startparameter wurden dem jeweiligen Experiment angepasst von Hand eingegeben. Einzelne Werte, wie das Porenvolumen, die Protonenkonzentrationen $(\mathrm{H}+0)$, das 
Verhältnis unprotonierter zu protonierter Form puffernder Substanzen $[\mathrm{P}-] /[\mathrm{HP}]$ und daraus resultierend die Konzentrationen beider Pufferspezies wurden anhand anderer manuell eingetragener Werte berechnet. Die entsprechenden Eingaben sind in Abb. 8.3 aufgeführt.

\begin{tabular}{|c|c|c|c|c|c|}
\hline 4 & A & B & C & D & E \\
\hline 1 & & Kalium innen & Kalium aussen & Kalium innen + Puffer & Kalium aussen + Puffer \\
\hline 2 & Durchmesser Poren $/ \mu \mathrm{m}$ & 5,5 & 5,5 & 5,5 & 5,5 \\
\hline \multirow[t]{3}{*}{3} & Tiefe Poren / $\mu \mathrm{m}$ & 9 & 9 & 9 & 9 \\
\hline & & $=(B 2 * 0,000001$ & $=(C 2 * 0,000001)$ & & \\
\hline & & $(2)^{\wedge} 2 * B 3 * 0,00$ & 2)^ $2^{*} \mathrm{C} 3^{*} 0,0000$ & $=(\mathrm{D} 2 * 0,000001 / 2)^{\wedge} 2 * \mathrm{D} 3$ & $=(E 2 * 0,000001 / 2)^{\wedge} 2^{*} E 3^{*} 0,0$ \\
\hline 4 & Volumen Innen / L & $0001^{*} \mathrm{PI}()^{*} 1000$ & $01^{*} \mathrm{PI}()^{*} 1000$ & ${ }^{*} 0,000001{ }^{*} \mathrm{PI}()^{*} 1000$ & $00001 * \mathrm{PI}() * 1000$ \\
\hline 5 & Volumen Aussen /L & $3,00 \mathrm{E}-03$ & $3,00 \mathrm{E}-03$ & $3,00 \mathrm{E}-03$ & $3,00 E-03$ \\
\hline 6 & Anzahl der bedeckten Poren & 1 & 1 & 1 & 500 \\
\hline 7 & $\mathrm{pHO}$ innen & 7,3 & 7,3 & 7,3 & 7,3 \\
\hline 8 & pHO aussen & 7,3 & 7,3 & 7,3 & 7,3 \\
\hline \multicolumn{6}{|l|}{9} \\
\hline 10 & Konzentration Puffer in Poren $/ \mathrm{mM}$ & 0 & 0 & 10,5 & 10,5 \\
\hline 11 & pks Puffer & 7,2 & 7,2 & 7,2 & 7,2 \\
\hline 12 & Verhältnis [P-]/[HP] & $=10^{\wedge}(\mathrm{B} 7-\mathrm{B} 11)$ & $=10^{\wedge}(\mathrm{C} 7-\mathrm{C} 11)$ & $=10^{\wedge}(\mathrm{D} 7-\mathrm{D} 11)$ & $=10^{\wedge}(E 7-E 11)$ \\
\hline 13 & [HP]O in Pore / $\mathrm{M}$ & $\begin{array}{l}=\mathrm{B} 10 / 1000 /(\mathrm{B} 1 \\
2+1)\end{array}$ & $\begin{array}{l}=\mathrm{C} 10 / 1000 /(\mathrm{C} 12 \\
+1)\end{array}$ & $=D 10 / 1000 /(D 12+1)$ & $=E 10 / 1000 /(E 12+1)$ \\
\hline 14 & {$[\mathrm{P}-] 0$ in Pore $/ \mathrm{M}$} & $=\mathrm{B} 10 / 1000-\mathrm{B} 13$ & $=\mathrm{C} 10 / 1000-\mathrm{C} 13$ & $=\mathrm{D} 10 / 1000-\mathrm{D} 13$ & $=E 10 / 1000-E 13$ \\
\hline \multicolumn{6}{|l|}{15} \\
\hline 16 & Konzentration $\mathrm{K}+0$ in Poren $/ \mathrm{M}$ & 0,16 & 0 & 0,16 & 0 \\
\hline \multicolumn{6}{|l|}{17} \\
\hline 18 & Konzentration $\mathrm{H}+0$ in Poren $/ \mathrm{M}$ & $=10^{\wedge}(-B 7)$ & $=10^{\wedge}(-\mathrm{C} 7)$ & $=10^{\wedge}(-\mathrm{D} 7)$ & $=10^{\wedge}(-E 7)$ \\
\hline \multicolumn{6}{|l|}{19} \\
\hline 20 & Konzentration Puffer aussen $/ \mathrm{mM}$ & 0 & 0 & 10 & 10 \\
\hline 21 & pks Puffer & 7,2 & 7,2 & 7,2 & 7,2 \\
\hline 22 & Verhältnis [P-]/[HP] & $=10^{\wedge}(B 8-B 21)$ & $=10^{\wedge}(\mathrm{C} 8-\mathrm{C} 21)$ & $=10^{\wedge}(\mathrm{D} 8-\mathrm{D} 21)$ & $=10^{\wedge}(E 8-E 21)$ \\
\hline 23 & [HP]0 aussen / M & $\begin{array}{l}=B 20 / 1000 /(B 2 \\
2+1)\end{array}$ & $\begin{array}{l}=\mathrm{C} 20 / 1000 /(\mathrm{C} 22 \\
+1)\end{array}$ & $=\mathrm{D} 20 / 1000 /(\mathrm{D} 22+1)$ & $=E 20 / 1000 /(E 22+1)$ \\
\hline 24 & [P-]0 aussen / $M$ & $=B 20 / 1000-B 23$ & $=\mathrm{C} 20 / 1000-\mathrm{C} 23$ & $=\mathrm{D} 20 / 1000-\mathrm{D} 23$ & $=E 20 / 1000-E 23$ \\
\hline \multicolumn{6}{|l|}{25} \\
\hline 26 & Konzentration $\mathrm{K}+0$ aussen $/ \mathrm{M}$ & 0 & 0,16 & 0 & 0,16 \\
\hline \multicolumn{6}{|l|}{27} \\
\hline 28 & Konzentration $\mathrm{H}+0$ aussen $/ \mathrm{M}$ & $=10^{\wedge}(-B 8)$ & $=10^{\wedge}(-\mathrm{C} 8)$ & $=10^{\wedge}(-\mathrm{D} 8)$ & $=10^{\wedge}(-E 8)$ \\
\hline
\end{tabular}

Abb. 8.3: Variablen und Startparameter zur Berechnung der Konzentrationen von Kaliumionen und Protonen im Verlauf eines nigericininduzierten Antiports. Verwendete Gleichungen sind in Form ihrer Eingabe dargestellt.

Ausgehend von den hier eingefügten Startbedingungen, wurden die Konzentrationen der beiden transportierten Ionensorten, $[\mathrm{K}+\mathrm{i}]$ (Kaliumionen in einer Pore), $[\mathrm{K}+\mathrm{a}]$ (Kaliumionen in der überstehenden Pufferlösung), [H+i] (Protonen in einer Pore) und $[\mathrm{H}+\mathrm{a}]$ (Protonen in der überstehenden Pufferlösung) als Funktionen der Anzahl transportierter Teilchen $N$ berechnet. $N=1$ bedeutet hierbei, dass ein Proton auf einer Seite der Membran gegen ein Kaliumion auf der anderen Seite der Membran ausgetauscht wurde. Eine Darstellung der Werte für den Fall Kaliumionen im Poreninneren und keinen Kaliumionen in der überstehenden Lösung (Startbedingungen Abb. 8.2, Spalte B) ist in Abb. 8.4 dargestellt. 


\begin{tabular}{|c|c|c|c|c|c|}
\hline 4 & $\mathrm{~F}$ & G & H & I & J \\
\hline 1 & & Kalium innen & & & \\
\hline 2 & Anzahl der gepumpten Protonen & {$[\mathrm{K}+\mathrm{i}] / \mathrm{M}$} & {$[\mathrm{K}+\mathrm{a}] / \mathrm{M}$} & {$[\mathrm{H}+\mathrm{i}] / \mathrm{M}$} & {$[\mathrm{H}+\mathrm{a}] / \mathrm{M}$} \\
\hline 3 & 0 & 0,16 & $0,00 E+00$ & $5,01187 \mathrm{E}-08$ & $5,01187 \mathrm{E}-08$ \\
\hline 4 & 1 & 0,16 & $5,54 \mathrm{E}-22$ & $5,01265 E-08$ & $5,01187 \mathrm{E}-08$ \\
\hline 5 & 10 & 0,16 & $5,54 \mathrm{E}-21$ & $5,01964 E-08$ & $5,01187 \mathrm{E}-08$ \\
\hline 6 & 100 & 0,159999999 & $5,54 \mathrm{E}-20$ & $5,08953 E-08$ & $5,01187 \mathrm{E}-08$ \\
\hline 7 & 1000 & 0,159999992 & 5,54E-19 & $5,78848 \mathrm{E}-08$ & $5,01187 \mathrm{E}-08$ \\
\hline 8 & $1,00 E+04$ & 0,159999922 & $5,54 \mathrm{E}-18$ & $1,27779 \mathrm{E}-07$ & $5,01187 E-08$ \\
\hline 9 & $1,00 E+05$ & 0,159999223 & $5,54 \mathrm{E}-17$ & $8,26726 \mathrm{E}-07$ & $5,01187 \mathrm{E}-08$ \\
\hline 10 & $1,00 E+06$ & 0,159992234 & $5,54 \mathrm{E}-16$ & $7,81619 \mathrm{E}-06$ & $5,01187 \mathrm{E}-08$ \\
\hline 11 & $1,00 E+07$ & 0,159922339 & $5,54 \mathrm{E}-15$ & $7,77109 \mathrm{E}-05$ & $5,01187 \mathrm{E}-08$ \\
\hline 12 & $1,00 E+08$ & 0,159223393 & $5,54 \mathrm{E}-14$ & 0,000776657 & $5,01187 \mathrm{E}-08$ \\
\hline 13 & $1,00 E+09$ & 0,152233927 & $5,54 \mathrm{E}-13$ & 0,007766123 & $5,01182 \mathrm{E}-08$ \\
\hline 14 & $1,00 \mathrm{E}+10$ & 0,082339268 & $5,54 \mathrm{E}-12$ & 0,077660782 & $5,01132 \mathrm{E}-08$ \\
\hline 15 & $1,00 E+11$ & 0 & $1,14 \mathrm{E}-11$ & 0,16000005 & $5,01073 E-08$ \\
\hline 16 & $1,00 E+12$ & 0 & $1,14 \mathrm{E}-11$ & 0,16000005 & $5,01073 E-08$ \\
\hline 17 & $1,00 E+13$ & 0 & $1,14 \mathrm{E}-11$ & 0,16000005 & $5,01073 E-08$ \\
\hline 18 & $1,00 E+14$ & 0 & $1,14 \mathrm{E}-11$ & 0,16000005 & $5,01073 \mathrm{E}-08$ \\
\hline 19 & $1,00 E+15$ & 0 & $1,14 \mathrm{E}-11$ & 0,16000005 & $5,01073 \mathrm{E}-08$ \\
\hline 20 & $1,00 E+16$ & 0 & $1,14 \mathrm{E}-11$ & 0,16000005 & $5,01073 E-08$ \\
\hline 21 & $1,00 E+17$ & 0 & 1,14E-11 & 0,16000005 & $5,01073 \mathrm{E}-08$ \\
\hline 22 & $1,00 E+18$ & 0 & $1,14 \mathrm{E}-11$ & 0,16000005 & $5,01073 \mathrm{E}-08$ \\
\hline 23 & $1,00 E+19$ & 0 & $1,14 \mathrm{E}-11$ & 0,16000005 & $5,01073 E-08$ \\
\hline 24 & $1,00 E+20$ & 0,157475706 & $1,80 \mathrm{E}-13$ & 0,002524344 & $5,01185 \mathrm{E}-08$ \\
\hline
\end{tabular}

Abb. 8.4: Errechnete Konzentrationen von Kaliumionen und Protonen auf beiden Seiten einer porenüberspannenden Membran in Abhängigkeit der Zahl ausgetauschter Teilchen. Darstellung für den Fall von Kaliumionen iim Poreninneren und kaliumionenfreier überstehender Lösung ohne Puffer.

Die zugrundeliegenden Gleichungen, nach denen sich die Werte errechnen sind exemplarisch für Zeile 3 in Abb. 8.5 aufgeführt.

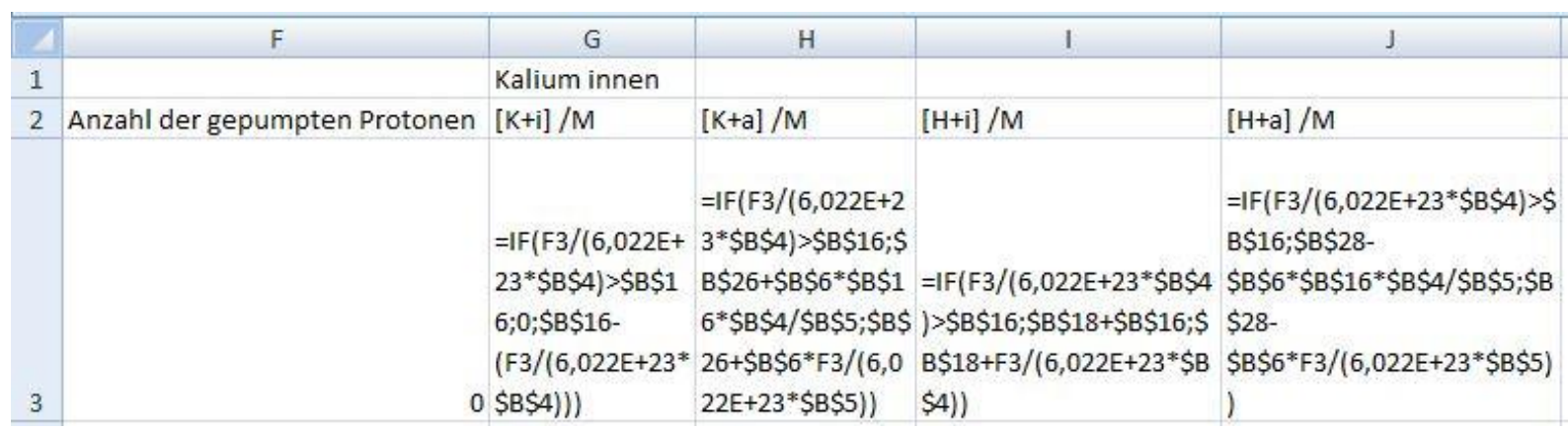

Abb. 8.5: Darstellung der Abb. 8.4, Zeile 3 in Form der verwendeten Gleichungen zur Berechnung der Ionenkonzentrationen in Abhängigkeit der Zahl transportierter Teilchen.

Die Ionenkonzentrationen werden in Form von „IF-Funktionen“ bestimmt, mit der Rahmenbedingung, dass z. B. kein Transport mehr statt findet, wenn die aus den Poren heraus transportierte Ionenspezies vollständig aus den Poren entfernt wurde $([\mathrm{X}+\mathrm{i}]=0)$.

Für einen umgekehrten Kaliumionengradienten ergeben sich die unter Abb. 8.6 dargestellten Gleichungen zur Bestimmung der Ionenkonzentrationen. 


\begin{tabular}{|c|c|c|c|c|c|}
\hline 4 & $\mathrm{~F}$ & G & H & 1 & J \\
\hline 1 & & Kalium aussen & & & \\
\hline 2 & $\begin{array}{l}\text { Anzahl der } \\
\text { gepumpten } \\
\text { Protonen }\end{array}$ & {$[\mathrm{K}+\mathrm{i}] / \mathrm{M}$} & {$[\mathrm{K}+\mathrm{a}] / \mathrm{M}$} & {$[\mathrm{H}+\mathrm{i}] / \mathrm{M}$} & {$[\mathrm{H}+\mathrm{a}] / \mathrm{M}$} \\
\hline & & $=I F\left(F 3 /\left(6,022 E+23^{*} \$ C\right.\right.$ & $=I F\left(F 3 /\left(6,022 E+23^{*} \$ C \$ 4\right)>\$ C \$ 1\right.$ & $=I F\left(F 3 /\left(6,022 E+23^{*} \$\right.\right.$ & $=I F\left(F 3 /\left(6,022 E+23^{*} \$ C \$ 4\right)>\$\right.$ \\
\hline & & $\$ 4)>\$ C \$ 18 ; \$ C \$ 16+\$ C \$$ & $8 ; \$ C \$ 26-$ & $C \$ 4)>\$ C \$ 18 ; 0 ; \$ C \$ 18-$ & $\mathrm{C} \$ 18 ; \$ C \$ 28+\$ C \$ 6^{*} \$ C \$ 18^{*} \$$ \\
\hline & & $18 ; \$ C \$ 16+F 3 /(6,022 E+$ & \$C\$6*\$C\$18*\$C\$4/\$C\$5;\$C\$26- & $\left(\mathrm{F} 3 /\left(6,022 \mathrm{E}+23^{*} \$ \mathrm{C} \$\right.\right.$ & $\mathrm{C} \$ 4 / \$ C \$ 5 ; \$ C \$ 28+\$ C \$ 6^{*} \mathrm{~F} 3 /$ \\
\hline 3 & & $23 * \$(\$ 4))$ & $\left.\$ C \$ 6^{*} \mathrm{~F} 3 /\left(6,022 \mathrm{E}+23^{*} \$ \mathrm{C} \$ 5\right)\right)$ & 4))) & $\left.\left(6,022 \mathrm{E}+23^{*} \$ \mathrm{C} \$ 5\right)\right)$ \\
\hline
\end{tabular}

Abb. 8.6: Darstellung der verwendeten Gleichungen zur Berechnung der Ionenkonzentrationen in Abhängigkeit der Zahl transportierter Teilchen für einen Transport von Kaliumionen in die Poren hinein und von Protonen aus den Poren heraus ohne Berücksichtigung von Puffer (Abb. 8.2, Spalte C).

Unter Berücksichtigung von Puffer in den Poren und in der überstehenden Lösung, kann die Henderson-Hasselbalch-Gleichung angewendet werden. Dadurch sind weitere „IF-Funktionen“" nötig, um den Pufferbereich zu definieren und die Gleichungen gewinnen an Umfang. Die entsprechenden Gleichungen für einen Transport von Protonen in die Poren hinein und Kaliumionen heraus ist in Abb. 8.7 aufgeführt.

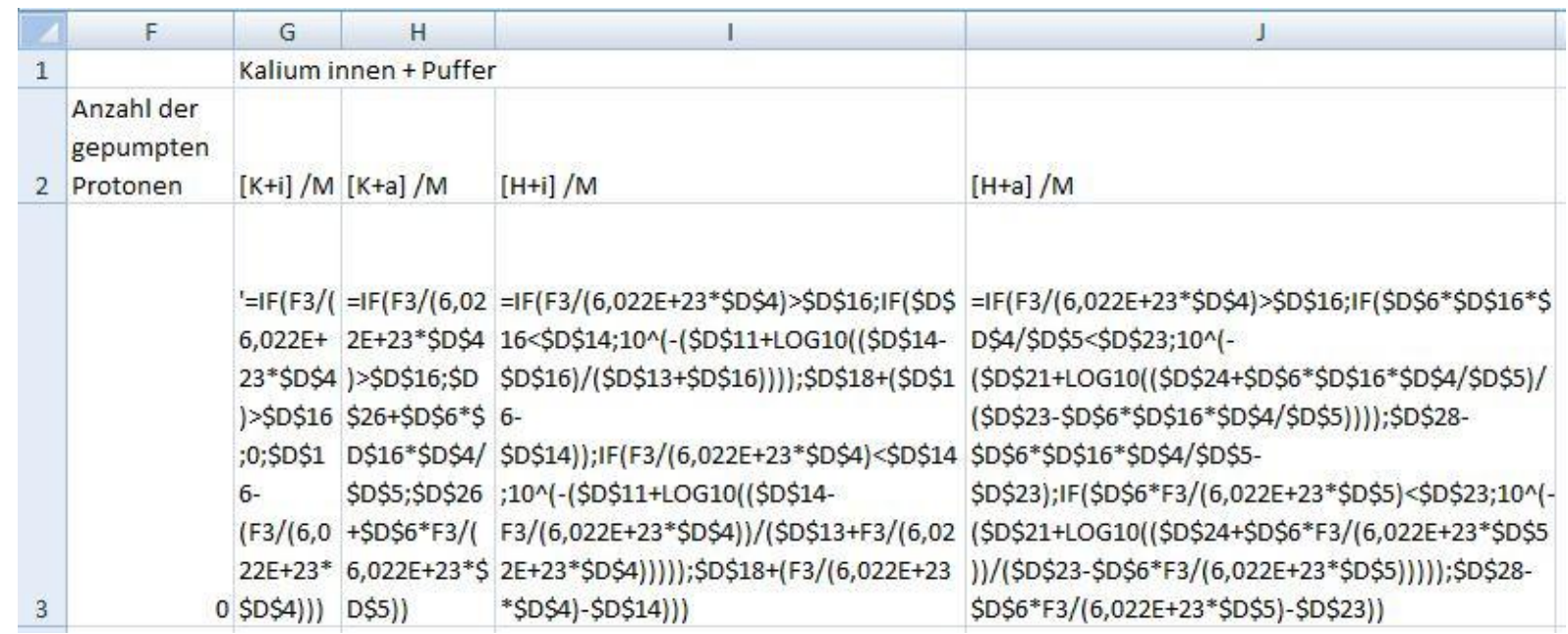

Abb. 8.7: Darstellung der verwendeten Gleichungen zur Berechnung der Ionenkonzentrationen in Abhängigkeit der Zahl transportierter Teilchen für einen Transport von Protonen in die Poren hinein und von Kaliumionen aus den Poren heraus unter Berücksichtigung von Puffer (Abb. 8.2, Spalte D).

Schließlich wurden die Ionenkonzentrationen für einen entgegengesetzten Transport unter Berücksichtigung von Puffer berechnet. Die zugehörigen Gleichungen finden sich in Abb. 8.8. 


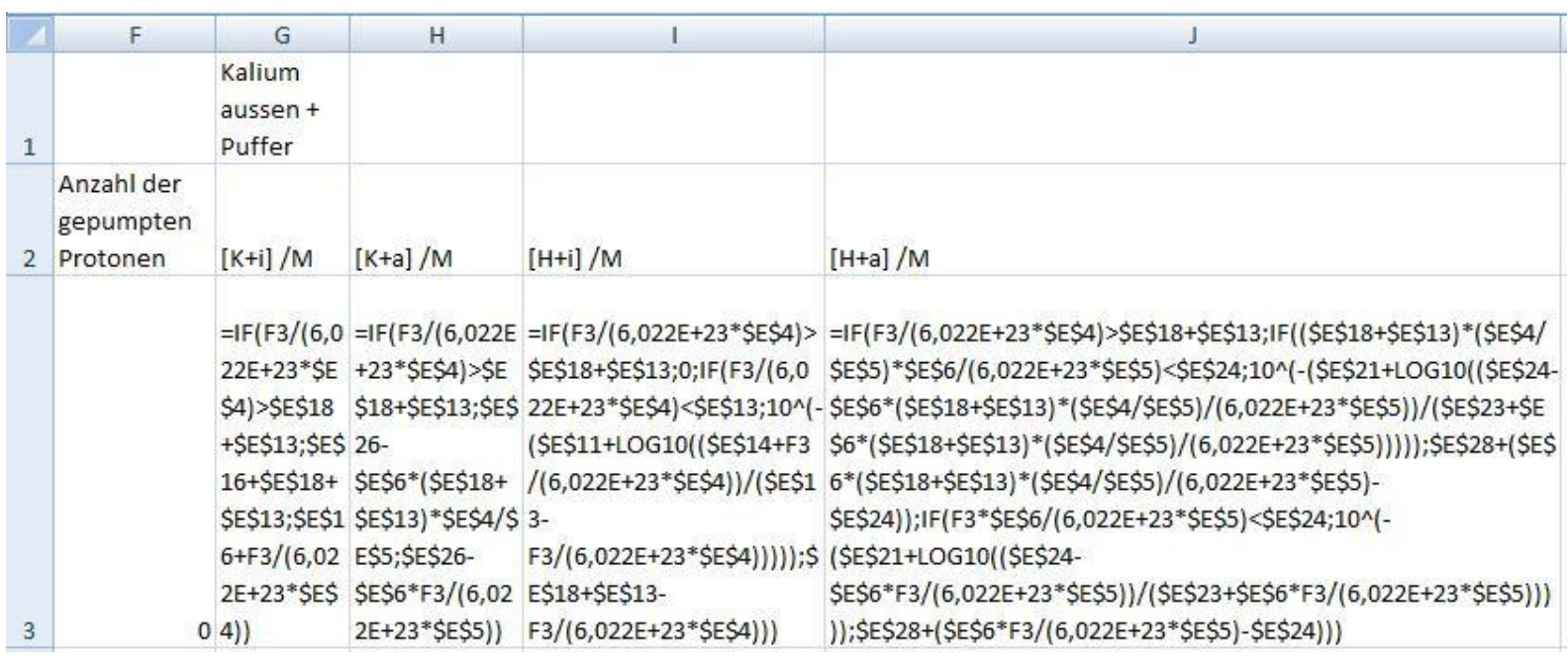

Abb. 8.8: Darstellung der verwendeten Gleichungen zur Berechnung der Ionenkonzentrationen in Abhängigkeit der Zahl transportierter Teilchen für einen Transport von Kaliumionen in die Poren hinein und von Protonen aus den Poren heraus unter Berücksichtigung von Puffer (Abb. 8.2, Spalte E).

Für die beiden Fälle ohne Berücksichtigung von Puffer in den Lösungen lässt sich eine Anzahl transportierte Protonen errechnen, bei der G1. 5.2 erfüllt ist. Durch Einsetzen der hier beschriebenen Funktionen für die Ionenkonzentrationen in Gl. 5.2 und Auflösen nach der Anzahl transportierter Protonen, ergibt sich für den Transport von Protonen in die Poren hinein (Abb. 8.9):

\begin{tabular}{|c|c|c|}
\hline 4 & $\mathrm{~F}$ & G \\
\hline 1 & & Kalium innen \\
\hline 2 & Anzahl der gepumpten Protonen & \\
\hline 3 & $\begin{array}{l}=6,022 \mathrm{E}+23^{*} \mathrm{~B} 4{ }^{*} \mathrm{~B} 5^{*}\left(\mathrm{~B} 16^{*} \mathrm{~B} 28-\right. \\
\left.\mathrm{B} 18^{*} \mathrm{~B} 26\right) /\left(\mathrm{B} 16^{*} \mathrm{~B} 4{ }^{*} \mathrm{~B} 6+\mathrm{B} 28^{*} \mathrm{~B} 5+\mathrm{B} 18^{*} \mathrm{~B}\right. \\
\left.4^{*} \mathrm{~B} 6+\mathrm{B} 26^{*} \mathrm{~B} 5\right)\end{array}$ & {$[K+i] /[K+a]=[H+i] /[H+a]$} \\
\hline
\end{tabular}

Abb. 8.9: Bestimmung des Gleichgewichtswertes transportierter Protonen, bei welchem Gleichung Gl. 5.2 erfüllt ist für eine Transport von Protonen in die Poren hinein und Kaliumionen aus den Poren heraus ohne Berücksichtigung von Puffer.

Bei Umkehr des vorgelegten Ionengradienten folgt die Gleichung, wie sie in Abb. 8.10 dargestellt ist.

\begin{tabular}{r|l|l|}
\hline 1 & \multicolumn{1}{|c|}{$\mathrm{C}$} & \multicolumn{1}{c|}{$\mathrm{G}$} \\
\hline 1 & & \multicolumn{1}{c|}{ Kalium aussen } \\
\hline 2 & Anzahl der gepumpten Protonen & \\
$=6,022 \mathrm{E}+23^{*} \mathrm{C} 4^{*} \mathrm{C} 5^{*}(-$ & \\
$\left.\mathrm{C} 16^{*} \mathrm{C} 28+\mathrm{C} 18^{*} \mathrm{C} 26\right) /\left(\mathrm{C} 16^{*} \mathrm{C} 4^{*} \mathrm{C} 6+\mathrm{C} 28^{*}\right.$ & \\
3 & $\left.\mathrm{C} 5+\mathrm{C} 18^{*} \mathrm{C} 4^{*} \mathrm{C} 6+\mathrm{C} 26^{*} \mathrm{C} 5\right)$ & {$[\mathrm{K}+\mathrm{i}] /[\mathrm{K}+\mathrm{a}]=[\mathrm{H}+\mathrm{i}] /[\mathrm{H}+\mathrm{a}]$} \\
\hline
\end{tabular}

Abb. 8.10: Bestimmung des Gleichgewichtswertes transportierter Protonen, bei welchem Gleichung Gl. 5.2 erfüllt ist für eine Transport von Kaliumionen in die Poren hinein und Protonen aus den Poren heraus ohne Berücksichtigung von Puffer. 
Aufgrund des Umfangs der Gleichungen zur Bestimmung der Ionenkonzentrationen unter Berücksichtigung von Puffer, wurden Gleichgewichtswerte für die Zahl transportierter Protonen hierfür nicht berechnet, sondern iterativ bestimmt.

Abschließend sind die zugrundeliegenden Gleichungen für Kaliumionengradienten in beide Richtungen unter Berücksichtigung von puffernden Substanzen nachfolgend aufgeführt.

$\left[\mathrm{K}^{+}{ }_{\mathrm{i}}\right]>\left[\mathrm{K}_{\mathrm{a}}^{+}\right]$:

$$
\begin{gathered}
{\left[K_{i}^{+}\right](N)=\left[K_{i}^{+}\right]^{0}-\frac{N}{V_{i} \cdot N_{A}}} \\
{\left[K_{a}^{+}\right](N)=\left[K_{a}^{+}\right]^{0}+\frac{N \cdot N(\text { Poren })}{V_{a} \cdot N_{A}}} \\
{\left[H_{i}^{+}\right]\left(N<\left[P_{i}^{-}\right]^{0} \cdot V_{i} \cdot N_{A}\right)=10} \\
{\left[H_{i}^{+}\right]\left(N \geq\left[P_{i}^{-}\right]^{0} \cdot V_{i} \cdot N_{A}\right)=\left[H_{i}^{+}\right]^{0}+\frac{N}{V_{i} \cdot N_{A}}-\left[\frac{\left.\left[P_{i}^{-}\right]^{0}-\frac{N}{V_{i} \cdot N_{A}}\right)}{\left.\left[H P_{i}\right]^{0}+\frac{N}{V_{i} \cdot N_{A}}\right)}\right)} \\
{\left[P_{a}^{-}\right]^{0}} \\
{\left[H_{a}^{+}\right]\left(N \cdot N(\text { Poren }) \geq\left[H P_{a}\right]^{0} \cdot V_{a} \cdot N_{A}\right)=\left[H_{a, a}^{+}\right]^{0}-\frac{N \cdot \log \left(\frac{\left[P_{a}^{-}\right]^{0}+\frac{N \cdot N(\text { Poren })}{V_{a} \cdot N_{A}}}{\left[H P_{a}\right]^{0}-\frac{N \cdot N(P \text { oren })}{V_{a} \cdot N_{A}}}\right)}{V_{a} \cdot N_{A}}+[\text { Poren })} \\
\end{gathered}
$$

$\left[\mathrm{K}_{\mathrm{i}}^{+}\right]<\left[\mathrm{K}_{\mathrm{a}}^{+}\right]:$

$$
\begin{aligned}
& {\left[K_{i}^{+}\right](N)=\left[K_{i}^{+}\right]^{0}+\frac{N}{V_{i} \cdot N_{A}}} \\
& {\left[K_{a}^{+}\right](N)=\left[K_{a}^{+}\right]^{0}-\frac{N \cdot N(\text { Poren })}{V_{a} \cdot N_{A}}} \\
& {\left[H_{i}^{+}\right]\left(N<\left[H P_{i}\right]^{0} \cdot V_{i} \cdot N_{A}\right)=10 \underbrace{-\left(p K_{S, i}+\log \left(\frac{\left[P_{i}^{-}\right]^{0}+\frac{N}{V_{i} \cdot N_{A}}}{\left[H P_{i}\right]^{0}-\frac{N}{V_{i} \cdot N_{A}}}\right)\right)}} \\
& {\left[H_{i}^{+}\right]\left(N \geq\left[H P_{i}\right]^{0} \cdot V_{i} \cdot N_{A}\right)=\left[H_{i}^{+}\right]^{0}-\frac{N}{V_{i} \cdot N_{A}}+\left[H P_{i}\right]^{0}} \\
& {\left[H_{a}^{+}\right]\left(N \cdot N(\text { Poren })<\left[P_{a}^{-}\right]^{0} \cdot V_{a} \cdot N_{A}\right)=10-\left(p K_{S, a}+\log \left(\frac{\left[P_{a}^{-}\right]^{0}-\frac{N \cdot N(\text { Poren })}{V_{a} \cdot N_{A}}}{\left[H P_{a}\right]^{0}+\frac{N \cdot N(\text { Poren })}{V_{a} \cdot N_{A}}}\right)\right)}
\end{aligned}
$$




$$
\left[H_{a}^{+}\right]\left(N \cdot N(\text { Poren }) \geq\left[P_{a}^{-}\right]^{0} \cdot V_{a} \cdot N_{A}\right)=\left[H_{a}^{+}\right]^{0}+\frac{N \cdot N(\text { Poren })}{V_{a} \cdot N_{A}}-\left[P_{a}^{-}\right]^{0}
$$

Dabei gelten als weitere Randbedingungen (hier nicht explizit aufgeführt), dass kein Transport mehr möglich ist, wenn die zu transportierende Spezies im Kompartiment, aus welchem heraus transportiert wird, nicht mehr vorhanden ist $([X]=0)$. Eine Berücksichtigung findet in den in Excel eingetragenen Funktionen statt. Die Indices i und a stehen für Parameter in den Poren (i) bzw. außerhalb der Poren in der überstehenden Lösung (a). HP beschreibt Puffermoleküle in ihrer Protonierten, neutralen Form, $\mathrm{P}^{-}$welche in ihrer deprotonierten, geladenen Form. Für die Protonenkonzentrationen wird jeweils unterschieden zwischen Bereichen in denen entsprechende Substanzen noch puffernde Wirkung haben und dem Bereich jenseits der Pufferkapazität. 
8 A nhang 


\section{Danksagung}

Danken möchte ich Claudia Steinem für die Möglichkeit, mit viel Freiheit rund um porenüberspannende Membranen in ihrem Arbeitskreis geforscht haben zu dürfen und für den nötigen Input, wenn es mal hakte. Danke auch für die Möglichkeit an nationalen und internationalen Tagungen teilnehmen zu können und für die Ermutigung, sich dafür auf Reisestipendien zu bewerben - auch wenn das bedeutet, dass man plötzlich seine Abhandlung über den falschen Gebrauch von Power Point und die Messung der Aufmerksamkeitsspanne des Publikums anhand der Zahl betriebener Laptops in einem Rundschreiben einer deutschlandweiten wissenschaftlichen Organisation wiederfindet. Danke für die schnelle Korrektur der Arbeit, auch wenn es zum Ende mal übers Wochenende sein musste und für die vielen Ideen rund ums Paper.

An Markus Zweckstetter richtet sich mein Dank für die bereitwillige Übernahme des Korreferats und die problemlose Durchführung der Thesis Committee-Treffen.

Nach Bonn geht mein Dank an Siegfried Steltenkamp und Sam Schmitz (caesar) für die maßgefertigte Präparation der Siliziumsubstrate (,runde Poren“) und den Beitrag zum gemeinsamen Paper. Für weitere Siliziumsubstrate (,eckige Poren“) danke ich Stefan Schweizer von der Universität Halle-Wittenberg.

Korrekturen kleiner und größerer Fehler ermöglichten die fleißigen Korrekturleser Corinna, Conrad und Ole. Vielen Dank dafür.

Ein besonderes Dankeschön geht an David Andelman von der Universität Tel Aviv, sowie seinen Mitarbeitern Dan Ben-Yaakov und Tomer Markovich für die spontane, unkomplizierte und dabei umfassende Hilfe bei der Entwicklung des Modells zum entropiegetriebenen Spreiten von GUVs, dotiert mit geladenen Lipiden.

Neben der alltäglichen Unterstützung im Labor möchte ich Jutta besonders für die Züchtung unserer „Halos“, die Isolierung der PM-Fragmente und die alljährliche Hilfestellung beim Lehrämtlerpraktikum danken.

An meine fleißigen Bachelor- und Masterstudenten Oliver und Martin ein herzliches Dankeschön für die gute Zusammenarbeit. Ich drück euch die Daumen für euren weiteren Werdegang. Eine hohe Frustrationsgrenze haben wir jedenfalls gemeinsam schon mal entwickelt, das kann nur helfen. Martin und Michaela gilt weiterhin mein Dank für die Unterstützung bei SEM-Messungen.

Dem Team der Elektronik-Werkstatt des IOBC rund um Herrn Pohl danke ich für die Ausarbeitung und passgenaue Anfertigung des LED-Rings.

Julia sei in ihrer Funktion als Schreibraumpartnerin und Leidensgenossin in den letzten Monaten gedankt für gegenseitigen Frustabbau (klingt das komisch..?), aber auch für gegenseitige Motivation. Dank dir wurde ich sozusagen als Nutznießer von Nora, Toni, Teffen und Co mit Süßigkeiten versorgt und dank deiner sorgsamen Planung habe ich (hoffentlich) keinen wichtigen Termin verpasst. Auf das unsere Promotion so gut verläuft, wie unser Bundesliga-Tippspiel, wetten?!

AK Steinem und AK Janshoff sei in ihrer Gesamtheit für das gute Arbeitsklima gedankt. Da ich - aus Gründen - keinen Platz für weitere, detailliertere Dankesbekundungen habe, muss jeder, den es interessiert, seinen individuellen Beitrag zu dieser Arbeit persönlich bei mir erfragen. 


\section{Lebenslauf}

\section{Daniel Frese}

geboren am 16.03.1985 in Nienburg/Weser, Deutschland

Staatsangehörigkeit: deutsch

A us bildung

Seit 09/2009

Promotionsstudium, Georg-August-Universität Göttingen,

Arbeitskreis Prof. C. Steinem

09/2004 - 06/2009 Diplomstudium Chemie, Georg-August-Universität Göttingen

16.06.2009 Diplomprüfung, Note 1,3

10/2008-03/2009 Diplomarbeit „Rekonstitution von Bacteriorhodopsin in porenüberspannenden Membranen und dessen Einfluss auf die laterale Mobilität der Matrixlipide“", Arbeitskreis Prof. C. Steinem, Note 1,0

25.10.2006

Diplomvorprüfung, Note 2,0

08/1997-06/2004

Gymnasium Hindenburgschule, Nienburg/Weser, Abitur, Note 2,2

Wissenschaftliche Publikationen

Zeitschriftenbeiträge: $\quad$ D. Frese, S. Steltenkamp, S. Schmitz, C. Steinem, In situ generation of electrochemical gradients across pore-spanning membranes, Lab Chip 2013, submitted.

Posterpräsentationen: $\quad$ D. Frese, C. Steinem, Reconstitution of proton-translocating proteins into pore-spanning membranes, Physical Chemistry of Biointerfaces 2010, San Sebastian, Spanien.

D. Frese, C. Steinem, Proton gradients across pore spanning membranes: towards on-chip energy conversion, 8th European Biophysical Congress 2011, Budapest, Ungarn. 
D. Frese, C. Steinem, Fluorescence-sensing of pico-litre cavities to monitor proton transport across pore spanning membranes, Biomembrane Days 2012, Potsdam.

D. Frese, A. Orth, I. Höfer, S. Steltenkamp, C. Steinem, Lipid Bilayer Spanning Picolitre Cavities for Biosensing Applications, Forschungsforum Sartorius AG 2012, Göttingen.

\section{Stipendien}

Federation of European Biochemical Societies, Youth Travel Fund (für die Teilnahme am Workshop Physical Chemistry of Biointerfaces, 19.-24.07.2010 in San Sebastian, Spanien).

Deutsche Gesellschaft für Biophysik, Reisestipendium (für die Teilnahme am 8th European Biophysical Congress, 23.-27.08.2011 in Budapest, Ungarn).

\section{Mitgliedschaften}

Seit 04/2010 Mitglied der Gesellschaft für Biochemie und Molekularbiologie e. V. (GBM).

Seit 08/2011 Mitglied der Deutschen Gesellschaft für Biophysik e. V. (DGfB).

\section{Qualifikationen}

Sprachen: Deutsch (Muttersprache), Englisch (fließend), Russisch (Anfänger, kyrillisches Alphabet)

Sonstiges: MS Office (sicherer Umgang mit Word, Excel, Powerpoint), Sachkundenachweis gemäß § 5 ChemVerbotsV, Führerschein Klasse B, Betriebswirtschaftliche Module (Buchführung und Abschluß, Makroökonomik I)

Hiermit bestätige ich die Richtigkeit aller Angaben:

Datum

Unterschrift 
